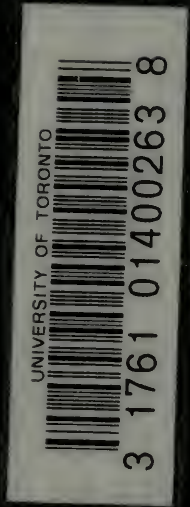


Digitized by the Internet Archive in 2007 with funding from Microsoft Corporation 




\section{THE PEOPLE'S LIBRARY}

\section{LECTURES AND ESSAYS}

THOMAS HENRY HUXLEY 


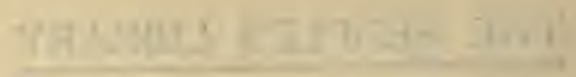

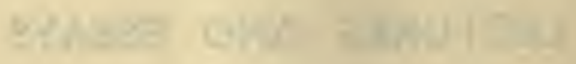

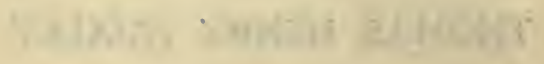




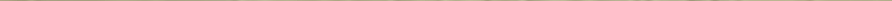




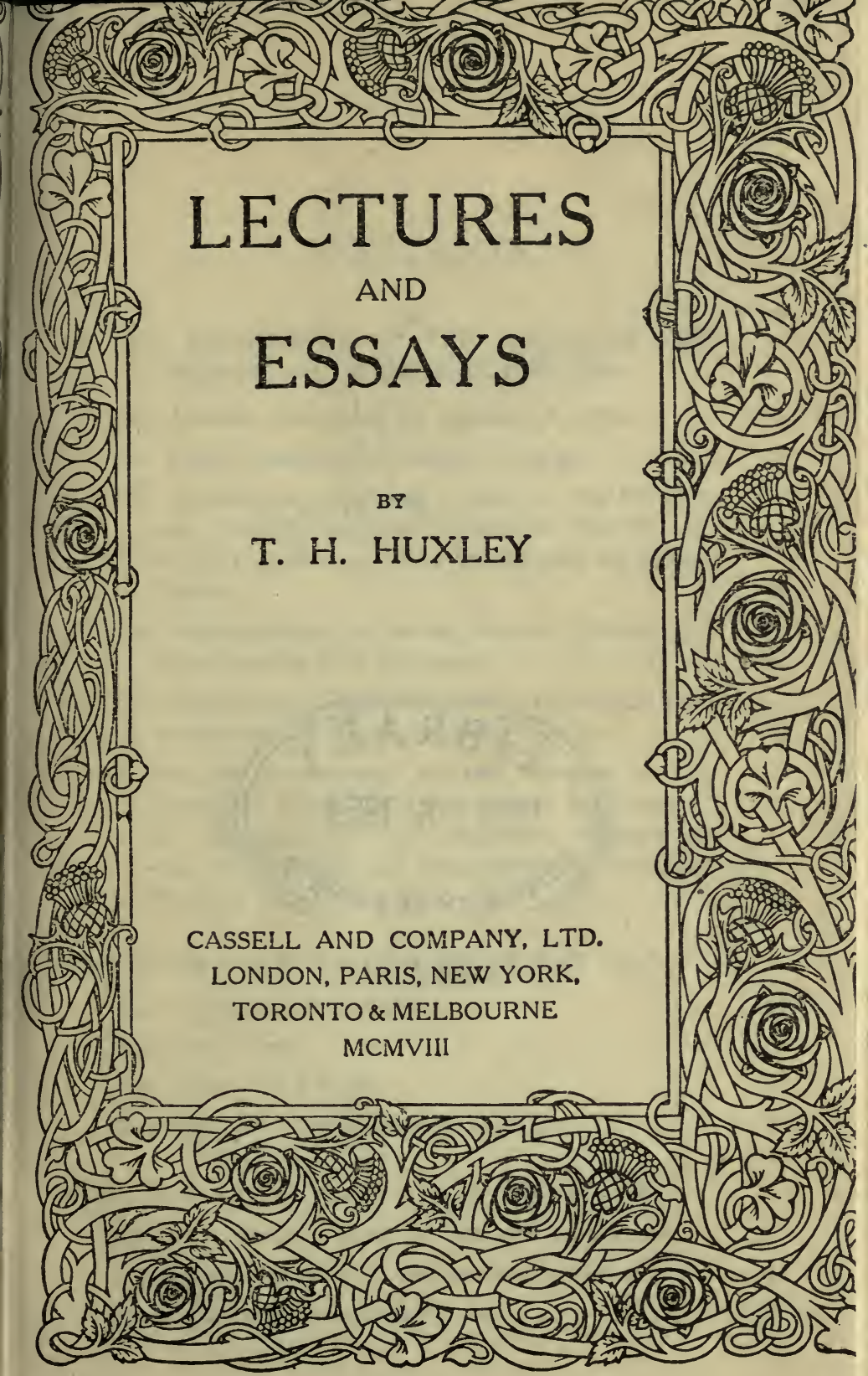


Q

171

H9183

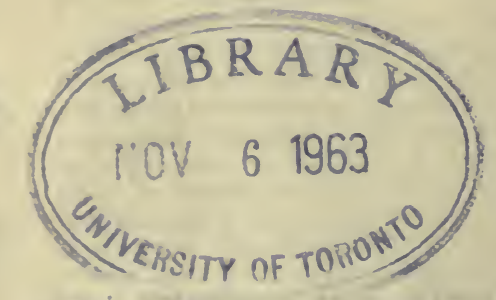

ร6 $6: 01$ 


\section{CONTENTS}

ON OUR KNOWLEDGE OF THE CAUSES OF THE PHENOMENA OF ORGANIC NATURE-

The Present Condition of Organic Nature . • 11

The Past Condition of Organic Nature • • 27

The Method by which the Causes of the Present and Past Conditions of Organic Nature are to be Discovered.-The Origination of Livina BeINGS • • • • • • • • .

The Perpetuation of Living Beings, Hereditary Transmission and Variation . • • •

The Conditions of Existence as Affecting the Perpetuation of Living Beings . • . •

A Critical Examination of the Position of Mr. DARWIN'S Work, "ON THE ORIGIN OF SPECIES," in Relation to the Complete Theony of the Causes of the Phenomena of Oranic Nature.

ESSAYS ON DARWIN'S " ORIGIN OF SPECIES "-

The Darivinian Hypothesis • • • • 117

TIME AND LIFE • • • • • • • • • • 131

The Origin of Species • . • . • • • 143

Criticisms on "The Origin of Species" . $\quad . \quad 177$

EVIDENCE AS TO MAN'S PLACE IN NATURE-

On the Natural History of the Man-Like Afes 197

On the Relations of Man to the Lower Animals 244

On Some Fossil Remains of Man • • • • 298 
pags

ON THE ADVISABLENESS OF IMPROVING NATURAL KNOWLEDGE • • • • • • • • 335 ON THE STUDY OF ZOOLOGY • • • • • 351 GEOLOGICAL CONTEMPORANEITY AND PERSISTENT TYPES OF LIFE • • . • • • 373 CORAL AND CORAL REEFS • • • • • 395

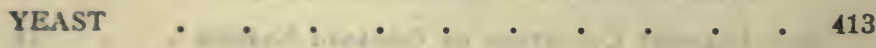
THE CIRCULATION OF THE BLOOD . . . . 431

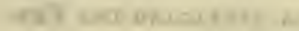
whe an 


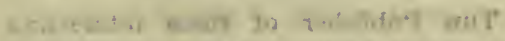

\section{ON OUR KNOWLEDGE}

$$
\text { 2.) } 2 \text { OF THE }
$$

CAUSES OF THE PHENOMENA

\section{or \\ ORGANIC NATURE}




\section{NOTICE}

\section{TO THE FIRST EDITION}

TuE Publisher of these interesting Lectures, having made an arrangement for their publication with Mr. J. A. Mays, the Reporter, begs to append the following note from Professor Huxley :-

"Mr. J. Aldous Mays, who is taking shorthand notes of my "Lectures to Working Men,' has asked me to allow him, on his own account, to print those Notes for the use of $\mathrm{my}$ audience. I willingly accede to this request, on the understanding that a notice is prefixed to the effect that I have no leisure to revise the Lectures, or to make alterations in them, beyond the correction of any important error in a matter of tact." 


\section{THE PRESENT CONDITION OF ORGANIC NATURE}

WhEN it was my duty to consider what subject I would select for the six lectures* which I shall now have the pleasure of delivering to you, it occurred to me that I could not do better than endeavour to put before you in a true light, or in what I might perhaps with more modesty call, that which I conceive myself to be the true light, the position of a book which has been more praised and more abused, perhaps, than any book which has appeared for some years;-I mean Mr. Darwin's work on the Origin of Species. That work, I doubt not, many of you have read; for I know the inquiring spirit which is rife among you. At any rate, all of you will have heard of it,- - some by one kind of report and some by another kind of report; the attention of all and the curiosity of all have been probably more or less excited on the subject of that work. All I can do, and all I shall attempt to do, is to put before you that kind of judgment which has been formed by a man, who, of course, is liable to judge erroneously; but at any rate, of one whose business and profession it is to form judgments upon questions of this nature.

And here, as it will always happen when dealing with an extensive subject, the greater part of my course-if, indeed, so small a number of lectures can be properly called a course - must be devoted to preliminary matters, or rather to a statement of those facts and of those principles which the work itself dwells upon, and brings more or less directly before us. I have no right to suppose that all or any of you are naturalists; and even if you were, the misconceptions and misunderstandings prevalent even among naturalists on these matters would make it desirable that I should take the course I now propose to take,- that I should start from the beginning,-that I should endeavour

- To Working Men, at the Museum of Practical Geology, 1863. 
to point out what is the existing state of the organic world, - that I should point out its past condition,- that I should state what is the precise nature of the undertaking which Mr. Darwin has taken in hand; that I should endeavour to show you what are the only methods by which that undertaking can be brought to an issue, and to point out to you how far the author of the work in question has satisfied those conditions, how far he has not satisfied then, how far they are satisfiable by man, and how far they are not satisfiable by man.

To-night, in taking up the first part of this question, I shall cndeavour to put before you a sort of broad notion of our knowledge of the condition of the living world. There are many ways of doing this. I might deal with it pictorially and graphically. Following the example of Humboldt in his Aspects of Nature, I might endeavour to point out the infinite variety of organic life in everv mode of its existence, with reference to the variations of climate and the like; and such an attempt would be fraught with interest to us all ; but considering the subject before us, such a course would not be that best calculated to assist us. In an argument of this kind we must go further and dig deeper into the matter ; we must endeavour to look into the foundations of living Nature, if I may so say, and discover the principles involved in some of her most secret operations. I propose, therefore, in the first place, to take some ordinary animal with which you are all familiar, and, by easily comprehensible and obvious examples drawn from it, to show what are the kind of problems which living beings in general lay before us; and I shall then show you that the same problems are laid open to us by all kinds of living beings. But, first, let me say in what sense I have used the words "organic nature." In speaking of the causes which lead to our present knowledge of organic nature, I have used it almost as an equivalent of the word "living," and for this reason,that in almost all living beings you can distinguish several distinct portions set apart to do particular things and work in a particular way. These are termed "organs," and the whole together is called "organic." And as it is universally characteristic of them, this term "organic" has been very conveniently employed to denote the whole of living nature, - the whole of the plant world, and the whole of the animal world. 
Few animals can be more familiar to you than that whose skeleton is shown on our diagram. You need not bother yourselves with this "Equus caballus" written under it; that is only the Latin name of it, and does not make it any better. It simply means the common Horse. Suppose we wish to understand all about the Horse. Our first object must be to study the structure of the animal. The whole of his body is inclosed within a hide, a skin covered with hair ; and if that hide or skin be taken off, we find a great mass of flesh, or what is technically called muscle, being the substance which by its power of contraction enables the animal to move. These muscles move the hard parts one upon the other, and so give that strength and power of motion which renders the Horse so useful to us in the performance of those services in which we employ him.

And then, on separating and removing the whole of this skin and flesh, you have a great series of bones, hard structures, bound together with ligaments, and forming the skeleton which is represented here.

In that skeleton there are a number of parts to be recognized. The long series of bones, beginning from the skull and ending in the tail, is called the spine, and those in front are the ribs; and then there are two pairs of limbs, one before and one behind ; and there are what we all know as the fore-legs and the hind-legs. If we pursue our researches into the interior of this animal, we find within the framework of the skeleton a great cavity, or rather, I should say, two great cavities,-one cavity beginning in the skull and running through the neck-bones, along the spine, and ending in the tail, containing the brain and the spinal marrow, which are extremely important organs. The second great cavity, commencing with the mouth, contains the gullet, the stomach, the long intestine, and all the rest of those internal apparatus which are essential for digestion; and then in the same great cavity, there are lodged the heart and all the great vessels going from it; and, besides that, the organs of respiration-the lungs; and then the kidneys; and the organs of reproduction, and so on. Let us now endeavour to reduce this notion of a horse that we now have, to some such kind of simple expression as can be at once, and without difficulty, retained in the mind, apart from all minor details. If I make a transverse section, 
that is, if I were to saw a dead horse across, I should find that, if I left out the details, and supposing I took my section through the anterior region, and through the forelimbs, I should have here this kind of section of the body (Fig. 1). Here would be the upper part of the animalthat great mass of bones that we spoke of as the spine ( $a$, Fig. 1). Here I should have the alimentary canal (b, Fig. 1). Here I should have ithe heart (c, Fig. 1); and then you see, there would be a kind of double tube, the whole being inclosed within the hide; the spinal marrow would be placed in the upper tube ( $a$, Fig. 1), and in the lower tube ( $d d$, Fig. 1) there would be the

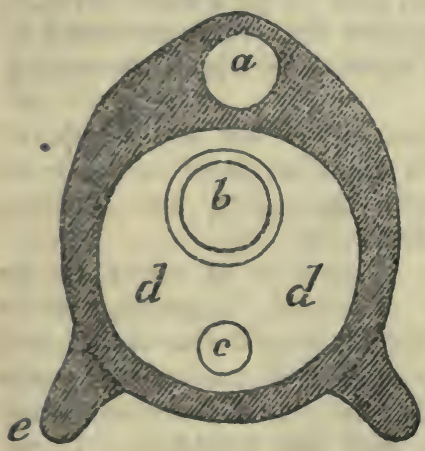

Fro 1. alimentary canal $(b)$, and the heart $(c)$; and here I shall have the legs proceeding from each side. For simplicity's sake, I represent them merely as stumps (e e , Fig. 1). Now that is a horse-as mathematicians would say-reduced to its most simple expression. Carry that in your minds, if you please, as a simplified idea of the structure of the Horse. The considerations which I have now put before you belong to what we technically call the 'Anatomy' of the Horse. Now, suppose we go to work upon these several parts, -flesh and hair, and skin and bone, and lay open these various organs with our scalpels, and examine them by means of our magnifyingglasses, and see what we can make of them. We shall find that the flesh is made up of bundles of strong fibres. The brain and nerves, too, we shall find, are made up of fibres, and these queer-looking things that are called ganglionic corpuscles. If we take a slice of the bone and examine it, we shall find that it is very like this diagram of a section of the bone of an ostrich, though differing, of course, in some details; and if we take any part whatsoever of the tissue, and examine it, we shall find it all has a minute structure, visible only under the microscope. All these parts constitute microscopic anatomy or 'Histology.' 'These parts are constantly being changed; every part is 
constantly growing, decaying, and being replaced during the life of the animal. The tissue is constantly replaced by new material; and if you go back to the young state of the tissue in the case of muscle, or in the case of skin, or any of the organs I have mentioned, you will find that they all come under the same condition. Every one of these microscopic filaments and fibres (I now speak merely of the general character of the whole process)--every one of these parts-could be traced down to some modification of a tissue which can be readily divided into little particles of fleshy matter, of that substance which is composed of the chemical elements, carbon, hydrogen, oxygen, and nitrogen, having such a shape as this (Fig. 2). These particles, into which all primitive tissues break up, are called cells. If I were to make a section of a piece of the skin of my hand, I should find that it was made up of these cells. If I examine the fibres which form the various organs of all living animals, I should find that all of them, at one time or other, had been formed out of a substance consisting of similar elements; so that you see, just as we reduced the whole body in the gross to that sort of simple expression given in Fig. 1, so we may reduce the

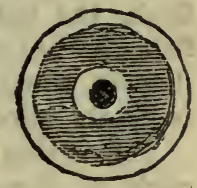

Frg. 2. whole of the microscopic structural elcments to a form of even greater simplicity; just as the plan of the whole body may be so represented in a sense (Fig. 1), so the primary structure of every tissue may be represented by a mass of cells (Fig. 2).

Having thus, in this sort of general way, sketched to you what I may call, perhaps, the architecture of the body of the Horse (what we term technically its Morphology), I must now turn to another aspect. A horse is not a mere dead structure : it is an active, living, working machine. Hitherto we have, as it were, becn looking at a steamengine with the fires out, and nothing in the boiler; but the body of the living animal is a beautifully-formed active machine, and every part has its different work to do in the working of that machine, which is what we call its life. The Horse, if you see him after his day's work is done, is cropping the grass in the fields, as it may be, or munching the oats in his stable. What is he doing? His jaws are working as a mill-and a very complex mill toogrinding the corn, or crushing the grass to a pulp. As 
soon as that operation has taken place, the food is passed down to the stomach, and there it is mixed with the chemical fluid called the gastric juice, a substance which has the peculiar property of making soluble and dissolving out the nutritious matter in the grass, and leaving behind those parts which are not nutritious; so that you have, first, the mill, then a sort of chemical digester; and then the food, thus partially dissolved, is carried back by the muscular contractions of the intestines into the hinder parts of the body, while the soluble portions are taken up into the blood. The blood is contained in a vast system of pipes, spreading through the whole body, connected with a force-pump, - the heart, - which, by its position and by the contractions of its valves, keeps the blood constantly circulating in one direction, never allowing it to rest; and then, by means of this circulation of the blood, laden as it is with the products of digestion, the skin, the flesh, the hair, and every other part of the body, draws from it that which it wants, and every one of these organs derives those materials which are necessary to enable it to do its work.

The action of each of these organs, the performance of each of these various duties, involve in their operation a continual absorption of the matters necessary for their support, from the blood, and a constant formation of waste products, which are returned to the blood, and conveyed by it to the lungs and the kidneys, which are organs that have allotted to them the office of extracting, separating, and getting rid of these waste products; and thus the general nourishment, labour, and repair of the whole machine is kept up with order and regularity. But not only is it a machine which feeds and appropriates to its own support the nourishment necessary to its existenceit is an engine for locomotive purposes. The Horse desires to go from one place to another; and to enable it to do this, it has those strong contractile bundles of muscles attached to the bones of its limbs, which are put in motion by means of a sort of telegraphic apparatus formed by the brain and the great spinal cord running through the spine or backbone; and to this spinal cord are attached a number of fibres termed nerves, which proceed to all parts of the structure. By means of these the eyes, nose, tongue, and skin-all the organs of perception-transmit impressions or sensations to the brain, 
which acts as a sort of great central telegraph-office, receiving impressions and sending messages to all parts of the body, and putting in motion the muscles necessary to accomplish any movement that may be desired. So that you have here an extremely complex and beautifullyproportioned machine, with all its parts working harmoniously together towards one common object-the preservation of the life of the animal.

Now; note this : the Horse makes up its waste by feeding, and its food is grass or oats, or perhaps other vegetable products; therefore, in the long run, the source of all this complex machinery lies in the vegetable kingdom. But where does the grass, or the oat, or any other plant, obtain this nourishing food-producing matérial ? At first it is a little seed, which soon begins to draw into itself from the earth and the surrounding air matters which in themselves contain no vital properties whatever; it absorbs into its own substance water, an inorganic body ; it draws into its substance carbonic acid, an inorganic matter ; and ammonia, another inorganic matter, found in the air; and then, by some wonderful chemical process, the details of which chemists do not yet understand, though they are near foreshadowing them, it combines them into one substance, which is known to us as 'Protein,' a complex compound of carbon, hydrogen, oxygen, and nitrogen, which alone possesses the property of manifesting vitality and of permanently supporting animal life. So that, you see, the waste products of the animal economy, the effete materials which are continually being thrown off by all living beings, in the form of organic matters, are constantly replaced by supplies of the necessary repairing and rebuilding materials drawn from the plants, which in their turn manufacture them, so to speak, by a mysterious combination of those same inorganic materials.

Let us trace out the history of the Forse in another direction. After a certain time, as the result of sickness or disease, the effect of accident, or the consequence of old age, sooner or later, the aninial dies. The multitudinous operations of this beautiful mechanism flag in their performance, the Horse loses its vigour, and after passing through the curious series of changes comprised in its formation and preservation, it finally decays, and ends its life by going back into that inorganic world from which all but an inappreciable fraction of its substance was 
derived. Its bones become mere carbonate and phosphate of lime; the matter of its flesh, and of its other parts, becomes, in the long run, converted into carbonic acid, into water, and into ammonia. You will now, perhaps, understand the curious relation of the animal with the plant, of the organic with the inorganic world, which is shown in this diagram.

The plant gathers these inorganic materials together and makes them up into its own substance. The animal eats the plant and appropriates the nutritious portions to its own sustenance, rejects and gets rid of the useless matters ; and, finally, the animal itself dies, and its whole body is decomposed and returned into the inorganic world. There is thus a constant circulation from one to the other, a continual formation of organic life from inorganic matters, and as constant a return of the matter of living bodies to the inorganic world; so that the materials of which our bodies are composed are largely, in all probability, the substances which constituted the matter of long extinct creations, but which have in the interval constituted a part of the inorganic world.

Thus we come to the conclusion, strange at first sight, that the MATTER constituting the living world is identical with that which forms the inorganic world. And not less true is it that, remarkable as are the powers or, in other words, as are the Fonces which are exerted by living beings, yet all these forces are either identical with those which exist in the inorganic world, or they are convertible into them; I mean in just the same sense as the researches of physical philosophers have shown that heat is convertible into electricity, that electricity is convertible into magnetism, magnetism into mechanical force or chemical force, and any one of them with the other, each being measurable in terms of the other,-even so, I say, that great law is applicable to the living world. Consider why is the skeleton of this horse capable of supporting the masses of flesh and the various organs forming the living body, unless it is because of the action of the same forces of cohesion which combines together the particles of matter composing this piece of chalk? What is there in the muscular contractile power of the animal but the force which is expressible, and which is in a certain sense convertible, into the force of gravity which it overcomes? Or, If you go to more hidden processes, in what does the process 
of digestion differ from those processes which are carried on in the laboratory of the chemist ? Even if we take the most recondite and most complex operations of animal life-those of the nervous system, these of late years have been shown to be-I do not say identical in any sense with the electrical processes-but this has been shown, that they are in some way or other associated with them; that is to say, that every amount of nervous action is accompanied by a certain amount of electrical disturbance in the particles of the nerves in which that nervous action is carried on. In this way the nervous action is related to electricity in the same way that heat is related to electricity; and the same sort of argument which demonstrates the

INORGANIC WORLD.

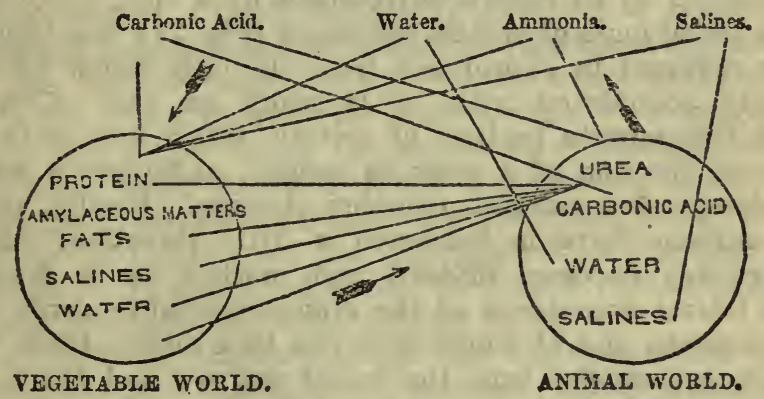

FIG. 3.

two latter to be related to one another shows that the nervous forces are correlated to electricily; for the experiments of M. Dubois Reymond and others have shown that whenever a nerve is in a state of excitement, sending a message to the muscles or conveying an impression to the brain, there is a disturbance of the electrical condition of that nerve which does not exist at other times; and there are a number of other facts and phenomena of that sort; so that we come to the broad conclusion that not only as to living matter itself, but as to the forces that matter exerts, there is a close relationship between the organic and the inorganic world-the difference between them arising from the diverse combination and disposition of identical forces, and not from any primary diversity, so far as we can see.

I said just now that the Horse eventually died and became converted into the same inorganic substances 
from whence all but an inappreciable fraction of its substance demonstrably originated, so that the actual wanderings of matter are as remarkable as the transmigrations of the soul fabled by Indian tradition. But before death has occurred, in the one sex or the other, and in fact in both, certain products or parts of the organism have been set free, cerlain parts of the organisms of the two sexes have come into contact with one another, and from that conjunction, from that union which then takes place, there results the formation of a new being. At stated times the mare, from a particular part of the interior of her body, called the ovary, gets rid of a minute particle of matter comparable in all essential respects with that which we called a cell a little while since, which cell contains a kind of nuclcus in its centre, surrounded by a clear space and by a viscid mass of protein substance (Fig. 2); and though it is different in appearance from the eggs which we are mostly acquainted with, it is really an egg. After a time this minute particle of matter, which may only be a small fraction of a grain in weight, undergoes a series of changes,-wonderful, complex changes. Finally, upon Its surface there is fashioned a little elevation, which afterwards beccmes divided and marked by a groove. The lateral boundaries of the groove extend upwards and downwards, and at length give rise to a double tube. In the upper smaller tube the spinal marrow and brain are fashioned; in the lower, the alimentary canal and heart, and at length two pairs of buds shoot out at the sides of the body, which are the rudiments of the limbs. In fact a true drawing of a section of the embryo in this state would in all essential respects rescmble that diagram of a horse reduced to its simplest expression, which I first placed before you (Fig. 1).

Slowly and gradually these changes take place. The whole of the body, at first, can be broken up into " cells," which become in one place metamorphosed into muscle, -in another place into gristle and bone,-in another place into fibrous tissue, - and in another into hair; every part becoming gradually and slowly fashioned, as if there were an artificer at work in each of these complex structures that we have mentioned. This embryo, as it is called, then passes into other conditions. I should tell you that there is a time when the embryos of neither dog, nor horse, nor porpoise, nor monkey, nor man, can be distinguished by any 
essential feature one from the other; there is a time when they each and all of them resemble this one of the Dog. But as development advances, all the parts acquire their speciality, till at length you have the embryo converted into the form of the parent from which it started. So that you see, this living animal, this horse, begins its existence as a minute particle of introgenous matter, which, being supplied with nutriment (derived, as I have shown, from the inorganic world), grows up according to the special type and construction of its parents, works and undergoes a constant waste, and that waste is made good by nutriment derived from the inorganic world; the waste given off in this way being directly added to the inorganic world; and eventually the animal itself dies, and, by the process of decomposition, its whole body is returned to those conditions of inorganic matter in which its substance originated.

This, then, is that which is true of every living form, from the lowest plant to the highest animal - to man hinself. You might define the life of every one in exactly the same terms as those which I have now used; the difference between the highest and the lowest being simply in the complexity of the developmental changes, the variety of the structural forms, the diversity of the physiological functions which are exerted by each.

If I were to take an oak tree as a specimen of the plant world, I should find that it originated in an acorn, which, too, commenced in a cell ; the acorn is placed in the ground, and it very speedily begins to absorb the inorganic matters I have named, adds enormously to its bulk, and we can see it, year after year, extending itself upward and downward, attracting and appropriating to itself inorganic materials, which it vivifies, and eventually, as it ripens, gives off its own proper acorns, which again run the same course. But I need not multiply examples,-from the highest to the lowest the essential features of life are the same, as I have described in each of these cases.

So much, then, for these particular features of the organic world, which you can understand and comprehend, so long as you confine yourself to one sort of living being, and study that only.

But, as you know, horses are not the only living creatures in the world; and again, horses, like all other animals, have certain limits-are confined to a certain area on the surface of the earth on which we live,-and, as that is the 
simpler matter, I may take that first. In its wild state, and before the discovery of America, when the natural state of things was interfered with by the Spaniards, the Horse was only to be found in parts of the earth which are known to geographers as the Old World; that is to say, you might meet with horses in Europe, Asia, or Africa; but there were none in Australia, and there were none whatsoever in the whole continent of America, from Labrador down to Cape Horn. This is an empirical fact, and it is what is called, stated in the way I have given it you, the 'Geographical Distribution' of the Horse.

Why horses should be found in Europe, Asia, and Africa, and not in America, is not obvious; the explanation that the conditions of life in America are unfavourable to their existence, and that, therefore, they had not been created there, evidently does not apply; for when the invading Spaniards, or our own yeomen farniers, conveyed horses to these countries for their own use, they were found to thrive well and multiply very rapidly ; and many are even now running wild in those countries, and in a perfectly natural condition. Now, suppose we were to do for every animal what we have here done for the Horse, - that is, to mark off and distinguish the particular district or region to which each belonged; and supposing we tabulated all these results, that would be called the Geographical Distribution of animals, while a corresponding study of plants would yield as a result the Geographical Distribution of plants.

I pass on from that now, as I merely wished to explain to you what I meant by the use of the term ' Geographical Distribution.' As I said, there is another aspect, and a much more important one, and that is, the relations of the various animals to one another. The Horse is a very welldefined matter-of-fact sort of animal, and we are all pretty familiar with its structure. I dare say it may have struck you, that it resembles very much no other member of the animal kingdom, except perhaps the Zebra or the Ass. But let me ask you to look along these diagrams. Here is the skeleton of the Horse, and here the skeleton of the Dog. You will notice that we have in the Horse a skull, a backbone and ribs, shoulder-blades and haunch-bones. In the fore-limb, one upper arm-bone, two fore arm-bones, wrist-bones (wrongly called knee), and middle hand-bones, ending in the three bones of a finger, the last of which is 
sheathed in the horny hoof of the fore-foot: in the hindlimb, one thigh-bone, two leg-bones, ankle-bones, and middle foot-bones, ending in the three bones of a toe, the last of which is encased in the hoof of the hind-foot. Now turn to the Dog's skeleton. We find identically the same bones, but more of them, there being more toes in each foot, and hence more toe-bones.

Well, that is a very curious thing! The fact is that the Dog and the Horse-when one gets a look at them without the outward impediments of the skin-are found to be made in very much the same sort of fashion. And if I were to make a transverse section of the Dog, I should find the same organs that $I$ have already shown you as forming parts of the Horse. Well, here is another skeleton-that of a kind of Lemur-you see he has just the same bones; and if I were to make a transverse section of it, it would be just the same again. In your mind's eye turn him round, so as to put his backbone in a position inclined obliquely upwards and forwards, just as in the next three diagrams, which represent the skeletons of an Orang, a Chimpanzee, a Gorilla, and you find you have no trouble in identifying the bones throughout; and lastly turn to the end of the series, the diagram representing a man's skeleton, and still you find no great structural feature essentially altered. There are the same bones in the same relations. From the Horse we pass on and on, with gradual steps, until we arrive at last at the highest known forms. On the other hand, take the other line of diagrams, and pass from the Horse downwards in the scale to this fish ; and still, though the modifications are vastly greater, the essential framework of the organization remains unchanged. Here, for instance, is a Porpoise; here is its strong backbone, with the cavity running through it, which contains the spinal cord; here are the ribs, here the shoulder-blade; here is the little short upper-arm bone, here are the two forearm bones, the wrist-bone, and the finger-bones.

Strange, is it not, that the Porpoise should have in this queer-looking affair-its flapper (as it is called), the same fundamental elements as the fore-leg of the Horse or the Dog, or the Ape or Man; and here you will notice a very curious thing, - the hinder limbs are absent. Now, let us make another jump. Let us go to the Codfish: here you see is the forearm, in this large pectoral fin-carrying your 
mind's eye onward from the flapper or the Porpoise. And here you have the hinder limbs restored in the shape of these ventral fins. If $I$ were to make a transverse section of this, I should find just the same organs that we have before noticed. So that, you see, there comes out this strange conclusion as the result of our investigations, that the Horse, when examined and compared with other animals, is found by no means to stand alone in nature; but that there are an enormous number of other creatures which have backbones, ribs, and legs, and other parts arranged in the same general manner, and in all their formation exhibiting the same broad peculiarities.

I am sure that you cannot have followed me even in this extremely elementary exposition of the structural relations of animals, without seeing what I have been driving at all through, which is, to show you that, step by step, naturalists have come to the idea of a unity of plan, or conformity of construction, among animals which appeared at first sight to be extremely dissimilar.

And here you have evidence of such a unity of plan among all the animals which have backbones, and which we technically call Vertebrata. But there are multitudes of other animals, such as crabs, lobsters, spiders, and so on, which we term Annulosa. In these I could not point out to you the parts that correspond with those of the Horse, - the backbone, for instance,-as they are constructed upon a very different principle, which is also common to all of them ; that is to say, the Lobster, the Spider, and the Centipede, have a common plan running through their whole arrangement, in just the same way that the Horse, the Dog, and the Porpoise assimilate to each other.

Yet other creatures-whelks, cuttlefishes, oysters, snails, and all their tribe (Mollusca)-resemble one another in the same way, but differ from both Vertebrata and Annulosa; and the like is true of the animals called Coelenterata (Polypes) and Protozoa (animalcules and sponges).

Now, by pursuing this sort of comparison, naturalists have arrived at the conviction that there are,-some think five, and some seven,--but certainly not more than the latter number-and perhaps it is simpler to assume five-distinct plans or constructions in the whole of the animal world ; and that the hundreds of thousands of species of creatures on the surface of the earth, are all reducible to those five, or, at most, seven, plans of organization. 
But can we go no further than that ?hen one has got so far, one is tempted to go on a step and inquire whether we cannot go back yet further and bring down the whole to modifications of one primordial unit. The anatomist cannot do this; but if he call to his aid the study of development, he can do it. For we shall find that, distinct as those plans are, whether it be a porpoise or man, or lobster, or any of those other kinds I have mentioned, every one begins its existence with one and the same primitive form, - that of the egg, consisting, as we have seen, of an introgenous substance, having a smalt particle or nucleus in the centre of it. Furthermore, the earlier changes of each are substantially the same. And it is in this that lies that true "unity of organization" of the animal kingdom which has been guessed at and fancied for many years ; but which it has been left to the present time to be demonstrated by the careful study of development. But is it possible to go another step further still; and to show that in the same way the whole of the organic world is reducible to one primitive condition of form ? Is there among the plants the same primitive form of organization, and is that identical with that of the animal kingdom ? The reply to that question, too, is not uncertain or doubtful. It is now proved that every plant begins its existence under the same form ; that is to say, in that of a cell-a particle of introgenous matter having substantially the same conditions. So that if you trace back the oak to its first germ, or a man, or a horse, or lobster, or oyster, or any other animal you choose to name, you shall find each and all of these commencing their existence in forms essentially similar to each other: and, furthermore, that the first processes of growth, and many of the subsequent modifications, are essentially the same in principle in almost all.

In conclusion, let me, in a few words, recapitulate the positions which I have laid down. And you must understand that I have not been talking mere theory; I have been speaking of matters which are as plainly demonstrable as the commonest propositions of Euclid-of facts that must form the basis of all speculations and beliefs in Biological science. We have gradually traced down all organic forms, or, in other words, we have analyzed the present condition of animated nature, until we found that each species took its origin in a form similar to that under which all the others commence their existence. We have 


\section{PRESENT CONDITION OF ORGANIC NATURE}

found the whole of the vast array of living forms, with which we are surrounded, constantly growing, increasing, decaying, and disappearing; the animal constantly attracting, modifying, and applying to its sustenance the matter of the vegetable kingdom, which derived its support from the absorption and conversion of inorganic matter. And so constant and universal is this absorption, waste, and reproduction, that it may be said with perfect certainty that there is left in no one of our bodies at the present moment a millionth part of the matter of which they were originally formed! We have seen, again, that not only is the living matter derived from the inorganic world, but that the forces of that matter are all of them correlative with and convertible into those of inorganic nature.

This, for our present purposes, is the best view of the present condition of organic nature which I can lay before you: it gives you the great outlines of a vast picture, which you must fill up by your own study.

In the next lecture I shall endeavour in the same way to go back into the past, and to sketch in the same broad manner the history of life in epochs preceding our own. 


\section{THE PAST CONDITION OF ORGANIC NATURE}

IN the lecture which I delivered last Monday evening, I endeavoured to sketch in a very brief manner, but as well as the time at my disposal would permit, the present condition of organic nature, meaning by that large title simply an indication of the great, broad, and general principles which are to be discovered by those who look attentively at the phenomena of organic nature as at present displayed. The general result of our investigations might be summed up thus : we found that the multiplicity of the forms of animal life, great as that may be, may be reduced to a comparatively few primitive plans or types of construction; that a further study of the development of those different forms revealed to us that they were again reducible, until we at last brought the infinite diversity of animal, and even vegetable life, down to the primordial form of a single cell.

We found that our analysis of the organic world, whether animals or plants, showed, in the long run, that they might both be reduced into, and were, in fact, composed of the same constituents. And we saw that the plant obtained the materials constituting its substance by a peculiar combination of matters belonging entirely to the inorganic world; that, then, the animal was constantly appropriating the nitrogenous matters of the plant to its own nourishment, and returning them back to the inorganic world, in what we spoke of as its waste ; and that, finally, when the animal ceased to exist, the constituents of its body were dissolved and transmitted to that inorganic world whence they had been at first abstracted. Thus we saw in both the blade of grass and the horse but the same elements differently combined and arranged. We discovered a continual circulation going on,-the plant drawing in the elements of inorganic nature and combining them into food for the animal creation ; the animal borrow- 
ing from the plant the matter for its own support, giving off during its life products which returned immediately to the inorganic world; and that, eventually, the constituent materials of the whole structure of both animals and plants were thus returned to their original source: there was a constant passage from one state of existence to another, and a returning back again.

Lastly, when we endeavoured to form some notion of the nature of the forces exercised by living beings, we ciscovered that they-if not capable of being subjected to the same minute analysis as the constituents of those beings themselves-that they were correlative with-that they were the equivalents of the forces of inorganic nature - that they were, in the sense in which the term is now used, convertible with them. That was our general result.

And now, leaving the Present, I must endeavour in the same manner to put before you the facts that are to be discovered in the Past history of the living world, in the past conditions of organic nature. We have, to-night, to deal with the facts of that history-a history involving periods of time before which our mere human records sink into utter insignificance-a history the variety and physical magnitude of whose events cannot even be foreshadowed by the history of human life and human phenomena-a history of the most varied and complex character.

We must deal with the history, then, in the first place, as we should deal with all other histories. The historical student knows that his first business should be to inquire into the validity of his evidence, and the nature of the record in which the evidence is contained, that he may be able to form a proper estimate of the correctness of the conclusions which have been drawn from that evidence. So, here, we must pass, in the first place, to the consideration of a matter which may seem foreign to the question under discussion. We must dwell upon the nature of the records, and the credibility of the evidence they contain; we must look to the completeness or incompleteness of those records themselves, before we turn to that which they contain and reveal. The question of the credibility of the history, happily for us, will not require much consideration, for, in this history, unlike those of human origin, there can be no cavilling, no differences, as to the reality and truth of the facts of which it is made up ; the facts state themselves, and are laid out clearly before us 
But, although one of the greatest difficulties of the historical student is cleared out of our path, there are other difficulties-difficulties in rightly interpreting the facts as they are presented to us-which may be compared with the greatest difficulties of any other kinds of historical study.

What is this record of the past history of the globe, and what are the questions which are involved in an inquiry into its completeness or incompleteness? That record is composed of mud; and the question which we have to investigate this evening resolves itself into a question of the formation of mud. You may think, perhaps, that this is a vast step-of almost from the sublime to the ridiculous-from the contemplation of the history of the past ages of the world's existence to the consideration of the history of the formation of mud! But, in nature, there is nothing mean and unworthy of attention; there is nothing ridiculous or contemptible in any of her works; and this inquiry, you will soon see, I hope, takes us to the very root and foundations of our subject.

How, then, is mud formed? Always, with some trifling exception, which I need not consider now-always, as the result of the action of water, wearing down and disintegrating the surface of the earth and rocks with which it comes in contact-pounding and grinding it down, and carrying the particles away to places where they cease to be disturbed by this mechanical action, and where they can subside and rest. For the ocean, urged by winds, washes, as we know, a long extent of coast, and every wave, loaded as it is with particles of sand and gravel as it breaks upon the shore, does something towards the disintegrating process. And thus, slowly but surely, the hardest rocks are gradually ground down to a powdery substance; and the mud thus formed, coarser or finer, as the case may be, is carried by the rush of the tides, or currents, till it reaches the comparatively deeper parts of the ocean, in which it can sink to the bottom, that is, to parts where there is a depth of about fourteen or fifteen fathoms, a depth at which the water is, usually, nearly motionless, and in which, of course, the finer particles of this detritus, or mud as we call it, sinks to the bottom.

Or, again, if you take a river, rushing down from its mountain sources, brawling over the stones and rocks that intersect its path, loosening, removing, and carrying. with 
it in its downward course the pebbles and lighter matters from its banks, it crushes and pounds down the rocks and earths in precisely the same way as the wearing action of the sea waves. The matters forming the deposit are torn from the mountain-side and whirled impetuously into the valley, more slowly over the plain, thence into the estuary, and from the estuary they are swept into the sea. The coarser and heavier fragments are obviously deposited first, that is, as soon as the current begins to lose its force by becoming amalgamated with the stiller depths of the ocean, but the finer and lighter particles are carried further on, and eventually deposited in a decper and stiller portion of the ocean.

It clearly follows from this that mud gives us a chronology ; for it is evident that supposing this, which I now sketch, to be the sea bottom, and supposing this to be a coast-line; from the washing action of the sea upon the rock, wearing and grinding it down into a sediment of mud, the mud will be carried down, and at length, deposited in the deeper parts of this sea bottom, where it will form a layer; and then, while that first layer is hardening, other mud which is coming from the same source will, of course, be carried to the same place; and, as it is quite impossible for it to get beneath the layer already there, it deposits itself above it, and forms another layer, and in that way you gradually have layers of mud constantly forming and hardening one above the other, and conveying a record of time.

It is a necessary result of the operation of the law of gravitation that the uppermost layer shall be the youngest and the lowest the oldest, and that the different beds shall be older at any particular point or spot in exactly the ratio of their depth from the surface. So that if they were upheaved afterwards, and you had a series of these different layers of mud, converted into sandstone, or limestone, as the case might be, you might be sure that the bottom layer was deposited first, and that the upper layers were formed afterwards. Here, you see, is the first step in the history-these layers of mud give us an Idea of time.

The whole surface of the earth,-I speak broadly, and leave out minor qualifications, - is made up of such layers of mud, so hard, the majority of them, that we call them rock, whether limestone or sandstone, or other varieties 
of rock. And, seeing that every part of the crust of the earth is made up in this way, you might think that the determination of the chronology, the fixing of the time which it has taken to form this crust is a comparatively simple matter. Take a broad average, ascertain how fast the mud is deposited upon the bottom of the sea, or in the estuary of rivers; take it to be an inch, or two, or three inches a year, or whatever you may roughly estimate it at; then take the total thickness of the whole series of stratified rocks, which geologists estimate at twelve or thirteen miles, or about seventy thousand feet, make a sum in short division, divide the total thickness by that of the quantity deposited in one year, and the result will, of course, give you the number of years which the crust has taken to form.

Truly, that looks a very simple process! It would be so except for certain difficulties, the very first of which is that of finding how rapidly sediments are deposited; but the main dificulty-a difficulty which renders any certain calculations of such a matter out of the question -is this, the sea-bottom on which the deposit takes place is continually shifting.

Instead of the surface of the earth being that stable, fixed thing that it is popularly believed to be, being, in common parlance, the very emblem of fixity itself, it is incessantly moving, and is, in fact, as unstable as the surface of the sea, except that its undulations are infinitely slower and enormously higher and deeper.

Now, what is the effect of this oscillation? Take the case to which I have previously referred. The finer or coarser sediments that are carried down by the current of the river, will only be carried out a certain distance, and eventually, as we have already seen, on reaching the stiller part of the ocean, will be deposited at the bottom.

Let C $y$ (Fig. 4) be the sea-bottom, $y$ D the sliore, $x y$ the sea-level, then the coarser deposit will subside over the region $B$, the finer over $A$, while beyond $A$ there will be no deposit at all ; and, consequently, no record will be kept, simply because no deposit is going on. Now, suppose that the whole land, $\mathrm{C}, \mathrm{D}$, which we have regarded as stationary, goes down; as it does so, both $\mathrm{A}$ and $\mathrm{B}$ go further out from the shore, which will be at $y^{1}, x^{1} y^{1}$ being the new sea-level. The consequence will be that the layer of mud (A), being now, for the most part, further 
than the force of the current is strong enough to convey even the finest débris, will, of course, receive no more deposits, and having attained a certain thickness, will now grow no thicker.

We should be misled in taking the thickness of that layer, whenever it may be exposed to our view, as a record of time in the manner in which we are now regarding this subject, as it would give us only an imperfect and partial record: it would seem to represent too short a period of time.

Suppose, on the other hand, that the land (C D) had gone on rising slowly and gradually-say an inch or two inches in the course of a century, - what would be the practical effect of that movement? Why, that the sediment A and B which has been already deposited, would

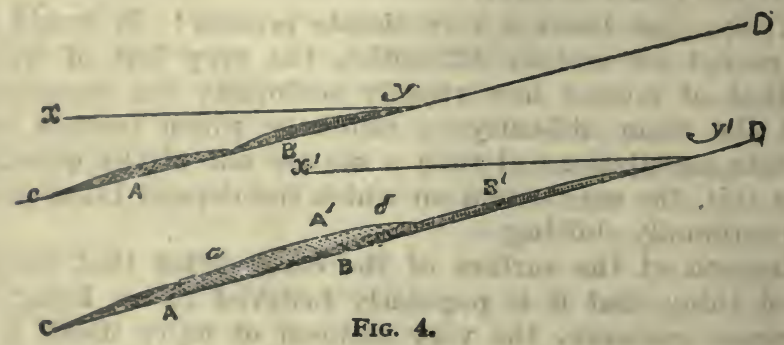

eventually be brought nearer to the shore-level, and again subjected to the wear and tear of the sea; and directly the sea begins to act upon it, it would of course soon cut up and carry it away, to a greater or less extent, to be re-deposited further out.

Well, as there is, in all probability, not one single spot on the whole surface of the earth, which has not been up and down in this way a great many times, it follows that the thickness of the deposits formed at any particular spot cannot be taken (even supposing we had at first obtained correct data as to the rate at which they took place) as affording reliable information as to the period of time occupled in its deposit. So that you see it is absolutely necessary from these facts, seeing that our record entirely consists of accumulations of mud, superimposed one on the other; seeing in the next place that any particular spots on which accumulations have occurred, have been constantly moving up and down, and sometimes out of 
the reach of a deposit, and at other times its own deposit broken up and carried away, it follows that our record must be in the highest degree imperfect, and we have hardly a trace left of thick deposits, or any definite knowledge of the area that they occupied in a great many cases. And mark this! That supposing even that the whole surface of the earth had been accessible to the geologist, - that man had had access to every part of the earth, and had made sections of the whole, and put them all together, - even then his record must of necessity be imperfect.

But to how much has man really access? If you will look at this Map you will see that it represents the proportion of the sea to the earth : this coloured part indicates all the dry land, and this other portion is the water. You will notice at once that the water covers three-fifths of the whole surface of the globe, and has covered it in the same manner ever since man has kept any record of his own observations, to say nothing of the minute period during which he has cultivated geological inquiry. So that three-fifths of the surface of the earth is shut out from us because it is under the sea. Let us look at the other two-fifths, and see what are the countries in which anything that may be termed searchir. geological inquiry has been carried out : a good deal of France, Germany, and Great Britain and Ireland, bits of Spain, of Italy, and of Russia, have been examined, but of the whole great mass of Africa, except parts of the southern extremity, we know next to nothing; little bits of India, but of the greater part of the Asiatic continent nothing; bits of the Northern American States and of Canada, but of the greater part of the continent of North America, and in still larger proportion, of South America, nothing!

Under these circumstances, it follows that even with reference to that kind of imperfect information which we can possess, it is only of about the ten-thousandth part of the accessible parts of the earth that has been examined properly. Therefore, it is with justice that the most thoughtful of those who are concerned in these inquiries insist continually upon the imperfection of the geological record; for, I repeat, it is absolutely necessary, from the nature of things, that that record should be of the most fragmentary and imperfect character. Unfortunately this circumstance has been constantly forgotten. Men of science, like young colts in a fresh pasture, are apt to be 
exhilarated on being turned into a new field of inquiry, and to go off at a hand-gallop, in total disregard of hedges and ditches, losing sight of the real limitation of their inquiries, and to forget the extreme imperfection of what is really known. Geologists have imagined that they could tell us what was going on at all parts of the earth's surface during a given epoch; they have talked of this deposit being contemporaneous with that deposit, until, from our little local histories of the changes at limited spots of the earth's surface, they have constructed a universal history of the globe as full of wonders and portents as any other story of antiquity.

But what does this attempt to construct a universal history of the globe imply? It implies that we shall not only have a precise knowledge of the events which have occurred at any particular point, but that we shall be able to say what events, at any one spot, took place at the same time with those at other spots.

Let us see how far that is in the nature of things practicable. Suppose that here I make a section of the Lake of Killarney, and here the section of another lake-that of Loch Lomond in Scotland for instance. The rivers that flow into them are constantly carrying down deposits of mud, and beds, or strata, are being as constantly formed, one above the other, at the bottom of those lakes. Now, there is not a shadow of doubt that in these two lakes the lower beds are all older than the upper-there is no doubt about that; but what does this tell us about the age of any given bed in Loch Lomond, as compared with that of any given bed in the Lake of Killarney ? It is, indeed, obvious that if any two sets of deposits are separated and discontinuous, there is absolutely no means whatever given you by the nature of the deposit of saying whether one is much younger or older than the other; but you may say, as many have said and think, that the case is very much altered if the beds which we are comparing are continuous. Suppose two beds of mud hardened into rock, $-\mathrm{A}$ and $B$ are seen in section (Fig. 5).

Well, you say, it is admitted that the lowermost bed is always the older. Very well; $\mathrm{B}$, therefore, is older than A. No doubt, as a whole, it is so; or if any parts of the two beds which are in the same vertical line are compared, it is so. But suppose you take what seems a very natural step further, and say that the part $\alpha$ of the 
bed $A$ is younger than the part $b$ of the bed $B$. Is this sound reasoning? If you find any record of changes taking place at $b$, did they occur before any events which took place while $a$ was being deposited ? It looks all very plain sailing, indeed, to say that they did ; and yet there is no proof of anything of the kind. As the former Director of this Institution, Sir H. De la Beche, long ago showed, this reasoning may involve an entire fallacy. It is extremely possible that $a$ may have been deposited ages before $b$. It is very easy to understand how that can be. To return to Fig. 4; when $A$ and $B$ were deposited, they were substantially contemporaneous; A being simply the finer deposit, and $B$ the coarser of the same detritus or waste of land. Now suppose that that sea-bottom goes down (as shown in Fig. 4), so that the

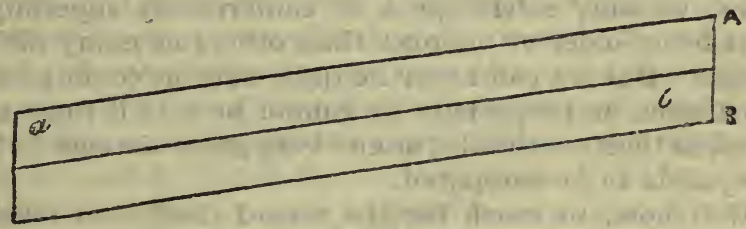

Fig. 5.

fine deposit is carried no farther than $a$, forming the bed $A^{1}$, and the coarse no farther than $b$, forming the bed $\mathrm{B}^{1}$, the result will be the formation of two continuous beds, one of fine sediment (A $\mathrm{A}^{1}$ ) over-lapping another of coarse sediment $\left(B, B^{1}\right)$. Now suppose the whole sea-bottom is raised up, and a section exposed about the point $\mathbf{A}^{\mathbf{1}}$; no doubt, at this spot, the upper bed is younger than the lower. But we should obviously greatly err if we concluded that the mass of the upper bed at $A$ was younger than the lower bed at B ; for we have just seen that they are contemporancous deposits. Still more should we be in error if we supposed the upper bed at $A$ to be younger than the continuation of the lower bed at $\mathrm{B}^{\mathbf{1}}$; for $\mathrm{A}$ was deposited long before $\mathrm{B}^{\mathbf{1}}$. In fine, if, instead of comparing immediately adjacent parts of two beds, one of which lies upon another, we compare distant parts, it is quite possible that the upper may be any number of years older than the under, and the under any number of years younger than the upper. 
Now you must not suppose that I put this before you for the purpose of raising a paradoxical difficulty; the fact is, that the great mass of deposits have taken place in sea-bottoms which are gradually sinking, and have been formed under the very conditions I am here supposing.

Do not run away with the notion that this subverts the principle I laid down at first. The error lies in extending a principle which is perfectly applicable to deposits in the same vertical line to deposits which are not in that relation to one another.

It is in consequence of circumstances of this kind, and of others that I might mention to you, that our conclusions on and interpretations of the record are really and strictly only valid so long as we confine ourselves to one vertical section. I do not mean to tell you that there are no qualifying circumstances, so that, even in very considerable areas, we may safely speak of conformably superimposed beds being older or younger than others at many different points. But we can never be quite sure in coming to that conclusion, and especially we cannot be sure if there is any break in their continuity, or any very great distance between the points to be compared.

Well now, so much for the record itself,-so much for its imperfections,-so much for the conditions to be observed in interpreting it, and its chronological indications, the moment we pass beyond the limits of a vertical linear section.

Now let us pass from the record to that which it contains, - from the book itself to the writing and the figures on its pages. This writing and these figures consist of remains of animals and plants which, in the great majority of cases, have lived and died in the very spot in which we now find them, or at least in the immediate vicinity. You must all of you be aware-and I referred to the fact in my last lecture-that there are vast numbers of creatures living at the bottom of the sea. These creatures, like all others, sooner or later die, and their shells and hard parts lie at the bottom; and then the fine mud which is being constantly brought down by rivers and the action of the wear and tear of the sea, covers them over and protects them from any further change or alteration; and, of course, as in process of time the mud becomes hardened and solidifled, the shells of these animals are preserved and firmly imbedded in the limestone or sandstone which 
is being thus formed. You may see in the galleries of the Museum upstairs specimens of limestones in which such fossil remains of existing animals are imbedded. There are some specimens in which turtles' eggs have been imbedded in calcareous sand, and before the sun had hatched the young turtles, they became covered over with calcareous mud, and thus have been preserved and fossilized.

Not only does this process of imbedding and fossilization occur with marine and other aquatic animals and plants, but it affects those land animals and plants which are drifted away to sea, or become buried in bogs or morasses ; and the animals which have been trodden down by their fellows and crushed in the mud at the river's bank, as the herd have come to drink. In any of these cases, the organisms may be crushed or be mutilated, before or after putrefaction, in such a manner that perhaps only a part will be left in the form in which it reaches us. It is, indeed, a most remarkable fact, that it is quite an exceptional case to find a skeleton of any one of all the thousands of wild land animals that we know are constantly being killed, or dying in the course of nature: they are preyed on and devoured by other animals or die in places where their bodies are not afterwards protected by mud. There are other animals existing in the sea, the shells of which form exceedingly large deposits. You are probably aware that before the attempt was made to lay the Atlantic telegraphic cable, the Government employed vessels in making a series of very careful observations and soundings of the bottom of the Atlantic; and although, as we must all regret, up to the present time that project has not succeeded, we have the satisfaction of knowing that it yielded some most remarkable. results to science. The Atlantic Ocean had to be sounded right across, to depths of several miles in some places, and the nature of its bottom was carefully ascertained. Well, now, a space of about 1,000 miles wide from east to west, and I do not exactly know how many from north to south, but at any rate 600 or 700 miles, was carefully examined, and it was found that over the whole of that immense area an excessively fine chalky mud is being deposited; and this deposit is entirely made up of animals whose hard parts are deposited in this part of the ocean, and are doubtless gradually acquiring solidity and becoming metamorphosed into a chalky limestone. Thus, you see, it is quite possible 
in this way to preserve unmistakable records of animal and vegetable life. Whenever the sea-bottom, by some of those undulations of the earth's crust that I have referred to, becomes upheaved, and sections or borings are made, or pits are dug, then we become able to examine the contents and constituents of these ancient sea-bottoms, and find out what manner of animals lived at that period.

Now it is a very important consideration in its bearing on the completeness of the record, to inquire how far the remains contained in these fossiliferous limestones are able to convey anything like an accurate or complete account of the animals which were in existence at the time of its formation. Upon that point we can form a very clear judgment, and one in which there is no possible room for any mistake. There are of course a great number of animals-such as jelly-fishes, and other animals-without any hard parts, of which we cannot reasonably expect to find any traces whatever: there is nothing of them to preserve. Within a very short time, you will have noticed, after they are removed from the water, they dry up to a mere nothing; certainly they are not of a nature to leave any very visible traces of their existence on such bodies as chalk or mud. Then again, look at land animals ; it is, as I have said, a very uncommon thing to find a land animal entire after death. Insects and other carnivorous animals very speedily pull them to pieces, putrefaction takes place, and so, out of the hundreds of thousands that are known to die every year, it is the rarest thing in the world to see one imbedded in such a way that its remains would be preserved for a lengthened period. Not only is this the case, but even when animal remains have been safely imbedded, certain natural agents may wholly destroy and remove them.

Almost all the hard parts of animals-the bones and so on-are composed chiefly of phosphate of lime and carbonate of lime. Some years ago, I had to make an inquiry into the nature of some very curious fossils sent to me from the North of Scotland. Fossils are usually hard bony structures that have become imbedded in the way I have described, and have gradually acquired the nature and solidity of the body with which they are associated; but in this case I had a series of holes in some pieces of rock, and nothing else. Those holes, however, 
had a certain definite shape about them, and when I got a skilful workman to make castings of the interior of these holes, I found that they were the impressions of the joints of a backbone and of the armour of a great reptile, twelve or more feet long. This great beast had died and got buried in the sand, the sand had gradually hardened over the bones, but remained porous. Water had trickled through it, and that water being probably charged with a superfluity of carbonic acid, had dissolved all the phosphate and carbonate of lime, and the bones themselves had thus decayed and entirely disappeared; but as the sandstone happened to have consolidated by that time, the precise shape of the bones was retained. If that sandstone had remained soft a little longer, we should have known nothing whatsoever of the existence of the reptile whose bones it had encased.

How certain it is that a vast number of animals which have existed at one period on this earth have entirely perished, and left no trace whatever of their forms, may be proved to you by other considerations. There are large tracts of sandstone in various parts of the world, in which nobody has yet found anything but footsteps. Not a bone of any description, but an enormous number of traces of footsteps. There is no question about them. There is a whole valley in Connecticut covered with these footsteps, and not a single fragment of the animals which made them has yet been found. Let me mention another case while upon that matter, which is even more surprising than those to which $I$ have yet referred. There is a limestone formation near Oxford, at a place called Stonesfield, which has yielded the remains of certain very interesting mammalian animals, and up to this time, if I recollect rightly, there have been found seven specimens of its lower jaws, and not a bit of anything else, neither limbbones nor skull, or any part whatever; not a fragment of the whole system! Of course, it would be preposterous to imagine that the beasts had nothing else but a lower jaw ! The probability is, as Dr. Buckland showed, as the result of his observations on dead dogs in the river Thames, that the lower jaw, not being secured by very firm ligaments to the bones of the head, and being a weighty affair, would easily be knocked off, or might drop away from the body as it floated in water in a state of decomposition. The jaw would thus be deposited immediately, while the rest 
of the body would float and drift away altogether, ultimately reaching the sea, and perhaps becoming destroyed. The jaw becomes covered up and preserved in the river silt, and thus it comes that we have such a curious circumstance as that of the lower jaws in the Stonesfield slates. So that, you see, faulty as these layers of stone in the earth's crust are, defective as they necessarily are as a record, the account of contemporaneous vital phenomena presented by them is, by the necessity of the case, infinitely more defective and fragmentary.

It was necessary that I should put all this very strongly before you, because, otherwise, you might have been led to think differently of the completeness of our knowledge by the next facts I shall state to you.

The researches of the last three-quarters of a century have, in truth, revealed a wonderful richness of organic life in those rocks. Certainly not fewer than thirty or forty thousand different species of fossils have been discovered. You have no more ground for doubting that these creatures really lived and died at or near the places in which we find them than you have for like scepticism about a shell on the sea-shore. The evidence is as good in the one case as in the other.

Our next business is to look at the general character of these fossil remains, and it is a subject which it will be requisite to consider carefully; and the first point for us is to examine how much the extinct Flora and Fauna as a whole-disregarding altogether the succession of their constituents, of which I shall speak afterwardsdiffer from the Flora and Fauna of the present day;how far they differ in what we do know about them, leaving altogether out of consideration speculations based on what we do not know.

I strongly imagine that if it were not for the peculiar appearance that fossilized animals have, any of you might readily walk through a museum which contains fossil remains mixed up with those of the present forms of life, and I doubt very much whether your uninstructed eyes would lead you to see any vast or wonderful difference between the two. If you looked closely, you would notice, in the first place, a great many things very like animals with which you are acquainted now : you would see differences of shape and proportion, but on the whole a close similarity. 
I explained what I meant by ORDERs the other day, when I described the animal kingdom as being divided in sub-kingdoms, classes, and orders. If you divide the animal kingdom into orders, you will find that there are about one hundred and twenty. The number may vary on one side or the other, but this is a fair estimate. That is the sum total of the orders of all the animals which we know now, and which have been known in past times, and left remains behind.

Now, how many of those are absolutely extinct? That is to say, how many of these orders of animals have lived at a former period of the world's history, but have at present no representatives? That is the sense in which I meant to use the word " extinct." I mean that those animals did live on this earth at one time, but have left no one of their kind with us at the present moment. So that estimating the number of extinct animals is a sort of way of comparing the past creation as a whole with the present as a whole. Among the mammalia and birds there are none extinct; but when we come to the reptiles there is a most wonderful thing: out of the eight orders, or thereabouts, which you can make among reptiles, onehalf are extinct. These diagrams of the plesiosaurus, the ichthyosaurus, the pterodactyle, give you a notion of some of these extinct reptiles. And here is a cast of the pterodactyle and bones of the ichthyosaurus and the plesiosaurus, just as fresh as if it had been recently dug up in a churchyard. Thus, in the reptile class, there are no less than half of the orders which are absolutely extinct. If we turn to the Amphibia, there was one extinct order, the Labyrinthodonts, typified by the large salamander-like beast shown in this diagram.

No order of fishes is known to be extinct. Every fish that we find in the strata - to which I have been referringcan be identified and placed in one of the orders which exist at the present day. There is not known to be a single ordinal form of insect extinct. There are only two orders extinct among the Crustacea. There is not known to be an extinct order of these creatures, the parasitic and other worms; but there are two, not to say three, absolutely extinct orders of this class, the Echinodermata; out of all the orders of the Coelenterata and Protozoa only one, the Rugose Corals.

So that, you see, out of somewhere about 120 orders of 
animals, taking them altogether, you will not, at the outside estimate, find above ten or a dozen extinct. Summing up all the orders of animals which have left remains behind them, you will not find above ten or a dozen which cannot be arranged with those of the present day; that is to say, that the difference does not amount to much more than ten per cent.: and the proporfion of extinct orders of plants is still smaller. I think that that is a very astounding, a most astonishing fact, seeing the enormous epochs of time which have elapsed during the constitution of the surface of the earth as it at present exists ; it is, indeed, a most astounding thing that the proportion of extinct ordinal types should be so exceedingly small.

But now, there is another point of view in which we must look at this past creation. Suppose that we were to sink a vertical pit through the floor beneath us, and that I could succeed in making a section right through in the direction of New Zealand, I should find in each of the different beds through which I passed the remains of animals which I should find in that stratum and not in the others. First, I should come upon beds of gravel or drift containing the bones of large animals, such as the elephant, rhinoceros, and cave tiger. Rather curious things to fall across in Piccadilly! If I should dig lower still, I should come upon a bed of what we call the London clay, and in this, as you will see in our galleries upstairs, are found remains of strange cattle, remains of turtles, palms, and large tropical fruits; with shell-fish such as you see the like of now only in tropical regions. If I went below that, I should come upon the chalk, and there I should find something altogether different, the remains of ichthyosauri and pterodactyles, and ammonites, and so forth.

I do not know what Mr. Godwin Austin would say comes next, but probably rocks containing more ammonites, and more ichthyosauri and plesiosauri, with a vast number of other things; and under that I should meet with yet older rocks, containing numbers of strange shells and fishes; and in thus passing from the surface to the lowest depths of the earth's crust, the forms of animal life and vegetable life which I should meet with in the successive beds would, looking at them broadly, be the more different the further that I went down. Or, in other words, inasmuch as we started with the clear principle, that in a series of 
naturally-disposed mud beds the lowest are the oldest, we should come to this result, that the further we go back in time the more difference exists between the animal and vegetable life of an epoch and that which now exists. That was the conclusion to which I wished to bring you at the end of this Lecture. 
THE METHOD BY WHICH THE CAUSES OF THE PRESENT AND PAST CONDITIONS OF ORGANIC NATURE ARE TO BE DISCOVERED. - THE ORIGINATION OF LIVING BEINGS

Is the two preceding lectures I have endeavoured to indicate to you the extent of the subject-matter of the inquiry upon which we are engaged; and now, having thus acquired some conception of the Past and Present phenomena of Organic Nature, I must now turn to that which constitutes the great problem which we have set before ourselves;-I mean, the question of what knowledge we have of the causes of these phenomena of organic nature, and how such knowledge is obtainable.

Here, on the threshold of the inquiry, an objection meets us. There are in the world a number of extremely worthy, well-meaning persons, whose judgments and opinions are entitled to the utmost respect on account of their sincerity, who are of opinion that Vital Phenomena, and especially all questions relating to the origin of vital phenomena, are questions quite apart from the ordinary run of inquiry, and are, by their very nature, placed out of our reach. They say that all these phenomena originated miraculously, or in some way totally different from the ordinary course of nature, and that therefore they conceive it to be futile, not to say presumptuous, to attempt to inquire into them.

To such sincere and earnest persons, I would only say, that a question of this kind is not to be shelved upon theoretical or speculative grounds. You may remember the story of the Sophist who demonstrated to Diogenes in the most complete and satisfactory manner that he could not walk; that, in fact, all motion was an impossibility; and that Diogenes refuted him by simply getting up and walking round his tub. So, in the same way, the man of science replies to objections of this kind, by simply 
getting up and walking onward, and showing what science has done and is doing,-by pointing to that immense mass of facts which have been ascertained and systematized under the forms of the great doctrines of Morphology, of Development, of Distribution, and the like. He sees an enormous mass of facts and laws relating to organic beings, which stand on the same good sound foundation as every other natural law; and, therefore, with this mass of facts and laws before us, seeing that, as far as organic matters have hitherto been accessible and studied, they have shown themselves capable of yielding to scientific investigation, we may accept this as proof that order and law reign there as well as in the rest of nature ; and the man of science says nothing to objectors of this sort, but supposes that we can and shall walk to a knowledge of the origin of organic nature, in the same way that we have walked to a knowledge of the laws and principles of the inorganic world.

But there are objectors who say the same from ignorance. and ill-will. To such I would reply that the objection comes ill from them, and that the real presumption, I may almost say the real blasphemy, in this matter, is in the attempt to limit that inquiry into the causes of phenomena which is the source of all human blessings, and from which has sprung all human prosperity and progress; for, after all, we can accomplish comparatively little; the limited range of our own faculties bounds us on every side,-the field of our powers of observation is small enough, and he who endeavours to narrow the sphere of our inquiries is only pursuing a course that is likely to produce the greatest harm to his fellow-men.

But now, assuming, as we all do, I hope, that these phenomena are properly accessible to inquiry, and setting out upon our search into the causes of the phenomena of organic nature, or, at any rate, setting out to discover how much we at present know upon these abstruse matters, the question arises as to what is to be our course of proceeding, and what method we must lay down for our guidance. I reply to that question, that our method must be exactly the same as that which is pursued in any other scientific inquiry, the method of scientific investigation being the same for all orders of facts and phenomena whatsoever.

I must dwell a little on this point, for I wish you to leave this room with a very clear conviction that scientific 
investigation is not, as many people seem to suppose, some kind of modern black art. I say that you might easily gather this impression from the manner in which many persons speak of scientific inquiry, or talk about inductive and deductive philosophy, or the principles of the "Baconian philosophy." I do protest that, of the vast number of cants in this world, there are none, to my mind, so contemptible as the pseudo-scientific cant which is talked about the "Baconian philosophy."

To hear people talk about the great Chancellor,-and a very great man he certainly was,-you would think that it was he who had invented science, and that there was no such thing as sound reasoning before the time of Queen Elizabeth : Of course you say, that cannot possibly be true; you perceive, on a moment's reflection, that such an idea is absurdly wrong; and yet, so firmly rooted is this sort of impression,-I cannot call it an idea, or conception, -the thing is too absurd to be entertained,-but so completely does it exist at the bottom of most men's minds, that this has been a matter of observation with me for many years past. There are many men who, though knowing absolutely nothing of the subject with which they may be dealing, wish, nevertheless, to damage the author of some view with which they think fit to disagree. What they do, then, is not to go and learn something about the subject, which one would naturally think the best way of fairly dealing with it; but they abuse the originator of the view they question, in a general manner, and wind up by saying that, "After all, you know, the principles and method of this author are totally opposed to the canons of the Baconian philosophy." Then everybody applauds, as a matter of course, and agrees that it must be so. But if you were to stop them all in the middle of their applause, you would probably find that neither the speaker nor his applauders could tell you how or in what way. it was so; neither the one nor the other having the slightest idea of what they mean when they speak of the "Baconian philosophy."

You will understand, I hope, that I have not the slightest desire to join in the outcry against either the morals, the intellect, or the great genius of Lord Chancellor Bacon. He was undoubtedly a very great man, let people say what they will of him; but notwithstanding all that he did for philosophy, it would be entirely wrong to suppose 
that the methods of modern scientific inquiry originated with him, or with his age ; they originated with the first man, whoever he was; and indeed existed long before him, for many of the essential processes of reasoning are exerted by the higher order of brutes as completely and effectively as by ourselves. We see in many of the brute creation the exercise of one, at least, of the same powers of reasoning as that which we ourselves employ.

The method of scientific investigation is nothing but the expression of the necessary mode of working of the human mind. It is simply the mode at which all phenomena are reasoned about, rendered precise and exact. There is no more difference, but there is just the same kind of difference, between the mental operations of a man of science and those of an ordinary person, as there is between the operations and methods of a baker or of a butcher weighing out his goods in common scales, and the operations of a chemist in performing a difficult and complex analysis by means of his balance and finely-graduated weights. It is not that the action of the scales in the one case, and the balance in the other, differ in the principles of their construction or manner of working; but the beam of one is set on an infinitely finer axis than the other, and of course turns by the addition of a much smaller weight.

You will understand this better, perhaps, if I give you some familiar example. You have all heard it repeated, I dare say, that men of science work by means of Induction and Deduction, and that by the help of these operations, they, in a sort of sense, wring from Nature certain other things, which are called Natural Laws, and Causes, and that out of these, by some cunning skill of their own, they build up Hypotheses and Theories. And it is imagined by many, that the operations of the common mind can be by no means compared with these processes, and that they have to be acquired by a sort of special apprenticeship to the craft. To hear all these large words, you would think that the mind of a man of science must be constituted differently from that of his fellow men; but if you will not be frightened by terms, you will discover that you are quite wrong, and that all these terrible apparatus are being used by yourselves every day and every hour of your lives.

There is a well-known incident in one of Molière's plays, where the author makes the hero express unbounded 
delight on being told that he had been talking prose during the whole of his life. In the same way, I trust, that you will take comfort, and be delighted with yourselves, on the discovery that you have been acting on the principles of inductive and deductive philosophy during the same period. Probably there is not one here who has not in the course of the day had occasion to set in motion a complex train of reasoning, of the very same kind, though differing of course in degree, as that which a scientific man goes through in tracing the causes of natural phenomena.

A very trivial circumstance will serve to exemplify this. Suppose you go into a fruiterer's shop, wanting an apple, -you take up one, and, on biting it, you find it is sour ; you look at it, and see that it is hard and green. You take up another one, and that too is hard, green, and sour. The shopman offers you a third ; but, before biting it, you examine it, and find that it is hard and green, and you immediately say that you will not have it, as it must be sour, like those that you have already tried.

Nothing can be more simple than that, you think; but if you will take the trouble to analyze and trace out into its logical elements what has been done by the mind, you will be greatly surprised. In the first place, you have performed the operation of Induction. You found that, in two experiences, hardness and greenness in apples go together with sourness. It was so in the first case, and it was confirmed by the second. True, it is a very small basis, but still it is enough to make an induction from; you generalize the facts, and you expect to find sourness in apples where you get hardness and greenness. You found upon that a general law, that all hard and green apples are sour ; and that, so far as it goes, is a perfect induction. Well, having got your natural law in this way, when you are offered another apple which you find is hard and green, you say, "All hard and green apples are sour; this apple is hard and green, therefore this apple is sour." That train of reasoning is what logicians call a syllogism, and has all its varlous parts and terms,-its major premiss, its minor premiss, and its conclusion. And, by the help of further reasoning, which, if drawn out, would have to be exhibited in two or three other syllogisms, you arrive at your final determination, "I will not have that apple." So that, you see, you have, in the first place, established a law by Induction, and upon that you have founded a 
Deduction, and reasoned out the special conclusion of the particular case. Well now, suppose, having got your law, that at some time afterwards, you are discussing the qualities of apples with a friend: you will say to him, "It is a very curious thing,--but $I$ find that all hard and green apples are sour!" Your friend says to you, "But how do you know that?" You at once reply, "Oh, because I have tried it over and over again, and have always found them to be so." Well, if we were talking science instead of common sense, we should call that an Experimental Verification. And, if still opposed, you go further, and say, "I have heard from the people in Somersetshire and Devonshire, where a large number of apples are grown, that they have observed the same thing. It is also found to be the case in Normandy, and in North America. In short, I find it to be the universal experience of mankind wherever attention has been directed to the subject." Whereupon, your friend, unless he is a very unreasonable man, agrees with you, and is convinced that you are quite right in the conclusion you have drawn. He believes, although perhaps he does not know he believes it, that the more extensive Verifications are,- - that the more frequently experiments have been made, and results of the same kind arrived at,- - that the more varied the conditions under which the same results have been attained, the more certain is the ultimate conclusion, and he disputes the question no further. He sces that the experiment has been tried under all sorts of conditions, as to time, place, and people, with the same result; and he says with you, therefore, that the law you have laid down must be a good one, and he must believe it.

In science we do the same thing;-the philosopher exercises precisely the same faculties, though in a much more delicate manner. In scientific inquiry it becomes a matter of duty to expose a supposed law to every possible kind of verification, and to take care, moreover, that this is done intentionally, and not left to a mere accident, as in the case of the apples. And in science, as in common life, our confidence in a law is in exact proportion to the absence of variation in the result of our experimental verifications. For instance, if you let go your grasp of an article you may have in your hand, it will immediately fall to the ground. That is a very common verification of one of the best established laws of nature-that of 
gravitation. The method by which men of science establish the existence of that law is exactly the same as that by which we have established the trivial proposition about the sourness of hard and green apples. But we believe it in such an extensive, thorough, and unhesitating manner because the universal experience of mankind verifies it, and we can verify it ourselves at any time; and that is the strongest possible foundation on which any natural law can rest.

So much by way of proof that the method of establishing laws in science is exactly the same as that pursued in common life. Let us now turn to another matter (though really it is but another phase of the same question), and that is, the method by which, from the relations of certain phenomena, we prove that some stand in the position of causes towards the others.

I want to put the case clearly before you, and I will therefore show you what I mean by another familiar example. I will suppose that one of you, on coming down in the morning to the parlour of your house, finds that a tea-pot and some spoons which had been left in the room on the previous evening are gone,-the window is open, and you observe the mark of a dirty hand on the window-frame, and perhaps, in addition to that, you notice the impress of a hob-nailed shoe on the gravel outside. All these phenomena have struck your attention instantly, and before two minutes have passed you say, "Oh, somebody has broken open the window, entered the room, and run off with the spoons and the tea-pot!" That speech is out of your mouth in a moment. And you will probably add, "I know there has; I am quite sure of it !" You mean to say exactly what you know ; but in reality what you have said has been the expression of what is, in all essential particulars, an Hypothesis. You do not know it at all ; it is nothing but an hypothesis rapidly framed in your own mind ! And it is an hypothesis founded on a long train of inductions and deductions.

What are those inductions and deductions, and how have you got at this hypothesis? You have observed, in the first place, that the window is open; but by a train of reasoning involving many Inductions and Deductions, you have probably arrived long before at the General Law-and a very good one it is-that windows do not open of themselves; and you therefore conclude that 
something has opened the window. A second general law that you have arrived at in the same way is, that tea-pots and spoons do not go out of a window spontaneously, and you are satisfied that, as they are not now where you left them, they have been removed. In the third place, you look at the marks on the window-sill, and the shoe-marks outside, and you say that in all previous experience the former kind of mark has never been produced by anything else but the hand of a human being; and the same experience shows that no other animal but man at present wears shoes with hob-nails on them such as would produce the marks in the gravel. I do not know, even if we could discover any of those " missing links" that are talked about, that they would help us to any other conclusion! At any rate the law which states our present experience is strong enough for my present purpose. You next reach the conclusion, that as these kinds of marks have not been left by any other animals than men, or are liable to be formed in any other way than by a man's hand and shoe, the marks in question have been formed by a man in that way. You have, further, a general law, founded on observation and experience, and that, too, is, I am sorry to say, a very universal and unimpeachable one,-that some men are thieves; and you assume at once from all these premisses-and that is what constitutes your hypothesis - that the man who made the marks outside and on the window-sill, opened the window, got into the room, and stole your tea-pot and spoons. You have now arrived at a Vera Causa;-you have assumed a Cause which it is plain is competent to produce all the phenomena you have observed. You can explain ail these phenomena only by the hypothesis of a thief. But that is a hypothetical conclusion, of the justice of which you have no absolute proof at all ; it is only rendered highly probable by a series of inductive and deductive reasonings.

I suppose your first action, assuming you are a man of ordinary common sense, and that you have established this hypothesis to your own satisfaction, will very likely be to go off for the police, and set them on the track of the burglar, with the view to the recovery of your property. But just as you are starting with this object, some person comes in, and on learning what you are about, says, "My good friend, you are going on a great deal too fast. How 
do you know that the man who really made the marks took the spoons? It might have been a monkey that took them, and the man may have merely looked in afterwards." You would probably reply, "Well, that is all very well, but you see it is contrary to all experience of the way tea-pots and spoons are abstracted; so that, at any rate, your hypothesis is less probable than mine." While you are talking the thing over in this way, another friend arrives, one of that good kind of people that I was talking of a little while ago. And he might say, "Oh, my dear sir, you are certainly going on a great deal too fast. You are most presumptuous. You admit that all these occurrences took place when you were fast asleep, at a time when you could not possibly have known anything about what was taking place. How do you know that the laws of Nature are not suspended during the night ? It may be that there has been some kind of supernatural interference in this case." In point of fact, he declares that your hypothesis is one of which you cannot at all demonstrate the truth, and that you are by no means sure that the laws of Nature are the same when you are asleep as when you are awake.

Well, now, you cannot at the moment answer that kind of reasoning. You feel that your worthy friend has you somewhat at a disadvantage. You will feel perfectly convinced in your own mind, however, that you are quite right, and you say to him, "My good friend, I can only be guided by the natural probabilities of the case, and if you will be kind enough to stand aside and permit me to pass, I will go and fetch the police." Well, we will suppose that your journey is successful, and that by good luck you meet with a policeman; that eventually the burglar is found with your property on his person, and the marks correspond to his hand and to his boots. Probably any jury would consider those facts a very good experimental verification of your hypothesis, touching the cause of the abnormal phenomena observed in your parlour, and would act accordingly.

Now, in this supposititious case, I have taken phenomena of a very common kind, in order that you might see what are the different steps in an ordinary process of reasoning, If you will only take the trouble to analyze it carefully. All the operations I have described, you will see, are involved in the mind of any man of sense in leading him 
to a conclusion as to the course he should take in order to make good a robbery and punish the offender. I say that you are led, in that case, to your conclusion by exactly the same train of reasoning as that which a man of science pursues when he is endeavouring to discover the origin and laws of the most occult phenomena. The process is, and always must be, the same; and precisely the same mode of reasoning was employed by Newton and Laplace in their endeavours to discover and define the causes of the movements of the heavenly bodies, as you, with your own common sense, would employ to detect a burglar. The only difference is, that the nature of the inquiry being more abstruse, every step has to be most carefully watched, so that there may not be a single crack or flaw in your hypothesis. A flaw or crack in many of the hypotheses of daily life may be of little or no moment as affecting the general correctness of the conclusions at which we may arrive; but in a scientific inquiry a fallacy, great or small, is always of importance, and is sure to be constantly productive of mischievous, if not fatal, results in the long run.

Do not allow yourselves to be misled by the common notion that an hypothesis is untrustworthy simply because it is an hypothesis. It is often urged, in respect to some scientific conclusion, that, after all, it is only an hypothesis. But what more have we to guide us in nine-tenths of the most important affairs of daily life than hypotheses, and often very ill-based ones ? So that in science, where the evidence of an hypothesis is subjected to the most rigid examination, we may rightly pursue the same course. You may have hypotheses and hypotheses. A man may say, if he likes, that the moon is made of green cheese : that is an hypothesis. But another man, who has devoted a great deal of time and attention to the subject, and availed himself of the most powerful telescopes and the results of the observations of others, declares that in his opinion it is probably composed of materials very similar to those of which our own earth is made up : and that is also only an hypothesis. But I need not tell you that there is an enormous difference in the value of the two hypotheses. That one which is based on sound scientific knowledge is sure to have a corresponding value; and that which is a mere hasty random guess is likely to have but little value. Every great step in our progress in discovering causes has been made in exactly the same 
way as that which I have detailed to you. A person observing the occurrence of certain facts and phenomena asks, naturally enough, what process, what kind of operation known to occur in nature applied to the particular case, will unravel and explain the mystery? Hence you have the scientific hypothesis; and its value will be proportionate to the care and completeness with which its basis had been tested and verified. It is in these matters as in the commonest affairs of practical life : the guess of the fool will be folly, while the guess of the wise man will contain wisdom. In all cases, you see that the value of the result depends on the patience and faithfulness with which the investigator applies to his hypothesis every possible kind of verification.

I dare say I may have to return to this point by-and-by ; but having dealt thus far with our logical methods, I must now turn to something which, perhaps, you may consider more interesting, or, at any rate, more tangible. But in reality there are but few things that can be more important for you to understand than the mental processes and the means by which we obtain scientific conclusions and theories.* Having granted that the inquiry is a proper one, and having determined on the nature of the methods we are to pursue and which only can lead to success, I must now turn to the consideration of our knowledge of the nature of the processes which have resulted in the present condition of organic nature.

Here, let me say at once, lest some of you misunderstand me, that I have extremely little to report. The question of how the present condition of organic nature came about, resolves itself into two questions. The first is: How has organic or living matter commenced its existence? And the second is: How has it been perpetuated? On the second question I shall have more to say hereafter. But on the first one, what I now have to say will be for the most part of a negative character.

If you consider what kind of evidence we can have upon this matter, it will resolve itself into two kinds. We may have historical evidence and we may have experimental evidence. It is, for example, conceivable, that inasmuch as the hardened mud which forms a considerable portion

Those who wish to study fully the doctrines of which I have endeavoured to give some rough and ready illustrations, must read Mr. John Stuart Mill's Syslem of Logic. 
of the thickness of the earth's crust contains faithful records of the past forms of life, and inasmuch as these differ more and more as we go further down,-it is possible and conceivable that we might come to some particular bed or stratum which should contain the remains of those creatures with which organic life began upon the earth. And if we did so, and if such forms of organic life were preservable, we should have what I would call historical evidence of the mode in which organic life began upon this planet. Many persons will tell you, and indeed you will find it stated in many works on geology, that this has been done, and that we really possess such a record; there are some who imagine that the earliest forms of life of which we have as yet discovered any record, are in truth the forms in which animal life began upon the globe. The grounds on which they base that supposition are these:That if you go through the enormous thickness of the earth's crust and get down to the older rocks, the higher vertebrate animals-the quadrupeds, birds, and fishes-cease to be found; beneath them you find only the invertebrate animals ; and in the deepest and lowest rocks those remains become scantier and scantier, not in any very gradual progression, however, until, at length, in what are supposed to be the oldest rocks, the animal remains which are found are almost always confined to four forms,-Oldhamia, whose precise nature is not known, whether plant or animal ; Lingula, a kind of mollusc ; Trilobites, a crustacean animal, having the same essential plan of construction, though differing in many details from a lobster or crab; and Hymenocaris, which is also a crustacean. So that you have all the Fauna reduced, at this period, to four forms : one a kind of animal or plant that we know nothing about, and three undoubted animals - two crustaceans and one mollusc.

I think, considering the organization of these mollusca and crustacea, and looking at their very complex nature, that it does indeed require a very strong imagination to conceive that these were the first created of all living things. And you must take into consideration the fact that we have not the slightest proof that these which we call the oldest beds are really so: I repeat, we have not the slightest proof of it. When you find in some places that in an enormous thickness of rocks there are but very scanty traces of life, or absolutely none at all; and that in other parts of the world rocks of the very same formation 
are crovided with the records of living forms; I think it is impossible to place any reliance on the supposition, or to feel oneself justified in supposing that these are the forms in which life first commenced. I have not time here to enter upon the technical grounds upon which I am led to this conclusion,- that could hardly be done properly in half a dozen lectures on that part alone;-I must content myself with saying that I do not at all believe that these are the oldest forms of life.

I turn to the experimental side to see what evidence we have there. To enable us to say that we know anything about the experimental origination of organization and life, the investigator ought to be able to take inorganic matters, such as carbonic acid, ammonia, water, and salines, in any sort of inorganic combination, and be able to build them up into Protein matter, and that that Protein matter ought to begin to live in an organic form. That, nobody has done as yet, and I suspect it will be a long while before anybody does do it. But the thing is by no means so impossible as it looks; for the researches of modern chemistry have shown us-I won't say the road towards it, but, if I may so say, they have shown the finger-post pointing to the road that may lead to it.

It is not many years ago-and you must recollect that Organic Chemistry is a young science, not above a couple of generations old,-you must not expect too much of it ; it is not many years ago since it was said to be perfectly impossible to fabricate any organic compound; that is to say, any non-mineral compound which is to be found in an organized being. It remained so for a very long period; but it is now a considerable number of years since a distinguished foreign chemist contrived to fabricate Urea, a substance of a very complex character, which forms one of the waste products of animal structures. And of late years a number of other compounds, such as Butyric Acid, and others, have been added to the list. I need not tell you that chemistry is an enormous distance from the goal I indicate; all I wish to point out to you is, that it is by no means safe to say that that goal may not be reached one day. It may be that it is impossible for us to produce the conditions requisite to the origination of life; but we must speak modestly about the matter, and recollect that Science has put her foot upon the bottom round of the 
ladder. Truly he would be a bold man who would venture to predict where she will be fifty years hence.

There is another inquiry which bears indirectly upon this question, and upon which I must say a few words. You are all of you aware of the phenomena of what is called spontaneous generation. Our forefathers, down to the seventeenth century, or thereabouts, all imagined, in perfectly good faith, that certain vegetable and animal forms gave birth, in the process of their decomposition, to insect life. Thus, if you put a piece of meat in the sun, and allowed it to putrefy, they conceived that the grubs which soon began to appear were the result of the action of a power of spontaneous generation which the meat contained. And they could give you receipts for making various animal and vegetable preparations which would produce particular kinds of animals. A very distinguished Italian naturalist, named Redi, took up the question, at a time when everybody believed in it; among others our own great Harvey, the discoverer of the circulation of the blood. You will constantly find his name quoted, however, as an opponent of the doctrine of spontaneous generation; but the fact is, and you will see it if you will take the trouble to look into his works, Harvey believed it as profoundly as any man of his time ; but he happened to enunciate a very curious proposition - that every living thing came from an egg; he did not mean to use the word in the sense in which we now employ it, he only meant to say that every living thing originated in a little rounded particle of organized substance; and it is from this circumstance, probably, that the notion of Harvey having opposed the doctrine originated. Then came Redi, and he proceeded to upset the doctrine in a very simple manner. He merely covered the piece of meat with some very fine gauze, and then he exposed it to the same conditions. The result of this was that no grubs or insects were produced; he proved that the grubs originated from the insects who came and deposited their eggs in the meat, and that they were hatched by the heat of the sun. By this kind of inquiry he thoroughly upset the doctrine of spontaneous generation, for his time at least.

Then came the discovery and application of the microscope to scientific inquiries, which showed to naturalists that besides the organisms which they already knew as living beings and plants, there were an immense number 
of minute things which could be obtained apparently almost at will from decaying vegetable and animal forms. Thus, if you took some ordinary black pepper or some hay, and steeped it in water, you would find in the course of a few days that the water had become impregnated with an immense number of animalcules swimming about in all directions. From facts of this kind naturalists were led to revive the theory of spontaneous generation. They were headed here by an English naturalist,-Needham,-and afterwards in France by the learned Buffon. They said that these things were absolutely begotten in the water of the decaying substances out of which the infusion was made. It did not matter whether you took animal or vegetable matter, you had only to steep it in water and expose it, and you would soon have plenty of animalcules. They made an hypothesis about this which was a very fair one. They said, this matter of the animal world, or of the higher plants, appears to be dead, but in reality it has a sort of dim life about it, which, if it is placed under fair conditions, will cause it to break up into the forms of these little animalcules, and they will go through their lives in the same way as the animal or plant of which they once formed a part.

The question now became very hotly debated. Spallanzani, an Italian naturalist, took up opposite views to those of Needham and Bufion, and by means of certain experiments he showed that it was quite possible to stop the process by boiling the water, and closing the vessel in which it was contained. "Oh !" said his opponents; "but what do you know you may be doing when you heat the air over the water in this way? You may be destroying some property of the air recuisite for the spontaneous generation of the animalcules."

However, Spallanzani's views were supposed to be upon the right side, and those of the others fell into discredit; although the fact was that Spallanzani had not made good his views. Well, then, the subject continued to be revived from time to time, and experiments were made by several persons ; but these experiments were not altogether satisfactory. It was found that if you put an infusion in which animalcules would appear if it were exposed to the air into a vessel and boiled it, and then sealed up the mouth of the vessel, so that no air, save such as had been heated to $212^{\circ}$, could reach its contents, that then no animalcules would 
be found; but if you took the same vessel and exposed the infusion to the air, then you would get animalcules. Furthermore; it was found that if you connected the mouth of the vessel with a red-hot tube in such a way that the air would have to pass through the tube before reaching the infusion, that then you would get no animalcules. Yet another thing was noticed: if you took two flasks containing the same kind of infusion, and left one entirely exposed to the air, and in the mouth of the other placed a ball of cotton wool, so that the air would have to filter itself through it before reaching the infusion, that then, although you might have plenty of animalcules in the first flask, you would certainly obtain none from the second.

These experiments, you see, all tended towards one conclusion-that the infusoria were developed from little minute spores or eggs which were constantly floating in the atmosphere, which lose their power of germination if subjected to heat. But one observer now made another experiment, which seemed to go entirely the other way, and puzzled him altogether. He took some of this boiled infusion that I have been speaking of, and by the use of a mercurial bath - a kind of trough used in laboratorieshe deftly inverted a vessel containing the infusion into the mercury, so that the latter reached a little beyond the level of the mouth of the inverted vessel. You see that he thus had a quantity of the infusion'shut off from any possible communication with the outer air by being inverted upon a bed of mercury.

He then prepared some pure oxygen and nitrogen gases, and passed them by means of a tube going from the outside of the vessel, up through the mercury into the infusion; so that he thus had it exposed to a perfectly pure atmosphere of. the same constituents as the external air. Of course, he expected he would get no infusorial animalcules at all in that infusion; but, to his great dismay and discomfiture, he found he almost always did get them.

Furthermore, it has been found that experiments made in the manner described above answer well with most infusions; but that if you fill the vessel with boiled milk, and then stop the neck with cotton-wool, you will have infusoria. So that you see there were two experiments that brought you to one kind of conclusion, and threge to another; which was a most unsatisfactory state of things to arrive at in a scientific inquiry. 
Some few years after this, the question began to be very hotly discussed in France. There was M. Pouchet, a professor at Rouen, a very learned man, but certainly not a very rigid experimentalist. He published a number of experiments of his own, some of which were very ingenious, to show that if you went to work in a proper way, there was a truth in the doctrine of spontaneous generation. Well, it was one of the most fortunate things in the world that M. Pouchet took up this question, because it induced a distinguished French chemist, M. Pasteur, to take up the question on the other side; and he has certainly worked it out in the most perfect manner. I am glad to say, too, that he has published his researches in time to enable me to give you an account of them. He verified all the experiments which I have just mentioned to you-and then finding those extraordinary anomalies, as in the case of the mercury bath and the milk, he set himself to work to discover their nature. In the case of milk he found it to De a question of temperature. Milk in a fresh state is slightly alkaline; and it is a very curious circumstance, but this very slight degree of alkalinity seems to have the effect of preserving the organisms which fall into it from the air from being destroyed at a temperature of $212^{\circ}$, which is the boiling point. But if you raise the temperature $10^{\circ}$ when you boil it, the milk behaves like everything else ; and if the air with which it comes in contact, after being boiled at this temperature, is passed through a red-hot tube, you will not get a trace of organisms.

He then turned his attention to the mercury bath, and found on examination that the surface of the mercury was almost always covered with a very fine dust. He found that even the mercury itself was positively full of organic matters; that from being constantly exposed to the air, it had collected an immense number of these infusorial organisms from the air. Well, under these circumstances he felt that the case was quite clear, and that the mercury was not what it had appeared to M. Schwann to be,-a bar to the admission of these organisms; but that, in reality, it acted as a reservoir from which the infusion was immediatcly supplied with the large quantity that had so puzzled him.

But not content with explaining the experiments of others, M. Pasteur went to work to satisfy himself completely. He said to himself : "If my view is right, and 
if, in point of fact, all these appearances of spontaneous generation are altogether due to the falling of minute germs suspended in the atmosphere,- - why, I ought not only to be able to show the germs, but I ought to be able to catch and sow them, and produce the resulting organisms." $\mathrm{He}$, accordingly, constructed a very ingenious apparatus to enable him to accomplish this trapping of this "germ dust" in the air. He fixed in the window of his room a glass tube, in the centre of which he had placed a ball of guncotton, which, as you all know, is ordinary cotton-wool, which, from having been steeped in strong acid, is converted into a substance of great explosive power. It is also soluble in alcohol and ether. One end of the glass tube was, of course, open to the external air ; and at the other end of it he placed an aspirator, a contrivance for causing a current of the external air to pass through the tube. He kept this apparatus going for four-and-twenty hours, and then removed the dusted gun-cotton, and dissolved it in alcohol and ether. He then allowed this to stand for a few hours, and the result was, that a very fine dust was gradually deposited at the bottom of it. That dust, on being transferred to the stage of a microscope, was found to contain an enormous number of starch grains. You know that the materials of our food and the greater portion of plants are composed of starch, and we are constantly making use of it in a variety of ways, so that there is always a quantity of it suspended in the air. It is these starch grains which form many of those bright specks that we see dancing in a ray of light sometimes. But besides these, M. Pasteur found also an immense number of other organic substances such as spores of fungi, which had been floating about in the air and had got caged in this way.

He went farther, and said to himself, "If these really are the things that give rise to the appearance of spon. taneous generation, I ought to be able to take a ball of this dusted gun-cotton and put it into one of my vessels, containing that boiled infusion which has been kept away from the air, and in which no infusoria are at present developed, and then, if I am right, the introduction of this gun-cotton will give rise to organisms."

Accordingly, he took one of these vessels of infusion, which had been kept eighteen months, without the least appearance of life, and by a most ingenious contrivance, 
he managed to break it open and introduce such a ball of gun-cotton, without allowing the infusion or the cotton ball to come into contact with any air but that which had been subjected to a red heat, and in twenty-four hours he had the satisfaction of finding all the indications of what had been hitherto called spontaneous generation. He had succeeded in catching the germs and developing organisms in the way he had anticipated.

It now struck him that the truth of his conclusions might be demonstrated without all the apparatus he had employed. To do this, he took some decaying animal or vegetable substance, such as urine, which is an extremely decomposable substance, or the juice of yeast, or perhaps some other artificial preparation, and filled a vessel having a long tubular neck, with it. He then boiled the liquid and bent that long neck into an S shape or zig-zag, leaving it open at the end. The infusion then gave no trace of any appearance of spontaneous generation, however long it night be left, as all the germs in the air were deposited in the beginning of the bent neck. He then cut the tube close to the vessel, and allowed the ordinary air to have free and direct access; and the result of that was the appearance of organisms in it, as soon as the infusion had been allowed to stand long enough to allow of the growth of those it received from the air, which was about fortyeight hours. The result of M. Pasteur's experiments proved, therefore, in the most conclusive manner, that all the appearances of spontaneous generation arose from nothing more than the deposition of the germs of organisms which were constantly floating in the air.

To this conclusion, however, the objection was made, that if that were the cause, then the air would contain such an enormous number of these germs, that it would be a continual fog. But M. Pasteur replied that they are not there in anything like the number we might suppose, and that an exaggerated view has been held on that subject; he showed that the chances of animal or vegetable life appearing in infusions, depend entirely on the conditions under which they are exposed. If they are exposed to the ordinary atmosphere around us, why, of course, you may have organisms appearing early. But, on the other hand, if they are exposed to air from a great height, or from some very quiet cellar, you will often not find a single trace of life. 


\section{ORIGINATION OF LIVING BEINGS}

So that M. Pasteur arrived at last at the clear and definite result, that all these appearances are like the case of the worms in the piece of meat, which was refuted by Redi, simply germs carried by the air and deposited in the liquids, in which they afterwards appear. For my own part, I conceive that, with the particulars of M. Pasteur's experiments before us, we cannot fail to arrive at his conclusions ; and that the doctrine of spontaneous generation has received a final coup de grâce.

You, of course, understand that all this in no way interferes with the possibility of the fabrication of organic matters by the direct method to which I have referred, remote as that possibility may be. 


\section{THE PERPETUATION OF LIVING BEINGS, HEREDITARY TRANSMISSION AND VARIATION}

THE inquiry which we undertook, at our last meeting, into the state of our knowledge of the causes of the phenomena of organic nature,- of the past and of the present,resolved itself into two subsidiary inquiries : the first was, whether we know anything, either historically or experimentally, of the mode of origin of living beings ; the second subsidiary inquiry was, whether, granting the origin, we know anything about the perpetuation and modifications of the forms of organic beings. The reply which I had to give to the first question was altogether negative, and the chief result of my last lecture was, that, neither historically nor experimentally, do we at present know anything whatsoever about the origin of living forms. We saw that, historically, we are not likely to know anything about it, although we may perhaps learn something experimentally; but that at present we are an enormous distance from the goal $I$ indicated.

I now, then, take up the next question, What do we know of the reproduction, the perpetuation, and the modifications of the forms of living beings, supposing that we have put the question as to their origination on one side, and have assumed that at present the causes of their origination are beyond us, and that we know nothing about them? Upon this question the state of our knowledge is extremely different; it is exceedingly large, and, if not complete, our experience is certainly most extensive. It would be impossible to lay it all before you, and the most I can do, or need do to-night, is to take up the principal points and put them before you with such prominence as may subserve the purposes of our present argument.

The method of the perpetuation of organic beings is of two kinds, - the asexual and the sexual. In the first the perpetuation takes place from and by a particular act of 
classed as belonging to any sex at all. In the second case, it is in consequence of the mutual action and interaction of certain portions of the organisms of usually two distinct individuals, - the male and the female. The cases of asexual perpetuation are by no means so common as the cases of sexual perpetuation ; and they are by no means so common in the animal as in the vegetable world. You are all probably familiar with the fact, as a matter of experience, that you can propagate plants by means of what are called " cuttings ; " for example, that by taking a cutting from a geranium plant, and rearing it properly, by supplying it with light and warmth and nourishment from the earth, it grows up and takes the form of its parent, having all the properties and peculiarities of the original plant.

Sometimes this process, which the gardener periorms artificially, takes place naturally; that is to say, a little bulb, or portion of the plant, detaches itself, drops off, and becomes capable of growing as a separate thing. That is the case with many bulbous plants, which throw off in this way secondary bulbs, which are lodged in the ground and become developed into plants. This is an asexual process, and from it results the repetition or reproduction of the form of the original being from which the bulb proceeds.

Among animals the same thing takes place. Among the lower forms of animal life, the infusorial animalculæ we have already spoken of throw off certain portions, or break themselves up in various directions, sometimes transversely or sometimes longitudinally; or they may give off buds, which detach themselves and develop into their proper forms. There is the common fresh-water Polype, for instance, which multiplies itself in this way. Just in the same way as the gardener is able to multiply and reproduce the peculiarities and characters of particular plants by means of cuttings, so can the physiological experimentalist, -as was shown by the Abbé Trembley many years ago,so can he do the same thing with many of the lower forms of animal life. M. de Trembley showed that you could take a polype and cut it into two, or four, or many pieces, mutilating it in all directions, and the pieces would still grow up and reproduce completely the original form of the animal. These are all cases of asexual multiplication, and there are other instances, and still more extraordinary ones, in which this process takes place naturally, in a more 
hidden, a more recondite kind of way. You are all of you familiar with those little green insects, the Aphis or blight, as it is called. These little animals, during a very considerable part of their existence, multiply themselves by means of a kind of internal budding, the buds being developed into essentially asexual animals, which are neither male nor female; they become converted into young Aphides, which repeat the process, and their offspring after them, and so on again; you may go on for nine or ten, or even twenty or more successions; and there is no very good reason to say how soon it might terminate, or how long it might not go on if the proper conditions of warmth and nourishment were kept up.

Sexual reproduction is quite a distinct mattcr. Here, in all these cases, what is required is the detachment of two portions of the parental organisms, which portions we know as the egg and the spermatozoon. In plants it is the ovule and the pollen-grain, as in the flowering plants, or the ovule and the antherozooid, as in the flowerless. Among all forms of animal life, the spermatozoa proceed from the male sex, and the egg is the product of the female. Now, what is remarkable about this mode of reproduction is this, that the egg by itself, or the spermatozoa by themselves, are unable to assume the parental form; but if they be brought into contact with one another, the effect of the mixture of organic substances procecding from two sources appears to confer an altogether new vigour to the mixed product. This process is brought about, as we all know, by the sexual intercourse of the two sexes, and is called the act of impregnation. The result of this act on the part of the male and female is, that the formation of a new being is set up in the ovule or egg; this ovule or egg soon begins to be divided and subdivided, and to be fashioned into various complex organisms, and eventually to develop into the form of one of its parents, as I explained in the first lecture. These are the processes by which the perpetuation of organic beings is secured. Why there should be the two modes-why this re-invigoration should be required on the part of the female element we do not know ; but it is most assuredly the fact, and it is presumable, that, however long the process of asexual multiplication could be continued, - I say there is good reason to believe that it would come to an end if a new commencement were not obtained by a conjunction of the two sexual elements. 
That character which is common to these two distinct processes is this, that, whether we consider the reproduction, or perpetuation, or modification of organic beings as they take place asexually, or as they may take place sexually, -in either case, I say, the offspring has a constant tendency to assume, speaking generally, the character of the parent. As I said just now, if you take a slip of a plant, and tend it with care, it will eventually grow up and develop into a plant like that from which it had sprung; and this tendency is so strong that, as gardeners know, this mode of multiplying by means of cuttings is the only secure mode of propagating very many varieties of plants ; the peculiarity of the primitive stock seems to be better preserved if you propagate it by means of a slip than if you resort to the sexual mode.

Again, in experiments upon the lower animals, such as the polype, to which $I$ have referred, it is most extraordinary that, although cut up into various pieces, each particular piece will grow up into the form of the primitive stock ; the head, if separated, will reproduce the body and the tail ; and if you cut off the tail, you will find that that will reproduce the body and all the rest of the members, without in any way deviating from the plan of the organism from which these portions have been detached. And so far does this go, that some experimentalists have carefully examined the lower orders of animals,-among them the Abbé Spallanzani, who made a number of experiments upon snails and salamanders, - and have found that they might mutilate them to an incredible extent; that you might cut off the jaw or the greater part of the head, or the leg or the tail, and repeat the experiment several times, perhaps, cutting off the same member again and again; and yet each of those types would be reproduced according to the primitive type : nature making no mistake, never putting on a fresh kind of leg, or head, or tail, but always tending to repeat and to return to the primitive type.

It is the same in sexual reproduction: it is a matter of perfectly common experience, that the tendency on the part of the offspring always is, speaking broadly, to reproduce the form of the parents. The proverb has it that the thistle does not bring forth grapes; so, among ourselves, there is always a likeness, more or less marked and distinct, between children and their parents. That is a matter of familiar and ordinary observation. We notice 
the same thing occurring in the cases of the domestic animals-dogs, for instance, and their offspring. In all these cases of propagation and perpetuation, there seems to be a tendency in the offspring to take the characters of the parental organisms. To that tendency a special name is given-it is called Atavism; it expresses this tendency to revert to the ancestral type, and comes from the Latin word atavus, ancestor.

Well, this Atavism which I shall speak of, is, as I said before, one of the most marked and striking tendencies of organic beings; but, side by side with this hereditary tendency there is an equally distinct and remarkable tendency to variation. The tendency to reproduce the original stock has, as it were, its limits, and side by side with it there is a tendency to vary in certain directions, as if there were two opposing powers working upon the organic being, one tending to take it in a straight line, and the other tending to make it diverge from that straight line, first to one side and then to the other.

So that you see these two tendencies need not precisely contradict one another, as the ultimate result may not always be very remote from what would have been the case if the line had been quite straight.

This tendency to variation is less marked in that mode of propagation which takes place asexually; it is in that mode that the minor characters of animal and vegetable structures are most completely preserved. Still, it will happen sometimes, that the gardener, when he has planted a cutting of some favourite plant, will find, contrary to his expectation, that the slip grows up a little different from the primitive stock-that it produces flowers of a different colour or make, or some deviation in one way or another. This is what is called the 'sporting' of plants.

In animals the phenomena of asexual propagation are so obscure, that at present we cannot be said to know much about them ; but if we turn to that mode of perpetuation which results from the sexual process, then we find variation a perfectly constant occurrence, to a certain extent; and, indeed, I think that a certain amount of variation from the primitive stock is the necessary result of the method of sexual propagation itself ; for, inasmuch as the thing propagated proceeds from two organisms of 
different sexes and different makes and temperaments, and as the offspring is to be either of one sex or the other, it is quite clear that it cannot be an exact diagonal of the two, or it would be of no sex at all; it cannot be an exact intermediate form between that of each of its parents-it must deviate to one side or the other. You do not find that the male follows the precise type of the male parent, nor does the female always inherit the precise characteristics of the mother,-there is always a proportion of the female character in the male offspring, and of the male character in the female offspring. That must be quite plain to all of you who have looked at all attentively on your own children or those of your neighbours; you will have noticed how very often it may happen that the son shall exhibit the maternal type of character, or the daughter possess the characteristics of the father's family. There are all sorts of intermixtures and intermediate conditions between the two, where complexion, or beauty, or fifty other different peculiarities belonging to either side of the house, are reproduced in other members of the same family. Indeed, it is sometimes to be remarked in this kind of variation, that the variety belongs, strictly speaking, to neither of the immediate parents; you will see a child in a family who is not like either its father or its mother; but some old person who knew its grandfather or grandmother, or, it may be, an uncle, or, perhaps, even a more distant relative, will see a great similarity between the child and one of these. In this way it constantly happens that the characteristic of some previous member of the family comes out and is reproduced and recognized in the most unexpected manner.

But apart from that matter of general experience, there are some cases which put that curious mixture in a very clear light. You are aware that the offspring of the Ass and the Horse, or rather of the he-Ass and the Mare, is what is called a Mule ; and, on the other hand, the offspring of the Stallion and the she-Ass is what is called a Hinny. It is a very rare thing in this country to see a Hinny. I never saw one myself ; but they have been very carefully studied. Now, the curious thing is this, that although you have the same elements in the experiment in each case, the offspring is entirely different in character, according as the male influence comes from the Ass or the Horse. Where the Ass is the male, as in the case of the Mule, you 
find that the head is like that of the Ass, that the ears are long, the tail is tufted at the end, the feet are small, and the voice is an unmistakable bray; these are all points of similarity to the Ass; but, on the other hand, the barrel of the body and the cut of the neck are much more like those of the Mare. Then, if you look at the Hinny,- the result of the union of the Stallion and the she-Ass, then you find it is the Horse that has the predominance; that the head is more like that of the Horse, the ears are shorter, the legs coarser, and the type is altogether altered; while the voice, instead of being a bray, is the ordinary neigh of the Horse. Here, you see, is a most curious thing: you take exactly the same elements, Ass and Horse, but you combine the sexes in a different manner, and the result is modified accordingly. You have in this case, however, a result which is not general and universal-there is usually an important preponderance, but not always on the same side.

Here, then, is one intelligible, and, perhaps, necessary cause of variation: the fact, that there are two sexes sharing in the production of the offspring, and that the share taken by each is different and variable, not only for each combination, but also for different members of the same family.

Secondly, there is a variation, to a certain cxtent,though in all probability the influence of this cause has been very much exaggerated-but there is no doubt that variation is produced, to a certain extent, by what are commonly known as external conditions, - such as temperature, food, warmth, and moisture. In the long run, every variation depends, in some sense, upon external conditions, secing that everything has a cause of its own. I use the term " external conditions" now in the sense in which it is ordinarily employed : certain it is, that external conditions have a definite effect. You may take a plant which has single flowers, and by dealing with the soil, and nourishment, and so on, you may by-and-by convert single flowers into double flowers, and make thorns shoot out into branches. You may thicken or make various modifications in the shape of the fruit. In animals, too, you may produce analogous changes in this way, as in the case of that deep bronze colour which persons rarely lose after having passed any length of time in tropical countries. You may also alter the development of the muscles very much, by dint 
of training; all the world knows that exercise has a great effect in this way; we always expect to find the arm of a blacksmith hard and wiry, and possessing a large development of the brachial muscles. No doubt, training, which is one of the forms of external conditions, converts what are originally only instructions, teachings, into habits, or, in other words, into organizations, to a great extent; but this second cause of variation cannot be considered to be by any means a large one. The third cause that $I$ have to mention, however, is a very extensive one. It is one that, for want of a better name, has been called "spontaneous variation;" which means that when we do not know anything about the cause of phenomena, we call it spontaneous. In the orderly chain of causes and effects in this world, there are very few things of which it can be said with truth that they are spontaneous. Certainly not in these physical matters, -in these there is nothing of the kind,-everything depends on previous conditions. But when we cannot trace the cause of phenomena, we call them spontaneous.

Of these variations, multitudinous as they are, but little is known with perfect accuracy. I will mention to you some two or three cases, because they are very remarkable in themselves, and also because I shall want to use them afterwards. Réaumur, a famous French naturalist, a great many years ago, in an essay which he wrote upon the art of hatching chickens, - which was indeed a very curious essay,-had occasion to speak of variations and monstrosities. One very remarkable case had come under his notice of a variation in the form of a human member, in the person of a Maltese, of the name of Gratio Kelleia, who was born with six fingers upon each hand, and the like number of toes to each of his feet. That was a case of spontaneous variation. Nobody knows why he was born wilh that number of fingers and toes, and as we don't know, we call it a case of "spontaneous" variation. There is another remarkable case also. I select these, because they happen to have been observed and noted very carefully. at the time. It frequently happens that a variation occurs, but the persons who notice it do not take any care in noting down the particulars, until at length, when inquiries come to be made, the exact circumstances are forgotten; and hence, multitudinous as may be such " spontaneous " variations, it is exceedingly difficult to get at the origin of them. 
The second case is one of which you may find the whole details in the "Philosophical Transactions" for the year 1813, in a paper conmunicated by Colonel Humphrey to the President of the Royal Society, "On a new Variety in the Breed of Sheep," giving an account of a very remarkable breed of sheep, which at one time was well known in the northern states of America, and which went by the name of the Ancon or the Otter breed of sheep. In the year 1791, there was a farmer of the name of Seth Wright in Massachusetts, who had a flock of sheep, consisting of a ram and, I think, of some twelve or thirtcen ewes. Of this flock of ewes, one at the breeding-time bore a lamb which was very singularly formed; it had a very long body, very short legs, and those legs were bowed I I will tell you by-and-by how this singular variation in the breed of sheep came to be noted, and to have the prominence that it now has. For the present, I mention only these two cases; but the extent of variation in the breed of animals is perfectly obvious to any one who has studied natural history with ordinary attention, or to any person who compares animals with others of the same kind. It is strictly true that there are never any two specimens which are exactly alike; however similar, they will always differ in some certain particular.

Now let us go back to Atavism,-to the hereditary tendency I spoke of. What will come of a variation when you breed from it, when Atavism comes, if I may say so, to intersect variation? The two cases of which I have mentioned the history, give a most excellent illustration of what occurs. Gratio Kelleia, the Maltese, married when he was twenty-two years of age, and, as I suppose there were no six-fingered ladies in Malta, he married an ordinary five-fingered person. The result of that marriage was four children; the first, who was christened Salvator, had six fingers and six toes, like his father; the second was George, who had five fingers and toes, but one of them was deformed, showing a tendency to variation; the third was Andre; he had five fingers and five toes, quite perfect; the fourth was a girl, Marie; she had five fingers and five toes, but her thumbs were deformed, showing a tendency towards the sixth.

These children grew up, and when they came to adult years, they all married, and of course it happened that they all married five-fingered and five-toed persons. Now 
let us see what were the results. Salvator had four children ; they were two boys, a girl, and another boy: the first two boys and the girl were six-fingered and sixtoed like their grandfather; the fourth boy had only five fingers and five toes. George had only four children: there were two girls with six fingers and six toes; there was one girl with six fingers and five toes on the right side, and five fingers and five toes on the left side, so that she was half and half. The last, a boy, had five fingers and five toes. The third, Andrè, you will recollect, was perfectly well-formed, and he had many children whose hands and feet were all regularly developed. Marie, the last, who, of course, married a man who had only five fingers, had four children : the first, a boy, was born with six toes, but the other three were normal.

Now observe what very extraordinary phenomena are presented here. You have an accidental variation arising from what you may call a monstrosity; you have that monstrosity tendency or variation diluted in the first instance by an admixture with a female of normal construction, and you would naturally expect that, in the results of such an union, the monstrosity, if repeated, would be in equal proportion with the normal type; that is to say, that the children would be half and half, some taking the peculiarity of the father, and the others being of the purely normal type of the mother ; but you see we have a great preponderance of the abnormal type. Well, this comes to be mixed once more with the pure, the normal type, and the abnormal is again produced in large proportion, notwithstanding the second dilution. Now what would have happened if these abnormal types had intermarried with each other ; that is to say, suppose the two boys of Salvator had taken it into their heads to marry their first cousins, the two first girls of George, their uncle? You will remember that these are all of the abnormal type of their grandfather. The result would probably have been, that their offspring would have been in every case a further development of that abnormal type. You see it is only in the fourth, in the person of Marie, that the tendency, when it appears but slightly in the second generation, is washed out in the third, while the progeny of Andrè, who escaped in the first instance, escape altogether.

We have in this case a good example of nature's tendency 
to the perpetuation of a variation. Here it is certainly a variation which carried with it no use or benefit; and yet you see the tendency to perpetuation may be so strong, that, notwithstanding a great admixture of pure blood, the variety continues itself up to the third generation, which is largely marked with it. In this case, as I have said, there was no means of the second generation intermarrying with any but five-fingered persons, and the question naturally suggests itself, What would have been the result of such marriage ? Réaumur narrates this case only as far as the third generation. Certainly it would have been an exceedingly curious thing if we could have traced this matter any further; had the cousins intermarried, a six-fingered variety of the human race might have been set up.

To show you that this supposition is by no means an unreasonable one, let me now point out what took place in the case of Seth Wright's sheep, where it happened to be a matter of moment to him to obtain a breed or raise a flock of sheep like that accidental variety that I have described-and I will tell you why. In that part of Massachusetts where Seth Wright was living, the fields were separated by fences, and the sheep, which were very active and robust, would roam abroad, and without much difficulty jump over these fences into other people's farms. As a matter of course, this exuberant activity on the part of the sheep constantly gave rise to all sorts of quarrels, bickerings, and contentions anong the farmers of the neighbourhood; so it occurred to Seth Wright, who was, like his successors, more or less 'cute, that if he could get a stock of sheep like those with the bandy legs, they would not be able to jump over the fences so readily, and he acted upon that idea. He killed his old ram, and as soon as the young one arrived at maturity, he bred altogether from it. The result was even more striking than in the human experiment which I mentioned just now. Colonel Humphreys testifies that it always happened that the offspring were either pure Ancons or pure ordinary sheep; that in no case was there any mixing of the Ancons with the others. In consequence of this, in the course of a very few years, the farmer was able to get a very considerable flock of this variety, and a large number of them were spread throughout Massachusetts. Most unfortunately, however-I suppose it was because they were so common-nobody took chough 
notice of them to preserve their skeletons; and although Colonel Humphreys states that he sent a skeleton to the president of the Royal Society at the same time that he forwarded his paper, I am afraid that the variety has entirely disappeared; for a short time after these sheep had become prevalent in that district, the Merino sheep were introduced; and as their wool was much more valuable, and as they were a quiet race of sheep, and showed no tendency to trespass or jump over fences, the Otter breed of sheep, the wool of which was inferior to that of the Merino, was gradually allowed to die out.

You see that these facts illustrate perfectly well what may be done if you take care to breed from stocks that are similar to each other. After having got a variation, if, by crossing a variation with the original stock, you multiply that variation, and then take care to keep that variation distinct from the original stock, and make them breed together,-then you may almost certainly produce a race whose tendency to continue the variation is exceedingly strong.

This is what is called "selection"; and it is by exactly the same process as that by which Seth Wright bred his Ancon sheep, that our breeds of cattle, dogs, and fowls, are obtained. There are some possibilitics of exception, but still, speaking broadly, I may say that this is the way in which all our varied races of domestic animals have arisen; and you must understand that it is not one peculiarity or one characteristic alone in which animals may vary. There is not a single peculiarity or characteristic of any kind, bodily or mental, in which offspring may not vary to a certain extent from the parent and other animals.

Among ourselves this is well known. The simplest physical peculiarity is mostly reproduced. I know a case of a man whose wife has the lobe of one of her ears a little flattened. An ordinary observer might scarcely notice it, and yet every one of her children has an approximation to the same peculiarity to some extent. If you look at the other extreme, too, the gravest diseases, such as gout, scrofula, and consumption, may be handed down with just the same certainty and persistence as we noticed in the perpetuation of the bandy legs of the Ancon sheep.

However, these facts are best illustrated in animals, and the extent of the variation, as is well known, is very re- 
markable in dogs. For example, there are some dogs very much smaller than others; indeed, the variation is so enormous that probably the smallest dog would be about the size of the head of the largest; there are very great variations in the structural forms not only of the skeleton but also in the shape of the skull, and in the proportions of the face and the disposition of the teeth.

The Pointer, the Retriever, Bulldog, and the Terrier, differ very greatly, and yet there is every reason to believe that every one of these races has arisen from the same source,- that all the most important races have arisen by this selective breeding from accidental variation.

A still more striking case of what may be done by selective breeding, and it is a better case, because there is no chance of that partial infusion of error to which I alluded, has been studied very carefully by Mr. Darwin, -the case of the domestic pigeons. I dare say there may be some among you who may be pigeon fanciers, and I wish you to understand that in approaching the subject, I would speak with all humility and hesitation, as I regret to say that I am not a pigeon fancier. I know it is a great art and mystery, and a thing upon which a man must not speak lightly; but I shall endeavour, as far as my understanding goes, to give you a summary of the published and unpublished information which I have gained from Mr. Darwin.

Among the enormous variety, - I believe there are somewhere about a hundred and fifty kinds of pigeons, -there are four kinds which may be' selected as representing the extremest divergences of one kind from another. Their names are the Carrier, the Pouter, the Fantail, and the Tumbler. In the large diagrams they are each represented in their relative sizes to each other. This first one is the Carrier; you will notice this large excrescence on its beak; it has a comparatively small head; there is a bare space round the eyes; it has a long neck, a very long beak, very strong legs, large feet, long wings, and so on. The second one is the Pouter, a very large bird, with very long legs and beak. It is called the Pouter because it is in the habit of causing its gullet to swell up by inflating it with air. I should tell you that all pigeons have a tendency to do this at times, but in the Pouter it is carried to an enormous extent. The birds appear to be quite proud of their power of swelling and 
puffing themselves out in this way; and I think it is about as droll a sight as you can well see to look at a cage full of these pigeons puffing and blowing themselves out in this ridiculous manner.

The third kind I mentioned-the Fantail-is a small bird with exceedingly small legs and a very small beak. It is most curiously distinguished by the size and extent of its tail, which, instead of containing twelve feathers, may have many more,-say thirty, or even more-I believe there are some with as many as forty-two. This bird has a curious habit of spreading out the feathers of its tail in such a way that they reach forward, and touch its head; and if this can be accomplished, I believe it is looked upon as a point of great beauty.

But here is the last great variety,-the Tumbler; and of that great variety, one of the principal kinds, and one most prized, is the specimen represented here-the shortfaced Tumbler. Its beak is reduced to a mere nothing. Just compare the beak of this one and that of the first one, the Carrier-I believe the orthodox comparison of the head and beak of a thoroughly well-bred Tumbler is to stick an oat into a cherry, and that will give you the proper relative proportions of the head and beak. The feet and legs are exceedingly small, and the bird appears to be quite a dwarf when placed side by side with this great Carrier.

These are differences enough in regard to their external appearance; but these differences are by no means the whole or even the most important of the differences which obtain between these birds. There is hardly a single point of their structure which has not become more or less altered; and to give you an idea of how extensive these alterations are, I have here some very good skeletons, for which I am indebted to my friend Mr. Tegetmeier, a great authority in these matters; by means of which, if you examine them by-and-by, you will be able to see the enormous difference in their bony structures.

I had the privilege, some time ago, of access to some important MSS. of Mr. Darwin, who, I may tell you, has taken very great pains and spent much valuable time and attention on the investigation of these variations, and getting together all the facts that bear upon them. I obtained from these MSS. the following summary of the differences between the domestic breeds of pigeons; that 
is to say, a notification of the various points in wnich their organization differs. In the first place, the back of the skull may differ a good deal, and the development of the bones of the face may vary a great deal; the back varies a good deal; the shape of the lower jaw varies; the tongue varies very greatly, not only in correlation to the length and size of the beak, but it secms also to have a kind of independent variation of its own. Then the amount of naked slin round the eyes, and at the base of the beak, may vary enormously; so may the length of the eyclids, the shape of the nostrils, and the length of the neck. I have already noticed the habit of blowing out the gullet, so remarkable in the Pouter, and comparatively so in the others. There are great differences, too, in the size of the female and the male, the shape of the body, the number and width of the processes of the ribs, the development of the ribs, and the size, shape, and development of the breastbone. We may notice, too,-and I mention the fact because it has been disputed by what is assumed to be high authority, - the variation in number of the sacral vertebræ. The number of these varies from eleven to fourteen, and that without any diminution in the number of the vertebræ of the back or of the tail. Then the number and position of the tail-feathers may vary enormously, and so may the number of the primary and secondary feathers of the wings. Again, the length of the feet and of the beak, -although they have no relation to each other, yet appear to go together,-that is, you have a long beak wherever you have long feet. There are differences also in the periods of the acquirement of the perfect plumage,the size and shape of the eggs, - the nature of flight, and the powers of flight,-so-called "homing" birds having enormous flying powers; * while, on the other hand, the little Tumbler is so called because of its extraordinary faculty of turning head over heels in the air, instead of pursuing a distinct course. And, lastly, the dispositions and voices of the birds may vary. Thus the case of the pigeons shows you that there is hardly a single particular, -whether of instinct, or habit, or bony structure, or of plumage, - of either the internal cconomy or the external

- The " Carricr," I learn from Mr. Tegetmeier, does not carry; a high-bred bird of this breed being but a poor flier. The birds which ny long distances, and come home,- "homing" birds,-and are consequently used as carriers, are not " carriers" in the fancy sense. 
shape, in which some variation or change may not take place, which, by selective breeding, may become perpetuated, and form the foundation of, and give rise to, a new race.

If you carry in your mind's eye these four varieties of pigeons, you will bear with you as good a notion as you can have, perhaps, of the enormous extent to which a deviation from a primitive type may be carried by means of this process of selective breeding. 


\section{THE CONDITIONS OF EXISTENCE AS AFFECTING THE PERPETUATION OF LIVING BEINGS}

In the last lecture I endeavoured to prove to you that, while, as a general rule, organic beings tend to reproduce their kind, there is in them, also, a constantly recurring tendency to vary - to vary to a greater or to a less extent. Such a variety, I pointed out to you, might arise from causes which we do not understand; we therefore called it spontaneous; and it might come into existence as a definite and marked thing, without any gradations between itself and the form which preceded it. I further pointed out, that such a variety having once arisen, might be perpetuated to some extent, and indeed to a very marked extent, without any direct interference, or without any exercise of that process which we called selection. And then I stated further, that by such selection, when exercised artificially-if you took care to breed only from those forms which presented the same peculiaritics of any variety which had arisen in this manner-the variation might be perpetuated, as far as we can see, indefinitely.

The next question, and it is an important one for us, is this: Is there any limit to the amount of variation from the primitive stock which can be produced by this process of selective breeding? In considering this question, it will be useful to class the characteristics, in respect of which organic beings vary, under two heads: we may consider structural characteristics, and we may consider physiological characteristics.

In the first place, as regards structural characteristics, I endeavoured to show you, by the skeletons which I had upon the table, and by reference to a great many wellascertained facts, that the different breeds of Pigeons, the Carriers, Pouters, and Tumblers, might vary in any of their internal and important structural characters to a very great degree; not only might there be changes in the proportions of the skull, and the characters of the fect 
and beaks, and so on; but that there might be an absolute difference in the number of the vertebræ of the back, as in the sacral vertebræ of the Pouter; and so great is the extent of the variation in these and similar characters that I pointed out to you, by reference to the skeletons and the diagrams, that these extreme varieties may absolutely differ more from one another in their structural characters than do what naturalists call distinct SPECIES of pigeons ; that is to say, that they differ so much in structure that there is a greater difference between the Pouter and the Tumbler than there is between such wild and distinct forms as the Rock Pigeon or the Ring Pigeon, or the Ring Pigeon and the Stock Dove ; and indeed the differences are of greater value than this, for the structural differences between these domesticated pigeons are such as would be admitted by a naturalist, supposing he knew nothing at all about their origin, to entitle them to constitute even distinct genera.

As I have used this term Species, and shall probably use it a good deal, I had better perhaps devote a word or two to explaining what I mean by it.

Animals and plants are divided into groups, which become gradually smaller, beginning with a KrNGDOM, which is divided into Sub-Krngdoms; then come the smaller divisions called Provinces; and so on from a Province to a Class, from a Class to an Order, from Orders to Families, and from these to Genera, until we come at length to the smallest groups of animals which can be defined one from the other by constant characters, which are not sexual; and these are what naturalists call Species in practice, whatever they may do in theory.

If in a state of nature you find any two groups of living beings, which are separated one from the other by some constantly-recurring characteristic, I don't care how slight and trivial, so long as it is defined and constant, and does not depend on sexual peculiarities, then all naturalists agree in calling them two species; that is what is meant by the use of the word species-that is to say, it is, for the practical naturalist, a mere question of structural differences.*

We have seen now-to repeat this point once more, and

* I lay stress here on the practical signification of " Species." Whether a physiological test between species exist or not, it is hardly ever applicable by the practical naturalist. 
it is very essential that we should rightly understand it -we have seen that brecds, known to have been derived from a common stock by selection, may be as different in their structure from the original stock as species may be distinct from each other.

But is the like true of the physiological characteristics of animals? Do the plysiological differences of varieties amount in degree to those observed between forms which naturalists call distinct species ? This is a most important point for us to consider.

As regards the great majority of physiological characteristics, there is no doubt that they are capable of being developed, increased, and modified by selection.

There is no doubt that breeds may be made as different as species in many physiological characters. I have already pointed out to you very briefly the different habits of the breeds of Pigeons, all of which depend upon their physiological peculiarities, - as the peculiar habit of tumbling, in the Tumbler,-the peculiarities of flight, in the "homing" birds,-the strange habit of spreading out the tail, and walking in a peculiar fashion, in the Fantail,-and, lastly, the habit of blowing out the gullet, so characteristic of the Pouter. These are all due to physiological modifications, and in all these respects these birds differ as much from each other as any two ordinary species do.

So with Dogs in their habits and instincts. It is a physiological peculiarity which leads the Greyhound to chase its prey by sight, - that enables the Beagle to track it by the scent,- - that impels the Terrier to its rat-hunting propensity, - and that leads the Retriever to its habit of retrieving. 'These habits and instincts are all the results of physiological differences and pcculiarities, which have been developed from a common stock, at least there is every reason to believe so. But it is a most singular circumstance, that while you may run through almost the whole series of physiological processes, without finding a check to your argument, you come at last to a point where you do find a check, and that is in the reproductive processes. For there is a most singular circumstance in respect to natural species---at least about some of themand it would be sufficient for the purposes of this argument, if it were true of only one of them, but there is, in fact, a great number of such cases-and that is, that similar as 
they may appear to be to mere races or breeds, they present a marked peculiarity in the reproductive process. If you breed from the male and female of the same race, you of course have offspring of the like kind, and if you make the offspring breed together, you obtain the same result, and if you breed from these again, you will still have the same kind of offspring; there is no check. But if you take members of two distinct species, however similar they may be to each other, and make them breed together, you will find a check, with some modifications and exceptions, however, which I shall speak of presently. If you cross two such species with each other, then,-although you may get offspring in the case of the first cross, yet, if you attempt to breed from the products of that crossing, which are what are called HyBrids - that is, if you couple a male and a female hybrid-then the result is that in ninety-nine cases out of a hundred you will get no offspring at all : there will be no result whatsoever.

The reason of this is quite obvious in some cases; the male hybrids, although possessing all the external appearances and characteristics of perfect animals, are physiologically imperfect and deficient in the structural parts of the reproductive elements necessary to generation. It is said to be invariably the case with the male mule, the cross between the Ass and the Mare ; and hence it is, that, although crossing the Horse with the Ass is easy enough, and is constantly done, as far as I am aware, if you take two mules, a male and a female, and endeavour to breed from them, you get no offspring whatever; no generation will take place. This is what is called the sterility of the hybrids between two distinct species.

You see that this is a very extraordinary circumistance; one does not see why it should be. The common teleological explanation is, that it is to prevent the impurity of the blood resulting from the crossing of one species with another, but you see it does not in reality do anything of the kind. There is nothing in this fact that hybrids cannot breed with each other, to establish such a theory; there is nothing to prevent the Horse breeding with the Ass, or the Ass with the Horse. So that this explanation breaks down, as a great many explanations of this kind do, that are only founded on mere assumptions.

Thus you see that there is a great difference between " mongrels," whicls are crosses between distinct races, and 
"hybrids," which are crosses between distinct species. The mongrels are, so far as we know, fertile with one another. But between species, in many cases, you cannot succeed in obtaining even the first cross : at any rate it is quite certain that the hybrids are often absolutely infertile one with another.

Here is a feature, then, great or small as it may be, which distinguishes natural species of animals. Can we find any approximation to this in the different races known to be produced by selective brecding from a common stock ? Up to the present time the answer to that question is absolutely a negative one. As far as we know at present, there is nothing approximating to this check. In crossing the breeds between the Fantail and the Pouter, the Carrier and the Tumbler, or any other variety or race you may name-so far as we know at present-there is no difficulty in breeding together the mongrels. Take the Carrier and the Fantail, for instance, and let them represent the Horse and the Ass in the case of distinct species; then you have, as the result of their breeding, the Carrier-Fantail mongrel, -we will say the male and female mongrel,-and, as far as we know, these two when crossed would not be less fertile than the original cross, or than Carrier with Carricr. Here, you see, is a physiological contrast between the races produced by selective modification and natural species. I shall inquire into the value of this fact, and of some modifying circumstances by and by; for the present I merely put it broadly before you.

But while considering this question of the limitations of species, a word must be said about what is called Recurrence-the tendency of races which have been developed by selective breeding from varieties to return to their primitive type. This is supposed by many to put an absolute limit to the extent of selective and all other variations. People say, "It is all very well to talk about producing these different races, but you know very well that if you turned all these birds wild, these Pouters, and Carriers, and so on, they would all return to their primitive stock." This is very commoniy assumed to be a fact, and it is an argument that is commonly brought forward as conclusive; but if you will take the trouble to inquire into it rather closely, I think you will find that it is not worth very much. The first question of course is, Do they thus return to the primitive stock? And commonly as 
the thing is assumed and accepted, it is extremely difficult to get anything like good evidence of it. It is constantly said, for example, that if domesticated Horses are turned wild, as they have been in some parts of Asia Minor and South America, that they return at once to the primitive stock from which they were bred. But the first answer that you make to this assumption is, to ask who knows what the primitive stock was; and the second answer is, that in that case the wild Horses of Asia Minor ought to be exactly like the wild Horses of South America. If they are both like the same thing, they ought manifestly to be like each other! The best authorities, however, tell you that it is quite different. The wild Horse of Asia is said to be of a dun colour, with a largish head, and a great many other peculiarities; while the best authorities on the wild Horses of South America tell you that there is no similarity between their wild Horses and those of Asia Minor; the cut of their heads is very different, and they are commonly chestnut or bay-coloured. It is quite clear, therefore, that as by these facts there ought to have been two primitive stocks, they go for nothing in support of the assumption that races recur to one primitive stock, and so far as this evidence is concerned, it falls to the ground.

Suppose for a moment that it were so, and that domesticated races, when turned wild, did return to some common condition, I cannot see that this would prove much more than that similar conditions are likely to produce similar results; and that when you take back domesticated animals into what we call natural conditions, you do exactly the same thing as if you carefully undid all the work you had gone through, for the purpose of bringing the animal from its wild to its domesticated state. I do not see anything very wonderful in the fact, if it took all that trouble to get it from a wild state, that it should go back into its original state as soon as you removed the conditions which produced the variation to the domesticated form. There is an important fact, however, forcibly brought forward by Mr. Darwin, which has been noticed in connection with the breeding of domesticated pigeons; and it is, that however different these breeds of pigeons may be from each other, and we have already noticed the great differences in these breeds, that if, among any of those variations, you chance to have a blue pigeon turn up, it will be sure to have the black bars across the wings, 
which are characteristic of the original wild stock, the Fock Pigeon.

Now, this is certainly a very remarkable circumstance ; but I do not see myself how it tells very strongly either one way or the other. I think, in fact, that this argument in favour of recurrence to the primitive type might prove a great deal too much for those who so constantly bring it forward. For example, Mr. Darwin has very forcibly urged, that nothing is commoner than if you examine a dun hor'se-and I had an opportunity of verifying this illustration lately, while in the islands of the West Highlands, where there are a great many dun horses-to find that horse exhibit a long black stripe down his back, very often stripes on his shoulder, and very often stripes on his legs. I, myself, saw a pony of this description a short time ago, in a baker's cart, near Rothesay, in Bute : it had the long stripe down the back, and stripes on the shoulders and legs, just like those of the Ass, the Quagga, and the Zebra. Now, if we interpret the theory of recurrence as applied to this case, might it not be said that here was a case of a variation exhibiting the characters and conditions of an animal occupying something like an intermediate position between the Horse, the Ass, the Quagga, and the Zebra, and from which these liad been developed? In the same way with regard even to Man. Every anatomist will tell you that there is nothing commoner, in dissecting the human body, than to meet with what are called muscular variations - that is, if you dissect two bodies very carefully, you will probably find that the modes of attachment and insertion of the muscles are not exactly the same in both, there being great peculiarities in the mode in which the muscles are arranged; and it is very singular, that in some dissections of the human body you will come upon arrangements of the muscles very similar indeed to the same parts in the Apes. Is the conclusion in that case to be, that this is like the black bars in the case of the Pigeon, and that it indicates a recurrence to the primitive type from which the animals have been probably developed? Truly, I think that the opponents of modification and variation had better leave the argument of recurrence alone, or it may prove altogether too strong for them.

To sum up,- the evidence as far as we have gone is against the argument as to any limit to divergences, so far as structure is concerned; and in favour of a physiological 
limitation. By selective breeding we can produce structural divergences as great as those of species, but we cannot produce equal physiological divergences. For the present I leave the question there.

Now, the next problem that lies before us-and it is an extremely-important one-is this: Does this selective breeding occur in nature? Because, if there is no proof of it, all that I have been telling you goes for nothing in accounting for the origin of species. Are natural causes competent to play the part of selection in perpetuating varieties? Here we labour under very great difficulties. In the last lecture I had occasion to point out to you the extreme difficulty of obtaining evidence even of the first origin of those varieties which we know to have occurred in domesticated animals. I told you, that almost always the origin of these varieties is overlooked, so that I could only produce two of three cases, as that of Gratio Kelleia and of the Ancon sheep. People forget, or do not take notice of them until they come to have a prominence; and if that is true of artificial cases, under our own eyes, and in animals in our own care, how much more difficult it must be to have at first hand good evidence of the origin of varieties in nature ! Indeed, I do not know that it is possible by direct evidence to prove the origin of a variety in nature, or to prove selective breeding; but I will tell you what we can prove-and this comes to the same thing -that varieties exist in nature within the limits of species, and, what is more, that when a variety has come into existence in nature, there are natural causes and conditions, which are amply competent to play the part of a selective breeder; and although that is not quite the evidence that one would like to have-though it is not direct testimony -yet it is exceeding good and exceedingly powerful evidence in its way.

As to the first point, of varieties existing among natural species, I might appeal to the universal experience of every naturalist, and of any person who has ever turned any attention at all to the characteristics of plants and animals in a state of nature ; but I may as well take a few deñnite cases, and I will begin with Man himself.

I am one of those who believe that, at present, there is no evidence whatever for saying, that mankind sprang originally from any more than a single pair; I must say, that I cannot see any good ground whatever, or even any 
tenable sort of evidence, for believing that there is more than one species of Man. Nevertheless, as you know, just as there are numbers of varieties in animals, so there are remarkable varieties of men. I speak not merely of those broad and distinct variations which you see at a glance. Everybody, of course, knows the difference between a Negro and a white man, and can tell a Chinaman from an Englishman. They each have peculiar characteristics of colour and physiognomy; but you must recollect that the characters of these races go very far deeper-they extend to the bony structure, and to the characters of that most important of all organs to us-the brain ; so that, among men belonging to different races, or even within the same race, one man shall have a brain a third, or half, or even seventy per cent. bigger than another; and if you take the whole range of human brains, you will find a variation in some cases of a hundred per cent. Apart from these variations in the size of the brain, the characters of the skull vary. Thus if I draw the figures of a Mongul and of a Negro head on the blackboard, in the case of the last the breadth would be about seven-tenths, and in the other it would be nine-tenths of the total length. So that you see there is abundant evidence of variation among men in their natural condition. And if you turn to other animals there is just the same thing. The fox, for example, which has a very large geographical distribution all over Europe, and parts of Asia, and on the American Continent, varies greatly. There are mostly large foxes in the North, and smaller ones in the South. In Germany alone, the foresters reckon some eight different sorts.

Of the tiger, no one supposes that there is more than one species; they extend from the hottest parts of Bengal, into the dry, cold, bitter steppes of Siberia, into a latitude of $50^{\circ}$, - so that they may even prey upon the reindeer. These tigers have exceedingly different characteristics, but still they all keep their general features, so that there is no doubt as to their being tigers. The Siberian tiger has a thick fur, a small mane, and a longitudinal stripe down the back, while the tigers of Java and Sumatra differ in many important respects from the tigers of Northern Asia. So lions vary; so birds vary; and so, if you go further back and lower down in creation, you find that fishes vary. In different streams, in the same country even, you will find the trout to be quite different to each other and easily 
recognizable by those who fish in the particular streams. There is the same differences in leeches; leech collectors can easily point out to you the differences and the peculiarities which you yourself would probably pass by; so with fresh-water mussels ; so, in fact, with every animal you can mention.

In plants there is the same kind of variation. Take such a case even as the common bramble. The botanists are all at war about it ; some of them wanting to make out that there are many species of it, and others maintaining that they are but many varieties of one species; and they cannot settle to this day which is a species and which is a variety!

So that there can be no doubt whatsoever that any plant and any animal may vary in nature; that varieties may arise in the way $I$ have described,-as spontaneous varieties, -and that those varieties may be perpetuated in the same way that I have shown you spontaneous varieties are perpetuated; I say, therefore, that there can be no doubt as to the origin and perpetuation of varieties in nature.

But the question now is:-Does selection take place in nature? is there anything like the operation of man in exercising selective breeding, taking place in nature ? You will observe that, at present, I say nothing about species; I wish to confine myself to the consideration of the production of those natural races which everybody admits to exist. The question is, whether in nature there are causes competent to produce races, just in the same way as man is able to produce, by selection, such races of animals as we have already noticed.

When a variety has arisen, the Condrtions of ExistENCE are such as to exercise an influence which is exactly comparable to that of artificial selection. By Conditions of Existence I mean two things,-there are conditions which are furnished by the physical, the inorganic world, and there are conditions of existence which are furnished by the organic world. There is, in the first place, Climate; under that head I include only temperature and the varied amount of moisture of particular places. In the next place there is what is technically called Station, which means-given the climate, the particular kind of place in which an animal or a plant lives or grows ; for example, the station of a fish is in the water, of a fresh-water fish in 
fresh water ; the station of a marine fish is in the sea, and a marine animal may have a station higher or deeper. So again with land animals: the differences in their stations are those of different soils and neighbourhoods ; some being best adapted to a calcareous, and others to an arenaceous soil. The third condition of existence is Foon, by which I mean food in the broadest sense, the supply of the materials necessary to the existence of an organic being; in the case of a plant the inorganic matters, such as carbonic acid, water, ammonia, and the earthy salts or salines; in the case of the animal the inorganic and organic matters, which we have seen they require; then these are all, at lcast the two first, what we may call the inorganic or physical conditions of existence. Food takes a mid-place, and then come the organic conditions; by which I mean the conditions which depend upon the state of the rest of the organic creation, upon the number and kind of living beings, with which an animal is surrounded. You may class these under two heads: there are organic beings, which operate as opponents, and there are organic bcings which operate as helpers to any given organic creature. The opponents may be of two kinds : there are the indirect opponents, which are what we may call rivals; and there are the direct opponents, those which strive to destroy the creature; and these we call enemies. By rivals I mean, of course, in the case of plants, those which require for their support the same kind of soil and station, and, among animals, those which require the same kind of station, or food, or climate; those are the indirect opponents the direct opponents are, of course, those which prey upon an animal or vegetable. The helpers may also be regarded as direct and indirect : in the case of a carnivorous animal, for example, a particular herbaceous plant may in multiplying be an indirect helper, by enabling the herbivora on which the carnivore preys to get more food, and thus to nourish the carnivore more abundantly ; the direct helper may be best illustrated by reference to some parasitic creature, sucis as the tape-worm. The tape-worm exists in the human intestines, so that the fewer there are of men the fewer there will be of tape-worms, other things being alike. It is a humiliating reflection, perhaps, that we may be classed as direct helpers to the tape-worm, but the fact is so: we can all see that if there were no men there would be no tape-worms. 
It is extremely difficult to estimate, in a proper way, the importance and the working of the Conditions of Existence. I do not think there were any of us who had the remotest notion of properly estimating them until the publication of Mr. Darwin's work, which has placed them before us with remarkable clearness; and I must endeavour, as far as I can in my own fashion, to give you some notion of how they work. We shall find it easiest to take a simple case, and -one as free as possible from every kind of complication.

I will suppose, therefore, that all the habitable part of this globe-the dry land, amounting to about $51,000,000$ square miles,-I will suppose that the whole of that dry land has the same climate, and that it is composed of the same kind of rock or soil, so that there will be the same station everywhere; we thus get rid of the peculiar influence of different climates and stations. I will then imagine that there shall be but one organic being in the world, and that shall be a plant. In this we start fair. Its food is to be carbonic acid, water and ammonia, and the saline matters in the soil,-which are, by the supposition, everywhere alike. We take one single plant, with no opponents, no helpers, and no rivals ; it is to be a " fair field, and no favour." Now, I will ask you to imagine further that it shall be a plant which shall produce every year fifty seeds, which is a very moderate number for a plant to produce; and that, by the action of the winds and currents, these seeds shall be equally and gradually distributed over the whole surface of the land. I want you now to trace out what will occur, and you will observe that I am not talking fallaciously any more than a mathematician does when he expounds his problem. If you show that the conditions of your problem are such as may actually occur in nature and do not transgress any of the known laws of nature in working out your proposition, then you are as safe in the conclusion you arrive at as is the mathematician in arriving at the solution of his problem. In science, the only way of getting rid of the complications with which a subject of this kind is environed, is to work in this deductive method. What will be the result, then ? I will suppose that every plant requires one square foot of ground to live upon; and the result will be that, in the course of nine years, the plant will have occupied every single available spot in the whole globe! I have chalked 
upon the blackboard the figures by which I arrive at the result :

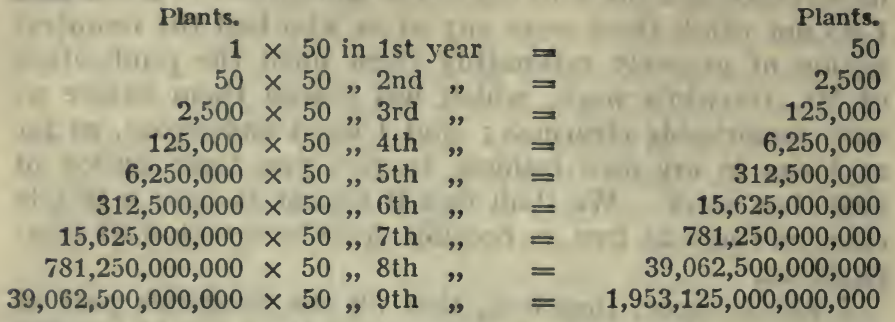

$51,000,000$ sq. miles-the dry sur-

face of the earth $\times 27,878,400-$ =sq. $\mathrm{ft}$. $1,421,798,400,000,000$ the number of sq. $\mathrm{ft}$. in 1 sq. mile

being $531,326,600,000,000$ square feet less than would be required at the end of the ninth year.

You will see from this that, at the end of the first year the single plant will have produced fifty more of its kind; by the end of the second year these will have increased to 2,500 ; and so on, in succeeding years, you get beyond even trillions; and I am not at all sure that I could tell you what the proper arithmetical denomination of the total number really is; but, at any rate, you will understand the meaning of all those noughts. Then you see that, at the bottom, I have taken the $51,000,000$ of square miles, constituting the surface of the dry land; and as the number of square feet are placed under and subtracted from the number of seeds that would be produced in the ninth year, you can see at once that there would be an immense number more of plants than there would be square feet of ground for their accommodation. This is certainly quite enough to prove my point; that between the eighth and ninth year after being planted the single plant would have stocked the whole available surface of the earth.

This is a thing which is hardly conceivable-it seems hardly imaginable-yet it is so. It is indeed simply the law of Malthus exemplified. Mr. Malthus was a clergyman, who worked out this subject most minutely and truthfully some years ago; he showed quite clearly,and although he was much abused for his conclusions at the time, they have never yet been disproved and never will be-he showed that in consequence of the increase in the number of organic beings in a geometrical ratio, while 
the means of existence cannot be made to increase in the same ratio, that there must come a time when the number of organic beings will be in excess of the power of production of nutriment, and that thus some check must arise to the further increase of those organic beings. At the end of the ninth year we have seen that each plant would not be able to get its full square foot of ground, and at the end of another year it would have to share that space with fifty others the produce of the seeds which it would give off.

What, then, takes place? Every plant grows up, flourishes, occupies its square foot of ground, and gives off its fifty seeds; but notice this, that out of this number only one can come to anything; there is thus, as it were, forty-nine chances to one against its growing up; it depends upon the most fortuitous circumstances whether any one of these fifty seeds shall grow up and flourish, or whether it shall die and perish. This is what Mr. Darwin has drawn attention to, and called the "STRUGGLE For ExISTENCE" ; and I have taken this simple case of a plant because some people imagine that the phrase seems to imply a sort of fight.

I have taken this plant and shown you that this is the result of the ratio of the increase, the necessary result of the arrival of a time coming for every species when exactly as many members must be destroyed as are born; that is the inevitable ultimate result of the rate of production. Now, what is the result of all this ? I have said that there are forty-nine struggling against every one ; and it amounts to this, that the smallest possible start given to any one seed may give it an advantage which will enable it to get ahead of all the others; anything that will enable any one of these seeds to germinate six hours before any of the others will, other things being alike, enable it to choke them out altogether. I have shown you that there is no particular in which plants will not vary from each other; it is quite possible that one of our imaginary plants may vary in such a character as the thickness of the integument of its seeds; it might happen that one of the plants might produce seeds having a thinner integument, and that would enable the seeds of that plant to germinate a little quicker than those of any of the others, and those seeds would most inevitably extinguish the forty-nine times as many that were struggling with them.

I have put it in this way, but you see the practical result 
of the process is the same as if some person had nurtured the one and destroyed the other seeds. It does not matter how the variation is produced, so long as it is once allowed to occur. The variation in the plant once fairly started tends to become hereditary and reproduce itself; the seeds would spread themselves in the same way and take part in the struggle with the forty-nine hundred, or forty-nine thousand, with which they might be exposed. Thus, by degrees, this variety, with some slight organic change or modification, must spread itself over the whole surface of the habitable globe, and extirpate or replace the other kinds. That is what is meant by Natural Selection ; that is the kind of argument by which it is perfectly demonstrable that the conditions of existence may play exactly the same part for natural varieties as man does for domesticated varieties. No one doubts at all that particular circumstances may be more favourable for one plant and less so for another, and the moment you admit that, you admit the selective power of nature. Now, although I have been putting a hypothetical case, you must not suppose that I have been reasoning hypothetically. There are plenty of direct experiments which bear out what we may call the theory of natural selection ; there is extremely good authority for the statement that if you take the seed of mixed varieties of wheat and sow it, collecting the seed next year and sowing it again, at length you will find that out of all your varieties only two or three have lived, or perhaps even only one. There were one or two varieties which were best fitted to get on, and they have killed out the other kinds in just the same way and with just the same certainty as if you had taken the trouble to remove them. As I have already said, the operation of nature is exactly the same as the artificial operation of man.

But if this be true of that simple case, which I put before you, where there is nothing but the rivalry of one member of a species wilh others, what must be the operation of selective conditions, when you recollect as a matter of fact, that for every species of animal or plant there are fifty or a hundred species which might all, more or less, be comprehended in the same climate, food, and station ;that every plant has multitudinous animals which prey upon it, and which are its direct opponents; and that these have other animals preying upon them,-that every Dlant has its indirect helpers in the birds that scatter 
abroad its seed, and the animals that manure it with their dung;-I, say, when these things are considered, it seems impossible that any variation which may arise in a species in nature should not tend in some way or other either to be a little better or worse than the previous stock; if it is a little better it will have an advantage over and tend to extirpate the latter in this crush and struggle; and if it is a little worse it will itself be extirpated.

I know nothing that more appropriately expresses this, than the phrase, "the struggle for existence"; because it brings before your minds, in a vivid sort of way, some of the simplest possible circumstances connected with it. When a struggle is intense there must be some who are sure to be trodden down, crushed, and overpowered by others ; and there will be some who just manage to get through only by the help of the slightest accident. I recollect reading an account of the famous retreat of the French troops, under Napoleon, from Moscow. Worn out, tired, and dejected, they at length came to a great river over which there was but one bridge for the passage of the vast army. Disorganized and demoralized as that army was, the struggle must certainly have been a terrible one-every one heeding only himself, and crushing through the ranks and treading down his fellows. The writer of the narrative, who was himself one of those who were fortunate enough to succeed in getting over, and not among the thousands who were left behind or forced into the river, ascribed his escape to the fact that he saw striding onward through the mass a great istrong fellow,-one of the French Cuirassiers, who had on a large blue cloak-and he had enough presence of mind to catch and retain a hold of this strong man's cloak. He says, "I caught hold of his cloak, and although he swore at me and cut at and struck me by turns, and at last, when he found he could not shake me off, fell to entreating me to leave go or I should prevent him from escaping, besides not assisting myself, I still kept tight hold of him, and would not quit my grasp until he had at last dragged me through." Here you see was a case of selective saving-if we may so term it-depending for its success on the strength of the cloth of the Cuirassier's cloak. It is the same in nature; every species has its bridge of Beresina; it has to fight its way through and struggle with other species; and when well nigh overpowered, it may be that the smallest chance, something 
in its colour, perhaps-the minutest circumstance-will turn the scale one way or the other.

Suppose that by a variation of the black race it had produced the white man at any time-you know that the Negroes are said to believe this to have been the case, and to imagine that Cain was the first white man, and that we are his descendants-suppose that this had ever happened, and that the first residence of this human being was on the West Coast of Africa. There is no great structural difference between the white man and the Negro, and yet there is something so singularly different in the constitution of the two, that the malarias of that country, which do not hurt the black at all, cut off and destroy the white. Then you see there would have been a selective operation performed; if the white man had risen in that way, he would have been selected out and removed by means of the malaria. Now there really is a very curious case of selection of this sort among pigs, and it is a case of selection of colour, too. In the woods of Florida there are a great many pigs, and it is a very curious thing that they are all black, every one of them. Professor Wyman was there some years ago, and on noticing 110 pigs but these black ones, he asked some of the people how it was that they had no white pigs, and the reply was that in the woods of Florida there was a root which they called the Paint Root, and that if the white pigs were to eat any of it, it had the effect of making their hoofs crack, and they died, but if the black pigs eat any of it, it did not hurt them at all. Here was a very simple case of natural selection. A skilful breedér could not more carefully develope the black breed of pigs, and weed out all the white pigs, than the Paint Root does.

To show you how remarkably indirect may be such natural selective agencies as I have referred to, I will conclude by noticing a case mentioned by Mr. Darwin, and which is certainly one of the most curious of its kind. It is that of the Humble Bee. It has been noticed that there are a great many more humble bees in the neighbourhood of towns, than out in the open country; and the explanation of the matter is this: the humble bees build nests, in which they store their honey and deposit the larvæe and eggs. The field mice are amazingly fond of the honey and larva ; therefore, wherever there are plenty of field mice, as in the country, the humble bees are kept 
down; but in the neighbourhood of towns, the number of cats which prowl about the fields eat up the field mice, and of course the more mice they eat up the less there are to prey upon the larvæ of the bees-the cats are therefore the INDIRECT HELPERS of the bees.* Coming back a step farther we may say that the old maids are also indirect friends of the humble bees, and indirect enemies of the field mice, as they keep the cats which eat up the latter ! This is an illustration somewhat beneath the dignity of the subject, perhaps, but it occurs to me in passing, and with it I.will conclude this lecture.

* The humble bees, on the other hand, are direct helpers of some plants, such as the heartsease and red clover, which are fertilized by the visits of the bees; and they are indirect helpers of the numerous insects which are more or less completely supported by the heartsease and red clover. 


\section{A CRITICAL EXAMINATION OF THE POSI- TION OF MR. DARWIN'S WORK, “ON THE ORIGIN OF SPECIES," IN RELATION TO THE COMPLETE THEORY OF THE CAUSES OF THE PHENOMENA OF ORGANIC NATURE}

IN the preceding five lectures I have endeavoured to give you an account of those facts, and of those reasonings from facts, which form the data upon which all theories regarding the causes of the phenomena of organic nature must be based. And, although I have had frequent occasion to quote Mr. Darwin-as all persons hereafter, in speaking upon these subjects, will have occasion to quote his famous book on the "Origin of Species,"-you inust yet remember that, wherever I have quoted him, it has not been upon theoretical points, or for statements in any way connected with his particular speculations, but on matters of fact, brought forward by himself, or collected by himself, and which appear incidentally in his book. If a man will make a book, professing to discuss a single question, an encyclopædia, I cannot help it.

Now, having had an opportunity of considering in this sort of way the different statements bearing upon all theories whatsoever, I have to lay before you, as fairly as I can, what is Mr. Darwin's view of the matter and what position his theories hold, when judged by the principles which I have previously laid down, as deciding our judgments upon all theories and hypotheses.

I have already stated to you that the inquiry respecting the causes of the phenomena of organic nature resolves itself into two problems-the first being the question of the origination of living or organic beings; and the second heing the totally distinct problem of the modification and jerpetuation of organic beings when they have already come into existence. The first question Mr. Darwin does 
not touch: he does not deal with it at all; but he says -given the origin of organic matter-supposing its creation to have already taken place, my object is to show in consequence of what laws and what demonstrable properties of organic matter, and of its environments, such states of organic nature as those with which we are acquainted must have come about. This, you will observe, is a perfectly legitimate proposition; every person has a right to define the limits of the inquiry which he sets before himself; and yet it is a most singular thing that in all the multifarious, and, not unfrequently, ignorant attacks which have been made upon the Origin of Species, there is nothing which has been more speciously criticised than this particular limitation. If people have nothing else to urge against the book, they say-" Well, after all, you see, Mr. Darwin's explanation of the 'Origin of Species' is not good for much, because, in the long run, he admits that he does not know how organic matter began to exist. But if you admit any special creation for the first particle of organic matter you may just as well admit it for all the rest ; five hundred or five thousand distinct creations are just as intelligible, and just as little dificult to understand, as one." The answer to these cavils is two-fold. In the first place, all human inquiry must stop somewhere ; all our knowledge and all our investigation cannot take us beyond the limits set by the finite and restricted character of our faculties, or destroy the endless unknown, which accompanies, like its shadow, the endless procession of phenomena. So far as I can venture to offer an opinion on such a matter, the purpose of our being in existence, the highest object that human beings can set before themselves, is not the pursuit of any such chimera as the annihilation of the unknown; but it is simply the unwearied endeavour to remove its boundaries a little further from our little sphere of action.

I wonder if any historian would for a moment admit the objection, that it is preposterous to trouble ourselves about the history of the Roman Empire, because we do not know anything positive about the origin and first building of the city of Rome! Would it be a fair objection to urge, respecting the sublime discoveries of a Newton, or a Kepler, those great philosophers, whose discoveries have been of the profoundest benefit and service to all men, - to say to them-" After all that you have told us as to 
how the planets revolve, and how they are maintained in their orbits, you cannot tell us what is the cause of the origin of the sun, moon, and stars. So what is the use of what you have done?" Yet these objections would not be one whit more preposterous than the objections which have been made to the Origin of Species. Mr. Darwin, then, had a perfect right to limit his inquiry as he pleased, and the only question for us-the inquiry being so limited -is to ascertain whether the method of his inquiry is sound or unsound; whether he has obeyed the canons which must guide and govern all investigation, or whether he has broken them; and it was because our inquiry this evening is essentially limited to that question, that I spent a good deal of time in a former lecture (which, perhaps, some of you thought might have been better employed) in endeavouring to illustrate the method and nature of scientific inquiry in general. We shall now have to put in practice the principles that I then laid down.

I stated to you in substance, if not in words, that wherever there are complex masses of phenomena to be inquired into, whether they be phenomena of the affairs of daily life, or whether they belong to the more abstruse and difficult problems laid before the philosopher, our course of proceeding in unravelling that complex chain of phenomena with a view to get at its cause, is always the same; in all cases we must invent an hypothesis ; we must place before ourselves some more or less likely supposition respecting that cause; and then, having assumed an hypothesis, having supposed a cause for the phenomena in question, we must endeavour, on the one hand, to demonstrate our hypothesis, or, on the other, to upset and reject it altogether, by testing it in three ways. We must, in the first place, be prepared to prove that the supposed causes of the phenomena exist in nature; that they are what the logicians call vera causa-true causes ; in the next place, we should be prepared to show that the assumed causes of the phenomena are competent to produce such phenomena as those which we wish to explain by them ; and in the last place, we ought to be able to show that no other known causes are competent to produce these phenomena. If we can succeed in satisfying these three conditions we shall have demonstrated our hypothesis; or rather I ought to say, we shall have proved it as far as certainty is possible for us ; for, after all, there 
Is no one of our surest convictions which may not be upset, or at any rate modified by a further accession of knowledge. It was because it satisfied these conditions that we accepted the hypothesis as to the disappearance of the tea-pot and spoons in the case I supposed in a previous lecture; we found that our hypothesis on that subject was tenable and valid, because the supposed cause existed in nature, because it was competent to account for the phenomena, and because no other known cause was competent to account for them ; and it is upon similar grounds that any hypothesis you choose to name is accepted in science as tenable and valid.

What is Mr. Darwin's hypothesis ? As I apprehend it-for I have put it into a shape more convenient for common purposes than I could find verbatim in his book -as I apprehend it, I say, it is, that all the phenomena of organic nature, past and present, result from, or are caused by, the inter-action of those properties of organic matter, which we have called ATAvisM and VARIABILITY, with the Condrtans of ExIstence; or, in other words, - given the existence of organic matter, its tendency to transmit its properties, and its tendency occasionally to vary; and, lastly, given the conditions of existence by which organic matter is surrounded-that these put together are the causes of the Present and of the Past conditions of Organic Nature.

Such is the hypothesis as I understand it. Now let us see how it will stand the various tests which I laid down just now. In the first place, do these supposed causes of the phenomena exist in nature? Is it the fact that in nature these properties of organic matter -atavism and variability-and those phenomena which we have called the conditions of existence, -is it true that they exist? Well, of course, if they do not exist, all that I have told you in the last three or four lectures must be incorrect, because I have been attempting to prove that they do exist, and I take it that there is abundant evidence that they do exist; so far, therefore, the hypothesis does not break down.

But in the next place comes a much more difficult inquiry:-Are the causes indicated competent to give rise to the phenomena of organic nature? I suspect that this is indubitable to a certain extent. It is demonstrable, I think, as I have endeavoured to show you, that they are 
perfectly competent to give rise to all the phenomena which are exhibited by RAcEs in nature. Furthermore, I believe that they are quite competent to account for all that we may call purely structural phenomena which are exhibited by Species in nature. On that point also I have already enlarged somewhat. Again, I think that the causes assumed are competent to account for most of the physiological characteristics of spectes, and I not only think that they are competent to account for them, but I think that they account for many things which otherwise remain wholly unaccountable and inexplicable, and I may say incomprehensible. For a full exposition of the grounds on which this conviction is based, I must refer you to Mr. Darwin's work; all that I can do now is to illustrate what I have said by two or three cases taken almost at random.

I drew your attention, on a previous evening, to the facts which are embodied in our systems of Classification, which are the results of the examination and comparison of the different members of the animal kingdom one with another. I mentioned that the whole of the animal kingdom is divisible into five sub-kingdoms; that each of these sub-kingdoms is again divisible into provinces; that each province may be divided into classes, and the classes into the successively smaller groups, orders, families, genera, and species.

Now, in each of these groups, the resemblance in structure among the members of the group is closer in proportion as the group is smaller. Thus, a man and a worm are members of the animal kingdom in virtue of certain apparently slight though really fundamental resemblances which they present. But a man and a fish are members of the same Sub-kingdom Vertebrata, because they are much more like one another than either of them is to a worm, or a snail, or any member of the other sub-kingdoms. For similar reasons men and horses are arranged as members of the same Class, Mammalia; men and apes as members of the same Order, Primates; and if there were any animals more like men than they were like any of the apes, and yet different from men in important and constant particulars of thcir organization, we should rank them as members of the same Family, or of the same Genus, but as of distinct Species.

Thiat it is possible to arrange all the varied forms of 
animals into groups, having this sort of singular subordination one to the other, is a very remarkable circumstance; but, as Mr. Darwin remarks, this is a result which is quite to be expected, if the principles which he lays down be correct. Take the case of the races which are known to be produced by the operation of atavism and variability, and the conditions of existence which check and modify these tendencies. Take the case of the pigeons that I brought before you: there it was shown that they might be all classed as belonging to some one of five principal divisions, and that within these divisions other subordinate groups might be formed. The members of these groups are related to one another in just the same way as the genera of a family, and the groups themselves as the families of an order, or the orders of a class; while all have the same sort of structural relations with the wild rock-pigeon, as the members of any great natural group have with a real or imaginary typical form. Now, we know that all varieties of pigeons of every kind have arisen by a process of selective breeding from a common stock, the rock-pigeon; hence, you see, that if all species of animals have proceeded from some common stock, the general character of their structural relations, and of our systems of classification, which express those relations, would be just what we find them to be. In other words, the hypothetical cause is, so far, competent to produce effects similar to those of the real cause.

Take, again, another set of very remarkable facts,the existence of what are called rudimentary organs, organs for which we can find no obvious use, in the particular animal economy in which they are found, and yet which are there.

Such are the splint-like bones in the leg of the horse, which I here show you, and which correspond with bones which belong to certain toes and fingers in the human hand and foot. In the horse you see they are quite rudimentary, and bear neither toes nor fingers; so that the horse has only one "finger" in his fore-foot and one "toe" in his hind-foot. But it is a very curious thing that the animals closely allied to the horse show more toes than he; as the rhinoceros, for instance: he has these extra toes well formed, and anatomical facts show very clearly that he is very closely related to the horse indeed. So we may say that animals, in an anatomical sense nearly 
related to the horse, have those parts which are rudimentary in him, fully developed.

Again, the sheep and the cow have no cutting-teeth, but only a hard pad in the upper jaw. That is the common characteristic of ruminants in general. But the calf has in its upper jaw some rudiments of tecth which never are developed, and never play the part of teeth at all. Well, if you go back in time, you find some of the older, now extinct, allies of the ruminants have well-developed teeth in their upper jaws; and at the present day the pig (which is in structure closely connected with ruminants) has well-developed teeth in its upper jaw; so that here is another instance of organs well developed and very useful, in one animal, represented by rudimentary organs, for which we can discover no purpose whatsoever, in another closely allied animal. The whalebone whale, again, has horny "whalebone" plates in its mouth, and no teeth; but the young fotal whale, before it is born, has tecth in its jaws; they, however, are never used, and they never come to anything. But other members of the group to which the whale belongs have well-developed teeth in both jaws.

Upon any hypothesis of special creation, facts of this kind appear to me to be entirely unaccountable and inexplicable, but they cease to be so if you accept Mr. Darwin's hypothesis, and see reason for believing that the whalebone whale and the whale with teeth in its mouth both sprang from a whale that had tecth, and that the teeth of the fotal whale are merely remnants -recollections, if we may so say-of the extinct whale. So in the case of the horse and the rhinoceros: suppose that both have descended by modification from some earlier form which had the normal number of toes, and the persistence of the rudimentary bones which no longer support toes in the horse becomes comprehensible.

In the language that we speak in England, and in the language of the Greeks, there are identical verbal roots, or elements entering into the composition of words. That fact remains unintelligible so long as we suppose English and Greek to be independently created tongues; but when it is shown that both languages are descended from one original, the Sanscrit, we give an explanation of that resemblance. In the same way the existence of identical structural roots, if I may so term them, entering into the 
composition of widely different animals, is striking evidence in favour of the descent of those animals from a common original.

To turn to another kind of illustration :-If you regard the whole series of stratified rocks - that enormous thickness of sixty or seventy thousand feet that I have mentioned before, constituting the only record we have of a most prodigious lapse of time, that time being, in all probability, but a fraction of that of which we have no record;-if you observe in these successive strata of rocks successive groups of animals arising and dying out, a constant succession, giving you the same kind of impression, as you travel from one group of strata to another, as you would have in travelling from one country to another ;-when you find this constant succession of forms, their traces obliterated except to the man of science,-when you look at this wonderful history, and ask what it means, it is only a paltering with words if you are offered the reply, ' They were so created.'

But if, on the other hand, you look on all forms of organized beings as the results of the gradual modification of a primitive type, the facts receive a meaning, and you see that these older conditions are the necessary predecessors of the present. Viewed in this light the facts of palæontology receive a meaning-upon any other hypothesis, I am unable to see, in the slightest degree, what knowledge or signification we are to draw out of them. Again, note as bearing upon the same point, the singular likeness which obtains between the successive Faunæ and Floræ, whose remains are preserved on the rocks: you never find any great and enormous difference between the immediately successive Faunæ and Floræ, unless you have reason to believe there has also been a great lapse of time or a great change of conditions. The animals, for instance, of the newest tertiary rocks, in any part of the world, are always, and without exception, found to be closely allied with those which now live in that part of the world. For example, in Europe, Asia, and Africa, the large mammals are at present rhinoceroses, hippopotamuses, elephants, lions, tigers, oxen, horses, etc.; and if you examine the newest tertiary deposits, which contain the animals and plants which immediately preceded those which now exist in the same country, you do not find gigantic specimens of ant-eaters and kangaroos, but you 
find rhinoceroses, elephants, lions, tigers, etc., - of different species to those now living, - but still their close allies. If you turn to South America, where, at the present day, we have great sloths and armadilloes and creatures of that kind, what do you find in the newest tertiaries? You find the great sloth-like creature, the Megatherium, and the great armadillo, the Glyptodon, and so on. And if you go to Australia you find the same law holds good, namely, that that condition of organic nature which has preceded the one which now exists, presents differences perhaps of species, and of genera, but that the great types of organic structure are the same as those which now flourish.

What meaning has this fact upon any other hypothesis or supposition than one of successive modification? But If the population of the world, in any age, is the result of the gradual modification of the forms which peopled it in the preceding age,-if that has been the case, it is intelligible enough; because we may expect that the creature that results from the modification of an elephantine mammal shall be something like an elephant, and the creature which is produced by the modification of an armadillo-like mammal shall be like an armadillo. Upon that supposition, I say, the facts are intelligible; upon any other, that I am aware of, they are not.

So far, the facts of palæontology are consistent with almost any form of the doctrine of progressive modification ; they would not be absolutely inconsistent with the wild speculations of De Maillet, or with the less objectionable hypothesis of Lamarck. But Mr. Darwin's views have one peculiar merit; and that is, that they are perfectly consistent with an array of facts which are utterly inconsistent with and fatal to, any other hypothesis of progressive modification which has yet been advanced. It is one remarkable peculiarity of Mr. Darwin's hypothesis that it involves no necessary progression or incessant modification, and that it is perfectly consistent with the persistence for any length of time of a given primitive stock, contemporaneously with its modifications. To return to the case of the domestic breeds of pigeons, for example; you have the Dove-cot pigeon, which closely resembles the Rock pigeon, from which they all started, existing at the same time with the others. And if species are developed in the same way in nature, a primitive stock and its modifications may, occasionally, all find the con- 
ditions fitted for their existence; and though they come into competition, to a certain extent, with one another, the derivative species may not necessarily extirpate the primitive one, or vice versa.

- Now palæontology shows us many facts which are perfectly harmonious with these observed effects of the process by which Mr. Darwin supposes species to have originated, but which appear to me to be totally inconsistent with any other hypothesis which has been proposed. There are some groups of animals and plants, in the fossil world, which have been said to belong to "persistent types," because they have persisted, with very little change indeed, through a very great range of time, while everything about them has changed largely. There are families of fishes whose type of construction has persisted all the way from the carboniferous rock right up to the cretaceous; and others which have lasted through almost the whole range of the secondary rocks, and from the lias to the older tertiaries. It is something stupendous this-to consider a genus lasting without essential modifications through all this enormous lapse of time while almost everything else was changed and modified.

Thus I have no doubt that Mr. Darwin's hypothesis will be found competent to explain the majority of the phenomena exhibited by species in nature; but in an earlier lecture I spoke cautiously with respect to its power of explaining all the physiological peculiarities of species.

There is, in fact, one set of these peculiarities which the theory of selective modification, as it stands at present, is not wholly competent to explain, and that is the group of phenomena which I mentioned to you under the name of Hybridism, and which I explained to consist in the sterility of the offspring of certain species when crossed one with another. It matters not one whit whether this sterility is universal, or whether it exists only in a single case. Every hypothesis is bound to explain, or, at any rate, not be inconsistent with, the whole of the facts which it professes to account for ; and if there is a single one of these facts which can be shown to be inconsistent with (I do not merely mean inexplicable by, but contrary to) the hypothesis, the hypothesis falls to the ground,it is worth nothing. One fact with which it is positively inconsistent is worth as much, and as powerful in negativing the hypothesis, as five hundred. If I am right in thus 
defining the obligations of an hypothesis, Mr. Darwin, in order to place his views beyond the reach of all possible assault, ought to be able to demonstrate the possibility of developing from a particular stock by selective breeding, two forms, which should either be unable to cross one with another, or whose cross-bred offspring should be infertile with one another.

For, you see, if you have not done that you have not strictly fulfilled all the conditions of the problem; you have not shown that you can produce, by the cause assumed, all the phenomena which you have in nature. Here are the phenomena of Hybridism staring you in the face, and you cannot say, 'I can, by selective modification, produce these same results.' Now, it is admitted on all hands that, at present, so far as experiments have gone, it has not been found possible to produce this complete physiological divergence by selective breeding. I stated this very clearly before, and I now refer to the point, because, if it could be proved, not only that this has not been done, but that it cannot be done; if it could be demonstrated that it is impossible to breed selectively, from any stock, a form which shall not breed with another, produced from the same stock; and if we were shown that this must be the necessary and inevitable result of all experiments, I hold that Mr. Darwin's hypothesis would be utterly shattered.

But has this been done? or what is really the state of the case? It is simply that, so far as we have gone yet with our breeding, we have not produced from a common stock two breeds which are not more or less fertile with one another.

I do not know that there is a single fact which would justify any one in saying that any degree of sterility has been observed between breeds absolutely known to have been produced by selective breeding from a common stock. On the other hand, I do not know that there is a single fact which can justify any one in asserting that such sterility cannot be produced by proper experimentation. For my own part, I see every reason to believe that it may, and will be so produced. For, as Mr. Darwin has very properly urged, when we consider the phenomena of sterility, we find they are most capricious; we do not know what it is that the sterility depends on. There are some animals which will not breed in captivity; whether 
it arises from the simple fact of their being shut up and deprived of their liberty, or not, we do not know, but they certainly will not breed. What an astounding thing this is, to find one of the most important of all functions annihilated by mere imprisonment !

So, again, there are cases known of animals which have been thought by naturalists to be undoubted species, which have yielded perfectly fertile hybrids; while there are other species which present what everybody believes to be varieties* which are more or less infertile with one another. There are other cases which are truly extraordinary; there is one, for example, which has been carefully examined,- of two kinds of sea-weed, of which the male element of the one, which we may call $\mathrm{A}$, fertilizes the female element of the other, B ; while the male element of $\mathrm{B}$ will not fertilize the female element of A; so that, while the former experiment seems to show us that they are varieties, the latter leads to the conviction that they are species.

When we see how capricious and uncertain this sterility is, how unknown the conditions on which it depends, I say that we have no right to affirm that those conditions will not be better understood by and by, and we have no ground for supposing that we may not be able to experiment so as to obtain that crucial result which I mentioned just now. So that though Mr. Darwin's hypothesis does not completely extricate us from this difficulty at present, we have not the least right to say it will not do so.

There is a wide gulf between the thing you cannot explain and the thing that upsets you altogether. There is hardly any hypothesis in this world which has not some fact in connection with it which has not been explained, but that is a very different affair to a fact that entirely opposes your hypothesis; in this case all you can say is, that your hypothesis is in the same position as a good many others.

Now, as to the third test, that there are no other causes competent to explain the phenomena, I explained to you that one should be able to say of an hypothesis, that no other known causes than those supposed by it are competent

* And as I conceive with very good reason; but if any objector urges that we cannot prove that they have been produced by artificial or natural selection, the objection must be admitted-ultrasceptical as it is. But in science, scepticism is a duty. 
to give rise to the phenomena. Here, I think, Mr. Darwin's view is pretty strong. I really believe that the alternative is either Darwinism or nothing, for I do not know of any rational conception or theory of the organic universe which has any scientific position at all beside Mr. Darwin's. I do not know of any proposition that has been put before us with the intention of explaining the phenomena of organic nature, which has in its favour a thousandth part of the evidence which may be adduced in favour of Mr. Darwin's views. Whatever may be the objections to his views, certainly all others are absolutely out of court.

Take the Lamarckian hypothesis, for example. Lamarck was a great naturalist, and to a certain extent went the right way to work; he argued from what was undoubtedly a true cause of some of the phenomena of organic nature. He said it is a matter of experience that an animal may be modified more or less in consequence of its desires and consequent actions. Thus, if a man exercise himself as a blacksmith, his arms will become strong and muscular; such organic modification is a result of this particular action and exercise. Lamarck thought that by a very simple supposition based on this truth he could explain the origin of the various animal species : he said, for example, that the short-legged birds which live on fish, had been converted into the long-legged waders by desiring to get the fish without wetting their feet, and so stretching their legs more and more through successive generations. If Lamarck could have shown experimentally, that even races of animals could be produced in this way, there might have been some ground for his speculations. But he could show nothing of the kind, and his hypothesis has pretty well dropped into oblivion, as it deserved to do. I said in an earlier lecture that there are hypotheses and hypotheses, and when people tell you that Mr. Darwin's strongly-based hypothesis is nothing but a mere modification of Lamarck's, you will know what to think of their capacity for forming a judgment on this subject.

But you must recollect that when I say I think it is either Mr. Darwin's hypothesis or nothing; that either we must take his view, or look upon the whole of organic nature as an enigma, the meaning of which is wholly hidden from us; you must understand that I mean that I accept it provisionally, in exactly the same way as I accept any other hypothesis. Men of science do not pledge themselves 


\section{THE PHENOMENA OF ORGANIC NATURE 111}

to creeds; they are bound by articles of no sort; there is not a single belief that it is not a bounden duty with them to hold with a light hand and to part with it, cheerfully, the moment it is really proved to be contrary to any fact, great or small. And if in course of time I see good reasons for such a proceeding, I shall have no hesitation in coming before you, and pointing out any change in my opinion without finding the slightest occasion to blush for so doing. So I say that we accept this view as we accept any other, so long as it will help us, and we feel bound to retain it only so long as it will serve our great purpose - the improvement of Man's estate and the widening of his knowledge. The moment this, or any other conception, ceases to be useful for these purposes, away with it to the four winds ; we care not what becomes of it !

But to say truth, although it has been my business to attend closely to the controversies roused by the publication of Mr. Darwin's book, I think that not one of the enormous mass of objections and obstacles which have been raised is of any very great value, except that sterility case which I brought before you just now. All the rest are misunderstandings of some sort, arising either from prejudice, or want of knowledge, or still more from want of patience and care in reading the work.

For you must recollect that it is not a book to be read with as much ease as its pleasant style may lead you to imagine. You spin through it as if it were a novel the first time you read it, and think you know all about it; the second time you read it you think you know rather less about it; and the third time, you are amazed to find how little you have really apprehended its vast scope and objects. I can positively say that I never take it up without finding in it some new view, or light, or suggestion that I have not noticed before. That is the best characteristic of a thorough and profound book; and I believe this feature of the Origin of Species explains why so many persons have ventured to pass judgment and criticisms upon it which are by no means worth the paper they are written on.

Before concluding these lectures there is one point to which I must advert,-though, as Mr. Darwin has said nothing about man in his book, it concerns myself rather than him;- for I have strongly maintained on sundry occasicns that if Mr. Darwin's views are sound, they apply 
as much to man as to the lower mammals, seeing that it is perfectly demonstrable that the structural differences which separate man from the apes are not greater than those which separate some apes from others. There cannot be the slightest doubt in the world that the argument which applies to the improvement of the horse from an earlier stock, or of ape from ape, applies to the improvement of man from some simpler and lower stock than man. There is not a single faculty-functional or structural, moral, intellectual, or instinctive,-there is no faculty whatever that is not capable of improvement; there is no faculty whatsoever which does not depend upon structure, and as structure tends to vary, it is capable of being improved.

Well, I have taken a good deal of pains at various times to prove this, and I have endeavoured to meet the objections of those who maintain, that the structural differences between man and the lower animals are of so vast a character and enormous extent, that even if Mr. Darwin's views are correct, you cannot imagine this particular modification to take place. It is, in fact, easy matter to prove that, so far as structure is concerned, man differs to no greater extent from the animals which are immediately below him than these do from other members of the same order. Upon the other hand, there is no one who estimates more highly than I do the dignity of human nature, and the width of the gulf in intellectual and moral matters, which lies between man and the whole of the lower creation.

But I find this very argument brought forward vehemently by some. "You say that man has proceeded from a modification of some lower animal, and you take pains to prove that the structural differences which are said to exist in his brain do not exist at all, and you teach that all functions, intellectual, moral, and others, are the expression or the result, in the long run, of structures, and of the molecular forces which they exert." It is quite true that I do so.

" Well, but," I am told at once, somewhat triumphantly, "you say in the same breath that there is a great moral and intellectual chasm between man and the lower animals. How is this possible when you declare that moral and intellectual characteristics depend on structure, and yet tell us that there is no such gulf between the structure of man and that of the lower animals?" 
I think that objection is based upon a misconception of the real relations which exist between structure and function, between mechanism and work. Function is the expression of molecular forces and arrangements no doubt; but, does it follow from this, that variation in function so depends upon variation in structure that the former is always exactly proportioned to the latter? If there is no such relation, if the variation in function which follows on a variation in structure, may be enormously greater than the variation of the structure, then, you see, the objection falls to the ground.

Take a couple of watches-made by the same maker, and as completely alike as possible; set them upon the table, and the function of each-which is its rate of going -will be performed in the same manner, and you shall be able to distinguish no difference between them; but let me take a pair of pincers, and if my hand is steady enough to do it, let me just lightly crush together the bearings of the balance-wheel, or force to a slightly different angle the teeth of the escapement of one of them, and of course you know the immediate result will be that the watch, so treated, from that moment will cease to go. But what proportion is there between the structural alteration and the functional result? Is it not perfectly obvious that the alteration is of the minutest kind, yet that slight as it is, it has produced an infinite difference in the performance of the functions of these two instruments ?

Well, now, apply that to the present question. What is it that constitutes and makes man what he is ? What is it but his power of language-that language giving him the means of recording his experience-making every generation somewhat wiser than its predecessor,-more in accordance with the established order of the universe ?

What is it but this power of speech, of recording experience, which enables men to be men-looking before and after and, in some dim sense, understanding the working of this wondrous universe-and which distinguishes man from the whole of the brute world ? I say that this functional difference is vast, unfathomable, and truly infinite in its consequences; and I say at the same time, that it may depend upon structural differences which shall be absolutely inappreciable to us with our present means of investigation. What is this very speech that we are talking about ? I am speaking to you at this moment, but if you 
were to alter, in the minutest degree, the proportion of the nervous forces now active in the two nerves which supply the muscles of my glottis, I should become suddenly dumb. The voice is produced only so long as the vocal chords are parallel; and these are parallel only so long as certain muscles contract with exact equality; and that again depends on the equality of action of those two nerves I spoke of. So that a change of the minutest kind in the structure of one of these nerves, or in the structure of the part in which it originates, or of the supply of blood to that part, or of one of the muscles to which it is distributed, might render all of us dumb. But a race of dumb men, deprived of all communication with those who could speak, would be little indeed removed from the brutes. And the moral and intellectual difference between them and ourselves would be practically infinite, though the naturalist should not be able to find a single shadow of even specific structural difference.

But let me dismiss this question now, and, in conclusion, let me say that you may go away with it as my mature conviction, that Mr. Darwin's work is the greatest contribution which has been made to biological science since the publication of the Regne Animal of Cuvier, and since that of the History of Development of Von Baer. I believe that if you strip it of its theoretical part it still remains one of the greatest encycloprdias of biological doctrine that any one man ever brought forth; and I believe that, if you take it as the embcdiment of an hypothesis, it is destined to be the guide of biological and psychological speculation for the next three or four generations. 
ESSAYS

ON

DARWIN'S “ORIGIN OF SPECIES" 



\section{THE DARWINIAN HYPOTHESIS *}

\section{Darwin on the Origin of Species.}

THERE is a growing immensity in the speculations of science to which no human thing or thought at this day is comparable. Apart from the results which science brings us home and securely harvests, there is an expansive force and latitude in its tentative efforts, which lifts us out of ourselves and transfigures our mortality. We may have a preference for moral themes, like the Homeric sage, who had seen and known much :

\section{"Cities of men}

And manners, climates, councils, governments ";

yet we must end by confessing that

“The windy ways of men

Are but dust which rises up

And is lightly laid again,"

in comparison with the work of nature, to which science testifies, but which has no boundaries in time or space to which science can approximate.

There is something altogether out of the reach of science, and yet the compass of science is practically illimitable. Hence it is that from time to time we are startled and perplexed by theories which have no parallel in the contracted moral world; for the generalizations of science sweep on in ever-widening circles, and more aspiring flights, though a limitless creation. While astronomy, with its telescope, ranges beyond the known stars, and physiology, with its microscope, is subdividing infinite minutiæ, we may expect that our historic centuries may be treated as inadequate counters in the history of the planet on which we are placed. We must expect new conceptions of the nature and relations of its denizens, as science acquires the materials for fresh generalizations; nor have we occa- 
sion for alarms if a highly advanced knowledge, like that of the eminent Naturalist before us, confronts us with an hypothesis as vast as it is novel. This hypothesis may or may not be sustainable hereafter; it may give way to something else, and higher science may reverse what science has here built up with so much skill and patience, but its sufficiency must be tried by the tests of science alone, if we are to maintain our position as the heirs of Bacon and the acquitters of Galileo. We must weigh this hypothesis strictly in the controversy which is coming, by the only tests which are appropriate, and by no others whatsoever.

The hypothesis to which we point, and of which the present work of Mr. Darwin is but the preliminary outline, may be stated in his own language as follows:- "Species originated by means of natural selection, or through the preservation of the favoured races in the struggle for life." To render this thesis intelligible, it is necessary to interpret its terms. In the first place, what is a species? The question is a simple one, but the right answer to it is hard to find, even if we appeal to those who should know most about it. It is all those animals or plants which have descended from a single pair of parents; it is the smallest distinctly definable group of living organisms; it is an eternal and immutable entity; it is a mere abstraction of the human intellect having no existence in nature. Such are a few of the significations attached to this simple word which may be culled from authoritative sources; and if, leaving terms and theoretical subtleties aside, we turn to facts and endeavour to gather a meaning for ourselves, by studying the things to which, in practice, the name of species is applied, it profits us little. For practice varies as much as theory. Let the botanist or the zoologist examine and describe the productions of a country, and one will pretty certainly disagree with the other as to the number, limits, and definitions of the species into which he groups the very same things. In these islands we are in the habit of regarding mankind as of one species, but a fortnight's steam will land us in a country where divines and savans, for once in agreement, vie with one another in loudness of assertion, if not in cogency of proof, that men are of different species ; and, more particularly, that the species negro is so distinct from our own that the Ten Commandments have actually no reference to him. Even in the calm region of entomology, where, if anywhere in this sinful world, passion and 
prejudice should fail to stir the mind, one learned coleopterist will fill ten attractive volumes with descriptions of species of beetles, nine-tenths of which are immediately declared by his brother beetle-mongers to be no species at all.

The truth is that the number of distinguishable living creatures almost surpasses imagination. At least a hundred thousand such kinds of insects alone have been described and may be identified in collections, and the number of separable kinds of living things is under estimated at half a million. Seeing that most of these obvious kinds have their accidental varieties, and that they often shade into others by imperceptible degrees, it may well be imagined that the task of distinguishing between what is permanent and what fleeting, what is a species and what a mere variety, is sufficiently formidable.

But is it not possible to apply a test whereby a true species may be known from a mere variety? Is there no criterion of species? Great authorities affirm that there is-that the unions of members of the same species are always fertile, while those of distinct species are either sterile, or their offspring, called hybrids, are so. It is affirmed not only that this is an experimental fact, but that it is a provision for the preservation of the purity of species. Such a criterion as this would be invaluable; but, unfortunately, not only is it not obvious how to apply it in the great majority of cases in which its aid is needed, but its general validity is stoutly denied. The Hon. and Rev. Mr. Herbert, a most trustworthy authority, not only asserts as the result of his own observations and experiments that many hybrids are quite as fertile as the parent species, but he goes so far as to assert that the particular plant Crinum capense is much more fertile when crossed by a distinct species than when fertilised by its proper pollen ! On the other hand the famous Gaertner, though he took the greatest pains to cross the primrose and cowslip, succeeded only once or twice in several years; and yet it is a well-established fact that the primrose and the cowslip are only varieties of the same kind of plant. Again, such cases as the following are well established. The female of species A if crossed with the male of species B is fertile, but if the female of $B$ is crossed with the male of $A$, she remains barren. Facts of this kind destroy the value of the supposed criterion. 
If, weary of the endless difficulties involved in the determination of species, the investigator, contenting himself with the rough practical distinction of separable kinds, endeavours to study them as they occur in nature-to ascertain their relations to the conditions which surround them, their mutual harmonies and discordances of structure, the bond of union of their parts and their past history, he finds himself, according to the received notions, in a mighty maze, and with, at most, the dimmest adumbration of a plan. If he starts with any one clear conviction, it is that every part of a living creature is cunningly adapted to some special use in its life. Has not his Paley told him that that seemingly useless organ, the spleen, is beautifully adjusted as so much packing between the other organs ? And yet, at the outset of his studies, he finds that no adaptive reason whatsoever can be given for one-half of the peculiarities of vegetable structure; he also discovers rudimentary teeth, which are never used, in the gums of the young calf and in those of the fotal whale; insects which never bite have rudimental jaws, and others which never fly have rudimental wings ; naturally blind creatures have rudimental eyes; and the halt have rudimentary limbs. So, again, no animal or plant puts on its perfect form at once, but all have to start from the same point, however varioas the course which each has to pursue. Not only men and horses, and cats and dogs, lobsters and beetles, periwinkles and mussels, but even the very sponges and animalcules commence their existence under forms which are essentially undistinguishable; and this is true of all the infinite variety of plants. Nay, more, all living beings march side by side along the high road of development, and separate the later the more like they are; like people leaving church, who all go down the aisle, but having reached the door some turn into the parsonage, others go down the village, and others part only in the next parish. A man in his development runs for a little while parallel with, though never passing through, the form of the meanest worm, then travels for a space beside the fish, then journeys along with the bird and the reptile for his fellow travellers; and only at last, after a brief companionship with the highest of the four-footed and four-handed world, rises into the dignity of pure manhood. No competent thinker of the present day dreams of explaining these indubitable facts by the notion of the existence of unknown and 
undiscoverable adaptations to purpose. And we would remind those who, ignorant of the facts, must be moved by authority, that no one has asserted the incompetence of the doctrine of final causes, in its application to physiology and anatomy, more strongly than our own eminent anatomist, Professor Owen, who, speaking of such cases, says (On the Nature of Limbs, pp. 39, 40): "I think it will be obvious that the principle of final adaptations fails to satisfy all the conditions of the problem."

But, if the doctrine of final causes will not help us to comprehend the anomalies of living structure, the principle of adaptation must surely lead us to understand why certain living beings are found in certain regions of the world and not in others. The palm, as we know, will not grow in our climate, nor the oak in Greenland. The white bear cannot live where the tiger thrives, nor vice vers $\hat{\text {, }}$, and the more the natural habits of animal and vegetable species are examined, the more do they seem, on the whole, limited to particular provinces. But when we look into the facts established by the study of the geographical distribution of animals and plants it seems utterly hopeless to attempt to understand the strange and apparently capricious relations which they exhibit. One would be inclined to suppose $\alpha$ priori that every country must be naturally peopled by those animals that are fittest to live and thrive in it. And yet how, on this hypothesis, are we to account for the absence of cattle in the Pampas of South America when those parts of the New World were discovered ? It is not that they were unfit for cattle, for millions of cattle now run wild there; and the like holds good of Australia and New Zealand. It is a curious circumstance, in fact, that the animals and plants of the Northern Hemisphere are not only as well adapted to live in the Southern Hemisphere as its own autochthones, but are in many cases absolutely better adapted, and so overrun and extirpate the aborigines. Clearly, therefore, the species which naturally inhabit a country are not necessarily the best adapted to its climate and other conditions. The inhabitants of islands are often distinct from any other known species of animal of plants (witness our recent examples from the work of Sir Emerson Tennent, on Ceylon), and yet they have almost always a sort of general family resemblance to the animals and plants of the nearest mainland. On the other hand, there is hardly a species of fish, shell, or crab common to 
the opposite sides of the narrow isthmus of Panama. Wherever we look, then, living nature oflers us riddles of difficult solution, if we suppose that what we see is all that can be known of it.

But our knowledge of life is not confined to the existing world. Whatever their minor differences, geologists are agreed as to the vast thickness of the accumulated strata which compose the visible part of our earth, and the inconceivable immensity of the time of whose lapse they are the imperfect, but the only accessible witnesses. Now, throughout the greater part of this long series of stratified rocks are scattered, sometimes very abundantly, multtudes of organic remains, the fossilized exuviæ of animals and plants which lived and died while the mud of which the rocks are formed was yet soft ooze, and could receive and bury them. It would be a great error to suppose that these organic remains were fragmentary relics. Our museums exhibit fossil shells of immeasurable antiquity, as perfect as the day they were formed, whole skeletons without a limb disturbed-nay, the changed flesh, the developing embryos, and even the very footsteps of primeval organisms. Thus the naturalist finds in the bowels of the earth species as well defined as, and in some groups of animals more numerous than, those that breathe the upper air. But, singularly enough, the majority of these entombed species are wholly distinct from those that now live. Nor is this unlikeness without its rule and order. As a broad fact, the further we go back in time the less the buried species are like existing forms; and the further apart the sets of extinct creatures are the less they are like one another. In other words, there has been a regular succession of living beings, each younger set being in a very broad and general sense somewhat more like those which now live.

It was once supposed that this succession had been the result of vast successive catastrophes, destructions, and re-creations en masse; but catastrophes are now almost eliminated from geological, or at least paleontological speculation; and it is admitted on all hands that the secming breaks in the chain of being are not absolute, but only relative to our imperfect knowledge; that species have replaced species, not in assemblages, but one by one ; and that, if it were possible to have all the phenomena of the past presented to us, the convenient epochs and forma- 
tions of the geologist, though having a certain distinctness, would fade into one another with limits as undefinable as those of the distinct and yet separable colours of the solar spectrum.

Such is a brief summary of the main truths which have been established concerning species. Are these truths ultimate and irresolvable facts, or are their complexities and perplexities the mere expressions of a higher law ?

A large number of persons practically assume the former position to be correct. They believe that the writer of the Pentateuch was empowered and commissioned to teach us scientific as well as other truth, that the account we find there of the creation of living things is simply and literally correct, and that anything which seems to contradict it is, by the nature of the case, false. All the phenomena which have been detailed are, on this view, the immediate product of a creative fiat and consequently are out of the domain of science altogether.

Whether this view prove ultimately to be true or false, it is, at any rate, not at present supported by what is commonly regarded as logical proof, even if it be capable of discussion by reason; and hence we consider ourselves at liberty to pass it by, and to turn to those views which profess to rest on a scientific basis only, and therefore admit of bcing argued to their consequences. And we do this with the less hesitation as it so happens that those persons who are practically conversant with the facts of the case (plainly a considerable advantage) have always thought fit to range themselves under the latter category.

The majority of these competent persons have up to the present time maintained two positions, - the first, that every species is, within ccrtain defined or definable limits, fixed and incapable of modification; the second, that every species was originally produced by a distinct creative act. The second position is obviously incapable of proof or disproof, the direct operations of the Creator not being subjects of science; and it must therefore be regarded as a corollary from the first, the truth or falsehood of which is a matter of evidence. Most persons imagine that the arguments in favour of it are overwhelming ; but to some few minds, and these, it must be confessed, intellects of no small power and grasp of knowledge, they have not brought conviction. Among these minds that of the famous naturalist Lamarck, who possessed a greater 
acquaintance with the lower forms of life than any man of his day, Cuvier not excepted, and was a good botanist to boot, occupies a prominent place.

Two facts appear to have strongly affected the course of thought of this remarkable man-the one, that finer or stronger links of affinity connect all living beings with one another, and that thus the highest creature grades by multitudinous steps into the lowest; the other, that an organ may be developed in particular directions by exerting itself in particular ways, and that modifications once induced may be transmitted and become hereditary. Putting these facts together, Lamarck endeavoured to account for the first by the operation of the second. Place an animal in new circumstances, says he, and its needs will be altered; the new needs will create new desires, and the attempt to gratify such desires will result in an appropirate modification of the organs exerted. Make a man a blacksmith, and his brachial muscles will develope in accordance with the demands made upon them, and in like manner, says Lamarck, "the efforts of some shortnecked bird to catch fish without wetting himself have, with time and perseverance, given rise to all our herons and long-necked waders."

The Lamarckian hypothesis has long since been justly condemned, and it is the established practice for every tyro to raise his heel against the carcass of the dead lion. But it is rarely either wise or instructive to treat even the errors of a really great man with mere ridicule, and in the present case the logical form of the doctrine stands on a very different footing from its substance.

If species have really arisen by the operation of natural conditions, we ought to be able to find those conditions now at work; we ought to be able to discover in nature some power adequate to modify any given kind of animal or plant in such a manner as to give rise to another kind, which would be admitted by naturalists as a distinct species. Lamarck imagined that he had discovered this vera causa in the admitted facts that some organs may be modified by exercise; and that modifications, once produced, are capable of hereditary transmission. It does not seem to have occurred to him to inquire whether there is any reason to believe that there are any limits to the amount of modification producible, or to ask how long an animal is likely to endeavour to gratify an impossible desire. The 
bird, in our example, would surely have renounced fish dinners long before it had produced the least effect on leg or neck.

Since Lamarck's time almost all competent naturalists have left speculations on the origin of species to such dreamers as the author of the Vestiges, by whose wellintentioned efforts the Lamarckian theory received its final condemnation in the minds of all sound thinkers. Notwithstanding this silence, however, the transmutation theory, as it has been called, has been a "skeleton in the closet" to many an honest zoologist and botanist who had a soul above the mere naming of dried plants and skins. Surely, has such an one thought, nature is a mighty and consistent whole, and the providential order established in the world of life must, if we could only see it rightly, be consistent with that dominant over the multiform shapes of brute matter. But what is the history of astronomy, of all the branches of physics, of chemistry, of medicine, but a narration of the steps by which the human mind has been compelled, often sorely against its will, to recognize the operation of secondary causes in events where ignorance beheld an immediate intervention of a higher power? And when we know that living things are formed of the same elements as the inorganic world, that they act and react upon it, bound by a thousand ties of natural piety, is it probable, nay is it possible, that they, and they alone, should have no order in their seeming disorder, no unity in their seeming multiplicity, should suffer no explanation by the discovery of some central and sublime law of mutual connexion?

Questions of this kind have assuredly often arisen, but it might have been long before they received such expression as would have commanded the respect and attention of the scientific world, had it not been for the publication of the work which prompted this article. Its author, Mr. Darwin, inheritor of a once celebrated name, won his spurs in science when most of those now distinguished were young men, and has for the last 20 years held a place in the front ranks of British philosophers. After a circumnavigatory voyage, undertaken solely for the love of his science, Mr. Darwin published a series of researches which at once arrested the attention of naturalists and geologists; his generalizations have since received ample confirmation, and now command universal assent, nor is 
it questionable that they have had the most important influence on the progress of science. More recently Mr. Darwin, with a versatility which is among the rarest of gifts, turned his attention to a most difficult question of zoology and minute anatomy ; and no living naturalist and anatomist has published a better monograph than that which resulted from his labours. Such a man, at all events, has not entered the sanctuary with unwashed hands, and when he lays before us the results of 20 years' investigation and reflection we must listen even though we be disposed to strike. But, in reading his work it must be confessed that the attention which might at first be dutifully, soon becomes willingly, given, so clear is the author's thought, so outspoken his conviction, so honest and fair the candid expression of his doubts. Those who would judge the book must read it ; we shall endeavour only to make its line of argument and its philosophical position intelligible to the general reader in our own way.

The Baker-street Bazaar has just been exhibiting its familiar annual spectacle. Straight-backed, small-headed, big-barrelled oxen, as dissimilar from any wild species as can well be imagined, contended for attention and praise with sheep of half-a-dozen different breeds and styes of bloated preposterous pigs, no more like a wild boar or sow than a city alderman is like an ourang-outang. The cattle show has been, and perhaps may again be, succeeded by a poultry show, of whose crowing and clucking prodigies it can only be certainly predicated that they will be very unlike the aboriginal Phasianus Gallus. If the seeker after animal anomalies is not satisfied, a turn or two in Seven Dials will convince him that the breeds of pigeons are quite as extraordinary and unlike one another and their parent stock, while the Horticultural Society will provide him with any number of corresponding vegetable aberrations from nature's types. He will learn with no little surprise, too, in the course of his travels, that the proprietors and producers of these animal and vegetable anomalies regard them as distinct species, with a firm belief, the strength of which is exactly proportioned to their ignorance of scientific biology, and which is the more remarkable as they are all proud of their skill in originating such "species."

On careful inquiry it is found that all these, and the many other artificial breeds or races of animals and 
plants, have been produced by one method. The breeder -and a skilful one must be a person of much sagacity and natural or acquired perceptive faculty-notes some slight difference, arising lie knows not how, in some individuals of his stock. If he wish to perpetuate the difference, to form a breed with the peculiarity in question strongly marked, he selects such male and female individuals as exhibit the desired character, and breeds from them. Their offspring are then carefully examined, and those which exhibit the peculiarity the most distinctly are selected for breeding, and this operation is repeated until the desired amount of divergence from the primitive stock is reached. It is then found that by continuing the process of selection-aiways breeding, that is, from well-marked forms, and allowing no impure crosses to interfere, - a race may be formed, the tendency of which to reproduce itself is exceedingly strong; nor is the limit to the amount of divergence which may be thus produced known, but one thing is certain, that, if certain breeds of dogs, or of pigeons, or of horses, were known only in a fossil state, no naturalist would hesitate in regarding them as distinct species.

But, in all these cases we have human interference. Without the breeder there would be no selection, and without the selection no race. Before admitting the possibility of natural species having originated in any similar way, it must be proved that there is in nature some power which takes the place of man, and performs a selection suâ sponte. It is the claim of Mr. Darwin that he professes to have discovered the existence and the modus operandi of this natural selection, as he terms it; and, if he be right, the process is perfectly simple and comprehensible, and irresistibly deducible from very familiar but well nigh forgotten facts.

Who, for instance, has duly reflected upon all the consequences of the marvellous struggle for existence which is daily and hourly going on among living beings? Not only does every animal live at the expense of some other animal or plant, but the very plants are at war. The ground is full of seeds that cannot rise into seedlings; the seedlings rob one another of air and light and water, the strongest robber winning the day, and extinguishing his competitors. Year after year, the wild animals with which man never interferes are, on the average, neither 
more nor less numerous than they were; and yet we know that the annual produce of every pair is from one to perhaps a million young,-so that it is mathematically certain that, on the average, as many are killed by natural causes as are born every year, and those only escape which happen to be a little better fitted to resist destruction than those which die. The individuals of a species are like the crew of a foundered ship, and none but good swimmers have a chance of reaching the land.

Such being unquestionably the necessary conditions under which living creatures exist, Mr. Darwin discovers in them the instrument of natural selection. Suppose that in the midst of this incessant competition some individuals of a species (A) present accidental variations which happen to fit them a little better than their fellows for the struggle in which they are engaged, then the chances are in favour, not only of these individuals being better nourished than the others, but of their predominating over their fellows in other ways, and of having a better chance of leaving offspring, which will of course tend to reproduce the peculiarities of their parents. Their offspring will, by a parity of reasoning, tend to predominate over their contemporaries, and there being (suppose) no room for more than one species such as $A$, the weaker variety will eventually be destroyed by the new destructive influence which is thrown into the scale, and the stronger will take its place. Surrounding conditions remaining unchanged, the new variety (which we may call B)supposed, for argument's sake, to be the best aaapted for these conditions which can be got out of the original stock -will renain unchanged, all accidental deviations from the type becoming at once extinguished, as less fit for their post than B itself. The tendency of B to persist will grow with its persistence through successive generations, and it will acquire all the characters of a new species.

But, on the other hand, if the conditions of life change in any degree, however slight, B may no longer be that form which is best adapted to withstand their destructive, and profit by their sustaining, influence; in which case if it should give rise to a more competent variety $(C)$, this will take its place and become a new species; and thus, by natural selection, the species $B$ and $C$ will be successively derived from $A$.

That this most ingenious hypothesis enables us to give 
a reason for many apparent anomalies in the distribution of living beings in time and space, and that it is not contradicted by the main phenomena of life and organization appear to us to be unquestionable, and so far it must be admitted to have an immense advantage over any of its predecessors. But it is quite another matter to affirm absolutely either the truth or falsehood of Mr. Darwin's views at the present stage of the inquiry. Goethe has an excellent aphorism defining that state of mind which he calls Thätige Skepsis-active doubt. It is doubt which so loves truth that it neither dares rest in doubting, nor extinguish itself by unjustified belief; and we commend this state of mind to students of species, with respect to Mr. Darwin's or any other hypothesis, as to their origin. The combined investigations of another 20 years may, perhaps, enable naturalists to say whether the modifying causes and the selective power, which Mr. Darwin has satisfactorily shown to exist in nature, are competent to produce all the effects he ascribes to them, or whether, on the other hand, he has been led to over-estimate the value of his principle of natural selection, as greatly as Lamarck over-estimated his vera causa of modification by exercise.

But there is, at all events, one advantage possessed by the more recent writer over his predecessor. Mr. Darwin abhors mere speculation as nature abhors a vacuum. He is as greedy of cases and precedents as any constitutional lawyer, and all the principles he lays down are capable of being brought to the test of observation and experiment. The path he bids us follow professes to be not a mere airy track, fabricated of ideal cobwebs, but a solid and broad bridge of facts. If it be so, it will carry us safely over many a chasm in our knowledge, and lead us to a region free from the snares of those fascinating but barren Virgins, the Final Causes, against whom a high authority has so justly warned us. "My sons, dig in the vineyard," were the last words of the old man in the fable; and, though the sons found no treasure, they made their fortunes by the grapes. 


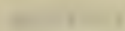

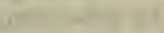

,

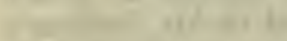

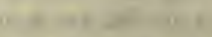

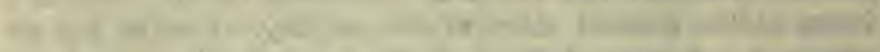

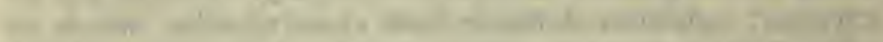

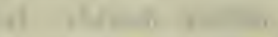

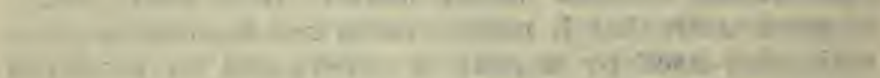

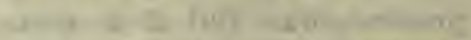

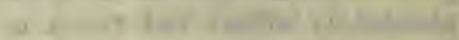

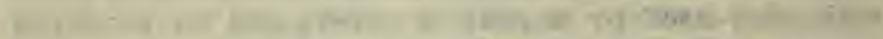

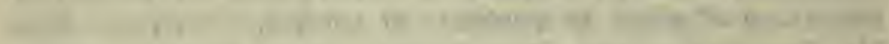

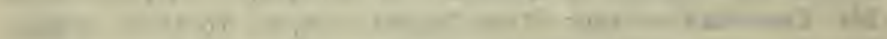

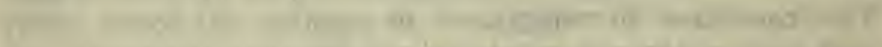

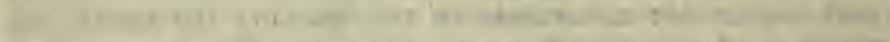

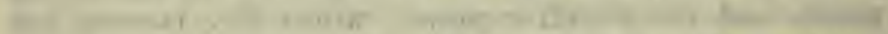

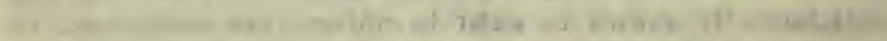

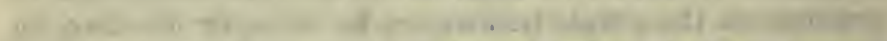

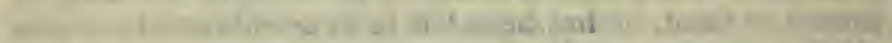

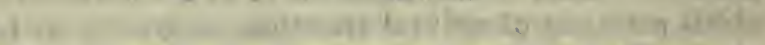

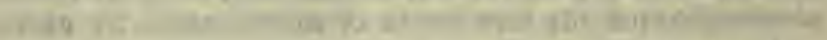

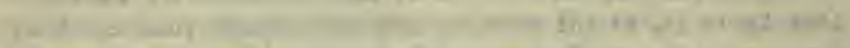

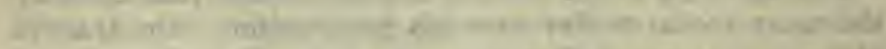

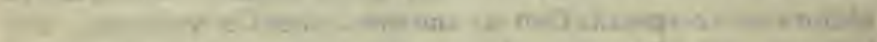

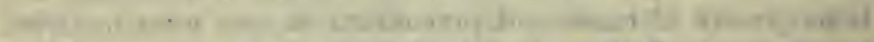

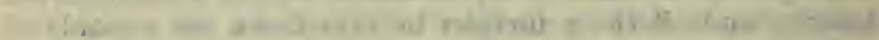

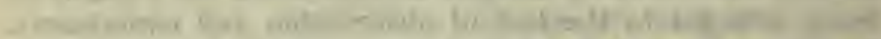
a

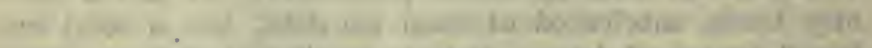

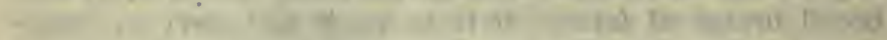

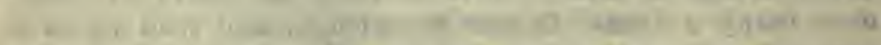

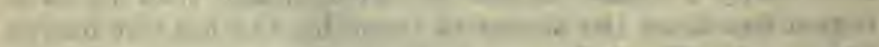

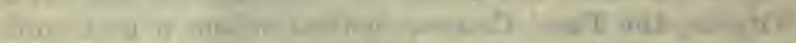

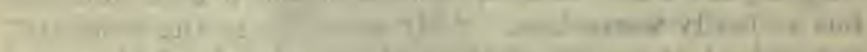

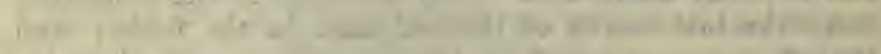

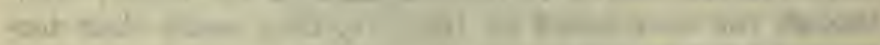

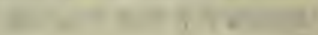




\section{TIME AND LIFE*}

\section{Mr. Darwin's "Origin of Species"}

Everyone knows that that superficial film of the earth's substance, hardly ten miles thick, which is accessible to human investigation, is composed for the most part of beds or strata of stone, the consolidated muds and sands of former seas and lakes, which have been deposited one upon the other, and hence are the older the deeper they lie. These multitudinous strata present such resemblances and differences among themselves that they are capable of classification into groups or formations, and these formations again are brigaded together into still larger assemblages, called by the older geologists, primary, secondary, and tertiary; by the moderns, palæozoic, mesozoic, and cainozoic : the basis of the former nomenclature being the relative age of the groups of strata; that of the latter, the kinds of living forms contained in them.

Though but a film if compared with the total diameter of our planet, the total series of formations is vast indeed when measured by any human standard, and, as all action implies time, so are we compelled to regard these mineral masses as a measure of the time which has elapsed during their accumulation. The amount of the time which they represent is, of course, in the inverse proportion of the intensity of the forces which have been in operation. If, in the ancient world, mud and sand accumulated on seabottoms at tenfold their present rate, it is clear that a bed of mud or sand ten feet thick would have been formed then in the same time as a stratum of similar materials one foot thick would be formed now, and vice versa.

At the outset of his studies, therefore, the physical geologist had to choose between two hypotheses; either, throughout the ages which are represented by the accumulated strata, and which we may call geologic time, the 
forces of nature have operated with much the same average intensity as at present, and hence the lapse of time which they represent must be something prodigious and inconceivable, or, in the primeval epochs, the natural powers were infinitely more intense than now, and hence the time through which they acted to produce the effects we see was comparatively short.

The earlier geologists adopted the latter view almost with one consent. For they had little knowledge of the present workings of nature, and they read the records of geologic time as a child reads the history of Rome or Greece, and fancies that antiquity was grand, heroic, and unlike the present because it is unlike his little experience of the present.

Even so the earlier observers were moved with wonder at the seeming contrast between the ancient and the present order of nature. The elemental forces seemed to have been grander and more energetic in primeval times. Upheaved and contorted, rifted and fissured, pierced by dykes of molten matter or worn away over vast areas by aqueous action, the older rocks appeared to bear witness to a state of things far different from that exhibited by the peaceful epoch on which the lot of man has fallen.

But by degrees thoughtful students of geology have been led to perceive that the earliest efforts of nature have been by no means the grandest. Alps and Andes are children of yesterday when compared with Snowdon and the Cumberland hills; and the so-called glacial epoch -that in which perhaps the most extensive physical changes of which any record remains occurred-is the last and the newest of the revolutions of the globe. And in proportion as pliysical geography-which is the geology of our own epoch-has grown into a science, and the present order of nature has been ransacked to find what, hibernice, we may call precedents for the phenomena of the past, so the apparent necessity of supposing the past to be widely different from the present has diminished.

The transporting power of the greatest deluge which can be imagined sinks into insignificance beside that of the slowly floating, slowly melting iceberg, or the glacier creeping along at its snail's pace of a yard a day. The study of the deltas of the Nile, the Ganges, and the Mississippi has taught us how slow is the wearing action of water, how vast its effects when time is allowed for its operation. 
The reefs of the Pacific, the deep-sea soundings of the Atlantic, show that it is to the slow-growing coral and to the imperceptible animalcule, which lives its brief space and then adds its tiny shell to the muddy cairn left by its brethren and ancestors, that we must look as the agents in the formation of limestone and chalk, and not to hypothetical oceans saturated with calcareous salts and suddenly depositing them.

And while the inquirer has thus learnt that existing forces-give them time-are competent to produce all the physical phenomena we meet with in the rocks, so, on the other side, the study of the marks left in the ancient strata by past physical actions shows that these were similar to those which now obtain. Ancient beaches are met with whose pebbles are like those found on modern shores; the hardened sea-sands of the oldest epochs show ripple-marks, such as may now be found on every sandy coast; nay, more, the pits left by ancient rain-drops prove that even in the very earliest ages, the "bow in the clouds" must have adorned the palæozoic firmament. So that if we could reverse the legend of the Seven Sleepers,-if we could sleep back through the past, and awake a million ages before our own epoch, in the midst of the earliest geologic times,- there is no reason to believe that sea, or sky, or the aspect of the land would warn us of the marvellous retrospection.

Such are the beliefs which modern physical geologists hold, or, at any rate, tend towards holding. But, in so doing, it is obvious that they by no means prejudge the question, as to what the physical condition of the globe may have been before our chapters of its history begin, in what may be called (with that licence which is implied in the often-used term " prehistoric epoch") "pregeologic time." The views indicated, in fact, are not only quite consistent with the hypothesis, that, in the still earlier period referred to, the condition of our world was very different; but they may be held by some to necessitate that hypothesis. The physical philosopher who is accurately acquainted with the velocity of a cannon-ball, and the precise character of the line which it traverses for a yard of its course, is necessitated by what he knows of the laws of nature to conclude that it came from a certain spot, whence it was impelled by a certain force, and that it has followed a certain trajectory. In like manner, the 
student of physical geology, who fully believes in the uniformity of the general condition of the earth through geologic time, may feel compelled by what he knows of causation, and by the general analogy of nature, to suppose that our solar system was once a nebulous mass, that it gradually condensed, that it broke up into that wonderful group of harmoniously rolling balls we call planets and satellites, and that then each of these underwent its appointed metamorphosis, until at last our own share of the cosmic vapour passed into that condition in which we first meet with definite records of its state, and in which it has since, with comparatively little change, remained.

The doctrine of uniformity and the doctrine of progression are, therefore, perfectly consistent ; perhaps, indeed, they might be shown to be necessarily connected with one another.

If, however, the condition of the world, which has obtained throughout geologic time, is but the sequel to a vast series of changes which took place in pregeologic time, then it seems not unlikely that the duration of this latter is to that of the former as the vast extent of geologic time is to the length of the brief epoch we call the historical period; and that even the oldest rocks are records of an epoch almost infinitely remote from that which could have witnessed the first shaping of our globe.

It is probable that no modern geologist would hesitate to admit the general validity of these reasonings when applied to the physics of his subject, whence it is the more remarkable that the moment the question changes from one of physics and chemistry to one of natural history, scientific opinions and the popular prejudices, which reflect them in a distorted form, undergo a sudden metamorphosis. Geologists and palæontologists write about the "beginning of life" and the "first-created forms of living beings," as if they were the most familiar things in the world; and even cautious writers seem to be on quite friendly terms with the "archetype" whereby the Creator was guided " amidst the crash of falling worlds." Just as it used to be imagined that the ancient universe was physically opposed to the present, so it is still widely assumed that the living population of our globe, whether animal or vegetable, in the older epochs, exhibited forms so strikingly contrasted with those which we see around us, that there is hardly anything in common between the 
two. It is constantly tacitly assumed that we have before us all the forms of life which have ever existed; and though the progress of knowledge, yearly and almost monthly, drives the defenders of that position from their ground, they entrench themselves in the new line of defences as if nothing had happened, and proclaim that the new beginning is the real beginning.

Without for an instant denying or endeavouring to soften down the considerable positive differences (the negative ones are met by another line of argument) which undoubtedly obtain between the ancient and the modern worlds of life, we believe they have been vastly overstated and exaggerated, and this belief is based upon certain facts whose value does not seem to have been fully appreciated, though they have long been more or less completely known.

The multitudinous kinds of animals and plants, both recent and fossil, are, as is well known, arranged by zoologists and botanists, in accordance with their natural relations, into groups which receive the names of sub-kingdoms, classes, orders, families, genera and species. Now it is a most remarkable circumstance that, viewed on the great scale, living beings have differed so little throughout all geologic time that there is no sub-kingdom and no class wholly extinct or without living representatives.

If we descend to the smaller groups, we find that the number of orders of plants is about two hundred; and I have it on the best authority that not one of these is exclusively fossil ; so that there is absolutely not a single extinct ordinal type of vegetable life; and it is not until we descend to the next group, or the families, that we find types which are wholly extinct. The number of orders of animals, on the other hand, may be reckoned at a hundred and twenty, or thereabouts, and of these, eight or nine have no living representatives. The proportion of extinct ordinal types of animals to the existing types, therefore, does not exceed seven per cent.-a marvellously small proportion when we consider the vastness of geologic time.

Another class of considerations - of a different kind, it is true, but tending in the same direction-seems to have been overlooked. Not only is it true that the general plan of construction of animals and plants has been the 
same in all recorded time as at present, but there are particular kinds of animals and plants which have existed throughout vast epochs, sometimes through the whole range of recorded time, with very little change. By reason of this persistency, the typical form of such a kind might be called a "persistent type," in contradistinction to those types which have appeared for but a short time in the course of the world's history. Examples of these persistent types are abundant enough in both the vegetable and the animal kingdoms. The oldest group of plants with which we are well acquainted is that of whose remains coal is constituted; and, so far as they can be identified, the carboniferous plants are ferns, or club-mosses, or Coniferæ, in many cases generically identical with those now living !

Among animals, instances of the same kind may be found in every sub-kingdom. The Globigerina of the Atlantic soundings is identical with that which occurs in the chalk; and the casts of lower silurian Foraminifera, which Ehrenberg has recently described, seem to indicate the existence at that remote period of forms singularly like those which now exist. Among the corals, the palæozoic Tabulata are constructed on precisely the same type as the modern millepores; and if we turn to molluscs, the most competent malacologists fail to discover any generic distinction between the Craniæ, Lingulæ, and Discinæ of the silurian rocks and those which now live. Our existing Nautilus has its representative species in every great formation, from the oldest to the newest; and Loligo, the squid of modern seas, appears in the lias, or at the bottom of the mesozoic series, in a form, at most, specifically different from its living congeners. In the great assemblage of annulose animals, the two highest classes, the insects and spider tribe, exhibit a wonderful persistency of type. The cockroaches of the carboniferous epoch are exceedingly similar to those which now run about our coal-cellars; and its locusts, termites, and dragon-flies are closely allied to the members of the same groups which now chirrup about our fields, undermine our houses, or sail with swift grace about the banks of our sedgy pools. And, in like manner, the palæozoic scorpions can only be distinguished by the eye of a naturalist from the modern ones.

Finally, with respect to the Verlebrata, the same law holds good: certain types, such as those of the ganoid 
and placoid fishes, having persisted from the palæozoic epoch to the present time without a greater amount of deviation from the normal standard than that which is seen within the limits of the group as it now exists. Even among the Reptilia - the class which exhibits the largest proportion of entirely extinct forms of any-one type, that of the Crocodilia, has persisted from at least the commencement of the Mesozoic epoch up to the present time with so much constancy, that the amount of change which it exhibits may fairly, in relation to the time which has elapsed, be called insignificant. And the imperfect knowledge we have of the ancient mammalian population of our earth leads to the belief that certain of its types, such as that of the Marsupialia, have persisted with correspondingly little change through a similar range of time.

Thus it would appear to be demonstrable, that, notwithstanding the great change which is exhibited by the animal population of the world as a whole, certain types have persisted comparatively without alteration, and the question arises, What bearing have such facts as these on our notions of the history of life through geological time? The answer to this question would seem to depend on the view we take respecting the origin of species in general. If we assume that every species of animal and of plant was formed by a distinct act of creative power, and if the species which have incessantly succeeded one another were placed upon the globe by these separate acts, then the existence of persistent types is simply an unintelligible irregularity. Such assumption, however, is as unsupported by tradition or by Revelation as it is opposed by the analogy of the rest of the operations of nature; and those who imagine that, by adopting any such hypothesis, they are strengthening the hands of the advocates of the letter of the Mosaic account, are simply mistaken. If, on the other hand, we adopt that hypothesis to which alone the study of physiology lends any support-that hypothesis which, having struggled beyond the reach of those fatal supporters, the Telliameds and Vestigiarians, who so nearly caused its suffocation by wind in early infancy, is now winning at least the provisional assent of all the best thinkers of the day-the hypothesis that the forms or species of living beings, as we know them, have been produced by the gradual modification of pre-existing species-then the existence of persistent types seems to 
teach us much. Just as a small portion of a great curve appears straight, the apparent absence of change in direction of the line being the exponent of the vast extent of the whole, in proportion to the part we see; so, if it be true that all living species are the result of the modification of other and simpler forms, the existence of these little altered persistent types, ranging through all geological time, must indicate that they are but the final terms of an enormous series of modifications, which had their being in the great lapse of pregeologic time, and are now perhaps for ever lost.

In other words, when rightly studied, the teachings of palæontology are at one with those of physical geology. Our farthest explorations carry us back but a little way above the mouth of the great river of Life: where it arose, and by what channels the noble tide has reached the point when it first breaks upon our view, is hidden from us.

The foregoing pages contain the substance of a lecture delivered before the Royal Institution of Great Britain many months ago, and of course long before the appearance of the remarkable work on the "Origin of Species," just published by Mr. Darwin, who arrives at very similar conclusions. Although, in one sense, I might fairly say that my own views have been arrived at independently, I do not know that I can claim any equitable right to property in them; for it has long been my privilege to enjoy Mr. Darwin's friendship, and to profit by corresponding with him, and by, to some extent, becoming acquainted with the workings of his singularly original and well-stored mind. It was in consequence of my knowledge of the general tenor of the researches in which Mr. Darwin had been so long engaged; because I had the most complete confidence in his perseverance, his knowledge, and, above all things, his high-minded love of truth; and, moreover, because I found that the better I became acquainted with the opinions of the best naturalists regarding the vexéd question of species, the less fixed they seemed to be, and the more inclined they were to the hypothesis of gradual modification, that I ventured to speak as strongly as I have done in the final paragraphs of iny discourse.

Thus, my daw having so many borrowed plumes, I seo no impropriety in making a tail to this bricf paper by 
taking another handful of feathers from Mr. Darwin; endeavouring to point out in a few words, in fact, what, as I gather from the perusal of his book, his doctrines really are, and on what sort of basis they rest. And I do this the more willingly, as I observe that already the hastier sort of critics have begun, not to review my friend's book, but to howl over it in a manner which must tend greatly to distract the public mind.

No one will be better satisfied than I to see Mr. Darwin's book refuted, if any person be competent to perform that feat; but $I$ would suggest that refutation is retarded, not aided, by mere sarcastic misrepresentation. Every one who has studied cattle-breeding, or turned pigeonfancier, or "pomologist," must have been struck by the extreme modifiability or plasticity of those kinds of animals and plants which have been subjected to such artificial conditions as are imposed by domestication. Breeds of dogs are more different from one another than are the dog and the wolf; and the purely artificial races of pigeons, if their origin were unknown, would most assuredly be reckoned by naturalists as distinct species and even genera.

These breeds are always produced in the same way. The breeder selects a pair, one or other, or both, of which present an indication of the peculiarity he wishes to perpetuate, and then selects from the offspring of them those which are most characteristic, rejecting the others. From the selected offspring he breeds again, and, taking the same precautions as before, repeats the process until he has obtained the precise degree of divergence from the primitive type at which he aimed.

If he now breeds from the variety thus established for some generations, taking care always to keep the stock pure, the tendency to produce this particular variety becomes more and more strongly hereditary; and it does not appear that there is any limit to the persistency of the race thus developed.

Men like Lamarck, apprehending these facts, and knowing that varieties comparable to those produced by the breeder are abundantly found in nature, and finding it impossible to discriminate in some cases between varieties and true species, could hardly fail to divine the possibility that species even the most distinct were, after all, only exceedingly persistent varieties, and that they had arisen by the modification of some common stock, just as it is 
with good reason believed that turnspits and greyhounds, carrier and tumbler pigeons, have arisen.

But there was a link wanting to complete the parallel. Where in nature was the analogue of the breeder to be found? How could that operation of selection, which is his essential function, be carried out by mere natural agencies ? Lamarck did not value this problem; neither did he admit his impotence to solve it; but he guessed a solution. Now, guessing in science is a very hazardous proceeding, and Lamarck's reputation has suffered woefully for the absurdities into which his baseless suppositions led him.

Lamarck's conjectures, equipped with a new hat and stick, as Sir Walter Scott was wont to say of an old story renovated, formed the foundation of the biological speculations of the Vestiges, a work which has done more harm to the progress of sound thought on these matters than any that could be named; and, indeed, I mention it here simply for the purpose of denying that it has anything in common with what essentially characterises Mr. Darwin's work.

The peculiar feature of the latter is, in fact, that it professes to tell us what in nature takes the place of the breeder; what it is that favours the development of one variety into which a species may run, and checks that of another; and, finally, shows how this natural selection, as it is termed, may be the physical cause of the production of species by modification.

That which takes the place of the breeder and selector in nature is Death. In a most remarkable chapter, On the Struggle for Existence, Mr. Darwin draws attention to the marvellous destruction of life which is constantly going on in nature. For every species of living thing, as for man, "Eine Bresche ist ein jeder Tag."-Every species has its enemies; every species has to compete with others for the necessaries of existence; the weakest goes to the wall, and death is the penalty inflicted on all laggards and stragglers. Every variety to which a species may give rise is either worse or better adapted to surrounding circumstances than its parent. If worse, it cannot maintain itself against death, and speedily vanishes again. But if better adapted, it must, sooner or later, "improve" its progenitor from the face of the earth, and take its place. If circumstances change, the victor will be similarly supplanted by its own progeny; and thus, by the operation 
of natural causes, unlimited modification may in the lapse of long ages occur.

For an explanation of what I have here called vaguely "surrounding circumstances," and of why they continually change-for ample proof that the "struggle for existence" is a very great reality, and assuredly tends to exert the influence ascribed to it-I must refer to Mr. Darwin's book. I believe I have stated fairly the position upon which his whole theory must stand or fall ; and it is not my purpose to anticipate a full review of his work. If it can be proved that the process of natural selection, operating upon any species, can give rise to varieties of species so different from one another that none of our tests will distinguish them from true species, Mr. Darwin's hypothesis of the origin of species will take its place among the established theories of science, be its consequences whatever they may. If, on the other hand, Mr. Darwin has erred, either in fact or in reasoning, his fellow-workers will soon find out the weak points in his doctrines, and their extinction by some nearer approximation to the truth will exemplify his own principle of natural selection.

In either case the question is one to be settled only by the painstaking, truth-loving investigation of skilled naturalists. It is the duty of the general public to await the result in patience ; and, above all things, to discourage, as they would any other crimes, the attempt to enlist the prejudices of the ignorant, or the uncharitableness of the bigoted, on either side of the controversy. 


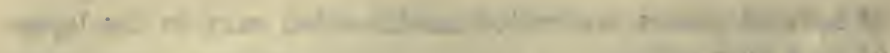

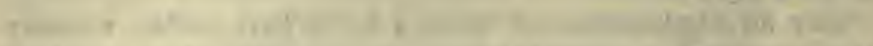

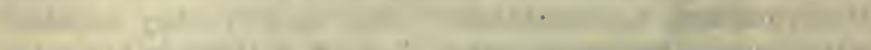

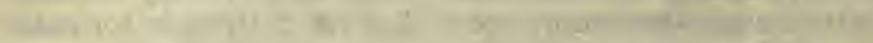

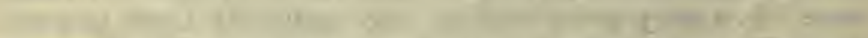

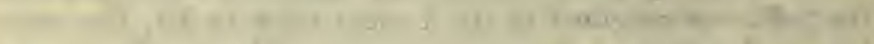

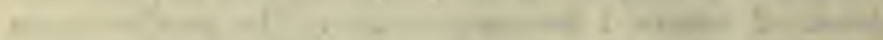

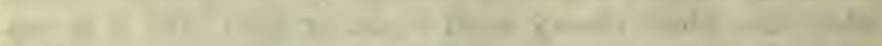

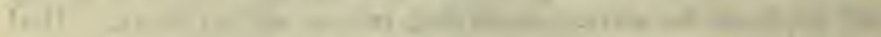

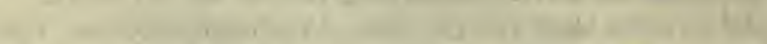
at

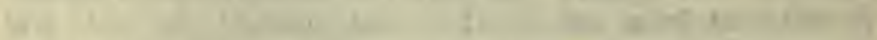
1 I the 20.

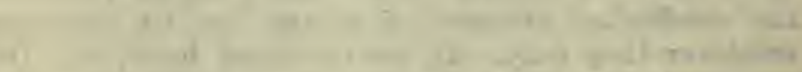

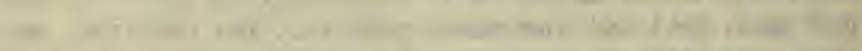

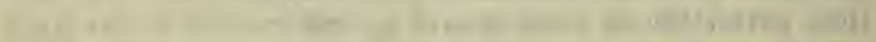
in

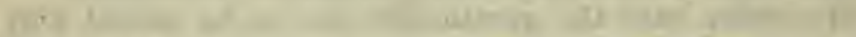

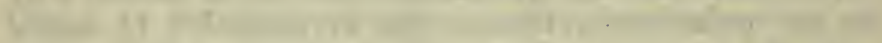

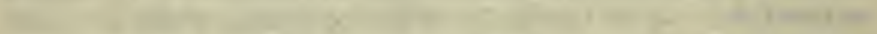

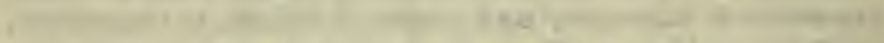

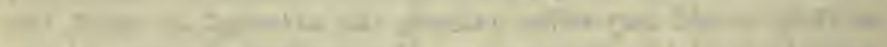
4h - L

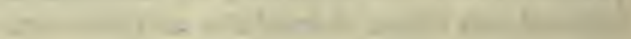




\section{THE ORIGIN OF SPECIES *}

Mr. DARwin's long-standing and well-earned scientific eminence probably renders him indifferent to that social notoriety which passes by the name of success; but if the calm spirit of the philosopher have not yet wholly superseded the ambition and the vanity of the carnal man within him, he must be well satisfied with the results of his venture in publishing the Origin of Species. Overflowing the narrow bounds of purely scientific circles, the "species question" divides with Italy and the Volunteers the attention of general society. Everybody has read Mr. Darwin's book, or, at least, has given an opinion upon its merits or demerits ; pietists, whether lay or ecclesiastic, decry it with the mild railing which sounds so charitable; bigots denounce it with ignorant invective; old ladies of both sexes consider it a decidedly dangerous book, and even savants, who have no better mud to throw, quote antiquated writers to show that its author is no better than an ape himself; while every philosophical thinker hails it as a veritable Whitworth gun in the armoury of liberalism; and all competent naturalists and physiologists, whatever their opinions as to the ultimate fate of the doctrines put forth, acknowledge that the work in which they are embodied is a solid contribution to knowledge and inaugurates a new epoch in natural history.

Nor has the discussion of the subject been restrained within the limits of conversation. When the public is eager and interested, reviewers must minister to its wants ; and the genuine littérateur is too much in the habit of acquiring his knowledge from the book he judges-as the Abyssinian is said to provide himself with steaks from the ox which carries him - to be withheld from criticism of a profound scientific work by the mere want of the requisite preliminary scientific acquirement; while, on the other hand, the men of science who wish well to the new views, 
no less than those who dispute their validity, have naturally sought opportunities of expressing their opinions. Hence it is not surprising that almost all the critical journals have noticed Mr. Darwin's work at greater or less length ; and so many disquisitions, of every degree of excellence, from the poor product of ignorance, too often stimulated by prejudice, to the fair and thoughtful essay of the candid student of Nature, have appeared, that it seems an almost lielpless task to attempt to say anything new upon the question.

But it may be doubted if the knowledge and acumen of prejudged scientific opponents, or the subtlety of orthodox special pleaders, have yet exerted their full force in mystifying the real issues of the great controversy which has been set afoot, and whose end is hardly likely to be seen by this generation; so that at this eleveth hour, and even failing anything new, it may be useful to state afresh that which is true, and to put the fundamental positions advocated by Mr. Darwin in such a form that they may be grasped by those whose special studies lie in other directions. And the adoption of this course may be the more advisable, because notwithstanding its great deserts, and indeed partly on account of them, the Origin of Species is by no means an easy book to read-if by reading is implied the full comprehension of an author's meaning.

We do not speak jestingly in saying that it is Mr. Darwin's misfortune to know more about the question he has taken up than any man living. Personally and practically exercised in zoology, in minute anatomy, in geology; a student of geographical distribution, not on maps and in museums only, but by long voyages and laborious collection ; having largely advanced each of these branches of science, and having spent many years in gathering and sifting materials for his present work, the store of accurately registered facts upon which the author of the Origin of Species is able to draw at will is prodigious.

But this very superabundance of matter must have been embarrassing to a writer who, for the present, can only put forward an abstract of his views; and thence it arises, perhaps, that notwithstanding the clearness of the style, those who attempt fairly to digest the book find much of it a sort of intellectual pemmican-a mass of facts crushed and pounded into shape, rather than held together by the ordinary medium of an obvious logical bond : due attention 
will, without doubt, discover this bond, but it is often hard to find.

Again, from sheer want of room, much has to be taken for granted which might readily enough be proved; and hence, while the adept, who can supply the missing links in the evidence from his own knowledge, discovers fresh proof of the singular thoroughness with which all difficulties have been considered and all unjustifiable suppositions avoided, at every reperusal of Mr. Darwin's pregnant paragraphs, the novice in biology is apt to complain of the frequency of what he fancies is gratuitous assumption.

Thus while it may be doubted if, for some years, any one is likely to be competent to pronounce judgment on all the issues raised by Mr. Darwin, there is assuredly abundant room for him, who, assuming the humbler, though perhaps as useful, office of an interpreter between the Origin of Species and the public, contents himself with endeavouring to point out the nature of the problems which it discusses; to distinguish between the ascertained facts and the theoretical views which it contains; and finally, to show the extent to which the explanation it offers satisfies the requirements of scientific logic. At any rate, it is this office which we purpose to undertake in the following pages.

It may be safely assumed that our readers have a general conception of the nature of the objects to which the word "species" is applied; but it has, perhaps, occurred to a few, even to those who are naturalists ex professo, to reflect, that, as commonly employed, the term has a double sense and denotes two very different orders of relations. When we call a group of animals, or of plants, a species, we may imply thereby, either that all these animals or plants have some common peculiarity of form or structure ; or, we may mean that they possess some common functional character. That part of biological science which deals with form and structure is called Morphology-that which concerns itself with function, Physiology-so that we may conveniently speak of these two senses, or aspects, of "species"-the one as morphological, the other as physiological. Regarded from the former point of view, a species is nothing more than a kind of animal or plant, which is distinctly definable from all others, by certain constant, and not merely sexual, morphological peculiarities. Thus horses form a species, because the group of animals to which that name is applied 
is distinguished from all others in the world by the following constantly associated characters. They have-1, A vertebral column ; 2 , Mammæ ; 3 , A placental embryo ; 4, Four legs; 5, A single well-developed toe in each foot provided with a hoof ; 6, A bushy tail ; and 7, Callosities on the inner sides of both the fore and the hind legs. The asses, again, form a distinct species, because, with the same characters, as far as the fifth in the above list, all asses have tufted tails, and have callosities only on the inner side of the fore-legs. If animals were discovered having the general characters of the horse, but sometimes with callosities only on the fore-legs, and more or less tufted tails ; or animals having the general characters of the ass, but with more or less bushy tails, and sometimes with callosities on both pairs of legs, besides being intermediate in other respects - the two species would have to be merged into one. They could no longer be regarded as morphologically distinct species, for they would not be distinctly definable one froin the other.

However bare and simple this definition of species may appear to be, we confidently appeal to all practical naturalists, whether zoologists, botanists, or palæontologists, to say if, in the vast majority of cases, they know, or mean to affirm, anything more of the group of animals or plants they so denominate than what has just been stated. Even the most decided advocates of the received doctrines respecting species admit this.

"I apprehend," says Professor Owen," "that few naturalists nowadays, in describing and proposing a name for what they call ' a new species,' use that term to signify what was meant by it twenty or thirty years ago ; that is, an originally distinct creation, maintaining its primitive distinction by obstructive generative peculiarities. The proposer of the new species now intends to state no more than he actually knows; as, for example, that the differences on which he founds the specific character are constant in individuals of both sexes, so far as observation has reached; and that they are not due to domestication or to artificially superinduced external circumstances, or to any outward influence within his cognizance; that the species is wild, or is such as it appears by Nature."

If we consider, in fact, that by far the largest proportion of recorded existing species are known only by the study

* On the Osteology of the Chimpanzees and Orangs : Transactions of the Zoological Society, 1858. 
of their skins, or bones, or other lifeless exuvia; that we are acquainted with none, or next to none, of their physiological peculiarities, beyond those which can be deduced from their structure, or are open to cursory observation ; and that we cannot hope to learn more of any of those extinct forms of life which now constitute no inconsiderable proportion of the known Flora and Fauna of the world: it is obvious that the definitions of these species can be only of a purely structural or morphological character. It is probable that naturalists would have avoided much confusion of ideas if they had more frequently borne the necessary limitations of our knowledge in mind. But while it may safely be admitted that we are acquainted with only the morphological characters of the vast majority of species - the functional, or physiological, peculiarities of a few have been carefully investigated, and the result of that study forms a large and most interesting portion of the physiology of reproduction.

The student of Nature wonders the more and is astonished the less, the more conversant he becomes with her operations; but of all the perennial miracles she offers to his inspection, perhaps the most worthy of admiration is the development of a plant or of an animal from its embryo. Examine the recently laid egg of some common animal, such as a salamander or a newt. It is a minute spheroid in which the best microscope will reveal nothing but a structureless sac, enclosing a glairy fluid, holding granules in suspension. But strange possibilities lie dormant in that semi-fluid globule. Let a moderate supply of warmth reach its watery cradle, and the plastic matter undergoes changes so rapid and yet so steady and purposelike in their succession, that one can only compare them to those operated by a skilled modeller upon a formless lump of clay. As with an invisible trowel, the mass is divided and subdivided into smaller and smaller portions, until it is reduced to an aggregation of granules not too large to build withal the finest fabrics of the nascent organism. And, then, it is as if a delicate finger traced out the line to be occupied by the spinal column, and moulded the contour of the body; pinching up the head at one end, the tail at the other, and fashioning flank and limb into due salamandrine proportions, in so artistic a way, that, after watching the process hour by hour, one is almost involuntarily possessed by the notion, that some more subtle aid 
to vision than an achromatic, would show the hidden artist, with his plan before him, striving with skilful manipulation to perfect his work.

As life advances, and the young amphibian ranges the waters, the terror of his insect contemporaries, not only are the nutritious particles supplied by its prey, by the addition of which to its frame growth takes place, laid down, each in its proper spot, and in such due proportion to the rest, as to reproduce the form, the colour, and the size, characteristic of the parental stock ; but even the wonderful powers of reproducing lost parts possessed by these animals are controlled by the same governing tendency. Cut off the legs, the tail, the jaws, separately or all together, and, as Spallanzani showed long ago, these parts not only grow again, but the redintegrated limb is formed on the same type as those which were lost. The new jaw, or leg, is a newt's, and never by any accident more like that of a frog. What is true of the newt is true of every animal and of every plant; the acorn tends to build itself up again into a woodland giant such as that from whose twig it fell; the spore of the humblest lichen reproduces the green or brown incrustation which gave it birth; and at the other end of the scale of life, the child that resembled neither the paternal nor the maternal side of the house would be regarded as a kind of monster.

So that the one end to which, in all living beings, the formative impulse is tending-the one scheme which the Archæus of the old speculators strives to carry out, seems to be to mould the offspring into the likeness of the parent. It is the first great law of reproduction, that the ofispring tends to resemble its parent or parents, more closely than anything else.

Science will some day show us how this law is a necessary consequence of the more general laws which govern matter ; but, for the present, more can hardly be said than that it appears to be in harmony with them. We know that the phenomena of vitality are not something apart from other physical phenomena, but one with them; and matter and force are the two names of the one artist who fashions the living as well as the lifeless. Hence living bodies should obey the same great laws as other matter-nor, throughout Nature, is there a law of wider application than this, that a body impelled by two forces takes the direction of their resultant. But living bodies may be regarded as nothing 
but extremely complex bundles of forces held in a mass of matter, as the complex forces of a magnet are held in the steel by its coercive force; and, since the differences of sex are comparatively slight, or, in other words, the sum of the forces in each has a very similar tendency, their resultant, the offspring, may reasonably be expected to deviate but little from a course parallel to either, or to both.

Represent the reason of the law to ourselves by what physical metaphor or analogy we will, however, the great matter is to apprehend its existence and the importance of the consequences deducible from it. For things which are like to the same are like to one another, and if, in a great series of generations, every offspring is like its parent, it follows that all the offspring and all the parents must be like one another; and that, given an original parental stock, with the opportunity of undisturbed multiplication, the law in question necessitates the production, in course of time, of an indefinitely large group, the whole of whose members are at once very similar and are blood relations, having descended from the same parent, or pair of parents. The proof that all the members of any given group of animals, or plants, had thus descended, would be ordinarily considered sufficient to entitle them to the rank of physiological species, for most physiologists consider species to be definable as "the offspring of a single primitive stock."

But though it is quite true that all those groups we call species may, according to the known laws of reproduction, have descended from a single stock, and though it is very likely they really have done so, yet this conclusion rests on deduction and can hardly hope to establish itself upon a basis of observation. And the primitiveness of the supposed single stock, which, after all, is the essential part of the matter, is not only a hypothesis, but one which has not a shadow of foundation, if by "primitive" he meant " independent of any other living being." A scientific definition, of which an unwarrantable hypothesis forms an essential part, carries its condemnation within itself ; but even supposing such a definition were, in form, tenable, the physiologist who should attempt to apply it in Nature would soon find himself involved in great, if not inextricable, difficulties. As we have said, it is indubitable that offspring tend to resemble the parental organism, but it is equally true that the similarity attained never amounts to identity, 
either in form or in structure. There is always a certain amount of deviation, not only from the precise characters of a single parent, but when, as in most animals and many plants, the sexes are lodged in distinct individuals, from an exact mean between the two parents. And indeed, on general principles, this slight deviation seems as intelligible as the general similarity, if we reflect how complex the co-operating "bundles of forces" are, and how improbable it is that, in any case, their true resultant shall coincide with any mean between the more obvious characters of the two parents. Whatever be its cause, however, the co-existence of this tendency to minor variation with the tendency to general similarity, is of vast importance in its bearing on the question of the origin of species.

As a general rule, the extent to which an offspring differs from its parent is slight enough; but, occasionally, the amount of difference is much more strongly marked, and then the divergent offspring receives the name of a Variety. Multitudes, of what there is every reason to believe are such varieties, are known, but the origin of very few has been accurately recorded, and of these we will select two as more especially illustrative of the main features of variation. The first of them is that of the "Ancon," or " Otter" sheep, of which a careful account is given by Colonel David Humphreys, F.R.S., in a letter to Sir Joseph Banks, published in the Philosophical Transactions for 1813. It appears that one Seth Wright, the proprietor of a farm on the banks of the Charles River, in Massachusetts, possessed a flock of fifteen ewes and a ram of the ordinary kind. In the year 1791, one of the ewes presented her owner with a male lamb, differing, for no assignable reason, from its parents by a proportionally long body and short bandy legs, whence it was unable to emulate its relatives in those sportive leaps over the neighbours' fences, in which they were in the habit of indulging, much to the good farmer's vexation.

The second case is that detailed by a no less unexceptionable authority than Réaumur, in his Art de faire éclore les Poulets. A Maltese couple, named Kelleia, whose hands and feet were constructed upon the ordinary human model, had born to them a son, Gratio, who possessed six perfectly movable fingers on each hand, and six toes, not quite so well formed, on each foot. No cause could be assigned for the appearance of this unusual variety of the human species. 
Two circumstances are well worthy of remark in both these cases. In each, the variety appears to have arisen in full force, and, as it were, per saltum; a wide and definite difference appearing, at once, between the Ancon ram and the ordinary sheep; between the six-fingered and six-toed Gratio Kelleia and ordinary men. In neither case is it possible to point out any obvious reason for the appearance of the variety. Doubtless there were determining causes for these as for all other phenomena; but they do not appear, and we can be tolerably certain that what are ordinarily understood as changes in physical conditions, as in climate, in food, or the like, did not take place and had nothing to do with the matter. It was no case of what is commonly called adaptation to circumstances; but, to use a conveniently erroneous phrase, the variations arose spontaneously. The fruitless search after final causes leads their pursuers a long way ; but even those hardy teleologists, who are ready to break through all the laws of physics in chase of their favourite will-o'-the-wisp, may be puzzled to discover what purpose could be attained by the stunted legs of Seth Wright's ram or the hexadactyle members of Gratio Kelleia.

Varieties then arise we know not why; and it is more than probable that the majority of varieties have arisen in this "spontaneous" manner, though we are, of course, far from denying that they may be traced, in some cases, to distinct external influences; which are assuredly competent to alter the character of the tegumentary covering, to change colour, to increase or diminish the size of muscles, to modify constitution, and, among plants, to give rise to the metamorphosis of stamens into petals, and so forth. But however they may have arisen, what especially interests us at present is, to remark that, once in existence, varieties obey the fundamental law of reproduction that like tends to produce like, and their offspring exemplify it by tending to exhibit the same deviation from the parental stock as themselves. Indeed, there seems to be, in many instances, a pre-potent influence about a newly-arisen variety which gives it what one may call an unfair advantage over the normal descendants from the same stock. This is strikingly exemplified by the case of Gratio Kelleia, who married a woman with the ordinary pentadactyle extremities, and had by her four children, Salvator, George, André, and Marie. Of these children Salvator, the eldest 
boy, had six fingers and six toes, like his father ; the second and third, also boys, had five fingers and five toes, like their mother, though the hands and feet of George were slightly deformed. The last, a girl, had five fingers and five toes, but the thumbs were slightly deformed. The variety thus reproduced itself purely in the eldest, while the normal type reproduced itself purely in the third, and almost purely in the second and last: so that it would seem, at first, as if the normal type were more powerful than the variety. But all these children grew up and intermarried with normal wives and husband, and then, note what took place : Salvator had four children, three of whom exhibited the hexadactyle members of their grandfather and father, while the youngest had the pentadactyle limbs of the mother and grandmother; so that here, notsvithstanding a double pentadactyle dilution of the blood, the hexadactyle variety had the best of it. The same prepotency of the variety was still more markedly exemplified in the progeny of two of the other children, Marie and George. Marie (whose thumbs only were deformed) gave birth to a boy with six toes, and three other normally formed children; but George, who was not quite so pure a pentadactyle, begot, first, two girls, each of whom had six fingers and toes; then a girl with six fingers on each hand and six toes on the right foot, but only five toes on the left ; and lastly, a boy with only five fingers and toes. In these instances, therefore, the variety, as it were, leaped over one generation to reproduce itself in full force in the next. Finally, the purely pentadactyle André was the father of many children, not one of whom departed from the normal parental type.

If a variation which approaches the nature of a monstrosity can strive thus forcibly to reproduce itself, it is not wonderful that less aberrant modifications should tend to be preserved even more strongly ; and the history of the Ancon sheep is, in this respect, particularly instructive. With the "'cuteness" characteristic of their nation, the neighbours of the Massachusetts farmer imagined it would be an excellent thing if all his sheep were imbued with the stay-at-home tendencies enforced by Nature upon the newly-arrived ram; and they advised Wright to kill the old patriarch of his fold, and install the Ancon ram in his place. The result justifled their sagacious anticipations, and coincided very nearly with what occurred to the 
progeny of Gratio Kelleia. The young lambs were almost always either pure Ancons, or pure ordinary sheep.* But when sufficient Ancon sheep were obtained to interbreed with one another, it was found that the offspring was always pure Ancon. Colonel Humphreys, in fact, states that he was acquainted with only " one questionable case of a contrary nature." Here, then, is a remarkable and wellestablished instance, not only of a very distinct race being established per saltum, but of that race breeding "true" at once, and showing no mixed forms, even when crossed with another breed.

By taking care to select Ancons of both sexes, for breeding from, it thus became easy to establish an extremely wellmarked race ; so peculiar that, even when herded with other sheep, it was noted that the Ancons kept together. And there is every reason to believe that the existence of this breed might have been indefinitely protracted; but the introduction of the Merino sheep, which were not only very superior to the Ancons in wool and meat, but quite as quiet and orderly, led to the complete neglect of the new breed, so that, in 1813, Colonel Humphreys found it difficult to obtain the specimen, whose skeleton was presented to Sir Joseph Banks. We believe that, for many years, no remnant of it has existed in the United States.

Gratio Kelleia was not the progenitor of a race of sixfingered men, as Seth Wright's ram became a nation of Ancon sheep, though the tendency of the variety to perpetuate itself appears to have been fully as strong in the one case as in the other. And the reason of the difference is not far to seek. Seth Wright took care not to weaken the Ancon blood by matching his Ancon ewes with any but males of the same variety, while Gratio Kelleia's sons were too far removed from the patriarchal times to intermarry with their sisters; and his grandchildren seem not to have

* Colonel Humphreys' statements are exceedingly explicit on this point :- "When an Ancon ewe is impregnated by a common ram, the increase resembles wholly either the ewe or the ram. The increase of the common ewe impregnated by an Ancon ram follows entirely the one or the other, without blending any of the distinguishing and essential peculiarities of both. Frequent instances have happened where common ewes have had twins by Ancon rams, when one exhibited the complete marks and features of the ewe, the other of the ram. The contrast has been rendered singularly striking, when one short-legged and one long-legged lamb, produced at a birth, have been seen sucking the dam at the same time." Philosophical Transactions, 1813, Pt. I. pp. 89, 90. 
been attracted by their six-fingered cousins. In other words, in the one example a race was produced, because, for several generations, care was taken to select both parents of the breeding stock from animals exhibiting a tendency to vary in the same condition; while, in the other, no race was evolved, because no such selection was exercised. A race is a propagated variety ; and as, by the laws of reproduction, offspring tend to assume the parental forms, they will be more likely to propagate a variation exhibited by both parents than that possessed by only one.

There is no organ of the body of an animal which may not, and does not, occasionally, vary more or less from the normal type ; and there is no variation which may not be transmitted, and which, if selectively transmitted, may not become the foundation of a race. This great truth, sometimes forgotten by philosophers, has long been familiar to practical agriculturists and breeders; and upon it rest all the methods of improving the breeds of domestic animals, which, for the last century, have been followed with so much success in England. Colour, form, size, texture of hair or wool, proportions of various parts, strength or weakness of constitution, tendency to fatten or to remain lean, to give much or little milk, speed, strength, temper, intelligence, special instincts; there is not one of these characters whose transmission is not an every-day occurrence within the experience of cattle-breeders, stockfarmers, horse-dealers, and dog and poultry fanciers. Nay, it is only the other day that an eminent physiologist, Dr. Brown-Séquard, communicated to the Royal Society his discovery that epilepsy, artificially produced in guineapigs, by a means which he has discovered, is transmitted to their offspring.

But a race, once produced, is no more a fixed and immutable entity than the stock whence it sprang; variations arise among its members, and as these variations are transmitted like any others, new races may be developed out of the pre-existing one ad infinitum, or, at least, within any limit at present determined. Given sufmeient time and sufficiently careful selection, and the inultitude of races which may arise from a common stock is as astonishing as are the extreme structural differences which they may present. A remarkable example of this is to be found in the rock-pigeon, which Dr. Darwin has, in our opinion, satisfactorily demonstrated to be the progenitor of all our 
domestic pigeons, of which there are certainly more than a hundred well-marked races. The most noteworthy of these races are, the four great stocks known to the "fancy" as tumblers, pouters, carriers, and fantails; birds which not only differ most singularly in size, colour, and habits, but in the form of the beak and of the skull: in the proportions of the beak to the skull; in the number of tailfeathers ; in the absolute and relative size of the feet; in the presence or absence of the uropygial gland; in the number of vertebræ in the back; in short, in precisely those characters in which the genera and species of birds differ from one another.

And it is most remarkable and instructive to observe, that none of these races can be shown to have been originated by the action of changes in what are commonly called external circumstances, upon the wild rock-pigeon. On the contrary, from time immemorial, pigeon fanciers have had essentially similar methods of treating their pets, which have been housed, fed, protected and cared for in much the same way in all pigeonries. In fact, there is no case better adapted than that of the pigeons to refute the doctrine which one sees put forth on high authority, that " no other characters than those founded on the development of bone for the attachment of muscles " are capable of variation. In precise contradiction of this hasty assertion, Mr. Darwin's researches prove that the skeleton of the wings in domestic pigeons has hardly varied at all from that of the wild type; while, on the other hand, it is in exactly those respects, such as the relative length of the beak and skull, the number of the vertebræ, and the number of the tail-feathers, in which muscular exertion can have no important influence, that the utmost amount of variation has taken place.

We have said that the following out of the properties exhibited by physiological species would lead us into difficulties, and at this point they begin to be obvious; for if, as the result of spontaneous variation and of selective breeding, the progeny of a common stock may become separated into groups distinguished from one another by constant, not sexual, morphological characters, it is clear that the physiological definition of species is likely to clash with the morphological definition. No one would hesitate to describe the pouter and the tumbler as distinct 
species, if they were found fossil, or if their skins and skeletons were imported, as those of exotic wild birds commonly are-and without doubt, if considered alone, they are good and distinct morphological species. On the other hand, they are not physiological species, for they are descended from a common stock, the rock-pigeon.

Under these circumstances, as it is admitted on all sides that races occur in Nature, how are we to know whether any apparently distinct animals are really of different physiological species, or not, secing that the amount of morphological difference is no safe guide? Is there any test of a physiological species ? The usual answer of physiologists is in the affirmative. It is said that such a test is to be found in the phenomena of hybridization-in the results of crossing races, as compared with the results of crossing species.

So far as the evidence goes at present, individuals, of what are certainly known to be mere races produced by selection, however distinct they may appear to be, not only breed freely together, but the offspring of such crossed races are only perfectly fertile with one another. Thus, the spaniel and the greyhound, the dray-horse and the Arab, the pouter and the tumbler, breed together with perfect freedom, and their mongrels, if matched with other mongrels of the same kind, are equally fertile.

On the other hand, there can be no doubt that the individuals of many natural species are either absolutely infertile, if crossed with individuals of other species, or, if they give rise to hybrid offspring, the hybrids so produced are infertile when paired together. The horse and the ass, for instance, if so crossed, give rise to the mule, and there is no certain evidence of offspring ever having been produced by a male and female mule. The unions of the rock-pigeon and the ring-pigeon appear to be equally barren of result. Here, then, says the physiologist, we have a means of distinguishing any two true species from any two varieties. If a male and a female, selected from each group, produce ofispring, and that ofispring is fertile with others produced in the same way, the groups are races and not species. If, on the other hand, no result ensues, or if the offspring are infertile with others produced in the same way, they are true physiological species. The test would be an admirable one, if, in the first place, it were always practicable to apply it, and if, in the second, it always yielded results 
susceptible of a definite interpretation. Unfortunately, in the great majority of cases, this touchstone for species is wholly inapplicable.

The constitution of many wild animals is so altered by confinement that they will not breed even with their own females, so that the negative results obtained from crosses are of no value; and the antipathy of wild animals of different species for one another, or even of wild and tame members of the same species, is ordinarily so great, that it is hopeless to look for such unions in Nature. The hermaphrodism of most plants, the difficulty in the way of insuring the absence of their own, or the proper working of other pollen, are obstacles of no less magnitude in applying the test to them. And in both animals and plants is superadded the further difficulty, that experiments must be continued over a long time for the purpose of ascertaining the fertility of the mongrel or hybrid progeny, as well as of the first crosses from which they spring.

Not only do these great practical difficulties lie in the way of applying the hybridization test, but even when this oracle can be questioned, its replies are sometimes as doubtful as those of Delphi. For example, cases are cited by Mr. Darwin, of plants which are more fertile with the pollen of another species than with their own; and there are others, such as certain fuci, whose male element will fertilize the ovule of a plant of distinct species, while the males of the latter species are ineffective with the females of the first. So that, in the last-named instance, a physiologist, who should cross the two species in one way, would decide that they were true species; while another, who should cross them in the reverse way, would, with equal justice, according to the rule, pronounce them to be mere races. Several plants, which there is great reason to believe are mere varieties, are almost sterile when crossed; while both animals and plants, which have always been regarded by naturalists as of distinct species, turn out, when the test is applied, to be perfectly fertile. Again, the sterility or fertility of crosses seems to bear no relation to the structural resemblances or differences of the members of any two groups.

Mr. Darwin has discussed this question with singular ability and circumspection, and his conclusions are summed up as follows, at page 276 of his work :- 
"First crosses between forms sufficiently distinct to be ranked as species, and their hybrids, are very generally, but not universally, sterile. The sterility is of all degrees, and is often so slight that the two most careful experimentalists who have ever lived have come to diametrically opposite conclusions in ranking forms by this test. The sterility is innately variable in individuals of the same species, and is eminently susceptible of favourable and unfavourable conditions. The degree of sterility does not strictly follow systematic affinity, but is governed by several curious and complex laws. It is generally different, and sometimes widely different, in reciprocal crosses between the same two species. It is not always equal in degree in a first cross, and in the hybrid produced from this cross.

"In the same manner as in grafting trees, the capacity of one species or variety to take on another is incidental on generally unknown differences in their vegetative systems; so in crossing, the greater or less facility of one species to unite with another is incidental on unknown differences in their reproductive systems. There is no more reason to think that species lave been specially endowed with various degrees of sterility to prevent them crossing and breeding in Nature, than to think that trees have been specially endowed with various and somewhat analogous degrees of difficulty in being grafted together, in order to prevent them becoming inarched in our forests.

"The sterility of first crosses between pure species, which have their reproductive systems perfect, seems to depend on several circumstances; in some cases largely on the early death of the embryo. The sterility of hybrids which have their reproductive systems imperfect, and which have had this system and their whole organization disturbed by being compounded of two distinct species, seems closely allied to that sterility which so frequently affects pure species when their natural conditions of life have been disturbed. This view is supported by a parallelism of another kind : nainely, that the crossing of forms, only slightly different, is favourable to the vigour and fertility of the offspring; and that slight changes in the conditions of life are apparently favourable to the vigour and fertility of all organic beings. It is not surprising that the degree of difficulty in uniting two species, and the degree of sterility of their hybrid offspring, should generally correspond, though due to distinct causes ; for both depend on the amount of difference of some kind between the species which are crossed. Nor is it surprising that the facility of effecting a first cross, the fertility of hybrids produced from it, and the capacity of being grafted together-though this latter capacity evidently depends on widely different circumstances $\rightarrow$ should all run to a certain extent parallel with the systematic affinity of the forms which are subjected to experiment; for systematic affinity attempts to express all kinds of resemblance between all species.

"First crosses between forms known to be varieties, or sufficiently alike to be considered as varieties, and their mongrel offspring, are 
very generally, but not quite universally, fertile. Nor is this nearly general and perfect fertility surprising, when we remember how liable we are to argue in a circle with respect to varieties in a state of Nature; and when we remember that the greater-number of varieties have been produced under domestication by the selection of mere external differences, and not of differences in the reproductive system. In all other respects, excluding fertility, there is a close general resemblance between hybrids and mongrels." Pp. 276-8.

We fully agree with the general tenor of this weighty passage; but forcible as are these arguments, and little as the value of fertility or infertility as a test of species may be, it must not be forgotten that the really important fact, so far as the inquiry into the origin of species goes, is, that there are such things in Nature as groups of animals and of plants, whose members are incapable of fertile union with those of other groups; and that there are such things as hybrids, which are absolutely sterile when crossed with other hybrids. For if such phenomena as these were exhibited by only two of those assemblages of living objects, to which the name of species (whether it be used in its physiological or in its morphological sense) is given, it would have to be accounted for by any theory of the origin of species, and every theory which could not account for it would be, so far, inperfect.

Up to this point we have been dealing with matters of fact, and the statements which we have laid before the reader would, to the best of our knowledge, be admitted to contain a fair exposition of what is at present known respecting the essential properties of species, by all who have studied the question. And whatever may be his theoretical views, no naturalist will probably be disposed to demur to the following summary of that exposition :-

Living beings, whether animals or plants, are divisible into multitudes of distinctly definable kinds, which are morphological species. They are also divisible into groups of individuals, which breed freely together, tending to reproduce their like, and are physiological species. Normally resembling their parents, the offspring of members of these species are still liable to vary, and the variation may be perpetuated by selection, as a race, which race, in many cases, presents all the characteristics of a morphological species. But it is not as yet proved that a race ever exhibits, when crossed with another race of the same species, 
those p§enomena of hybridization which are exhibited by many species when crossed with other species. On the other hand, not only is it not proved that all species give rise to hybrids infertile inter se, but there is much reason to believe that, in crossing, species exhibit every gradation from perfect sterility to perfect fertility.

Such are the most essential characteristics of species. Even were man not one of them-a member of the same system and subject to the same laws-the question of their origin, their causal connexion, that is, with the other phenomena of the universe, must have attracted his attention, as soon as his intelligence had raised itself above the level of his daily wants.

Indeed history relates that such was the case, and has embalmed for us the speculations upon the origin of living beings, which were among the earliest products of the dawning intellectual activity of man. In those early days positive knowledge was not to be had, but the craving after it needed, at all hazards, to be satisfied, and according to the country, or the turn of thought of the speculator, the suggestion that all living things arose from the mud of the Nile, from a primeval egg, or from some more anthropomorphic agency, afforded a sufficient resting-place for his curiosity. The myths of Paganism are as dead as Osiris or Zeus, and the man who should revive them, in opposition to the knowledge of our time, would be justly laughed to scorn; but the coeval imaginations current among the rude inhabitants of Palestine, recorded by writers whose very name and age are admitted by every scholar to be unknown, have unfortunately not yet shared their fate, but, even at this day, are regarded by nine-tenths of the civilized world as the authoritative standard of fact and the criterion of the justice of scientific conclusions, in all that relates to the origin of things, and, among them, of species. In this nineteenth century, as at the dawn of modern physical science, the cosmogony of the semibarbarous Hebrew is the incubus of the philosopher and the opprobrium of the orthodox. Who shall number the patient and earnest seekers after truth, from the days of Galileo until now, whose lives have been embittered and their good name blasted by the mistaken zeal of Bibliolaters? Who shall count the host of weaker men whose sense of truth has been destroyed in the effort to harmonize 
impossibilities-whose life has been wasted in the attempt to force the generous new wine of Science into the old bottles of Judaism, compelled by the outcry of the same strong party?

It is true that if philosophers have suffered, their cause has been amply avenged. Extinguished theologians lie about the cradle of every science as the strangled snakes beside that of Hercules ; and history records that whenever science and orthodoxy have been fairly opposed, the latter has been forced to retire from the lists, bleeding and crushed, if not annihilated; scotched, if not slain. But orthodoxy is the Bourbon of the world of thought. It learns not, neither can it forget; and though, at present, bewildered and afraid to move, it is as willing as ever to insist that the first chapter of Genesis contains the beginning and the end of sound science; and to visit, with such petty thunderbolts as its half-paralysed hands can hurl, those who refuse to degrade Nature to the level of primitive Judaism.

Philosophers, on the other hand, have no such aggressive tendencies. With eyes fixed on the noble goal to which "per aspera et ardua" they tend, they may, now and then, be stirred to momentary wrath by the unnecessary obstacles with which the ignorant, or the malicious, encumber, if they cannot bar, the difficult path ; but why should their souls be deeply vexed? The majesty of Fact is on their side, and the elemental forces of Nature are working for them. Not a star comes to the meridian at its calculated time but testifies to the justice of their methods-their beliefs are "one with falling rain and with the growing corn." By doubt they are established, and open inquiry is their bosom friend. Such men have no fear of traditions however venerable, and no respect for them when they become mischievous and obstructive; but they have better than mere antiquarian business in hand, and if dogmas, which ought to be fossil but are not, are not forced upon their notice, they are too happy to treat them as non-existent.

The hypotheses respecting the origin of species which profess to stand upon a scientific basis, and, as such, alone demand serious attention, are of two kinds. The one, the "special creation" hypothesis, presumes every species to have originated from one or more stocks, these not $66-\mathrm{r}$ 
being the result of the modification of any other form of living matter-or arising by natural agencies-but being produced, as such, by a supernatural creative act.

The other, the so-called "transmutation" hypothesis, considers that all existing species are the result of the modification of pre-existing species, and those of their predecessors, by agencies similar to those which at the present day produce varieties and races, and therefore in an altogether natural way; and it is a probable, though not a necessary consequence of this hypothesis, that all living beings have arisen from a single stock. With respect to the origin of this primitive stock, or stocks, the doctrine of the origin of species is obviously not necessarily concerned. The transmutation hypothesis, for example, is perfectly consistent either with the conception of a special creation of the primitive germ, or with the supposition of its having arisen, as a modification of inorganic matter, by natural causes.

The doctrine of special creation owes its existence very largely to the supposed necessity of making science accord with the Hebrew cosmogony ; but it is curious to observe that, as the doctrine is at present maintained by men of science, it is as hopelessly inconsistent with the Hebrew view as any other hypothesis.

If there be any result which has come more clearly out of geological investigation than another, it is, that the vast series of extinct animals and plants is not divisible, as it was once supposed to be, into distinct groups, separated by sharply-marked boundaries. There are no great gulfs between epochs and formations-no successive periods marked by the appearance of plants, of water animals, and of land animals, en masse. Every year adds to the list of links between what the older geologists supposed to be widely separated epochs : witness the crags linking the drift with older tertiaries; the Maestricht beds linking the tertiaries with the chalk; the St. Cassian beds exhibiting an abundant fauna of mixed mesozoic and palæozoic types, in rocks of an epoch once supposed to be eminently poor in life; witness, lastly, the incessant disputes as to whether a given stratum shall be reckoned devonian or carboniferous, silurian or devonian, cambrian or silurian.

This truth is further illustrated in a most interesting manner by the impartial and highly competent testimony 
of M. Pictet, from whose calculations of what percentage of the genera of animals, existing in any formation, lived during the preceding formation, it results that in no case is the proportion less than one-third, or 33 per cent. It is the triassic formation, or the commencement of the mesozoic epoch, which has received the smallest inheritance from preceding ages. The other formations not uncommonly exhibit 60,80 , or even 94 per cent. of genera in common with those whose remains are imbedded in their predecessor. Not only is this true, but the subdivisions of each formation exhibit new species characteristic of, and found only in, them; and, in many cases, as in the lias for example, the separate beds of these subdivisions are distinguished by well-marked and peculiar forms of life. A section, a hundred feet thick, will exhibit, at different heights, a dozen species of ammonite, none of which passes beyond its particular zone of limestone, or clay, into the zone below it or into that above it; so that those who adopt the doctrine of special creation must be prepared to admit, that at intervals of time, corresponding with the thickness of these beds, the Creator thought fit to interfere with the natural course of events for the purpose of making a new ammonite. It is not easy to transplant oneself into the frame of mind of those who can accept such a conclusion as this, on any evidence short of absolute demonstration; and it is difficult to see what is to be gained by so doing, since, as we have said, it is obvious that such a view of the origin of living beings is utterly opposed to the Hebrew cosmogony. Deserving no aid from the powerful arm of Bibliolatry, then, does the received form of the hypothesis of special creation derive any support from science or sound logic? Assuredly not much. The arguments brought forward in its favour all take one form : If species were not supernaturally created, we cannot understand the facts $x$, or $y$, or $z$; we cannot understand the structure of animals or plants, unless we suppose they were contrived for special ends; we cannot understand the structure of the eye, except by supposing it to have been made to see with ; we cannot understand instincts, unless we suppose animals to have been miraculously endowed with them.

As a question of dialectics, it must be admitted that this sort of reasoning is not very formidable to those who are not to be frightened by consequences. It is an argumentum ad ignorantiam-take this explanation or be ignorant. 
But suppose we prefer to admit our ignorance rather than adopt a hypothesis at variance with all the teachings of Nature? Or, suppose for a moment we admit the explanation, and then seriously ask ourselves how much the wiser are we; what does the explanation explain? Is it any more than a grandiloquent way of announcing the fact, that we really know nothing about the matter ? A phenomenon is explained when it is shown to be a case of some general law of Nature; but the supernatural interposition of the Creator can, by the nature of the case, exemplify no law, and if species have really arisen in this way, it is absurd to attempt to discuss their origin.

Or, lastly, let us ask ourselves whether any amount of evidence which the nature of our faculties permits us to attain, can justify us in asserting that any phenomenon is out of the reach of natural causation. To this end it is obviously necessary that we should know all the consequences to which all possible combinations, continued through unlimited time, can give rise. If we knew these, and found none competent to originate species, we should have good ground for denying their origin by natural causation. Till we know them, any hypothesis is better than one which involves us in such miserable presumption.

But the hypothesis of special creation is not only a mere specious mask for our ignorance ; its existence in Biology marks the youth and imperfection of the science. For what is the history of every science, but the history of the elimination of the notion of creative, or other interferences, with the natural order of the phenomena which are the subject-matter of that science? When Astronomy was young "the morning stars sang together for joy," and the planets were guided in their courses by celestial hands. Now, the harmony of the stars has resolved itself into gravitation according to the inverse squares of the distances, and the orbits of the planets are deducible from the laws of the forces which allow a schoolboy's stone to break a window. The lightning was the angel of the Lord; but it has pleased Providence, in these modern times, that science should make it the humble messenger of man, and we know that every flash that shimmers about the horizon on a summer's evening is determined by ascertainable conditions, and that its direction and brightness might, if our knowledge of these were great enough, have been calculated. 
The solvency of great mercantile companies rests on the validity of the laws which have been ascertained to govern the seeming irregularity of that human life which the moralist bewails as the most uncertain of things ; plague, pestilence, and famine are admitted, by all but fools, to be the natural result of causes for the most part fully within human control, and not the unavoidable tortures inflicted by wrathful Omnipotence upon His helpless handiwork.

Harmonious order governing eternally contínuous progress-the web and woof of matter and force interweaving by slow degrees, without a broken thread, that veil which lies between us and the Infinite-that universe which alone we know or can know ; such is the picture which science draws of the world, and in proportion as any part of that picture is in unison with the rest, so may we feel sure that it is rightly painted. Shall Biology alone remain out of harmony with her sister sciences?

Such arguments against the hypothesis of the direct creation of species as these are plainly enough deducible from general considerations; but there are, in addition, phenomena exhibited by species themselves, and yet not so much a part of their very essence as to have required earlier mention, which are in the highest degree perplexing, if we adopt the popularly accepted hypothesis. Such are the facts of distribution in space and in time; the singular phenomena brought to light by the study of development; the structural relations of species upon which our systems of classification are founded; the great doctrines of philosophical anatomy, such as that of homology, or of the community of structural plan exhibited by large groups of species differing very widely in their habits and functions.

The species of animals which inhabit the sea on opposite sides of the isthmus of Panama are wholly distinct ; * the animals and plants which inhabit islands are commonly distinct from those of the neighbouring mainlands, and yet have a similarity of aspect. The mammals of the latest tertiary epoch in the Old and New Worlds belong to the same genera, or family groups, as those which now inhabit the same great geographical area. The crocodilian reptiles which existed in the earliest secondary epoch were similar in general structure to those now living, but exhibit

* Recent investigations tend to show that this statement is not strictly accurate. -1870 . 
slight differences in their vertebræ, nasal passages, and one or two other points. The guinea-pig has teeth which are shed before it is born, and hence can never subserve the masticatory purpose for which they seem contrived, and, in like manner, the female dugong has tusks which never cut the gum. All the members of the same great group run through similar conditions in their development, and all their parts, in the adult state, are arranged according to the same plan. Man is more like a gorilla than a gorilla is like a lemur. Such are a few, taken at random, among the multitudes of similar facts which modern research has established; but when the student seeks for an explanation of them from the supporters of the received hypothesis of the origin of species, the reply he receives is, in substance, of Oriental simplicity and brevity-" Mashallah! it so pleases God!" There are different species on opposite sides of the isthmus of Panama, because they were created different on the two sides. The pliocene mammals are like the existing ones, because such was the plan of creation ; and we find rudimental organs and similarity of plan, because it has pleased the Creator to set before Himșelf a " divine exemplar or archetype," and to copy it in His works; and somewhat ill, those who hold this view imply, in some of them. That such verbal hocus-pocus should be received as science will one day be regarded as evidence of the low state of intelligence in the nineteenth century, just as we amuse ourselves with the phraseology about Nature's abhorrence of a vacuum, wherewith Torricelli's compatriots were satisfied to explain the rise of water in a pump. And be it recollected that this sort of satisfaction works not only negative but positive ill, by discouraging inquiry, and so depriving man of the usufruct of one of the most fertile fields of his great patrimony, Nature.

The objections to the doctrine of the origin of species by special creation which have been detailed, must have occurred, with more or less force, to the mind of every one who has seriously and independently considered the subject. It is therefore no wonder that, from time to time, this hypothesis should have been met by counter hypotheses, all as well, and some better, founded than itself ; and it is curious to remark that the inventors of the opposing views seem to have been led into them as much by their knowledge of geology, as by their acquaintance with biology. In fact, when the mind has once admitted the conception of 
the gradual production of the present physical state of our globe, by natural causes operating through long ages of time, it will be little disposed to allow that living beings have made their appearance in another way, and the speculations of De Maillet and his successors are the natural complement of Scilla's demonstration of the true nature of fossils.

A contemporary of Newton and of Leibnitz, sharing therefore in the intellectual activity of the remarkable age which witnessed the birth of modern physical science, Benoît de Maillet spent a long life as a consular agent of the French Government in various Mediterranean ports. For sixteen years, in fact, he held the office of ConsulGeneral in Egypt, and the wonderful phenomena offered by the valley of the Nile appear to have strongly impressed his mind, to have directed his attention to all facts of a similar order which came within his observation, and to have led him to speculate on the origin of the present condition of our globe and of its inhabitants. But, with all his ardour for science, De Maillet seems to have hesitated to publish views which, notwithstanding the ingenious attempts to reconcile them with the Hebrew hypothesis contained in the preface to Telliamed, were hardly likely to be received with favour by his contemporaries.

But a short time had elapsed since more than one of the great anatomists and physicists of the Italian school had paid dearly for their endeavours to dissipate some of the prevalent errors; and their illustrious pupil, Harvey, the founder of modern physiology, had not fared so well, in a country less oppressed by the benumbing influences of theology, as to tempt any man to follow his example. Probably not uninfluenced by these considerations, his Catholic majesty's Consul-General for Egypt kept his theories to himself throughout a long life, for Telliamed, the only scientific work which is known to have proceeded from his pen, was not printed till 1735 , when its author had reached the ripe age of seventy-nine; and though De Maillet lived three years longer, his book was not given to the world before 1748. Even then it was anonymous to those who were not in the secret of the anagrammatic character of its title; and the preface and dedication are so worded as, in case of necessity, to give the printer a fair chance of falling back on the excuse that the work was intended for a mere jeu d'esprit.

The speculations of the supposititious Indian sage, 
though quite as sound as those of many a "Mosaic Geology," which sells exceedingly well, have no great value if we consider them by the light of modern science. The waters are supposed to have originally covered the whole globe; to have deposited the rocky masses which compose its mountains by processes comparable to those which are now forming mud, sand, and shingle; and then to have gradually lowered their level, leaving the spoils of their animal and vegetable inhabitants embedded in the strata. As the dry land appeared, certain of the aquatic animals are supposed to have taken to it, and to have become gradually adapted to terrestrial and aërial modes of existence. But if we regard the general tenor and style of the reasoning in relation to the state of knowledge of the day, two circumstances appear very well worthy of remark. The first, that De Maillet had a notion of the modifiability of living forms (though without any precise information on the subject), and how such modifiability might account for the origin of species; the second, that he very clearly apprehended the great modern geological doctrine, so strongly insisted upon by Hutton, and so ably and comprehensively expounded by Lyell, that we must look to existing causes for the explanation of past geological events. Indeed, the following passage of the preface, in which De Maillet is supposed to speak of the Indian philosopher Telliamed, his alter ego, might have been written by the most philosophical uniformitarian of the present day :-

" Ce qu'il y a d'étonnant, est que pour arriver à ces connoissances il semble avoir perverti l'ordre naturel, puisqu'au lieu de s'attacher d'abord rechercher l'origine de notre globe il a commencé par travailler à g'instruire de la nature. Mais à l'entendre, ce renversement de l'ordre a été pour luí l'effet d'un génie favorable qui l'a conduit pas pas et comme par la main aux découvertes les plus sublimes. C'est en décomposant la substance de ce globe par une anatomie exacte de toutes ses parties qu'il a premicrement appris de quelles matières il était composé et quels arrangemens ces mêmes matières observaient entre elles. Ces lumières jointes à l'esprit de comparaison toujours nécessaire à quiconque entreprend de percer les voiles dont la nature aime à se cacher, ont servi de guide à notre philosophe pour parvenir à des connoissances plus intéressantes. Par la matière et l'arrangement de ces compositions il prétend avoir reconnu quelle est la véritable origine de ce globe que nous habitons, comment et par qui il a été formé." Pp. xix. xx. 
But De Maillet was before his age, and as could hardly fail to happen to one who speculated on a zoological and botanical question before Linnæus, and on a physiological problem before Haller, he fell into great errors here and there ; and hence, perhaps, the general neglect of his work. Robinet's speculations are rather behind, than in advance of, those of De Maillet; and though Linnæus may have played with the hypothesis of transmutation, it obtained no serious support until Lamarck adopted it, and advocated it with great ability in his Philosophie Zoologique.

Impelled towards the hypothesis of the transmutation of species, partly by his general cosmological and geological views; partly by the conception of a graduated, though irregularly branching, scale of being, which had arisen out of his profound study of plants and of the lower forms of animal life, Lamarck, whose general line of thought often closely resembles that of De Maillet, made a great advance upon the crude and merely speculative manner in which that writer deals with the question of the origin of living beings, by endeavouring to find physical causes competent to effect that change of one species into another, which De Maillet had only supposed to occur. And Lamarck conceived that he had found in nature such causes, amply sufficient for the purpose in view. It is a physiological fact, he says, that organs are increased in size by action, atrophied by inaction ; it is another physiological fact that modifications produced are transmissible to offspring. Change the actions of an animal, therefore, and you will change its structure, by increasing the development of the parts newly brought into use and by the diminution of those less used ; but by altering the circumstances which surround it you will alter its actions, and hence, in the long run, change of circumstance must produce change of organization. All the species of animals, therefore, are, in Lamarck's view, the result of the indirect action of changes of circumstance upon those primitive germs which he considered to have originally arisen, by spontaneous generation, within the waters of the globe. It is curious, however, that Lamarck should insist so strongly* as he has done, that circumstances never in any degree directly modify the form or the organization of animals but only operate by changing their wants and consequently their actions; for he thereby brings upon himself the obvious question, how, then, do plants, which cannot be

* See Phil. Zoologique, vol. i. p. 222, et seq. 
said to have wants or actions, become modified ? To this he replies, that they are modified by the changes in their nutritive processes, which are effected by changing circumstances; and it does not seem to have occurred to him that such changes might be as well supposed to take place among animals.

When we have said that Lamarck felt that mere speculation was not the way to arrive at the origin of species, but that it was necessary, in order to the establishment of any sound theory on the subject, to discover by observation or otherwise, some vera causa, competent to give rise to them; that he affirmed the true order of classification to coincide with the order of their development one from another; that he insisted on the necessity of allowing sufficient time, very strongly ; and that all the varieties of instinct and reason were traced back by him to the same cause as that which has given rise to species, we have enumerated his chief contributions to the advance of the question. On the other hand, from his ignorance of any power in Nature competent to modify the structure of animals, except the development of parts, or atrophy of them, in consequence of a change of needs, Lamarck was led to attach infinitely greater weight than it deserves to this agency, and the absurdities into which he was led have met with deserved condemnation. Of the struggle for existence, on which, as, we shall see, Mr. Darwin lays such great stress, he had no conception; indeed, he doubts whether there really are such things as extinct species, unless they be such large animals as may have met their death at the hands of man; and so little does he dream of there being any other destructive causes of work, that, in discussing the possible existence of fossil shells, he asks, "Pourquoi d'ailleurs seroient-ils perdues dès que l'homme n'a pu opérer leur destruction?" (Phil. Zool., vol.i.p. 77.) Of the influence of selection Lamarck has as little notion, and he makes no use of the wonderful phenomena which are exhibited by domesticated animals, and illustrate its powers. The vast influence of Cuvier was employed against the Lamarckian views, and, as the untenability of some of his conclusions was easily shown, his doctrines sank under the opprobrium of scientific, as well as of theological, heterodoxy. Nor have the efforts made of late years to revive them tended to re-establish their credit in the minds of sound thinkers acquainted with the facts of the case; indeed it may be 
doubted whether Lamarck has not suffered more from his friends than from his foes.

Two years ago, in fact, though we venture to question if even the strongest supporters of the special creation hypothesis had not, now and then, an uneasy consciousness that all was not right, their position seemed more impregnable than ever, if not by its own inherent strength, at any rate by the obvious failure of all the attempts which had been made to carry it. On the other hand, however much the few, who thought deeply on the question of species, might be repelled by the generally received dogmas, they saw no way of escaping from them, save by the adoption of suppositions, so little justified by experiment or by observation, as to be at least equally distasteful.

The choice lay between two absurdities and a middle condition of uneasy scepticism; which last, however unpleasant and unsatisfactory, was obviously the only justifable state of mind under the circumstances.

Such being the general ferment in the minds of naturalists, it is no wonder that they mustered strong in the rooms of the Linnæan Society, on the 1st of July of the year 1858, to hear two papers by authors living on opposite sides of the globe, working out their results independently, and yet professing to have discovered one and the same solution of all the problems connected with species. The one of these authors was an able naturalist, Mr. Wallace, who had been employed for some years in studying the productions of the islands of the Indian Archipelago, and who had forwarded a memoir embodying his views to Mr. Darwin, for communication to the Linnæan Society. On perusing the essay, Mr. Darwin was not a little surprised to find that it embodied some of the leading ideas of a great work which he. had been preparing for twenty years, and parts of which, containing a development of the very same views, had been perused by his private friends fifteen or sixteen years before. Perplexed in what manner to do full justice. both to his friend and to himself, Mr. Darwin placed the matter in the hands of Dr. Hooker and Sir Charles Lyell, by whose advice he communicated a brief abstract of his own views to the Linnæan Society, at the same time that Mr. Wallace's paper was read. Of that abstract, the work on the Origin of Species is an enlargement; but a complete statement of Mr. Darwin's doctrine is looked. 
for in the large and well-illustrated work which he is said to be preparing for publication.

The Darwinian hypothesis has the merit of being eminently simple and comprehensible in principle, and its essential positions may be stated in a very few words: all species have been produced by the development of varieties from common stocks by the conversion of these first into permanent races and then into new species, by the process of natural selection, which process is essentially identical with that artificial selection by which man has originated the races of domestic animals-the struggle for existence taking the place of man, and exerting, in the case of natural selection, that selective action which he performs in artificial selection.

The evidence brought forward by Mr. Darwin in support of his hypothesis is of three kinds. First, he endeavours to prove that species may be originated by selection ; secondly, he attempts to show that natural causes are competent to exert selection; and thirdly, he tries to prove that the most remarkable and apparently anomalous phenomena exhibited by the distribution, development, and mutual relations of species, can be shown to be deducible from the general doctrine of their origin, which he propounds, combined with the known facts of geological change; and that, even if all these phenomena are not at present explicable by it, none are necessarily inconsistent with it.

There cannot be a doubt that the method of inquiry which Mr. Darwin has adopted is not only rigorously in accordance with the canons of scientific logic, but that it is the only adequate method. Critics exclusively trained in classics or in mathematics, who have never determined a scientific fact in their lives by induction from experiment or observation, prate learnedly about Mr. Darwin's method, which is not inductive enough, not Baconian enough, forsooth, for them. But even if practical acquaintance with the process of scientific investigation is denied them, they may learn, by the perusal of Mr. Mill's admirable chapter "On the Deductive Method," that there are multitudes of scientific inquiries, in which the method of pure induction helps the investigator but a very little way.

"The mode of investigation," says Mr. Mill, "which, from the proved inapplicability of direct methods of observation and experiment, remains to us as the main source of the knowledge we possess, 
or can acquire, respecting the conditions and laws of recurrence of the more complex phenomena, is called, in its most general expression, the deductive method, and consists of three operations : the first, one of direct induction; the second, of ratiocination ; and the third, of verification."

Now, the conditions which have determined the existence of species are not only exceedingly complex, but, so far as the great majority of them are concerned, are necessarily beyond our cognizance. But what Mr. Darwin has attempted to do is in exact accordance with the rule laid down by $\mathrm{Mr}$. Mill ; he has endeavoured to determine certain great facts inductively, by observation and experiment; he has then reasoned from the data thus furnished; and lastly, he has tested the validity of his ratiocination by comparing his deductions with the observed facts of Nature. Inductively, Mr. Darwin endeavours to prove that species arise in a given way. Deductively, he desires to show that, if they arise in that way, the facts of distribution, development, classification, etc., may be accounted for, i.e. may be deduced from their mode of origin, combined with admitted changes in physical geography and climate, during an indefinite period. And this explanation, or coincidence of observed with deduced facts, is, so far as it extends, a verification of the Darwinian view.

There is no fault to be found with Mr. Darwin's method, then ; but it is another question whether he has fulfilled all the conditions imposed by that method. Is it satisfactorily proved, in fact, that species may be originated by selection ? that there is such a thing as natural selection ? that none of the phenomena exhibited by species are inconsistent with the origin of species in this way? If these questions can be answered in the affirmative, Mr. Darwin's view steps out of the rank of hypotheses into those of proved theories; but, so long as the evidence at present adduced falls short of enforcing that affirmation, so long, to our minds, must the new doctrine be content to remain among the former-an extremely valuable, and in the highest degree probable, doctrine, indeed the only extant hypothesis which is worth anything in a scientific point of view; but still a hypothesis, and not yet the theory of species.

After much consideration, and with assuredly no bias against Mr. Darwin's views, it is our clear conviction that, as the evidence stands, it is not absolutely proven that a group of animals, having all the characters exhibited by 
species in Nature, has ever been originated by selection, whether artificial or natural. Groups having the morphological character of species, distinct and permanent races in fact, have been so produced over and over again ; but there is no positive evidence, at present, that any group of animals has, by variation and selective breeding, given rise to another group which was even in the least degree infertile with the first. Mir. Darwin is perfectly aware of this weak point, and brings forward a multitude of ingenious and important arguments to diminish the force of the objection. We admit the value of these arguments to their fullest extent; nay, we will go so far as to express our belief that experiments, conducted by a skilful physiologist, would very probably obtain the desired production of mutually more or less infertile breeds from a common stock, in a comparatively few years ; but still, as the case stands at present, this "little rift within the lute" is not to be disguised nor overlooked.

In the remainder of Mr. Darwin's argument our own private ingenuity has not hitherto enabled us to pick holes of any great importance; and judging by what we hear and read, other adventurers in the same field do not seem to have been much more fortunate. It has been urged, for instance, that in his chapters on the struggle for existence and on natural selection, Mr. Darwin does not so much prove that natural selection does occur, as that it must occur; but, in fact, no other sort of demonstration is attainable. A race does not attract our attention in Nature until it has, in all probability, existed for a considerable time, and then it is too late to inquire into the conditions of its origin. Again, it is said that there is no real analogy between the selection which takes place under domestication, by human influence, and any operation which can be effected by Nature, for man interferes intelligently. Reduced to its elements, this argument implies that an effect produced with trouble by an intelligent agent must, $d$ fortiori, be more troublesome, if not impossible, to an unintelligent agent. Even putting aside the question whether Nature, acting as she does according to definite and invariable laws, can be rightly called an unintelligent agent, such a position as this is wholly untenable. Mix salt and sand, and it shall puzzle the wisest of men, with his mere natural appliances, to separate all the grains of sand from all the grains of salt; but a shower of rain will effect the same object in ten minutes. And so, while man may find 
it tax all his intelligence to separate any variety which arises, and to breed selectively from it, the destructive agencies incessantly at work in Nature, if they find one variety to be more soluble in circumstances than the other, will inevitably, in the long run, eliminate it.

A frequent and a just objection to the Lamarckian hypothesis of the transmutation of species is based upon the absence of transitional forms between many species. But against the Darwinian hypothesis this argument has no force. Indeed, one of the most valuable and suggestive parts of Mr. Darwin's work is that in which he proves, that the frequent absence of transitions is a necessary consequence of his doctrine, and that the stock whence two or more species have sprung, need in no respect be intermediate between these species. If any two species have arisen from a common stock in the same way as the carrier and the pouter, say, have arisen from the rock-pigeon, then the common stock of these two species need be no more intermediate between the two than the rock-pigeon is between the carrier and pouter. Clearly appreciate the force of this analogy, and all the arguments against the origin of species by selection, based on the absence of transitional forms, fall to the ground. And Mr. Darwin's position might, we think, have been even stronger than it is if he had not embarrassed himself with the aphorism, "Natura non facit saltum," which turns up so often in his pages. We believe, as we have said above, that Nature does make jumps now and then, and a recognition of the fact is of no small importance in disposing of many minor objections to the doctrine of transmutation.

But we must pause. The discussion of Mr. Darwin's arguments in detail would lead us far beyond the limits within which we proposed, at starting, to confine this article. Our object has been attained if we have given an intelligible, however brief, account of the established facts connected with species, and of the relation of the explanation of those facts offered by Mr. Darwin to the theoretical views held by his predecessors and his contemporaries, and, above all, to the requirements of scientific logic. We have ventured to point out that it does not, as yet, satisfy all those requirements ; but we do not hesitate to assert that it is as superior to any preceding or contemporary hypothesis, in the extent of observational and experimental basis on which it rests, in its rigorously scientific method, and in its power of explaining biological phenomena, as was the hypothesis of Copernicus 
to the speculations of Ptolemy. But the planetary orbits turned out to be not quite circular after all, and, grand as was the service Copernicus rendered to science, Kepler and Newton had to come after him. What if the orbit of Darwinism should be a little too circular! What if species should offer residual phenomena, here and there, not explicable by natural selection? Twenty years hence naturalists may be in a position to say whether this is, or is not, the case; but in either event they will owe the author of The Origin of Species an immense debt of gratitude. We should leave a very wrong impression on the reader's mind if we permitted him to suppose that the value of that work depends wholly on the ultimate justification of the theoretical views which it contains. On the contrary, if they were disproved to-morrow, the book would still be the best of its kind-the most compendious statement of well-sifted facts bearing on the doctrine of species that has ever appeared. The chapters on Variation, on the Struggle for Existence, on Instinct, on Hybridism, on theImperfection of the Geological Record, on Geographical Distribution, have not only no equals, but, so far as our knowledge goes, no competitors, within the range of biological literature. And viewed as a whole, we do not believe that, since the publication of Von Baer's Researches on Development, thirty years ago, any work has appeared calculated to exert so large an influence, not only on the future of Biology, but in extending the domination of Science over regions of thought into which she has, as yet, hardly penetrated. 


\section{CRITICISMS ON "THE ORIGIN OF SPECIES" *}

1. Ueber die Darwin'sche Schöfungstheorie ein Vortrag, von A. Kölliker. Leipzig, 1864.

2. Examination du Livre de M. Darwin sur l'Origine des Espèces. Par P. Flourens. Paris, 1864.

IN the course of the present year several foreign commentaries upon Mr. Darwin's great work have made their appearance. Those who have perused that remarkable chapter of the Antiquity of Man, in which Sir Charles Lyell draws a parallel between the development of species and that of languages, will be glad to hear that one of the most eminent philologers of Germany, Professor Schleicher, has, independently, published a most instructive and philosophical pamphlet (an excellent notice of which is to be found in the Reader, for February 27th of this year) supporting similar views with all the weight of his special knowledge and established authority as a linguist. Professor Haeckel, to whom Schleicher addresses himself, previously took occasion, in his splendid monograph on the Radiolaria, $\dagger$ to express his high appreciation of, and general concordance with, Mr. Darwin's views.

But the most elaborate criticisms of the Origin of Species which have appeared are two works of very widely different merit, the one by Professor Kölliker, the well-known anatomist and histologist of Würzburg; the other by $\mathbf{M}$. Flourens, Perpetual Secretary of the French Academy of Sciences.

Professor Kölliker's critical essay Upon the Darwinian Theory is, like all that proceeds from the pen of that thoughtful and accomplished writer, worthy of the most careful consideration. It comprises a brief but clear sketch of Darwin's views followed by an enumeration of the leading difficulties in the way of their acceptance; difficulties which would appear to be insurmountable to Professor 
Kölliker, inasmuch as he proposes to replace Mr. Darwin's Theory by one which he terms the Theory of Heterogeneous Generation. We shall proceed to consider first the destructive, and secondly, the constructive portion of the essay.

We regret to find ourselves compelled to dissent very widely from many of Professor Kölliker's remarks; and from none more thoroughly than from those in which he seeks to define what we may term the philosophical position of Darwinism.

"Darwin," says Professor Kölliker, "is, in the fullest sense of the word, a Teleologist. He says quite distinctly (First Edition, pp. 199,200 ) that every particular in the structure of an animal has been created for its benefit, and he regards the whole series of animal forms only from this point of view."

\section{And again :}

“7. The teleological general conception adopted by Darwin is a mistaken one.

"Varieties arise irrespectively of the notion of purpose, or of utility, according to general laws of Nature, and may be eitler useful, or hurtful, or indifferent.

" The assumption that an organism exists only on account of some definite end in view, and represents something more than the incorporation of a general idea, or law, implies a one-sided conception of the universe. Assuredly, every organ has, and every organism fulfils, its end, but its purpose is not the condition of its existence. Every organism is also sufficiently perfect for the purpose it serves, and in that, at least, it is useless to seek for a cause of its improvement."

It is singular how differently one and the same book will impress different minds. That which struck the present writer most forcibly on his first perusal of the Origin of Species was the conviction that Teleology, as commonly understood, had received its deathblow at Mr. Darwin's hands. For the teleological argument runs thus: an organ or organism (A) is precisely fitted to perform a function or purpose (B) ; therefore it was specially constructed to perform that function. In Paley's famous illustration, the adaptation of all the parts of the watch to the function, or purpose, of showing the time, is held to be evidence that the watch was specially contrived to that end; on the ground, that the only cause we know of, competent to produce such an effect as a watch which shall 
keep time, is a contriving intelligence adapting the means directly to that end.

Suppose, however, that any one had been able to show that the watch had not been made directly by any person, but that it was the result of the modification of another watch which kept time but poorly; and that this again had proceeded from a structure which could hardly be called a watch at all-seeing that it had no figures on the dial and the hands were rudimentary; ani that going back and back in time we came at last to a revolving barrel as the earliest traceable rudiment of the whole fabric. And imagine that it had been possible to show that all these changes had resulted, first, from a tendency of the structure to vary indefinitely; and secondly, from something in the surrounding world which helped all variations in the direction of an accurate time-keeper, and checked all those in other directions; then it is obvious that the force of Paley's argument would be gone. For it would be demonstrated that an apparatus thoroughly well adapted to a particular purpose might be the result of a method of trial and error worked by unintelligent agents, as well as of the direct application of the means appropriate to that end, by an intelligent agent.

Now it appears to us that what we have here, for illustration's sake, supposed to be done with the watch, is exactly what the establishment of Darwin's Theory will do for the organic world. For the notion that every organism has been created as it is and launched straight at a purpose, Mr. Darwin substitutes the conception of something which may fairly be termed a method of trial and error. Organisms. vary incessantly; of these variations the few meet with surrounding conditions which suit them and thrive; the many are unsuited and become extinguished.

According to Teleology, each organism is like a rifle bullet fired straight at a mark; according to Darwin, organisms. are like grapeshot of which one hits something and the rest fall wide.

For the teleologist an organism exists because it was. made for the conditions in which it is found; for the Darwinian an organism exists because, out of many of its. kind, it is the only one which has been able to persist in the conditions in which it is found.

Teleology implies that the organs of every organism are perfect and cannot be improved; the Darwinian theory 
simply affirms that they work well enough to enable the organism to hold its own against such competitors as it has met with, but admits the possibility of indefinite improvement. But an example may bring into clearer light the profound opposition between the ordinary teleological, and the Darwinian, conception.

Cats catch mice, small birds and the like, very well. Teleology tells us that they do so because they were expressly constructed for so doing - that they are perfect mousing apparatuses, so perfect and so delicately adjusted that no one of their organs could be altered, without the change involving the alteration of all the rest. Darwinism affirms, on the contrary, that there was no express construction concerned in the matter; but that among the multitudinous variations of the Feline stock, many of which died out from want of power to resist opposing influences, some, the cats, were better fitted to catch mice than others, whence they throve and persisted, in proportion to the advantage over their fellows thus offered to them.

Far from imagining that cats exist in order to catch mice well, Darwinism supposes that cats exist because they catch mice well-mousing being not the end, but the condition, of their existence. And if the cat type has long persisted as we know it, the interpretation of the fact upon Darwinian principles would be, not that the cats have remained invariable, but that such varieties as have incessantly occurred have been, on the whole, less fitted to get on in the world than the existing stock.

If we apprehend the spirit of the Origin of Species rightly, then, nothing can be more entirely and absolutely opposed to Teleology, as it is commonly understood, than the Darwinian Theory. So far from being a "Teleologist in the fullest sense of the word," we would deny that he is a Teleologist in the ordinary sense at all ; and we should say that, apart from his merits as a naturalist, he has rendered a most remarkable service to philosophical thought by enabling the student of Nature to recognise, to their fullest extent, those adaptations to purpose which are so striking in the organic world, and which Telcology has done good service in keeping before our minds, without being false to the fundamental principles of a scientific conception of the universe. The apparently diverging teachings of the Teleologist and of the Morphologist are reconciled by the Darwinian hypothesis. 
But leaving our own impressions of the Origin of Species, and turning to those passages specially cited by Professor Kölliker, we cannot admit that they bear the interpretation he puts upon them. Darwin, if we read him rightly, does not affirm that every detail in the structure of an animal has been created for its benefit. His words are (p. 199) :-

“ The foregoing remarks lead me to say a few words on the protest lately made by some naturalists against the utilitarian doctrine that every detail of structure has been produced for the good of its possessor. They believe that very many structures have been created for beauty in the eyes of man, or for mere variety. This doctrine, if true, would be absolutely fatal to my theory-yet I fully admit that many structures are of no direct use to their possessor."

And after sundry illustrations and qualifications, he concludes (p. 200):-

" Hence every detail of structure in every living creature (making some little allowance for the direct action of physical conditions) may be viewed either as having been of special use to some ancestral form, or as being now of special use to the descendants of this formeither directly, or indirectly, through the complex laws of growth."

But it is one thing to say, Darwinically, that every detail observed in an animal's structure is of use to it, or has been of use to its ancestors ; and quite another to affirm, teleologically, that every detail of an animal's structure has been created for its benefit. On the former hypothesis, for example, the teeth of the fœtal Balæna have a meaning; on the latter, none. So far as we are aware, there is not a phrase in the Origin of Species, inconsistent with Professor Kölliker's position, that "varieties arise irrespectively of the notion of purpose, or of utility, according to general laws of Nature, and may be either useful, or hurtful, or indifferent."

On the contrary, Mr. Darwin writes (Summary of Chap. V.) :-

"Our ignorance of the laws of variation is profound. Not in one case out of a hundred can we pretend to assign any reason why this or that part varies more or less from the same part in the parents. ... The external conditions of life, as climate and food, etc. seem to have induced some slight modifications. Habit, in producing constitutional differences, and use, in strengthening, and disuse, in weakening and diminishing organs, seem to have been more potent in their effects." 
And finally, as if to prevent all possible misconception, Mr. Darwin concludes his Chapter on Variation with these pregnant words :-

"Whatever the cause may be of each slight difference in the offspring from their parents-and a cause for each must exist-it is the steady accumulation, through natural selection of such differences, when beneficial to the individual, that gives rise to all the more important modifications of structure, by which the innumerable beings on the face of the earth are enabled to struggle with each other, and the best adapted to survive."

We have dwelt at length upon this subject, because of its great general importance, and because we believe that Professor Kölliker's criticisms on this head are based upon a misapprehension of Mr. Darwin's views-substantially they appear to us to coincide with his own. The other objections which Professor Kölliker enumerates and discusses are the following:

“1. No transitional forms between existing species are known; and known varieties, whether selected or spontaneous, never go so far as to establish new species."

To this Professor Kölliker appears to attach some weight. He makes the suggestion that the short-faced tumbler pigeon may be a pathological product.

“2. No transitional forms of animals are met with among the organic remains of earlier epochs."

Upon this, Professor Kölliker remarks that the absence of transitional forms in the fossil world, though not necessarily fatal to Darwin's views, weakens his case.

" 3. The struggle for existence does not take place."

To this objection, urged by Pelzeln, Kölliker, very justly, attaches no weight.

“4. A tendency of organisms to give rise to useful varieties, and a natural selection, do not exist.

"The varieties which are found arise in consequence of manifold external influences, and it is not obvious why they all, or partially, should be particularly useful. Each animal suffices for its own ends,

- Space will not allow us to give Professor Kolliker's arguments in detail ; our readers will find a full and accurate version of them in the Reader for August 13th and 20th, 1864. 
is perfect of its kind, and needs no further development. Should, howerer, a variety be useful and even maintain itself, there is no obvious reason why it should change any further. The whole conception of the imperfection of organisms and the necessity of their becoming periected is plainly the weakest side of Darwin's Theory, and a pis aller (Nothbehelf) because Darwin could think of no other principle by which to explain the metamorphoses which, as I also believe, have occurred."

Here again we must venture to dissent completely from Professor Kölliker's conception of Mr. Darwin's hypothesis. It appears to us to be one of the many peculiar merits of that hypothesis that it involves no belief in a necessary and continual progress of organisms.

Again, Mr. Darwin, if we read him aright, assumes no special tendency of organisms to give rise to useful varieties, and knows nothing of needs of development, or necessity of perfection. What he says is, in substance: All organisms vary. It is in the highest degree improbable that any given variety should have exactly the same relations to surrounding conditions as the parent stock. In that case it is either better fitted (when the variation may be called useful), or worse fitted, to cope with them. If better, it will tend to supplant the parent stock; if worse, it will tend to be extinguished by the parent stock.

If (as is hardly conceivable) the new variety is so perfectly adapted to the conditions that no improvement upon it is possible,-it will persist, because, though it does not cease to vary, the varieties will be inferior to itself.

If, as is more probable, the new variety is by no means perfectly adapted to its conditions, but only fairly well adapted to them, it will persist, so long as none of the varieties which it throws off are better adapted than itself.

On the other hand, as soon as it varies in a useful way, i.e. when the variation is such as to adapt it more perfectly to its conditions, the fresh variety will tend to supplant the former.

So far from a gradual progress towards perfection forming any necessary part of the Darwinian creed, it appears to us that it is perfectly consistent with indefinite persistence in one estate, or with a gradual retrogression. Suppose, for example, a return of the glacial epoch and a spread of polar climatal conditions over the whole globe. The operation of natural selection under these circumstances would tend, on the whole, to the weeding out of the higher 


\section{CRITIGISMS ON "THE ORIGIN OF SPECIES"}

organisms and the cherishing of the lower forms of life. Cryptogamic vegetation would have the advantage over Phanerogamic; Hydrozoa over Corals; Crustacea over Insecta, and Amphipoda and Isopoda over the higher Crustacea; Cetaceans and Seals over the Primates; the civilization of the Esquimaux over that of the European.

" 5. Pelzeln has also objected that if the later organisms have proceeded from the earlier, the whole developmental series, from the simplest to the highest, could not now exist ; in such a case the simpler organisms must have disappeared."

To this Professor Kölliker replies, with perfect justice, that the conclusion drawn by Pelzeln does not really follow from Darwin's premisses, and that, if we take the facts of Palæontology as they stand, they rather support than oppose Darwin's theory.

"6. Great weight must be attached to the objection brought forward by Huxley, otherwise a warm supporter of Darwin's hypothesis, that we know of no varieties which are sterile with one another, as is the rule among sharply distinguished animal forms.

"If Darwin is right, it must be demonstrated that forms may be produced by selection, which, like the present sharply distinguished animal forms, are infertile, when coupled with one another, and this has not been done."

The weight of this objection is obvious ; but our ignorance of the conditions of fertility and sterility, the want of carefully conducted experiments extending over long series of years, and the strange anomalies presented by the results of the cross-fertilization of many plants, should all, as Mr. Darwin has urged, be taken into account in considering it.

The seventh objection is that we have already discussed (supra, p. 178).

The eighth and last stands as follows :-

" 8. The developmental theory of Darwin is not needed to enable us to understand the regular harmonious progress of the complete series of organic forms from the simpler to the more perfect.

"The existence of general laws of Nature explains this harmony, even if we assume that all beings have arisen separately and independent of one another. Darwin forgets that inorganic nature, in which there can be no thought of genetic connexion of forms, exhibits the same regular plan, the same harmony, as the organic world; and that, to cite only one example, there is as much a natural system of minerals as of plants and animals." 
We do not feel quite sure that we seize Professor Kölliker's meaning here, but he appears to suggest that the observation of the general order and harmony which pervade inorganic nature, would lead us to anticipate a similar order and harmony in the organic world. And this is no doubt true, but it by no means follows that the particular order and harmony observed among them should be that which we see. Surely the stripes of dun horses, and the teeth of the fœtal Balæna, are not explained by the "existence of general laws of Nature." Mr. Darwin endeavours to explain the exact order of organic nature which exists; not the mere fact that there is some order.

And with regard to the existence of a natural system of minerals ; the obvious reply is that there may be a natural classification of any objects-of stones on a sea-beach, or of works of art; a natural classification being simply an assemblage of objects in groups, so as to express their most important and fundamental resemblances and differences. No doubt Mr. Darwin believes that those resemblances and differences upon which our natural systems or classifications of animals and plants are based, are resemblances and differences which have been produced genetically, but we can discover no reason for supposing that he denies the existence of natural classifications of other kinds.

And, after all, is it quite so certain that a genetic relation may not underlie the classification of minerals ? The inorganic world has not always been what we see it. It has certainly had its metamorphoses, and, very probably, a long "Entwickelungsgeschichte" out of a nebular blastema. Who knows how far that amount of likeness among sets of minerals, in virtue of which they are now grouped into families and orders, may not be the expression of the common conditions to which that particular patch of nebulous fog, which may have been constituted by their atoms, and of which they may be, in the strictest sense, the descendants, was subjected ?

It will be obvious from what has preceded, that we do not agree with Professor Kölliker in thinking the objections which he brings forward so weighty as to be fatal to Darwin's view. But even if the case were otherwise, we should be unable to accept the "Theory of Heterogeneous Generation" which is offered as a substitute. That theory is thus stated :- 
"The fundamental conception of this hypothesis is, that, under the influence of a general law of development, the germs of organisms produce others different from themselves. This might happen (1) by the fecundated ova passing, in the course of their development, under particular circumstances, into higher forms; (2) by the primitive and later organisms producing other organisms without fecundation, out of germs or eggs (Parthenogenesis)."

In favour of this hypothesis, Professor Kölliker adduces the well-known facts of Agamogenesis, or "alternate generation"; the extreme dissimilarity of the males and females of many animals ; and of the males, females, and neuters of those insects which live in colonies: and he defines its relations to the Darwinian theory as follows :-

"It is obvious that my hypothesis is apparently very similar to Darwin's, inasmuch as I also consider that the various forms of animals have proceeded directly from one another. My hypothesis of the creation of organisms by heterogeneous generation, however, is distinguished very essentially from Darwin's by the entire absence of the principle of useful variations and their natural selection: and my fundamental conception is this, that a great plan of development lies at the foundation of the origin of the whole organia world, impelling the simpler forms to more and more complex developments. How this law operates, what influences determine the development of the eggs and germs, and impel them to assume constantly new forms, I naturally cannot pretend to say; but I can at least adduce the great analogy of the alternation of generations. If a Bipinnaria, a Brachialaria, a Pluteus, is competent to produce the Echinoderm, which is so widely different from it; if a hydroid polype can produce the higher Medusa; if the vermiform Trematode ' nurse ' can develop within itself the very unlike Cercaria, it will not appear impossible that the egg, or ciliated embryo, of a sponge, for once, under special conditions, might become a hydroid polype, or the embryo of a Medusa, an Echinoderm."

It is obvious, from these extracts, that Professor Kölliker's hypothesis is based upon the supposed existence of a close analogy between the phenomena of Agamogenesis and the production of new species from pre-existing ones. But is the analogy a real one? We think that it is not, and, by the hypothesis, cannot be.

For what are the phenomena of Agamogenesis, stated generally? An impregnated egg develops into an asexual form, A ; this gives rise, asexually, to a second form or forms, B, more or less different from A. B may multiply asexually again; in the simpler cases, however, it does 
not, but, acquiring sexual characters, produces impregnated eggs from whence A once more arises.

No case of Agamogenesis is known in which, when $A$ differs widely from $B$, it is itself capable of sexual propagation. No case whatever is known in which the progeny of $\mathrm{B}$, by sexual generation, is other than a reproduction of $\mathbf{A}$.

But if this be a true statement of the nature of the process of Agamogenesis, how can it enable us to comprehend the production of new species from already existing ones ? Let us suppose Hyænas to have preceded Dogs, and to have produced the latter in this way. Then the Hyæna will represent $A$, and the Dog, $B$. The first difficulty that presents itself is that the Hyæna must be asexual, or the process will be wholly without analogy in the world of Agamogenesis. But passing over this difficulty, and supposing a male and female Dog to be produced at the same time from the Hyæna stock, the progeny of the pair, if the analogy of the simpler kinds of Agamogenesis * is to be followed, should be a litter, not of puppies, but of young Hyænas. For the Agamogenetic series is always, as we have seen, $\mathrm{A}: \mathrm{B}: \mathrm{A}: \mathrm{B}$, etc. ; whereas, for the production of a new species, the series must be $\mathrm{A}: \mathrm{B}$ : B : B, etc. The production of new species, or genera, is the extreme permanent divergence from the primitive stock. All known Agamogenetic processes, on the other hand, end in a complete return to the primitive stock. How then is the production of new species to be rendered intelligible by the analogy of Agamogenesis ?

The other alternative put by Professor Kölliker-the passage of fecundated ova in the course of their development into higher forms-would, if it occurred, be merely an extreme case of variation in the Darwinian sense, greater in degree than, but perfectly similar in kind to, that which occurred when the well-known Ancon Ram was developed

* If, on the contrary, we follow the analogy of the more complex forms of Agamogenesis, such as that exhibited by some Trematoda and by the Aphides, the Hyæna must produce, asexually, a brood of asexual Dogs, from which other sexless Dogs must proceed. At the end of a certain number of terms of the series, the Dogs would acquire sexes and generate young; but these young would be, not Dogs, but Hyænas. In fact, we have demonstrated, in Agamogenetic phenomena, that inevitable recurrence to the original type, which is asserted to be true of variations in general, by Mr. Darwin's opponents; and which, if the assertion could be changed into a demonstration, would, in fact, be fatal to his hypothesis. 
from an ordinary Ewe's ovum. Indeed we have always thought that Mr. Darwin has unnecessarily hampered himself by adhering so strictly to his favourite "Natura non facit saltum." We greatly suspect that she does make considerable jumps in the way of variation now and then, and that these saltations give rise to some of the gaps which appear to exist in the series of known forms.

Strongly and freely as we have ventured to disagree with Professor Kölliker, we have always done so with regret, and we trust without violating that respect which is due, not only to his scientific eminence and to the careful study which he has devoted to the subject, but to the perfect fairness of his argumentation, and the generous appreciation of the worth of Mr. Darwin's labours which he always displays. It would be satisfactory to be able to say as much for M. Flourens.

But the Perpetual Secretary of the French Academy of Sciences deals with Mr. Darwin as the first Napoleon would have treated an "idéologue"; and while displaying a painful weakness of logic and shallowness of information, assumes a tone of authority, which always touches upon the ludicrous, and sometimes passes the limits of good breeding.

For example (p. 56) :-

“M. Darwin continue: 'Aucune distinction absolue n'a été et ne peut être établie entre les espèces et les variétés.' Je vous ai déjà dit que vous vous trompiez; une distinction absolue sépare les variétés d'avec les espèces."

“ Je vous ai déjd dit; moi, M. le Secrétaire perpétuel de l'Académie des Sciences : et vous

" Qui n’êtes rien,.
Pas même Académicien ;"

what do you mean by asserting the contrary?" Being devoid of the blessings of an Academy in England, we are unaccustomed to see our ablest men treated in this fashion, even by a "Perpetual Secretary."

Or again, considering that if there is any one quality of Mr. Darwin's work to which friends and foes have alike borne witness, it is his candour and fairness in admitting and discussing objections, what is to be thought of $\mathbf{M}$. Flourens' assertion, that 
CRITICISMS ON "THE ORIGIN OF SPECIES" 189

" M. Darwin ne cite que les auteurs qui partagent ses opinions." (P. 40.)

\section{Once more (p. 65):-}

“Enfin l'ouvrage de M. Darwin a paru. On ne peut qu'être frappé du talent de l'auteur. Mais que d'idées obscures, que d'idées fausses! Quel jargon métaphysique jeté mal à propos dans l'histoire naturelle, qui tombe dans le galimatias dès qu'elle sort des idées claires, des idées justes! Quel langage prétentieux et vide ! Quelles personifications puériles et surannées ! O lucidité $! O$ solidité de l'esprit Français, que devenez-vous ?"

" Obscure ideas," " metaphysical jargon," " pretentious and empty language," " puerile and superannuated personifications." Mr. Darwin has many and hot opponents on this side of the Channel and in Germany, but we do not recollect to have found precisely these sins in the long catalogue of those hitherto laid to his charge. It is worth while, therefore, to examine into these discoveries effected solely by the aid of the "lucidity and solidity" of the mind of $M$. Flourens.

According to M. Flourens, Mr. Darwin's great error is that he has personified Nature (p. 10), and further that he has

"imagined a natural selection: he imagines afterwards that this power of selection (pouvoir d'élire) which he gives to Nature is similar to the power of man. These two suppositions admitted, nothing stops him : he plays with Nature as he likes, and makes her do all he pleases." (P. 6.)

And this is the way M. Flourens extinguishes natural selection :

"Voyons donc encore une fois, ce qu'il peut y avoir de fondé dans ce qu'on nomme élection naturelle.

" L'élection naturelle n'est sous un autre nom que la nature. Pour un être organisé, la nature n'est que l'organisation, ni plus ni moins.

"Il faudra donc aussi personnifier l'organisation, et dire que l'organisation choisit l'organisation. L'élection naturelle est cette forme substantielle dont on jouait autrefois avec tant de facilité. Aristote disait que 'Si l'art de bâtir était dans le bois, cet art agirait comme la nature.' A la place de l'art de batir M. Darwin met l'élection naturelle; et c'est tout un : l'un n'est pas plus chimérique que l'autre." (P. 31.)

And this is really all that $M$. Flourens can make of Natural Selection. We have given the original, in fear lest 
a translation should be regarded as a travesty; but with the original before the reader, we may try to analyse the passage. " For an organized being, Nature is only organization, neither more nor less."

Organized beings then have absolutely no relation to inorganic nature: a plant does not depend on soil or sunshine, climate, depth in the ocean, height above it; the quantity of saline matters in water have no influence upon animal life ; the substitution of carbonic acid for oxygen in our atmosphere would hurt nobody! That these are absurdities no one should know better than M. Flourens ; but they are logical deductions from the assertion just quoted, and from the further statement that natural selection means only that " organization chooses and selects organization."

For if it be at once admitted (what no sane man denies) that the chances of life of any given organism are increased by certain conditions (A) and diminished by their opposites (B), then it is mathematically certain that any change of conditions in the direction of (A) will exercise a selective influence in favour of that organism, tending to its increase and multiplication, while any change in the direction of (B) will exercise a selective influence against that organism, tending to its decrease and extinction.

Or, on the other hand, conditions remaining the same, let a given organism vary (and no one doubts that they do vary) in two directions : into one form $(a)$ better fitted to cope with these conditions than the original stock, and a second $(b)$ less well adapted to them. Then it is no less certain that the conditions in question must exercise a selective influence in favour of $(a)$ and against $(b)$, so that $(a)$ will tend to predominance, and $(b)$ to extirpation.

That M. Flourens should be unable to perceive the logical necessity of these simple arguments, which lie at the foundation of all Mr. Darwin's reasoning; that he should confound an irrefragable deduction from the observed relations of organisms to the conditions which lie around them, with a metaphysical "forme substantielle," or a chimerical personification of the powers of Nature, would be incredible, were it not that other passages of his work leave no room for doubt upon the subject.

" On imagine une election naturelle que, pour plus de ménagement, on me dit être inconsciente, sans s'apercevoir que le contre-sens littéral est précisément là : élection inconsciente." (P. 52.) 
" J'ai déjà dit ce qu'il faut penser de l'élection naturelle. Ou l'élection naturelle n'est rien, ou c'est la nature : mais la nature douée d'élection, mais la nature personnifiée: dernière erreur du dernier siecle : Le xix• ne fait plus de personnifications." (P. 53.)

M. Flourens cannot imagine an unconscious selection-it is for him a contradiction in terms. Did M. Flourens ever visit one of the prettiest watering-places of " la belle France," the Baie d'Arcachon? If so, he will probably have passed through the district of the Landes, and will have had an opportunity of observing the formation of "dunes" on a grand scale. What are these "dunes"? The winds and waves of the Bay of Biscay have not much consciousness, and yet they have with great care " selected," from among an infinity of masses of silex of all shapes and sizes, which have been submitted to their action, all the grains of sand below a certain size, and have heaped them by themselves over a great area. This sand has been "unconsciously selected" from amidst the gravel in which it first lay with as much precision as if man had " consciously selected " it by the aid of a sieve. Physical Geology is full of such selections-of the picking out of the soft from the hard, of the soluble from the insoluble, of the fusible from the infusible, by natural agencies to which we are certainly not in the habit of ascribing consciousness.

But that which wind and sea are to a sandy beach, the sum of influences, which we term the "conditions of existence," is to living organisms. The weak are sifted out from the strong. A frosty night "selects" the hardy plants in a plantation from among the tender ones as effectually as if it were the wind, and they, the sand and pebbles, of our illustration; or, on the other hand, as if the intelligence of a gardener had been operative in cutting the weaker organisms down. The thistle, which has spread over the Pampas, to the destruction of native plants, has been more effectually "selected" by the unconscious operation of natural conditions than if a thousand agriculturists had spent their time in sowing it.

It is one of Mr. Darwin's many great services to Biological science that he has demonstrated the significance of these facts. He has shown that-given variation and given change of conditions - the inevitable result is the exercise of such an influence upon organisms that one is helped and another is impeded; one tends to predominate, another to disappear; and thus the living world bears within itself, 
and is surrounded by, impulses towards incessant change.

But the truths just stated are as certain as any other physical laws, quite independently of the truth, or falsehood, of the hypothesis which Mr. Darwin has based upon them; and that M. Flourens, missing the substance and grasping at a shadow, should be blind to the admirable exposition of them, which Mr. Darwin has given, and see nothing there but a "dernière erreur du dernier siècle" a personification of Nature-leads us indeed to cry with him: "O lucidité ! O solidité de l'esprit Français, que devenez-vous?"

M. Flourens has, in fact, utterly failed to comprehend the first principles of the doctrine which he assails so rudely. His objections to details are of the old sort, so battered and hackneyed on this side of the Channel, that not even a Quarterly Reviewer could be induced to pick them up for the purpose of pelting Mr. Darwin over again. We have Cuvier and the mummies; M. Roulin and the domesticated animals of America ; the difficulties presented by hybridism and by Palæontology; Darwinism a rifacciamento of De Maillet and Lamarck; Darwinism a system without a commencement, and its author bound to believe in $M$. Pouchet, etc. etc. How one knows it all by heart, and with what relief one reads at p. $65-$

$$
\text { "Je laisse M. Darwin!" }
$$

But we cannot leave $M$. Flourens without calling our readers' attention to his wonderful tenth chapter, "De la Préexistence des Germes et de l'Epigénèse," which opens thus :-

"Spontaneous generation is only a chimera. This point established, two hypotheses remain: that of pre-existence and that of epigenesis. The one of these hypotheses has as little foundation as the other." (P. 163.)

"The doctrine of epigenesis is derived from Harvey : following by ocular inspection the development of the new being in the Windsor does, he saw each part appear successively, and taking the moment of appearance for the moment of formation he imagined epigenesis." (P. 165.)

On the contrary, says M. Flourens (p. 167),

“ The new being is formed at a stroke (tout d"un coup), as a whole, instantaneously; it is not formed part by part, and at different 
times. It is formed at once at the single individual moment at which the conjunction of the male and female elements takes place."

It will be observed that M. Flourens uses language which cannot be mistaken. For him, the labours of Von Baer, of Rathke, of Coste, and their contemporaries and successors in Germany, France, and England, are non-existent: and, as Darwin "imagina" natural selection, so Harvey " imagina" that doctrine which gives him an even greater claim to the veneration of posterity than his better known discovery of the circulation of the blood.

Language such as that we have quoted is, in fact, so preposterous, so utterly incompatible with anything but absolute ignorance of some of the best established facts, that we should have passed it over in silence had it not appeared to afford some clue to M. Flourens' unhesitating, $d$ priori, repudiation of all forms of the doctrine of progressive modification of living beings. He whose mind remains uninfluenced by an acquaintance with the phenomena of development, must indeed lack one of the chief motives towards the endeavour to trace a genetic relation between the different existing forms of life. Those who are ignorant of Geology, find no difficulty in believing that the world was made as it is ; and the shepherd, untutored in history, sees no reason to regard the green mounds which indicate the site of a Roman camp, as aught but part and parcel of the primeval hill-side. So M. Flourens, who believes that embryos are formed "tout d'un coup," naturally finds no difficulty in conceiving that species came into existence in the same way. 



\section{EVIDENCE}

AS TO

MAN'S PLACE IN NATURE

1863 


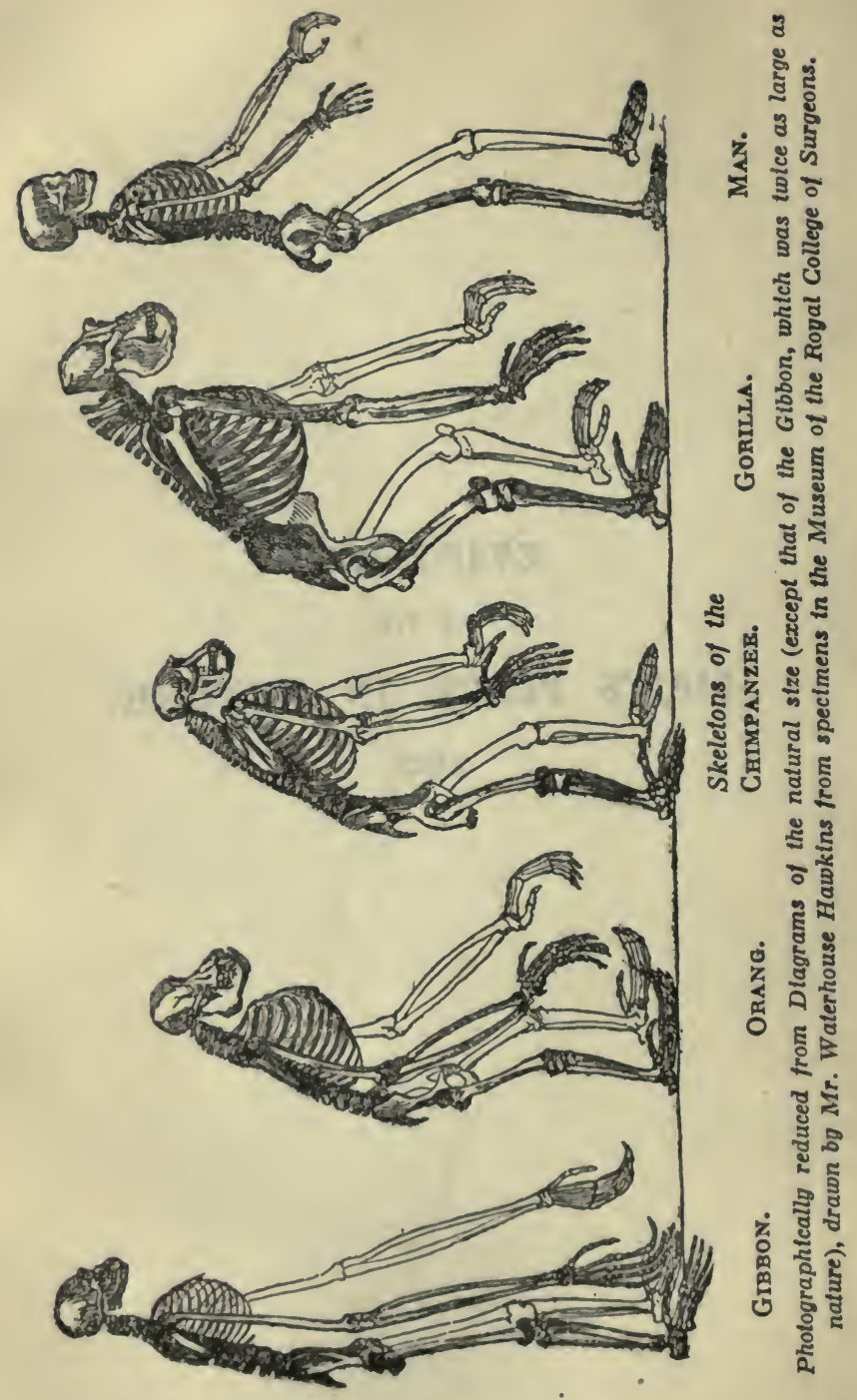




\section{ON THE NATURAL HISTORY OF THE MAN-LIKE APES}

ANcrent traditions, when tested by the severe processes of modern investigation, commonly enough fade away into mere dreams : but it is singular how often the dream turns out to have been a half-waking one, presaging a reality. Ovid foreshadowed the discoveries of the geologist: the Atlantis was an imagination, but Columbus found a western world: and though the quaint forms of Centaurs and Satyrs have an existence only in the realms of art, creatures approaching man more nearly than they in essential structure, and yet as thoroughly brutal as the goat's or horse's half of the mythical compound, are now not only known, but notorious.

I have not met with any notice of one of these MAN-LIKE Apes of earlier date than that contained in Pigafetta's Description of the Kingdom of Congo,* drawn up from the notes of a Portuguese sailor, Eduardo Lopez, and published in 1598. The tenth chapter of this work is entitled "De Animalibus quæ in hac provincia reperiuntur," and contains a brief passage to the effect that "in the Songan country, on the banks of the Zaire, there are multitudes of apes, which afford great delight to the nobles by imitating human gestures." As this might apply to almost any kind of apes, I should have thought little of it, had not the brothers De Bry, whose engravings illustrate the work, thought fit. in their eleventh Argumentum, to figure two of these "Simiæ magnatum deliciæ." So much of the plate as contains these apes is faithfully copied in the woodcut (Fig. 1), and it will be observed that they are tail-less, long-armed, and

- Regnum Congo: hoc est Vera Descriptro Regni Africani QUOD tAM AB incolis qUaM Lusitanis Congus appellatur, per Philippum Pigafettam, olim ex Edoardo Lopez acroamatis lingua Italica excerpta, num Latio sermone donata ab August. Cassiod. Reinio. Iconibus et imaginibus rerum memorabilium quasi vivis, opera et industria Joan. Theodori et Joan. Israelis de Bry, fratrum exornata. Francofurti, MDXcvir. 
large-eared; and about the size of Chimpanzees. It may be that these apes are as much figments of the imagination of the ingenious brothers as the winged, two-legged, crocodile-headed dragon which adorns the same plate; or, on the other hand, it may be that the artists have constructed their drawings from some essentially faithful description of a Gorilla or a Chimpanzee. And, in either case, though these figures are worth a passing notice, the oldest trustworthy and definite accounts of any animal of this kind date from the 17 th century, and are due to an Englishman.

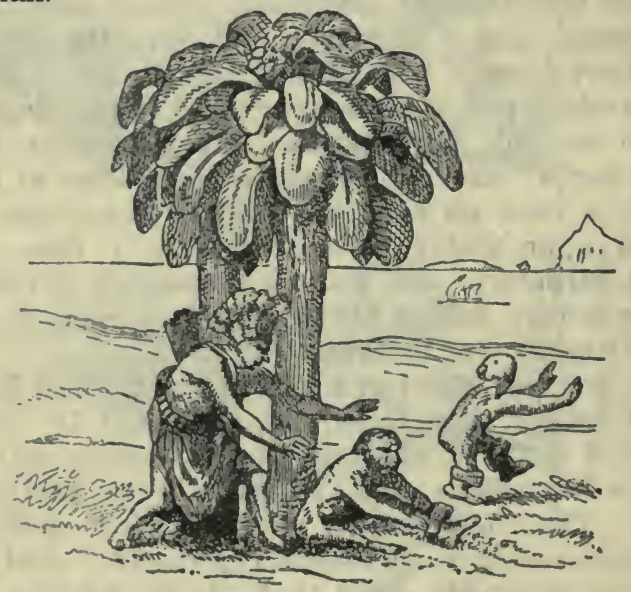

Fig. 1.-Simiæ magnatum deliciæ.-De Bry, 1598.

The first edition of that most amusing old book, Purchas his Pilgrimage, was published in 1613, and therein are to be found many references to the statements of one whom Purchas terms "Andrew Battell (my neere neighbour, dwelling at Leigh in Essex) who served under Manuel Silvera Perera, Governor under the King of Spaine, at his city of Saint Paul, and with him went farre into the countrey of Angola" ; and again, "my friend, Andrew Battle, who lived in the kingdom of Congo many yeares," and who, "upon some quarell betwixt the Portugals (among whom he was a sergeant of a band) and him, lived eight or nine moneths in the woodes." From this weather-beaten old. soldier, Purchas was amazed to hear " of a kinde of Great Apes, if they might so bee termed, of the height of a man, 
but twice as bigge in feature of their limmes, with strength proportionable, hairie all over, otherwise altogether like men and women in their whole bodily shape.* They lived on such wilde fruits as the trees and woods yielded, and in the night time lodged on the trees."

This extract is, however, less detailed and clear in its statements than a passage in the third chapter of the second part of another work-Purchas his Pilgrimes, published in 1625, by the same author-which has been often, though hardly ever quite rightly, cited. The chapter is entitled, "The strange adventures of Andrew Battell, of Leigh in Essex, sent by the Portugals prisoner to Angola, who lived there and in the adioining regions neere eighteene yeeres." And the sixth section of this chapter is headed"Of the Provinces of Bongo, Calongo, Mayombe, Manikesocke, Motimbas: of the Ape Monster Pongo, their hunting : Idolatries ; and divers other observations."

" This province (Calongo) toward the east bordereth upon Bongo, and toward the north upon Mayombe, which is nineteen leagues from Longo along the coast.

"This province of Mayombe is all woods and groves, so overgrowne that a man may travaile twentie days in the shadow without any sunne or heat. Here is no kind of corne nor graine, so that the people liveth onely upon plantanes and roots of sundrie sorts, very good; and. nuts ; nor any kinde of tame cattell, nor hens.

"But they have great store of elephant's flesh, which they greatly esteeme, and many kinds of wild beasts ; and great store of fish. Here is a great sandy bay, two leagues to the northward of Cape Negro, $\dagger$ which is the port of Mayombe. Sometimes the Portugals lade logwood in this bay. Here is a great river, called Banna : in the winter it hath no barre, because the generall winds cause a great sea. But when the sunne hath his south declination, then a boat may goe in ; for then it is smooth because of the raine. This river is very great, and hath many ilands and people dwelling in them. The woods are so covered with baboones, monkies, apes and parrots, that it will feare any man to travaile in them alone. Here are also two kinds of monsters, which are common in these woods, and very dangerous.

" "Except this that their legges had no calves."-[Ed. 1626.] And in a marginal note, "These great apes are called Pongo's."

† Purchas' note. - Cape Negro is in 16 degrees south of the line. 
"The greatest of these two monsters is called Pongo in their language, and the lesser is called Engeco. This Pongo is in all proportion like a man; but that he is more like a giant in stature than a man; for he is very tall, and hath a man's face, hollow-eyed, with long haire upon his browes. His face and eares are without haire, and his hands also. His bodie is full of haire, but not very thicke; and it is of a dunnish colour.

" He differeth not from a man but in his legs ; for they have-no calfe. Hee goeth alwaies upon his legs, and carrieth his hands clasped in the nape of his necke when he goeth upon the ground. They sleepe in the trees, and build shelters for the raine. They feed upon fruit that they find in the woods, and upon nuts, for they eate no kind of flesh. They cannot speake, and have no understanding more than a beast. The people of the countrie, when they travaile in the woods make fires where they sleepe in the night; and in the morning when they are gone, the Pongoes will come and sit about the fire till it goeth out; for they have no understanding to lay the wood together. They goe many together and kill many negroes that travaile in the woods. Many times they fall upon the elephants which come to feed where they be, and so beate them with their clubbed fists, and pieces of wood, that they will runne roaring away from them. Those Pongoes are never taken alive because they are so strong, that ten men cannot hold one of them; but yet they take many of their young ones with poisoned arrowes.

"The young Pongo hangeth on his mother's belly with his hands fast clasped about her, so that when the countrie people kill any of the females they take the young one, which hangeth fast upon his mother.

"When they die among themselves, they cover the dead with great heaps of boughs and wood, which is commonly found in the forest." *

"Purchas' marginal note, p. 982 :- “ The Pongo a giant ape. He told me in conference with him, that one of these Pongoes tooke a negro boy of his which lived a moneth with them. For they hurt not those which they surprise at unawares, except they look on them ; which he avoyded. He said their highth was like a man's, but their bignesse twice as great. I saw the negro boy. What the other monster should be he hath forgotten to relate; and these papers came to my hand since his death, which, otherwise, in my often conferences, I might have learned. Perhaps he meaneth the Pigmy Pongo killers mentioned." 
It does not appear difficult to identify the exact region of which Battell speaks. Longo is doubtless the name of the place usually spelled Loango on our maps. Mayombe still lies some nineteen leagues northward from Loango, along the coast; and Cilongo or Kilonga, Manikesocke, and Motimbas are yet registered by geographers. The Cape Negro of Battell, however, cannot be the modern Cape Negro in $16^{\circ} \mathrm{S}$., since Loango itself is in $4^{\circ} \mathrm{S}$. latitude. On the other hand, the "great river called Banna" corresponds very well with the "Camma" and "Fernand Vas," of modern geographers, which form a great delta on this part of the African coast.

Now this "Camma" country is situated about a degree and a-half south of the Equator, while a few miles to the north of the line lies the Gaboon, and a degree or so north of that, the Money River-both well known to modern naturalists as localities where the largest of man-like Apes has been obtained. Moreover, at the present day, the word Engeco, or N'schego, is applied by the natives of these regions to the smaller of the two great Apes which inhabit them ; so that there can be no rational doubt that Andrew Battell spoke of that which he knew of his own knowledge, or, at any rate, by immediate report from the natives of Western Africa. The "Engeco," however, is that "other monster" whose nature Battell "forgot to relate," while the name "Pongo"-applied to the animal whose characters and habits are so fully and carefully described-seems to have died out, at least in its primitive form and signification. Indeed, there is evidence that not only in Battell's time, but up to a very recent date, it was used in a totally different sense from that in which he employs it.

For example, the second chapter of Purchas' work, which I have just quoted, contains " A Description and Historicall Declaration of the Golden Kingdom of Guinea, etc. etc. Translated from the Dutch, and compared also with the Latin," wherein it is stated (p. 986) that-

"The River Gaboon lyeth about fifteen miles northward from Rio de Angra, and eight miles northward from Cape de Lope Gonsalvez (Cape Lopez), and is right under the Equinoctial line, about fifteene miles from St. Thomas, and is a great land, well and easily to be knowne. At the mouth of the river there lieth a sand, three or foure fathoms deepe, whereon it beateth mightily with the 
streame which runneth out of the river into the sea. This river, in the mouth thereof, is at least four miles broad; but when you are about the Iland called Pongo, it is not above two miles broad. . . . On both sides the river there standeth many trees. ... The Iland called Pongo, which hath a monstrous high hill."

The French naval officers, whose letters are appended to the late M. Isidore Geoff. Saint Hilaire's excellent essay on the Gorilla,* note in similar terms the width

\section{Homo Sytveftris.}

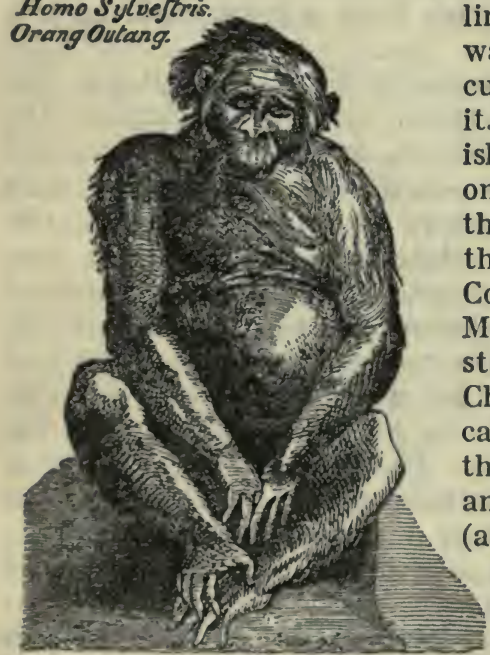

FIG. 2.-The Orang of Tulpius, 1641. of the Gaboon, the trees that line its banks down to the water's edge, and the strong current that sets out of it. They describe two islands in its estuary ; one low, called Perroquet; the other high, presenting three conical hills, called Coniquet ; and one of them, M. Franquet, expressly states that, formerly, the Chief of Coniquet was called Meni-Pongo, meaning thereby Lord of Pongo; and that the $N^{\prime}$ Pongues (as, in agreement with Dr. Savage, he affirms the natives call themselves) term the estuary of the Gaboon itself N'Pongo.

It is so easy, in dealing with savages, to misunderstand their applications of words to things, that one is at first inclined to suspect Battell of having confounded the name of this region, where his "greater monster" still abounds, with the name of the animal itself. But he is so right about other matters (including the name of the "lesser monster") that one is loth to suspect the old traveller of error; and, on the other hand, we shall find that a voyager of a hundred years' later date speaks of the name "Boggoe," as applied to a great Ape, by the inhabitants of quite another part of Africa-Sierra Leone.

But I must leave this question to be settled by philo- 
logers and travellers; and I should hardly have dwelt so long upon it except for the curious part played by this word 'Pongo' in the later history of the man-like Apes.

The generation which succeeded Battell saw the first of the man-like Apes which was ever brought to Europe, or, at any rate, whose visit found a historian. In the third book of Tulpius' Observationes Medicæ, published in 1641, the 56th chapter or section is devoted to what he calls Satyrus indicus, " called by the Indians Orang-autang, or Man-of-the-Woods, and by the Africans Quoias Morrou." He gives a very good figure, evidently from the life, of the specimen of this animal, " nostra memoria ex Angola delatum," presented to Frederick Henry Prince of Orange. Tulpius says it was as big as a child of three years old, and as stout as one of six years: and that its back was covered with black hair. It is plainly a young Chimpanzee.

In the meanwhile, the existence of other, Asiatic, manlike Apes became known, but at first in a very mythical fashion. Thus Bontius (1658) gives an altogether fabulous and ridiculous account and figure of an animal which he calls "Orang-outang" ; and though he says, "vidi Ego cujus effigiem hic exhibeo," the said effigies (see Fig. 6 for Hoppius' copy of it) is nothing but a very hairy woman of rather comely aspect, and with proportions and feet wholly human. The judicious English anatomist, Tyson, was justified in saying of this description by Bontius, "I confess I do mistrust the whole representation."

It is to the last mentioned writer, and his coadjutor Cowper, that we owe the first account of a man-like ape which has any pretensions to scientiflc accuracy and completeness. The treatise entitled, "Orang-outang, sive Homo Sylvestris; or the Anatomy of a Pygmie compared with that of a Monkey, an Ape, and a Man," published by the Royal Society in 1699, is, indeed, a work of remarkable merit, and has, in some respects, served as a model to subsequent inquirers. This "Pygmie," Tyson tells us, " was brought from Angola, in Africa; but was first taken a great deal higher up the country" ; its hair "was of a coal-black colour, and strait," and "when it went as a quadruped on all four, 'twas awkwardly; not placing the palm of the hand flat to the ground, but it walk'd upon its knuckles, as I observed it to do when weak and had not strength enough to support its body."-" From the 
top of the head to the heel of the foot, in a strait line, it measured twenty-six inches."

These characters, even without Tyson's good figures (Figs. 3 and 4), would have been sufficient to prove his "Pygmie" to be a young Chimpanzee. But the opportunity of examining the skeleton of the very animal Tyson anatomised having most unexpectedly presented itself to me, I am able to bear independent testimony to its being
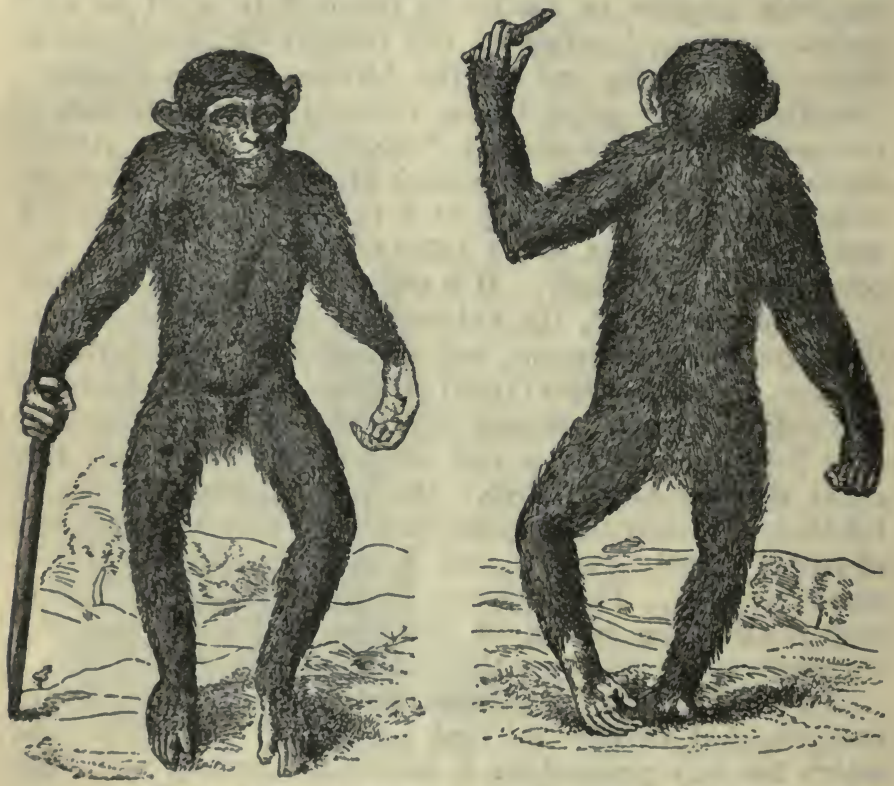

Fios. 3 and 4.-The 'Pygmie' reduced from Tyson's figures 1 and 2, 1699.

a veritable Troglodytes niger,* though still very young. Although fully appreciating the resemblances between his

- I am indebted to Dr. Wright, of Cheltenham, whose paleontological labours are so well known, for bringing this interesting relic to my knowledge. Tyson's granddaughter, it appears, married Dr. Allardyce, a physician of repute in Cheltenham, and brought, as part of her dowry, the skeleton of the 'Pygmie.' Dr. Allardyce presented it to the Cheltenham Museum, and, through the good offices of my friend Dr. Wright, the authorities of the Museum have permitted me to borrow, what is, perhaps, its most remarkable ornament. 


\section{OF THE MAN-LIKE APES}

Pygmie and Man, Tyson by no means overlooked the differences between the two, and he concludes his memoir by summing up first, the points in which " the Ourangoutang or Pygmie more resembled a Man than Apes and Monkeys do," under forty-seven distinct heads ; and then giving, in thirty-four similar brief paragraphs, the respects in which " the Ourang-outang or Pygmie differ'd from a Man and resembled more the Ape and Monkey kind."

After a careful survey of the literature of the subject extant in his time, our author arrives at the conclusion that his "Pygmie" is identical neither with the Orangs of Tulpius and Bontius, nor with the Quoias Morrou of Dapper (or rather of Tulpius), the Barris of d'Arcos, nor with the Pongo of Battell ; but that it is a species of ape probably identical with the Pygmies of the Ancients, and, says Tyson, though it "does so much resemble a Man in many of its parts, more than any of the ape kind, or any other animal in the world, that I know of: yet by no means do I look upon it as the product of a mixt generation-'tis a Brute-Animal sui generis, and a particular species of Ape."

The name of "Chimpanzee," by which one of the African Apes is now so well known, appears to have come into use in the first half of the eighteenth century, but the only important addition made, in that period, to our acquaintance with the man-like apes of Africa is contained in A New Voyage to Guinea, by William Smith, which bears the date 1744 .

In describing the animals of Sierra Leone, p. 51, this writer says :-

"I shall next describe a strange sort of animal, called by the white men in this country Mandrill,* but why it is so called I know not, nor did I ever hear the name before, neither can those who call them so tell, except it be for

" Mandrill" seems to signify a "man-like ape," the word "Drill " or "Dril" having been anciently employed in England to denote an Ape or Baboon. Thus in the fifth edition of Blount's "Glossographia, or a Dictionary interpreting the hard words of whatsoever language now used in our refined English tongue . : very useful for all such as desire to understand what they read," published in 1681, I find, "Dril-a stone-cutter's tool wherewith he bores little holes in marble, etc. Also a large overgrown Ape and Baboon, so called." "Drill" is used in the same sense in Charleton's " Onomasticon Zoicon," 1668. The singular etymology of the word given by Buffon seems hardly a probable one. 
their near resemblance of a human creature, though nothing at all like an Ape. Their bodies, when full grown, are as big in circumference as a middle-sized man's - their legs much shorter, and their feet larger; their arms and hands in proportion. The head is monstrously big, and the face broad and flat, without any other hair but the eyebrows; the nose very small, the mouth wide, and the lips thin. The face, which is covered by a white skin, is monstrously ugly, being all over wrinkled as with old age ; the teeth broad and yellow; the hands have no more hair than the face, but the same white skin, though all

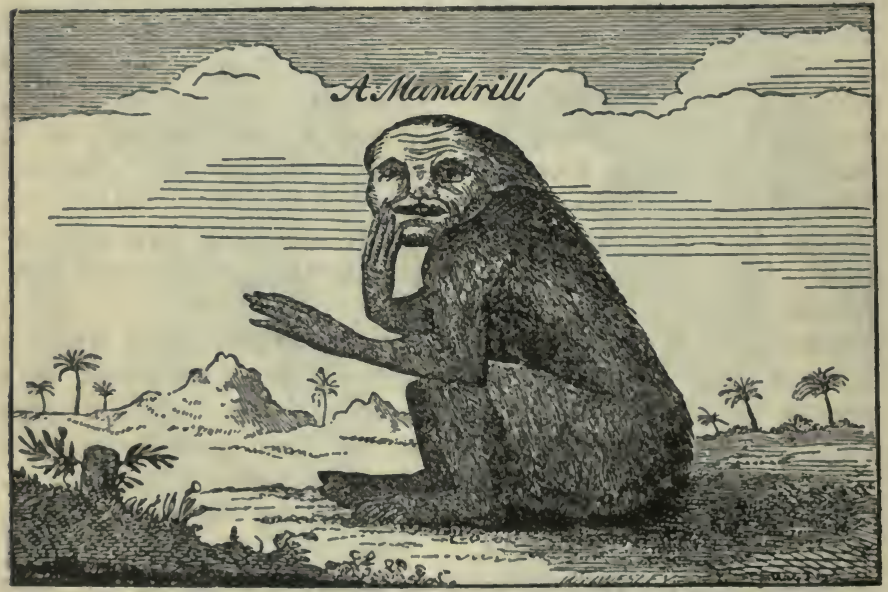

Fia. 5.-Facsimile of William Smith's figure of the "Mandrill," 1744.

the rest of the body is covered with long black hair, like a bear. They never go upon all fours, like apes; but cry, when vexed or teased, just like children. . . .

"When I was at Sherbro, one Mr. Cummerbus, whom I shall have occasion hereafter to mention, made me a present of one of these strange animals, which are called by the natives Boggoe: it was a she-cub, of six months' age, but even then larger than a Baboon. I gave it in charge to one of the slaves, who knew how to feed and nurse it, being a very tender sort of animal ; but whenever I went off the deck the sailors began to teaze itsome loved to see its tears and hear it cry ; others hated its snotty-nose; one who hurt it, being checked by the 
negro that took care of it, told the slave he was very fond of his country-woman, and asked him if he should not like her for a wife? To which the slave very readily replied, "No, this no my wife ; this a white womanthis fit wife for you.' This unlucky wit of the negro's, I fancy, hastened its death, for next morning it was found dead under the windlass."

William Smith's 'Mandrill,' or 'Boggoe,' as his description and figure testify, was, without doubt, a Chimpanzee.

Linnæus knew nothing, of his own observation, of the man-like Apes of either Africa or Asia, but a dissertation by his pupil Hoppius in the Amonitates Academicæ (VI.

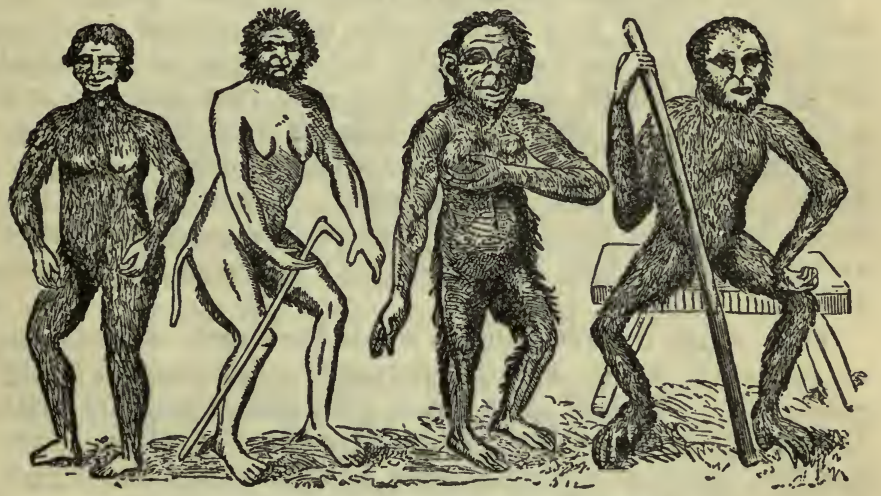

Fig. 6. -The Anthropomorpha of Linnæus.

'Anthropomorpha') may be regarded as embodying his views respecting these animals.

The dissertation is illustrated by a plate, of which the accompanying woodcut, Fig. 6 , is a reduced copy. The figures are entitled (from left to right) 1. Troglodyta Bontii; 2. Lucifer Aldrovandi; 3. Satyrus Tulpii; 4. Pygmæus Edwardi. The first is a bad copy of Bontius' fictitious 'Ourang-outang,' in whose existence, however, Linnæus appears to have fully believed ; for in the standard edition of the Systema Naturæ, it is enumerated as a second species of Homo ; "H. nocturnus." Lucifer Aldrovandi is a copy of a figure in Aldrovandus, De Quadrupedibus digitatis viviparis, Lib. 2, p. 249 (1645), entitled " Cercopithecus formæ raræ Barbilius vocatus et originem a china ducebat." Hoppius is of opinion that this may be 
one of that cat-tailed people, of whom Nicolaus Köping affirms that they eat a boat's crew, "gubernator navis" and all ! In the Systema Naturæ Linnæus calls it in a note, Homo caudatus, and seems inclined to regard it as a third species of man. According to Temminck, Satyrus Tulpii is a copy of the figure of a Chimpanzee published by Scotin in 1738, which I have not seen. It is the Satyrus indicus of the Systema Naturæ, and is regarded by Linnæus as possibly a distinct species from Satyrus sylvestris. The last, named Pygmæus Edwardi, is copied from the figure of a young "Man of the Woods," or true Orang-Utan, given in Edwards' Gleanings of Natural History (1758).

Buffon was more fortunate than his great rival. Not only had he the rare opportunity of examining a young Chimpanzee in the living state, but he became possessed of an adult Asiatic man-like Ape-the first and the last adult specimen of any of these animals brought to Europe for many years. With the valuable assistance of Daubenton, Buffon gave an excellent description of this creature, which, from its singular proportions, he termed the long-armed Ape, or Gibbon. It is the modern Hylobates lar.

Thus when, in 1766, Buffon wrote the fourteenth volume of his great work, he was personally familiar with the young of one kind of African man-like Ape, and with the adult of an Asiatic species-while the Orang-Utan and the Mandrill of Smith were known to him by report. Furthermore, the Abbe Prevost had translated a good deal of Purchas' Pilgrims into French, in his Histoire générale des Voyages (1748), and there Buffon found a version of Andrew Battell's account of the Pongo and the Engeco. All these data Buffon attempts to weld together into harmony in his chapter entitled "Les Orangoutangs ou le Pongo et le Jocko." To this title the following note is appended :-

“ Orang-outang nom de cet animal aux Indes orientales: Pongo nom de cet animal a Lowando Province de Congo.

"Jocko, Enjocko, nom de cet animal à Congo que nous avons adopté. En est l'article que nous avons retranché."

Thus it was that Andrew Battell's " Engeco" became metamorphosed into "Jocko," and, in the latter shape, was spread all over the world, in consequence of the extensive popularity of Buffon's works. The Abbé Prevost 
and Buffon between them, however, did a good deal more disfigurement to Battell's sober account than 'cutting off an article.' Thus Battell's statement that the Pongos " cannot speake, and have no understanding more than a beast," is rendered by Buffon " qu'il ne peut parler quoiqu'il ait plus d'entendement que les autres animaux" ; and again, Purchas' affirmation, " He told me in conference with him, that one of these Pongos tooke a negro boy of his which lived a moneth with them," stands in the French version, " un pongo lui enleva un petit negre qui passa un an entier dans la societé de ces animaux."

After quoting the account of the great Pongo, Buffon justly remarks, that all the 'Jockos' and ' Orangs' hitherto brought to Europe were young; and he suggests that, in their adult condition, they might be as big as the Pongo or ' great Orang'; so that, provisionally, he regarded the Jockos, Orangs, and Pongos as all of one species. And perhaps this was as much as the state of knowledge at the time warranted. But how it came about that Buffon failed to perceive the similarity of Smith's 'Mandrill' to his own 'Jocko,' and confounded the former with so totally different a creature as the blue-faced Baboon, is not so easily intelligible.

Twenty years later Buffon changed his opinion,* and expressed his belief that the Orangs constituted a genus with two species, - a large one, the Pongo of Battell, and a small one, the Jocko : that the small one (Jocko) is the East Indian Orang; and that the young animals from Africa, observed by himself and Tulpius, are simply young Pongos.

In the meanwhile, the Dutch naturalist, Vosmaer, gave, in 1778, a very good account and figure of a young Orang, brought alive to Holland, and his countryman, the famous anatomist, Peter Camper, published (1779) an essay on the Orang-Utan of similar value to that of Tyson on the Chimpanzee. He dissected several females and a male, all of which, from the state of their skeleton and their dentition, he justly supposes to have been young. However, judging by the analogy of man, he concludes that they could not have exceeded four feet in height in the adult condition. Furthermore, he is very clear as to the specific distinctness of the true East Indian Orang.

"The Orang," says he, " differs not only from the Pigmy

*Histoire Naturelle, Suppl. tome 7ème, 1789. 
of Tyson and from the Orang of Tulpius by its peculiar colour and its long toes, but also by its whole external form. Its arms, its hands, and its feet are longer, while the thumbs, on the contrary, are much shorter, and the great toes much smaller in proportion." * And again, "The true Orang, that is to say, that of Asia, that of Borneo, is consequently not the Pithecus, or tailless Ape, which the Greeks, and especially Galen, have described. It is neither the Pongo nor the Jocko, nor the Orang of Tulpius, nor the Pigmy of Tyson,-it is an animal of a peculiar species, as I shall prove in the clearest manner by the organs of voice and the skeleton in the following chapters " (1. c. p. 64).

A few years later, M. Radermacher, who held a high office in the Government of the Dutch dominions in India, and was an active member of the Batavian Society of Arts and Sciences, published, in the second part of the Transactions of that Society, $f$ Description of the Island of Borneo, which was written between the years 1779 and 1781, and, among much other interesting matter, contains some notes upon the Orang. The small sort of Orang-Utan, viz. that of Vosmaer and of Edwards, he says, is found only in Borneo, and chiefly about Banjermassing, Mampauwa, and Landak. Of these he had seen some fifty during his residence in the Indies; but none exceeded $2 \frac{1}{2}$ feet in length. The larger sort, often regarded as chimæra, continues Radermacher, would perhaps long have remained so, had it not been for the exertions of the Resident at Rembang, M. Palm, who, on returning from Landak towards Pontiana, shot one, and forwarded it to Batavia in spirit, for transmission to Europe.

Palm's letter describing the capture runs thus :- "Herewith I send your Excellency, contrary to all expectation (since long ago I offered more than a hundred ducats to the natives for an Orang-Utan of four or five feet high) an Orang which I heard of this morning about eight o'clock. For a long time we did our best to take the frightful beast alive in the dense forest about half way to Landak. We forgot even to eat, so anxious were we not to let him escape ; but it was necessary to take care he did not revenge himself, as he kept continually breaking off heavy pieces of wood and green branches, and dashing them at us. This game

* Camper, Euvres, i. p. 56.

† Verhandelingen van het Bataviaasch Genootschap. Tweede Deel. Derde Druk. 1826. 
lasted till four o'clock in the afternoon, when we determined to shoot him ; in which I succeeded very well, and indeed better than I ever shot from a boat before ; for the bullet went just into the side of his chest, so that he was not much damaged. We got him into the prow still living, and bound him fast, and next morning he died of his wounds. All Pontiana came on board to see him when we arrived." Palm gives his height from the head to the heel as 49 inches.

A very intelligent German officer, Baron Von Wurmb, who at this time held a post in the Dutch East India service, and was Secretary of the Batavian Society, studied this animal, and his careful description of it, entitled

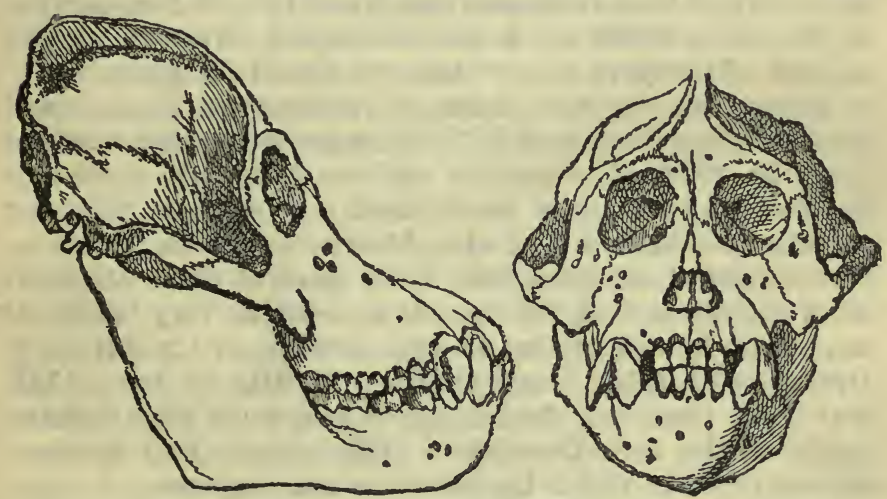

Fig. 7. - The Pongo Skull, sent by Radermacher to Camper, after Camper's original sketches, as reproduced by Lucæ.

"Beschrijving van der Groote Borneosche Orang-outang of de Oost-Indische Pongo," is contained in the same volume of the Batavian Society's Transactions. After Von Wurmb had drawn up his description he states, in a letter dated Batavia, Feb. 18, 1781,* that the specimen was sent to Europe in brandy to be placed in the collection of the Prince of Orange ; " unfortunately," he continues, "we hear that the ship has been wrecked." Von Wurmb died in the course of the year 1781, the letter in which this passage occurs being the last he wrote; but in his posthumous papers, published in the fourth part of the Transactions of the Batavian Society, there is a brief

* "Briefe des Herrn v. Wurmb und des H. Baron von Wollzogen. Gotha, 1794." 
description, with measurements, of a female Pongo four feet high.

Did either of these original specimens, on which Von Wurmb's descriptions are based, ever reach Europe ? It is commonly supposed that they did; but I doubt the fact. For, appended to the memoir De l'Ourang-outang, in the collected edition of Camper's works, tome i., pp. 64-66, is a note by Camper himself, referring to Von Wurmb's papers, and continuing thus :- " Heretofore, this kind of ape had never been known in Europe. Radermacher has had the kindness to send me the skull of one of these animals, which measured fifty-three inches, or four feet five inches, in height. I have sent some sketches of it to M. Soemmering at Mayence, which are better calculated, however, to give an idea of the form than of the real size of the parts."

These sketches have been reproduced by Fischer and by Lucæ, and bear date 1783 , Soemmering having received them in 1784. Had either of Von Wurmb's specimens reached Holland, they would hardly have been unknown at this time to Camper, who, however, goes on to say :"It appears that since this, some more of these monsters have been captured, for an entire skeleton, very badly set up, which had been sent to the Museum of the Prince of Orange, and which I saw only on the 27th of June, 1784, was more than four feet high. I examined this skeleton again on the 19th December, 1785, after it had been excellently put to rights by the ingenious Onymus."

It appears evident, then, that this skeleton, which is doubtless that which has always gone by the name of Wurmb's Pongo, is not that of the animal described by him, though unquestionably similar in all essential points.

Camper proceeds to note some of the most important features of this skeleton; promises to describe it in detail by-and-bye; and is evidently in doubt as to the relation of this great "Pongo' to his " petit Orang."

The promised further investigations were never carried out; and so it happened that the Pongo of Von Wurmb took its place by the side of the Chimpanzee, Gibbon, and Orang as a fourth and colossal species of man-like Ape. And indeed nothing could look much less like the Chimpanzees or the Orangs, then known, than the Pongo ; for all the specimens of Chimpanzee and Orang which had been observed were small of stature, singularly human 
in aspect, gentle and docile; while Wurmb's Pongo was a monster almost twice their size, of vast strength and fierceness, and very brutal in expression; its great projecting muzzle, armed with strong teeth, being further disfigured by the outgrowth of the cheeks into fleshy lobes.

Eventually, in accordance with the usual marauding habits of the Revolutionary armies, the 'Pongo' skeleton was carried away from Holland into France, and notices of it, expressly intended to demonstrate its entire distinctness from the Orang and its affinity with the baboons, were given, in 1798, by Geoffroy St. Hilaire and Cuvier.

Even in Cuvier's Tableau Elementaire, and in the first edition of his great work, the Regne Animal, the 'Pongo' is classed as a species of Baboon. However, so early as 1818 , it appears that Cuvier saw reason to alter this opinion, and to adopt the view suggested several years before by Blumenbach,* and after him by Tilesius, that the Bornean Pongo is simply an adult Orang. In 1824, Rudolphi demonstrated, by the condition of the dentition, more fully and completely than had been done by his predecessors, that the Orangs described up to that time were all young animals, and that the skull and teeth of the adult would probably be such as those seen in the Pongo of Wurmb. In the second edition of the Regne Animal (1829), Cuvier infers, from the 'proportions of all the parts' and 'the arrangements of the foramina and sutures of the head,' that the Pongo is the adult of the Orang-Utan, ' at least of a very closely allied species,' and this conclusion was eventually placed beyond all doubt by Professor Owen's Memoir published in the Zoological Transactions for 1835, and by Temminck in his Monographies de Mammalogie. Temminck's memoir is remarkable for the completeness of the evidence which it affords as to the modification which the form of the Orang undergoes according to age and sex. Tiedemann first published an account of the brain of the young Orang, while Sandifort, Müller and Schlegel, described the muscles and the viscera of the adult, and gave the earliest detailed and trustworthy history of the habits of the great Indian Ape in a state of nature ; and as important additions have been made by later observers, we are at this moment better acquainted with the adult of the Orang-Utan,

* See Blumenbach, Abbildungen Naturhistorichen Gegenstände, No. 12, 1810; and Tilesius, Naturhistoriche Früchte der ersten Kaiserlich-Russischen Erdumsegelung, p. 115, 1813. 
than with that of any of the other greater man-like Apes.

It is certainly the Pongo of Wurmb; * and it is as certainly not the Pongo of Battell, seeing that the OrangUtan is entirely confined to the great Asiatic islands of Borneo and Sumatra.

And while the progress of discovery thus cleared up the history of the Orang, it also became established that the only other man-like Apes in the eastern world were the various species of Gibbon-Apes of smaller stature, and therefore attracting less attention than the Orangs, though they are spread over a much wider range of country, and are hence more accessible to observation.

Although the geographical area inhabited by the 'Pongo' and 'Engeco' of Battell is so much nearer to Europe than that in which the Orang and Gibbon are found, our acquaintance with the African Apes has been of slower growth; indeed, it is only within the last few years that the truthful story of the old English adventurer has been rendered fully intelligible. It was not until 1835 that the skeleton of the adult Chimpanzee became known, by the publication of Professor Owen's above-mentioned very excellent memoir On the osteology of the Chimpanzee and Orang, in the Zoological Transactions-a memoir which, by the accuracy of its descriptions, the carefulness of its comparisons, and the excellence of its figures, made an epoch in the history of our knowledge of the bony framework, not only of the Chimpanzee, but of all the anthropoid Apes.

By the investigations herein detailed, it became evident that the old Chimpanzee acquired a size and aspect as different from those of the young known to Tyson, to Buffon, and to Traill, as those of the old Orang from the young Orang; and the subsequent very important researches of Messrs. Savage and Wyman, the American missionary and anatomist, have not only confirmed this conclusion, but have added many new details. $\uparrow$

* Speaking broadly and without prejudice to the question, whether there be more than one species of Orang.

† See " Observations on the external characters and habits of the Troglodytes niger, by Thomas N. Savage, M.D., and on its organization, by Jeffries Wyman, M.D.," Boston Journal of Natural History, vol. iv., 1843-4 ; and "External characters, habits, and osteology of Troglodytes Gorilla," by the same authors, ibid., vol. v., 1847. 
One of the most interesting among the many valuable discoveries made by Dr. Thomas Savage is the fact, that the natives in the Gaboon country at the present day, apply to the Chimpanzee a name-" Enché-eko"-which is obviously identical with the "Engeko" of Battell; a discovery which has been confirmed by all later inquirers. Battell's "lesser monster," being thus proved to be a veritable existence, of course a strong presumption arose that his " greater monster," the 'Pongo,' would sooner or later be discovered. And, indeed, a modern traveller, Bowdich, had, in 1819, found strong evidence, among the natives, of the existence of a second great Ape, called the 'Ingena,' " five feet high, and four across the shoulders," the builder of a rude house, on the outside of which it slept.

In 1847, Dr. Savage had the good fortune to make another and most important addition to our knowledge of the man-like Apes; for, being unexpectedly detained at the Gaboon river, he saw in the house of the Rev. Mr. Wilson, a missionary resident there, " a skull represented by the natives to be a monkey-like animal, remarkable for its size, ferocity, and habits." From the contour of the skull, and the information derived from several intelligent natives, "I was induced," says Dr. Savage (using the term Orang in its old general sense), " to believe that it belonged to a new species of Orang. I expressed this opinion to Mr. Wilson, with a desire for further investigation ; and, if possible, to decide the point by the inspection of a specimen alive or dead." The result of the combined exertions of Messrs. Savage and Wilson was not only the obtaining of a very full account of the habits of this new creature, but a still more important service to science, the enabling the excellent American anatomist already mentioned, Professor Wyman, to describe, from ample materials, the distinctive osteological characters of the new form. This animal was called by the natives of the Gaboon "Engé-ena," a name obviously identical with the "Ingena" of Bowdich ; and Dr. Savage arrived at the conviction that this last discovered of all the great Apes was the long-sought " Pongo" of Battell.

The justice of this conclusion, indeed, is beyond doubt -for not only does the 'Engé-ena' agree with Battell's "greater monster" in its hollow eyes, its great stature, and its dun or iron-grey colour, but the only other manlike Ape which inhabits these latitudes-the Chimpanzee 
-is at once identified, by its smaller size, as the "lesser monster," and is excluded from any possibility of being the 'Pongo'' by the fact that it is black and not dun, to say nothing of the important circumstance already mentioned that it still retains the name of ' Engeko,' or ' Enchéeko,' by which Battell knew it.

In seeking for a specific name for the 'Enge-ena,' however, Dr. Savage wisely avoided the much misused 'Pongo'; but finding in the ancient Periplus of Hanno the word "Gorilla" applied to certain hairy savage people, discovered by the Carthaginian voyager in an island on the African coast, he attached the specific name "Gorilla" to his new ape, whence arises its present well-known appellation. But Dr. Savage, more cautious than some of his successors, by no means identifles his ape with Hanno's ' wild men.' He merely says that the latter were " probably one of the species of the Orang;" and I quite agree with $M$. Brulle that there is no ground for identifying the modern 'Gorilla' with that of the Carthaginian admiral.

Since the memoir of Savage and Wyman was published, the skeleton of the Gorilla has been investigated by Professor Owen and by the late Professor Duvernoy, of the Jardin des Plantes, the latter having further supplied a valuable account of the muscular system and of many of the other soft parts; while African missionaries and travellers have confirmed and expanded the account originally given of the habits of this great man-like Ape, which has had the singular fortune of being the first to be made known to the general world and the last to be scientifically investigated.

Two centuries and a half have passed away since Battell told his stories about the 'greater' and the 'lesser monsters' to Purchas, and it has taken nearly that time to arrive at the clear result that there are four distinct kinds of Anthropoids-in Eastern Asia, the Gibbons and the Orangs; in Western Africa, the Chimpanzees and the Gorilla.

The man-like Apes, the history of whose discovery has just been detailed, have certain characters of structure and of distribution in common. Thus they all have the same number of teeth as man-possessing four incisors, two canines, four false molars, and six true molars in each jaw, or 32 teeth in all, in the adult condition; while the milk dentition consists of 20 teeth-or four incisors, two 
canines, and four molars in each jaw. They are what are called catarrhine Apes - that is, their nostrils have a narrow partition and look downwards ; and, furthermore, their arms are always longer than their legs, the difference being sometimes greater and sometimes less; so that if the four were arranged in the order of the length of their arms in proportion to that of their legs, we should have

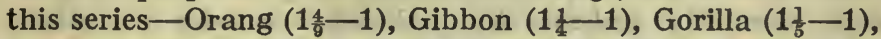
Chimpanzee $\left(1 \frac{1}{18}-1\right)$. In all, the fore limbs are terminated by hands, provided with longer or shorter thumbs; while the great toe of the foot, always smaller than in Man, is far more moveable than in him and can be opposed, like a thumb, to the rest of the foot. None of these apes have tails, and none of them possess the cheek pouches common among monkeys. Finally, they are all inhabitants of the old world.

The Gibbons are the smallest, slenderest, and longestlimbed of the man-like apes; their arms are longer in proportion to their bodies than those of any of the other man-like Apes, so that they can touch the ground when erect; their hands are longer than their feet, and they are the only Anthropoids which possess callosities like the lower monkeys. They are variously coloured. The Orangs have arms which reach to the ankles in the erect position of the animal ; their thumbs and great toes are very short, and their feet are longer than their hands. They are covered with reddish-brown hair, and the sides of the face, in adult males, are commonly produced into two crescentic, flexible excrescences, like fatty tumours. The Chimpanzees have arms which reach below the knees; they have large thumbs and great toes, their hands are longer than their feet, and their hair is black, while the skin of the face is pale. The Gorilla, lastly, has arms which reach to the middle of the leg, large thumbs and great toes, feet longer than the hands, a black face, and dark-grey or dun hair.

For the purpose which $I$ have at present in view, it is unnecessary that I should enter into any further minutiæ respecting the distinctive characters of the genera and species into which these man-like Apes are divided by naturalists. Suffice it to say, that the Orangs and the Gibbons constitute the distinct genera, Simia and Hylobates; while the Chimpanzees and Gorillas are by some regarded simply as distinct species of one genus, Troglodytes; by others as distinct genera-Troglodytes being 
reserved for the Chimpanzees, and Gorilla for the Engeena or Pongo.

Sound knowledge respecting the habits and mode of life of the man-like Apes has been even more difficult of attainment than correct information regarding their structure.

Once in a generation, a Wallace may be found physically, mentally, and morally qualified to wander unscathed through the tropical wilds of America and of Asia ; to form magnificent collections as he wanders; and withal to think out sagaciously the conclusions suggested by his collections : but, to the ordinary explorer or collector, the dense forests of equatorial Asia and Africa, which constitute the favourite habitation of the Orang, the Chimpanzee, and the Gorilla, present difficulties of no ordinary magnitude : and the man who risks his life by even a short visit to the malarious shores of those regions may well be excused if he shrinks from facing the dangers of the interior; if he contents himself with stimulating the industry of the better seasoned natives, and collecting and collating the more or less mythical reports and traditions with which they are too ready to supply him.

In such a manner most of the earlier accounts of the habits of the man-like Apes originated; and even now a good deal of what passes current must be admitted to have no very safe foundation. The best information we possess is that, based almost wholly on direct European testimony respecting the Gibbons; the next best evidence relates to the Orangs; while our knowledge of the habits of the Chimpanzee and the Gorilla stands much in need of support and enlargement by additional testimony from instructed European eye-witnesses.

It will therefore be convenient in endeavouring to form a notion of what we are justified in believing about these animals, to commence with the best known man-like Apes, the Gibbons and Orangs ; and to make use of the perfectly reliable information respecting them as a sort of criterion of the probable truth or falsehood of assertions repecting the others.

Of the Gibions, half a dozen species are found scattered over the Asiatic islands, Java, Sumatra, Borneo, and through Malacca, Siam, Arracan, and an uncertain extent of Hindostan, on the main land of Asia. The largest attain a few inches above three feet in height, from the 
crown to the heel, so that they are shorter than the other man-like Apes; while the slenderness of their bodies renders their mass far smaller in proportion even to this diminished height.

Dr. Salomon Müller, an accomplished Dutch naturalist, who lived for many years in the Eastern Archipelago, and to the results of whose personal experience I shall frequently have occasion to refer, states that the Gibbons are true mountaineers, loving the slopes and edges of the hills, though they rarely ascend beyond the limit of the fig-trees. All day long they haunt the tops of the tall trees; and though, towards evening, they descend in small troops to the open ground, no sooner do they spy a man than they dart up the hill-sides, and disappear in the darker valleys.

All observers testify to the prodigious volume of voice possessed by these animals. According to the writer whom I have just cited, in one of them, the Siamang, " the voice is grave and penetrating, resembling the sounds gōek, gōek, gōek, gōek, goek ha ha ha ha haaā̄āa, and may easily be heard at a distance of half a league." While the cry is being uttered, the great membranous bag under the throat which communicates with the organ of voice, the so-called "laryngeal sac," becomes greatly distended, diminishing again when the creature relapses into silence.

M. Duvaucel, likewise, affirms that the cry of the Siamang may be heard for miles - making the woods ring again. So Mr. Martin * describes the cry of the agile Gibbon as " overpowering and deafening " in a room, and "from its strength, well calculated for resounding through the vast forests." Mr. Waterhouse, an accomplished musician as well as zoologist, says, "The Gibbon's voice is certainly much more powerful than that of any singer I have ever heard." And yet it is to be recollected that this animal is not half the height of, and far less bulky in proportion than, a man.

There is good testimony that various species of Gibbon readily take to the erect posture. Mr. George Bennett, $\uparrow$ a very excellent observer, in describing the habits of a male Hylobates syndactylus which remained for some time in his possession, says : "He invariably walks in the erect posture when on a level surface; and then the arms either 
hang down, enabling him to assist himself with his knuckles ; or what is more usual, he keeps his arms uplifted in nearly an erect position, with the hands pendent ready to seize a rope, and climb up on the approach of danger or on the obtrusion of strangers. He walks rather quick in the erect posture, but with a waddling gait, and is soon run down if, whilst pursued, he has no opportunity of escaping by climbing. . . When he walks in the erect posture he turns the leg and foot outwards, which occasions him to have a waddling gait and to seem bow-legged."

Dr. Burrough states of another Gibbon, the Horlack or Hooluk :

"They walk erect; and when placed on the floor, or in an open field, balance themselves very prettily, by raising their hands over their head and slightly bending the arm at the wrist and elbow, and then run tolerably fast, rocking from side to side; and, if urged to greater speed, they let fall their hands to the ground, and assist themselves forward, rather jumping than running, still keeping the body, however, nearly erect."

Somewhat different evidence, however, is given by Dr. Winslow Lewis : *

"Their only manner of walking was on their posterior or inferior extremities, the others being raised upwards to preserve their equilibrium, as rope-dancers are assisted by long poles at fairs. Their progression was not by placing one foot before the other, but by simultaneously using both, as in jumping." Dr. Salomon Müller also states that the Gibbons progress upon the ground by a short series of tottering jumps, effected only by the hind limbs, the body being held altogether upright.

But Mr. Martin (1. c. p. 418), who also speaks from direct observation, says of the Gibbons generally :

"Pre-eminently qualifed for arboreal habits, and displaying among the branches amazing activity, the Gibbons are not so awkward or embarrassed on a level surface as might be imagined. They walk erect, with a waddling or unsteady gait, but at a quick pace ; the equilibrium of the body requiring to be kept up, either by touching the ground with the knuckles, first on one side then on the other, or by uplifting the arms so as to poise it. As with the Chimpanzee, the whole of the narrow, long sole of the foot is placed upon the 
ground at once and raised at once, without any elasticity of step."

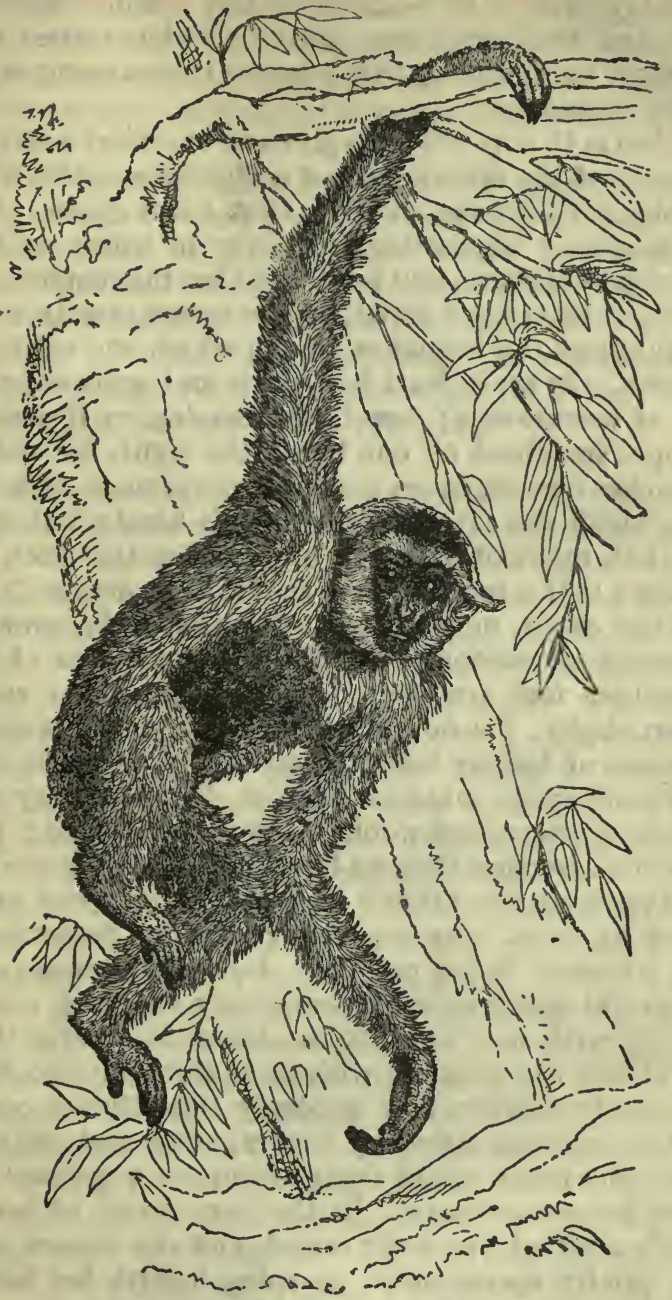

Fig. 8.-A Gibbon ( $H$. plleatus), after Wolf.

After this mass of concurrent and independent testimony, it cannot reasonably be doubted that the Gibbons commonly and habitually assume the erect attitude. 
But level ground is not the place where these animals can display their very remarkable and peculiar locomotive powers, and that prodigious activity which almost tempts one to rank them among flying rather than among ordinary climbing mammals.

Mr. Martin (1. c. p. 430) has given so excellent and graphic an account of the movements of a Hylobates agilis, living in the Zoological Gardens, in 1840, that I will quote it in full :

"It is almost impossible to convey in words an idea of the quickness and graceful address of her movements : they may indeed be termed aërial, as she seems merely to touch in her progress the branches among which she exhibits her evolutions. In these feats her hands and arms are the sole organs of locomotion; her body hanging as if suspended by a rope, sustained by one hand (the right, for example), she launches herself, by an energetic movement, to a distant branch, which she catches with the left hand; but her hold is less than momentary: the impulse for the next launch is acquired: the branch then aimed at is attained by the right hand again, and quitted instantaneously, and so on, in alternate succession. In this manner spaces of twelve and eighteen feet are cleared, with the greatest ease and uninterruptedly, for hours together, without the slightest appearance of fatigue being manifested; and it is evident that, if more space could be allowed, distances very greatly exceeding eighteen feet would be as easily cleared; so that Duvaucel's assertion that he has seen these animals launch themselves from one branch to another, forty feet asunder, startling as it is, may be well credited. Sometimes, on seizing a branch in her progress, she will throw herself, by the power of one arm only, completely round it, making a revolution with such rapidity as almost to deceive the eye, and continue her progress with undiminished velocity. It is singular to observe how suddenly this Gibbon can stop, when the impetus given by the rapidity and distance of her swinging leaps would seem to require a gradual abatement of her movements. In the very midst of her flight a branch is seized, the body raised, and she is seen, as if by magic, quietly seated on it, grasping it with her feet. As suddenly she again throws herself into action.

"The following facts will convey some notion of her dexterity and quickness. A live bird was let loose in her apartment; she marked its flight, made a long swing to a distant branch, caught the bird with one hand in her 
passage, and attained the branch with her other hand; her aim, both at the bird and at the branch, being as successful as if one object only had engaged her attention. It may be added that she instantly bit off the head of the bird, picked its feathers, and then threw it down without attempting to eat it.

"On another occasion this animal swung herself from a perch, across a passage at least twelve feet wide, against a window which it was thought would be immediately broken: but not so; to the surprise of all, she caught the narrow framework between the panes with her hand, in an instant attained the proper impetus, and sprang back again to the cage she had left-a feat requiring not only great strength, but the nicest precision."

The Gibbons appear to be naturally very gentle, but there is very good evidence that they will bite severely when irritated-a female Hylobates agilis having so severely lacerated one man with her long canines, that he died; while she had injured others so much that, by way of precaution, these formidable teeth had been filed down; but, if threatened, she would still turn on her keeper. The Gibbons eat insects, but appear generally to avoid animal food. A Siamang, however, was seen by Mr. Bennett to seize and devour greedily a live lizard. They commonly drink by dipping their fingers in the liquid and then licking them. It is asserted that they sleep in a sitting posture.

Duvaucel affirms that he has seen the females carry their young to the waterside and there wash their faces, in spite of resistance and cries. They are gentle and affectionate in captivity-full of tricks and pettishness, like spoiled children, and yet not devoid of a certain conscience, as an anecdote, told by Mr. Bennett (l. c. p. 156), will show. It -would appear that his Gibbon had a peculiar inclination for disarranging things in the cabin. Among these articles, a piece of soap would especially attract his notice, and for the removal of this he had been once or twice scolded. "One morning," says Mr. Bennett, "I was writing, the ape being present in the cabin, when casting my eyes towards him, I saw the little fellow taking the soap. I watched him without his perceiving that I did so : and he occasionally would cast a furtive glance towards the place where I sat. I pretended to write; he, seeing me busily occupied, took the soap, and moved away with it in his paw. When he had walked 
half the length of the cabin, I spoke quietly, without frightening him. The instant he found I saw him, he walked back again, and deposited the soap nearly in the same place from whence he had taken it. There was certainly something more than instinct in that action: he evidently betrayed a consciousness of having done wrong both by his first and last actions-and what is reason if that is not an exercise of it ?"

The most elaborate account of the natural history of the Orang-Utan extant, is that given in the "Verhandelingen over de Natuurlijke Geschiedenis der Nederlandsche overzeesche Bezittingen (1839-45)," by Dr. Salomon Müller and Dr. Schlegel, and I shall base what I have to say upon this subject almost entirely on their statements, adding here and there, particulars of interest from the writings of Brooke, Wallace, and others.

The Orang-Utan would rarely seem to exceed four feet in height, but the body is very bulky, measuring two-thirds of the height in circumference.*

The Orang-Utan is found only in Sumatra and Borneo, and is common in neither of these islands-in both of which it occurs always in low, flat plains, never in the mountains. It loves the densest and most sombre of the forests, which extend from the sea-shore inland, and thus is found only in the eastern half of Sumatra, where alone such forests occur, though, occasionally, it strays over to the western side.

On the other hand, it is generally distributed through Borneo, except in the mountains, or where the population

* The largest Orang-Utan, cited by Temminck, measured, when standing upright, $4 \mathrm{ft}$.; but he mentions having just received news of the capture of an Orang $5 \mathrm{ft}$. $3 \mathrm{in}$. high. Schlegel and Müller say that their largest old male measured, upright, 1.25 Netherlands " el"; and from the crown to the end of the toes, $1.5 \mathrm{el}$; the circumference of the body being about $1 \mathrm{el}$. The largest old female was $1.09 \mathrm{el} \mathrm{high,} \mathrm{when} \mathrm{standing.} \mathrm{The} \mathrm{adult} \mathrm{skeleton} \mathrm{in} \mathrm{the} \mathrm{College}$ of Surgeons' Museum, if set upright, would stand $3 \mathrm{ft}$. 6-8 in. from crown to sole. Dr. Humphry gives $3 \mathrm{ft} .8 \mathrm{in}$. as the mean height of two Orangs. Of seventeen Orangs examined by Mr. Wallace, the largest was $4 \mathrm{ft}$. $2 \mathrm{in}$. high, from the heel to the crown of the head. Mr. Spencer St. John, however, in his Life in the Forests of the Far East, tells us of an Orang of " $5 \mathrm{ft}$. 2 in., measuring fairly from the head to the heel," 15 in. across the face, and 12 in. round the wrist. It does not appear, however, that Mr. St. John measured this Orang himself. 
is dense. In favourable places, the hunter may, by good fortune, see three or four in a day.

Except in the pairing time, the old males usually live by

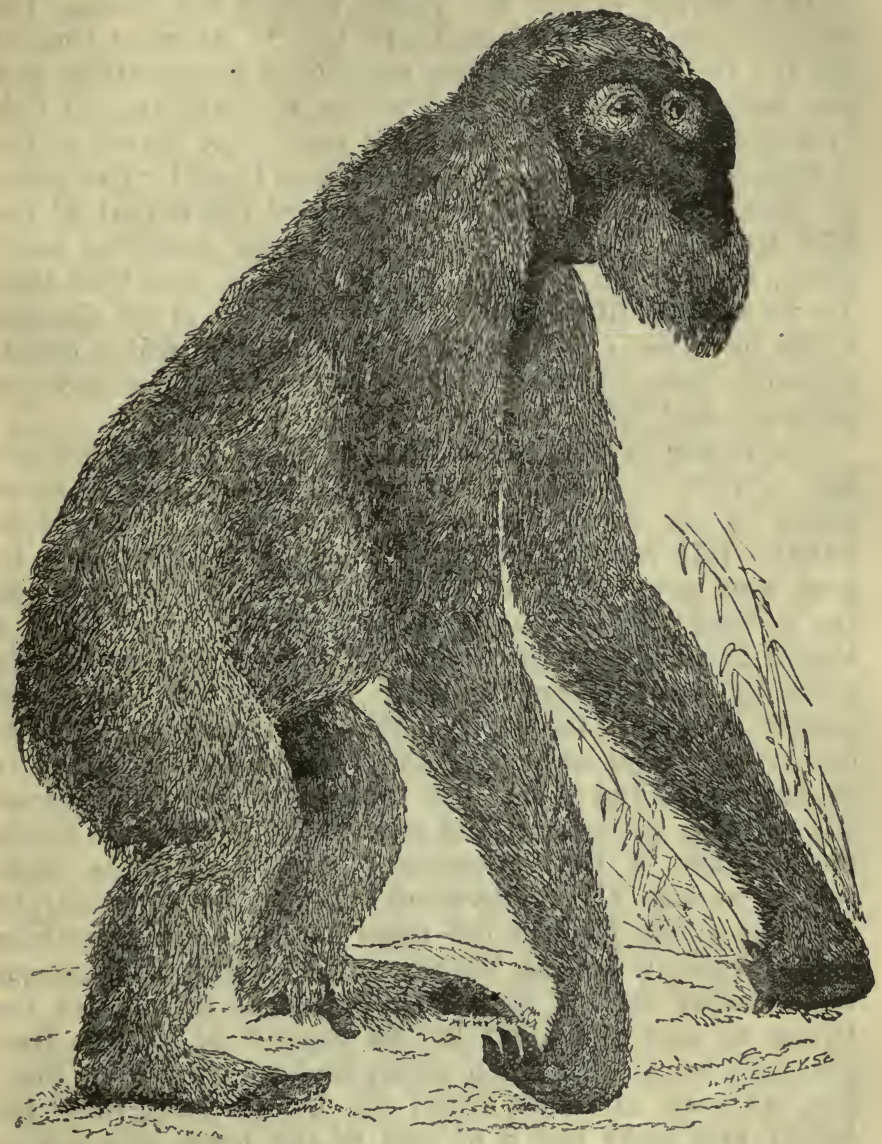

Fig. 9.-An aduIt male Orang-Utan, after Mülier and Schlegel.

themselves. The old females, and the immature males, on the other hand, are often met with in twos and threes; and the former occasionally have young with them, though the pregnant females usually separate themselves, and sometimes remain apart after they have given birth to 
their offspring. The young Orangs seem to remain unusually long under their mother's protection, probably in consequence of their slow growth. While climbing, the mother always carries her young against her bosom, the young holding on by his mother's hair.* At what time of life the Orang-Utan becomes capable of propagation, and how long the females go with young, is unknown, but it is probable that they are not adult until they arrive at ten or fifteen years of age. A female which lived for five years at Batavia, had not attained one-third the height of the wild females. It is probable that, after reaching adult years, they go on growing, though slowly, and that they live to forty or fifty years. The Dyaks tell of old Orangs, which have not only lost all their teeth, but which find it so troublesome to climb, that they maintain themselves on windfalls and juicy herbage.

The Orang is sluggish, exhibiting none of that marvellous activity characteristic of the Gibbons. Hunger alone seems to stir him to exertion, and when it is stilled he relapses into repose. When the animal sits, it curves its back and bows its head, so as to look straight down on the ground; sometimes it holds on with its hands by a higher branch, sometimes lets them hang phlegmatically down by its side-and in these positions the Orang will remain, for hours together, in the same spot, almost without stirring, and only now and then giving utterance to its deep, growling voice. By day, he usually climbs from one tree-top to another, and only at night descends to the ground, and if then threatened with danger, he seeks refuge among the underwood. When not hunted, he remains a long time in the same locality, and sometimes stops for many days on the same tree-a firm place among its branches serving him for a bed. It is rare for the Orang to pass the night in the summit of a large tree, probably because it is too windy and cold there for him; but, as soon as night draws on, he descends from the height and seeks out a fit bed in the lower and darker part, or in the leafy top of a small tree, among which he

"See Mr. Wallace's account of an infant "Orang-utan," in the Annals of Natural History for 1856. Mr. Wallace provided his interesting charge with an artificial mother of buffalo-skin, but the cheat was too successful. The infant's entire experience led it to associate teats with hair, and feeling the latter, it spent its existence in vain endeavours to discover the former. 


\section{OF THE MAN-LIKE APES}

prefers Nibong Palms, Pandani, or one of those parasitic Orchids which give the primeval forests of Borneo so characteristic and striking an appearance. But wherever he determines to sleep, there he prepares himself a sort of nest : little boughs and leaves are drawn together round the selected spot, and bent crosswise over one another; while to make the bed soft, great leaves of Ferns, of Orchids, of Pandanus fascicularis, Nipa fruticans, etc., are laid over them. Those which Müller saw, many of them being very fresh, were situated at a height of ten to twenty-five feet above the ground, and had a circumference, on the average, of two or three feet. Some were packed many inches thick with Pandanus leaves; others were remarkable only for the cracked twigs, which, united in a common centre, formed a regular platform. "The rude hut," says Sir James Brooke, "which they are stated to build in the trees, would be more properly called a seat or nest, for it has no roof or cover of any sort. The facility with which they form this nest is curious, and I had an opportunity of seeing a wounded female weave the branches together and seat herself, within a minute."

According to the Dyaks, the Orang rarely leaves his bed before the sun is well above the horizon and has dissipated the mists. He gets up about nine, and goes to bed again about five; but sometimes not till late in the twilight. He lies sometimes on his back; or, by way of change, turns on one side or the other, drawing his limbs up to his body, and resting his head on his hand. When the night is cold, windy, or rainy, he usually covers his body with a heap of Pandanus, Nipa, or Fern leaves, like those of which his bed is made, and he is especially careful to wrap up his head in them. It is this habit of covering himself up which has probably led to the fable that the Orang builds huts in the trees.

Although the Orang resides mostly amid the boughs of great trees, during the daytime, he is very rarely seen squatting on a thick branch, as other apes, and particularly the Gibbons, do. The Orang, on the contrary, confines himself to the slender leafy branches, so that he is seen right at the top of the trees, a mode of life which is closely related to the constitution of his hinder limbs, and especially to that of his seat. For this is provided with no callosities, such as are possessed by many of the lower apes, and even by the Gibbons; and those bones of the 
pelvis, which are termed the ischia, and which form the solid framework of the surface on which the body rests in the sitting posture, are not expanded like those of the apes which possess callosities, but are more like those of man.

An Orang climbs so slowly and cautiously,* as, in this act, to resemble a man more than an ape, taking great care of his feet, so that injury of them seems to affect him far more than it does other apes. Unlike the Gibbons, whose forearms do the greater part of the work, as they swing from branch to branch, the Orang never makes even the smallest jump. In climbing, he moves alternately one hand and one foot, or, after having laid fast hold with the hands, he draws up both feet together. In passing from one tree to another, he always seeks out a place where the twigs of both come close together, or interlace. Even when closely pursued, his circumspection is amazing: he shakes the branches to see if they will bear him, and then bending an overhanging bough down by throwing his weight gradually along it, he makes a bridge from the tree he wishes to quit to the next. $\dagger$

On the ground the Orang always goes laboriously and shakily, on all fours. At starting he will run faster than a man, though he may soon be overtaken. The very long arms which, when he runs, are but little bent, raise the body of the Orang remarkably, so that he assumes much the posture of a very old man bent down by age, and making his way along by the help of a stick. In walking, the body is usually directed straight forward, unlike the other apes, which run more or less obliquely; except the Gibbons, who in these, as in so many other respects, depart remarkably from their fellows.

The Orang cannot put its feet flat on the ground, but is supported upon their outer edges, the heel resting more on the ground, while the curved toes partly rest upon the ground by the upper side of their first joint, the two outermost toes of each foot completely resting on this surface. The hands are held in the opposite manner, their inner edges

* "They are the slowest and least active of all the monkey tribe, and their motions are surprisingly awkward and uncouth."-Sir James Brooke, in the Proceedings of the Zoological Society, 1841.

+ Mr. Wallace's account of the progression of the Orang almost exactly corresponds with this. 


\section{OF THE MAN-LIKE APES}

serving as the chief support. The fingers are then bent out in such a manner that their foremost joints, especially those of the two innermost fingers, rest upon the ground by their upper sides, while the point of the free and straight thumb serves as an additional fulcrum.

The Orang never stands on its hind legs, and all the pictures, representing it as so doing, are as false as the assertion that it defends itself with sticks, and the like.

The long arms are of especial use, not only in climbing, but in the gathering of food from boughs to which the animal could not trust his weight. Figs, blossoms, and young leaves of various kinds, constitute the chief nutriment of the Orang; but strips of bamboo two or three feet long were found in the stomach of a male. They are not known to eat living animals.

Although, when taken young, the Orang-Utan soon becomes domesticated, and indeed seems to court human society, it is naturally a very wild and shy animal, though apparently sluggish and melancholy. The Dyaks affirm, that when the old males are wounded with arrows only, they will occasionally leave the trees and rush raging upon their enemies, whose sole safety lies in instant flight, as they are sure to be killed if caught.*

* Sir James Brooke, in a letter to Mr. Waterhouse, published in the proceedings of the Zoological Society for 1841, says :- " On the habits of the Orangs, as far as I have been able to observe them, I may remark that they are as dull and slothful as can well be conceived, and on no occasion, when pursuing them, did they move so fast as to preclude my keeping pace with them easily through a moderately clear forest ; and even when obstructions below (such as wading up to the neck) allowed them to get away some distance, they were sure to stop and allow me to come up. I never observed the slightest attempt at defence, and the wood which sometimes rattled about our ears was broken by their weight, and not thrown, as some persons represent. If pushed to extremity, however, the Pappan could not be otherwise than formidable, and one unfortunate man, who, with a party, was trying to catch a large one alive, lost two of his fingers, besides being severely bitten on the face, whilst the animal finally beat off his pursuers and escaped."

Mr. Wallace, on the other hand, affirms that he has several times observed them throwing down branches when pursued. "It is true he does not throw them at a person, but casts them down vertically; for it is evident that a bough cannot be thrown to any distance from the top of a lofty tree. In one case a female Mias, on a durian tree, kept up for at least ten minutes a continuous shower of branches and of the heavy, spined fruits, as large as 32-pounders, which most effectually kept us clear of the tree she was on. She could be seen breaking them off and throwing them down with every appearance 
But, though possessed of immense strength, it is rare for the Orang to attempt to defend itself, especially when attacked with fire-arms. On such occasions he endeavours to hide himself, or to escape along the topmost branches of the trees, breaking off and throwing down the boughs as he goes. When wounded he betakes himself to the highest attainable point of the tree, and emits a singular cry, consisting at first of high notes, which at length deepen into a low roar, not unlike that of a panther. While giving out the high notes the Orang thrusts out his lips into a funnel shape; but in uttering the low notes he holds his mouth wide open, and at the same time the great throat bag, or laryngeal sac, becomes distended.

According to the Dyaks, the only animal the Orang measures his strength with is the crocodile, who occasionally seizes him on his visits to the water side. But they say that the Orang is more than a match for his enemy, and beats him to death, or rips up his throat by pulling the jaws asunder !

Much of what has been here stated was probably derived by Dr. Müller from the reports of his Dyak hunters ; but a large male, four feet high, lived in captivity, under his observation, for a month, and receives a very bad character.

" He was a very wild beast," says Müller, " of prodigious strength, and false and wicked to the last degree. If any one approached he rose up slowly with a low growl, fixed his eyes in the direction in which he meant to make his attack, slowly passed his hand between the bars of his cage, and then extending his long arm, gave a sudden grip-usually at the face." He never tried to bite (though Orangs will bite one another), his great weapons of offence and defence being his hands.

His intelligence was very great; and Müller remarks, that though the faculties of the Orang have been estimated too highly, yet Cuvier, had he seen this specimen, would not have considered its intelligence to be only a little higher than that of the dog.

His hearing was very acute, but the sense of vision

of rage, uttering at intervals a loud pumping grunt, and evidently meaning mischief."- "On the Habits of the Orang-Utan," Annals of Nat. History, 1856. This statement, it will be observed, is quite in accordance with that contained in the letter of the Resident Palm quoted above (p. 210). 
seemed to be less perfect. The under lip was the great organ of touch, and played a very important part in drinking, being thrust out like a trough, so as either to catch the falling rain, or to receive the contents of the half cocoa-nut shell full of water with which the Orang was supplied, and which, in drinking, he poured into the trough thus formed.

In Borneo the Orang-Utan of the Malays goes by the name of "Mias" among the Dyaks, who distinguish several kinds as Mias Pappan, or Zimo, Mias Kassu, and Mias Rambi. Whether these are distinct species, however, or whether they are mere races, and how far any of them are identical with the Sumatran Orang, as Mr. Wallace thinks the Mias Pappan to be, are problems which are at present undecided; and the variability of these great apes is so extensive, that the settlement of the question is a matter of great difficulty. Of the form called "Mias Pappan," Mr. Wallace * observes, "It is known by its large size, and by the lateral expansion of the face into fatty protuberances, or ridges, over the temporal muscles, which have been mis-termed callosities, as they are perfectly soft, smooth, and flexible. Five of this form, measured by me, varied only from 4 feet 1 inch to 4 feet 2 inches in height, from the heel to the crown of the head, the girth of the body from 3 feet to 3 feet $7 \frac{1}{2}$ inches, and the extent of the outstretched arms from 7 feet 2 inches to 7 feet 6 inches; the width of the face from 10 to $13 \frac{1}{4}$ inches. The colour and length of the hair varied in different individuals, and in different parts of the same individual ; some possessed a rudimentary nail on the great toe, others none at all; but they otherwise present no external differences on which to establish even varieties of a species.

"Yet, when we examine the crania of these individuals, we find remarkable differences of form, proportion, and dimension, no two being exactly alike. The slope of the profile, and the projection of the muzzle, together with the size of the cranium, offer differences as decided as those existing between the most strongly marked forms of the Caucasian and African crania in the human species. The orbits vary in width and height, the cranial ridge is either single or double, either much or little developed, and the

* On the Orang-Utan, or Mias of Borneo, Annals of Natural History, 1856. 
zygomatic aperture varies considerably in size. This variation in the proportions of the crania enables us satisfactorily to explain the marked difference presented by the single-crested and double-crested skulls, which have been thought to prove the existence of two large species of Orang. The external surface of the skull varies considerably in size, as do also the zygomatic aperture and the temporal muscle ; but they bear no necessary relation to each other, a small muscle often existing with a large cranial surface, and vice versa. Now, those skulls which have the largest and strongest jaws and the widest zygomatic aperture, have the muscles so large that they meet on the crown of the skull, and deposit the bony ridge which separates them, and which is the highest in that which has the smallest cranial surface. In those which combine a large surface with comparatively weak jaws, and small zygomatic aperture, the muscles, on each side, do not extend to the crown, a space of from 1 to 2 inches remaining between them, and along their margins small ridges are formed. Intermediate forms are found, in which the ridges meet only in the hinder part of the skull. The form and size of the ridges are therefore independent of age, being sometimes more strongly developed in the less aged animal. Professor Temminck states that the series of skulls in the Leyden Museum shows the same result."

Mr. Wallace observed two male adult Orangs (Mias Kassu of the Dyaks), however, so very different from any of these that he concludes them to be specifically distinct; they were respectively 3 feet $8 \frac{1}{2}$ inches and 3 feet $9 \frac{1}{2}$ inches high, and possessed no sign of the cheek excrescences, but otherwise resembled the larger kinds. The skull has no crest, but two bony ridges, $1 \frac{s}{4}$ inches to 2 inches apart, as in the Simia morio of Professor Owen. The teeth, however, are immense, equalling or surpassing those of the other species. The females of both these kinds, according to Mr. Wallace, are devoid of excrescences, and resemble the smaller males, but are shorter by $1 \frac{1}{2}$ to 3 inches, and their canine teeth are comparatively small, subtruncated and dilated at the base, as in the so-called Simia morio, which is, in all probability, the skull of a female of the same species as the smaller males. Both males and females of this smaller species are distinguishable, according to $\mathrm{Mr}$. Wallace, by the comparatively large size of the middle incisors of the upper jaw. 
So far as I am aware, no one has attempted to dispute the accuracy of the statements which I have just quoted regarding the habits of the two Asiatic man-like Apes; and if true, they must be admitted as evidence, that such an Ape-

Firstly, May readily move along the ground in the erect, or semi-erect, position, and without direct support from its arms.

Secondly, That it may possess an extremely loud voice, so loud as to be readily heard one or two miles.

Thirdly, That it may be capable of great viciousness and violence when irritated: and this is especially true of adult males.

Fourthly, That it may build a nest to sleep in.

Such being well-established facts respecting the Asiatic Anthropoids, analogy alone might justify us in expecting the African species to offer similar peculiarities, separately or combined; or, at any rate, would destroy the force of any attempted $d$ priori argument against such direct testimony as might be adduced in favour of their existence. And, if the organization of any of the African Apes could be demonstrated to fit it better than either of its Asiatic allies for the erect position and for efficient attack, there would be still less reason for doubting its occasional adoption of the upright attitude or of aggressive proceedings.

From the time of Tyson and Tulpius downwards, the habits of the young CHIMPANzeE in a state of captivity have been abundantly reported and commented upon. But trustworthy evidence as to the manners and customs of adult anthropoids of this species, in their native woods, was almost wanting up to the time of the publication of the paper by Dr. Savage, to which I have already referred; containing notes of the observations which he made, and of the information which he collected from sources which he considered trustworthy, while resident at Cape Palmas, at the north-western limit of the Bight of Benin.

The adult Chimpanzees, measured by Dr. Savage, never exceeded, though the males may almost attain, five feet in height.

"When at rest, the sitting posture is that generally assumed. They are sometimes seen standing and walking, but when thus detected, they immediately take to all fours, and flee from the presence of the observer. Such 
is their organization that they cannot stand erect, but lean forward. Hence they are seen, when standing, with the hands clasped over the occiput, or the lumbar region, which would seem necessary to balance or ease of posture. "The toes of the adult are strongly flexed and turned inwards, and cannot be perfectly straightened. In the attempt the skin gathers into thick folds on the back, shewing that the full expansion of the foot, as is necessary in walking, is unnatural. The natural position is on all fours, the body anteriorly resting upon the knuckles. These are greatly enlarged, with the skin protuberant and thickened like the sole of the foot.

"They are expert climbers, as one would suppose from their organization. In their gambols they swing from limb to limb to a great distance, and leap with astonishing agility. It is not unusual to see the 'old folks' (in the language of an observer) sitting under a tree regaling themselves with fruit and friendly chat, while their 'children' are leaping around them, and swinging from tree to tree with boisterous merriment.

"As seen here, they cannot be called gregarious, seldom more than five, or ten at most, being found together. It has been said, on good authority, that they occasionally assemble in large numbers, in gambols. My informant asserts that he saw once not less than fifty so engaged; hooting, screaming, and drumming with sticks upon old logs, which is done in the latter case with equal facility by the four extremities. They do not appear ever to act on the offensive, and seldom, if ever really, on the defensive. When about to be captured, they resist by throwing their arms about their opponent, and attempting to draw him into contact with their teeth." (Savage, l. c. p. 384.)

With respect to this last point Dr. Savage is very explicit in another place:

"Biting is their principal art of defence. I have seen one man who had been thus severely wounded in the feet.

"The strong development of the canine teeth in the adult would seem to indicate a carnivorous propensity; but in no state save that of domestication do they manifest it. At first they reject flesh, but easily acquire a fondness for it. The canines are early developed, and evidently designed to act the important part of weapons of defence. 
When in contact with man almost the first effort of the animal is-to bite.

"They avoid the abodes of men, and build their habitations in trees. Their construction is more that of nests than huts, as they have been erroneously termed by some naturalists. They generally build not far above the ground. Branches or twigs are bent, or partly broken, and crossed, and the whole supported by the body of a limb or a crotch. Sometimes a nest will be found near the end of a strong leafy branch twenty or thirty feet from the ground. One I have lately seen that could not be less than forty feet, and more probably it was fifty. But this is an unusual height.

"Their dwelling-place is not permanent, but changed in pursuit of food and solitude, according to the force of circumstances. We more often see them in elevated places ; but this arises from the fact that the low grounds, being more favourable for the natives' rice-farms, are the oftener cleared, and hence are almost always wanting in suitable trees for their nests. . . . It is seldom that more than one or two nests are seen upon the same tree, or in the same neighbourhood: five have been found, but it was an unusual circumstance." ...

"They are very filthy in their habits. . . It is a tradition with the natives generally here, that they were once members of their own tribe : that for their depraved habits they were expelled from all human society, and, that through an obstinate indulgence of their vile propensities, they have degenerated into their present state and organization. They are, however, eaten by them, and when cooked with the oil and pulp of the palm-nut considered a highly palatable morsel.

" They exhibit a remarkable degree of intelligence in their habits, and, on the part of the mother, much affection for their young. The second female described was upon a tree when first discovered, with her mate and two young ones (a male and a female). Her first impulse was to descend with great rapidity, and make off into the thicket, with her mate and female offspring. The young male remaining behind, she soon returned to the rescue. She ascended and took him in her arms, at which moment she was shot, the ball passing through the forearm of the young one, on its way to the heart of the mother. ...

"In a recent case, the mother, when discovered, 
remained upon the tree with her offspring, watching intently the movements of the hunter. As he took aim, she motioned with her hand, precisely in the manner of a human being, to have him desist and go away. When the wound has not proved instantly fatal, they have been known to stop the flow of blood by pressing with the hand upon the part, and when this did not succeed, to apply leaves and grass.... When shot, they give a sudden screech, not unlike that of a human being in sudden and acute distress."

The ordinary voice of the Chimpanzee, however, is affirmed to be hoarse, guttural, and not very loud, somewhat like "whoo-whoo" (l. c. p. 365).

The analogy of the Chimpanzee to the Orang, in its nest-building habit and in the mode of forming its nest, is exceedingly interesting; while, on the other hand, the activity of this ape, and its tendency to bite, are particulars in which it rather resembles the Gibbons. In extent of geographical range, again, the Chimpanzees-which are found from Sierra Leone to Congo-remind one of the Gibbons, rather than of either of the other man-like apes; and it seems not unlikely that, as is the case with the Gibbons, there may be several species spread over the geographical area of the genus.

The same excellent observer, from whom I have borrowed the preceding account of the habits of the adult Chimpanzee, published, fifteen years ago,* an account of the Gorilis, which has, in its most essential points, been confirmed by subsequent observers, and to which so very little has really been added, that in justice to Dr. Savage I give it almost in full.

" It should be borne in mind that my account is based upon the statements of the aborigines of that region (the Gaboon). In this connection, it may also be proper for me to remark, that having been a missionary resident for several years, studying, from habitual intercourse, the African mind and character, I felt myself prepared to discriminate and decide upon the probability of their statements. Besides, being familiar with the history and habits of its interesting congener (Trog. niger, Geoff.), I was able to separate their accounts of the two animals, which, having the same locality and a similarity of habit,

* Notice of the external characters and habits of Troglodytes Gorilla. Boston Journal of Natural History, 1847. 
are confounded in the minds of the mass, especially as but few-such as traders to the interior and huntsmenhave ever seen the animal in question.

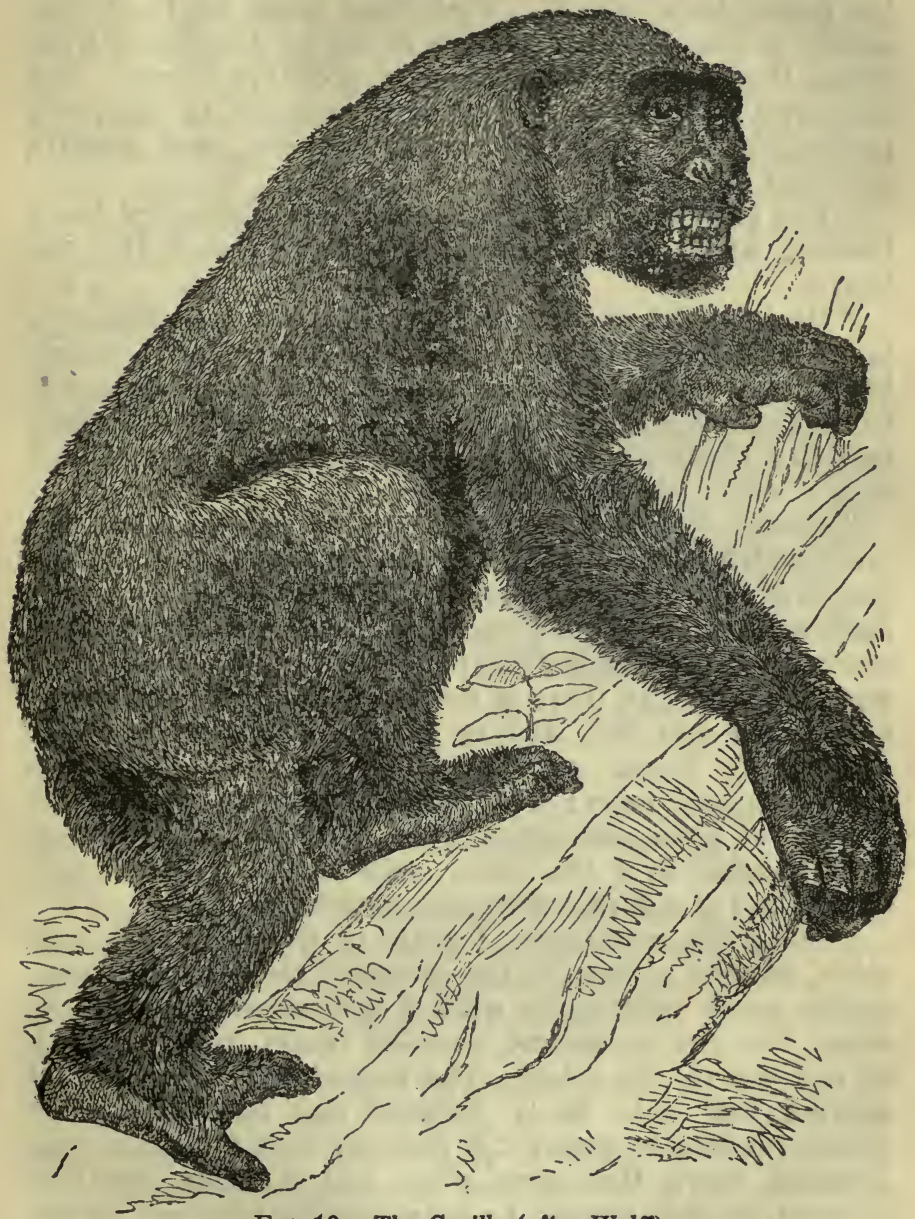

FIG. 10.-The Gorilla (after Wolff).

"The tribe from which our knowledge of the animal is derived, and whose territory forms its habitat, is the Mpongwe, occupying both banks of the River Gaboon, from its mouth to some fifty or sixty miles upward. . . . 
"If the word 'Pongo' be of African origin, it is probably a corruption of the word Mpongwe, the name of the tribe on the banks of the Gaboon, and hence applied to the region they inhabit. Their local name for the Chimpanzee is Enché-eko, as near as it can be Anglicized, from which the common term 'Jocko' probably comes. The Mpongwe appellation for its new congener is Enge-ena, prolonging the sound of the first vowel, and slightly sounding the second.

"The habitat of the Engé-ena is the interior of lower Guinea, whilst that of the Enche-eko is nearer the seaboard.

"Its height is about five feet; it is disproportionately broad across the shoulders, thickly covered with coarse black hair, which is said to be similar in its arrangement to that of the Enche-eko; with age it becomes grey, which fact has given rise to the report that both animals are seen of different colours.

"Head.-The prominent features of the head are, the great width and elongation of the face, the depth of the molar region, the branches of the lower jaw being very deep and extending far backward, and the comparative smallness of the cranial portion; the eyes are very large, and said to be like those of the Enché-eko, a bright hazel; nose broad and flat, slightly elevated towards the root; the muzzle broad, and prominent lips and chin, with scattered grey hairs; the under lip highly mobile, and capable of great elongation when the animal is enraged, then hanging over the chin; skin of the face and ears naked, and of a dark brown, approaching to black.

"The most remarkable feature of the head is a high ridge, or crest of hair, in the course of the sagittal suture, which meets posteriorly with a transverse ridge of the same, but less prominent, running round from the back of one ear to the other. The animal has the power of moving the scalp freely forward and back, and when enraged is said to contract it strongly over the brow, thus bringing down the hairy ridge and pointing the hair forward, so as to present an indescribably ferocious aspect.

"Neck short, thick, and hairy; chest and shoulders very broad, said to be fully double the size of the Encheekos; arms very long, reaching some way below the knee - the fore-arm much the shortest; hands very large, the thumbs much larger than the fingers. . . 
"The gait is shuffling; the motion of the body, which is never upright as in man, but bent forward, is somewhat rolling, or from side to side. The arms being longer than the Chimpanzee, it does not stoop as much in walking; like that animal, it makes progression by thrusting its arms forward, resting the hands on the ground, and then giving the body a half jumping half swinging motion between them. In this act it is said not to flex the fingers, as does the Chimpanzee, resting on its knuckles, but to extend them, making a fulcrum of the hand. When it assumes the walking posture, to which it is said to be much inclined, it balances its huge body by flexing its arms upward.

"They live in bands, but are not so numerous as the Chimpanzees : the females generally exceed the other sex in number. My informants all agree in the assertion that but one adult male is seen in a band; that when the young males grow up, a contest takes place for mastery, and the strongest, by killing and driving out the others, establishes himself as the head of the

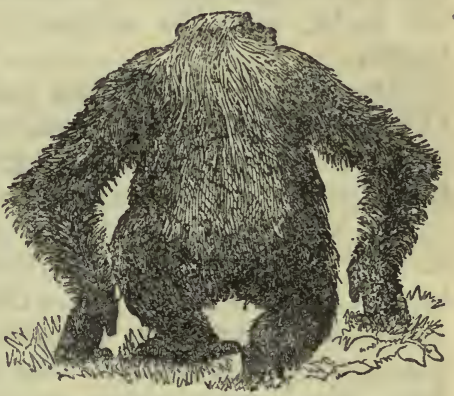

Fig. 11.-Gorilla walking (after Wolff). community."

Dr. Savage repudiates the stories about the Gorillas. carrying off women and vanquishing elephants, and then adds :

"Their dwellings, if they may be so called, are similar to those of the Chimpanzee, consisting simply of a few sticks and leafy branches, supported by the crotches and limbs of trees : they afford no shelter, and are occupied only at night.

"They are exceedingly ferocious, and always offensive in their habits, never running from man, as does the Chimpanzee. They are objects of terror to the natives, and are never encountered by them except on the defensive. The few that have been captured were killed by elephanthunters and native traders, as they came suddenly upon them while passing through the forests.

" It is said that when the male is first seen he gives a terrific yell, that resounds far and wide through the 
forest, something like $\mathrm{kh}-\mathrm{ah} ! \mathrm{kh}-\mathrm{ah}$ ! prolonged and shrill. His enormous jaws are widely opened at each expiration, his under lip hangs over the chin, and the hairy ridge and scalp are contracted upon the brow, presenting an aspect of indescribable ferocity.

"The females and young, at the first cry, quickly disappear. He then approaches the enemy in great fury, pouring out his horrid cries in quick succession. The hunter awaits his approach with his gun extended: if his aim is not sure, he permits the animal to grasp the barrel, and as he carries it to his mouth (which is his habit) he fires. Should the gun fail to go off, the barrel (that of the ordinary musket, which is thin) is crushed between his teeth, and the encounter soon proves fatal to the hunter.

"In the wild state, their habits are in general like those of the Troglodytes niger, building their nests loosely in trees, living on similar fruits, and changing their place of resort from force of circumstances."

Dr. Savage's observations were confirmed and supplemented by those of Mr. Ford, who communicated an interesting paper on the Gorilla to the Philadelphian Academy of Sciences, in 1852 . With respect to the geographical distribution of this greatest of all the man-like Apes, Mr. Ford remarks :

"This animal inhabits the range of mountains that traverse the interior of Guinea, from the Cameroon in the north, to Angola in the south, and about 100 miles inland, and called by the geographers Crystal Mountains. The limit to which this animal extends, either north or south, I am unable to define. But that limit is doubtless some distance north of this river [Gaboon]. I was able to certify myself of this fact in a late excursion to the headwaters of the Mooney (Danger) River, which comes into the sea some sixty miles from this place. I was informed (credibly, I think) that they were numerous among the mountains in which that river rises, and far north of that.

"In the south, this species extends to the Congo River, as I am told by native traders who have visited the coast between the Gaboon and that river. Beyond that, I am not informed. This animal is only found at a distance from the coast in most cases, and, according to my best information, approaches it nowhere so nearly as on the south side of this river, where they have been found within ten 
miles of the sea. This, however, is only of late occurrence. I am informed by some of the oldest Mpongwe men that formerly he was only found on the sources of the river, but that at present he may be found within half-a-day's walk of its mouth. Formerly he inhabited the mountainous ridge where Bushmen alone inhabited, but now he boldly approaches the Mpongwe plantations. This is doubtless the reason of the scarcity of information in years past, as the opportunities for receiving a knowledge of the animal have not been wanting; traders having for one hundred years frequented this river, and specimens, such as have been brought here within a year, could not have been exhibited without having attracted the attention of the most stupid."

One specimen Mr. Ford examined weighed 170 lbs., without the thoracic, or pelvic, viscera, and measured four feet four inches round the chest. This writer describes so minutely and graphically the onslaught of the Gorillathough he does not for a moment pretend to have witnessed the scene-that I am tempted to give this part of his paper in full, for comparison with other narratives :

" He always rises to his feet when making an attack, though he approaches his antagonist in a stooping posture. " Though he never lies in wait, yet, when he hears, sees, or scents a man, he immediately utters his characteristic cry, prepares for an attack, and always acts on the offensive. The cry he utters resembles a grunt more than a growl, and is similar to the cry of the Chimpanzee, when irritated, but vastly louder. It is said to be audible at a great distance. His preparation consists in attending the females and young ones, by whom he is usually accompanied, to a little distance. $\mathrm{He}$, however, soon returns, with his crest erect and projecting forward, his nostrils dilated, and his under-lip thrown down; at the same time uttering his characteristic yell, designed, it would seem, to terrify his antagonist. Instantly, unless he is disabled by a well-directed shot, he makes an onset, and, striking his antagonist with the palm of his hands, or seizing him with a grasp from which there is no escape, he dashes him upon the ground, and lacerates him with his tusks.

" He is said to seize a musket, and instantly crush the barrel between his teeth. ... This animal's savage nature is very well shewn by the implacable desperation of a young one that was brought here. It was taken very young, and 
kept four months, and many means were used to tame it ; but it was incorrigible, so that it bit me an hour before it died."

Mr. Ford discredits the house-building and elephantdriving stories, and says that no well-informed natives believe them. They are tales told to children.

I might quote other testimony to a similar effect, but, as it appears to me, less carefully weighed and sifted, from the letters of MM. Franquet and Gautier Laboullay, appended to the memoir of M. I. G. St. Hilaire, which I have already cited.

Bearing in mind what is known regarding the Orang and the Gibbon, the statements of Dr. Savage and Mr. Ford do not appear to me to be justly open to criticism on d priori grounds. The Gibbons, as we have seen, readily assume the erect posture, but the Gorilla is far better fitted by its organization for that attitude than are the Gibbons: if the laryngeal pouches of the Gibbons, as is very likely, are important in giving volume to a voice which can be heard for half a league, the Gorilla, which has similar sacs, more largely developed, and whose bulk is fivefold that of a Gibbon, may well be audible for twice that distance. If the Orang fights with its hands, the Gibbons and Chimpanzees with their teeth, the Gorilla may, probably enough, do either or both ; nor is there anything to be said against either Chimpanzee or Gorilla building a nest, when it is proved that the OrangUtan habitually performs that feat.

With all this evidence, now ten to fifteen years old, before the world, it is not a little surprising that the assertions of a recent traveller, who, so far as the Gorilla is concerned, really does very little more than repeat, on his own authority, the statements of Savage and of Ford, should have met with so much and such bitter opposition. If subtraction be made of what was known before, the sum and substance of what M. Du Chaillu has affirmed as a matter of his own observation respecting the Gorilla, is, that, in advancing to the attack, the great brute beats his chest with his fists. I confess I see nothing very improbable, or very much worth disputing about, in this statement.

With respect to the other man-like Apes of Africa, M. Du Chaillu tells us absolutely nothing, of his own knowledge, regarding the common Chimpanzee; but he informs us of a bald-headed species or variety, the nschiego mbouve, which builds itself a shelter, and of another rare kind with a 
comparatively small face, large facial angle, and peculiar note, resembling " Kooloo."

As the Orang shelters itself with a rough coverlet of leaves, and the common Chimpanzee, according to that eminently trustworthy observer Dr. Savage, makes a sound like "Whoo-whoo,"- the grounds of the summary repudiation with which M. Du Chaillu's statements on these matters have been met is not obvious.

If I have abstained from quoting M. Du Chaillu's work, then, it is not because I discern any inherent improbability in his assertions respecting the man-like Apes; nor from any wish to throw suspicion on his veracity; but because, in my opinion, so long as his narrative remains in its present state of unexplained and apparently inexplicable confusion, it has no claim to original authority respecting any subject whatsoever.

It may be truth, but it is not evidence. 


\section{ON THE RELATIONS OF MAN TO THE LOWER ANIMALS}

Multis videri poterit, majorem esse differentiam Simiæ et Hominis, quam diei et noctis; verum tamen hi, comparatione instituta inter summos Europæ Heroës et Hottentottos ad Caput bonæ spei degentes, difficillime sibi persuadebunt, has eosdem habere natales; vel si virginem nobilem aulicam, maxime comtam et humanissimam, conferre vellent cum homine sylvestri et sibi relicto, vix augurari possent, hunc et illam ejusdem esse speciei.-Linnæi Amænitates Acad. "Anthropomorpha."

THE question of questions for mankind-the problem which underlies all others, and is more deeply interesting than any other-is the ascertainment of the place which Man occupies in nature and of his relations to the universe of things. Whence our race has come; what are the limits of our power over nature, and of nature's power over us; to what goal we are tending; are the problems which present themselves anew and with undiminished interest to every man born into the world. Most of us, shrinking from the difficulties and dangers which beset the seeker after original answers to these riddles, are contented to ignore them altogether, or to smother the investigating spirit under the featherbed of respected and respectable tradition. But, in every age, one or two restless spirits, blessed with that constructive genius, which can only build on a secure foundation, or cursed with the mere spirit of scepticism, are unable to follow in the well-worn and comfortable track of their forefathers and contemporaries, and unmindful of thorns and stumbling-blocks, strike out into paths of their own. The sceptics end in the infidelity which asserts the problem to be insoluble, or in the atheism which denies the existence of any orderly progress and governance of things: the men of genius propound solutions which grow into systems of Theology or of Philosophy, or veiled in musical language which suggests more than it asserts, take the shape of the Poetry of an epoch. 
Each such answer to the great question, invariably asserted by the followers of its propounder, if not by himself, to be complete and final, remains in high authority and esteem, it may be for one century, or it may be for twenty : but, as invariably, Time proves each reply to have been a mere approximation to the truth-tolerable chiefly on account of the ignorance of those by whom it was accepted, and wholly intolerable when tested by the larger knowledge of their successors.

In a well-worn metaphor, a parallel is drawn between the life of man and the metamorphosis of the caterpillar into the butterfly ; but the comparison may be more just as well as more novel, if for its former term we take the mental progress of the race. History shows that the human mind, fed by constant accessions of knowledge, periodically grows too large for its theoretical coverings, and bursts them asunder to appear in new habiliments, as the feeding and growing grub, at intervals, casts its too narrow skin and assumes another, itself but temporary. Truly the imago state of Man seems to be terribly distant, but every moult is a step gained, and of such there have been many.

Since the revival of learning, whereby the Western races of Europe were enabled to enter upon that progress towards true knowledge, which was commenced by the philosophers of Greece, but was almost arrested in subsequent long ages of intellectual stagnation, or, at most, gyration, the human larva has been feeding vigorously, and moulting in proportion. A skin of some dimension was cast in the 16th century, and another towards the end of the 18th, while, within the last fifty years, the extraordinary growth of every department of physical science has spread among us mental food of so nutritious and stimulating a character that a new ecdysis seems imminent. But this is a process not unusually accompanied by many throes and some sickness and debility, or, it may be, by graver disturbances; so that every good citizen must feel bound to facilitate the process, and even if he have nothing but a scalpel to work withal, to ease the cracking integument to the best of his ability.

In this duty lies my excuse for the publication of these essays. For it will be admitted that some knowledge of man's position in the animate world is an indispensable preliminary to the proper understanding of his relations to the universe-and this again resolves itself, in the long run, into an inquiry into the nature and the closeness 
of the ties which connect him with those singular creatures whose history * has been sketched in the preceding pages.

The importance of such an inquiry is indeed intuitively manifest. Brought face to face with these blurred copies of himself, the least thoughtful of men is conscious of a certain shock, due perhaps not so much to disgust at the aspect of what looks like an insulting caricature, as to the awakening of a sudden and profound mistrust of timehonoured theories and strongly-rooted prejudices regarding his own position in nature, and his relations to the underworld of life; while that which remains a dim suspicion for the unthinking, becomes a vast argument, fraught with the deepest consequences, for all who are acquainted with the recent progress of the anatomical and physiological sciences.

I now propose briefly to unfold that argument, and to set forth, in a form intelligible to those who possess no special acquaintance with anatomical science, the chief facts upon which all conclusions respecting the nature and the extent of the bonds which connect man with the brute world must be based: I shall then indicate the one immediate conclusion which, in my judgment, is justified by those facts, and I shall finally discuss the bearing of that conclusion upon the hypotheses which have been entertained respecting the Origin of Man.

The facts to which I would first direct the reader's attention, though ignored by many of the professed instructors of the public mind, are easy of demonstration and are universally agreed to by men of science; while their significance is so great, that whoso has duly pondered over them will, I think, find little to startle him in the other revelations of Biology. I refer to those facts which have been made known by the study of Development.

It is a truth of very wide, if not of universal, application, that every living creature commences its existence under a form different from, and simpler than, that which it eventually attains.

The oak is a more complex thing than the little rudimentary plant contained in the acorn; the caterpillar is more complex than the egg; the butterfly than the caterpillar; and each of these beings, in passing from its rudi-

- It will be understood that, in the preceding Essay, I have selected for notice from the vast mass of papers which have been written upon the man-like Apes, only those which seem to me to be of snecial moment. 
mentary to its perfect condition, runs through a series of changes, the sum of which is called its Development. In the higher animals these changes are extremely complicated; but, within the last half-century, the labours of such men as Von Baer, Rathke, Reichert, Bischof, and Remak have almost completely unravelled them, so that the successive stages of development which are exhibited by a Dog, for example, are now as well known to the embryologist as are the steps of the metamorphosis of the silkworm moth to the school-boy. It will be useful to consider with attention the
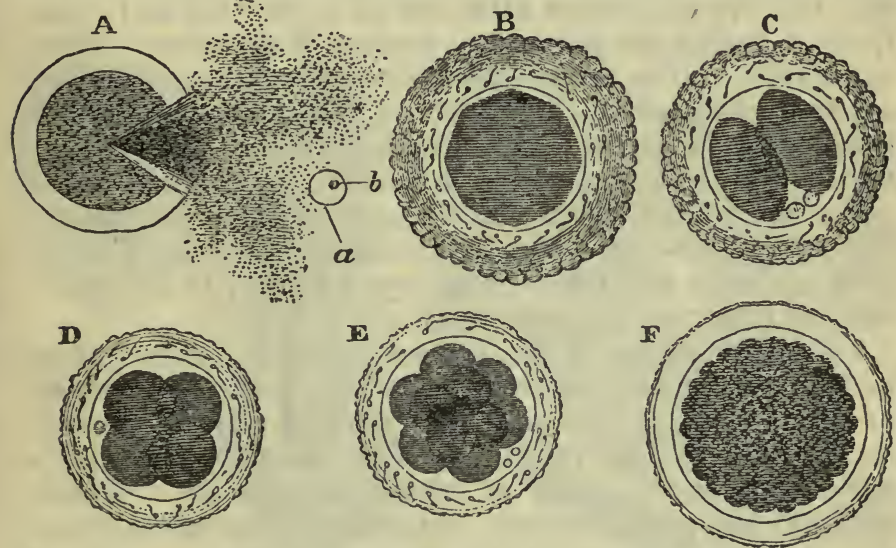

Frg. 12.-A. Egg of the Dog, with the vitelline membrane burst, so as to give exit to the yelk, the germinal vesicle $(a)$, and its included spot $(b)$.

B. C. D. E. F. Successive changes of the yelk indicated in the text. After Bischofr.

nature and the order of the stages of canine development, as an example of the process in the higher animals generally.

The Dog, like all animals, save the very lowest (and further inquiries may not improbably remove the apparent exception), commences its existence as an egg : as a body which is, in every sense, as much an egg as that of a hen, but is devoid of that accumulation of nutritive matter which confers upon the bird's egg its exceptional size and domestic utility; and wants the shell, which would not only be useless to an animal incubated within the body of its parent, but would cut it off from access to the source of that nutriment which the young creature requires, but which the minute egg of the mammal does not contain within itself. 
The Dog's egg is, in fact, a little spheroidal bag (Fig. 12), formed of a delicate transparent membrane called the vitelline membrane, and about $\Gamma_{1}^{\frac{1}{3} \sigma}$ to $1^{\frac{1}{2}} \sigma \mathrm{th}$ of an inch in diameter. It contains a mass of viscid nutritive matter - the 'yelk'-within which is inclosed a second much more delicate spheroidal bag, called the 'germinal vesicle' (a). In this, lastly, lies a more solid rounded body, termed the ' germinal spot' (b).

The egg, or 'Ovum,' is originally formed within a gland, from which, in due season, it becomes detached, and passes into the living chamber fitted for its protection and maintenance during the protracted process of gestation. Here, when subjected to the required conditions, this minute and apparently insignificant particle of living matter becomes animated by a new and mysterious activity. The germinal vesicle and spot cease to be discernible (their precise fate being one of the yet unsolved problems of embryology), but the yelk becomes circumferentially indented, as if an invisible knife had been drawn round it, and thus appears divided into two hemispheres (Fig. 12, C).

By the repetition of this process in various planes, these hemispheres become subdivided, so that four segments are produced (D); and these, in like manner, divide and subdivide again, until the whole yelk is converted into a mass of granules, each of which consists of a minute spheroid of yelk-substance, inclosing a central particle, the so-called 'nucleus' (F). Nature, by this process, has attained much the same result as that at which a human artificer arrives by his operations in a brickfield. She takes the rough plastic material of the yelk and breaks it up into well-shaped, tolerably even-sized masses, handy for building up into any part of the living edifice.

Next, the mass of organic bricks, or 'cells' as they are technically called, thus formed, acquires an orderly arrangement, becoming converted into a hollow spheroid with double walls. Then, upon one side of this spheroid, appears a thickening, and, by and bye, in the centre of the area of thickening, a straight shallow groove (Fig. 13, A) marks the central line of the edifice which is to be raised, or, in other words, indicates the position of the middle line of the body of the future dog. The substance bounding the groove on each side next rises up into a fold, the rudiment of the side wall of that long cavity, which will eventually lodge the spinal marrow and the brain; and in the floor 
of this chamber appears a solid cellular cord, the so-called ' notochord.' One end of the inclosed cavity dilates to form the head (Fig. 13, B), the other remains narrow, and eventually becomes the tail ; the side walls of the body are fashioned out of the downward continuation of the walls of the groove; and from them, by and bye, grow out little buds which, by degrees, assume the shape of limbs. Watching the fashioning process stage by stage, one is forcibly reminded of the modeller in clay. Every part, every organ, is at first, as it were, pinched up rudely, and
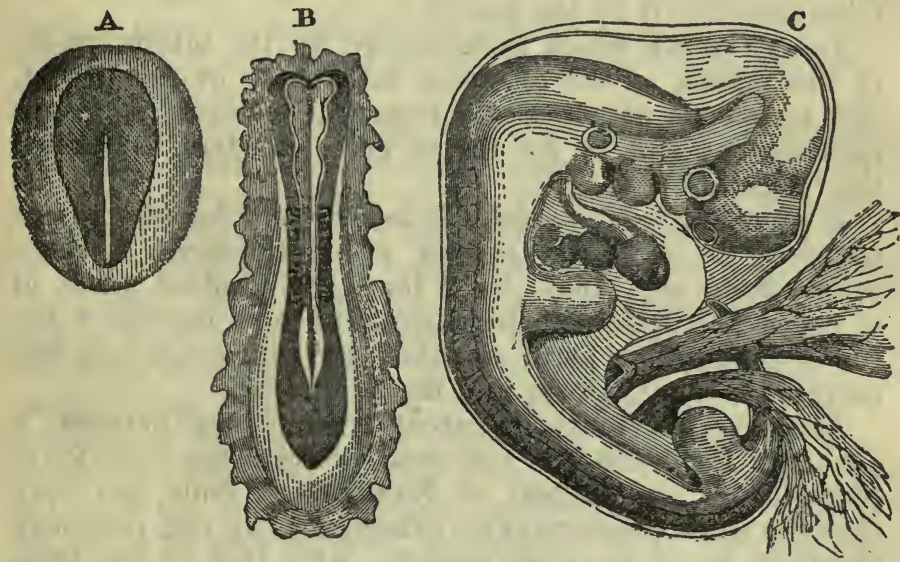

Fig. 13.-A. Earliest rudiment of the Dog. B. Rudiment further advanced, showing the foundations of the head, tail, and vertebral column. C. The very young puppy, with attached ends of the yelk-sac and allantois, and invested in the amnion.

sketched out in the rough ; then shaped more accurately; and only, at last, receives the touches which stamp its final character.

Thus, at length, the young puppy assumes such a form as is shown in Fig. 13, C. In this condition it has a disproportionately large head, as dissimilar to that of a dog as the bud-like limbs are unlike his legs.

The remains of the yelk, which have not yet been applied to the nutrition and growth of the young animal, are contained in a sac attached to the rudimentary intestine, and termed the yelk-sac, or ' umbilical vesicle.' Two membranous bags, intended to subserve respectively the 
protection and nutrition of the young creature, have been developed from the skin and from the under and hinder surface of the body; the former, the so-called 'amnion,' is a sac filled with fluid, which invests the whole body of the embryo, and plays the part of a sort of waterbed for it ; the other, termed the 'allantois,' grows out, loaded with blood-vessels, from the ventral region, and eventually applying itself to the walls of the cavity, in which the developing organism is contained, enables these vessels to become the channel by which the stream of nutriment, required to supply the wants of the offspring, is furnished to it by the parent.

The structure which is developed by the interlacement of the vessels of the offspring with those of the parent, and by means of which the former is enabled to receive nourishment and to get rid of effete matters, is termed the 'Placenta.'

It would be tedious, and it is unnecessary for my present purpose, to trace the process of development further; suffice it to say, that, by a long and gradual series of changes, the rudiment here depicted and described becomes a puppy, is born, and then, by still slower and less perceptible steps, passes into the adult Dog.

There is not much apparent resemblance between a barndoor Fowl and the Dog who protects the farm-yard. Nevertheless the student of development finds, not only that the chick commences its existence as an egg, primarily identical, in all essential respects, with that of the Dog, but that the yelk of this egg undergoes division-that the primitive groove arises, and that the contiguous parts of the germ are fashioned, by precisely similar methods, into a young chick, which, at one stage of its existence, is so like the nascent Dog, that ordinary inspection would hardly distinguish the two.

The history of the development of any other vertebrate animal, Lizard, Snake, Frog, or Fish, tells the same story. There is always, to begin with, an egg having the same essential structure as that of the Dog:-the yelk of that egg always undergoes division, or 'segmentation' as it is often called: the ultimate products of that segmentation constitute the building materials for the body of the young animal; and this is built up round a primitive groove, in the floor of which a notochord is developed. 
Furthermore, there is a period in which the young of all these animals resemble one another, not merely in outward form, but in all essentials of structure, so closely, that the differences between them are inconsiderable, while, in their subsequent course, they diverge more and more widely from one another. And it is a general law, that, the more closely any animals resemble one another in adult structure, the longer and the more intimately do their embryos resemble one another : so that, for example, the embryos of a Snake and of a Lizard remain like one another longer than do those of a Snake and of a Bird; and the embryo of a Dog and of a Cat remain like one another for a far longer period than do those of a Dog and a Bird ; or of a Dog and an Opossum ; or even than those of a Dog and a Monkey.

Thus the study of development affords a clear test of closeness of structural affinity, and one turns with impatience to inquire what results are yielded by the study of the development of Man. Is he something apart? Does he originate in a totally different way from Dog, Bird, Frog, and Fish, thus justifying those who assert him to have no place in nature and no real affinity with the lower world of animal life ? Or does he originate in a similar germ, pass through the same slow and gradually progressive modifications,- depend on the same contrivances for protection and nutrition, and finally enter the world by the help of the same mechanism ? The reply is not doubtful for a moment, and has not been doubtful any time these thirty years. Without question, the mode of origin and the early stages of the development of man are identical with those of the animals immediately below him in the scale :-without a doubt, in these respects, he is far nearer the Apes, than the Apes are to the Dog.

The Human ovum is about $\frac{1}{125}$ of an inch in diameter, and might be described in the same terms as that of the Dog, so that I need only refer to the figure illustrative (14 A) of its structure. It leaves the organ in which it is formed in a similar fashion and enters the organic chamber prepared for its reception in the same way, the conditions of its development being in all respects the same. It has not yet been possible (and only by some rare chance can it ever be possible) to study the human ovum in so early a developmental stage as that of yelk division, but there is every reason to conclude that the 
changes it undergoes are identical with those exhibited by the ova of other vertebrated animals ; for the formative materials of which the rudimentary human body is composed, in the earliest conditions in which it has been observed, are the same as those of other animals. Some of these earliest stages are figured below, and, as will be seen, they are strictly comparable to the very early states of the Dog; the marvellous correspondence between the two which is kept up, even for some time, as development advances, becoming apparent by the simple comparison of the figures with those on page 249 .

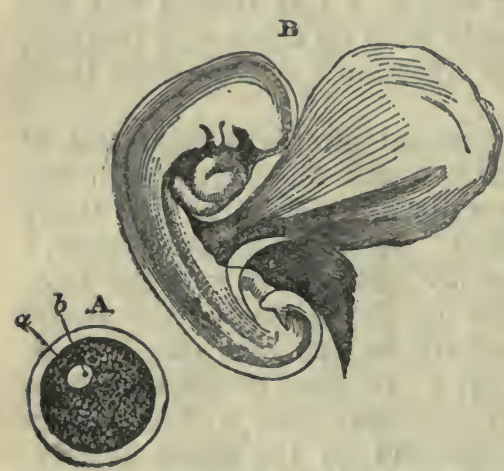

Fig. 14.-A. Human ovum (after Kolliker). b. germinal spot.

B. A very early condition of Man, with yelk-sac, allantois, and amnion (original).

C. A more advanced stage (after Kölliker), compare fig. 13, C.

Indeed, it is very long before the body of the young human being can be readily discriminated from that of the young puppy; but, at a tolerably early period, the two become distinguishable by the different form of their adjuncts, the yelk-sac and the allantois. The former, in the Dog, becomes long and spindle-shaped, while in Man it remains spherical; the latter, in the Dog, attains an extremely large size, and the vascular processes which are developed from it and eventually give rise to the formation of the placenta (taking root, as it were, in the parental organism, so as to draw nourishment therefrom, as the root of a tree extracts it from the soil) are arranged in an encircling zone, while in Man, the allantois remains comparatively small, and its vascular rootlets are eventually 
restricted to one disk-like spot. Hence, while the placenta of the Dog is like a girdle, that of Man has the cake-like form, indicated by the name of the organ.

But, exactly in those respects in which the developing Man differs from the Dog, he resembles the ape, which, like man, has a spheroidal yelk-sac and a discoidalsometimes partially lobed-placenta.

So that it is only quite in the later stages of development that the young human being presents marked differences from the young ape, while the latter departs as much from the dog in its development, as the man does.

Startling as the last assertion may appear to be, it is demonstrably true, and it alone appears to me sufficient to place beyond all doubt the structural unity of man with the rest of the animal world; and more particularly and closely with the apes.

Thus, identical in the physical processes by which he originates-identical in the early stages of his formation -identical in the mode of his nutrition before and after birth, with the animals which lie immediately below him in the scale-Man, if his adult and perfect structure be compared with theirs, exhibits, as might be expected, a marvellous likeness of organization. He resembles them as they resemble one another-he differs from them as they differ from one another.-And, though these differences and resemblances cannot be weighed and measured, their value may be readily estimated ; the scale or standard of judgment, touching that value, being afforded and expressed by the system of classification of animals now current among zoologists.

A careful study of the resemblances and differences presented by animals has, in fact, led naturalists to arrange them into groups, or assemblages, all the members of each group presenting a certain amount of definable resemblance, and the number of points of similarity being smaller as the group is larger and vice versâ. Thus, all creatures which agree only in presenting the few distinctive marks of animality form the 'Kingdom' Animalia. The numerous animals which agree only in possessing the special characters of Vertebrates form one 'Sub-kingdom' of this Kingdom. Then the Sub-kingdom Vertebrata is subdivided into the five 'Classes,' Fishes, Amphibians, Reptiles, 
Birds, and Mammals, and these into smaller groups called 'Orders'; these into 'Families' and 'Genera'; while the last are finally broken up into the smallest assemblages, which are distinguished by the possession of constant, notsexual, characters. These ultimate groups are Species.

Every year tends to bring about a greater uniformity of opinion throughout the zoological world as to the limits and characters of these groups, great and small. At present, for example, no one has the least doubt regarding the characters of the classes Mammalia, Aves, or Reptilia; nor does the question arise whether any thoroughly wellknown animal should be placed in one class or the other. Again, there is a very general agreement respecting the characters and limits of the orders of Mammals, and as to the animals which are structurally necessitated to take a place in one or another order.

No one doubts, for example, that the Sloth and the Ant-eater, the Kangaroo and the Opossum, the Tiger and the Badger, the Tapir and the Rhinoceros, are respectively members of the same orders. These successive pairs of animals may, and some do, differ from one another immensely, in such matters as the proportions and structure of their limbs; the number of their dorsal and lumbar vertebræ; the adaptation of their frames to climbing, leaping, or running; the number and form of their teeth; and the characters of their skulls and of the contained brain. But, with all these differences, they are so closely connected in all the more important and fundamental characters of their organization, and so distinctly separated by these same characters from other animals, that zoologists find it necessary to group them together as members of one order. And if any new animal were discovered, and were found to present no greater difference from the Kangaroo and the Opossum, for example, than these animals do from one another, the zoologist would not only be logically compelled to rank it in the same order with these, but he would not think of doing otherwise.

Bearing this obvious course of zoological reasoning in mind, let us endeavour for a moment to disconnect our thinking selves from the mask of humanity; let us imagine ourselves scientific Saturnians, if you will, fairly acquainted with such animals as now inhabit the Earth, and employed in discussing the relations they bear to a new and singular 'erect and featherless biped,' which some 
enterprising traveller, overcoming the difficulties of space and gravitation, has brought from that distant planet for our inspection, well preserved, may be, in a cask of rum. We should all, at once, agree upon placing him among the mammalian vertebrates; and his lower jaw, his molars, and his brain, would leave no room for doubting the systematic position of the new genus among those mammals, whose young are nourished during gestation by means of a placenta, or what are called the 'placental mammals.'

Further, the most superficial study would at once convince us that, among the orders of placental mammals, neither the Whales nor the hoofed creatures, nor the Sloths and Ant-eaters, nor the carnivorous Cats, Dogs, and Bears, still less the Rodent Rats and Rabbits, or the Insectivorous Moles and Hedgehogs, or the Bats, could claim our 'Homo' as one of themselves.

There would remain then, but one order for comparison, that of the Apes (using that word in its broadest sense), and the question for discussion would narrow itself to this-is Man so different from any of these Apes that he must form an order by himself? Or does he differ less from them than they differ from one another, and hence must take his place in the same order with them ?

Being happily free from all real, or imaginary, personal interest in the results of the inquiry thus set afoot, we should proceed to weigh the arguments on one side and on the other, with as much judicial calmness as if the question related to a new Opossum. We should endeavour to ascertain, without seeking either to magnify or diminish them, all the characters by which our new Mammal differed from the Apes ; and if we found that these were of less structural value, than those which distinguish certain members of the Ape order from others universally admitted to be of the same order, we should undoubtedly place the newly discovered tellurian genus with them.

I now proceed to detail the facts which seem to me to leave us no choice but to adopt the last mentioned course.

It is quite certain that the Ape which most nearly approaches man, in the totality of its organization, is either the Chimpanzee or the Gorilla; and as it makes no practical difference, for the purposes of my present argument, which is selected for comparison, on the one 
hand, with Man, and on the other hand, with the rest of the Primates,* I shall select the latter (so far as its organization is known)-as a brute now so celebrated in prose and verse, that all must have heard of him, and have formed some conception of his appearance. I shall take up as many of the most important points of difference between man and this remarkable creature, as the space at my disposal will allow me to discuss, and the necessities of the argument demand; and I shall inquire into the value and magnitude of these differences, when placed side by side with those which separate the Gorilla from other animals of the same order.

In the general proportions of the body and limbs there is a remarkable difference between the Gorilla and Man, which at once strikes the eye. The Gorilla's brain-case is smaller, its trunk larger, its lower limbs shorter, its upper limbs longer in proportion than those of Man.

I find that the vertebral column of a full-grown Gorilla, in the Museum of the Royal College of Surgeons, measures 27 inches along its anterior curvature, from the upper edge of the atlas, or first vertebra of the neck, to the lower extremity of the sacrum; that the arm, without the hand, is $31 \frac{1}{2}$ inches long; that the leg, without the foot, is $26 \frac{1}{2}$ inches long; that the hand is $9 \frac{3}{4}$ inches long; the foot $11 \frac{1}{4}$ inches long.

In other words, taking the length of the spinal column as 100 , the arm equals 115 , the leg 96 , the hand 36 , and the foot 41 .

In the skeleton of a male Bosjesman, in the same collection, the proportions, by the same measurement, to the spinal column, taken as 100 , are - the arm 78 , the leg 110 , the hand 26, and the foot 32 . In a woman of the same race the arm is 83 , and the leg 120 , the hand and foot remaining the same. In a European skeleton I find the arm to be 80 , the leg 117 , the hand 26 , the foot 35 .

Thus the leg is not so different as it looks at first sight, in its proportions to the spine in the Gorilla and in the Man-being very slightly shorter than the spine in the former, and between $\frac{1}{10}$ and $\frac{1}{6}$ longer than the spine in the latter. The foot is longer and the hand much longer in the Gorilla; but the great difference is caused by the

- We are not at present thoroughly acquainted with the brain of the Gorilla, and therefore, in discussing cerebral characters, I shall take that of the Chimpanzee as my highest term among the Apes. 
arms, which are very much longer than the spine in the Gorilla, very much shorter than the spine in the Man.

The question now arises how are the other Apes related to the Gorilla in these respects-taking the length of the spine, measured in the same way, at 100 . In an adult Chimpanzee, the arm is only 96 , the leg 90 , the hand 43 . the foot 39-so that the hand and the leg depart more from the human proportion and the arm less, while the foot is about the same as in the Gorilla.

In the Orang, the arms are very much longer than in the Gorilla (122), while the legs are shorter (88); the foot is longer than the hand (52 and 48), and both are much longer in proportion to the spine.

In the other man-like Apes again, the Gibbons, these proportions are still further altered; the length of the arms being to that of the spinal column as 19 to 11 ; while the legs are also a third longer than the spinal column, so as to be longer than in Man, instead of shorter. The hand is half as long as the spinal column, and the foot, shorter than the hand, is about $\frac{5}{11}$ ths of the length of the spinal column.

Thus Hylobates is as much longer in the arms than the Gorilla, as the Gorilla is longer in the arms than Man; while, on the other hand, it is as much longer in the legs than the Man, as the Man is longer in the legs than the Gorilla, so that it contains within itself the extremest deviations from the average length of both pairs of limbs (see the illustration on page 196).

The Mandrill presents a middle condition, the arms and legs being nearly equal in length, and both being shorter than the spinal column; while hand and foot have nearly the same proportions to one another and to the spine, as in Man.

In the Spider monkey (Ateles) the leg is longer than the spine, and the arm than the leg; and, finally, in that remarkable Lemurine form, the Indri (Lichanotus), the leg is about as long as the spinal column, while the arm is not more than $1 \frac{1}{8}$ of its length; the hand having rather less and the foot rather more, than one-third the length of the spinal column.

These examples might be greatly multiplied, but they suffice to show that, in whatever proportion of its limbs the Gorilla differs from Man, the other Apes depart still more widely from the Gorilla, and that, consequently, 
such differences of proportion can have no ordinal value.

We may next consider the differences presented by the trunk, consisting of the vertebral column, or backbone, and the ribs and pelvis, or bony hip-basin, which are connected with it, in Man and in the Gorilla respectively.

In Man, in consequence partly of the disposition of the articular surfaces of the vertebræ, and largely of the elastic tension of some of the fibrous bands, or ligaments, which connect these vertebræ together, the spinal column, as a whole, has an elegant S-like curvature, being convex forwards in the neck, concave in the back, convex in the loins, or lumbar region, and concave again in the sacral region; an arrangement which gives much elasticity to the whole backbone, and diminishes the jar communicated to the spine, and through it to the head, by locomotion in the erect position.

Furthermore, under ordinary circumstances, Man has seven vertebræ in his neck, which are called cervical; twelve succeed these, bearing ribs and forming the upper part of the back, whence they are termed dorsal; five lie in the loins, bearing no distinct, or free, ribs, and are called lumbar; five, united together into a great bone, excavated in front, solidly wedged in between the hip bones, to form the back of the pelvis, and known by the name of the sacrum, succeed these; and finally, three or four little more or less moveable bones, so small as to be insignificant, constitute the $\operatorname{coccy} x$ or rudimentary tail.

In the Gorilla, the vertebral column is similarly divided into cervical, dorsal, lumbar, sacral and coccygeal vertebræ, and the total number of cervical and dorsal vertebræ, taken together, is the same as in Man; but the development of a pair of ribs to the first lumbar vertebra, which is an exceptional occurrence in Man, is the rule in the Gorilla; and hence, as lumbar are distinguished from dorsal vertebræ only by the presence or absence of free ribs, the seventeen "dorso-lumbar" vertebræ of the Gorilla are divided into thirteen dorsal and four lumbar, while in Man they are twelve dorsal and five lumbar.

Not only, however, does Man occasionally possess 
thirteen pair of ribs,* but the Gorilla sometimes has fourteen pairs, while an Orang-Utan skeleton in the Museum
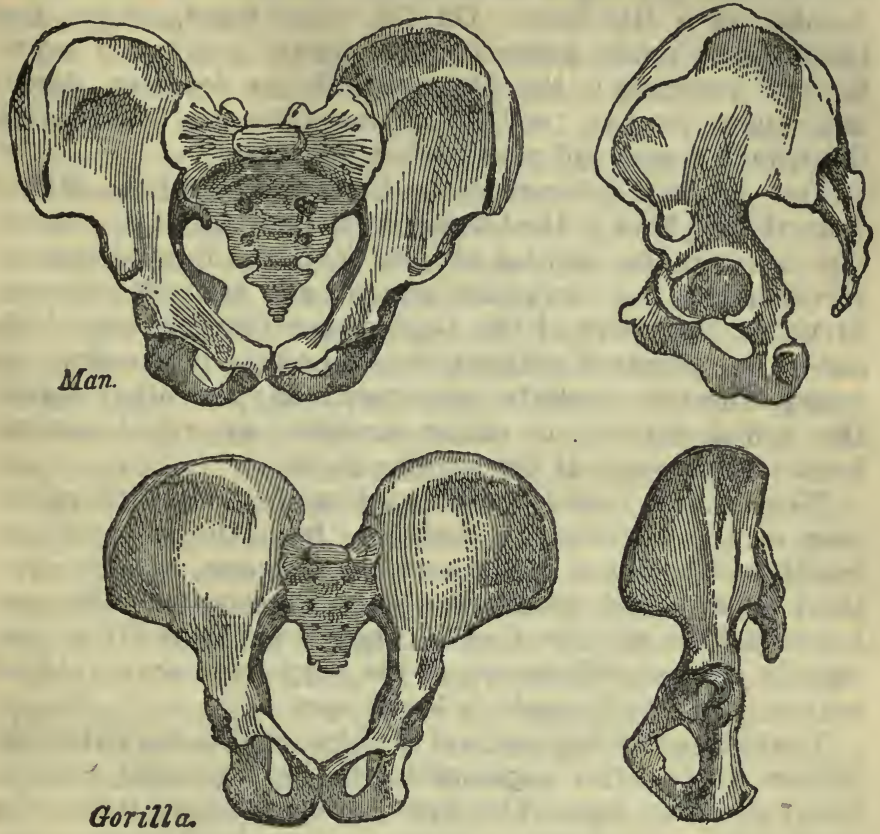

Gibbor
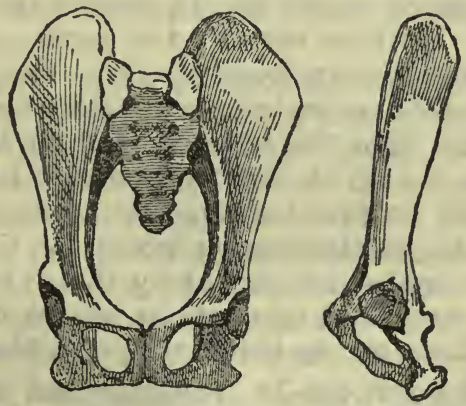

Frg. 15.-Front and side views of the bony pelvis of Man, the Gorilla and Gibbon: reduced from drawings made from nature, of the same absolute length, by Mr. Waterhouse Hawkins.

* "More than once," says Peter Camper, " have I met with more than six lumbar vertebræ in man.... Once I found thirteen 
of the Royal College of Surgeons has twelve dorsal and five lumbar vertebræ, as in Man. Cuvier notes the same number in a Hylobates. On the other hand, among the lower Apes, many possess twelve dorsal and six or seven lumbar vertebræ; the Douroucouli has fourteen dorsal and eight lumbar, and a Lemur (Stenops tardigradus) has fifteen dorsal and nine lumbar vertebræ.

The vertebral column of the Gorilla, as a whole, differs from that of Man in the less marked character of its curves, especially in the slighter convexity of the lumbar region. Nevertheless, the curves are present, and are quite obvious in young skeletons of the Gorilla and Chimpanzee which have been prepared without removal of the ligaments. In young Orangs similarly preserved, on the other hand, the spinal column is either straight, or even concave forwards, throughout the lumbar region.

Whether we take these characters then, or such minor ones as those which are derivable from the proportional length of the spines of the cervical vertebræ, and the like, there is no doubt whatsoever as to the marked difference between Man and the Gorilla; but there is as little, that equally marked differences, of the very same order, obtain between the Gorilla and the lower apes.

The Pelvis, or bony girdle of the hips, of Man is a strikingly human part of his organization; the expanded haunch bones affording support for his viscera during his habitually erect posture, and giving space for the attachment of the great muscles which enable him to assume and to preserve that attitude. In these respects the pelvis of the Gorilla differs very considerably from his (Fig. 15). But go no lower than the Gibbon, and see how vastly more he differs from the Gorilla than the latter does from Man, even in this structure. Look at the flat, narrow haunch bones -the long and narrow passage-the coarse, outwardly curved, ischiatic prominences on which the Gibbon habitually rests, and which are coated by the so-called "callosities," dense patches of skin, wholly absent in the Gorilla, in the Chimpanzee, and in the Orang, as in Man!

ribs and four lumbar vertebra." Fallopius noted thirteen pair of ribs and only four lumbar vertebræ; and Eustachius once found eleven dorsal vertebræ and six lumbar vertebræ.-QEuvres de Pierre Camper, T. 1, p. 42. As Tyson states, his 'Pygmie' had thirteen pair of ribs and five lumbar vertebræ. The question of the curves of the spinal column in the Apes requires further investigation. 
In the lower Monkeys and in the Lemurs the difference becomes more striking still, the pelvis acquiring an altogether quadrupedal character.

But now let us turn to a nobler and more characteristic organ - that by which the human frame seems to be, and indeed is, so strongly distinguished from all others,I mean the skull. The differences between a Gorilla's skull and a Man's are truly immense (Fig. 16). In the former, the face, formed largely by the massive jaw-bones, predominates over the brain case, or cranium proper: in the latter, the proportions of the two are reversed. In the Man, the occipital foramen, through which passes the great nervous cord connecting the brain with the nerves of the body, is placed just behind the centre of the base of the skull, which thus becomes evenly balanced in the erect posture ; in the Gorilla, it lies in the posterior third of that base. In the Man, the surface of the skull is comparatively smooth, and the supraciliary ridges or brow prominences usually project but little-while, in the Gorilla, vast crests are developed upon the skull, and the brow ridges overhang the cavernous orbits, like great penthouses.

Sections of the skulls, however, show that some of the apparent defects of the Gorilla's cranium arise, in fact, not so much from deficiency of brain case as from excessive development of the parts of the face. The cranial cavity is not ill-shaped, and the forehead is not truly flattened or very retreating, its really well-formed curve being simply disguised by the mass of bone which is built up against it (Fig. 16).

But the roofs of the orbits rise more obliquely into the cranial cavity, thus diminishing the space for the lower part of the anterior lobes of the brain, and the absolute capacity of the cranium is far less than that of Man. So far as I am aware, no human cranium belonging to an adult man has yet been observed with a less cubical capacity than 62 cubic inches, the smallest cranium observed in any race of men by Morton, measuring 63 cubic inches; while, on the other hand, the most capacious Gorilla skull yet measured has a content of not more than $34 \frac{1}{2}$ cubic inches. Let us assume, for simplicity's sake, that the lowest Man's skull has twice the capacity of that of the highest Gorilla.* 
No doubt, this is a very striking difference, but it loses much of its apparent systematic value, when viewed by the light of certain other equally indubitable facts respecting cranial capacities.

The first of these is, that the difference in the volume of the cranial cavity of different races of mankind is far greater, absolutely, than that between the lowest Man and the highest Ape, while, relatively, it is about the same. For the largest human skull measured by Morton contained 114 cubic inches, that is to say, had very nearly double the capacity of the smallest; while its absolute preponderance, of 52 cubic inches-is far greater than that by which the lowest adult male human cranium surpasses the largest of the Gorillas $\left(62-34 \frac{1}{2}=27 \frac{1}{2}\right)$. Secondly, the adult crania of Gorillas which have as yet been measured differ among themselves by nearly one-third, the maximum capacity being 34.5 cubic inches, the minimum 24 cubic inches; and, thirdly, after making all due allowance for difference of size, the cranial capacities of some of the lower Apes fall nearly as much, relatively, below those of the higher Apes as the latter fall below Man.

Thus, even in the important matter of cranial capacity, cubic inches. The minimum capacity which I have assumed above, however, is based upon the valuable tables published by Professor R. Wagner in his "Vorstudien zu einer wissenschaftlichen Morphologie und Physiologie des menschlichen Gehirns." As the result of the careful weighing of more than 900 human brains, Professor Wagner states that one-half weighed between 1200 and 1400 grammes, and that about two-ninths, consisting for the most part of male brains, exceed 1400 grammes. The lightest brain of an adult male, with sound mental faculties, recorded by Wagner, weighed 1020 grammes. As a gramme equals 15.4 grains, and a cubic inch of water contains 252.4 grains, this is equivalent to 62 cubic inches of water; so that as brain is heavier than water, we are perfectly safe against erring on the side of diminution in taking this as the smallest capacity of any adult male human brain. The only adult male brain, weighing as little as 970 grammes, is that of an idiot; but the brain of an adult woman, against the soundness of whose faculties nothing appears, weighed as little as 907 grammes (55.3 cubic inches of water); and Reid gives an adult female brain of still smaller capacity. The heaviest brain (1872 grammes, or about 115 cubic inches) was, however, that of a woman; next to it comes the brain of Cuvier (1861 grammes), then Byron (1807 grammes), and then an insane person (1783 grammes). The lightest adult brain recorded (720 grammes) was that of an idiotic female. The brains of five children, four years old, weighed between 1275 and 992 grammes. So that it may be safely said, that an average European child of four years old has a brain twice as large as that of an adult Gorilla. 
Men differ more widely from one another than they do from the Apes; while the lowest Apes differ as much, in proportion, from the highest, as the latter does from Man. The last proposition is still better illustrated by the study of the modifications which other parts of the cranium undergo in the Simian series.

It is the large proportional size of the facial bones and the great projection of the jaws which confers upon the Gorilla's skull its small facial angle and brutal character.

But if we consider the proportional size of the facial bones to the skull proper only, the little Chrysothrix (Fig. 16) differs very widely from the Gorilla, and in the same way as Man does; while the Baboons (Cynocephalus, Fig. 16) exaggerate the gross proportions of the muzzle of the great Anthropoid, so that its visage looks mild and human by comparison with theirs. The difference between the Gorilla and the Baboon is even greater than it appears at first sight ; for the great facial mass of the former is largely due to a downward development of the jaws ; an essentially human character, superadded upon that almost purely forward, essentially brutal, development of the same parts which characterizes the Baboon, and yet more remarkably distinguishes the Lemur.

Similarly, the occipital foramen of Mycetes (Fig. 16), and still more of the Lemurs, is situated completely in the posterior face of the skull, or as much further back than that of the Gorilla, as that of the Gorilla is further back than that of Man ; while, as if to render patent the futility of the attempt to base any broad classificatory distinction on such a character, the same group of Platyrhine, or American monkeys, to which the Mycetes belongs, contains the Chrysothrix, whose occipital foramen is situated far more forward than in any other ape, and nearly approaches the position it holds in Man.

Again, the Orang's skull is as devoid of excessively developed supraciliary prominences as a Man's, though some varieties exhibit great crests elsewhere (see pp. 231, 232); and in some of the Cebine apes and in the Chrysothrix, the cranium is as smooth and rounded as that of Man himself.

What is true of these leading characteristics of the skull, holds good, as may be imagined, of all minor features; so that for every constant difference between the Gorilla's skull and the Man's, a similar constant difference of the same order (that is to say, consisting in excess or defect of the 


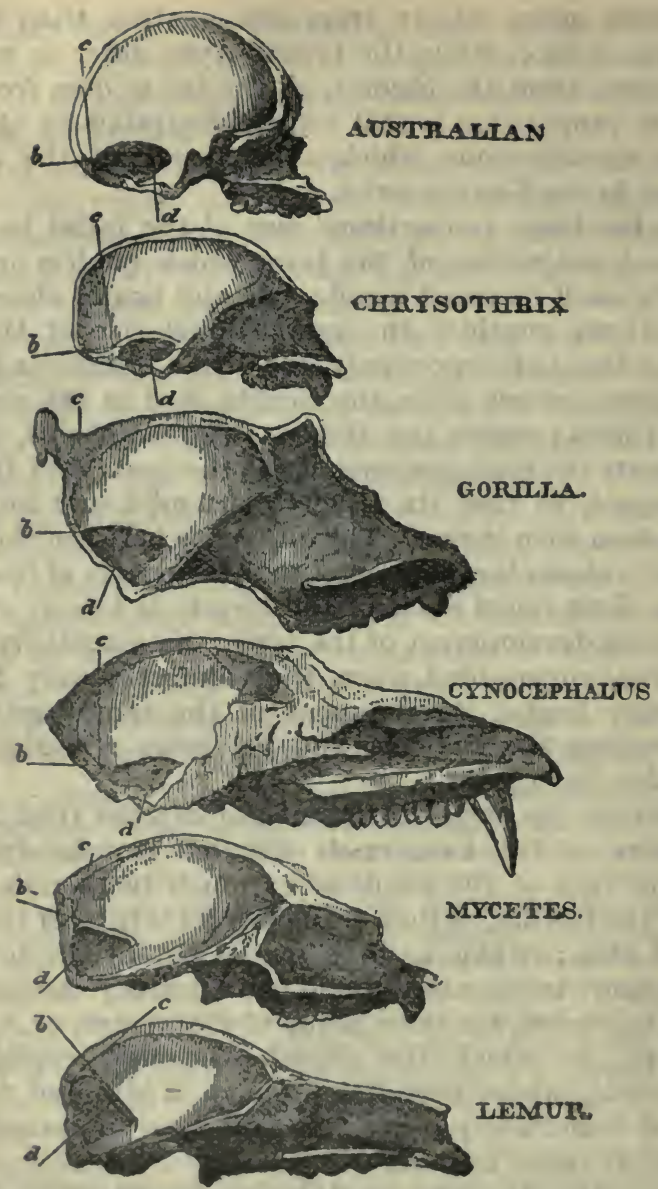

Frg. 16.-Sections of the skulls of Man and various Apes, drawn so as to give the cercbral cavity the same length in each case, thereby displaying the varying proportions of the faclal bones. The line $b$ indicates the plane of the tentorium, which separates the cerebrum from the cerebellum ; $d$, the axis of the occipital outlet of the skull. The extent of cerebral cavity behind $c$, which is a perpendicular erected on $b$ at the point where the tentorium is attached posterioriy, Indicates the degree to which the cerebrum overlaps the cerebellum - the space occupied by which is roughly indicated by the dark shading. In comparing these diagrams, it must be recollected, that figure on so small a scale as these simply exemplify the statements in the text, the proof of which is to be found in the objects themselves. 
same quality) may be found between the Gorilla's skull and that of some other ape. So that, for the skull, no less than for the skeleton in general, the proposition holds good, that the differences between Man and the Gorilla are of smaller value than those between the Gorilla and some other Apes.

In connection with the skull, I may speak of the teeth -organs which have a peculiar classificatory value, and whose resemblances and differences of number, form, and succession, taken as a whole, are usually regarded as more trustworthy indicators of affinity than any others.

Man is provided with two sets of teeth-milk teeth and permanent teeth. The former consist of four incisors, or cutting teeth ; two canines, or eye-teeth ; and four molars, or grinders, in each jaw-making twenty in all. The latter (Fig. 17) comprise four incisors, two canines, four small grinders, called premolars or false molars, and six large grinders, or true molars, in each jaw-making thirtytwo in all. The internal incisors are larger than the external pair, in the upper jaw, smaller than the external pair, in the lower jaw. The crowns of the upper molars exhibit four cusps, or blunt-pointed elevations, and a ridge crosses the crown obliquely, from the inner, anterior, cusp to the outer, posterior cusp (Fig. $17 \mathrm{~m}^{2}$ ). The anterior lower molars have five cusps, three external and two internal. The premolars have two cusps, one internal and one external, of which the outer is the higher.

In all these respects the dentition of the Gorilla may be described in the same terms as that of Man; but in other matters it exhibits many and important differences (Fig. 17).

Thus the teeth of man constitute a regular and even series-without any break and without any marked projection of one tooth above the level of the rest ; a peculiarity which, as Cuvier long ago showed, is shared by no other mammal save one-as different a creature from man as can well be imagined-namely, the long extinct Anoplotherium. The teeth of the Gorilla, on the contrary, exhibit a break, or interval, termed the diastema, in both jaws : in front of the eye-tooth, or between it and the outer incisor, in the upper jaw; behind the eye-tooth, or between it and the front false molar, in the lower jaw. Into this break in the series, in each jaw, fits the canine of the opposite jaw ; 
the size of the eye-tooth in the Gorilla being so great that it projects, like a tusk, far beyond the general level of the other teeth. The roots of the false molar teeth of the Gorilla, again, are more complex than in Man, and the proportional size of the molars is different. The Gorilla has the crown of the hindmost grinder of the lower jaw more complex, and the order of eruption of the permanent teeth is different; the permanent canines making their appearance before the second and third molars in Man, and after them in the Gorilla.

Thus, while the teeth of the Gorilla closely resemble those of Man in number, kind, and in the general pattern of their crowns, they exhibit marked differences from those of Man in secondary respects, such as relative size, number of fangs, and order of appearance.

But, if the teeth of the Gorilla be compared with those of an Ape, no further removed from it than a Cynocephalus, or Baboon, it will be found that differences and resemblances of the same order are easily observable ; but that many of the points in which the Gorilla resembles Man are those in which it differs from the Baboon; while various respects in which it differs from Man are exaggerated in the Cynocephalus. The number and the nature of the teeth remain the same in the Baboon as in the Gorilla and in Man. But the pattern of the Baboon's upper molars is quite different from that described above (Fig. 17), the canines are proportionally longer and more knife-like ; the anterior premolar in the lower jaw is specially modified; the posterior molar of the lower jaw is still larger and more complex than in the Gorilla.

Passing from the old-world Apes to those of the new world, we meet with a change of much greater importance than any of these. In such a genus as Cebus, for example (Fig. 17), it will be found that while in some secondary points, such as the projection of the canines and the diastema, the resemblance to the great ape is preserved ; in other and most important respects, the dentition is extremely different. Instead of 20 teeth in the milk set, there are 24: instead of 32 teeth in the permanent set, there are 36 , the false molars being increased from eight to twelve. And in form, the crowns of the molars are very unlike those of the Gorilla, and differ far more widely from the human pattern.

The Marmosets, on the other hand, exhibit the same 
number of teeth as Man and the Gorilla ; but, notwithstanding this, their dentition is very different, for they have four

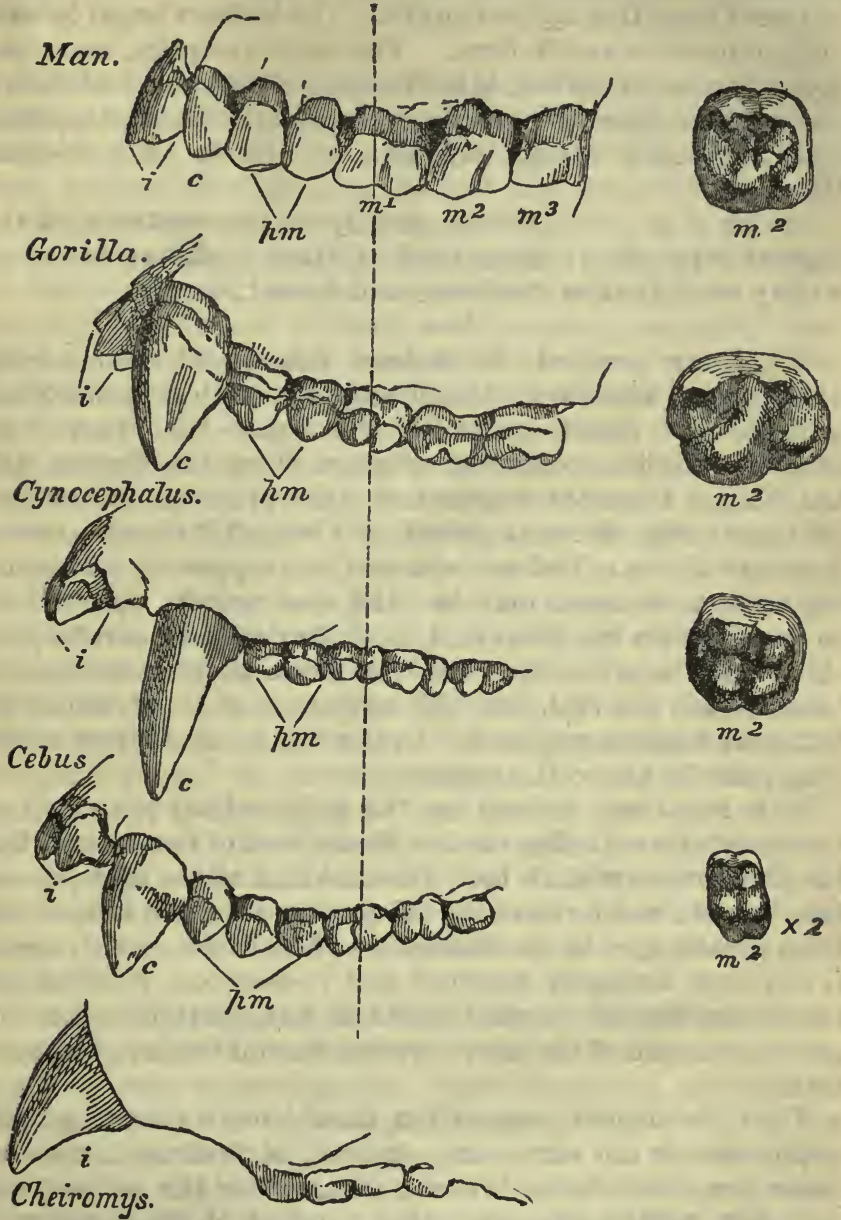

FIG. 17.-Lateral views, of the same length, of the upper jaws of various Primates. $t$, incisors ; $c$, canines ; $p m$, premolars ; $m$, molars. A line is drawn through the first molar of Man, Gorilla, Cynocephalus, and Cebus, and the grinding surface of the second molar is shown in each, its anterior and internal angle being just above the $m$ of $m^{2}$.

more false molars, like the other American monkeys-but as they have four fewer true molars, the total remains the same. 
And passing from the American apes to the Lemurs, the dentition becomes still more completely and essentially different from that of the Gorilla. The incisors begin to vary both in number and in form. The molars acquire, more and more, a many-pointed, insectivorous character, and in one Genus, the Aye-Aye (Cheiromys), the canines disappear, and the teeth completely simulate those of a Rodent (Fig. 17).

Hence it is obvious that, greatly as the dentition of the highest Ape differs from that of Man, it differs far more widely from that of the lower and lowest Apes.

Whatever part of the animal fabric-whatever series of muscles, whatever viscera might be selected for comparison-the result would be the same-the lower Apes and the Gorilla would differ more than the Gorilla and the Man. I cannot attempt in this place to follow out all these comparisons in detail, and indeed it is unnecessary I should do so. But certain real, or supposed, structural distinctions between man and the apes remain, upon which so much stress has been laid, that they require careful consideration, in order that the true value may be assigned to those which are real, and the emptiness of those which are fictitious may be exposed. I refer to the characters of the hand, the foot, and the brain.

Man has been defined as the only animal possessed of two hands terminating his fore limbs, and of two feet ending his hind limbs, while it has been said that all the apes possess four hands; and he has been affirmed to differ fundamentally from all the apes in the characters of his brain, which alone, it has been strangely asserted and re-asserted, exhibits the structures known to anatomists as the posterior lobe, the posterior cornu of the lateral ventricle, and the hippocampus minor.

That the former proposition should have gained general acceptance is not surprising -indeed, at first sight, appearances are much in its favour: but, as for the second, one can only admire the surpassing courage of its enunciator, sceing that it is an innovation which is not only opposed to generally and justly accepted doctrines, but which is directly negatived by the testimony of all original inquirers, who have specially investigated the matter: and that it neither has been, nor can be, supported by a single anatomical preparation. It would, in fact, be unworthy of serious 
refutation, except for the general and natural belief that deliberate and reiterated assertions must have some foundation.

Before we can discuss the first point with advantage we must consider with some attention, and compare together, the structure of the human hand and that of the human foot, so that we may have distinct and clear ideas of what constitutes a hand and what a foot.

The external form of the human hand is familiar enough to every one. It consists of a stout wrist followed by a broad palm, formed of flesh, and tendons, and skin, binding together four bones, and dividing into four long and flexible digits, or fingers, each of which bears on the back of its last joint a broad and flattened nail. The longest cleft between any two digits is rather less than half as long as the hand. From the outer side of the base of the palm a stout digit goes off, having only two joints instead of three; so short, that it only reaches to a little beyond the middle of the first joint of the finger next it; and further remarkable by its great mobility, in consequence of which it can be directed outwards, almost at a right angle to the rest. This digit is called the 'pollex,' or thumb; and, like the others, it bears a flat nail upon the back of its terminal joint. In consequence of the proportions and mobility of the thumb, it is what is termed " opposable" ; in other words, its extremity can, with the greatest ease, be brought into contact with the extremities of any of the fingers; a property upon which the possibility of our carrying into effect the conceptions of the mind so largely depends.

The external form of the foot differs widely from that of the hand; and yet, when closely compared, the two present some singular resemblances. Thus the ankle corresponds in a manner with the wrist; the sole with the palm; the toes with the fingers; the great toe with the thumb. But the toes, or digits of the foot, are far shorter in proportion than the digits of the hand, and are less moveable, the want of mobility being most striking in the great toe-which, again, is very much larger in proportion to the other toes than the thumb to the fingers. In considering this point, however, it must not be forgotten that the civilized great toe, confined and cramped from childhood upwards, is seen to a great disadvantage, and that in uncivilized and 
barefooted people it retains a great amount of mobility, and even some sort of opposability. The Chinese boatmen are said to be able to pull an oar, the artisans of Bengal to weave, and the Carajas to steal fishhooks, by its help; though, after all, it must be recollected that the structure of its joints and the arrangement of its bones, necessarily render its prehensile action far less perfect than that of the thumb.

But to gain a precise conception of the resemblances and differences of the hand and foot, and of the distinctive characters of each, we must look below the skin, and compare the bony framework and its motor apparatus in each (Fig. 18).

The skeleton of the hand exhibits, in the region which we term the wrist, and which is technically called the carpus - two rows of closely fitted polygonal bones, four in each row, which are tolerably equal in size. The bones of the first row with the bones of the forearm form the wrist joint, and are arranged side by side, no one greatly exceeding or overlapping the rest.

The four bones of the second row of the carpus bear the four long bones which support the palm of the hand. The fifth bone of the same character is articulated in a much more free and moveable manner than the others, with its carpal bone, and forms the base of the thumb. These are called metacarpal bones, and they carry the phalanges, or bones of the digits, of which there are two in the thumb, and three in each of the fingers.

The skeleton of the foot is very like that of the hand in some respects. Thus there are three phalanges in each of the lesser toes, and only two in the great toe, which answers to the thumb. There is a long bone, termed metatarsal, answering to the metacarpal, for each digit; and the tarsus, which corresponds with the carpus, presents four short polygonal bones in a row, which correspond very closely with the four carpal bones of the second row of the hand. In other respects the foot differs very widely from the hand. Thus the great toe is the longest digit but one ; and its metatarsal is far less moveably articulated with the tarsus, than the metacarpal of the thumb with the carpus. But a far more important distinction lies in the fact that, instead of four more tarsal bones there are only three; and that these three are not arranged side by side, or in one row. 
One of them, the os calcis or heel bone (ca), lies externally, and sends back the large projecting heel; another, the astragalus (as), rests on this by one face, and by another,

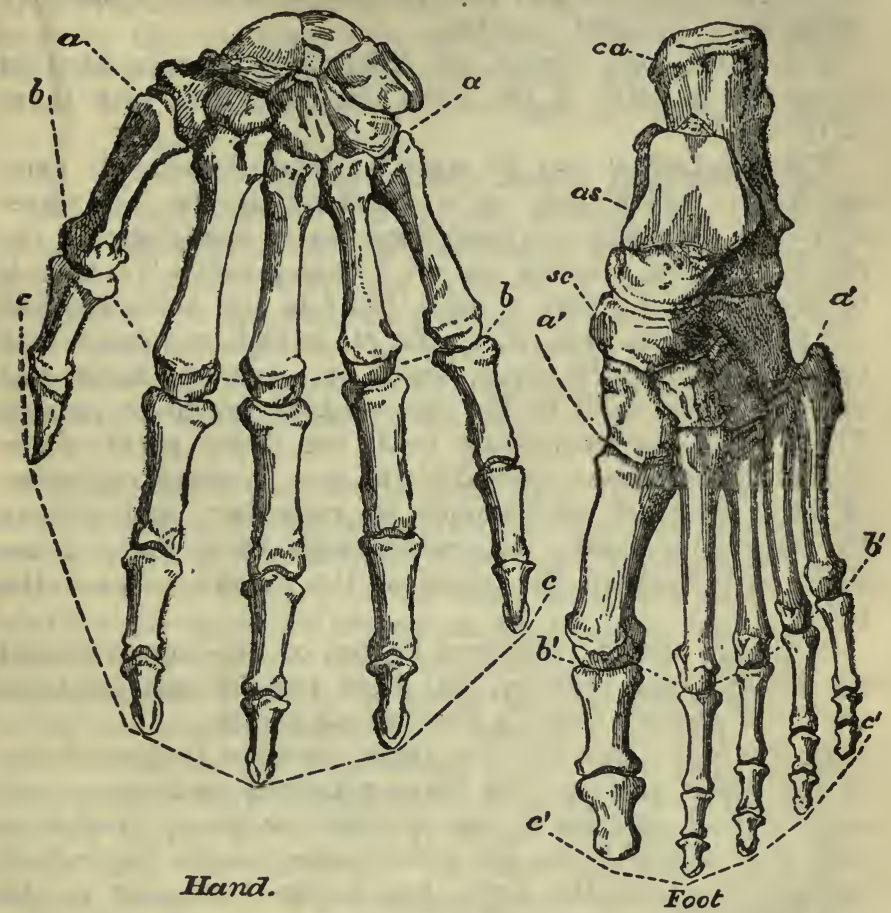

Fig. 18. - The skeleton of the Hand and Foot of Man reduced from Dr. Carter's drawings in Gray's "Anatomy." The hand is drawn to a larger scale than the foot. The line $a, a$ in the hand indicates the boundary between the carpus and the metacarpus ; $b$ b that between the latter and the proximal phalanges; $c c$ marks the ends of the distal phalanges. The line $a^{\prime} a^{\prime}$ in the foot indicates the boundary between the tarsus and metatarsus; $b^{\prime} b^{\prime}$ marks that between the metatarsus and the proximal phalanges; and $c^{\prime} c^{\prime}$ bounds the ends of the distal phalanges; $c a$, the calcaneum ; $a s$, the astragalus ; $s c$, the scaphoid bone in the tarsus.

forms, with the bones of the leg, the ankle joint; while a third face, directed forwards, is separated from the three inner tarsal bones of the row next the metatarsus by a bone called the scaphoid (sc).

Thus there is a fundamental difference in the structure 
of the foot and the hand, observable when the carpus and the tarsus are contrasted; and there are differences of degree noticeable when the proportions and the mobility of the metacarpals and metatarsals, with their respective digits, are compared together.

The same two classes of differences become obvious when the muscles of the hand are compared with those of the foot.

Three principal sets of muscles, called "flexors," bend the fingers and thumb, as in clenching the fist, and three sets - the extensors-extend them, as in straightening the fingers. These muscles are all "long muscles"; that is to say, the fleshy part of each, lying in and being fixed to the bones of the arm, is, at the other end, continued into tendons, or rounded cords, which pass into the hand, and are ultimately fixed to the bones which are to be moved. Thus, when the fingers are bent, the fleshy parts of the flexors of the fingers, placed in the arm, contract, in virtue of their peculiar endowment as muscles; and pulling the tendinous cords, connected with their ends, cause them to pull down the bones of the fingers towards the palm.

Not only are the principal flexors of the fingers and of the thumb long muscles, but they remain quite distinct from one another through their whole length.

In the foot, there are also three principal flexor muscles of the digits or toes, and three principal extensors; but one extensor and one flexor are short muscles; that is to say, their fleshy parts are not situated in the leg (which corresponds with the arm), but in the back and in the sole of the foot-regions which correspond with the back and the palm of the hand.

Again, the tendons of the long flexor of the toes, and of the long flexor of the great toe, when they reach the sole of the foot, do not remain distinct from one another, as the flexors in the palm of the hand do, but they become united and commingled in a very curious manner-while their united tendons receive an accessory muscle connected with the heel-bone.

But perhaps the most absolutely distinctive character about the muscles of the foot is the existence of what is termed the peronæus longus, a long muscle fixed to the outer bone of the leg, and sending its tendon to the outer ankle, behind and below which it passes, and then crosses 
the foot obliquely to be attached to the base of the great toc. No muscle in the hand exactly corresponds with this, which is eminently a foot muscle.

To resume-the foot of man is distinguished from his hand by the following absolute anatomical differences :-

1. By the arrangement of the tarsal bones.

2. By having a short flexor and a short extensor muscle of the digits.

3. By possessing the muscle termed peronæus longus. And if we desire to ascertain whether the terminal division of a limb, in other Primates, is to be called a foot or a hand, it is by the presence or absence of these characters that we must be guided, and not by the mere proportions and greater or lesser mobility of the great toe, which may vary indefinitely without any fundamental alteration in the structure of the foot.

Keeping these considerations in mind, let us now turn to the limbs of the Gorilla. The terminal division of the fore limb presents no difficulty-bone for bone and muscle for muscle, are found to be arranged essentially as in man, or with such minor differences as are found as varieties in man. The Gorilla's hand is clumsier, heavier, and has a thumb somewhat shorter in proportion than that of man; but no one has ever doubted its being a true hand.

At first sight, the termination of the hind limb of the Gorilla looks very hand-like, and as it is still more so in many of the lower apes, it is not wonderful that the appellation "Quadrumana," or four-handed creatures, adopted from the older anatomists * by Blumenbach, and unfortunately rendered current by Cuvier, should have 13:-

*In speaking of the foot of his "Pygmie," Tyson remarks, p.

"But this part in the formation and in its function too, being liker a Hand than a Foot : for the distinguishing this sort of animals from others, I have thought whether it might not be reckoned and called rather Quadru-manus than Quadrupes, i.e. a four-handed rather than a four-footed animal."

As this passage was published in 1699, M. I. G. St. Hilaire is clearly in error in ascribing the invention of the term "quadrumanous" to Buffon, though "bimanous" may belong to him. Tyson uses "Quadrumanus" in several places, as at p. 91. ... "Our Pygmie is no Man, nor yet the common Ape, but a sort of Animal between both; and though a Biped, yet of the Quadrumanus-kind : though some Men too have been observed to use their Feet like Hands, as I have seen several." 
gained such wide acceptance as a name for the Siman group. But the most cursory anatomical investigation at once proves that the resemblance of the so-called "hind hand" to a true hand, is only skin deep, and that, in all essential respects, the hind limb of the Gorilla is as truly terminated by a foot as that of man. The tarsal bones, in all important circumstances of number, disposition, and form, resemble those of man (Fig. 19). The metatarsals and digits, on the other hand, are proportionally longer and more slender, while the great toe is not only proportionally shorter and weaker, but its metatarsal bone is united by a more moveable joint with the tarsus. At the same time, the foot is set more obliquely upon the leg than in man.

As to the muscles, there is a short flexor, a short extensor, and a peronæus longus, while the tendons of the long flexors of the great toe and of the other toes are united together and with an accessory fleshy bundle.

The hind limb of the Gorilla, therefore, ends in a true foot, with a very moveable great toe. It is a prehensile foot, indeed, but is in no sense a hand: it is a foot which differs from that of man not in any fundamental character, but in mere proportions, in the degree of mobility, and in the secondary arrangement of its parts.

It must not be supposed, however, because I speak of these differences as not fundamental, that I wish to underrate their value. They are important enough in their way, the structure of the foot being in strict correlation with that of the rest of the organism in each case. Nor can it be doubted that the greater division of physiological labour in Man, so that the function of support is thrown wholly on the leg and foot, is an advance in organization of very great moment to him ; but, after all, regarded anatomically, the resemblances between the foot of Man and the foot of the Gorilla are far more striking and important than the differences.

I have dwelt upon this point at length, because it is one regarding which much delusion prevails; but I might have passed it over without detriment to my argument, which only requires me to show that, be the differences between the hand and foot of Man and those of the Gorilla what they may-the differences between those of the Gorilla and those of the lower Apes are much greater. 
It is not necessary to descend lower in the scale than the Orang for conclusive evidence on this head.

The thumb of the Orang differs more from that of the Gorilla than the thumb of the Gorilla differs from that of Man, not only by its shortness, but by the absence of any special long flexor muscle. The carpus of the Orang, like that of most lower apes, contains nine bones, while in the Gorilla, as in Man and the Chimpanzee, there are only eight.

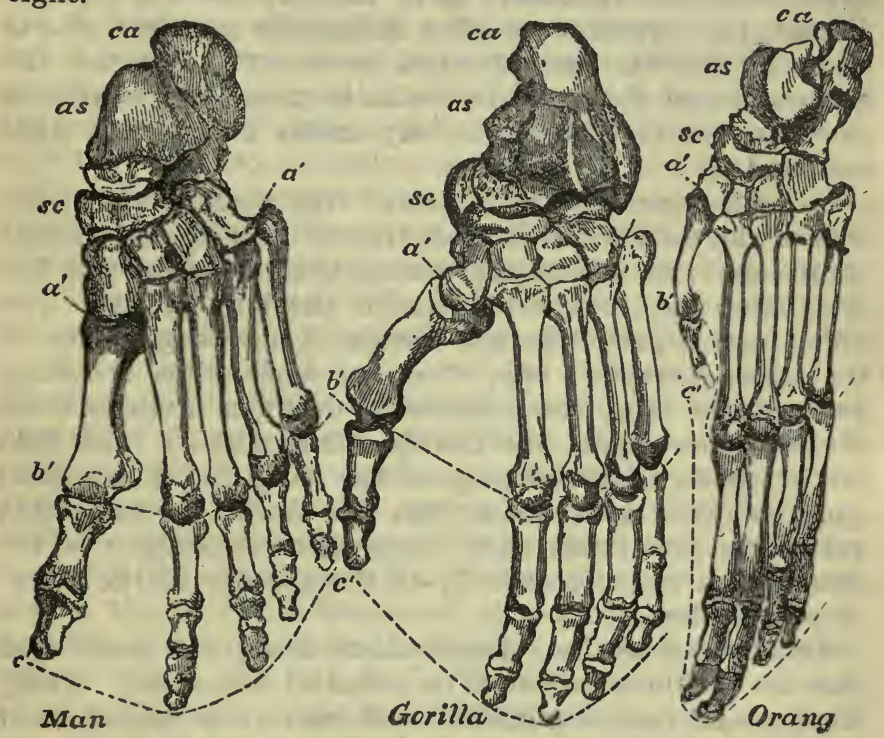

Fig. 19.-Foot of Man, Gorilla, and Orang-Utan of the same absolute length, to show the differences in proportion of each. Letters as in Fig. 18. Reduced from original drawings by Mr. Waterhouse Hawkins.

The Orang's foot (Fig. 19) is still more aberrant; its very long toes and short tarsus, short great toe, short and raised heel, great obliquity of articulation in the leg, and absence of a long flexor tendon to the great toe, separating it far more widely from the foot of the Gorilla than the latter is separated from that of Man.

But, in some of the lower apes, the hand and foot diverge still more from those of the Gorilla, than they do in the Orang. The thumb ceases to be opposable in the American monkeys; is reduced to a mere rudiment covered by the 
skin in the Spider Monkey; and is directed forwards and armed with a curved claw like the other digits, in the Marmosets - so that, in all these cases, there can be no doubt but that the hand is more different from that of the Gorilla than the Gorilla's hand is from Man's.

And as to the foot, the great toe of the Marmoset is still more insignificant in proportion than that of the Orangwhile in the Lemurs it is very large, and as completely thumb-like and opposable as in the Gorilla-but in these animals the second toe is often irregularly modified, and in some species the two principal bones of the tarsus, the astragalus and the os calcis, are so immensely elongated as to render the foot, so far, totally unlike that of any other mammal.

So with regard to the muscles. The short flexor of the toes of the Gorilla differs from that of Man by the circumstance that one slip of the muscle is attached, not to the heel bone, but to the tendons of the long flexors. The lower apes depart from the Gorilla by an exaggeration of the same character, two, three, or more, slips becoming fixed to the long flexor tendons-or by a multiplication of the slips.-Again, the Gorilla differs slightly from Man in the mode of interlacing of the long flexor tendons: and the lower apes differ from the Gorilla in exhibiting yet other, sometimes very complex, arrangements of the same parts, and occasionally in the absence of the accessory fleshy bundle.

Throughout all these modifications it must be recollected that the foot loses no one of its essential characters. Every Monkey and Lemur exhibits the characteristic arrangement of tarsal bones, possesses a short flexor and short extensor muscle, and a peronæus longus. Varied as the proportions and appearance of the organ may be, the terminal division of the hind limb remains, in plan and principle of construction, a foot, and never, in those respects, can be confounded with a hand.

Hardly any part of the bodily frame, then, could be found better calculated to illustrate the truth that the structural differences between Man and the highest Ape are of less value than those between the highest and the lower Apes, than the hand or the foot, and yet, perhaps, there is one organ the study of which enforces the same conclusion in a still more striking manner-and that is the Brain. 
But before entering upon the precise question of the amount of difference between the Ape's brain and that of Man, it is necessary that we should clearly understand what constitutes a great, and what a small difference in cerebral structure; and we shall be best enabled to do this by a brief study of the chief modifications which the brain exhibits in the series of vertebrate animals.

The brain of a fish is very small, compared with the spinal cord into which it is continued, and with the nerves which come off from it: of the segments of which it is composed-the olfactory lobes, the cerebral hemisphere, and the succeeding divisions-no one predominates so much over the rest as to obscure or cover them; and the so-called optic lobes are, frequently, the largest masses of all. In Reptiles, the mass of the brain, relatively to the spinal cord, increases and the cerebral hemispheres begin to predominate over the other parts; while in Birds this predominance is still more marked. The brain of the lowest Mammals, such as the duck-billed Platypus and the Opossums and Kangaroos, exhibits a still more definite advance in the same direction. The cerebral hemispheres have now so much increased in size as, more or less, to hide the representatives of the optic lobes, which remain comparatively small, so that the brain of a Marsupial is extremely different from that of a Bird, Reptile, or Fish. A step higher in the scale, among the placental Mammals, the structure of the brain acquires a vast modification-not that it appears much altered externally, in a Rat or in a Rabbit, from what it is in a Marsupial-nor that the proportions of its parts are much changed, but an apparently new structure is found between the cerebral hemispheres, connecting them together, as what is called the 'great commissure' or ' corpus callosum.' The subject requires careful reinvestigation, but if the currently received statements are correct, the appearance of the 'corpus callosum' in the placental mammals is the greatest and most sudden modification exhibited by the brain in the whole series of vertebrated animals - it is the greatest leap anywhere made by Nature in her brain work. For the two halves of the brain being once thus knit together, the progress of cerebral complexity is traceable through a complete series of steps from the lowest Rodent, or Insectivore, to Man; and that complexity consists, chiefly, in the disproportionate develop- 
ment of the cerebral hemispheres and of the cerebellum, but especially of the former, in respect to the other parts of the brain.

In the lower placental mammals, the cerebral hemispheres leave the proper upper and posterior face of the cerebellum completely visible, when the brain is viewed from above, but, in the higher forms, the hinder part of each hemisphere, separated only by the tentorium (p. 281) from the anterior face of the cerebellum, inclines backwards and downwards, and grows out, as the so-called " posterior lobe," so as at length to overlap and hide the cerebellum. In all Mammals, each cerebral hemisphere contains a cavity which is termed the 'ventricle,' and as this ventricle is prolonged, on the one hand, forwards, and on the other downwards, into the substance of the hemisphere, it is said to have two horns or 'cornua,' an ' anterior cornu,' and a 'descending cornu.' When the posterior lobe is well developed, a third prolongation of the ventricular cavity extends into it, and is called the " posterior cornu."

In the lower and smaller forms of placental Mammals the surface of the cerebral hemispheres is either smooth or evenly rounded, or exhibits a very few grooves, which are technically termed 'sulci,' separating ridges or ' convolutions' of the substance of the brain; and the smaller species of all orders tend to a similar smoothness of brain. But, in the higher orders, and especially the larger members of these orders, the grooves, or sulci, become extremely numerous, and the intermediate convolutions proportionately more complicated in their meanderings, until, in the Elephant, the Porpoise, the higher Apes, and Man, the cerebral surface appears a perfect labyrinth of tortuous foldings.

Where a posterior lobe exists and presents its customary cavity-the posterior cornu-it commonly happens that a particular sulcus appears upon the inner and under surface of the lobe, parellel with and beneath the floor of the cornu-which is, as it were, arched over the roof of the sulcus. It is as if the groove had been formed by indenting the floor of the posterior horn from without with a blunt instrument, so that the floor should rise as a convex eminence. Now this eminence is what has been termed the 'Hippocampus minor'; the 'Hippocampus major' being a larger eminence in the floor of the descending cornu. 

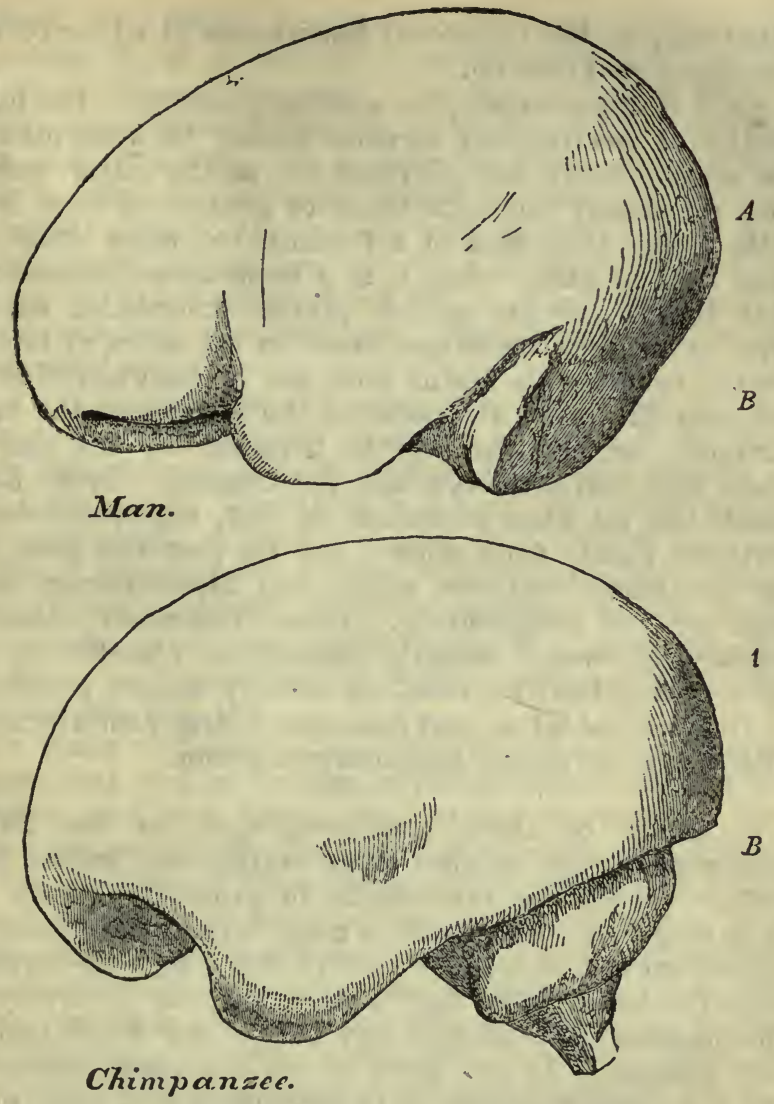

Fig. 20.-Drawings of the internal casts of a Man's and of a Chimpanzee's skull, of the same absolute length, and placed in corresponding positions, A. Cerebrum; $B$. Cerebellum. The former drawing is taken from a cast in the Museum of the Royal College of Surgeons, the latter from the photograph of the cast of a Chimpanzee's skull, which illustrates the paper by Mr. Marshall ' On the Brain of the Chimpanzee' in the Natural History Review for July, 1861. The sharper definition of the lower edge of the cast of the cerebral chamber in the Chimpanzee arises from the circumstance that the tentorium remained in that skull and not in the Man's. The cast more accurately represents the brain in Chimpanzee than in the Man; and the great backward projection of the posterior lobes of the cerebrum of the former, beyond the cerebellum, is conspicuous. 
What may be the functional importance of either of these structures we know not.

As if to demonstrate, by a striking example, the impossibility of erecting any cerebral barrier between man and the apes, Nature has provided us, in the latter animals, with an almost complete series of gradations from brains little higher than that of a Rodent, to brains little lower than that of Man. And it is a remarkable circumstance that though, so far as our present knowledge extends, there is one true structural break in the series of forms of Simian brains, this hiatus does not lie between Man and the man-like apes, but between the lower and the lowest Simians; or, in other words, between the old and new world apes and monkeys, and the Lemurs. Every Lemur which has yet been examined, in fact, has its cerebellum partially visible from above, and its posterior lobe, with the contained posterior cornu and hippocampus minor, more or less rudimentary. Every Marmoset, American monkey, old-world monkey, Baboon, or Man-like ape, on the contrary, has its cerebellum entirely hidden, posteriorly, by the cerebral lobes, and possesses a large posterior cornu, with a well-developed hippocampus minor.

In many of these creatures, such as the Saimiri (Chrysothrix), the cerebral lobes overlap and extend much further behind the cerebellum, in proportion, than they do in man (Fig. 16) -and it is quite certain that, in all, the cerebellum is completely covered behind, by well-developed posterior lobes. The fact can be verified by every one who possesses the skull of any old or new world monkey. For, inasmuch as the brain in all mammals completely fills the cranial cavity, it is obvious that a cast of the interior of the skull will reproduce the general form of the brain, at any rate with such minute and, for the present purpose, utterly unimportant differences as may result from the absence of the enveloping membranes of the brain in the dry skull. But if such a cast be made in plaster, and compared with a similar cast of the interior of a human skull, it will be obvious that the cast of the cerebral chamber, representing the cerebrum of the ape, as completely covers over and overlaps the cast of the cerebellar chamber, representing the cerebellum, as it does in the man (Fig. 20). A careless observer, forgetting that a soft structure like the brain loses its proper shape the moment it is taken out of 
the skull, may indeed mistake the uncovered condition of the cerebellum of an extracted and distorted brain for the natural relations of the parts; but his error must become patent even to himself if he try to replace the brain within the cranial chamber. To suppose that the cerebellum of an ape is naturally uncovered behind is a miscomprehension comparable only to that of one who should imagine that a man's lungs always occupy but a small portion of the thoracic cavity-because they do so when the chest is opened, and their elasticity is no longer neutralized by the pressure of the air.

And the error is the less excusable, as it must become apparent to every one who examines a section of the skull of any ape above a Lemur, without taking the trouble to make a cast of it. For there is a very marked groove in every such skull, as in the human skull-which indicates the line of attachment of what is termed the tentoriuma sort of parchment-like shelf, or partition, which, in the recent state, is interposed between the cerebrum and cerebellum, and prevents the former from pressing upon the latter (see Fig. 16).

This groove, therefore, indicates the line of separation between that part of the cranial cavity which contains the cerebrum, and that which contains the cerebellum; and as the brain exactly fills the cavity of the skull, it is obvious that the relations of these two parts of the cranial cavity at once informs us of the relations of their contents. Now in man, in all the old-world, and in all the new-world Simiæ, with one exception, when the face is directed forwards, this line of attachment of the tentorium, or impression for the lateral sinus, as it is technically called, is nearly horizontal, and the cerebral chamber invariably overlaps or.projects behind the cerebellar chamber. In the Howler Monkey or Mycetes (see Fig. 16), the line passes obliquely upwards and backwards, and the cerebral overlap is almost nil ; while in the Lemurs, as in the lower mammals, the line is much more inclined in the same direction, and the cerebellar chamber projects considerably beyond the cerebral.

When the gravest errors respecting points so easily settled as this question respecting the posterior lobes can be authoritatively propounded, it is no wonder that matters of observation, of no very complex character, but still requiring a certain amount of care, should have fared worse. Any one who cannot see the posterior lobe in an 

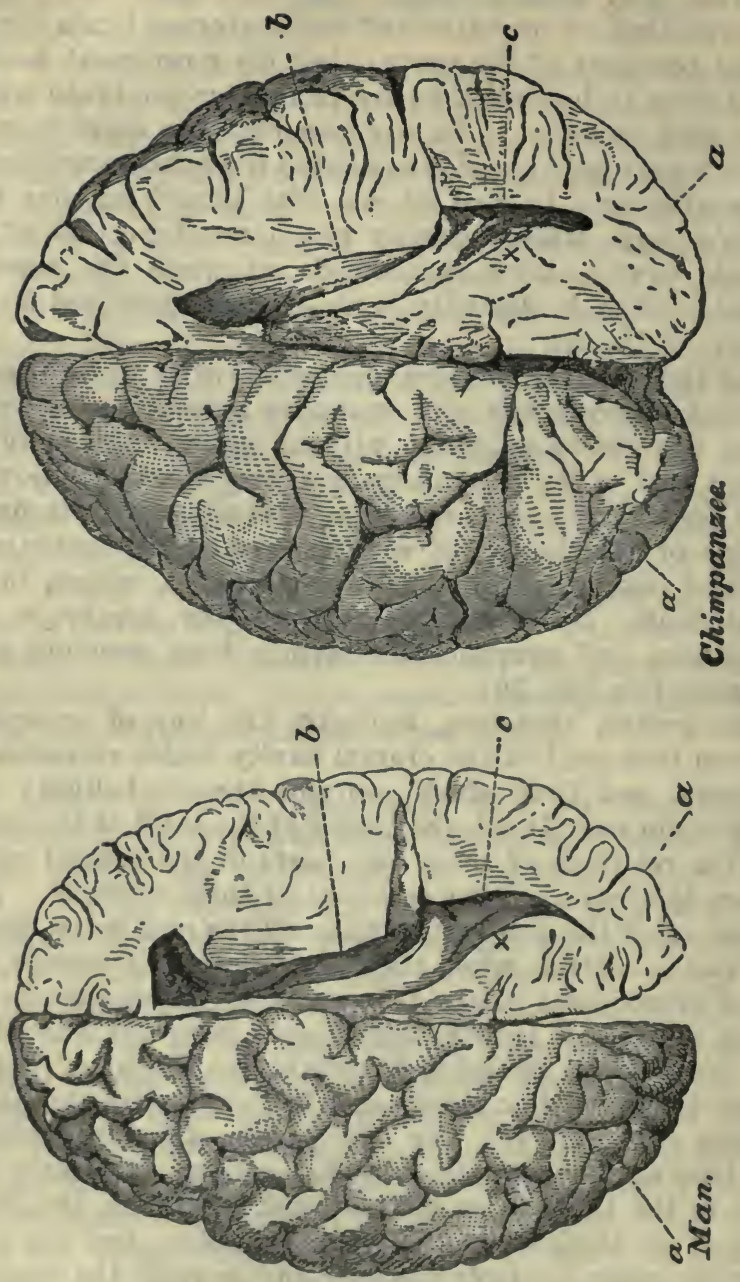

F1G. 21. - Drawings of the cerebral hemispheres of a Man and of a Chimpanzee of the same length, in order to show the relative proportions of the parts: the former taken from a specimen, which Mr. Flower, Conservator of the Museum of the Royal College of Surgeons, was good enough to dissect for me; the latter, from the photograph of a similarly dissected Chimpanzee's brain, given in Mr. Marshall's paper above referred to. $a$, posterior lobe; $b$, lateral ventricle: $c$, posterior cornu; $x$, the hippocampus minor. 
ape's brain is not likely to give a very valuable opinion respecting the posterior cornu or the hippocampus minor. If a man cannot see a church, it is preposterous to take his opinion about its altar-piece or painted window-so that I do not feel bound to enter upon any discussion of these points, but content myself with assuring the reader that the posterior cornu and the hippocampus minor, have now been seen-usually, at least as well developed as in man, and often better-not only in the Chimpanzee, the Orang, and the Gibbon, but in all the genera of the oldworld baboons and monkeys, and in most of the newworld forms, including the Marmosets.*

In fact, all the abundant and trustworthy evidence (consisting of the results of careful investigations directed to the determination of these very questions, by skilled anatomists) which we now possess, leads to the conviction that, so far from the posterior lobe, the posterior cornu, and the hippocampus minor, being structures peculiar to and characteristic of man, as they have been over and over again asserted to be, even after the publication of the clearest demonstration of the reverse, it is precisely these structures which are the most marked cerebral characters common to man with the apes. They are among the most distinctly Simian peculiarities which the human organism exhibits.

As to the convolutions, the brains of the apes exhibit every stage of progress, from the almost smooth brain of the Marmoset, to the Orang and the Chimpanzee, which fall but little below Man. And it is most remarkable that, as soon as all the principal sulci appear, the pattern according to which they are arranged is identical with that of the corresponding sulci of man. The surface of the brain of a monkey exhibits a sort of skeleton map of man's, and in the man-like apes the details become more and more filled in, until it is only in minor characters, such as the greater excavation of the anterior lobes, the constant presence of fissures usually absent in man, and the different disposition and proportions of some convolutions, that the Chimpanzee's or the Orang's brain can be structurally distinguished from Man's.

So far as cerebral structure goes, therefore, it is clear that Man differs less from the Chimpanzee or the Orang,

* See the note at the end of this essay for a succinct history of the controversy to which allusion is here made. 
than these do even from the Monkeys, and that the difference between the brains of the Chimpanzee and of Man is almost insignificant, when compared with that between the Chimpanzee brain and that of a Lemur.

It must not be overlooked, however, that there is a very striking difference in the absolute mass and weight between the lowest human brain and that of the highest ape-a difference which is all the more remarkable when we recollect that a full grown Gorilla is probably pretty nearly twice as heavy as a Bosjes man, or as many an European woman. It may be doubted whether a healthy human adult brain ever weighed less than thirty-one or two ounces, or that the heaviest Gorilla brain has exceeded twenty ounces.

This is a very noteworthy circumstance, and doubtless will one day help to furnish an explanation of the great gulf which intervenes between the lowest man and the highest ape in intellectual power ; ${ }^{*}$ but it has little

- I say help to furnish : for I by no means believe that it was any original difference of cerebral quality, or quantity, which caused that divergence between the human and the pithecoid stirpes, which has ended in the present enormous gulf between them. It is no doubt perfectly true, in a certain sense, that all difference of function is a result of difference of structure; or, in other words, of difference in the combination of the primary molecular forces of living substance ; and, starting from this undeniable axiom, objectors occasionally, and with much seeming plausibility, argue that the vast intellectual chasm between the Ape and Man implies a corresponding structural chasm in the organs of the intellectual functions; so that, it is said, the non-discovery of such vast differences proves, not that they are absent, but that Science is incompetent to detect them. A very little consideration, however, will, I think, show the fallacy of this reasoning. Its validity hangs upon the assumption, that intellectual power depends altogether on the brain-whereas the brain is only one condition out of many on which intellectual manifestations depend; the others being, chiefly, the organs of the senses and the motor apparatuses, especially those which are concerned in prehension and in the production of articulate speech.

A man born dumb, notwithstanding his great cerebral mass and his inheritance of strong intellectual instincts, would be capable of few higher intellectual manifestations than an Orang or a Chimpanzee, if he were confined to the society of dumb associates. And yet there might not be the slightest discernible difference between his brain and that of a highly intelligent and cultivated person. The dumbness might be the result of a defective structure of the mouth, or of the tongue, or a mere defective innervation of these parts; or it might result from congenital deafness, caused by some minute defect of the internal ear, which only a careful anatomist could discover. 
systematic value, for the simple reason that, as may be concluded from what has been already said respecting cranial capacity, the difference in weight of brain between the highest and the lowest men is far greater, both relatively and absolutely, than that between the lowest man and the highest ape. The latter, as has been seen, is represented by, say, twelve ounces of cerebral substance absolutely, or by 32 : 20 relatively; but as the largest recorded human brain weighed between 65 and 66 ounces, the former difference is represented by more than 33 ounces absolutely, or by $65: 32$ relatively. regarded systematically, the cerebral differences of man and apes are not of more than generic value-his Family distinction resting chiefly on his dentition, his pelvis, and his lower limbs.

Thus, whatever system of organs be studied, the comparison of their modifications in the ape series leads to one and the same result-that the structural differences which separate Man from the Gorilla and the Chimpanzee are not so great as those which separate the Gorilla from the lower apes.

But in enunciating this important truth $I$ must guard myself against a form of misunderstanding, which is very prevalent. I find, in fact, that those who endeavour to teach what nature so clearly shows us in this matter, are liable to have their opinions misrepresented and their phraseology garbled, until they seem to say that the structural differences between man and even the highest apes are small and insignificant. Let me take this oppor-

The argument, that because there is an immense difference between a Man's intelligence and an Ape's, therefore there must be an equally immense difference between their brains, appears to me to be about as well based as the reasoning by which one should endeavour to prove that, because there is a "great gulf" between a watch that keeps accurate time and another that will not go at all, there is therefore a great structural hiatus between the two watches. A hair in the balance-wheel, a little rust on a pinion, a bend in a tooth of the escapement, a something so slight that only the practised eye of the watchmaker can discover it, may be the source of all the difference.

And believing, as I do, with Cuvier, that the possession of articulate speech is the grand distinctive character of man (whether it be absolutely peculiar to him or not), I find it very easy to comprehend, that some equally inconspicuous structural difference may have been the primary cause of the immeasurable and practically infinite divergence of the Human from the Simian Stirps. 
tunity then of distinctly asserting, on the contrary, that they are great and significant; that every bone of a Gorilla bears marks by which it might be distinguished from the corresponding bone of a Man; and that, in the present creation, at any rate, no intermediate link bridges over the gap between Homo and Troglodytes.

It would be no less wrong than absurd to deny the existence of this chasm ; but it is at least equally wrong and absurd to exaggerate its magnitude, and, resting on the admitted fact of its existence, to refuse to inquire whether it is wide or narrow. Remember, if you will, that there is no existing link between Man and the Gorilla, but do not forget that there is a no less sharp line of demarcation, a no less complete absence of any transitional form, between the Gorilla and the Orang, or the Orang and the Gibbon. I say, not less sharp, though it is somewhat narrower. The structural differences between Man and the Man-like apes certainly justify our regarding him as constituting a family apart from them; though, inasmuch as he differs less from them than they do from other families of the same order, there can be no justification for placing him in a distinct order.

And thus the sagacious foresight of the great lawgiver of systematic zoology, Linnæus, becomes justified, and a century of anatomical research brings us back to his conclusion, that man is a member of the same order (for which the Linnæan term Primates ought to be retained) as the Apes and Lemurs. This order is now divisible into seven families, of about equal systematic value: the first, the ANThropini, contains Man alone; the second, the Catarinni, embraces the old-world apes; the third, the Platyrini, all new-world apes, except the Marmosets; the fourth, the Arctopituecini, contains the Marmosets; the fifth, the LEMURINI, the Lemurs-from which Cheiromys should probably be excluded to form a sixth distinct family, the CHEIROMYINI ; while the seventh, the Galeoprthecini, contains only the flying Lemur Galeopithecus, - a strange form which almost touches on the Bats, as the Cheiromys puts on a rodent clothing, and the Lemurs simulate Insectivora.

Perhaps no order of mammals presents us with so extraordinary a series of gradations as this-leading us insensibly from the crown and summit of the animal creation down to creatures, from which there is but a step, as it seems, 
to the lowest, smallest, and least intelligent of the placental Mammalia. It is as if nature herself had foreseen the arrogance of man, and with Roman severity had provided that his intellect, by its very triumphs, should call into prominence the slaves, admonishing the conqueror that he is but dust.

These are the chief facts, this the immediate conclusion from them to which $I$ adverted in the commencement of this Essay. The facts, I believe, cannot be disputed; and if so, the conclusion appears to me to be inevitable.

But if Man be separated by no greater structural barrier from the brutes than they are from one another-then it seems to follow that if any process of physical causation can be discovered by which the genera and families of ordinary animals have been produced, that process of causation is amply sufficient to account for the origin of Man. In other words, if it could be shown that the Marmosets, for example, have arisen by gradual modification of the ordinary Platyrhini, or that both Marmosets and Platyrhini are modified ramifications of a primitive stock-then, there would be no rational ground for doubting that man might have originated, in the one case, by the gradual modification of a man-like ape; or, in the other case, as a ramification of the same primitive stock as those apes.

At the present moment, but one such process of physical causation has any evidence in its favour; or, in other words, there is but one hypothesis regarding the origin of species of animals in general which has any scientific existence - that propounded by Mr. Darwin. For Lamarck, sagacious as many of his views were, mingled them with so much that was crude and even absurd, as to neutralize the benefit which his originality might have effected, had he been a more sober and cautious thinker; and though I have heard of the announcement of a formula touching "the ordained continuous becoming of organic forms," it is obvious that it is the first duty of a hypothesis to be intelligible, and that a qua-quâ-versal proposition of this kind, which may be read backwards, or forwards, or sideways, with exactly the same amount of signification, does not really exist, though it may seem to do so.

At the present moment, therefore, the question of the relation of man to the lower animals ressolves itself, in 
the end, into the larger question of the tenability or untenability of Mr. Darwin's views. But here we enter upon difficult ground, and it behoves us to define our exact position with the greatest care.

It cannot be doubted, I think, that Mr. Darwin has satisfactorily proved that what he terms selection, or selective modification, must occur, and does occur, in nature; and he has also proved to superfluity that such selection is competent to produce forms as distinct, structurally, as some genera even are. If the animated world presented us with none but structural differences, I should have no hesitation in saying that Mr. Darwin had demonstrated the existence of a true physical cause, amply competent to account for the origin of living species, and of man among the rest.

But, in addition to their structural distinctions, the species of animals and plants, or at least a great number of them, exhibit physiological characters-what are known as distinct species, structurally, being for the most part either altogether incompetent to breed one with another; or if they breed, the resulting mule, or hybrid, is unable to perpetuate its race with another hybrid of the same kind.

A true physical cause is, however, admitted to be such only on one condition-that it shall account for all the phenomena which come within the range of its operation. If it is inconsistent with any one phenomenon, it must be rejected; if it fails to explain any one phenomenon, it is so far weak, so far to be suspected; though it may have a perfect right to claim provisional acceptance.

Now, Mr. Darwin's hypothesis is not, so far as I am aware, inconsistent with any known biological fact; on the contrary, if admitted, the facts of Development, of Comparative Anatomy, of Geographical Distribution, and of Palæontology, become connected together, and exhibit a meaning such as they never possessed before; and I, for one, am fully convinced, that if not precisely true, that hypothesis is as near an approximation to the truth as, for example, the Copernican hypothesis was to the true theory of the planetary motions.

But, for all this, our acceptance of the Darwinian hypothesis must be provisional so long as one link in the chain of evidence is wanting; and so long as all the animals and plants certainly produced by selective breeding from 
a common stock are fertile, and their progeny are fertile with one another, that link will be wanting. For, so long, selective breeding will not be proved to be competent to do all that is required of it to produce natural species.

I have put this conclusion as strongly as possible before the reader, because the last position in which $I$ wish to find myself is that of an advocate for Mr. Darwin's, or any other views-if by an advocate is meant one whose business it is to smooth over real difficulties, and to persuade where he cannot convince.

In justice to Mr. Darwin, however, it must be admitted that the conditions of fertility and sterility are very ill understood, and that every day's advance in knowledge leads us to regard the hiatus in his evidence as of less and less importance, when set against the multitude of facts which harmonize with, or receive an explanation from, his doctrines.

I adopt Mr. Darwin's hypothesis, therefore, subject to the production of proof that physiological species may be produced by selective breeding; just as a physical philosopher may accept the undulatory theory of light, subject to the proof of the existence of the hypothetical ether ; or as the chemist adopts the atomic theory, subject to the proof of the existence of atoms ; and for exactly the same reasons, namely, that it has an immense amount of prima facie probability; that it is the only means at present within reach of reducing the chaos of observed facts to order ; and lastly, that it is the most powerful instrument of investigation which has been presented to naturalists since the invention of the natural system of classification, and the commencement of the systematic study of embryology.

But even leaving Mr. Darwin's views aside, the whole analogy of natural operations furnishes so complete and crushing an argument against the intervention of any but what are termed secondary causes, in the production of all the phenomena of the universe; that, in view of the intimate relations between Man and the rest of the living world; and between the forces exerted by the latter and all other forces, I can see no excuse for doubting that all are co-ordinated terms of Nature's great progression, from the formless to the formed-from the inorganic to the organic-from blind force to conscious intellect and will. 66-J 
Science has fulfilled her function when she has ascertained and enunciated truth; and were these pages addressed to men of science only, I should now close this essay, knowing that my colleagues have learned to respect nothing but evidence, and to believe that their highest duty lies in submitting to it, however it may jar against their inclinations.

But desiring, as I do, to reach the wider circle of the intelligent public, it would be unworthy cowardice were I to ignore the repugnance with which the majority of my readers are likely to meet the conclusions to which the most careful and conscientious study I have been able to give to this matter, has led me.

On all sides I shall hear the cry-"We are men and women, not a mere better sort of apes, a little longer in the leg, more compact in the foot, and bigger in brain than your brutal Chimpanzees and Gorillas. The power of knowledge - the conscience of good and evil - the pitiful tenderness of human affections, raise us out of all real fellowship with the brutes, however closely they may seem to approximate us."

To this I can only reply that the exclamation would be most just and would have my own entire sympathy, if it were only relevant. But, it is not I who seek to base Man's dignity upon his great toe, or insinuate that we are lost if an Ape has a hippocampus minor. On the contrary, I have done my best to sweep away this vanity. I have endeavoured to show that no absolute structural line of demarcation, wider than that between the animals which immediately succeed us in the scale, can be drawn between the animal world and ourselves; and I may add the expression of my belief that the attempt to draw a psychical distinction is equally futile, and that even the highest faculties of feeling and of intellect begin to germinate in lower forms of life.* At the same time, no one is

* It is so rare a pleasure for me to Ind Professor Owen's opinions in entire accordance with my own, that I cannot forbear from quoting a paragraph which appeared in his Essay "On the Characters, etc., of the Class Mammalia," in the Journal of the Proceedings of the Linnean Society of London for 1857, but is unaccountably omitted in the "Reade Lecture" delivered before the University of Cambridge two years later, which is otherwise nearly a reprint of the paper in question. Prof. Owen writes :

"Not being able to appreciate or conccive of the distinction between the psychical phenomona of a Chimpanzee and of a Boschis- 
more strongly convinced than I am of the vastness of the gulf between civilized man and the brutes; or is more certain that whether from them or not, he is assuredly not of them. No one is less disposed to think lightly of the present dignity, or despairingly of the future hopes, of the only consciously intelligent denizen of this world.

We are indeed told by those who assume authority in these matters, that the two sets of opinions are incompatible, and that the belief in the unity of origin of man and brutes involves the brutalization and degradation of the former. But is this really so ? Could not a sensible child confute, by obvious arguments, the shallow rhetoricians who would force this conclusion upon us ? Is it, indeed, true, that the Poet, or the Philosopher, or the Artist whose genius is the glory of his age, is degraded from his high estate by the undoubted historical probability, not to say certainty, that he is the direct descendant of some naked and bestial savage, whose intelligence was just sufficient to make him a little more cunning than the Fox, and by so much more dangerous than the Tiger? Or is he bound to howl and grovel on all fours because of the wholly unquestionable fact, that he was once an egg, which no ordinary power of discrimination could distinguish from that of a Dog? Or is the philanthropist or the saint to give up his endeavours to lead a noble. life, because the simplest study of man's nature reveals, at its foundations, all the selfish passions and fierce appetites of the merest quadruped? Is mother-love vile because a hen shows it, or fidelity base because dogs possess it ?

The common sense of the mass of mankind will answer these questions without a moment's hesitation. Healthy humanity, finding itself hard pressed to escape from real sin and degradation, will leave the brooding over speculative pollution to the cynics and the 'righteous overmuch'

man or of an Aztec, with arrested brain growth, as being of a nature so essential as to preclude a comparison between them, or as being other than a difference of degree, I cannot shut my eyes to the significance of that all-pervading similitude of structure-every tooth, every bone, strictly homologous-which makes the determination of the difference between Homo and Pithecus the anatomist's difficulty."

Surely it is a little singular that the 'anatomist,' who finds it ' difficult ' to ' determine the difference 'between Homo and Pithecus, should, yet range them on anatomical grounds, in distinct subclasses ! 
who, disagreeing in everything else, unite in blind insensibility to the nobleness of the visible world, and in inability to appreciate the grandeur of the place Man occupies therein.

Nay more, thoughtful men, once escaped from the blinding influences of traditional prejudice, will find in the lowly stock whence man has sprung, the best evidence of the splendour of his capacities; and will discern in his long progress through the Past, a reasonable ground of faith in his attainment of a nobler Future.

They will remember that in comparing civilized man with the animal world, one is as the Alpine traveller, who sees the mountains soaring into the sky and can hardly discern where the deep shadowed crags and roseate peaks end, and where the clouds of heaven begin. Surely the awe-struck voyager may be excused if, at first, he refuses to believe the geologist, who tells him that these glorious masses are, after all, the hardened mud of primeval seas, or the cooled slag of subterranean furnaces- of one substance with the dullest clay, but raised by inward forces to that place of proud and seemingly inaccessible glory.

But the geologist is right; and due reflection on his teachings, instead of diminishing our reverence and our wonder, adds all the force of intellectual sublimity to the mere æsthetic intuition of the uninstructed beholder.

And after passion and prejudice have died away, the same result will attend the teachings of the naturalist respecting that great Alps and Andes of the living worldMan. Our reverence for the nobility of manhood will not be lessened by the knowledge, that Man is, in substance and in structure, one with the brutes; for, he alone possesses the marvellous endowment of intelligible and rational speech, whereby, in the secular period of his existence, he has slowly accumulated and organized the experience which is almost wholly lost with the cessation of every individual life in other animals; so that now he stands raised upon it as on a mountain top, far above the level of his humble fellows, and transfigured from his grosser nature by reflecting, here and there, a ray from the infinite source of truth. 


\section{A succinct History of the Controversy respecting the Cerebral Structure of Man and the Apes}

OP to the year 1857 all anatomists of authority, who had occupied themselves with the cerebral structure of the Apes-Cuvier, Tiedemann, Sandifort, Vrolik, Isidore G. St. Hilaire, Schroeder van der Kolk, Gratiolet-were agreed that the brain of the Apes possesses a POSTERIOR LOBE.

Tiedemann, in 1825, figured and acknowledged in the text of his Icones the existence of the POSTERIor CORNU of the lateral ventricle in the Apes, not only under the title of ' Scrobiculus parvus loco cornu posterioris - $a$ fact which has been paraded-but as ' cornu posterius' (Icones, p. 54), a circumstance which has been, as sedulously, kept in the background.

Cuvier (Lecons, T. iii. p. 103) says, "the anterior or lateral ventricles possess a digital cavity [posterior cornu] only in Man and the Apes ... Its presence depends on that of the posterior lobes."

Schroeder van der Kolk and Vrolik, and Gratiolet, had also figured and described the posterior cornu in various Apes. As to the Hippocampus miNor Tiedemann had erroneously asserted its absence in the Apes; but Schroeder van der Kolk and Vrolik had pointed out the existence of what they considered a rudimentary one in the Chimpanzee, and Gratiolet had expressly affirmed its existence in these animals. Such was the state of our information on these subjects in the year 1856.

In the year 1857, however, Professor Owen, either in ignorance of these well-known facts or else unjustiflably suppressing them, submitted to the Linnæan Society a paper "On the Characters, Principles of Division, and Primary Groups of the Class Mammalia," which was printed in the Society's Journal, and contains the following passage :- " In Man, the brain presents an ascensive step in development, higher and more strongly marked than that by which the preceding sub-class was distinguished from the one below it. Not only do the cerebral hemispheres overlap the olfactory lobes and cerebellum, but they extend in advance of the one and further back than the other. The posterior development is so marked, that anatomists have assigned to that part the character of a third lobe ; it is peculiar to the genus Homo, and equally peculiar is the posterior horn of the lateral ventricle and the 'hippocampus minor,' which characterise the hind lobe of each hemisphere."-Journal of the Proceedings of the Linnæan Society, Vol. ii. p. 19.

As the essay in which this passage stands had no less ambitious an aim than the remodelling of the classification of the Mammalia, its author might be supposed to have written under a sense of peculiar responsibility, and to have tested, with especial care, the statements he ventured to promulgate. And even if this be expect- 
Ing too much, hastiness, or want of opportunity for due deliberation, cannot now be pleaded in extenuation of any shortcomings; for the propositions cited were repeated two years afterwards in the Reade Lecture, delivered before so grave a body as the University of Cambridge, in 1859.

When the assertions, which I have italicised in the above extract, first came under my notice, I was not a little astonished at so flat a contradiction of the doctrines current among well-informed anatomists; but, not unnaturally imagining that the deliberate statements of a responsible person must have some foundation in fact, I deemed it my duty to investigate the subject anew before the time at which it would be my business to lecture thereupon came round. The result of my inquiries was to prove that $\mathrm{Mr}$. Owen's three assertions, that "the third lobe, the posterior horn of the lateral ventricle, and the hippocampus minor," are "peculiar to the genus Homo," are contrary to the plainest facts. I communicated this conclusion to the students of my class; and then, having no desire to embark in a controversy which could not redound to the honour of British science, whatever its issue, I turned to more congenial occupations.

The time speedily arrived, however, when a persistence in this reticence would have involved me in an unworthy paltering with truth.

At the meeting of the British Association at Oxford, in 1860, Professor Owen repeated these assertions in my presence, and, of course, I immediately gave them a direct and unqualifled contradiction, pledging myself to justify that unusual procedure elsewhere. I redeemed that pledge by publishing, in the January number of the Natural History Review for 1861, an article wherein the truth of the three following propositions was fully demonstrated (l. c. p. 71):-

"1. That the third lobe is neither peculiar to, nor characteristic of, man, seeing that it exists in all the higher quadrumana."

"2. That the posterior cornu of the lateral ventricle is neither peculiar to, nor characteristic of, man, inasmuch as it also exists in the higher quadrumana."

" 3 . That the hippocampus minor is neither peculiar to, nor characteristic of, man, as it is found in certain of the higher quadrumana."

Furthermore, this paper contains the following paragraph (p. 76):

"And lastly, Schroeder van der Kolk and Vrolik (op. cit. p. 271), though they particularly note that 'the lateral ventricle is distinguished from that of Man by the very defective proportions of the posterior cornu, wherein only a stripe is visible as an indication of the hippocampus minor;' yet the Figure 4, in their second Plate, shows that this posterior cornu is a perfectly distinct and unmistakeable structure, quite as large as it often is in Man. It is the more remarkable that Professor Owen should have overlooked the explicit statement and figure of these authors, as it is guite obvious, on comparison of the figures, that his woodcut of the 
brain of a Chimpanzee (1. c. p. 19) is a reduced copy of the second figure of Messrs. Schroeder van der Kolk and Vrolik's first Plate.

"As M. Gratiolet (l. c. p. 18), however, is careful to remark, - unfortunately the brain which they have taken as a model was greatly altered (profondément affaissé), whence the general form of the brain is given in these plates in a manner which is altogether incorrect.' Indeed, it is perfectly obvious, from a comparison of a section of the skull of the Chimpanzee with these figures, that such is the case ; and it is greatly to be regretted that so inadequate a figure (should have been taken as a typical representation of the Chimpanzee's brain."

From this time forth, the untenability of his position might have been as apparent to Professor Owen as it was to every one else; but, so far from retracting the grave errors into which he had fallen, Professor Owen has persisted in and reiterated them; first, in a lecture delivered before the Royal Institution on the 19th of March, 1861, which is admitted to have been accurately reproduced in the Athenæum for the 23rd of the same month, in a letter addressed by Professor Owen to that journal on the 30th of March. The Athenæum report was accompanied by a diagram purporting to represent a Gorilla's brain, but in reality so extraordinary a misrepresentation, that Professor Owen substantially, though not explicitly, withdraws it in the letter in question. In amending this error, however, Professor Owen fell into another of much graver import, as his communication concludes with the following paragraph: "For the true proportion in which the cerebrum covers the cerebellum in the highest Apes, reference should be made to the figure of the undissected brain of the Chimpanzee in my Reade's Lecture on the Classification, etc., of the Mammalia, p. 25, fig. 7, 8vo, 1859."

It would not be credible, if it were not unfortunately true, that this flgure, to which the trusting public is referred, without a word of qualification, "for the true proportion in which the cerebrum covers the cerebellum in the highest Apes," is exactly that unacknowledged copy of Schroeder van der Kolk and Vrolik's figure whose utter inaccuracy had been pointed out years before by Gratiolet, and had been brought to Professor Owen's knowledge by mysclf in the passage of my article in the Natural History Review abovo quoted.

I drew public attention to this circumstance again in my reply to Professor Owen, published in the Athenæum for April 13th, 1861 ; but the exploded figure was reproduced once more by Professor Owen, without the slightest allusion to its inaccuracy, in the Annals of Natural History for June 1861 !

This proved too much for the patience of the original authors of the figure, Messrs. Schroeder van der Kolk and Vrolik, who, in a note addressed to the Academy of Amsterdam, of which they were members, declared themselves to be, though decided opponents 
of all forms of the doctrine of progressive development, above all things, lovers of truth : and that, therefore, at whatever risk of seeming to lend support to views which they disliked, they felt it their duty to take the first opportunity of publicly repudiating Professor Owen's misuse of their authority.

In this note they frankly admitted the justice of the criticisms of M. Gratiolet, quoted above, and they illustrated, by new and careful figures, the posterior lobe, the posterior cornu, and the hippocampus minor of the Orang. Furthermore, having demonstrated the parts, at one of the sittings of the Academy, they add, "la présence des parties contestées y a été universellement reconnue par les anatomistes présents à la séance. Le seul doute qui soit resté se rapporte au pes Hippocampi minor. . . A l'état frais l'indice du petit pied d'Hippocampe était plus prononcé que maintenant."

Professor Owen repeated his erroneous assertions at the meeting of the British Association in 1861, and again, without any obvious necessity, and without adducing a single new fact or new argument, or being able in any way to meet the crushing evidence from original dissections of numerous Apes' brains, which had in the meanwhile been brought forward by Prof. Rolleston,* F.R.S., Mr. Marshall, $\dagger$ F.R.S., Mr. Flower, $\ddagger$ Mr. Turner, $\S$ and myself, $\|$ revived the subject at the Cambridge meeting of the same body in 1862. Not content with the tolerably vigorous repudiation which these unprecedented proceedings met with in Section D, Professor Owen sanctioned the publication of a version of his own statements, accompanied by a strange misrepresentation of mine (as may be seen by comparison of the Times report of the discussion), in the Medical Times for October 11th, 1862. I subjoin the conclusion of my reply in the same journal for October 25th.

"If this were a question of opinion, or a question of interpretation of parts or of terms, - were it even a question of observation in which the testimony of my own senses alone was pitted against that of another person, I should adopt a very different tone in discussing this matter. I should, in all humility, admit the likelihood of having myself erred in judgment, failed in knowledge, or been blinded by prejudice.

"But no one pretends now, that the controversy is one of terms or of opinions. Novel and devoid of authority as some of Professor

- On the Afmnities of the Brain of the Orang. Nat. Hist. Review, April, 1861.

$\dagger$ On the Brain of a young Chimpanzee. Ibid., July, 1861.

$\mp$ On the Posterior lobes of the Cerebrum of the Quadrumana. Philosophical Transactions, 1862.

$\$$ On the anatomical Relations of the Surfaces of the Tentorium to the Cerebrum and Cerebellum in Man and the lower Mammals. Proceedings of the Royal Society of Edinburgh, March, 1862. 1861.

II On the Brain of Ateles. Proceedings of Zoclogical Society, 
Owen's proposed definitions may have been, they might be accepted without changing the great features of the case. Hence, though special investigations into these matters have been undertaken during the last two years by Dr. Allen Thomson, by Dr. Rolleston, by Mr. Marshall; and by Mr. Flower, all, as you are aware, anatomists of repute in this country, and by Professors Schroeder Van der Kolk, and Vrolik (whom Professor Owen incautiously tried to press into his own service) on the Continent, all these able and conscientious observers have with one accord testifled to the accuracy of my statements, and to the utter baselessness of the assertions of Professor Owen. Even the venerable Rudolph Wagner, whom no man will accuse of progressionist proclivities, has raised his voice on the same side; while not a single anatomist, great or small, has supported Professor Owen.

"Now, I do not mean to suggest that scientific differences should be settled by universal suffrage, but I do conceive that solid proofs must be met by something more than empty and unsupported assertions. Yet during the two years through which this preposterous controversy has dragged its weary length, Professor Owen has not ventured to bring forward a single preparation in support of his often-repeated assertions.

"The case stands thus, therefore:-Not only are the statements made by me in consonance with the doctrines of the best older authorities, and with those of all recent investigators, but I am quite ready to demonstrate them on the first monkey that comes to hand; while Professor Owen's assertions are not only in diametrical opposition to both old and new authorities, but he has not produced, and, I will add, cannot produce, a single preparation which justifies them."

I now leave this subject, for the present.-For the credit of my calling I should be glad to be, hereafter, for ever silent upon it. But, unfortunately, this is a matter upon which, after all that has occurred, no mistake or confusion of terms is possible-and in affirming that the posterior lobe, the posterior cornu, and the hippocampus minor exist in certain Apes, I am stating either that which is true, or that which I must know to be false. The question has thus become one of personal veracity. For myself, I will accept no other issue than this, grave as it is, to the present controversy. 


\section{ON SOME FOSSIL REMAINS OF MAN}

I HAVE endeavoured to show, in the preceding Essay, that the Anthropini, or Man Family, form a very well defined group of the Primates, between which and the immediately following Family, the CatarHini, there is, in the existing world, the same entire absence of any transitional form or connecting link, as between the CATARHINI and Platyrhini.

It is a commonly received doctrine, however, that the structural intervals between the various existing modiffcations of organic beings may be diminished, or even obliterated, if we take into account the long and varied succession of animals and plants which have preceded these now living and which are known to us only by their fossilized remains. How far this doctrine is well based, how far, on the other hand, as our knowledge at present stands, it is an overstatement of the real facts of the case, and an exaggeration of the conclusions fairly deducible from them, are points of grave importance, but into the discussion of which I do not, at present, propose to enter. It is enough that such a view of the relations of extinct to living beings has been propounded, to lead us to inquire, with anxiety, how far the recent discoveries of human remains in a fossil state bear out, or oppose, that view.

I shall confine myself, in discussing this question, to those fragmentary Human skulls from the caves of Engis in the valley of the Meuse, in Belgium, and of the Neanderthal near Düsseldorf, the geological relations of which have been examined with so much care by Sir Charles Lyell ; upon whose high authority I shall take it for granted, that the Engis skull belonged to a contemporary of the Mammoth (Elephas primigenius) and of the woolly Rhinoceros (Rhinocerus tichorhinus), with the bones of which it was found associated; and that the Neanderthal skull is of great, though uncertain, antiquity. Whatever be the geological age of the latter skull, I conceive it is quite safe (on the ordinary principles of paleontological reasoning) to assume 
that the former takes us to, at least, the further side of the vague biological limit, which separates the present geological epoch from that which immediately preceded it. And there can be no doubt that the physical geography of Europe has changed wonderfully, since the bones of Men and Mammoths, Hyænas and Rhinoceroses were washed pell-mell into the cave of Engis.

The skull from the cave of Engis was originally discovered by Professor Schmerling, and was described by him, together with other human remains disinterred at the same time, in his valuable work, Recherches sur les ossemens fossiles découverts dans les cavernes de la Province de Liege, published in 1833 (p. 59, et seq.), from which the following paragraphs are extracted, the precise expressions of the author being, as far as possible, preserved.

"In the first place, I must remark that these human remains, which are in my possession, are characterized, like the thousands of bones which I have lately been disinterring, by the extent of the decomposition which they have undergone, which is precisely the same as that of the extinct species: all, with a few exceptions, are broken; some few are rounded, as is frequently found to be the case in fossil remains of other species. The fractures are vertical or oblique ; none of them are eroded ; their colour does not differ from that of other fossil bones, and varies from whitish yellow to blackish. All are lighter than recent bones, with the exception of those which have a calcareous incrustation, and the cavities of which are filled with such matter.

"The cranium which I have caused to be figured, Plate I., Figs. 1, 2, is that of an old person. The sutures are beginning to be effaced: all the facial bones are wanting, and of the temporal bones only a fragment of that of the right side is preserved.

"The face and the base of the cranium had been detached before the skull was deposited in the cave, for we were unable to find those parts, though the whole cavern was regularly searched. The cranium was met with at a depth of a metre and a half [five feet nearly], hidden under an osseous breccia, composed of the remains of small animals, and containing one rhinoceros tusk, with several teeth of horses and of ruminants. This breccia, which has been spoken of above (p. 30), was a metre [3 feet about] wide, and rose to the height of a metre and a half above the floor of the cavern, to the walls of which it adhered strongly. 
"The earth which contained this human skull exhibited no trace of disturbance : teeth of rhinoceros, horse, hyæna, and bear, surrounded it on all sides.

"The famous Blumenbach * has directed attention to the differences presented by the form and the dimensions of human crania of different races. This important work would have assisted us greatly, if the face, a part essential

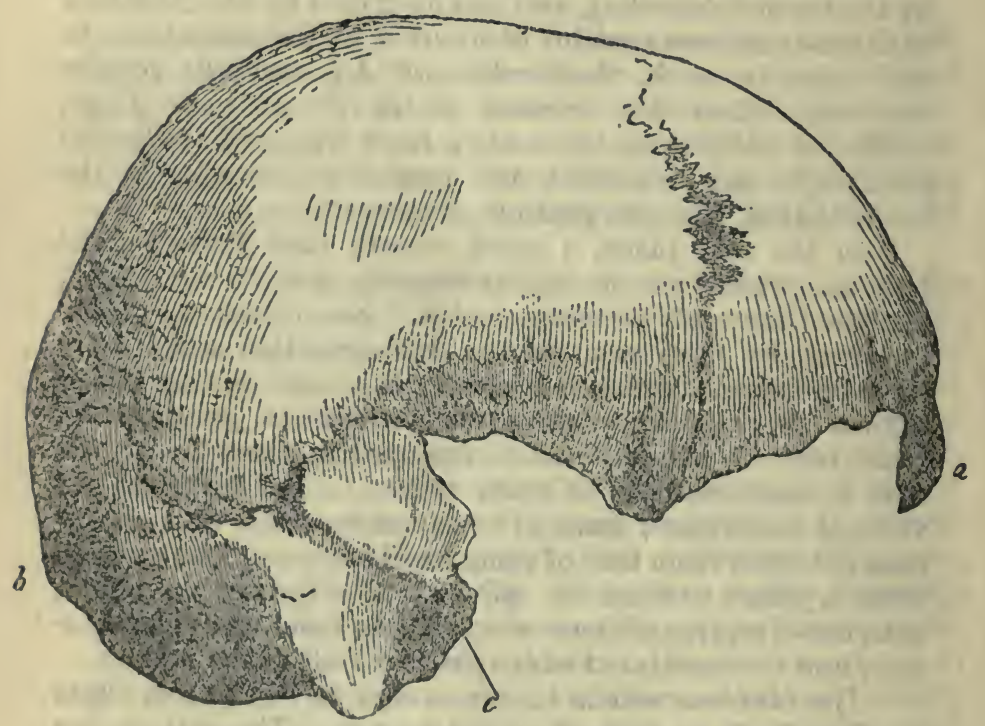

Frc. 22.-The skull trom the cave of Engis-viewed from the right side. $a$ glabella, $b$ occipital protuberance, ( $a$ to $b$ glabello-occipital line), c audițory foramen.

for the determination of race, with more or less accuracy, had not been wanting in our fossil cranium.

"We are convinced that even if the skull had been complete, it would not have been possible to pronounce, with certainty, upon a single specimen; for individual variations are so numerous in the crania of one and the same race, that one cannot, without laying oneself open to large chances of error, draw any inference from a single fragment

- Decas Collectionis suæ craniorum diversarum gentium illustrata. Gottingre, 1790-1820. 


\section{ON SOME FOSSIL REMAINS OF MAN 301}

of a cranium to the general form of the head to which it belonged.

"Nevertheless, in order to neglect no point respecting the form of this fossil skull, we may observe that, from the first, the elongated and narrow form of the forehead attracted our attention.

"In fact, the slight elevation of the frontal, its narrowness, and the form of the orbit, approximate it more nearly to the cranium of an Ethiopian than to that of an European : the elongated form and the produced occiput are also characters which we believe to be observable in our fossil cranium ; but to remove all doubt upon that subject I have caused the contours of the cranium of an European and of an Ethiopian to be drawn and the foreheads represented. Plate II., Figs. 1 and 2, and, in the same plate, Figs. 3 and 4, will render the differences easily distinguishable; and a single glance at the figures will be more instructive than a long and wearisome description.

"At whatever conclusion we may arrive as to the origin of the man from whence this fossil skull proceeded, we may express an opinion without exposing ourselves to a fruitless controversy. Each may adopt the hypothesis which seems to him most probable : for my own part, I hold it to be demonstrated that this cranium has belonged to a person of limited intellectual faculties, and we conclude thence that it belonged to a man of a low degree of civilization : a deduction which is borne out by contrasting the capacity of the frontal with that of the occipital region.

"Another cranium of a young individual was discovered in the floor of the cavern beside the tooth of an elephant; the skull was entire when found, but the moment it was lifted it fell into pieces, which I have not, as yet, been able to put together again. But I have represented the bones of the upper jaw, Plate I., Fig. 5. The state of the alveoli and the teeth, shows that the molars had not yet pierced the gum. Detached milk molars and some fragments of a human skull proceed from this same place. The Figure 3 represents a human superior incisor tooth, the size of which is truly remárkable.*

"Figure 4 is a fragment of a superior maxillary bone,

- In a subsequent passage, Schmerling remarks upon the occurrence of an incisor tooth ' of enormous size' from the caverns of Engihoul. The tooth figured is somewhat long, but its dimensious do not appear to me to be otherwise remarkable. 
the molar teeth of which are worn down to the roots.

“I possess two vertebræ, a first and last dorsal.

"A clavicle of the left side (see Plate III., Fig. 1); although it belonged to a young individual, this bone shows that he must have been of great stature.*

"Two fragments of the radius, badly preserved, do not indicate that the height of the man, to whom they belonged, exceeded five feet and a half.

"As to the remains of the upper extremities, those which are in my possession consist merely of a fragment of an ulna and of a radius (Plate III., Figs. 5 and 6 ).

"Figure 2, Plate IV., represents a metacarpal bone, contained in the breccia, of which we have spoken; it was found in the lower part above the cranium: add to this some metacarpal bones, found at very different distances, half-a-dozen metatarsals, three phalanges of the hand, and one of the foot.

"This is a brief enumeration of the remains of human bones collected in the cavern of Engis, which has preserved for us the remains of three individuals, surrounded by those of the Elephant, of the Rhinoceros, and of Carnivora of species unknown in the present creation."

From the cave of Engihoul, opposite that of Engis, on the right bank of the Meuse, Sclimerling obtained the remains of three other individuals of Man, among which were only two fragments of parietal bones, but many bones of the extremities. In one case, a broken fragment of an ulna was soldered to a like fragment of a radius by stalagmite, a condition frequently observed among the bones of the Cave Bear (Ursus spelæus), found in the Belgian caverns.

It was in the cavern of Engis that Professor Schmerling found, incrusted with stalagmite and joined to a stone, the pointed bone implement, which he has figured in Fig. 7 of his Plate XXXVI., and worked flints were found by him in all those Belgian caves, which contained an abundance of fossil bones.

A short letter from M. Geoffroy St. Hilaire, published in the Comples Rendus of the Academy of Sciences of Paris, for July 2nd, 1838, speaks of a visit (and apparently

- The figure of this clavicle measures 5 inches from end to end in a straight line-so that the bone is rather a small than a large one. 
a very hasty one) paid to the collection of Professor 'Schermidt' (which is presumably a misprint for Schmerling) at Liège. The writer briefly criticises the drawings which illustrate Schmerling's work, and affirms that the "human cranium is a little longer than it is represented" in Schmerling's figure. The only other remark worth quoting is this:- "The aspect of the human bones differs little from that of the cave bones, with which we are familiar, and of which there is a considerable collection in the same place. With respect to their special forms, compared with those of the varieties of recent human crania, few certain conclusions can be put forward; for much greater differences exist between the different specimens of well-characterized varieties, than between the fossil cranium of Liège and that of one of those varieties selected as a term of comparison."

Geoffroy St. Hilaire's remarks are, it will be observed, little but an echo of the philosophic doubts of the describer and discoverer of the remains. As to the critique upon Schmerling's figures, I find that the side view given by the latter is really about $\frac{8}{10}$ ths of an inch shorter than the original, and that the front view is diminished to about the same extent. Otherwise the representation is not, in any way, inaccurate, but corresponds very well with the cast which is in my possession.

A piece of the occipital bone, which Schmerling seems to have missed, has since been fitted on to the rest of the cranium by an accomplished anatomist, Dr. Spring, of Liège, under whose direction an excellent plaster cast was made for Sir Charles Lyell. It is upon and from a duplicate of that cast that my own observations and the accompanying figures, the outlines of which are copied from very accurate Camera lucida drawings, by my friend Mr. Busk, reduced to one-half of the natural size, are made.

As Professor Schmerling observes, the base of the skull is destroyed, and the facial bones are entirely absent; but the roof of the cranium, consisting of the frontal, parietal, and the greater part of the occipital bones, as far as the middle of the occipital foramen, is entire or nearly so. The left temporal bone is wanting. Of the right temporal, the parts in the immediate neighbourhood of the auditory foramen, the mastoid process, and a considerable portion of the squamous element of the temporal are well preserved (Fig. 22). 


\section{ON SOME FOSSIL REMAINS OF MAN}

The lines of fracture which remain between the coadjusted pieces of the skull, and are faithfully displayed in Schmerling's figure, are readily traceable in the cast. The sutures are also discernible, but the complex disposition of their serrations, shown in the figure, is not obvious in the cast. Though the ridges which give attachment to muscles are not excessively prominent, they are well marked, and taken together with the apparently well developed frontal sinuses, and the condition of the sutures, leave no doubt on my mind that the skull is that of an adult, if not middle-aged man.

The extreme length of the skull is 7.7 inches. Its extreme breadth, which corresponds very nearly with the interval between the parictal protuberances, is not more than 5.4 inches. The proportion of the length to the breadth is therefore very nearly as 100 to 70 . If a line be drawn from the point at which the brow curves in towards the root of the nose, and which is called the ' glabella' (a) (Fig. 22), to the occipital protuberance (b), and the distance to the highest point of the arch of the skull be measured perpendicularly from this line, it will be found to be 4.75 inches. Viewed from above, Fig. 23, $A$, the forehead presents an evenly rounded curve, and passes into the contour of the sides and back of the skull, which describes a tolerably regular elliptical curve.

The front view (Fig. 23, B) shows that the roof of the skull was very regularly and elegantly arclied in the transverse direction, and that the transverse diameter was a little less below the parictal protuberances, than above them. The forehead cannot be called narrow in relation to the rest of the skull, nor can it be called a retreating forchead; on the contrary, the antero-posterior contour of the skull is well arched, so that the distance along that contour, from the nasal depression to the occipital protuberance, measures about 13.75 inches. The transverse arc of the skull, measured from one auditory foramen to the other, across the middle of the sagittal suture, is about 13 inches. The sagittal suture itself is 5.5 inches long.

The supraciliary prominences or brow-ridges (on each side of $a$, Fig. 22) are well, but not excessively, developed, and are separated by a median depression. Their principal elevation is disposed so obliquely that I judge them to be due to large frontal sinuses.

If a line joining the glabella and the occipital protuber- 
ance $(a, b$, Fig. 22) be made horizontal, no part of the occipital region projects more than soth of an inch behind the posterior extremity of that line, and the upper edge of the auditory foramen $(c)$ is almost in contact with a line drawn parallel with this upon the outer surface of the skull.

A transverse line drawn from one auditory foramen to the other traverses, as usual, the forepart of the occipital foramen. The capacity of the interior of this fragmentary skull has not been ascertained.

The history of the Human remains from the cavern in the Neanderthal may best be given in the words of their original describer, Dr. Schaaffhausen, ${ }^{*}$ as translated by Mr. Busk.

"In the early part of the year 1857, a human skeleton was discovered in a limestone cave in the Neanderthal, near Hochdal, between Düsseldorf and Elberfeld. Of this, however, I was unable to procure more than a plaster cast of the cranium, taken at Elberfeld, from which I drew up an account of its remarkable conformation, which was, in the first instance, read on the 4th of February, 1857, at the meeting of the Lower Rhine Medical and Natural History Society, at Bonn. $\dagger$ Subsequently Dr. Fuhlrott, to whom science is indebted for the preservation of these bones, which were not at first regarded as human, and into whose possession they afterwards came, brought the cranium from Elberfeld to Bonn, and entrusted it to me for more accurate anatomical examination. At the General Meeting of the Natural History Society of Prussian Rhineland and Westphalia, at Bonn, on the 2nd of June, 1857, $\ddagger$ Dr. Fuhlrott himself gave a full account of the locality, and of the circumstances under which the discovery was made. He was of opinion that the bones might be regarded as fossil ; and in coming to this conclusion, he laid especial stress upon the existence of dendritic deposits, with which their surface was covered,

* On the Crania of the most ancient Races of Man. By Professor D. Schaaffhausen, of Bonn. (From Müller's Archiv., 1858, pp. 453.) With Remarks, and original Figures, taken from a Cast of the Neanderthal Cranium. By George Busk, F.R.S., etc. Natural History Review. April, 1861.

$\dagger$ Verhandl. d. Naturhist. Vereins der preuss. Rheinlande und Westphalens., xiv. Bonn, 1857.

$\ddagger I b$. Correspondenzblatt. No. 2 . 


\section{ON SOME FOSSIL REMAINS OF MAN}

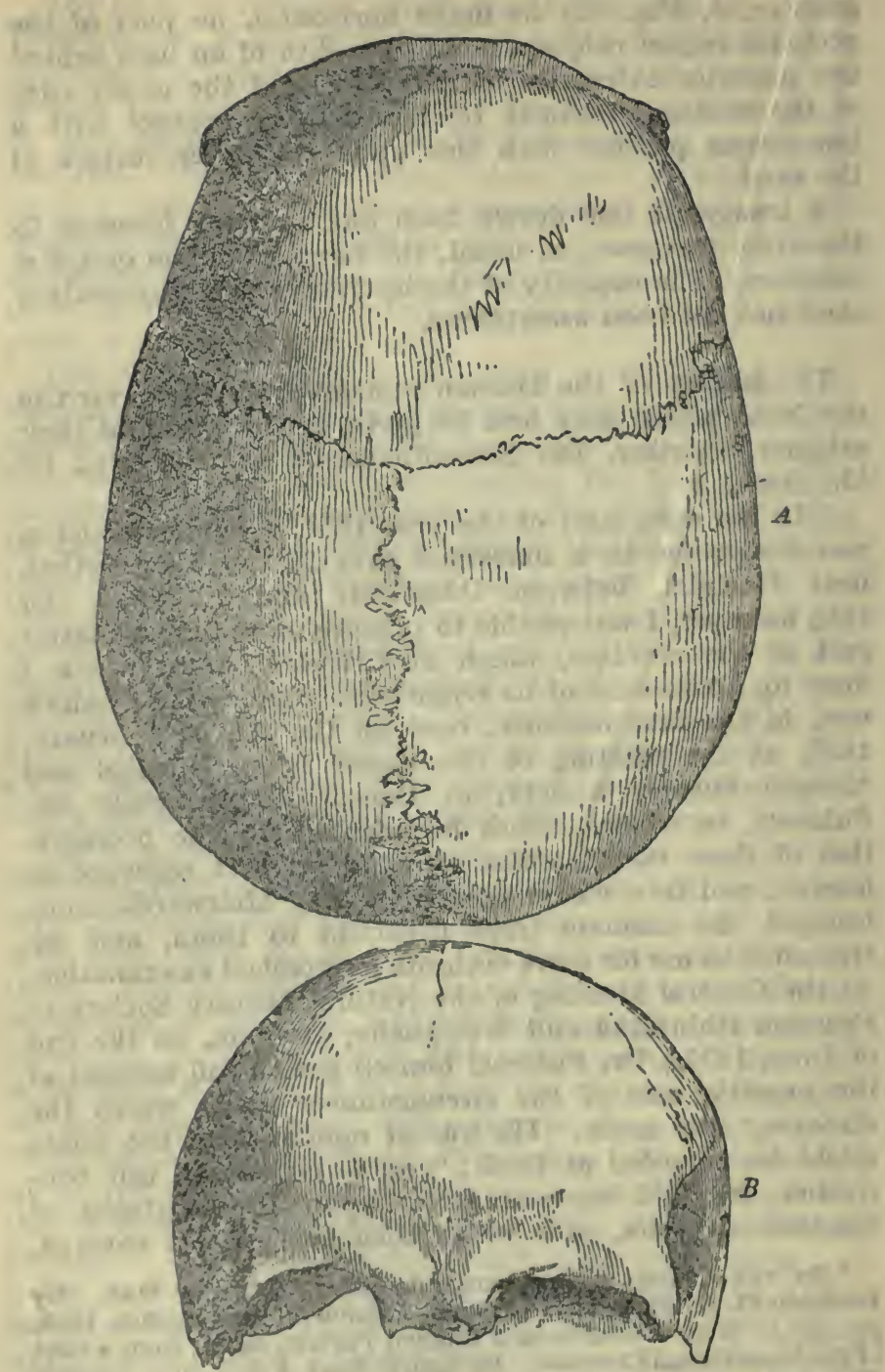

Fig. 23.-The Engis skull viewed trom above $(A)$ and in front $(B)$. 


\section{ON SOME FOSSIL REMAINS OF MAN 307}

and which were first noticed upon them by Professor Meyer. To this communication I appended a brief report on the results of my anatomical examination of the bones. The conclusions at which I arrived were:-1st. That the extraordinary form of the skull was due to a natural conformation hitherto not known to exist, even in the most barbarous races. 2nd. That these remarkable human remains belonged to a period antecedent to the time of the Celts and Germans, and were in all probability derived from one of the wild races of Northwestern Europe, spoken of by Latin writers; and which were encountered as autochthones by the German immigrants. And 3rdly. That it was beyond doubt that these human relics were traceable to a period at which the latest animals of the diluvium still existed; but that no proof of this assumption, nor consequently of their so-termed fossil condition, was afforded by the circumstances under which the bones were discovered.

"As Dr. Fuhlrott has not yet published his description of these circumstances, I borrow the following account of them from one of his letters. 'A small cave or grotto, high enough to admit a man, and about 15 feet deep from the entrance, which is 7 or 8 feet wide, exists in the southern wall of the gorge of the Neanderthal, as it is termed, at a distance of about 100 feet from the Düssel, and about 60 feet above the bottom of the valley. In its earlier and uninjured condition, this cavern opened upon a narrow plateau lying in front of it, and from which the rocky wall descended almost perpendicularly into the river. It could be reached, though with difficulty, from above. The uneven floor was covered to a thickness of 4 or 5 feet with a deposit of mud, sparingly intermixed with rounded fragments of chert. In the removing of this deposit, the bones were discovered. The skull was first noticed, placed nearest to the entrance of the cavern ; and further in, the other bones, lying in the same horizontal plane. Of this I was assured, in the most positive terms, by two labourers who were employed to clear out the grotto, and who were questioned by me on the spot. At first no idea was entertained of the bones being human ; and it was not till several weeks after their discovery that they were recognised as such by me, and placed in security. But, as the importance of the discovery was not at the time perceived, the labourers were very careless in the collecting, 
and secured chiefly only the larger bones; and to this circumstance it may be attributed that fragments merely of the probably perfect skeleton came into my possession.'

"My anatomical examination of these bones afforded the following results :-

"The cranium is of unusual size, and of a long elliptical form. A most remarkable peculiarity is at once obvious in the extraordinary development of the frontal sinuses, owing to which the superciliary ridges, which coalesce completely in the middle, are rendered so prominent, that the frontal bone exhibits a considerable hollow or depression above, or rather behind them, whilst a deep depression is also formed in the situation of the root of the nose. The forehead is narrow and low, though the middle and hinder portions of the cranial arch are well developed. Unfortunately, the fragment of the skull that has been preserved consists only of the portion situated above the roof of the orbits and the superior occipital ridges, which are greatly developed, and almost conjoined so as to form a horizontal eminence. It includes almost the whole of the frontal bone, both parietals, a small part of the squamous and the upper-third of the occipital. The recently fractured surfaces show that the skull was broken at the time of its disinterment. The cavity holds 16,876 grains of water, whence its cubical contents may be estimated at 57.64 inches, or 1033.24 cubic centimetres. In making this estimation, the water is supposed to stand on a level with the orbital plate of the frontal, with the deepest notch in the squamous margin of the parietal, and with the superior semicircular ridges of the occipital. Estimated in dried millet-seed, the contents equalled 31 ounces, Prussian Apothecaries' weight. The semicircular line indicating the upper boundary of the attachment of the temporal muscle, though not very strongly marked, ascends nevertheless to more than half the height of the parietal bone. On the right superciliary ridge is observable an oblique furrow or depression, indicative of an injury received during life.* The coronal and sagittal sutures are on the exterior nearly closed, and on the inside so completely ossified as to have left no traces whatever, whilst the lambdoidal remains quite open. The depressions for the Pacchionian glands are deep and numerous; and there

- This, Mr. Busk has pointed out, is probably the notch for the trontal nerve. 
is an unusually deep vascular groove immediately behind the coronal suture, which, as it terminates in a foramen, no doubt transmitted a vena emissaria. The course of the frontal suture is indicated externally by a slight ridge ; and where it joins the coronal, this ridge rises into a small protuberance. The course of the sagittal suture is grooved, and above the angle of the occipital bone the parietals are depressed.

The length of the skull from the nasal process of the frontal over the vertex to the superior semicircular lines of the occipital neasures . . . . . $303(300)=12.0^{\circ}$.

Circumference over the orbital ridges and the superior semicircular lines of the occipital

Width of the frontal from the middle of the temporal line on one side to the same point on the opposite

Length of the frontal from the nasal process to the coronal suture . . . $133(125)=5.25^{\circ}-5^{\prime \prime}$. Extreme width of the frontal sinuses . $25(23)=1.0^{\prime \prime}-0.9^{\prime \prime}$.

Vertical height above a line joining the deepest notches in the squamous border of the parietals .
Width of hinder part of skull from one parietal protuberance to the other
Distance from the upper angle of the occipital to the superior semicircular lines

Thickness of the bone at the parietal

protuberance . . . . . 8. at the angle of the occipital $\quad 9$.

- at the superior semicircular line of the occipital

$70=2.75^{\circ}$ $138(150)=5.4^{\prime \prime}-5.9^{\prime \prime}$

$51(60)=1.9^{\circ}-2.4^{*}$

9.

$10=0.3^{\circ}$.

"Besides the cranium, the following bones have been secured :-

"1. Both thigh-bones, perfect. These, like the skull, and all the other bones, are characterized by their unusual thickness, and the great development of all the elevations and depressions for the attachment of muscles. In the Anatomical Museum at Bonn, under the designation of 'Giant's-bones,' are some recent thigh-bones,

* The numbers in brackets are those which I should assign to the different measures, as taken from the plaster cast.-G. B. 
with which in thickness the foregoing pretty nearly correspond, although they are shorter.

Glant's bones. Fossil bones. mm. mm.

Length

Diameter of head of femur - $542=21.4^{\prime \prime} \ldots 438=17.4^{\prime \prime}$

" of lower articular end, from

$\begin{array}{cl}\text { one condyle to the other } & \text { - } 89=3.5^{\prime \prime} \ldots 87=3.4^{\prime \prime} \\ \text { Diameter of femur in the middle } & -33=1.2^{\circ} \ldots 30=1.1^{\circ}\end{array}$

“2. A perfect right humerus, whose size shows that it belongs to the thigh-bones.

I.ength .

Thickness in the middle

Diameter of head $\mathrm{mm}$.

$$
\begin{array}{r}
312=12.3^{\prime \prime} \\
26=1.0^{\prime \prime} \\
49=1.9^{\circ}
\end{array}
$$

"Also a perfect right radius of corresponding dimensions, and the upper-third of a right ulna corresponding to the humerus and radius.

"3. A left humerus," of which the upper-third is wanting, and which is so much slenderer than the right as apparently to belong to a distinct individual; a left ulna, which, though complete, is pathologically deformed, the coronoid process being so much enlarged by bony growtl, that flexure of the elbow beyond a right angle must have been impossible; the anterior fossa of the humerus for the reception of the coronoid process being also filled up with a similar bony growth. At the same time, the olecranon is curved strongly downwards. As the bone presents no sign of rachitic degeneration, it may be supposed that an injury sustained during life was the cause of the anchylosis. When the left ulna is compared with the right radius, it might at first sight be concluded that the bones respectively belonged to different individuals, the ulna being more than half an inch too short for articulation with a corresponding radius. But it is clear that this shortening, as well as the attenuation of the left humerus, are both consequent upon the pathological condition above described.

“4. A left ilium, almost perfect, and belonging to the femur; a fragment of the right scapula; the anterior extremity of a rib of the right side; and the same part of a rib of the left side; the hinder part of a rib of the right side; and, lastly, two hinder portions and one middle portion of ribs, which, from their unusually rounded shape, 
and abrupt curvature, more resemble the ribs of a carnivorous animal than those of a man. Dr. H. v. Meyer, however, to whose judgment I defer, will not venture to declare them to be ribs of any animal ; and it only remains to suppose that this abnormal condition has arisen from an unusually powerful development of the thoracic muscles.

"The bones adhere strongly to the tongue, although, as proved by the use of hydrochloric acid, the greater part of the cartilage is still retained in them, which appears, however, to have undergone that transformation into gelatine which has been observed by v. Bibra in fossil bones. The surface of all the bones is in many spots covered with minute black specks, which, more especially under a lens, are seen to be formed of very delicate dendrites. These deposits, which were first observed on the bones by Dr. Meyer, are most distinct on the inner surface of the cranial bones. They consist of a ferruginous compound, and, from their black colour, may be supposed to contain manganese. Similar dendritic formations also occur, not unfrequently, on laminated rocks, and are usually found in minute fissures and cracks. At the meeting of the Lower Rhine Society at Bonn, on the 1st April, 1857, Prof. Meyer stated that he had noticed in the museum of Poppelsdorf similar dendritic crystallizations on several fossil bones of animals, and particularly on those of Ursus spelæus, but still more abundantly and beautifully displayed on the fossil bones and teeth of Equus adamiticus, Elephas primigenius, etc., from the caves of Bolve and Sundwig. Faint indications of similar dendrites were visible in a Roman skull from Siegburg; whilst other ancient skulls, which had lain for centuries in the earth, presented no trace of them.* I am indebted to $H$. v. Meyer for the following remarks on this subject :-

- The incipient formation of dendritic deposits, which were formerly regarded as a sign of a truly fossil condition, is interesting. It has even been supposed that in diluvial deposits the presence of dendrites might be regarded as affording a certain mark of distinction between bones mixed with the diluvium at a somewhat later period and the true diluvial relics, to which alone it was supposed that these deposits were confined. But I have long been convinced that neither can the absence of dendrites be regarded as indicative of recent age, nor their presence as 
sufficient to establish the great antiquity of the objects upon which they occur. I have myself noticed upon paper, which could scarcely be more than a year old, dendritic deposits, which could not be distinguished from those on fossil bones. Thus I possess a dog's skull from the Roman colony of the neighbouring Heddersheim, Castrum Hadrianum, which is in no way distinguishable from the fossil-bones from the Frankish caves; it presents the same colour, and adheres to the tongue just as they do ; so that this character also, which, at a former meeting of German naturalists at Bonn, gave rise to amusing scenes between Buckland and Schmerling, is no longer of any value. In disputed cases, therefore, the condition of the bone can scarcely afford the means for determining with certainty whether it be fossil, that is to say, whether it belong to geological antiquity or to the historical period.'

"As we cannot now look upon the primitive world as representing a wholly different condition of things, from which no transition exists to the organic life of the present time, the designation of fossil, as applied to a bone, has no longer the sense it conveyed in the time of Cuvier. Sufficient grounds exist for the assumption that man coexisted with the animals found in the diluvium; and many a barbarous race may, before all historical time, have disappeared, together with the animals of the ancient world, whilst the races whose organization is improved have continued the genus. The bones which form the subject of this paper present characters which, although not decisive, as regards a geological epoch, are, nevertheless, such as indicate a very high antiquity. It may also be remarked that, common as is the occurrence of diluvial animal bones in the muddy deposits of caverns, such remains have not hitherto been met with in the caves of the Neanderthal ; and that the bones, which were covered by a deposit of mud not more than four or five feet thick, and without any protective covering of stalagmite, have retained the greatest part of their organic substance.

"These circumstances might be adduced against the probability of a geological antiquity. Nor should we be justifled in regarding the cranial conformation as perhaps representing the most savage primitive type of the human race, since crania exist among living savages, which, though not exhibiting, such a remarkable conformation of 
the forehead, which gives the skull somewhat the aspect of that of the large apes, still in other respects, as for instance in the greater depth of the temporal fossæ, the crest-like, prominent temporal ridges, and a generally less capacious cranial cavity, exhibit an equally low stage of development. There is no reason for supposing that the deep frontal hollow is due to any artificial flattening, such as is practised in various modes by barbarous nations in the Old and New World. The skull is quite symmetrical, and shows no indication of counter-pressure at the occiput, whilst, according to Morton, in the Flat-heads of the Columbia, the frontal and parietal bones are always unsymmetrical. Its conformation exhibits the sparing development of the anterior part of the head which has been so often observed in very ancient crania, and affords one of the most striking proofs of the influence of culture and civilization on the form of the human skull."

In a subsequent passage, Dr. Schaaffhausen remarks :

"There is no reason whatever for regarding the unusual development of the frontal sinuses in the remarkable skull from the Neanderthal as an individual or pathological deformity ; it is unquestionably a typical race-character, and is physiologically connected with the uncommon thickness of the other bones of the skeleton, which exceeds by about one-half the usual proportions. This expansion of the frontal sinuses, which are appendages of the airpassages, also indicates an unusual force and power of endurance in the movements of the body, as may be concluded from the size of all the ridges and processes for the attachment of the muscles or bones. That this conclusion may be drawn from the existence of large frontal sinuses, and a prominence of the lower frontal region, is confirmed in many ways by other observations. By the same characters, according to Pallas, the wild horse is distinguished from the domesticated, and, according to Cuvier, the fossil cave-bear from every recent species of bear, whilst, according to Roulin, the pig, which has become wild in America, and regained a resemblance to the wild boar, is thus distinguished from the same animal in the domesticated state, as is the chamois from the goat; and, lastly, the bull-dog, which is characterised by its large bones and strongly-developed muscles from every other kind of dog. The estimation of the facial angle, the determination of which, according to Professor Owen, is also difficult in 
the great apes, owing to the very prominent supra-orbital ridges, in the present case is rendered still more difficult from the absence both of the auditory opening and of the nasal spine. But if the proper horizontal position of the skull be taken from the remaining portions of the orbital plates, and the ascending line made to touch the surface of the frontal bone behind the prominent supra-orbital ridges, the facial angle is not found to exceed $56^{\circ} *$ Unfortunately, no portions of the facial bones, whose conformation is so decisive as regards the form and expression of the head, have been preserved. The cranial capacity, compared with the uncommon strength of the corporeal frame, would seem to indicate a small cerebral development. The skull, as it is, holds about 31 ounces of millet-seed ; and as, from the proportionate size of the wanting bones, the whole cranial cavity should have about 6 ounces more added, the contents, were it perfect, may be taken at 37 ounces. Tiedemann assigns, as the cranial contents in the Negro, 40,38 , and 35 ounces. The cranium holds rather more than 36 ounces of water, which corresponds to a capacity of 1033.24 cubic centimetres. Huschke estimates the cranial contents of a Negress at 1127 cubic centimetres; of an old Negro at 1146 cubic centimetres. The capacity of the Malay skulls, estimated by water, equalled 36,33 ounces, whilst in the diminutive Hindoos it falls to as little as 27 ounces."

After comparing the Neanderthal cranium with many others, ancient and modern, Professor Schaaffhausen concludes thus :-

"But the human bones and cranium from the Neanderthal exceed all the rest in those peculiarities of conformation which lead to the conclusion of their belonging to a barbarous and savage race. Whether the cavern in which they were found, unaccompanied with any trace of human art, were the place of their interment, or whether, like the bones of extinct.animals elsewhere, they had been washed into it, they may still be regarded as the most ancient memorial of the early inhabitants of Europe."

Mr. Busk, the translator of Dr. Schaaffhausen's paper, has enabled us to form a very vivid conception of the degraded character of the Neanderthal skull, by placing

* Estimating the facial angle in the way suggested, on the cast I should place it at $64^{\circ}$ to $67^{\circ}-\mathrm{G}$. B. 
side by side with its outline, that of the skull of a Chimpanzee, drawn to the same absolute size.

Some time after the publication of the translation of Professor Schaaffhausen's Memoir, I was led to study the cast of the Neanderthal cranium with more attention than I had previously bestowed upon it, in consequence of wishing to supply Sir Charles Lyell with a diagram, exhibiting the special peculiarities of this skull, as compared with other human skulls. In order to do this it was necessary to identify, with precision, those points in the skulls compared which corresponded anatomically. Of these points, the glabella was obvious enough; but when I had distinguished another, defined by the occipital protuberance and superior semicircular line, and had placed the outline of the Neanderthal skull against that of the Engis skull, in such a position that the glabella and occipital protuberance of both were intersected by the same straight line, the difference was so vast and the flattening of the Neanderthal skull so prodigious (compare Figs. 22 and 24, A.), that $I$ at first imagined I must have fallen into some error. And I was the more inclined to suspect this, as, in ordinary human skulls, the occipital protuberance and superior semicircular curved line on the exterior of the occiput correspond pretty closely with the 'lateral sinuses' and the line of attachment of the tentorium internally. But on the tentorium rests, as I have said in the preceding Essay, the posterior lobe of the brain; and hence, the occipital protuberance, and the curved line in question, indicate, approximately, the lower limits of that lobe. Was it possible for a human being to have the brain thus flattened and depressed; or, on the other hand, had the muscular ridges shifted their position? In order to solve these doubts, and to decide the question whether the great supraciliary projections did, or did not, arise from the development of the frontal sinuses, I requested Sir Charles Lyell to be so good as to obtain for me from Dr. Fuhlrott, the possessor of the skull, answers to certain queries, and if possible a cast, or at any rate drawings, or photographs, of the interior of the skull.

Dr. Fuhlrott replied with a courtesy and readiness for which I am infinitely indebted to him, to my inquiries, and furthermore sent three excellent photographs. One 


\section{ON SOME FOSSIL REMAINS OF MAN}
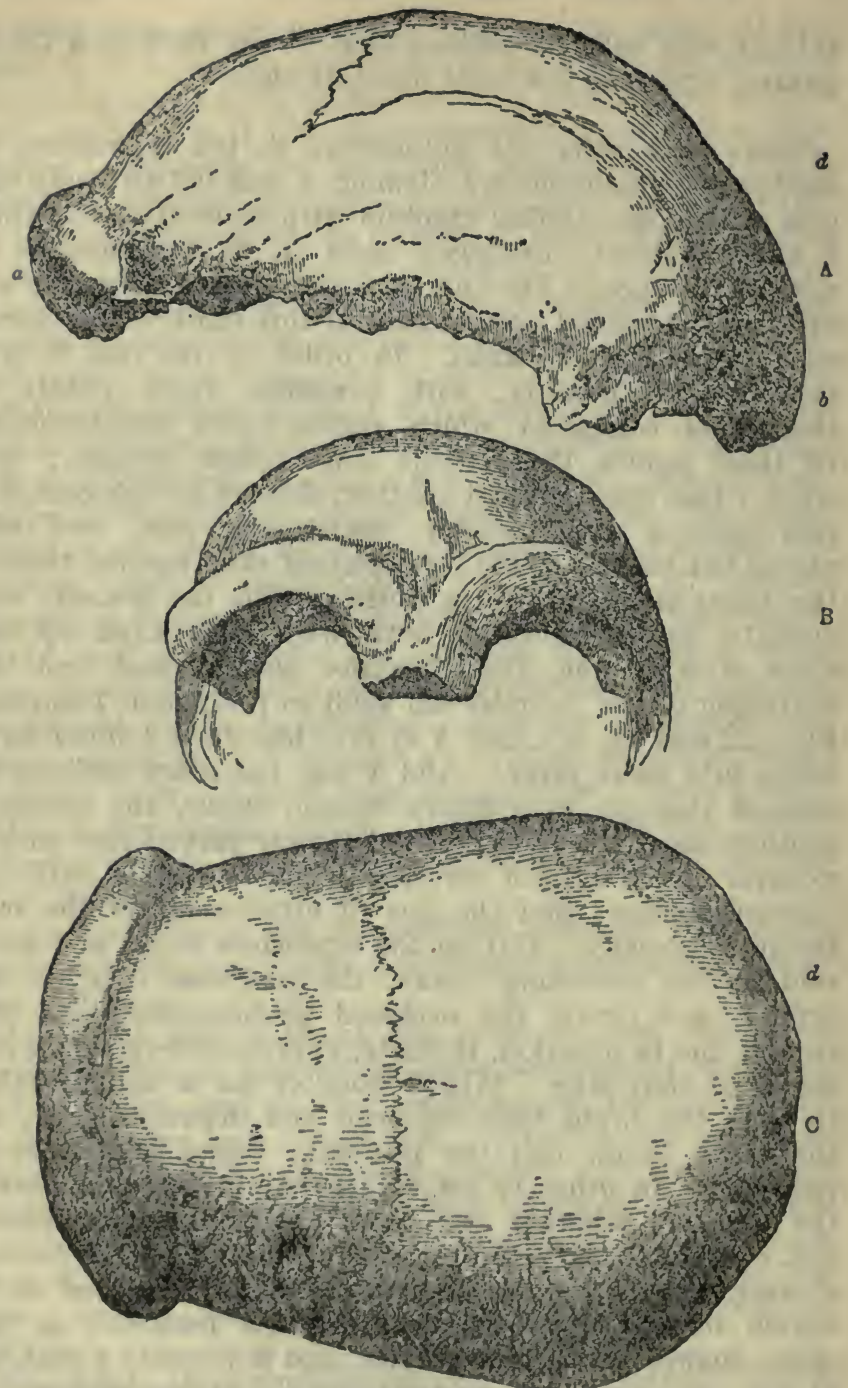

Fia. 24. - The skull from the Neanderthal cavern. A. side, B. front, and C. top view. One-third the natural size. The outlines from camera lucida drawings, one-halt the natural size, by Mr. Busk: the detalls from the cast and from Dr. Fuhlrott's photographs. a glabella : b occipital protuberance : d lambdoldal suture. 


\section{ON SOME FOSSIL REMAINS OF MAN 317}

of these gives a side view of the skull, and from it Fig. 24, A. has been shaded. The second (Fig. 25, A.) exhibits the wide openings of the frontal sinuses upon the inferior surface of the frontal part of the skull, into which, Dr. Fuhlrott writes, "a probe may be introduced to the depth of an inch," and demonstrates the great extension of the thickened supraciliary ridges beyond the cerebral cavity. The third, lastly (Fig. 25, B.), exhibits the edge and the interior of the posterior, or occipital, part of the skull, and shows very clearly the two depressions for the lateral sinuses, sweeping inwards towards the middle line of the roof of the skull, to form the longitudinal sinus. It was clear, therefore, that I had not erred in my interpretation, and that the posterior lobe of the brain of the Neanderthal man must have been as much flattened as I suspected it to be.

In truth, the Neanderthal cranium has most extraordinary characters. It has an extreme length of 8 inches, while its breadth is only 5.75 inches, or, in other words, its length is to its breadth as $100: 72$. It is exceedingly depressed, measuring only about 3.4 inches from the glabello-occipital line to the vertex. The longitudinal arc, measured in the same way as in the Engis skull, is 12 inches; the transverse arc cannot be exactly ascertained, in consequence of the absence of the temporal bones, but was probably about the same, and certainly exceeded 101 inches. The horizontal circumference is 23 inches. But this great circumference arises largely from the vast development of the supraciliary ridges, though the perimeter of the brain case itself is not small. The large supraciliary ridges give the forehead a far more retreating appearance than its internal contour would bear out.

To an anatomical eye the posterior part of the skull is even more striking than the anterior. The occipital protuberance occupies the extreme posterior end of the skull, when the glabello-occipital line is made horizontal, and so far from any part of the occipital region extending beyond it, this region of the skull slopes obliquely upward and forward, so that the lambdoidal suture is situated well upon the upper surface of the cranium. At the same time, notwithstanding the great length of the skull, the sagittal suture is remarkably short ( $4 \frac{1}{2}$ inches), and the squamosal suture is very straight. 


\section{ON SOME FOSSIL REMAINS OF MAN}

In reply to my questions Dr. Fuhlrott writes that the occipital bone "is in a state of perfect preservation as far as the upper semicircular line, which is a very strong ridge, linear at its extremities, but enlarging towards the middle, where it forms two ridges (bourrelets), united by a linear continuation, which is slightly depressed in the middle."
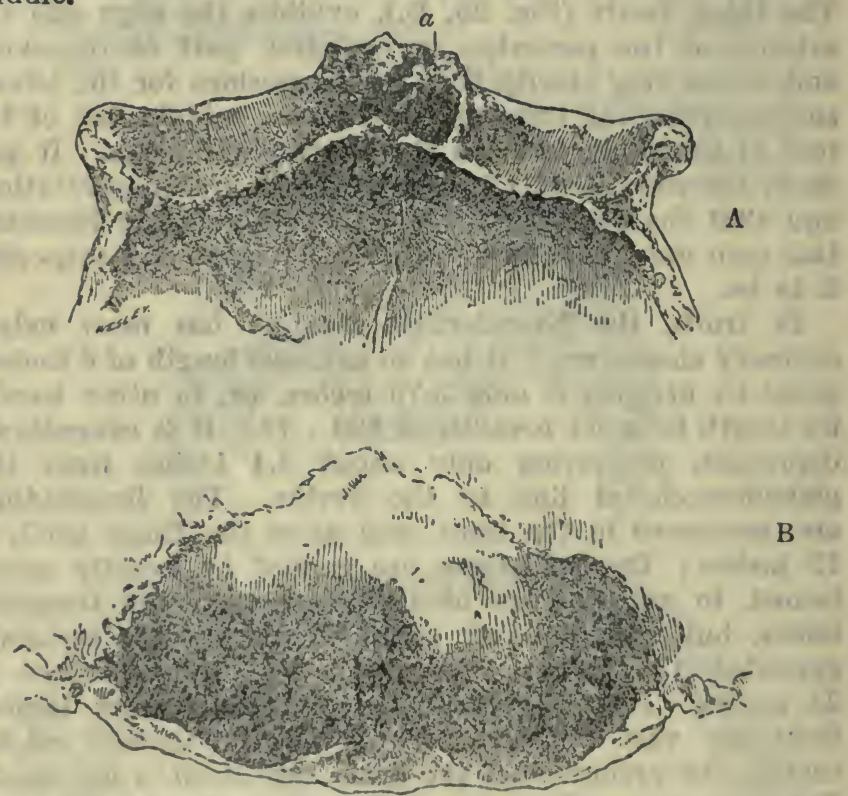

a

$a$

Fra. 25.-Drawings from Dr. Fuhlrolt's photographs of parts of the interior of the Neanderthal cramum. A. view of the under and inner surface of the frontal region, showing the inferior apertures of the frontal sinuses $(a)$. B. corresponding view of the occipital region of the skull, showing the impressions of the lateral sinuses $(a \quad a)$.

"Below the left ridge the bone exhibits an obliquely inclined surface, six lines (French) long, and twelve lines wide."

This last must be the surface, the contour of which is shown in Fig. 24, A., below $b$. It is particularly interesting, as it suggests that, notwithstanding the flattened condition of the occiput, the posterior cerebral lobes must have projected considerably beyond the cerebellum, and as it 
constitutes one among several points of similarity between the Neanderthal cranium and certain Australian skulls.

Such are the two best known forms of human cranium, which have been found in what may be fairly termed a fossil state. Can either be shown to fill up or diminish, to any appreciable extent, the structural interval which exists between Man and the man-like apes ? Or, on the other hand, does neither depart more widely from the average structure of the human cranium, than normally formed skulls of men are known to do at the present day ?

It is impossible to form any opinion on these questions, without some preliminary acquaintance with the range of variation exhibited by human structure in generala subject which has been but imperfectly studied, while even of what is known, my limits will necessarily allow me to give only a very imperfect sketch.

The student of anatomy is perfectly well aware that there is not a single organ of the human body the structure of which does not vary, to a greater or less extent, in different individuals. The skeleton varies in the proportions, and even to a certain extent in the connexions, of its constituent bones. The muscles which move the bones vary largely in their attachments. The varieties in the mode of distribution of the arteries are carefully classified, on account of the practical importance of a knowledge of their shiftings to the surgeon. The characters of the brain vary immensely, nothing being less constant than the form and size of the cerebral hemispheres, and the richness of the convolutions upon their surface, while the most changeable structures of all in the human brain, are exactly those on which the unwise attempt has been made to base the distinctive characters of humanity, viz. the posterior cornu of the lateral ventricle, the hippocampus minor, and the degree of projection of the posterior lobe beyond the cerebellum. Finally, as all the world knows, the hair and skin of human beings may present the most extraordinary diversities in colour and in texture.

So far as our present knowledge goes, the majority of the structural varieties to which allusion is here made, are individual. The ape-like arrangement of certain muscles which is occasionally met with * in the white

* See an excellent Essay by Mr. Church on the Myology of the Orang, in the Natural History Review, for 1861. 
races of mankind, is not known to be more common among Negroes or Australians: nor because the brain of the Hottentot Venus was found to be smoother, to have its convolutions more symmetrically disposed, and to be, so far, more ape-like than that of ordinary Europeans, are we justified in concluding a like condition of the brain to prevail universally among the lower races of mankind, however probable that conclusion may be.

We are, in fact, sadly wanting in information respecting the disposition of the soft and destructible organs of every Race of Mankind but our own ; and even of the skeleton, our Museums are lamentably deficient in every part but the cranium. Skulls enough there are, and since the time when Blumenbach and Camper first called attention to the marked and singular differences which they exhibit, skull collecting and skull measuring has been a zealously pursued branch of Natural History, and the results obtained have been arranged and classified by various writers, among whom the late active and able Retzius must always be the first named.

Human skulls have been found to differ from one another, not merely in their absolute size and in the absolute capacity of the brain case, but in the proportions which the diameters of the latter bear to one another; in the relative size of the bones of the face (and more particularly of the jaws and teeth) as compared with those of the skull; in the degree to which the upper jaw (which is of course followed by the lower) is thrown backwards and downwards under the fore-part of the brain case, or forwards and upwards in front of and beyond it. They differ further in the relations of the transverse diameter of the face, taken through the cheek bones, to the transverse diameter of the skull; in the more rounded or more gable-like form of the roof of the skull, and in the degree to which the hinder part of the skull is flattened or projects beyond the ridge, into and below which, the muscles of the neck are inserted.

In some skulls the brain case may be said to be 'round,' the extreme length not exceeding the extreme breadth by a greater proportion than 100 to 80 , while the difference may be much less. * Men possessing such skulls were termed by Retzius 'brachycephalic,' and the skull of a

- In no normal human skull does the breadth of the brain-case exceed its length. 
Calmuck, of which a front and side view (reduced outline copies of which are given in Figure 26) are depicted by Von Baer in his excellent " Crania selecta," affords a very admirable example of that kind of skull. Other skulls, such as that of a Negro copied in Fig. 27 from Mr. Busk's 'Crania typica,' have a very different, greatly elongated form, and may be termed 'oblong.' In this skull the extreme length is to the extreme breadth as 100 to not more than 67 , and the transverse diameter of the human skull may fall below even this proportion. People having such skulls were called by Retzius ' dolichocephalic.'

The most cursory glance at the side views of these two skulls will suffice to prove that they differ, in another respect, to a very striking extent. The profile of the face of the Calmuck is almost vertical, the facial bones being thrown downwards and under the forepart of the skull. The profile of the face of the Negro, on the other hand, is singularly inclined, the front part of the jaws projecting far forward beyond the level of the fore part of the skull. In the former case the skull is said to be 'orthognathous' or straight-jawed ; in the latter, it is called 'prognathous,' a term which has been rendered, with more force than elegance, by the Saxon equivalent,- ' snouty.'

Various methods have been devised in order to express with some accuracy the degree of prognathism or orthognathism of any given skull ; most of these methods being essentially modifications of that devised by Peter Camper, in order to attain what he called the 'facial angle.'

But a little consideration will show that any 'facial angle' that has been devised, can be competent to express the structural modifications involved in prognathism and orthognathism, only in a rough and general sort of way. For the lines, the intersection of which forms the facial angle, are drawn through points of the skull, the position of each of which is modified by a number of circumstances, so that the angle obtained is a complex resultant of all these circumstances, and is not the expression of any one definite organic relation of the parts of the skull.

I have arrived at the conviction that no comparison of crania is worth very much, that is not founded upon the establishment of a relatively fixed base line, to which the measurements, in all cases, must be referred. Nor do I think it is a very difficult matter to decide what that base line should be. The parts of the skull, like those of the 
322 ON SOME FOSSIL REMAINS OF MAN

rest of the animal framework, are developed in succession the base of the skull is formed before its sides and roof;

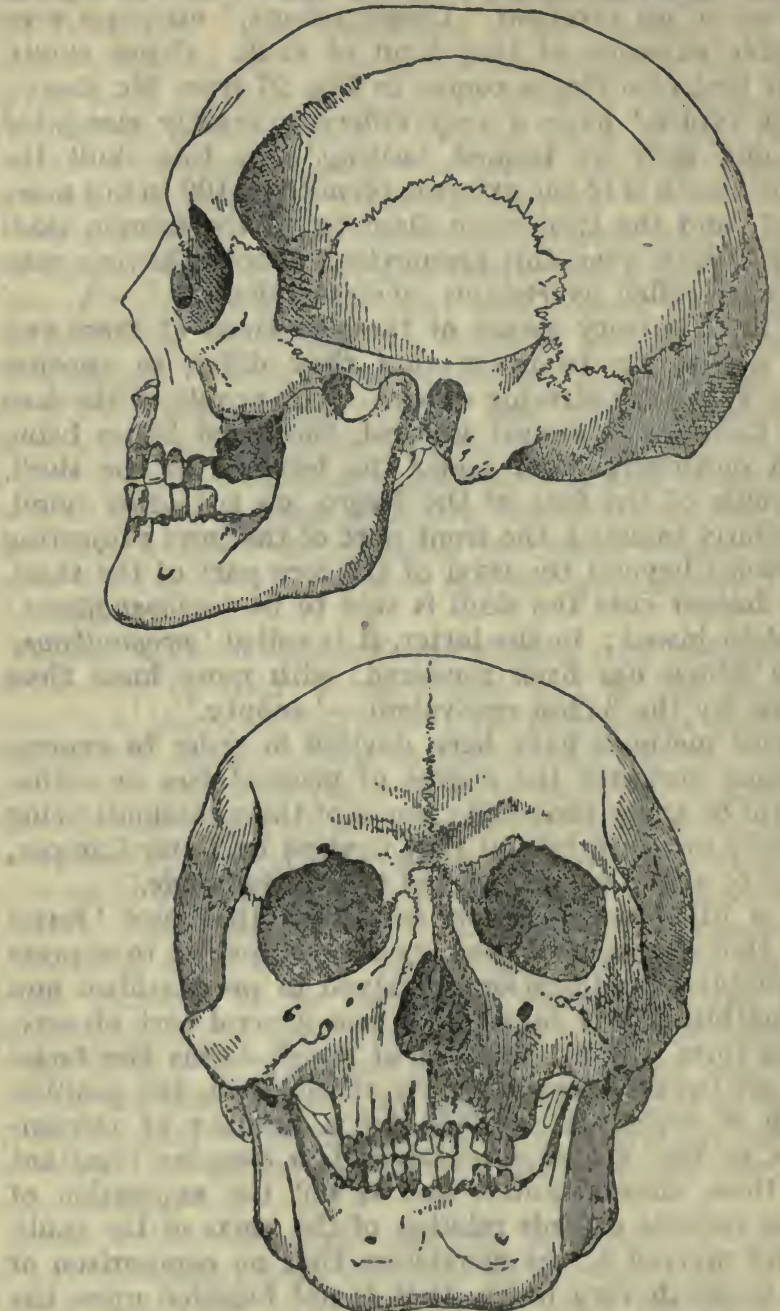

FiG. 26. - Side and front views of the round and orthognathous skull of a Calmuck, after Von Baer. One-third the natural size.

it is converted into cartilage earlier and more completely than the sides and roof: and the cartilaginous base ossi- 
fles, and becomes soldered into one piece long before the roof. I conceive then that the base of the skull may be demonstrated developmentally to be its relatively fixed part, the roof and sides being relatively moveable.

The same truth is exemplified by the study of the modifications which the skull undergoes in ascending from the lower animals up to man.

In such a mammal as a Beaver (Fig. 28), a line (a. b.) drawn through the bones, termed basioccipital, basisphenoid, and presphenoid, is very long in proportion to the extreme length of the cavity which contains the cerebral hemispheres $(g . h$.$) . The plane of the occipital foramen$ (b. c.) forms a slightly acute angle with this 'basicranial axis,' while the plane of the tentorium (i. T. ) is inclined at rather more than $90^{\circ}$ to the 'basicranial axis'; and so is the plane of the perforated plate $(a . d$.$) , by which$ the filaments of the olfactory nerve leave the skull. Again, a line drawn through the axis of the face, between the bones called ethmoid and vomer-the "basifacial axis" $(f . e$.$) forms an exceedingly obtuse angle, where, when$ produced, it cuts the 'basicranial axis.'

If the angle made by the line $b$. $c$. with $a . b$, be called the 'occipital angle,' and the angle made by the line $a$. $d$. with $a . b$. be termed the 'olfactory angle,' and that made by $i$. $T$. with $a$. $b$. the 'tentorial angle,' then all these, in the mammal in question, are nearly right angles, varying between $80^{\circ}$ and $110^{\circ}$. The angle e. $f$. b., or that made by the cranial with the facial axis, and which may be termed the 'cranio-facial angle,' is extremely obtuse, amounting, in the case of the Beaver, to at least $150^{\circ}$.

But if a series of sections of mammalian skulls, intermediate between a Rodent and a Man (Fig. 28), be examined, it will be found that in the higher crania the basicranial axis becomes shorter relatively to the cerebral length; that the 'olfactory angle' and 'occipital angle' become more obtuse; and that the 'cranio-facial angle' becomes more acute by the bending down, as it were, of the facial axis upon the cranial axis. At the same time, the roof of the cranium becomes more and more arched, to allow of the increasing height of the cerebral hemispheres, which is eminently characteristic of man, as well as of that backward extension, beyond the cerebellum, which reaches its maximum in the South America Monkeys. So that, at last, in the human skull (Fig. 29), 
324 ON SOME FOSSIL REMAINS OF MAN

the cerebral length is between twice and thrice as great as the length of the basicranial axis; the olfactory plane is

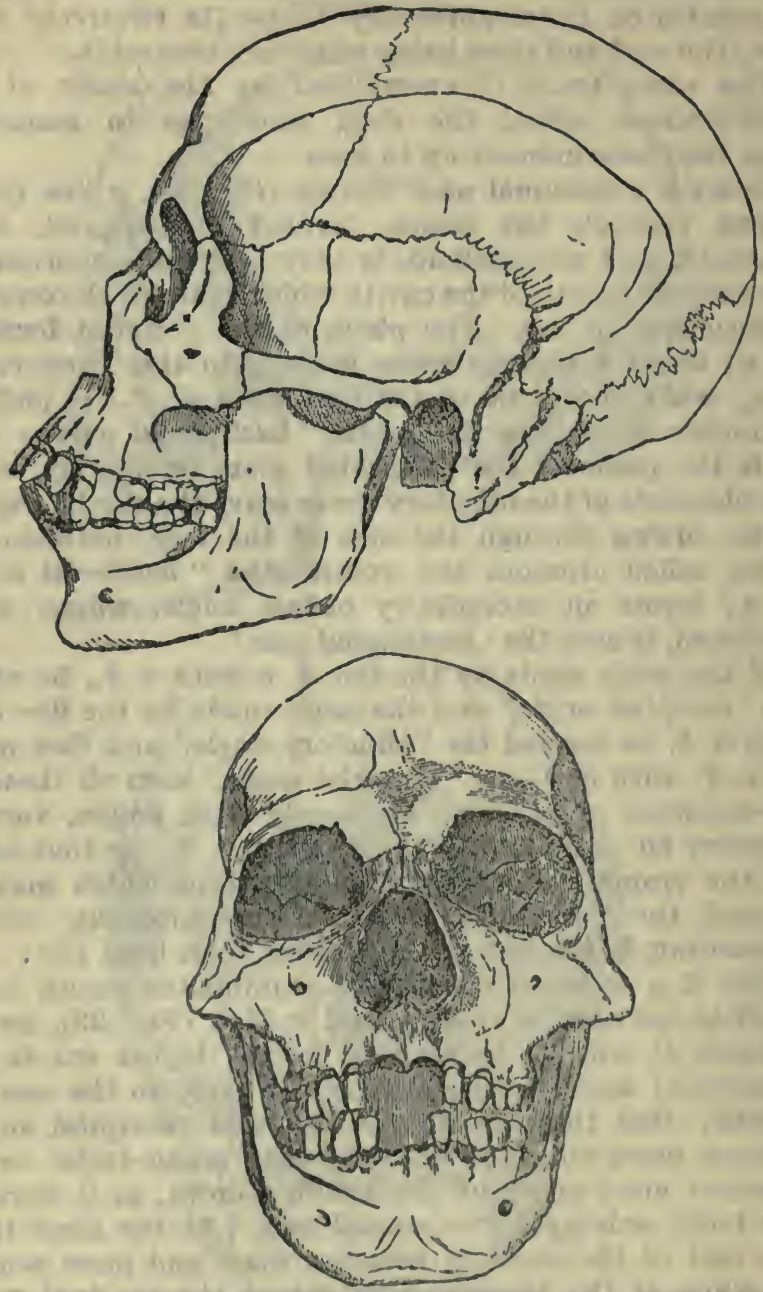

F16. 27.-Oblong and prognathous skull of a Negro : side and front vlews. One-third of the natural size.

$20^{\circ}$ or $30^{\circ}$ on the under side of that axis; the occipital angle, instead of being less than $90^{\circ}$, is as much as $150^{\circ}$ 
or $160^{\circ}$; the cranio-facial angle may be $90^{\circ}$ or less, and the vertical height of the skull may have a large proportion to its length.

It will be obvious, from an inspection of the diagrams, that the basicranial axis is, in the ascending series of Mammalia, a relatively fixed line, on which the bones of the sides and roof of the cranial cavity, and of the face, may be said to revolve downwards and forwards or backwards, according to their position. The arc described by any one bone or plane, however, is not by any means always in proportion to the arc described by another.

Now comes the important question, can we discern, between the lowest and the highest forms of the human cranium anything answering, in however slight a degree, to this revolution of the side and roof bones of the skull upon the basicranial axis observed upon so great a scale in the mammalian series? Numerous observations lead me to believe that we must answer this question in the affirmative.

The diagrams in Figure 29 are reduced from very carefully made diagrams of sections of four skulls, two round and orthognathous, two long and prognathous, taken longitudinally and vertically, through the middle. The sectional diagrams have then been superimposed, in such a manner, that the basal axes of the skulls coincide by their anterior ends, and in their direction. The deviations of the rest of the contours (which represent the interior of the skulls only) show the differences of the skulls from one another, when these axes are regarded as relatively fixed lines.

The dark contours are those of an Australian and of a Negro skull: the light contours are those of a Tartar skull, in the Museum of the Royal College of Surgeons; and of a well developed round skull from a cemetery in Constantinople, of uncertain race, in my own possession.

It appears, at once, from these views, that the prognathous skulls, so far as their jaws are concerned, do really differ from the orthognathous in much the same way as, though to a far less degree than, the skulls of the lower mammals differ from those of Man. Furthermore, the plane of the occipital foramen $(b c)$ forms a somewhat smaller angle with the axis in these particular prognathous skulls than in the orthognathous; and the like may be slightly true of the perforated plate of the ethmoid- 


\section{ON SOME FOSSIL REMAINS OF MAN}

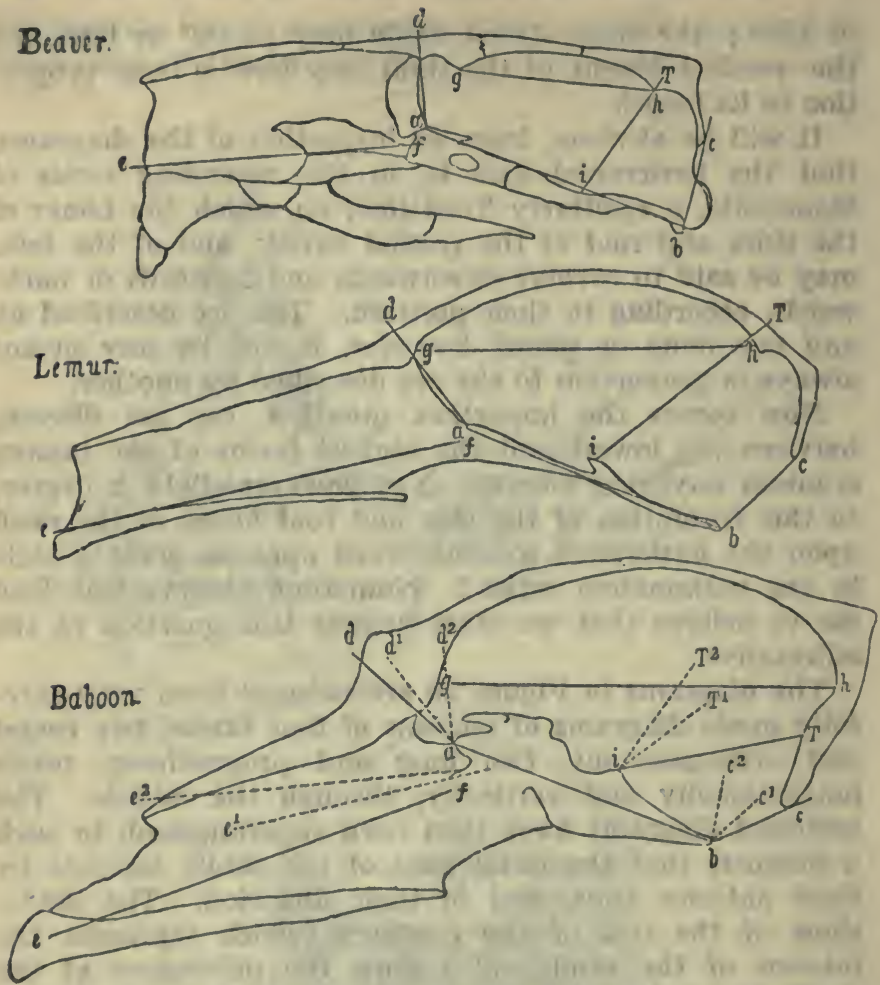

Fig. 28.-Longitudinal and vertical sections of the skulls of a Beaver (Castor Canadensis), a Lemur (L. Calla), and a Baboon (Cynocephalis $\left.l^{\prime} a p i o\right), a b$, the basicranial axis ; $b c$, the occipital plane ; $t T$, the tentorfal plane: $a d$, the olfactory plane; $f e$, the basifacial axis ; c $b a$, occipital angle; $T t a$, tentorial angle; $d a b$, olfactory angle ; $e f b$, cranio-facial angle; $g h$, extreme length of the cavity which lodges the cerebral hemisplieres or "cerebral length.' The length of the basicranial axis as to this length, or, in other words, the proportional length of the line $g h$ to that of $a b$ taken as 100 , in the three skulls, is as follows:-Beaver 70 to 100 ; Lemur 119 to 100 ; Baboon 144 to 100. In an adult male Gorilla the cerebral length is as 170 to the basicranial axis taken as 100, in the Negro (Fig. 29) as 236 to 100. In the Constantinople skull (Fig. 29) as 266 to 100 . The cranial difference between the highest Ape's skull and the lowest Man's is therefore very strikingly brought out by these measurements.

In the diagram of the Baboon's skull the dotted lines $d_{1} d_{2}$, etc., give the angles of the Lemur's and Beaver's skull, as laid down upon the basicranial axis of the Baboon. The line $a b$ has the same length in each diagram. 


\section{ON SOME FOSSIL REMAINS OF MAN}

though this point is not so clear. But it is singular to remark that, in another respect, the prognathous skulls are less ape-like than the orthognathous, the cerebral cavity projecting decidedly more beyond the anterior end of the axis in the prognathous, than in the orthognathous, skulls.

It will be observed that these diagrams reveal an immense range of variation in the capacity and relative proportion to the cranial axis, of the different regions of the cavity which contains the brain, in the different skulls. Nor is the difference in the extent to which the cerebral overlaps the cerebellar cavity less singular. A round skull (Fig. 29, Const.) may have a greater posterior cerebral projection than a long one (Fig. 29, Negro).

Until human crania have been largely worked out in a manner similar to that here suggested-until it shall be an opprobrium to an ethnological collection to possess a single skull which is not bisected longitudinally-until the angles and measurements here mentioned, together with a number of others of which I cannot speak in this place, are determined, and tabulated with reference to the basicranial axis as unity, for large numbers of skulls of the different races of Mankind, I do not think we shall have any very safe basis for that ethnological craniology which aspires to give the anatomical characters of the crania of the different Races of Mankind.

At present, I believe that the general outlines of what may be safely said upon that subject may be summed up in a very few words. Draw a line on a globe from the Gold Coast in Western Africa to the steppes of Tartary. At the southern and western end of that line there live the most dolichocephalic, prognathous, curly-haired, darkskinned of men - the true Negroes. At the northern and eastern end of the same line there live the most brachycephalic, orthognathous, straight-haired, yellow-skinned of men-the Tartars and Calmucks. The two ends of this imaginary line are indeed, so to speak, ethnological antipodes. A line drawn at right angles, or nearly so, to this polar line through Europe and Southern Asia to Hindostan, would give us a sort of equator, around which round-headed, oval-headed, and oblong-headed, prognathous and orthognathous, fair and dark races-but none possessing the excessively marked characters of Calmuck or Negro-group themselves. 
It is worthy of notice that the regions of the antipodal races are antipodal in climate, the greatest contrast the world affords, perhaps, being that between the damp, hot,

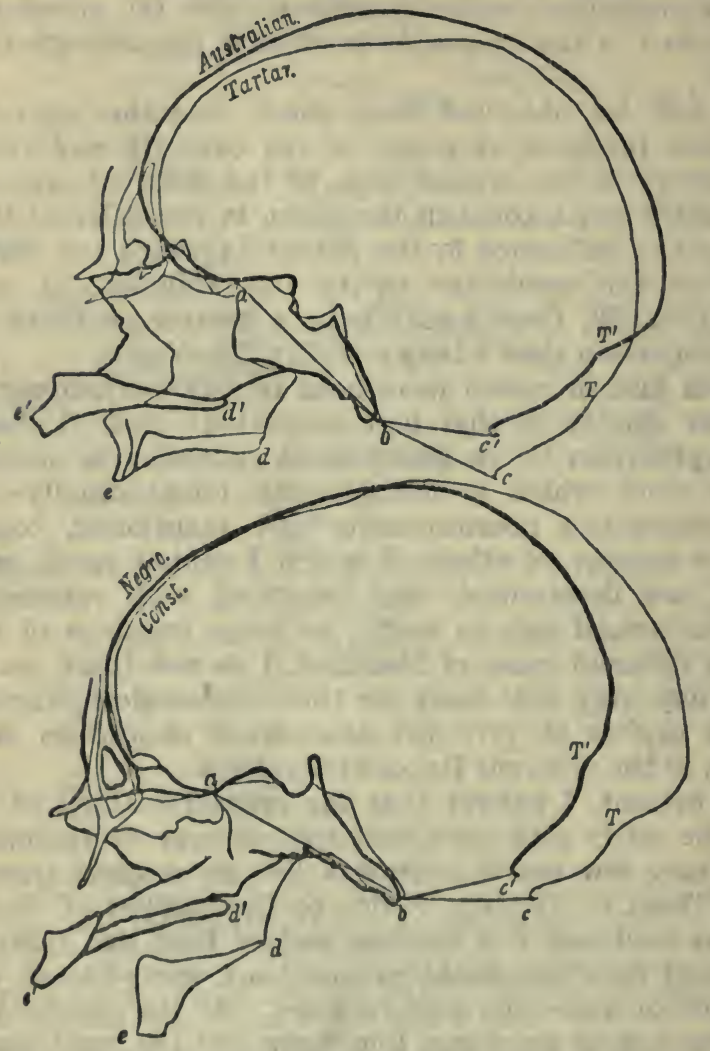

FiG. 29.-Sections of orthognathous (light contour) and prognathous (dark contour) skulls, one-third of the natural size. $a b$. Basicranial axis ; $b c, b^{\prime} c^{\prime}$, plane of the occipital foramen; $d d^{\prime}$, hinder end of the palatine bone; $e e^{\prime}$, tront end of the upper jaw; $T T^{\prime}$, insertion of the tentorium.

steaming, alluvial coast plains of the West Coast of Africa and the arid, elevated steppes and plateaux of Central Asia, bitterly cold in winter, and as far from the sea as any part of the world can be.

From Central Asia eastward to the Pacific Islands and 
subcontinents on the one hand, and to America on the other, brachycephaly and orthognathism gradually diminish, and are replaced by dolichocephaly and prognathism, less, however, on the American Continent (throughout the whole length of which a rounded type of skull prevails largely, but not exclusively) * than in the Pacific region, where, at length, on the Australian Continent and in the adjacent islands, the oblong skull, the projecting jaws, and the dark skin reappear; with so much departure, in other respects, from the Negro type, that ethnologists assign to these people the special title of 'Negritoes.'

The Australian skull is remarkable for its narrowness and for the thickness of its walls, especially in the region of the supraciliary ridge, which is frequently, though not by any means invariably, solid throughout, the frontal sinuses remaining undeveloped. The nasal depression, again, is extremely sudden, so that the brows overhang and give the countenance a particularly lowering, threaten. ing expression. The occipital region of the skull, also, not unfrequently becomes less prominent; so that it not only fails to project beyond a line drawn perpendicular to the hinder extremity of the glabello-occipital line, but even, in some cases, begins to shelve away from it, forwards, almost immediately. In consequence of this circumstance, the parts of the occipital bone which lie above and below the tuberosity make a much more acute angle with one another than is usual, whereby the hinder part of the base of the skull appears obliquely truncated. Many Australian skulls have a considerable height, quite equal to that of the average of any other race, but there are others in which the cranial roof becomes remarkably depressed, the skull, at the same time, elongating so much that, probably, its capacity is not diminished. The majority of skulls possessing these characters, which I have seen, are from the neighbourhood of Port Adelaide in South Australia, and have been used by the natives as water vessels; to which end the face has been knocked away, and a string passed through the vacuity and the occipital foramen, so that the skull was suspended by the greater part of its basis.

Figure 30 represents the contour of a skull of this kind from Western Port, with the jaw attached, and of the Nean-

"See Dr. D. Wilson's valuable paper " On the supposed prevalence of one Cranial Type throughout the American aborigines." Canadian Journal, vol. ii., 1857. 
derthal skull, both reduced to one-third of the size of nature. A small additional amount of flattening and lengthening, with a corresponding increase of the supraciliary ridge, would convert the Australian brain case into a form identical with that of the aberrant fossil.

And now, to return to the fossil skulls, and to the rank which they occupy among, or beyond, these existing varieties of cranial conformation. In the first place, I

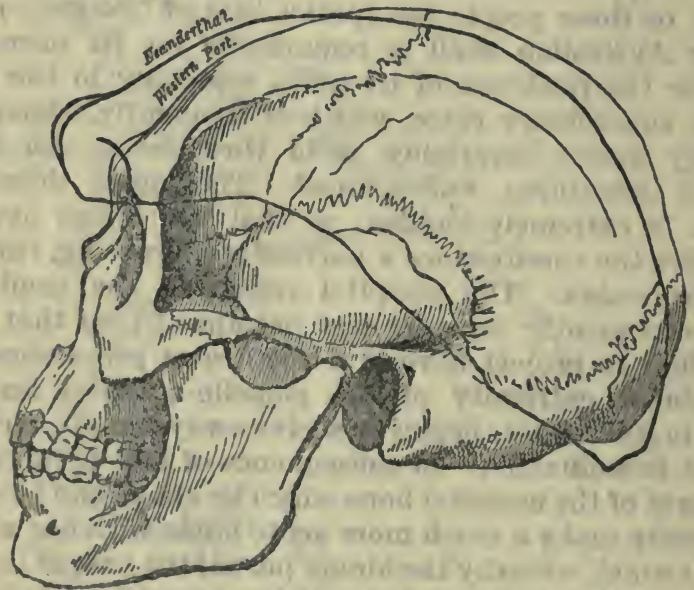

FIG. 30.-An Australian skull from Western Porf, In the Museum of the Royal College of Surgeons, with the contour of the Neanderthal skull. Both reduced to one-third the natural size.

must remark, that, as Professor Schmerling well observed (supra, p. 300) in commenting upon the Engis skull, the formation of a safe judgment upon the question is greatly hindered by the absence of the jaws from both the crania, so that there is no means of deciding, with certainty, whether they were more or less prognathous than the lower existing races of mankind. And yet, as we have seen, it is more in this respect than any other, that human skulls vary, towards and from, the brutal type - the brain case of an average dolichocephalic European differing far less from that of a Negro, for example, than his jaws do. In the absence of the jaws, then, any judgment on the relations of the fossil skulls to recent Races must be accepted with a certain reservation, 
But taking the evidence as it stands, and turning first to the Engis skull, I confess I can find no character in the remains of that cranium which, if it were a recent skull, would give any trustworthy clue as to the Race to which it might appertain. Its contours and measurements agree very well with those of some Australian skulls which I have examined-and especially has it a tendency towards that occipital flattening, to the great extent of which, in some Australian skulls, I have alluded. But all Australian skulls do not present this flattening, and the supraciliary ridge of the Engis skull is quite unlike that of the typical Australians.

On the other hand, its measurements agree equally well with those of some European skulls. And assuredly, there is no mark of degradation about any part of its structure. It is, in fact, a fair average human skull, which might have belonged to a philosopher, or might have contained the thoughtless brains of a savage.

The case of the Neanderthal skull is very different. Under whatever aspect we view this cranium, whether we regard its vertical depression, the enormous thickness of its supraciliary ridges, its sloping occiput, or its long and straight squamosal suture, we meet with ape-like characters, stamping it as the most pithecoid of human crania yet discovered. But Professor Schaaffhausen states (supra, p. 308), that the cranium, in its present condition, holds 1033.24 cubic centimetres of water, or about 63 cubic inches, and as the entire skull could hardly have held less than an additional 12 cubic inches, its capacity may be estimated at about 75 cubic inches, which is the average capacity given by Morton for Polynesian and Hottentot skulls.

So large a mass of brain as this, would alone suggest that the pithecoid tendencies, indicated by this skull, did not extend deep into the organization; and this conclusion is borne out by the dimensions of the other bones of the skeleton given by Professor Schaaffhausen, which show that the absolute height and relative proportions of the limbs were quite those of an European of middle stature. The bones are indeed stouter, but this and the great development of the muscular ridges noted by Dr. Schaaffhausen, are characters to be expected in savages. The Patagonians, exposed witlout shelter or protection to a climate possibly not very dissimilar from that of Europe at the time during 
which the Neanderthal man lived, are remarkable for the stoutness of their limb bones.

In no sense, then, can the Neanderthal bones be regarded
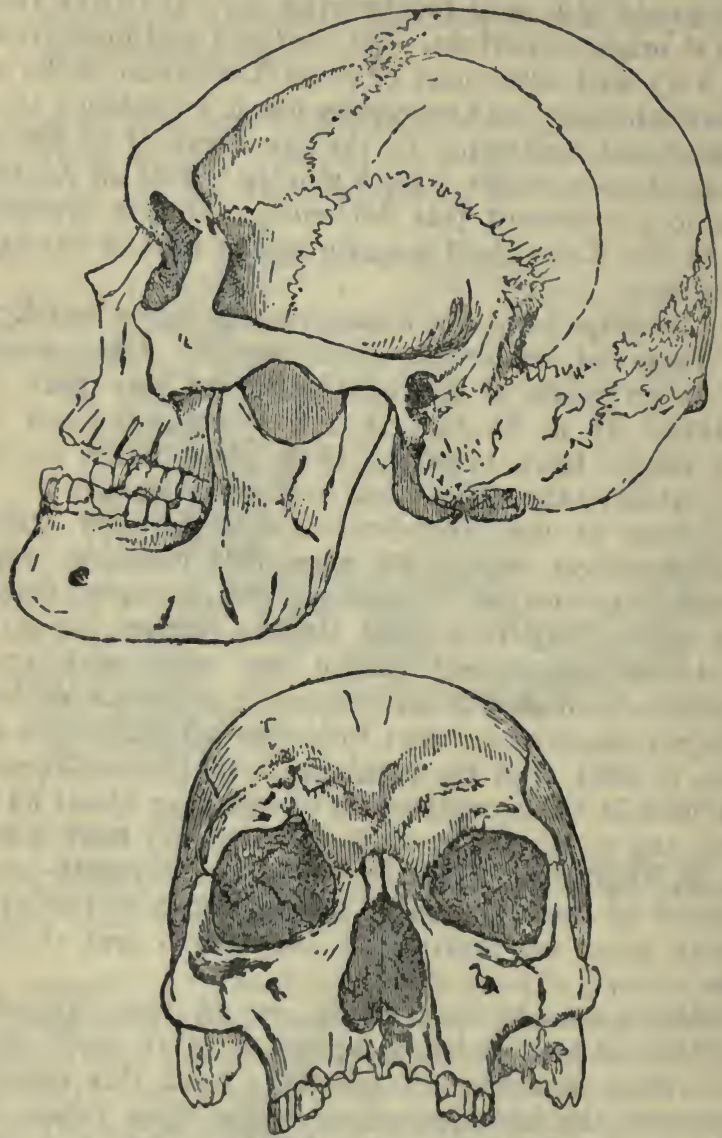

Fio. 31.-Ancient Danish skull from a tumulus at Borreby : onathird of the natural size. From a camera lucida drawing by Mr. Busk.

as the remains of a human being intermediate between Men and Apes. At most, they demonstrate the existence of a man whose skull may be said to revert somewhat towards the pithecoid type-just as a Carrier, or a Pouter, or a Tumbler, may sometimes put on the plumage of its primitive 
stock, the Columba livia. And indeed, though truly the most pithecoid of known human skulls, the Neanderthal cranium is by no means so isolated as it appears to be at first, but forms, in reality, the extreme term of a series leading gradually from it to the highest and best developed of human crania. On the one hand, it is closely approached by the flattened Australian skulls, of which I have spoken, from which other Australian forms lead us gradually up to skulls having very much the type of the Engis cranium. And, on the other hand, it is even more closely affined to the skulls of certain ancient people who inhabited Denmark during the 'stone period,' and were probably either contemporaneous with, or later than, the makers of the 'refuse heaps,' or 'Kjokkenmöddings' of that country.

The correspondence between the longitudinal contour of the Neanderthal skull and that of some of those skulls from the tumuli at Borreby, very accurate drawings of which have been made by Mr. Busk, is very close. The occiput is quite as retreating, the supraciliary ridges are nearly as prominent, and the skull is as low. Furthermore, the Borreby skull resembles the Neanderthal form more closely than any of the Australian skulls do, by the much more rapid retrocession of the forehead. On the other hand, the Borreby skulls are all somewhat broader, in proportion to their length, than the Neanderthal skull, while some attain that proportion of breadth to length (80:100) which constitutes brachycephaly.

In conclusion, I may say, that the fossil remains of Man hitherto discovered do not seem to me to take us appreciably nearer to that lower pithecoid form, by the modification of which he has, probably, become what he is. And considering what is now known of the most ancient races of men ; seeing that they fashioned flint axes and flint knives and bone-skewers, of much the same pattern as those fabricated by the lowest savages at the present day, and that we have every reason to believe the habits and modes of living os such people to have remained the same from the time of the Mammoth and the tichorhine Rhinoceros till now, I do not know that this result is other than might be expected.

Where, then, must we look for primæval Man ? Was the oldest Homo sapiens pliocene or miocene, or yet more ancient ? In still older strata do the fossilized bones of 


\section{ON SOME FOSSIL REMAINS OF MAN}

an Ape more anthropoid, or a Man more pithecoid, than any yet known await the researches of some unborn paleontologist ?

Time will show. But, in the meanwhile, if any form of the doctrine of progressive development is correct, we must extend by long epochs the most liberal estimate that has yet been made of the antiquity of Man. 


\section{ON THE \\ ADVISABLENESS OF IMPROVING \\ NATURAL KNOWLEDGE}




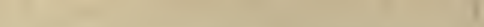

$\left(\frac{10}{2}\right.$

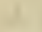
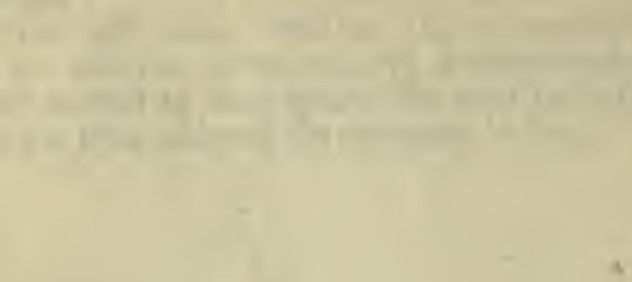

Wir $\log$

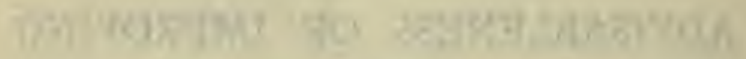

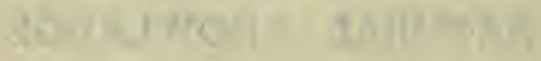




\section{ON THE ADVISABLENESS OF IMPROVING NATURAL KNOWLEDGE*}

Tris time two hundred years ago-in the beginning of January, 1666-those of our forefathers who inhabited this great and ancient city, took breath between the shocks of two fearful calamities: one not quite past, although its fury had abated; the other to come.

Within a few yards of the very spot on which we are assembled, so the tradition runs, that painful and deadly malady, the plague, appeared in the latter months of 1664 ; and, though no new visitor, smote the people of England, and especially of her capital, with a violence unknown before, in the course of the following year. The hand of a master has pictured what happened in those dismal months; and in that truest of fictions, The History of the Plague Year, Defoe shows death, with every accompaniment of pain and terror, stalking through the narrow streets of old London, and changing their busy hum into a silence broken only by the wailing of the mourners of fifty thousand dead; by the woful denunciations and mad prayers of fanatics; and by the madder yells of despairing profligates.

But, about this time in 1666 , the death-rate had sunk to nearly its ordinary amount; a case of plague occurred only here and there, and the richer citizens who had flown from the pest had returned to their dwellings. The remnant of the people began to toil at the accustomed round of duty, or of pleasure ; and the stream of city life bid fair to flow back along its old bed, with renewed and uninterrupted vigour.

The newly kindled hope was deceitful. The great plague, indeed, returned no more; but what it had done for the Londoners, the great fire, which broke out in the autumn of 1666, did for London; and, in September of that year, a heap

- A Lay Sermon delivered in St. Martin's Hall on Sunday, January 7th, 1866, and subsequently published in the Fortnightly Review. 
of ashes and the indestructible energy of the people were all that remained of the glory of five-sixths of the city within the walls.

Our forefathers had their own ways of accounting for each of these calamities. They submitted to the plague in humility and in penitence, for they believed it to be the judgment of God. But, towards the fire they were furiously indignant, interpreting it as the effect of the malice of man,as the work of the Republicans, or of the Papists, according as their prepossessions ran in favour of loyalty or of Puritanism.

It would, I fancy, have fared but ill with one who, standing where I now stand, in what was then a thickly peopled and fashionable part of London, should have broached to our ancestors the doctrine which I now propound to youthat all their hypotheses were alike wrong; that the plague was no more, in their sense, Divine judgment, than the fire was the work of any political, or of any religious, sect ; but that they were themselves the authors of both plague and fire, and that they must look to themselves to prevent the recurrence of calamities, to all appearance so peculiarly beyond the reach of human control-so evidently the result of the wrath of God, or of the craft and subtlety of an enemy.

And one may picture to one's self how harmoniously the holy cursing of the Puritan of that day would have chimed in with the unholy cursing and the crackling wit of the Rochesters and Sedleys, and with the revilings of the political fanatics, if my imaginary plain dealer had gone on to say that, if the return of such misfortunes were ever rendered impossible, it would not be in virtue of the victory of the faith of Laud, or of that of Milton; and, as little, by the triumph of republicanism, as by that of monarchy. But that the one thing needful for compassing this end was, that the people of England should second the efforts of an insignificant corporation, the establishment of which, a few years before the epoch of the great plague and the great fire, had been as little noticed, as they were conspicuous.

Some twenty years before the outbreak of the plague a few calm and thoughtful students banded themselves together for the purpose, as they phrased it, of " improving natural knowledge." The ends they proposed to attain cannot be stated more clearly than in the words of one of the founders of the organization :- 
" Our business was (precluding matters of theology and state affairs) to discourse and consider of philosophical enquiries, and such as related thereunto:-as Physick, Anatomy, Geometry, Astronomy, Navigation, Staticks, Magneticks, Chymicks, Mechanicks, and Natural Experiments; with the state of these studies and their cultivation at home and abroad. We then discoursed of the circulation of the blood, the valves in the veins, the venæ lacteæ, the lymphatic vessels, the Copernican hypothesis, the nature of comets and new stars, the satellites of Jupiter, the oval shape (as it then appeared) of Saturn, the spots on the sun and its turning on its own axis, the inequalities and selenography of the moon, the several phases of Venus and Mercury, the improvement of telescopes and grinding of glasses for that purpose, the weight of air, the possibility or impossibility of vacuities and nature's abhorrence thereof, the Torricellian experiment in quicksilver, the descent of heavy bodies and the degree of acceleration therein, with divers other things of like nature, some of which were then but new discoveries, and others not so generally. known and embraced as now they are ; with other things appertaining to what hath been called the New Philosophy, which from the times of Galileo at Florence, and Sir Francis Bacon (Lord Verulam) in England, hath been much cultivated in Italy, France, Germany, and other parts abroad, as well as with us in England."

The learned Dr. Wallis, writing in 1696, narrates in these words, what happened half a century before, or about 1645 . The associates met at Oxford, in the rooms of Dr.Wilkins, who was destined to become a bishop ; and subsequently coming together in London, they attracted the notice of the king. And it is a strange evidence of the taste for knowledge which the most obviously worthless of the Stuarts shared with his father and grandfather, that Charles the Second was not content with saying witty things about his philosophers, but did wise things with regard to them. For he not only bestowed upon them such attention as he could spare from his poodles and his mistresses, but, being in his usual state of impecuniosity, begged for them of the Duke of Ormond; and, that step being without effect, gave them Chelsea College, a charter, and a mace : crowning his favours in the best way they couid be crowned, by burdening them no further with royal patronage or state interference. 
Thus it was that the half-dozen young men, studious of the "New Philosophy," who met in one another's lodgings in Oxford or in London, in the middle of the seventeenth century, grew in numerical and in real strength, until, in its latter part, the "Royal Society for the Improvement of Natural Knowledge" had already become famous, and had acquired a claim upon the veneration of Englishmen, which it has ever since retained, as the principal focus of scientific activity in our islands, and the chief champion of the cause it was formed to support.

It was by the aid of the Royal Socicty that Newton published his Principia. If all the books in the world, except the Philosophical Transactions, were destroyed, it is safe to say that the foundations of physical science would remain unshaken, and that the vast intellectual progress of the last two centuries would be largely, though incompletely, recorded. Nor have any signs of halting or of decrepitude manifested themselves in our own times. As in Dr. Wallis's days, so in these, "our business is, precluding theology and state affairs, to discourse and consider of philosophical enquiries." But our " Mathematick" is one which Newton would have to go to school to learn; our "Staticks, Mechanicks, Magneticks, Chymicks, and Natural Experiments" constitute a mass of physical and chemical knowledge, a glimpse at which would compensate Galileo for the doings of a score of inquisitorial cardinals ; our " Physick" and "Anatomy" have embraced such infinite varieties of being, have laid open such new worlds in time and space, have grappled, not unsuccessfully, with such complex problems, that the eyes of Vesalius and of Harvey might be dazzled by the sight of the tree that has grown out of their grain of mustard seed.

The fact is perhaps rather too much, than too little, forced upon one's notice, nowadays, that all this marvellous intellectual growth has a no less wonderful expression in practical life; and that, in this respect, if in no other, the movement symbolized by the progress of the Royal Society stands without a parallel in the history of mankind.

A series of volumes as bulky as the Transactions of the Royal Society might possibly be filled with the subtle speculations of the Schoolmen; not improbably, the obtaining a mastery over the products of mediæval thought might necessitate an even greater expenditure of time and of energy than the acquirement of the "New Philosophy" : 
but though such work engrossed the best intellects of Europe for a longer time than has elapsed since the great fire, its effects were "writ in water," so far as our social state is concerned.

On the other hand, if the noble first President of the Royal Society could revisit the upper air and once more gladden his eyes with a sight of the familiar mace, he would find himself in the midst of a material civilization more different from that of his day, than that of the seventeenth was from that of the first century. And if Lord Brouncker's native sagacity had not deserted his ghost, he would need no long reflection to discover that all these great ships, these railways, these telegraphs, these factories, these printingpresses, without which the whole fabric of modern English society would collapse into a mass of stagnant and starving pauperism, - that all these pillars of our State are but the ripples, and the bubbles upon the surface of that great spiritual stream, the springs of which, only, he and his fellows were privileged to see ; and seeing, to recognise as that which it behoved them above all things to keep pure and undefiled.

It may not be too great a flight of imagination to conceive our noble revenant not forgetful of the great troubles of his own day, and anxious to know how often London had been burned down since his time, and how often the plague had carried off its thousands. He would have to learn that, although London contains tenfold the inflammable matter that it did in 1666 ; though, not content with filling our rooms "with woodwork and light draperies, we must needs lead inflammable and explosive gases into every corner of our streets and houses, we never allow even a street to burn down. And if he asked how this had come about, we should have to explain that the improvement of natural knowledge has furnished us with dozens of machines for throwing water upon fires, any one of which would have furnished the ingenious Mr. Hooke, the first " curator and experimenter" of the Royal Society, with ample materials for discourse before half a dozen meetings of that body; and that, to say truth, except for the progress of natural knowledge, we should not have been able to make even the tools by which these machines are constructed. And, further, it would be necessary to add, that although severe fires sometimes occur and inflict great damage, the loss is very generally compensated by societies, the operations of 
which have been rendered possible only by the progress of natural knowledge in the direction of mathematics, and the accumulation of wealth in virtue of other natural knowledge.

But the plague? My Lord Brouncker's observation would not, I fear, lead him to think that Englishmen of the nineteenth century are purer in life, or more fervent in religious faith, than the generation which could produce a Boyle, an Evelyn, and a Milton. He might find the mud of society at the bottom, instead of at the top, but I fear that the sum total would be as deserving of swift judgment as at the time of the Restoration. And it would be our duty to explain once more, and this time not without shame, that we have no reason to believe that it is the improvement of our faith, nor that of our morals, which keeps the plague from our city; but, again, that it is the improvement of our natural knowledge.

We have learned that pestilences will only take up their abode among those who have prepared unswept and ungarnished residences for them. Their cities must have narrow, unwatered streets, foul with accumulated garbage. Their houses must be ill-drained, ill-lighted, ill-ventilated. Their subjects must be ill-washed, ill-fed, ill-clothed. The London of 1665 was such a city. The cities of the East, where plague has an enduring dwelling, are such cities. We, in later times, have learned somewhat of Nature, and partly obey her. Because of this partial improvement of our natural knowledge and of that fractional obedience, we have no plague; because that knowledge is still very imperfect and that obedience yet incomplete, typhus is our companion and cholera our visitor. But it is not presumptuous to express the belief that, when our knowledge is more complete and our obedience the expression of our knowledge, London will count her centuries of freedom from typhus and cholera, as she now gratefully reckons her two hundred years of ignorance of that plague which swooped upon her thrice in the first half of the seventeenth century.

Surely, there is nothing in these expianations which is not fully borne out by the facts ? Surely, the principles involved in them are now admitted among the fixed beliefs of all thinking men? Surely, it is true that our countrymen are less subject to fire, famine, pestilence, and all the evils which result from a want of command over and due anticipation of the course of Nature, than were the countrymen of Milton; and health, wealth, and well-being are more 
abundant with us than with them ? But no less certainly is the difference due to the improvement of our knowledge of Nature, and the extent to which that improved knowledge has been incorporated with the household words of men, and has supplied the springs of their daily actions.

Granting for a moment, then, the truth of that which the depreciators of natural knowledge are so fond of urging, that its improvement can only add to the resources of our material civilization; admitting it to be possible that the founders of the Royal Society themselves looked for no other reward than this, I cannot confess that I was guilty of exaggeration when I hinted, that to him who had the gift of distinguishing between prominent events and important events, the origin of a combined effort on the part of mankind to improve natural knowledge might have loomed larger than the Plague and have outshone the glare of the Fire ; as a something fraught with a wealth of beneficence to mankind, in comparison with which the damage done by those ghastly evils would shrink into insignificance.

It is very certain that for every victim slain by the plague, hundreds of mankind exist and find a fair share of happiness in the world by the aid of the spinning jenny. And the great fire, at its worst, could not have burned the supply of coal, the daily working of which, in the bowels of the earth, made possible by the steam pump, gives rise to an amount of wealth to which the millions lost in old London are but as an old song.

But spinning jenny and steam pump are, after all, but toys, possessing an accidental value ; and natural knowledge creates multitudes of more subtle contrivances, the praises of which do not happen to be sung because they are not directly convertible into instruments of creating wealth. When I contemplate natural knowledge squandering such gifts among men, the only appropriate comparison I can find for her is, to liken her to such a peasant woman as one sees in the Alps, striding ever upward, heavily burdened, and with mind bent only on her home; but yet, without effort and without thought, knitting for her children. Now stockings are good and comfortable things, and the children will undoubtedly be much the better for them; but surely it would be short-sighted, to say the least of it, to depreciate this toiling mother as a mere stocking-machine-a mere provider of physical comforts ? 
However, there are blind leaders of the blind, and not a lew of them, who take this view of natural knowledge, and can see nothing in the bountiful mother of humanity but a sort of comfort-grinding machine. According to them, the improvement of natural knowledge always has been, and always must be, synonymous with no more than the improvement of the material resources and the increase of the gratifications of men.

Natural knowledge is, in their eyes, no real mother of mankind, bringing them up with kindness, and, if need be, with sternness, in the way they should go, and instructing them in all things needful for their welfare; but a sort of fairy godmother, ready to furnish her pets with shoes of swiftness, swords of sharpness, and omnipotent Aladdin's lamps, so that they may have telegraphs to Saturn, and see the other side of the moon, and thank God they are better than their benighted ancestors.

If this talk were true, I, for one, should not greatly care to toil in the service of natural knowledge. I think I would just as soon be quietly chipping my own flint axe, after the manner of my forefathers a few thousand years back, as be troubled with the endless malady of thought which now infests us all, for such reward. But I venture to say that such views are contrary alike to reason and to fact. Those who discourse in such fashion seem to me to be so intent upon trying to see what is above Nature, or what is behind her, that they are blind to what stares them in the face, in her.

I should not venture to speak thus strongly if my justification were not to be found in the simplest and most obvious facts, - if it needed more than an appeal to the most notorious truths to justify my assertion, that the improvement of natural knowledge, whatever direction it has taken, and however low the aims of those who may have commenced it-has not only conferred practical benefits on men, but, in so doing, has effected a revolution in their conceptions of the universe and of themselves, and has profoundly altered their modes of thinking and their views of right and wrong. I say that natural knowledge, seeking to satisfy natural wants, has found the ideas which can alone still spiritual cravings. I say that natural knowledge, in desiring to ascertain the laws of comfort, has been driven to discover those of conduct, and to lay the foundations of a new morality. 
Let us take these points separately ; and, first, what great ideas has natural knowledge introduced into men's minds ?

I cannot but think that the foundations of all natural knowledge were laid when the reason of man first came face to face with the facts of Nature : when the savage first learned that the fingers of one hand are fewer than those of both ; that it is shorter to cross a stream than to head it ; that a stone stops where it is unless it be moved, and that it drops from the hand which lets it go ; that light and heat come and go with the sun; that sticks burn away in a fire; that plants and animals grow and die; that if he struck his fellow-savage a blow he would make him angry, and perhaps get a blow in return, while if he offered him a fruit he would please him, and perhaps receive a fish in exchange. When men had acquired this much knowledge, the outlines, rude though they were, of mathematics, of physics, of chemistry, of biology, of moral, economical, and political science, were sketched. Nor did the germ of religion fail when science began to bud. Listen to words which, though new, are yet three thousand years old :-
“. When in heaven the stars about the moon
Look beautiful, when all the winds are laid, And every height comes out, and jutting peak And valley, and the immeasurable heavens Break open to their highest, and all the stars Shine, and the shepherd gladdens in his heart." *

If the half-savage Greek could share our feelings thus far, it is irrational to doubt that he went further, to find, as we do, that upon that brief gladness there follows a certain sorrow, - the little light of awakened human intelligence shines so mere a spark amidst the abyss of the unknown and unknowable; seems so insufficient to do more than illuminate the imperfections that cannot be remedied, the aspirations that cannot be realized, of man's own nature. But in this sadness, this consciousness of the limitation of man, this sense of an open secret which he cannot penetrate, lies the essence of all religion; and the attempt to embody it in the forms furnished by the intellect is the origin of the higher theologies.

Thus it seems impossible to imagine but that the foundations of all knowledge - secular or sacred-were laid when

* Need it be said that this is Tennyson's English for Homer's Greek ? 
intelligence dawned, though the superstructure remained for long ages so slight and feeble as to be compatible with the existence of almost any general view respecting the mode of governance of the universe. No doubt, from the first, there were certain phenomena which, to the rudest mind, presented a constancy of occurrence, and suggested that a fixed order ruled, at any rate, among them. I doubt if the grossest of Fetish worshippers ever imagined that a stone must have a god within it to make it fall, or that a fruit had a god within it to make it taste sweet. With regard to such matters as these, it is hardly questionable that mankind from the first took strictly positive and scientific views.

But, with respect to all the less familiar occurrences which present themselves, uncultured man, no doubt, has always taken himself as the standard of comparison, as the centre and measure of the world; nor could he well avoid doing so. And finding that his apparently uncaused will has a powerful effect in giving rise to many occurrences, he naturally enough ascribed other and greater events to other and greater volitions, and came to look upon the world and all that therein is, as the product of the volitions of persons like himself, but stronger, and capable of being appeased or angered, as he himself might be soothed or irritated. Through such conceptions of the plan and working of the universe all mankind have passed, or are passing. And we may now consider, what has been the effect of the improvement of natural knowledge on the views of men who have reached this stage, and who have begun to cultivate natural knowledge with no desire but that of "increasing God's honour and bettering man's estate."

For example, what could seem wiser, from a mere material point of view, more innocent, from a theological one, to an ancient people, than that they should learn the exact succession of the seasons, as warnings for their husbandmen; or the position of the stars, as guides to their rude navigators? But what has grown out of this search for natural knowledge of so merely useful a character? You all know the reply. Astronomy,-which of all sciences has filled men's minds with general ideas of a character most foreign to their daily experience, and has, more than any other, rendered it impossible for them to accept the beliefs of their fathers. Astronomy, - which tells them that this so vast and seemingly solid earth is but an atom 
among atoms, whirling, no man knows whither, through illimitable space; which demonstrates that what we call the peaceful heaven above us, is but that space, filled by an infinitely subtle matter whose particles are seething and surging, like the waves of an angry sea; which opens up to us infinite regions where nothing is known, or ever seems to have been known, but matter and force, operating according to rigid rules; which leads us to contemplate phenomena the very nature of which demonstrates that they must have had a beginning, and that they must have an end, but the very nature of which also proves that the beginning was, to our conceptions of time, infinitely remote, and that the end is as immeasurably distant.

But it is not alone those who pursue astronomy who ask for bread and receive ideas. What more harmless than the attempt to lift and distribute water by pumping it; what more absolutely and grossly utilitarian? But out of pumps grew the discussions about Nature's abhorrence of a vacuum; and then it was discovered that Nature does not abhor a vacuum, but that air has weight; and that notion paved the way for the doctrine that all matter has weight, and that the force which produces weight is co-extensive with the universe,-in short, to the theory of universal gravitation and endless force. While learning how to handle gases led to the discovery of oxygen, and to modern chemistry, and to the notion of the indestructibility of matter.

Again, what simpler, or more absolutely practical, than the attempt to keep the axle of a wheel from heating when the wheel turns round very fast? How useful for carters and gig drivers to know something about this ; and how good were it, if any ingenious person would find out the cause of such phenomena, and thence educe a general remedy for them. Such an ingenious person was Count Rumford; and he and his successors have landed us in the theory of the persistence, or indestructibility, of force. And in the infinitely minute, as in the infinitely great, the seekers after natural knowledge, of the kinds called physical and chemical, have everywhere found a definite order and succession of events which seem never to be infringed.

And how has it fared with "Physick" and Anatomy ? Have the anatomist, the physiologist, or the physician, whose business it has been to devote themselves assiduously 
to that eminently practical and direct end, the alleviation of the sufferings of mankind,-have they been able to confine their vision more absolutely to the strictly useful ? I fear they are worst offenders of all. For if the astronomer has set before us the infinite magnitude of space, and the practical eternity of the duration of the universe; if the physical and chemical philosophers have demonstrated the infinite minuteness of its constituent parts, and the practical eternity of matter and of force ; and if both have alike proclaimed the universality of a definite and predicable order and succession of events, the workers in biology have not only accepted all these, but have added more startling theses of their own. For, as the astronomers discover in the earth no centre of the universe, but an eccentric speck, so the naturalists find man to be no centre of the living world, but one amidst endless modifications of life; and as the astronomer observes the mark of practically endless time set upon the arrangements of the solar system so the student of life finds the records of ancient forms of existence peopling the world for ages, which, in relation to human experience, are infinite.

Furthermore, the physiologist finds life to be as dependent for its manifestation on particular molecular arrangements as any physical or chemical phenomenon; and, wherever he extends his researches, fixed order and unchanging causation reveal themselves, as plainly as in the rest of Nature.

Nor can I find that any other fate has awaited the germ of Religion. Arising, like all other kinds of knowledge, out of the action and interaction of man's mind, with that which is not man's mind, it has taken the intellectual coverings of Fetishism or Polytheism; of Theism or Atheism; of Superstition or Rationalism. With these, and their relative merits and demerits, I have nothing to do ; but this it is needful for my purpose to say, that if the religion of the present differs from that of the past, it is because the theology of the present has become more scientific than that of the past; because it has not only renounced idols of wood and idols of stone, but begins to see the necessity of breaking in pieces the idols built up of books and traditions and fine-spun ecclesiastical cobwebs : and of cherishing the noblest and most human of man's emotions, by worship " for the most part of the silent sort" at the altar of the Unknown and Unknowable. 
Such are a few of the new conceptions implanted in our minds by the improvement of natural knowledge. Men have acquired the ideas of the practically infinite extent of the universe and of its practical eternity; they are familiar with the conception that our earth is but an infinitesimal fragment of that part of the universe which can be seen; and that, nevertheless, its duration is, as compared with our standards of time, infinite. They have further acquired the idea that man is but one of innumerable forms of life now existing in the globe, and that the present existences are but the last of an immeasurable series of predecessors. Moreover, every step they have made in natural knowledge has tended to extend and rivet in their minds the conception of a definite order of the universewhich is embodied in what are called, by an unhappy metaphor, the laws of Nature-and to narrow the range and loosen the force of men's belief in spontaneity, or in changes other than such as arise out of that definite order itself.

Whether these ideas are well or ill founded is not the question. No one can deny that they exist, and have been the inevitable outgrowth of the improvement of natural knowledge. And if so, it cannot be doubted that they are changing the form of men's most cherished and most important convictions.

And as regards the second point-the extent to which the improvement of natural knowledge has remodelled and altered what may be termed the intellectual ethics of men, -what are among the moral convictions most fondly held by barbarous and semi-barbarous people.

They are the convictions that authority is the soundest basis of belief ; that merit attaches to a readiness to believe ; that the doubting disposition is a bad one, and scepticism a sin; that when good authority has pronounced what is to be believed, and faith has accepted it, reason has no further duty. There are many excellent persons who yet hold by these principles, and it is not my present business, or intention, to discuss their views. All I wish to bring clearly before your minds is the unquestionable fact, that the improvement of natural knowledge is effected by methods which directly give the lie to all these convictions, and assume the exact reverse of each to be true.

The improver of natural knowledge absolutely refuses to 
acknowledge authority, as such. For him, scepticism is the highest of duties; blind faith the one unpardonable sin. And it cannot be otherwise, for every great advance in natural knowledge has involved the absolute rejection of authority, the cherishing of the keenest scepticism, the annihilation of the spirit of blind faith; and the most ardent votary of science holds his firmest convictions, not because the men he most venerates hold them; not because their verity is testified by portents and wonders; but because his experience teaches him that whenever he chooses to bring these convictions into contact with their primary source, Nature-whenever he thinks fit to test them by appealing to experiment and to observationNature will confirm them. The man of science has learned to believe in justification, not by faith, but by verification.

Thus, without for a moment pretending to despise the practical results of the improvement of natural knowledge, and its beneficial influence on material civilization, it must, I think, be admitted that the great ideas, some of which I have indicated, and the ethical spirit which I have endeavoured to sketch, in the few moments which remained at my disposal, constitute the real and permanent significance of natural knowledge.

If these ideas be destined, as I believe they are, to be more and more firmly established as the world grows older ; if that spirit be fated, as I believe it is, to extend itself into all departments of human thought, and to become co-extensive with the range of knowledge; if, as our race approaches its maturity, it discovers, as I believe it will, that there is but one kind of knowledge and but one method of acquiring it ; then we, who are still children, may justly feel it our highest duty to recognise the advisableness of improving natural knowledge, and so to aid ourselves and our successors in their course towards the noble goal which lies before mankind. 


\section{ON}

THE STUDY OF ZOOLOGY 



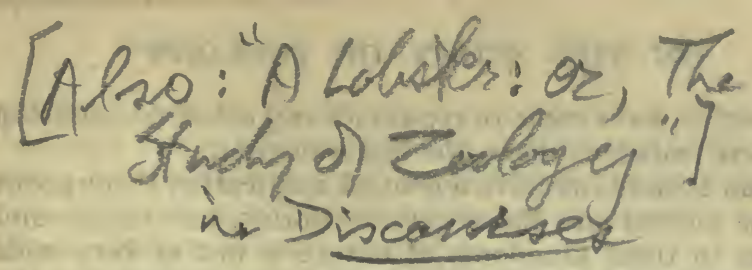

ON THE STUDY OF ZOOLOGY* $351-372$

Natural History is the name familiarly applied to the study of the properties of such natural bodies as minerals, plants, and animals; the sciences which embody the knowledge man has acquired upon these subjects are commonly termed Natural Sciences, in contradistinction to other so-called "physical" sciences; and those who devote themselves especially to the pursuit of such sciences have been and are commonly termed " Naturalists."

Linnæus was a naturalist in this wide sense, and his Systema Naturæ was a work upon natural history, in the broadest acceptation of the term; in it, that great methodizing spirit embodied all that was known in his time of the distinctive characters of minerals, animals, and plants. But the enormous stimulus which Linnæus gave to the investigation of nature soon rendered it impossible that any one man should write another Systema Naturæ, and extremely difficult for any one to become a naturalist such as Linnæus was.

Great as have been the advances made by all the three branches of science, of old included under the title of natural history, there can be no doubt that zoology and botany have grown in an enormously greater ratio than mineralogy ; and hence, as I suppose, the name of " natural history" has gradually become more and more definitely attached to these prominent divisions of the subject, and by "naturalist" people have meant more and more distinctly to imply a student of the structure and function of living beings.

However this may be, it is certain that the advance of knowledge has gradually widened the distance between mineralogy and its old associates, while it has drawn zoology and botany closer together; so that of late years it has been found convenient (and indeed necessary) to associate the sciences which deal with vitality and all its phenomena under the common head of "biology"; and

* A Lecture delivered at the South Kensington Museum in 1861. $\begin{array}{ll}66-\mathrm{L} & 353\end{array}$ 
the biologists have come to repudiate any blood-relationship with their foster-brothers, the mineralogists.

Certain broad laws have a general application throughout both the animal and the vegetable worlds, but the ground common to these kingdoms of nature is not of very wide extent, and the multiplicity of details is so great, that the student of living beings finds himself obliged to devote his attention exclusively either to the one or the other. If he elects to study plants, under any aspect, we know at once what to call him. He is a botanist, and his science is botany. But if the investigation of animal life be his choice, the name gencrally applied to him will vary according to the kind of animals he studies, or the particular phenomena of animal life to which he confines his attention. If the study of man is his object, he is called an anatomist, or a physiologist, or an ethnologist; but if he dissects animals, or examines into the mode in which their functions are performed, he is a comparative anatomist or comparative physiologist. If he turns his attention to Tossil animals, he is a paleontologist. If his mind is more particularly directed to the specific description, discrimination, classification, and distribution of animals, he is termed a zoologist.

For the purpose of the present discourse, however, I shall recognise none of these titles save the last, which I shall employ as the equivalent of botanist, and I shall use the term zoology as denoting the whole doctrine of animal life, in contradistinction to botany, which signifies the whole doctrine of vegetable life.

Employed in this sense, zoology, like botany, is divisible into three great but subordinate sciences, morphology, physiology, and distribution, each of which may, to a very great extent, be studied independently of the other.

Zoological morphology is the doctrine of animal form or structure. Anatomy is one of its branches; development is another; while classification is the expression of the relations which different animals bear to one another, in respect of their anatomy and their development.

Zoological distribution is the study of animals in relation to the terrestrial conditions which obtain now, or have obtained at any previous epoch of the earth's history.

Zoological physiology, lastly, is the doctrine of the functions or actions of animals. It regards animal bodies as machines impelled by certain forces, and performing an 
amount of work which can be expressed in terms of the ordinary forces of nature. The final object of physiology is to deduce the facts of morphology, on the one hand, and those of distribution on the other, from the laws of the molecular forces of matter.

Such is the scope of zoology. But if I were to content myself with the enunciation of these dry definitions, I should ill exemplify that method of teaching this branch of physical science, which it is my chief business to-night to recommend. Let us turn away then from abstract definitions. Let us take some concrete living thing, some animal, the commoner the better, and let us see how the application of common sense and common logic to the obvious facts it presents, inevitably leads us into all these branches of zoological science.

I have before me a lobster. When I exannine it, what appears to be the most striking character it presents ? Why, I observe that this part which we call the tail of the lobster, is made up of six distinct hard rings and a seventh terminal piece. If I separate one of the middle rings, say the third, I find it carries upon its under surface a pair of limbs or appendages, each of which consists of a stalk and two terminal pieces. So that I can represent a transverse section of the ring and its appendages upon the diagram board in this way.

If I now take the fourth ring I find it has the same structure, and so have the fifth and the second; so that, in each of these divisions of the tail, I find parts which correspond with one another, a ring and two appendages; and in each appendage a stalk and two end pieces. . These corresponding parts are called, in the technical language of anatomy, "homologous parts." The ring of the third division is the " homologue" of the ring of the fifth, the appendage of the former is the homologue of the appendage of the latter. And, as each division exhibits corresponding parts in corresponding places, we say that all the divisions are constructed upon the same plan. But now let us consider the sixth division. It is- similar to, and yet different from, the others. The ring is essentially the same as in the other divisions; but the appendages look at first as if they were very different; and yet when we regard them closely, what do we find ? A stalk and two terminal divisions, exactly as in the others, but the stalk is very short and very thick, the terminal divisions are very broad and flat, and one of them is divided into two pieces. 
I may say, therefore, that the sixth segment is like the others in plan, but that it is modified in its details.

-The first segment is like the others, so far as its ring is concerned, and though its appendages differ from any of those yet examined in the simplicity of their structure, parts corresponding with the stem and one of the divisions of the appendages of the other segments can be readily discerned in them.

Thus it appears that the lobster's tail is composed of a series of segments which are fundamentally similar, though each presents peculiar modifications of the plan common to all. But when I turn to the fore part of the body I see, at first, nothing but a great shield-like shell, called technically the " carapace," ending in front in a sharp spine, on either side of which are the curious compound eyes, set upon the ends of stout movable stalks. Behind these, on the under side of the body, are two pairs of long feelers, or antennæ, followed by six pairs of jaws folded against one another over the mouth, and five pairs of legs, the foremost of these being the great pinchers, or claws, of the lobster.

It looks, at first, a little hopeless to attempt to find in this complex mass a series of rings, each with its pair of appendages, such as I have shown you in the abdomen, and yet it is not difficult to demonstrate their existence. Strip off the legs, and you will find that each pair is attached to a very definite segment of the under wall of the body ; but these segments, instead of being the lower parts of free rings, as in the tail, are such parts of rings which are all solidly united and bound together; and the like is true of the jaws, the feelers, and the eye-stalks, every pair of which is borne upon its own special segment. Thus the conclusion is gradually forced upon us, that the body of the lobster is composed of as many rings as there are pairs of appendages, namely, twenty in all, but that the six hindmost rings remain free and movable, while the fourteen front rings become firmly soldered together, their backs forming one continuous shield-the carapace.

Unity of plan, diversity in execution, is the lesson taught by the study of the rings of the body, and the same instruction is given still more emphatically by the appendages. If I examine the outermost jaw I find it consists of three distinct portions, an inner, a middle, and an outer, mounted upon a common stem; and if I compare this jaw with the legs behind it, or the jaws in front of it, I find it quite easy 
to see, that, in the legs, it is the part of the appendage which corresponds with the inner division, which becomes modified into what we know familiarly as the "leg," while the middle division disappears, and the outer division is hidden under the carapace. Nor is it more difficult to discern that, in the appendages of the tail, the middle division appears again and the outer vanishes ; while, on the other hand, in the foremost jaw, the so-called mandible, the inner division only is left ; and, in the same way, the parts of the feelers and of the eye-stalks can be identified with those of the legs and jaws.

But whither does all this tend ? To the very remarkable conclusion that a unity of plan, of the same kind as that discoverable in the tail or abdomen of the lobster, pervades the whole organization of its skeleton, so that I can return to the diagram representing any one of the rings of the tail, which I drew upon the board, and by adding a third division to each appendage, I can use it as a sort of scheme or plan of any ring of the body. I can give names to all the parts of that figure, and then if I take any segment of the body of the lobster, I can point out to you exactly, what modification the general plan has undergone in that particular segment; what part has remained movable, and what has become fixed to another; what has been excessively developed and metamorphosed and what has been suppressed.

But I imagine I hear the question, How is all this to be tested? No doubt it is a pretty and ingenious way of looking at the structure of any animal, but is it anything more? Does Nature acknowledge, in any deeper way, this unity of plan we seem to trace ?

The objection suggested by these questions is a very valid and important one, and morphology was in an unsound state so long as it rested upon the mere perception of the analogies which obtain between fully formed parts. The unchecked ingenuity of speculative anatomists proved itself fully competent to spin any number of contradictory hypotheses out of the same facts, and endless morphological dreams threatened to supplant scientific theory.

Happily, however, there is a criterion of morphological truth, and a sure test of all homologies. Our lobșter has not always been what we see it; it was once an egg, a semifluid mass of yolk, not so big as a pin's head, contained in a transparent membrane, and exhibiting not the least 
trace of any one of those organs, whose multiplicity and complexity, in the adult, are so surprising. After a time a delicate patch of cellular membrane appeared upon one face of this yolk, and that patch was the foundation of the whole creature, the clay out of which it would be moulded. Gradually investing the yolk, it became subdivided by transverse constrictions into segments, the fore-runners of the rings of the body. Upon the ventral surface of each of the rings thus sketched out, a pair of bud-like prominences made their appearance-the rudiments of the appendages of the ring. At first, all the appendages were alike, but, as they grew, most of them became distinguished into a stem and two terminal divisions, to which, in the middle part of the body, was added a third outer division; and it was only at a later period, that by the modification, or absorption, of certain of these primitive constituents, the limbs acquired their perfect form.

Thus the study of development proves that the doctrine of unity of plan is not merely a fancy, that it is not merely one way of looking at the matter, but that it is the expression of deep-seated natural facts. The legs and jaws of the lobster may not merely be regarded as modifications of a common type,-in fact and in nature they are so,- the leg and the jaw of the young animal being, at first, indis-. tinguishable.

These are wonderful truths, the more so because the zoologist finds them to be of universal application. The investigation of a polype, of a snail, of a fish, of a horse, or of a man, would have led us, thouglı by a less easy path, perhaps, to exactly the same point. Unity of plan everywhere lies hidden under the mask of diversity of structure -the complex is everywhere evolved out of the simple. Every animal has at first the form of an egg, and every animal and every organic part, in reaching its adult state, passes through conditions common to other animals and other adult parts; and this leads me to anotlier point. I have hitherto spoken as if the lobster were alone in the world, but, as I need hardly remind you, there are myriads of other animal organisms. Of these, some, such as men, horses, birds, fishes, snails, slugs, oysters, corals, and sponges, are not in the least like the lobster. But other animals, though they may differ a good deal from the lobster, are yet either very like it, or are like something that is like it. The cray fish, the rock lobster, and the prawn, and the 
shrimp, for example, however different, are yet so like lobsters, that a child would group them as of the lobster kind, in contradistinction to snails and slugs; and these last again would form a kind by themselves, in contradistinction to cows, horses, and sheep; the cattle kind.

But this spontaneous grouping into "kinds" is the first essay of the human mind at classification, or the calling by a common name of those things that are alike, and the arranging them in such a manner as best to suggest the sum of their likenesses and unlikenesses to other things.

Those kinds which include no other subdivisions than the sexes, or various breeds, are called, in technical language, species. The English lobster is a species, our cray fish is another, our prawn is another. In other countries, however, there are lobsters, cray fish, and prawns, very like ours, and yet presenting sufficient differences to deserve distinction. Naturalists, therefore, express this resemblance and this diversity by grouping them as distinct species of the same " genus." But the lobster and the cray fish, though belonging to distinct genera, have many features in common, and hence are grouped together in an assemblage which is called a family. More distant resemblances connect the lobster with the prawn and the crab, which are expressed by putting all these into the same order. Again, more remote, but still very definite, resemblances unite the lobster with the woodlouse, the king crab, the water flea, and the barnacle, and separate them from all other animals; whence they collectively constitute the larger group, or class, Crustacea. But the Crustacea exhibit many peculiar features in common with insects, spiders, and centipedes, so that these are grouped into the still larger assemblage or " province" Articulata; and, finally, the relations which these have to worms and other lower animals, are expressed by combining the whole vast aggregate into the sub-kingdom of Annulosa.

If I had worked my way from a sponge instead of a lobster, I should have found it associated, by like ties, with a great number of other animals into the sub-kingdom Protozoa; if I had selected a fresh-water polype or a coral, the members of what naturalists term the sub-kingdom Coelenterata would have grouped themselves around my type; had a snail been chosen, the inhabitants of all univalve and bivalve, land and water, shells, the lamp shells, the squids, and the sea-mat would have gradually 
linked themselves on to it as members of the same subkingdom of Mollusca; and finally, starting from man, I should have been compelled to admit first, the ape, the rat, the horse, the dog, into the same class; and then the bird, the crocodile, the turtle, the frog, and the fish, into the same sub-kingdom of Vertebrata.

And if I had followed out all these various lines of classification fully, I should discover in the end that there was no animal, either recent or fossil, which did not at once fall into one or other of these sub-kingdoms. In other words, every animal is organized upon one or other of the five, or more, plans, whose existence renders our classification possible. And so definitely and precisely marked is the structure of each animal, that, in the present state of our knowledge, there is not the least evidence to prove that a form, in the slightest degree transitional between any of the two groups Vertebrata, Annulosa, Mollusca, and Coelenterata, either exists, or has existed, during that period of the earth's history which is recorded by the geologist. Nevertheless, you must not for a moment suppose, because no such transitional forms are known, that the members of the sub-kingdoms are disconnected from, or independent of, one another. On the contrary, in their earliest condition they are all alike, and the primordial germs of a man, a dog, a bird, a fish, a beetle, a snail, and a polype are, in no essential structural respects, distinguishable.

In this broad sense, it may with truth be said, that all living animals, and all those dead creations which geology reveals, are bound together by an all-pervading unity of organization, of the same character, though not equal in degree, to that which enables us to discern one and the same plan amidst the twenty different segments of a lobster's body. Truly it has been said, that to a clear eye the smallest fact is a window through which the Infinite may be seen.

Turning from these purely morphological considerations, let us now examine into the manner in which the attentive study of the lobster impels us into other lines of research.

Lobsters are found in all the European seas; but on the opposite shores of the Atlantic and in the seas of the southern hemisphere they do not exist. They are, however, represented in these regions by very closely allied, but distinct forms-the Homarus Americanus and the Homarus Capensis: so that.we may say that the European has one species of Homarus; the American, another; the African, 
another; and thus the remarkable facts of geographical distribution begin to dawn upon us.

Again, if we examine the contents of the earth's crust, we shall find in the latter of those deposits, which have served as the great burying grounds of past ages, numberless lobster-like animals, but none so similar to our living lobster as to make zoologists sure that they belonged even to the same genus. If we go still further back in time, we discover, in the oldest rocks of all, the remains of animals, constructed on the same general plan as the lobster, and belonging to the same great group of Crustacea; but for the most part totally different from the lobster, and indeed from any other living form of crustacean; and thus we gain a notion of that successive change of the animal population of the globe, in past ages, which is the most striking fact revealed by geology.

Consider, now, where our inquiries have led us. We studied our type morphologically, when we determined its anatomy and its development, and when comparing it, in these respects, with other animals, we made out its place in a system of classification. If we were to examine every animal in a similar manner, we should establish a complete body of zoological morphology.

Again, we investigated the distribution of our type in space and in time, and, if the like had been done with every animal, the sciences of geographical and geological distribution would have attained their limit.

But you will observe one remarkable circumstance, that, up to this point, the question of the life of these organisms has not come under consideration. Morphology and distribution might be studied almost as well, if animals and plants were a peculiar kind of crystals, and possessed none of those functions which distinguish living beings so remarkably. But the facts of morphology and distribution have to be accounted for, and the science, whose aim it is to account for them, is Physiology.

Let us return to our lobster once more. If we watched the creature in its native element, we should see it climbing actively the submerged rocks, among which it delights to live, by means of its strong legs; or swimming by powerful strokes of its great tail, the appendages of whose sixth joint are spread out into a broad fan-like propeller : seize it, and it will show you that its great claws are no mean weapons of offence; suspend a piece of carrion among its 
haunts, and it will greedily devour it, tearing and crushing the flesh by means of its multitudinous jaws.

Suppose that we had known nothing of the lobster but as an inert mass, an organic crystal, if I may use the phrase, and that we could suddenly see it exerting all these powers, what wonderful new ideas and new questions would arise in our minds! The great new question would be, " How does all this take place?" the chicf new idea would be, the idea of adaptation to purpose,-the notion, that the constituents of animal bodies are not mere unconnected parts, but organs working together to an end. Let us consider the tail of the lobster again from this point of view. Morphology has taught us that it is a series of segments composed of homologous parts, which undergo various modifications-beneath and through which a common plan of formation is discernible. But if $I$ look at the same part physiologically, I see that it is a most beautifully construçted organ of locomotion, by means of which the animal can swiftly propel itself either backwards or forwards.

But how is this remarkable propulsive machine made to perform its functions? If I were suddenly to kill one of these animals and to take out all the soft parts, I should find the shell to be perfectly inert, to have no more power of moving itself than is possessed by the machinery of a mill when disconnected from its steam-engine or waterwheel. But if I were to open it, and take out the viscera only, leaving the white flesh, I should perceive that the lobster could bend and extend its tail as well as before. It I were to cut off the tail, I should cease to find any spontaneous motion in it; but on pinching any portion of the flesh, I should observe that it underwent a very curious change-each fibre becoming shorter and thicker. By this act of contraction, as it is termed, the parts to which the ends of the fibre are attached are, of course, approximated; and according to the relations of their points of attacliment to the centres of motions of the different rings, the bending or the extension of the tail results. Close observation of the newly-opened lobster would soon show that all its movements are due to the same cause-the shortening and thickening of these fleshy fibres, which are technically called nuscies.

Here, then, is a capital fact. The movements of the lobster are due to muscular contractility. But why does 
a muscle contract at one time and not at another? Why does one whole group of muscles contract when the lobster wishes to extend his tail, and another group when he desires to bend it? What is it originates, directs, and controls the motive power?

Experiment, the great instrument for the ascertainment of truth in physical science, answers this question for us. In the head of the lobster there lies a small mass of that peculiar tissue which is known as nervous substance. Cords of similar matter connect this brain of the lobster, directly or indirectly, with the muscles. Now, if these communicating cords are cut, the brain remaining entire, the power of exerting what we call voluntary motion in the parts below the section is destroyed; and on the other hand, if, the cords remaining entire, the brain mass be destroyed, the same voluntary mobility is equally lost. Whence the inevitable conclusion is, that the power of originating these motions resides in the brain, and is propagated along the nervous cords.

In the higher animals the phenomena which attend this transmission have been investigated, and the exertion of the peculiar energy which resides in the nerves has been found to be accompanied by a disturbance of the electrical state of their molecules.

If we could exactly estimate the signification of this disturbance; if we could obtain the value of a given exertion of nerve force by determining the quantity of electricity, or of heat, of which it is the equivalent ; if we could ascertain upon what arrangement, or other condition of the molecules of matter, the manifestation of the nervous and muscular energies depends, (and doubtless science will some day or other ascertain these points,) physiologists would have attained their ultimate goal in this direction; they would have determined the relation of the motive force of animals to the other forms of force found in nature ; and if the same process had been successfully performed for all the operations which are carried on in, and by, the animal frame, physiology would be perfect, and the facts of morphology and distribution would be deducible from the laws which physiologists had established, combined with those determining the condition of the surrounding universe.

There is not a fragment of the organism of this humble animal whose study would not lead us into regions of 
thought as large as those which I have briefly opened up to you; but what I have been saying, I trust, has not only enabled you to form a conception of the scope and purport of zoology, but has given you an imperfect example of the manner in which, in my opinion, that science, or indeed any physical science, may be best taught. The great matter is, to make teaching real and practical, by fixing the attention of the student on particular facts; but at the same time it should be rendered broad and compreliensive, , by constant reference to the generalizations of which all particular facts are illustrations. The lobster has served as a type of the whole animal kingdom, and its anatomy and physiology have illustrated for us some of the greatest truths of biology. The student who has once secn for himself the facts which I have described, has had their relations explained to him, and has clearly comprehended them, has, so far, a knowledge of zoology, which is real and genuine; however limited it may be, and which is worth more than all the mere reading knowledge of the science he could ever acquire. His zoological information is, so far, knowledge and not mere liear-say.

And if it were my business to fit you for the certificate in zoological science granted by this department, I should pursue a course precisely similar in principle to that which I have taken to-night. I should select a fresh-water sponge, a fresh-water polype or a Cyanæa, a fresh-water mussel, a lobster, a fowl, as types of the five primary divisions of the animal kingdom. I should explain their structure very fully, and show how each illustrated the great principles of zoology. Having gone very carefully and fully over this ground, I should feel that you had a safe foundation, and I should then take you in the same way, but less minutely, over similarly selected illustrative types of the classes; and then I should direct your attention to the special forms enumerated under the head of types, in this syllabus, and to the other facts there mentioned.

That would, speaking generally, be my plan. But I have undertaken to explain to you the best mode of acquiring and communicating a knowledge of zoology, and you may therefore fairly ask me for a more detailed and precise account of the manner in which $I$ should propose to furnish you with the information I refer to.

My own impression is, that the best model for all kinds of training in physical science is that afforded by the 
method of teaching anatomy, in use in the medical schools. This method consists of three elements-lectures, demonstrations, and examinations.

The object of lectures is, in the first place, to awaken the attention and excite the enthusiasm of the student; and this, I am sure, may be effected to a far greater extent by the oral discourse and by the personal influence of a respected teacher than in any other way. Secondly, lectures have the double use of guiding the student to the salient points of a subject, and at the same time forcing him to attend to the whole of it, and not merely to that part which takes his fancy. And lastly, lectures afford the student the opportunity of seeking explanations of those difficulties which will, and indeed ought to, arise in the course of his studies.

But for a student to derive the utmost possible value from lectures, several precautions are needful.

I have a strong impression that the better a discourse is, as an oration, the worse it is as a lecture. The flow of the discourse carries you on without proper attention to its sense; you drop a word or a phrase, you lose the exact meaning for a moment, and while you strive to recover yourself, the speaker has passed on to something else.

The practice I have adopted of late years, in lecturing to students, is to condense the substance of the hour's discourse into a few dry propositions, which are read slowly and taken down from dictation; the reading of each being followed by a free commentary, expanding and illustrating the proposition, explaining terms, and removing any difficulties that may be attackable in that way, by diagrams made roughly, and seen to grow under the lecturer's hand. In this manner you, at any rate, insure the co-operation of the student to a certain extent. He cannot leave the lecture-room entirely empty if the taking of notes is enforced; and a student must be preternaturally dull and mechanical, if he can take notes and hear them properly explained, and yet learn nothing.

What books shall I read? is a question constantly put by the student to the teacher. My reply usually is, "None : write your notes out carefully and fully; strive to understand them thoroughly; come to me for the explanation of anything you cannot understand; and I would rather you did not distract your mind by reading." A properly composed course of lectures ought to contain fully as much 
matter as a student can assimilate in the time occupied by its delivery; and the teacher should always recollect that his business is to feed, and not to cram the intellect. Indeed, I believe that a student who gains from a course of lectures the simple habit of concentrating his attention upon a definitely limited series of facts, until they are thoroughly mastered, has made a step of immeasurable importance.

But, however good lectures may be, and however extensive the course of reading by which they are followed up, they are but accessories to the great instrument of scientific teaching-demonstration. If I insist unweariedly, nay fanatically, upon the importance of physical science as an educational agent, it is because the study of any branch of science, if properly conducted, appears to me to fill up a void left by all other means of education. I have the greatest respect and love for literature; nothing would grieve me more than to see literary training other than a very prominent branch of education : indeed, I wish that real literary discipline were far more attended to than it is ; but I cannot shut my eyes to the fact, that there is a vast difference between men who have had a purely literary, and those who have had a sound scientific, training.

Seeking for the cause of this difference, I imagine I can find it in the fact that, in the world of letters, learning and knowledge are one, and books are the source of both; whereas in science, as in life, learning and knowledge are distinct, and the study of things, and not of books, is the source of the latter.

All that literature has to bestow may be obtained by reading and by practical exercise in writing and in speaking ; but I do not exaggerate when I say, that none of the best gifts of science are to be won by these means. On the contrary, the great benefit which a scientific education bestows, whether as training or as knowledge, is dependent upon the extent to which the mind of the student is brought into immediate contact with facts-upon the degree to which he learns the habit of appealing directly to Nature, and of acquiring through his senses concrete images of those properties of things, which are, and always will be, but approximately expressed in human language. Our way of looking at Nature, and of speaking about her, varies from year to year; but a fact once seen, a relation of cause and effect, once demonstratively apprehended, are posses- 
sions which neither change nor pass away, but, on the contrary, form fixed centres, about which other truths aggregate by natural affinity.

Therefore, the great business of the scientific teacher is, to imprint the fundamental, irrefragable facts of his science, not only by words upon the mind, but by sensible impressions upon the eye, and ear, and touch of the student, in so complete a manner, that every term used, or law enunciated, should afterwards call up vivid images of the particular structural, or other, facts which furnished the demonstration of the law, or the illustration of the term.

Now this important operation can only be achieved by constant demonstration, which may take place to a certain imperfect extent during a lecture, but which ought also to be carried on independently, and which should be addressed to each individual student, the teacher endeavouring, not so much to show a thing to the learner, as to make him see it for himself.

I am well aware that there are great practical difficulties in the way of effectual zoological demonstrations. The dissection of animals is not altogether pleasant, and requires much time; nor is it easy to secure an adequate supply of the needful specimens. The botanist has here a great advantage; his specimens are easily obtained, are clean and wholesome, and can be dissected in a private house as well as anywhere else ; and hence, I believe, the fact, that botany is so much more readily and better taught than its sister science. But, be it difficult or be it easy, if zoological science is to be properly studied, demonstration, and, consequently, dissection, must be had. Without it, no man can have a really sound knowledge of animal organization.

A good deal may be done, however, without actual dissection on the student's part, by demonstration upon specimens and preparations; and in all probability it would not be very difficult, were the demand sufficient, to organize collections of such objects, sufficient for all the purposes of elementary teaching, at a comparatively cheap rate. Even without these, much might be effected, if the zoological collections, which are open to the public, were arranged according to what has been termed the "typical principle "'; that is to say, if the specimens exposed to public view were so selected that the public could learn something from them, instead of being, as at present, 
merely confused by their multiplicity. For example, the grand ornithological gallery at the British Museum contains between two and three thousand species of birds, and sometimes five or six specimens of a species. They are very pretty to look at, and some of the cases are, indeed, splendid ; but I will undertake to say, that no man but a professed ornithologist has ever gathered much information from the collection. Certainly, no one of the tens of thousands of the general public who have walked through that gallery ever knew more about the essential peculiarities of birds when he left the gallery than when he entered it. But if, somewhere in that vast hall, there were a few preparations, exemplifying the leading structural peculiarities and the mode of development of a common fowl; if the types of the genera, the leading modifications in the skeleton, in the plumage at various ages, in the mode of nidification, and the like, among birds, were displayed; and if the other specimens were put away in a place where the men of science, to whom they are alone useful, could have free access to them, I can conceive that this collection might become a great instrument of scientiflc education.

The last implement of the teacher to which I have adverted is examination-a means of education now so thoroughly understood that I need hardly enlarge upon it. I hold that both written and oral examinations are indispensable, and, by requiring the description of specimens, they may be made to supplement demonstration.

Such is the fullest repiy the time at my disposal will allow me to give to the question-how may a knowledge of zoology be best acquired and communicated ?

But there is a previous question which may be moved, and which, in tact, I know many are inclined to move. It is the question, why should training masters be encouraged to acquire a knowledge of this, or any other branch of physical science? What is the use, it is said, of attempting to make physical science a branch of primary education ? Is it not probable that teachers, in pursuing such studies, will be led astray from the acquirement of more important but less attractive knowledge? And, even if they can learn something of science without prejudice to their usefulness, what is the good of their attempting to instil that knowledge into boys whose real business is the acquisition of reading, writing, and arithmetic?

These questions are, and will be, very commonly asked, 
for they arise from that profound ignorance of the value and true position of physical science, which infests the minds of the most highly educated and intelligent classes of the community. But if I did not feel well assured that they are capable of being easily and satisfactorily answered; that they have been answered over and over again; and that the time will come when men of liberal education will blush to raise such questions, - I should be ashamed of my position here to-night. Without doubt, it is your great and very important function to carry out elementary education; without question, anything that should interfere with the faithful fulfilment of that duty on your part would be a great evil; and if I thought that your acquirement of the elements of physical science, and your communication of those elements to your pupils, involved any sort of interference with your proper duties, I should be the first person to protest against your being encouraged to do anything of the kind.

But is it true that the acquisition of such a knowledge of science as is proposed, and the communication of that knowledge, are calculated to weaken your usefulness? Or may I not rather ask, is it possible for you to discharge your functions properly without these aids ?

What is the purpose of primary intellectual education ? I apprehend that its first object is to train the young in the use of those tools wherewith men extract knowledge from the ever-shifting succession of phenomena which pass before their eyes; and that its second object is to inform them of the fundamental laws which have been found by experience to govern the course of things, so that they may not be turned out into the world naked, defenceless, and a prey to the events they might control.

$A$ boy is taught to read his own and other languages, in order that he may have access to infinitely wider stores of knowledge than could ever be opened to him by oral intercourse with his fellow men; he learns to write, that his means of communication with the rest of mankind may be indefinitely enlarged, and that he may record and store up the knowledge he acquires. He is taught elementary mathematics, that he may understand all those relations of number and form, upon which the transactions of men, associated in complicated societies, are built, and that be may have some practice in deductive reasoning.

All these operations of reading, writing, and ciphering, 
are intellectual tools, whose use should, before all thirgs, be learned, and learned thoroughly; so that the youth may be enabled to make his life that which it ought to be, a continual progress in learning and in wisdom.

But, in addition, primary education endeavours to fit a boy out with a certain equipment of positive knowledge. $\mathrm{He}$ is taught the great laws of morality; the religion of his sect; so much history and geography as will tell him where the great countries of the world are, what they are, and how they have become what they are.

Without doubt all these are most fitting and excellent things to teach a boy; I should be very sorry to oinit any of them from any scheme of primary intellectual education. The system is excellent, so far as it goes.

But if I regard it closely, a curious reflection arises. I suppose that, fifteen hundred years ago, the child of any well-to-do Roman citizen was taught just these same things; reading and writing in his own, and, perhaps, the Greek tongue; the elements of mathematics; and the religion, morality, history, and geography current in his time. Furthermore, I do not think I err in affirming, that, if such a Christian Roman boy, who had finished his education, could be transplanted into one of our public schools, and pass through its course of instruction, he would not meet with a single unfamiliar line of thought; amidst all the new facts he would have to learn, not one would suggest a different mode of regarding the universe from that current in his own time.

And yet surely there is some great difference between the civilization of the fourth century and that of the nineteenth, and still more between the intellectual habits and tone of thought of that day and this ?

And what has made this difference? I answer fearlessly, - The prodigious development of physical science within the last two centuries.

Modern civilization rests upon physical science; take away her gifts to our own country, and our position among the leading nations of the world is gone to-norrow ; for it is physical science only, that makes intelligence and moral energy stronger than brute force.

The whole of modern thought is steeped in science; it has made its way into the works of our best poets, and even the mere man of letters, who affects to ignore and despise science, is unconsciously impregnated with her spirit, and 
Indebted for his best products to her methods. I believe that the greatest intellectual revolution mankind has yet seen is now slowly taking place by her agency. She is teaching the world that the ultimate court of appeal is observation and experiment, and not authority; she is teaching it to estimate the value of evidence; she is creating a firm and living faith in the existence of immutable moral and physical laws, perfect obedience to which is the highest possible aim of an intelligent being.

But of all this your old stereotyped system of education takes no note. Physical science, its methods, its problems, and its difficulties, will meet the poorest boy at every turn, and yet we educate him in such a manner that he shall enter the world as ignorant of the existence of the methods and facts of science as the day he was born. The modern world is full of artillery ; and we turn out our children to do battle in it, equipped with the shield and sword of an ancient gladiator.

Posterity will cry shame on us if we do not remedy this deplorable state of things. Nay, if we live twenty years longer, our own consciences will cry shame on us.

It is my firm conviction that the only way to remedy it is, to make the elements of physical science an integral part of primary education. I have endeavoured to show you how that may be done for that branch of science which it is my business to pursue; and I can but add, that I should look upon the day when every schoolmaster throughout this land was a centre of genuine, however rudimentary, scientific knowledge, as an epoch in the history of the country.

But let me entreat you to remember my last words. Addressing myself to you, as teachers, I would say, mere book learning in physical science is a sham and a delusionwhat you teach, unless you wish to be impostors, that you must first know; and real knowledge in science means personal acquaintance with the facts, be they few or many.*

* It has been suggested to me that these words may be taken to imply a discouragement on my part of any sort of scientific instruction which does not give an acquaintance with the facts at first hand. But this is not my meaning. The ideal of scientific teaching is, no doubt, a system by which the scholar sees every fact for himself, and the teacher supplies only the explanations. Circumstances, however, do not often allow of the attainment of that ideal, and we must put up with the next best system-one in which the scholar takes a good deal on trust from a teacher, who, knowing the facts 
by his own knowledge, can describe them with so much vividness as to enable his audience to form competent ideas concerning them. The system which I repudiate is that which allows teachers who have not come into direct contact with the leading facts of a science to pass their second-hand information on. The scientiflc virus, like vaccine lymph, if passed through too long a succession of organisms, will lose all its effect in protecting the young against the intellectual epidemics to which they are exposed. 
GEOLOGICAL CONTEMPORANEITY AND

PERSISTENT TYPES OF LIFE 


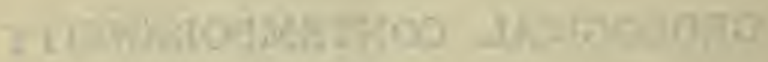

$$
=06 \mathrm{~A}
$$

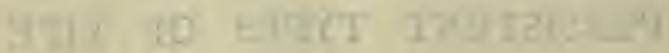

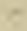




\section{GEOLOGICAL CONTEMPORANEITY AND PERSISTENT TYPES OF LIFE*}

Merchants occasionally go through a wholesome, though troublesome and not always satisfactory, process which they term "taking stock." After all the excitement of speculation, the pleasure of gain, and the pain of loss, the trader makes up his mind to face facts and to learn the exact quantity and quality of his solid and reliable possessions.

The man of science does well sometimes to imitate this procedure; and, forgetting for the time the importance of his own small winnings, to re-examine the common stock in trade, so that he may make sure how far the stock of bullion in the cellar-on the faith of whose existence so much paper has been circulating-is really the solid gold of truth.

The Anniversary Meeting of the Geological Society seems to be an occasion well suited for an undertaking of this kind-for an inquiry, in fact, into the nature and value of the present results of paleontological investigation; and the more so, as all those who have paid close attention to the late multitudinous discussions in which paleontology is implicated, must have felt the urgent necessity of some such scrutiny.

First in order, as the most definite and unquestionable of all the results of paleontology, must be mentioned the immense extension and impulse given to botany, zoology, and comparative anatomy, by the investigation of fossil remains. Indeed, the mass of biological facts has been so greatly increased, and the range of biological speculation has been so vastly widened, by the researches of the geologist and paleontologist, that it is to be feared there are naturalists in existence who look upon geology as Brindley regarded rivers. " Rivers," said the great engineer, "were

* The Anniversary Address to the Geological Society for 1862. 
made to feed canals" ; and geology, some seem to think, was solely created to advance comparative anatomy.

Were such a thought justifiable, it could hardly expect to be received with favour by this assembly. But it is not justifiable. Your favourite science has her own great aims independent of all others; and if, notwithstanding her steady devotion to her own progress, she can scatter such rich alms among her sisters, it should be remembered that her charity is of the sort that does not impoverish, but "blesseth him that gives and him that takes."

Regard the matter as we will, however, the facts remain. Nearly 40,000 species of animals and plants have been added to the Systema Naturæ by paleontological research. This is a living population equivalent to that of a new continent in mere number; equivalent to that of a new hemisphere, if we take into account the small population of insects as yet found fossil, and the large proportion and peculiar organization of many of the Vertebrata.

But, beyond this, it is perhaps not too much to say that, except for the necessity of interpreting paleontological facts, the laws of distribution would have received less careful study; while few comparative anatomists (and those not of the first order) would have been induced by mere love of detail, as such, to study the minutiæ of osteology, were il not that in such minutiæ lie the only keys to the most interesting riddles offered by the extinct animal world.

These assuredly are great and solid gains. Surely it is matter for no small congratulation that in half a century (for paleontology, though it dawned earlier, came into full day only with Cuvier) a subordinate branch of biology should have doubled the value and the interest of the whole group of sciences to which it belongs.

But this is not all. Allied with geology, paleontology has established two laws of inestimable importance: the first, that one and the same area of the earth's surface has been successively occupied by very different kinds of living beings ; the second, that the order of succession established in one locality holds good, approximately, in all.

The first of these laws is universal and irreversible; the second is an induction from a vast number of observations, though it may possibly, and even probably, have to admit of exceptions. As a consequence of the second law, it follows that a peculiar relation frequently subsists between 
series of strata, containing organic remains, in different localities. The series resemble one another, not only in virtue of a general resemblance of the organic remains in the two, but also in virtue of a resemblance in the order and character of the serial succession in each. There is a resemblance of arrangement; so that the separate terms of each series, as well as the whole series, exhibit a correspondence.

Succession implies time; the lower members of a series of sedimentary rocks are certainly older than the upper; and when the notion of age was once introduced as the equivaIent of succession, it was no wonder that correspondence in succession came to be looked upon as a correspondence in age, or "contemporaneity." And, indeed, so long as relative age only is spoken of, correspondence in succession is correspondence in age ; it is relative contemporaneity.

But it would have been very much better for geology if so loose and ambiguous a word as "contemporaneous" had been excluded from her terminology, and if, in its stead, some term expressing similarity of serial relation, and excluding the notion of time altogether, had been employed to denote correspondence in position in two or more series of strata.

In anatomy, where such correspondence of position has constantly to be spoken of, it is denoted by the word " homology" and its derivatives ; and for Geology (which after all is only the anatomy and physiology of the earth) it might be well to invent some single word, such as " homotaxis." (similarity of order), in order to express an essentially similar idea. This, however, has not been done, and most probably the inquiry will at once be made-To what end burden science with a new and strange term in place of one old, familiar, and part of our common language ?

The reply to this question will become obvious as the inquiry into the results of paleontology is pushed further.

Those whose business it is to acquaint themselves specially with the works of paleontologists, in fact, will be fully aware that very few, if any, would rest satisfied with such a statement of the conclusions of their branch of biology as that which has just been given.

Our standard repertories of paleontology profess to teach us far higher things-ta disclose the entire succession of living forms upon the surface of the globe; to tell us 
of a wholly different distribution of climatic conditions in ancient times; to reveal the character of the first of all living existences; and to trace out the law of progress from them to us.

It may not be unprofitable to bestow on these professions a somewhat more critical examination than they have hitherto received, in order to ascertain how far they rest on an irrefragable basis; or whether, after all, it might not be well for paleontologists to learn a little more carefully that scientific " ars artium," the art of saying "I don't know." And to this end let us define somewhat more exactly the extent of these pretensions of paleontology.

Every one is aware that Professor Bronn's Untersuchungen and Professor Pictet's Traité de Paléontologie are works of standard authority, familiarly consulted by every working paleontologist. It is desirable to speak of these excellent books, and of their distinguished authors, with the utmost respect, and in a tone as far as possible removed from carping criticism; indeed, if they are specially cited in this place, it is merely in justification of the assertion that the following propositions, which may be found implicitly, or explicitly, in the works in question, are regarded by the mass of paleontologists and geologists, not only on the Continent but in this country, as expressing some of the best-established results of paleontology. Thus :-

Animals and plants began their existence together, not long after the commencement of the deposition of the sedimentary rocks; and then succeeded one another, in such a manner, that totally distinct faunx and florx occupied the whole surface of the earth, one after the other, and during distinct epochs of time.

A geological formation is the sum of all the strata deposited over the whole surface of the earth during one of these epochs: a geological fauna or flora is the sum of all the species of animals or plants which occupied the whole surface of the globe, during one of these epochs.

The population of the earth's surface was at first very similar in all parts, and only from the middle of the Tertiary epoch onwards, began to show a distinct distribution in zones.

The constitution of the original population, as well as the numerical proportions of its members, indicates a warmer and, on the whole, somewhat tropical climate, which remained tolerably equable throughout the year. 
The subsequent distribution of living beings in zones is the result of a gradual lowering of the general temperature, which first began to be felt at the poles.

It is not now proposed to inquire whether these doctrines are true or false; but to direct your attention to a much simpler though very essential preliminary questionWhat is their logical basis? what are the fundamental assumptions upon which they all logically depend ? and what is the evidence on which those fundamental propositions demand our assent ?

These assumptions are two: the first, that the commencement of the geological record is coeval with the commencement of life on the globe; the second, that geological contemporaneity is the same thing as chronological synchrony. Without the first of these assumptions there would of course be no ground for any statement respecting the commencement of life; without the second, all the other statements cited, every one of which implies a knowledge of the state of different parts of the earth at one and the same time, will be no less devoid of demonstration.

The first assumption obviously rests entirely on negative evidence. This is, of course, the only evidence that ever can be available to prove the commencement of any series of phenomena ; but, at the same time, it must be recollected that the value of negative evidence depends entirely on the amount of positive corroboration it receives. If $\mathrm{A} B$ wishes to prove an alibi, it is of no use for him to get a thousand witnesses simply to swear that they did not see him in such and such a place, unless the witnesses are prepared to prove that they must have seen him had he been there. But the evidence that animal life commenced with the Lingula-flags, e.g., would seem to be exactly of this unsatisfactory uncorroborated sort. The Cambrian witnesses simply swear they "haven't seen anybody their way"; upon which the counsel for the other side immediately puts in ten or twelve thousand feet of Devonian sandstones to make oath they never saw a fish or a mollusk, though all the world knows there were plenty in their time.

But then it is urged that, though the Devonian rocks in one part of the world exhibit no fossils, in another they do, while the lower Cambrian rocks nowhere exhibit 
fossils, and hence no living being could have existed in their epoch.

To this there are two replies : the first, that the observational basis of the assertion that the lowest rocks are nowhere fossiliferous is an amazingly small one, seeing how very small an area, in comparison to that of the whole world, has yet been fully searched; the second, that the argument is good for nothing unless the unfossiliferous rocks in question were not only contemporaneous in the geological sense, but synchronous in the chronological sense. To use the alibi illustration again. If a man wishes to prove he was in neither of two places, $A$ and $B$, on a given day, his witnesses for each place must be prepared to answer for the whole day. If they can only prove that he was not at $A$ in the morning, and not at $B$ in the afternoon, the evidence of his absence from both is nil, because he might have been at $B$ in the morning and at $A$ in the afternoon.

Thus everything depends upon the validity of the second assumption. And we must proceed to inquire what is the real meaning of the word " contemporaneous" as employed by geologists. To this end a concrete example may be taken.

The Lias of England and the Lias of Germany, the Cretaceous rocks of Britain and the Cretaceous rocks of Southern India, are termed by geologists " contemporaneous" formations; but whenever any thoughtful geologist is asked whether he means to say that they were deposited synchronously, he says, "No,-only within the same great epoch." And if, in pursuing the inquiry, he is asked what may be the approximate value in time of a " great epoch "- whether it means a hundred years, or a thousand, or a million, or ten million years-his reply is, "I cannot tell."

If the further question be put, whether physical geology is in possession of any method by which the actual synchrony (or the reverse) of any two distant deposits can be ascertained, no such method can be heard of ; it being admitted by all the best authorities that neither similarity of mineral composition, nor of physical character, nor even direct continuity of stratum, are absolute proofs of the synchronism of even approximated sedimentary strata: while, for distant deposits, there seems to be no kind of physical evidence attainable of a nature competent to decide 
whether such deposits were formed simultaneously, or whether they possess any given difference of antiquity. To return to an example already given: All competent authorities will probably assent to the proposition that physical geology does not enable us in any way to reply to this question-Were the British Cretaceous rocks deposited at the same time as those of India, or are they a million of years younger or a million of years older ?

Is paleontology able to succeed where physical geology fails ? Standard writers on paleontology, as has been seen, assume that she can. They take it for granted, that deposits containing similar organic remains are synchronous - at any rate in a broad sense; and yet, those who will study the eleventh and twelfth chapters of Sir Henry De la Beche's remarkable Researches in Theoretical Geology, published now nearly thirty years ago, and will carry out the arguments there most luminously stated, to their logical consequences, may very easily convince themselves that even absolute identity of organic contents is no proof of the synchrony of deposits, while absolute diversity is no proof of difference of date. Sir Henry De la Beche goes even further, and adduces conclusive evidence to show that the different parts of one and the same stratum, having a similar composition throughout, containing the same organic remains, and having similar beds above and below it, may yet differ to any conceivable extent in age.

Edward Forbes was in the habit of asserting that the similarity of the organic contents of distant formations was prima facie evidence, not of their similarity, but of their difference of age; and holding as he did the doctrine of single specific centres, the conclusion was as legitimate as any other ; for the two districts must have been occupied by migration from one of the two, or from an intermediate spot, and the chances against exact coincidence of migration and of imbedding are infinite.

In point of fact, however, whether the hypothesis of single or of multiple specific centres be adopted, similarity of organic contents cannot possibly afford any proof of the synchrony of the deposits which contain them; on the contrary, it is demonstrably compatible with the lapse of the most prodigious intervals of time, and with interposition of vast changes in the organic and inorganic worlds, between the epochs in which such deposits were formed. 
On what amount of similarity of their faun $x^{\circ}$ is the doctrine of the contemporaneity of the European and of the North American Silurians based ? In the last edition of Sir Charles Lyell's Elementary Geology it is stated, on the authority of a former President of this Socicty, the late Daniel Sharpe, that between 30 and 40 per cent. of the species of Silurian Mollusca are common to both sides of the Atlantic. By way of due allowance for further discovery, let us double the lesser number and suppose that 60 per cent. of the species are common to the North American and the British Silurians. Sixty per cent. of species in common is, then, proof of contemporaneity.

Now suppose that, a million or two of years hence, when Britain has made another dip beneath the sea and has come up again, some geologist applies this doctrine, in comparing the strata laid bare by the upheaval of the bottom, say, of St. George's Channel with what may then remain of the Suffolk Crag. Reasoning in the same way, he will at once decide the Suffolk Crag and the St. George's Channcl beds to be contemporaneous ; although we happen to know that a vast period (even in the geological sense) of time, and physical changes of almost unprecedented extent, separate the two.

But if it be a demonstrable fact that strata containing more than 60 or 70 per cent. of species of Mollusca in common, and comparatively close together, may yet be separated by an amount of geological time sufficient to allow of some of the greatest physical changes the world has seen, what becomes of that sort of contemporancity the sole evidence of which is a similarity of facies, or the identity of half a dozen species, or of a good many genera?

And yet there is no better evidence for the contenporaneity assumed by all who adopt the hypotheses of universal faunæ and floræ, of a universally uniform climate, and of a sensible cooling of the globe during geological time.

There seems, then, no escape from the admission that neither physical geology, nor palcontology, possesses any method by which the absolute synchronism of two strata can be demonstrated. All that geology can prove is local order of succession. It is mathematically certain that, 
in any given vertical linear section of an undisturbed series of sedimentary deposits, the bed which lies lowest is the oldest. In many other vertical linear sections of the same series, of course, corresponding beds will occur in a similar order ; but, however great may be the probability, no man can say with absolute certainty that the beds in the two sections were synchronously deposited. For areas of moderate extent, it is doubtless true that no practical evil is likely to result from assuming the corresponding beds to be synchronous or strictly contemporaneous; and there are multitudes of accessory circumstances which may fully justify the assumption of such synchrony. But the moment the geologist has to deal with large areas, or with completely separated deposits, the mischief of confounding that " homotaxis" or " similarity of arrangement," which can be demonstrated, with "synchrony" or "identity of date," for which there is not a shadow of proof, under the one common term of "contemporaneity" becomes incalculable, and proves the constant source of gratuitous speculations.

For anything that geology or paleontology are able to show to the contrary, a Devonian fauna and flora in the British Islands may have been contemporaneous with Silurian life in North America, and with a Carboniferous fauna and flora in Africa. Geographical provinces and zones may have been as distinctly marked in the Paleozoic epoch as at present, and those seemingly sudden appearances of new genera and species, which we ascribe to new creation, may be simple results of migration.

It may be so; it may be otherwise. In the present condition of our knowledge and of our methods, one verdict - " not proven, and not proveable"-must be recorded against all the grand hypotheses of the paleontologist respecting the general succession of life on the globe. The order and nature of terrestrial life, as a whole, are open questions. Geology at present provides us with most valuable topographical records, but she has not the means of working them into a universal history. Is such a universal history, then, to be regarded as unattainable ? Are all the grandest and most interesting problems which offer themselves to the geological student essentially insoluble? Is he in the position of a scientific Tantalus -doomed always to thirst for a knowledge which he cannot obtain? The reverse is to be hoped; nay, it may 
not be impossible to indicate the source whence help will come.

In commencing these remarks, mention was made of the great obligations under which the naturalist lies to the geologist and paleontologist. Assuredly the time will come when these obligations will be repaid tenfold, and when the maze of the world's past history, through which the pure geologist and the pure paleontologist find no guidance, will be securely threaded by the clue furnished by the naturalist.

All who are competent to express an opinion on the subject are, at present, agreed that the manifold varieties of animal and vegetable form have not either come into existence by chance, nor result from capricious exertions of creative power; but that they have taken place in a definite order, the statement of which order is what men of science term a natural law. Whether such a law is to be regarded as an expression of the mode of operation of natural forces, or whether it is simply a statement of the manner in which a supernatural power has thought fit to act, is a secondary question, so long as the existence of the law and the possibility of its discovery by the human intellect are granted. But he must be a half-hearted philosopher who, believing in that possibility, and having watched the gigantic strides of the biological sciences during the last twenty years, doubts that science will sooner or later make this further step, so as to become possessed of the law of evolution of organic forms-of the unvarying order of that great chain of causes and effects of which all organic forms, ancient and modern, are the links. And then, if ever, we shall be able to begin to discuss, with profit, the questions respecting the commencement of life, and the nature of the successive populations of the globe, which so many seem to think are already answered.

The preceding arguments make no particular claim to novelty; indeed they have been floating more or less distinctly before the minds of geologists for the last thirty years; and if, at the present time, it has seemed desirable to give them more definite and systematic expression, it is because palcontology is every day assuming a greater importance, and now requires to rest on a basis the firmness of which is thoroughly well assured. Among its funda- 
mental conceptions, there must be no confusion between what is certain and what is more or less probable.* But, pending the construction of a surer foundation than paleontology now possesses, it may be instructive, assuming for the nonce the general correctness of the ordinary hypothesis of geological contemporaneity, to consider whether the deductions which are ordinarily drawn from the whole body of paleontological facts are justifiable.

The evidence on which such conclusions are based is of two kinds, negative and positive. The value of negative evidence, in connection with this inquiry, has been so fully and clearly discussed in an address from the chair of this Society, $\uparrow$ which none of us have forgotten, that nothing need at present be said about it; the more, as the considerations which have been laid before you have certainly not tended to increase your estimation of such evidence. It will be preferable to turn to the positive facts of paleontology, and to inquire what they tell us.

We are all accustomed to speak of the number and the extent of the changes in the living population of the globe during geological time as something enormous: and indeed they are so, if we regard only the negative differences which separate the older rocks from the more modern, and if we look upon specific and generic changes as great changes, which from one point of view they truly are. But leaving the negative differences out of consideration, and looking only at the positive data furnished by the fossil world from a broader point of view-from that of the comparative anatomist who has made the study of the greater modifications of animal form his chief businessa surprise of another kind dawns upon the mind; and under this aspect the smallness of the total change becomes as astonishing as was its greatness under the other.

There are two hundred known orders of plants ; of these not one is certainly known to exist exclusively in the fossil state. The whole lapse of geological time has as yet yielded not a single new ordinal type of vegetable structure. $\neq$

The positive change in passing from the recent to the

* "Le plus grand service qu'on puisse rendre à la science est d'y faire place nette avant d'y rien construire."-Cuvier.

† Anniversary Address for 1851, Quart. Journ. Geol. Soc. vol. vii.

¥ See Hooker's Introductory Essay to the Flora of Tasmania, p. xxiii. 
ancient animal world is greater, but still singularly small. No fossil animal is so distinct from those now living as to require to be arranged even in a separate class from those which contain existing forms. It is only when we come to the orders, which may be roughly estimated at about a hundred and thirty, that we meet with fossil animals so distinct from those now living as to require orders for themselves; and these do not amount, on the most liberal estimate, to more than about 10 per cent. of the whole.

There is no certainly known extinct order of Protozoa ; there is but one among the Colenterata-that of the rugose corals; there is none among the Mollusca; there are three, the Cystidea, Blastoidea, and Edrioasterida, among the Echinoderms; and two, the Trilobita and Eurypterida, among the Crustacea; making altogether five for the great sub-kingdom of Annulosa. Among Vertebrates there is no ordinally distinct fossil fish: there is only one extinct order of Amphibia-the Labyrinthodonts; but there are at least four distinct orders of Reptilia, viz. the Ichthyosauria, Plesiosauria, Pterosauria, Dinosauria, and perhaps another or two. There is no known extinct order of Birds, and no certainly known extinct order of Mammals, the ordinal distinctness of the "Toxodontia" being doubtful.

The objection that broad statements of this kind, after all, rest largely on negative evidence is obvious, but it has less force than may at first be supposed ; for, as might be expected from the circumstances of the case, we possess more abundant positive evidence regarding Fishes and marine Mollusks than respecting any other forms of animal life; and yet these offer us, through the whole range of geological time, no species ordinally distinct from those now living; while the far less numerous class of Echinoderms presents three, and the Crustacea two, such orders, though none of these come down later than the Paleozoic age. Lastly, the Reptilia present the extraordinary and exceptional phenomenon of as many extinct as existing orders, if not more; the four mentioned maintaining their existence from the Lias to the Chalk inclusive.

Some years ago one of your Secretaries pointed out another kind of positive paleontological evidence tending towards the same conclusion-afforded by the existence of what he termed "persistent types" of vegetable and of 
animal life.* He stated, on the authority of Dr. Hooker, that there are Carboniferous plants which appear to be generically identical with some now living; that the cone of the Oolitic Araucaria is hardly distinguishable from that of an existing species; that a true Pinus appears in the Purbecks, and a Juglans in the Chalk; while, from the Bagshot Sands, a Banksia, the wood of which is not distinguishable from that of species now living in Australia, had been obtained.

Turning to the animal kingdom, he affirmed the tabulate corals of the Silurian rocks to be wonderfully like those which now exist ; while even the families of the Aporosa were all represented in the older Mesozoic rocks.

Among the Molluska similar facts were adduced. Let it be borne in mind that Avicula, Mytails, Chiton, Natica, Patella, Trochus, Discina, Orbicula, Lingula, Rhynchonella, and Nautilus, all of which are existing genera, are given without a doubt as Silurian in the last edition of Siluria; while the highest forms of the highest Cephalopods are represented in the Lias by a genus, Belemnoteuthis, which presents the closest relation to the existing Loligo.

The two highest groups of the Annulosa, the Insecta and the Arachnida, are represented in the Coal, either by existing genera, or by forms differing from existing genera in quite minor peculiarities.

Turning to the Vertebrata, the only paleozoic Elasmobranch Fish of which we have any complete knowledge is the Devonian and Carboniferous Pleuracanthus, which differs no more from existing Sharks than these do from one another.

Again, vast as is the number of undoubtedly Ganoid fossil Fishes, and great as is their range in time, a large mass of evidence has recently been adduced to show that almost all those respecting which we possess sufficient information, are referable to the same sub-ordinal groups as the existing Lepidosteus, Polypterus, and Sturgeon; and that a singular relation obtains between the older and the younger Fishes ; the former, the Devonian Ganoids, being almost all members of the same sub-order as

* See the abstract of a Lecture "On the Persistent Types of Animal Life," in the Notices of the Meetings of the Royal Institution of Great Britain.-June 3, 1859, vol. iii. p. 151. 
Polypterus, while the Mesozoic Ganoids are almost all similarly allied to Lepidosteus.*

Again, what can be more remarkable than the singular constancy of structure preserved throughout a vast period of time by the family of the Pycnodonts and by that of the true Colacanths: the former persisting, with but insignificant modifications, from the Carboniferous to the Tertiary rocks, inclusive; the latter existing, with still less change, from the Carboniferous rocks to the Chalk, inclusive ?

Among Reptiles, the highest living group, that of the Crocodilia, is represented, at the early part of the Mesozoic epoch, by species identical in the essential characters of their organization with those now living, and differing from the latter only in such matters as the form of the articular facets of the vertebral centra, in the extent to which the nasal passages are separated from the cavity of the mouth by bone, and in the proportions of the limbs.

And even as regards the Mammalia, the scanty remains of Triassic and Oolitic species afford no foundation for the supposition that the organization of the oldest forms differed nearly so much from some of those which now live as these differ from one another.

It is needless to multiply these instances; enough has been said to justify the statement that, in view of the immense diversity of known animal and vegetable forms, and the enormous lapse of time indicated by the accumulation of fossiliferous strata, the only circumstance to be wondered at is, not that the changes of life, as exhibited by positive evidence, have been so great, but that they have been so small.

Be they great or small, however, it is desirable to attempt to estimate them. Let us, therefore, take each great division of the animal world in succession, and, whenever an order or a family can be shown to have had a prolonged existence, let us endeavour to ascertain how far the later members of the group differ from the earlier ones. If these later members, in all or in many cases, exhibit a certain amount of modification, the fact is, so far, evidence in favour of a general law of change; and, in a rough way,

* "Memoirs of the Geological Survey of the United Kingdom.Decade $x$. Preliminary Essay upon the Systematic Arrangement of the Fishes of the Devonian Epoch." 
the rapidity of that change will be measured by the demonstrable amount of modification. On the other hand, it must be recollected that the absence of any modification, while it may leave the doctrine of the existence of a law of change without positive support, cannot possibly disprove all forms of that doctrine, though it may afford a sufficient refutation of many of them.

The Protozoa.-The Protozoa are represented throughout the whole range of geological series, from the Lower Silurian formation to the present day. The most ancient forms recently made knowr by Ehrenberg are exceedingly like those which now exist: no one has ever pretended that the difference between any ancient and any modern Foraminifera is of more than generic value, nor are the oldest Foraminifera either simpler, more embryonic, or less differentiated, than the existing forms.

The Coelenterata. - The Tabulate Corals have existed from the Silurian epoch to the present day, but I am not aware that the ancient Heliolites possesses a single mark of a more embryonic or less differentiated character, or less high organization, than the existing Heliopora. As for the Aporose Corals, in what respect is the Silurian Paleocyclus less highly organized or more embryonic than the modern Fungia, or the Liassic Aporosa than the existing members of the same families ?

The Mollusca.-In what sense is the living Waldheimia less embryonic, or more specialized, than the paleozoic Spirifer; or the existing Rhynchonellæ, Craniæ, Discinæ, Lingulæ, than the Silurian species of the same genera? In what sense can Loligo or Spirula be said to be more specialized, or less embryonic, than Belemnites; or the modern species of Lamellibranch and Gasteropod genera, than the Silurian species of the same genera?

The Annulosa. - The Carboniferous Insecta and Arachnida are neither less specialized, nor more embryonic, than these that now live, nor are the Liassic Cirripedia and Macrura ; while several of the Brachyura, which appear in the Chalk, belong to existing genera; and none exhibit either an intermediate, or an embryonic, character.

The Vertebrata.-Among fishes I have referred to the Colacanthini (comprising the genera Colacanthus, Holophagus, Undina, and Macropoma) as affording an example of a persistent type ; and it is most remarkable to note the smallness of the differences between any of these fishes 
(affecting at most the proportions of the body and fins, and the character and sculpture of the scales), notwithstanding their enormous range in time. In all the essentials of its very peculiar structure, the Mácropoma of the Chalk is identical with the Colacanthus of the Coal. Look at the genus Lepidotus, again, persisting without a modification of importance from the Liassic to the Eocene formations inclusive.

Or among the Teleostei-in what respect is the Beryx of the Chalk more embryonic, or less differentiated, than Beryx lineatus of King George's Sound ?

Or to turn to the higher Vertebrata-in what sense are the Liassic Chelonia inferior to those which now exist? How are the Cretaceous Jchthyosauria, Plesiosauria, or Pterosauria less embryonic, or more differentiated, species than those of the Lias?

Or lastly, in what circumstance is the Phascolotherium more embryonic, or of a more generalized type, than the modern Opossum ; or a Lophiodon, or a Paleotherium, than a modern Tapirus or Hyrax?

These examples might be almost indefinitely multiplied, but surely they are sufficient to prove that the only safe and unquestionable testimony we can procure-positive evidence-fails to demonstrate any sort of progressive modification towards a less embryonic, or less generalised, type in a great many groups of animals of long-continued geological existence. In these groups there is abundant evidence of variation-none of what is ordinarily understood as progression; and, if the known geological record is to be regarded as even any considerable fragment of the whole, it is inconceivable that any theory of a necessarily progressive development can stand, for the numerous orders and families cited afford no trace of such a process.

But it is a most remarkable fact, that, while the groups which have been mentioned, and many besides, exhibit no sign of progressive modification, there are others, co-existing with them, under the same conditions, in which more or less distinct indications of such a process seems to be traceable. Among such indications I may remind you of the predominance of Holostome Gasteropoda in the older rocks as compared with that of Siphonostome Gasteropoda in the later. A case less open to the objection of negative evidence, however, is that afforded by the Tetrabranchiate Cephalopoda, the forms of the shells and of 
the septal sutures exhibiting a certain increase of complexity in the newer genera. Here, however; one is met at once with the occurrence of Orthoceras and Baculites at the two ends of the series, and of the fact that one of the simplest genera, Nautilus, is that which now exists.

The Crinoidea, in the abundance of stalked forms in the ancient formations as compared with their present rarity, seem to present us with a fair case of modification from a more embryonic towards a less embryonic condition. But then, on careful consideration of the facts, the objection arises that the stalk, calyx, and arms of the paleozoic Crinoid are exceedingly different from the corresponding organs of a larval Comatula; and it might with perfect justice be argued that Actinocrinus and Eucalyptocrinus, for example, depart to the full as widely, in one direction, from the stalked embryo of Comatula, as Comatula itself does in the other.

The Echinidea, again, are frequently quoted as exhibiting a gradual passage from a more generalized to a more specialized type, seeing that the elongated, or oval, Spatangoids appear after the spheroidal Echinoids. But here it might be argued, on the other hand, that the spheroidal Echinoids, in reality, depart further from the general plan and from the embryonic form than the elongated Spatangoids do; and that the peculiar dental apparatus and the pedicellariæ of the former are marks of at least as great differentiation as the petaloid ambulacra and semitæ of the latter.

Once more, the prevalence of Macrurous before Brachyurous Podophthalmia is, apparently, a fair piece of evidence in favour of progressive modification in the same order of Crustacea; and yet the case will not stand much sifting, seeing that the Macrurous Podophthalmia depart as far in one direction from the common type of Podophthalmia, or from any embryonic condition of the Brachyura, as the Brachyura do in the other; and that the middle terms between Macrura and Brachyura-the Anomura-are little better represented in the older Mesozoic rocks than the Brachyura are.

None of the cases of progressive modification which are cited from among the Invertebrata apear to me to have a foundation less open to criticism than these; and if this be so, no careful reasoner would, I think, be inclined to lay very great stress upon them. Among the Vertebrata, 
however, there are a few examples which appear to be far less open to objection.

It is, in fact, true of several groups of Vertebrata which have lived through a considerable range of time, that the endoskeleton (more particularly the spinal column) of the older genera presents a less ossified, and, so far, less differentiated, condition than that of the younger genera. Thus the Devonian Ganoids, though almost all members of the same sub-order as Polypterus, and presenting numerous important resemblances to the existing genus, which possesses biconclave vertebræ, are, for the most part, wholly devoid of ossified vertebral centra. The Mesozoic Lepidosteidæ, again, have, at most, biconcave vertebræ, while the existing Lepidosteus has Salamandroid, opisthocœlous, vertebræ. So, none of the Paleozoic Sharks have shown themselves to be possessed of ossified vertebræ, while the majority of modern Sharks possess such vertebræ. Again, the more ancient Crocodilia and Lacertilia have vertebræ with the articular facets of their centra flattened or biconcave, while the modern members of the same group have them procœlous. But the most remarkable examples of progressive modification of the vertebral column, in correspondence with geological age, are those afforded by the Pycnodonts among fish, and the Labyrinthodonts among Amphibia.

The late able ichthyologist Heckel pointed out the fact, that, while the Pycnodonts never possess true vertebral centra, they differ in the degree of expansion and extension of the ends of the bony arches of the vertebra upon the sheath of the notochord; the Carboniferous forms exhibiting hardly any such expansion, while the Mesozoic genera present a greater and greater development, until, in the Tertiary forms, the expanded ends become suturally united so as to form a sort of false vertebra. Hermann von Meyer, again, to whose luminous researches we are indebted for our present large knowledge of the organization of the older Labyrinthodonts, has proved that the Carboniferous Archegosaurus had very imperfectly developed vertebral centra, while the Triassic Mastodonsaurus had the same parts completely ossified.*

- As the Address is passing through the press (March 7, 1862), evidence lies before me of the existence of a new Labyrinthodont (Pholidogaster), from the Edinburgh coal-field, with well-ossifled vertebral centra. 
The regularity and evenness of the dentition of the Anoplotherium, as contrasted with that of existing Artiodactyles, and the assumed nearer approach of the dentition of certain ancient Carnivores to the typical arrangement, have also been cited as exemplifications of a law of progressive development, but I know of no other cases based on positive evidence which are worthy of particular notice.

What then does an impartial survey of the positively ascertained truths of paleontology testify in relation to the common doctrines of progressive modification, which suppose that modification to have taken place by a necessary progress from more to less embryonic forms, or from more to less generalized types, within the limits of the period represented by the fossiliferous rocks ?

It negatives those doctrines; for it either shows us no evidence of any such modification, or demonstrates it to have been very slight; and as to the nature of that modification, it yields no evidence whatsoever that the earlier members of any long-continued group were more generalized in structure than the later ones. To a certain extent, indeed, it may be said that imperfect ossification of the vertebral column is an embryonic character; but, on the other hand, it would be extremely incorrect to suppose that the vertebral columns of the older Vertebrata are in any sense embryonic in their whole structure.

Obviously, if the earliest fossiliferous rocks now known are coëval with the commencement of life, and if their contents give us any just conception of the nature and the extent of the earliest fauna and flora, the insignificant amount of modification which can be demonstrated to have taken place in any one group of animals, or plants, is quite incompatible with the hypothesis that all living forms are the results of a necessary process of progressive development, entirely comprised within the time represented by the fossiliferous rocks.

Contrariwise, any admissible hypothesis of progressive modification must be compatible with persistence without progression, through indefinite periods. And should such an hypothesis eventually be proved to be true, in the only way in which it can be demonstrated, viz. by observation and experiment upon the existing forms of life, the conclusion will inevitably present itself, that the Paleozoic, Mesozoic, and Cainozoic faunæ and floræ, taken together, bear somewhat the same proportion to the whole series of 
living beings which have occupied this globe, as the existing launa and flora do to them.

Such are the results of paleontology as they appear, and have for some years appeared, to the mind of an inquirer who regards that study simply as one of the applications of the great biological sciences, and who desires to see it placed upon the same sound basis as other branches of physical inquiry. If the arguments which have been brought forward are valid, probably no one, in view of the present state of opinion, will be inclined to think the time wasted which has been spent upon their claboration. 
CORAL AND CORAL REEFS 


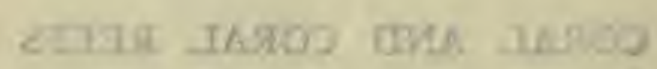




\section{CORAL AND CORAL REEFS *}

THE subject upon which I wish to address you to-night is the structure and origin of Coral and Coral Reefs. Under the head of "coral" there are included two very different things; one of them is that substance which I imagine a great number of us have champed when we were very much younger than we are now,- - the common red coral, which is used so much, as you know, for the edification and the delectation of children of tender years, and is also employed for the purposes of ornament for those who are much older, and as some think might know better. The other kind of coral is a very different substance ; it may for distinction's sake be called the white coral; it is a material which most assuredly not the hardest-hearted of baby farmers would give to a baby to chew, and it is a substance which is to be seen only in the cabinets of curious persons, or in museums, or, may be, over the mantelpieces of seafaring men. But although the red coral, as I have mentioned to you, has access to the very best society ; and although the white coral is comparatively a despised product, yet in this, as in many other cases, the humbler thing is in reality the greater; the amount of work which is done in the world by the white coral being absolutely infinite compared with that effected by its delicate and pampered namesake. Each of these substances, the white coral and the red, however, has a relationship to the other. They are, in a zoological sense, cousins, each of them being formed by the same kind of animals in what is substantially the same way. Each of these bodies is, in fact, the hard skeleton of a very curious and a very simple animal, more comparable to the bones of such animals as ourselves than 
to the shells of oysters or creatures of that kind; for it is the hardening of the internal tissue of the creature, of its internal substance, by the deposit in the body of a material which is exceedingly common, not only in fresh but in sea water, and which is specially abundant in those waters which we know as "hard," those waters, for example, which leave a "fur" upon the bottom of a tea-kettle. This "fur" is carbonate of lime, the same sort of substance as limestone and chalk. That material is contained in solution in sea water, and it is out of the sea water in which these coral creatures live that they get the lime which is needed for the forming of their hard skeleton.

But now what manner of creatures are these which form these hard skeletons? I dare say that in these days of keeping aquaria, of locomotion to the sea-side, most of those whom I am addressing may have seen one of those creatures which used to be known as the " sea anemone," receiving that name on account of its general resemblance, in a rough sort of way, to the flower which is known as the "anemone"; but being a thing which lives in the sea, it was qualified as the "sea anemone." Well, then, you must suppose a body shaped like a short cylinder, the top cut off, and in the top a hole rather oval than round. All round this aperture, which is the mouth, imagine that there are placed a number of feelers forming a circle. The cavity of the mouth leads into a sort of stomach, which is very unlike those of the higher animals, in the circumstance that it opens at the lower end into a cavity of the body, and all the digested matter, converted into nourishment, is thus distributed through the rest of the body. That is the general structure of one of these sea anemones. If you touch it it contracts immediately into a heap. It looks at first quite like a flower in the sea, but if you touch it you find that it exhibits all the peculiarities of a living animal ; and if anything which can serve as its prey comes near its tentacles, it closes them round it and sucks the material into its stomach and there digests it and turns it to the account of its own body.

These creatures are very voracious, and not at all particular what they seize; and sometimes it may be that they lay hold of a shellfish which is far too big to be packed into that interior cavity, and, of course, in any ordinary animal a proceeding of this kind would give rise to a very 
severe fit of indigestion. But this is by no means the case in the sea anemone, because when digestive difficulties of this kind arise he gets out of them by splitting himself in two; and then each half builds itself up into a fresh creature, and you have two polypes where there was previously one, and the bone which stuck in the way lying between them! Not only can these creatures multiply in this fashion, but they can multiply by buds. A bud will grow out of the side of the body (I am not speaking of the common sea anemone, but of allied creatures) just like the bud of a plant, and that will fashion itself into a creature like the parent. There are some of them in which these buds remain connected together, and you will soon see what would be the result of that. If I make a bud grow out here, and another on the opposite side, and each fashions itself into a new polype, the practical effect will be that before long you will see a single polype converted into a sort of tree or bush of polypes. And these will all remain associated together, like a kind of co-operative store, which is a thing I believe you understand very well here,-each mouth will help to feed the body and each part of the body help to support the multifarious mouths. I think that is as good an example of a zoological co-operative store as you can well have. Such are these wonderful creatures. But they are capable not only of multiplying in this way, but in other ways, by having a more ordinary and regular kind of offspring. Little eggs are produced in the bodies of these creatures, and those eggs are hatched and the young are passed out by the way of the mouth, and they go swimming about as little oval bodies covered with a very curious kind of hairlike processes. Each of these processes is capable of striking the water like an oar; and the consequence is that the young creature is propelled through the water. So that you have the young polype floating about in this fashion, covered by its vibratile cilia, as these long filaments, which are capable of vibration, are termed. And thus, although the polype itself may be a fixed creature unable to move about, it is able to spread its offspring over great areas. For these creatures not only propel themselves, but while swimming about in the sea for many hours, or perhaps days, it will be obvious that they must be carried hither and thither by the currents of the sea, which not unfrequently move at the rate of one or two miles an hour. Thus, in the course of a few days, the offspring of this stationary creature may be 
carried to a very great distance from its parent ; and having been so carried it loses these organs by which it is propelled, and settles down upon the bottom of the sea and grows up again into the form and condition of its parents. So that if you suppose a single polype of this kind settled upon the bottom of the sea, it may by these various methods-that is to say, by cutting itself in two, which we call "fission," or by budding ; or by sending out these swimming embryos,multiply itself to an enormous extent, and give rise to thousands, or millions, of progeny in a comparatively short time; and these thousands, or millions, of progeny may cover a very large surface of the sea bottom; in fact, you will readily perceive that, give them time, and there is no limit to the surface which they may cover.

Having understood thus far the general nature of these polypes, which are the fabricators both of the red and white coral, let us consider a little more particularly how the skeletons of the red coral and of the white coral are formed. The red coral polype perches upon the sea bottom, it then grows up into a sort of stem, and out of that stem there grow branches, each of which has its own polypes; and thus you have a kind of tree formed, every branch of the tree terminated by its polype. It is a tree, but at the end of the branches there are open mouths of polypes instead of flowers. Thus there is a common soft body connecting the whole, and as it grows up the soft body deposits in its interior a quantity of carbonate of lime, which acquires a beautiful red or flesh colour, and forms a kind of stem running through the whole, and it is that stem which is the red coral. The red coral grows principally at the bottom of the Mediterranean Sea, at very great depths, and the coral fishers, who are very adventurous seamen, take their drag nets, of a peculiar kind, roughly made, but efficient for their purpose, and drag them along the bottom of the sea to catch the branches of the red coral, which become entangled and are thus brought up to the surface. They are then allowed to putrefy, in order to get rid of the animal matter, and the red coral is the skeleton that is left.

In the case of the white coral, the skeleton is more complete. In the red coral, the skeleton belongs to the whole; in the white coral there is a special skeleton for every one of these polypes in addition to that for the whole body. There is a skeleton formed in the body of each of them, like a cup divided by a number of radiating partitions 
towards the outside ; and that cup is formed of carbonate of lime, only not stained red, as in the case of the red coral. And all these cups are joined together into a common branch, the result of which is the formation of, a beautiful coral tree. This is a great mass of madrepore, and in the living state every one of the ends of these branches was terminated by a beautiful little polype, like a sea anemone, and all the skeleton was covered by a soft body which united the polypes together. You must understand that all this skeleton has been formed in the interior of the body, to suit the branched body of the polype mass, and that it is as much its skeleton as our own bones are our skeleton. In this next coral the creature which has formed the skeleton has divided itself as it grew, and consequently has formed a great expansion; but scattered all over this surface there were polype bodies like those I previously described. Again, when this great cup was alive, the whole surface was covered with a beautiful body upon which were set innumerable small polype flowers, if we may so call them, often brilliantly coloured; and the whole cup was built up in the same fashion by the deposit of carbonate of lime in the interior of the combined polype body, formed by budding and by fission in the way I described. You will perceive that there is no necessary limit to this process. There is no reason why we should not have coral three or four times as big; and there are certain creatures of this kind that do fabricate very large masses, or half spheres several feet in diameter. Thus the activity of these animals in separating carbonate of lime from the sea and building it up into definite shapes is very considerable indeed.

Now I think I have said sufficient-as much as I can without taking you into technical details, of the general nature of these creatures which form coral. The animals which form coral are scattered over the seas of all countries in the world. The red coral is comparatively limited, but the polypes which form the white coral are widely scattered. There are some of them which remain single, or which give rise to only small accumulations; and the skeletons of these, as they die, accumulate upon the bottom of the sea, but they do not come to much; they are washed about and do not adhere together, but become mixed up with the mud of the sea. But there are certain parts of the world in which the coral polypes which live and grow are of a kind which remain, adhere together, and form 
great masses. They differ from the ordinary polypes just in the same way as those plants which form a peat-bog or meadow-turf differ from ordinary plants. They have a habit of growing together in masses in the same place; they are what we call "gregarious" things; and the consequence of this is, that as they die and leave their skeletons, those skeletons form a considerable solid aggregation at the bottom of the sea, and other polypes perch upon them, and begin building upon them, and so by degrees a great mass is formed. And just as we know there are some ancient cities in which you have a British city, and over that the foundations of a Roman city; and over that a Saxon city, and over that again a modern city, so in these localities of which I am speaking, you have the accumulations of the foundations of the houses, if I may use the term, of nation after nation of these coral polypes; and these accumulations may cover a very considerable space, and may rise in the course of time from the bottom to the surface of the sea.

Mariners have a name which they apply to all sorts of obstacles consisting of hard and rocky matter which comes in their way in the course of their navigation; they call such obstacles "reefs," and they have long been in the habit of calling the particular kind of reef, which is formed by the accumulation of the skeletons of dead corals, by the name of " coral reefs," therefore, those parts of the world in which these accumulations occur have been termed by them "coral reef areas," or regions in which coral reefs are found. There is a very notable example of a simple coral reef about the island of Mauritius, which I dare say you all know, lies in the middle of the Indian Ocean. It is a very considerable and beautiful island, and is surrounded on all sides by a mass of coral, which has been formed in the way I have described; so that if you could get upon the top of one of the peaks of the island, and look down upon the Indian Ocean, you would see that the beach round the Island was continued outward by a kind of shallow terrace, which is covered by the sea, and where the sea is quite shallow; and at a distance varying from three-quarters of a mile to a mile and a half from the proper beach, you would see a line of foam or surf which looks most beautiful in contrast with the bright green water in the inside, and the deep blue of the sea beyond. That line of surf indicates the point at which the waters 
of the ocean are breaking upon the coral reef which surrounds the island. You see it sweep round the island upon all sides, except where a river may chance to come down, and that always makes a gap in the shore.

There are two or three points which I wish to bring clearly before your notice about such a reef as this. In the first place, you perceive it forms a kind of fringe round the island, and is therefore called a "fringing reef." In the next place, if you go out in a boat, and take soundings at the edge of the reef, you find that the depth of the water is not more than from 20 to 25 fathoms-that is about 120 to $\mathbf{1 5 0}$ feet. Outside that point you come to the natural sea bottom; but all inside that depth is coral, built up from the bottom by the accumulation of the skeletons of innumerable generations of coral polypes. So that you see the coral forms a very considerable rampart round the island. What the exact circumference may be I do not remember, but it cannot be less than 100 miles, and the outward height of this wall of coral rock nowhere amounts to less than about 100 or 150 feet.

When the outward face of the reef is examined, you find that the upper edge, which is exposed to the wash of the sea, and all the seaward face, is covered with those living plant-like flowers which I have described to you. They are the coral polypes which grow, flourish, and add to the mass of calcareous matter which already forms the reef. But towards the lower part of the reef, at a depth of about 120 feet, these creatures are less active, and fewer of them at work ; and at greater depths than that you find no living coral polype at all; and it may be laid down as a rule, derived from very extensive observation, that these reefbuilding corals cannot live in a greater depth of water than about 120 to 150 feet. I beg you to recollect that fact, because it is one I shall have to come back to by and by, and to show to what very curious consequences that rule leads. Well then, coming back to the margin of the reef, you find that part of it which lies just within the surf to be coated by a very curious plant, a sort of seaweed, which contains in its substance a very great deal of carbonate of lime, and looks almost like rock; this is what is called the nulli pore. More towards the land, we come to the shallow water upon the inside of the reef, which has a particular name, derived from the Spanish or the Portuguese-it is called a "lagoon," or lake. In this laguon 
there is comparatively little living coral ; the bottom of it is formed of coral mud. If we pounded this coral in water, it would be converted into calcareous mud, and the waves during storms do for the coral skeletons exactly what we might do for this coral in a mortar; the waves tear off great fragments and crush them with prodigious force, until they are ground into the merest powder, and that powder is washed into the interior of the lagoon, and forms a muddy coating at the bottom. Beside that, there are a great many animals that prey upon the coral-fishes, worms', and creatures of that kind, and all these, by their digestive processes, reduce the coral to the same state, and contribute a very important element to this fine mud. The living coral found in the lagoon, is not the reef building coral; it does not give rise to the same massive skeletons. As you go in a boat over these shallow pools, you see these beautiful things, coloured red, blue, green, and all colours, building their houses; but these are mere tenements, and not to be compared in magnitude and importance to the masses which are built by the reef-builders themselves. Now, such a structure as this is what is termed a " fringing reef." You meet with fringing reefs of this kind not only in the Mauritius, but in a number of other parts of the world. If these were the only reefs to be seen anywhere, the problem of the formation of coral reefs would never have been a difficult one. Nothing can be easier than to understand how there must have been a time when the coral polypes came and settled on the shores of this island, everywhere within the 20 to 25 fathom line, and how, having perched there, they gradually grew until they built up the reef.

But these are by no means the only sort of coral reefs in the world; on the contrary, there are very large areas, not only of the Indian ocean, but of the Pacific, in which many many thousands of square miles are covered either with a peculiar kind of reef, which is called the "encircling reef," or by a still more curious reef which goes by the name of the "atoll." There is a very good picture, which Professor Roscoe has been kind enough to prepare for me, of one of these atolls, which will enable you to form a notion of it as a landscape. You have in the foreground the waters of the Pacific. You must fancy yourself in the middle of the great ocean, and you will perceive that there is an almost circular island, with a low beach, which is formed entirely of coral 


\section{CORAL AND CORAL REEFS}

sand; growing upon that beach you have vegetation, which takes, of course, the shape of the circular land; and then, in the interior of the circle, there is a pool of water, which is not very deep-probably in this case not more than eight or nine fathoms-and which forms a strange and beautiful contrast to the deep blue water outside. This circular island, or atoll, with a lagoon in the middle, is not a complete circle; upon one side of it there is a break, exactly like the entrance into a dock; and, as a matter of course, these circular islets, or atolls, form most efficient breakwaters, for if you can only get inside your ship is in perfect safety, with admirable anchorage in the interior. If the ship were lying within a mile of that beach, the water would be one or two thousand feet deep; therefore, a section of that atoll, with the soundings as deep as this all round, would give you the notion of a great cone, cut off at the top, and with a shallow cup in the middle of it. Now, what a very singular fact this is, that we should have rising from the bottom of the deep ocean a great pyramid, beside which all human pyramids sink into the most utter insignificance! These singular coral limestone structures are very beautiful, especially when crowned with cocoa-nut trees. There you see the long line of land, covered with vegetation-cocoa-nut trees-and you have the sea upon the inner and outer sides, with a vessel very comfortably riding at anchor. That is one of the remarkable forms of reef in the Pacific. Another is a sort of half-way house, between the atoll and the fringing reef; it is what is called an " encircling reef." In this case you see an island rising out of the sea, and at two or three miles distance, or more, and separated by a deep channel, which may be eight to twelve fathoms deep, there is a reef, which encircles it like a great girdle; and outside that again the water is one or two thousand feet deep. I spent three or four years of my life in cruising about a modification of one of these encircling reefs, called a "barrier reef," upon the east coast of Australia-one of the most wonderful accumulations of coral rock in the world. It is about 1,100 miles long, and varies in width from one or two to many miles. It is separated from the coast of Australia by a channel of about 25 fathoms deep ; while outside, looking toward America, the water is two or three thousand feet deep at a mile from the edge of the reef. This is an accumulation of limestone rock, built up by corals, to which we have no parallel any- 
where else. Imagine to yourself a heap of this material more than one thousand miles long, and several miles wide. That is a barrier reef; but a barrier reef is merely as it were a fragment of an encircling reef running parallel to the coast of a great continent.

I told you that the polypes which built these reefs were not able to live at a greater depth than 20 to 25 fathoms of water; and that is the reason why the fringing reef goes no farther from the land than it does. And for the same reason, if the Pacific could be laid bare we should have a most singular spectacle. There would be a number of mountains with truncated tops scattered over it, and those mountains would have an appearance just the very reverse of that presented by the mountains we see on shore. You know that the mountains on shore are covered with vegetation at their bases, while their tops are barren or covered with snow; but these mountains would be perfectly bare at their bases, and all round their tops they would be covered with a beautiful vegetation of coral polypes. And not only would this be the case, but we should find that for a considerable distance down, all the material of these atoll and encircling reefs was built up of precisely the same coral rock as the fringing reef. That is to say, you have an enormous mass of coral rock at a depth below the surface of the water where we know perfectly well that the coral animals could not have lived to form it. When those two facts were first put together, naturalists were quite as much puzzled as I daresay you are, at present, to understand how these two seeming contradictions could be reconciled; and all sorts of odd hypotheses were resorted to. It was supposed that the coral did not extend so far down, but that there was a great chain of submarine mountains stretching through the Pacific, and that the coral had grown upon them. But only fancy what supposition that was, for you would have to imagine that there was a chain of mountains a thousand miles or more long, and that the top of every mountain came within 20 fathoms of the surface of the sea, and neither rose above nor sunk beneath that level. That is highly improbable: such a chain of mountains was never known. Then how can you possibly account for the curious circular form of the atolls by any supposition of this kind? I believe there was some one who imagined that all these mountains were volcanoes, and that the reefs had grown round the tops of the craters, so we all stuck 


\section{CORAL AND CORAL REEFS}

fast. I may say "we," though it was rather before my time. And when we all stick fast, it is just the use of a man of genius that he comes and shows us the meaning of the thing. He generally gives an explanation which is so ridiculously simple that everybody is ashamed that he did not find it out before; and the way such a discoverer is often rewarded is by finding out that some one had made the discovery before him! I do not mean to say that it was so in this particular instance, because the great man who played the part of Columbus and the egg on this occasion had, I believe, always had the full credit which he so well deserves. The discoverer of the key to these problems was a man whose name you know very well in connection with other matters, and I should not wonder if some of you have heard it said that he was a superficial kind of person who did not know much about the subject on which he writes. He was Mr. Darwin, and this brilliant discovery of his was made public thirty years ago, long before he became the celebrated man he now is; and it was one of the most singular instances of that astonishing sagacity which he possesses of drawing consequences by way of deduction from simple principles of natural science - a power which has served him in good stead on other occasions. Well, Mr. Darwin, looking at these curious difficulties and having that sort of knowledge of natural phenomena in general, without which he could not have made a step towards the solution of the problem, said to himself- "It is perfectly clear that the coral which forms the base of the atolls and fringing reefs could not possibly have been formed there if the level of the sea has always been exactly where it is now, for we know for certain that these polypes cannot build at a greater depth than 20 to 25 fathoms, and here we find them at 50 to 100 fathoms."

That was the first point to make clear. The second point to deal with was-if the polypes cannot have built there while the level of the sea has remained stationary, then one of two things must have happened-either the sea has gone up, or the land has gone down.

There is no escape from one of these two alternatives. Now the objections to the notion of the sea having gone up are very considerable indeed; for you will readily perceive that the sea could not possibly have risen a thousand feet in the Pacific without rising pretty much the same distance everywhere else; "and if it had risen 
that height everywhere else since the reefs began to be formed, the geography of the world in general must have been very different indeed, at that time, from what it is now. And we have very good means of knowing that any such rise as this certainly has not taken place in the level of the sea since the time that the corals have been building their houses. And so the only other alternative was to suppose that the land had gone down, and at so slow a rate that the corals were able to grow upward as fast as it went downward. You will see at once that this is the solution of the mystery, and nothing can be simpler or more obvious when you come to think about it. Suppose we start with a coral sea and put in the middle of it an island such as the Mauritius. Now let the coral polypes come and perch on the shore and build a fringing reef, which will stop when they come to 20 or 25 fathoms, and you will have a fringing reef like that round the island in the illustration. So long as the land remains stationary, so long as it does not descend so long will that reef be unable to get any further out, because the moment the polype embryos try to get below they die. But now suppose that the land sinks very gradually indeed. Let it subside by slow degrees, until the mountain peak, which we have in the middle of it, alone projects beyond the sea level. The fringing reef would be carried down also; but we suppose that the sinking is so slow that the coral polypes are able to grow up as fast as the land is carried down; consequently they will add layer upon layer until they form a deep cup, because the inner part of the reef grows much more slowly than the outer part. Thus you have the reef forming a bed thicker upon the flanks of the island; but the edge of the reef will be very much further out from the land, and the lagoon will be many times deeper; in short, your fringing reef will be converted into an encircling reef. And if, instead of this being an island, it were a great continent like Australia, then you will have the phenomenon of a barrier reef which I have described. The barrier reef of Australia was originally a fringing reef; the land has gone slowly down; the consequence is the lagoon has deepened until its depth is now 25 fathoms and the corals have grown up at the outer edge until you have that prodigious accumulation which forms the barrier reel at present. Now let this process go on further still; let us take the land a further step down, so as to submerge 
even the peak. The coral, still growing up, will cover the surface of the land, and you will have an atoll reef; that is to say, a more or less circular or oval ring of coral rock with a lagoon in the middle. Thus you see that every peculiarity and phenomenon of these different forms of coral reef was explained at once by the simplest of all possible suppositions, namely, by supposing that the land has gone down at a rate not greater than that at which the coral polypes have grown up. You explain a Fringing Reef as a reef which is formed round land comparatively stationary; an Encircling Reef as one which is formed round land going down; and an Atoll as a reef formed upon land gone down; and the thing is so simple that a child may understand it when it is once explained.

But this would by no means satisfy the conditions of a scientific hypothesis. No man who is cautious would dream of trusting to an explanation of this kind simply because it explained one particular set of facts. Before you can possibly be safe in dealing with Nature-who is very properly made of the feminine gender, on account of the astonishing tricks. which she plays upon her admirers ! -I say before you can be safe in dealing with Nature, you must get two or three kinds of cross proofs, so as to make sure not only that your hypothesis fits that particular set of facts, but that it is not contradicted by some other set of facts which is just as clear and certain. And it so happens, that in this case Mr. Darwin supplied the cross proofs as well as the immediate evidence. You have all heard of volcanoes, those wonderful vents in the surface of the earth out of which pour masses of lava, cinders and ashes, and the like. Now, it is a matter of observation and experience that all volcanoes are placed in areas in which the surface of the earth is undergoing elevation, or at any rate is stationary; they are not placed in parts of the world in which the level of the land is being lowered. They are all indications of a great subterranean activity, of a something being pushed up, and therefore naturally the land either gives way and lets it come through, or else is raised up by its violence. And so $\mathrm{Mr}$. Darwin, being desirous not to merely put out a flashy hypothesis, but to get at the truth of the matter, said to himself, "If my notion of this matter is right, then atolls and encircling reefs, inasmuch as they are dependent upon subsidence, ought not to be found in company with volcanoes; and, 
vice vers $\hat{d}$, volcanoes ought not to be found in company with atolls, but they ought to be found in company with fringing reefs." And if you turn to Mr. Darwin's great work upon the coral reefs, you will see a very beautiful chart of the world, which he prepared with great pains and labour, showing the distribution on the one hand of the reefs, and on the other of the volcanoes; you will find that in no case does the atoll accompany the volcano, or the volcano burst up among the atolls. It is most instructive to look at the great area of the Pacific on the map, and see the great masses of atolls forming in one region of it a most enormous belt, running from north-west to southeast; while the volcanoes, which are very numerous in that region, go round the margin, so that we can picture the Pacific to ourselves a section of a kind of very shallow basin-shallow in proportion to its width, with the atolls rising from the bottom of it, and at the margins the volcanoes. It is exactly as if you had taken a flat mass and lifted up the edges of it; the subterranean force which lifted up the edges shows itself in volcanoes, and as the edges have been raised, the middle part of the mass has gone down. In other words, the facts of physical geography precisely and exactly correspond with the hypothesis which accounts for the infinite varieties of coral reefs.

One other point, before I conclude, about this matter. These reefs, as you have just perceived, are in a most singular and unexpected manner indications of physical changes of elevations and depressions going on upon the surface of the globe. I dare say it may have surprised you to hear me talk in this familiar sort of way of land going up and down; but it is one of the universal lessons of geology that the land is going down and going up, and has been going up and down, in all sorts of places and to all sorts of distances, through all recorded time. Geologists would be quite right in maintaining the seeming paradox that the stable thing in the world is the fluid sea and the shifting thing is the solid land. That may sound a very hard saying at first, but the more you look into geology, the more you will see ground for believing that it is not a mere paradox.

In an unexpected manner, again, these reefs afford us not only an indication of change of place, but they afford an indication of lapse of time. The reef is a timekeeper of a very curious character; and you can easily understand 
why. The coral polype, like everything else, takes a certain time to grow to its full size ; it does not do it in a minute ; just as a child takes a certain time to grow into a man so does the embryo polype take time to grow into a perfect polype and form its skeleton. Consequently every particle of coral limestone is an expression of time. It must have taken a certain time to separate the lime from the sea water. It is not possible to arrive at an accurate computation of the time it must have taken to form these coral islands, because we lack the necessary data; but we can form a rough calculation, which leads to very curious and striking results. The computations of the rate at which corals grow are so exceedingly variable, that we must allow the widest possible margin for error; and it is better in this case to make the allowance upon the side of excess. I think that anybody who knows anything about the matter will tell you that I am making a computation far in excess of what is probable, if I say that an inch of coral limestone may be added to one of these reefs in the course of a year. I think most naturalists would be inclined to laugh at me for making such an assumption, and would put the growth at certainly not more than half that amount. But supposing it is so, what a very curious notion of the antiquity of some of these great living pyramids comes out by a very simple calculation. There is no doubt whatever that the sea faces of some of them are fully a thousand feet high, and if you take the reckoning of an inch a year, that will give you 12,000 years for the age of that particular pyramid or cone of coral limestone; 12,000 long years have these creatures been labouring in conditions which must have been substantially the same as they are now, otherwisc the polypes could not have continued their work. But I believe I very much understate both the height of some of these masses, and overstate the amount which these animals can form in the course of a year; so that you might very safely double the period as the time during which the Pacific Ocean, the general state of the climate, and the sea, and the temperature has been substantially what it is now ; and yet that state of things which now obtains in the Pacific Ocean is the yesterday of the history of the life of the globe. Those pyramids of coral rock are built upon a foundation which is itself formed by the deposits which the geologist has to deal with. If we go back in time and search through the series of the rocks, we find at every 
age of the world's history which has yet been examined, accumulations of limestone, many of which have certainly been built up in just the same way as those coral reefs which are now forming the bottom of the Pacific Ocean. And even if we turn to the oldest periods of geologic history, although the nature of the materials is changed, although we cannot apply to them the same reasonings that we can to the existing corals, yet still there are vast masses of limestone formed of nothing else than the accumulations of the skeletons of similar animals, and testifying that even in those remote periods of the world's history, as now, the order of things implies that the earth had already endured for a period of which our ordinary standards of chronology give us not the slightest conception. In other words, the history of these coral reefs, traced out honestly and carefully, and with the same sort of reasoning that you would use in the ordinary affairs of life, testifies, like every fact that I know of, to the prodigious antiquity of the earth since it existed in a condition in the main similar to that in which it now is. 
YEAST 



\section{YEAST}

I HAVE selected to-night the particular subject of Yeast for two reasons-or, rather, I should say for three. In the first place, because it is one of the simplest and the most familiar objects with which we are acquainted. In the second place, because the facts and phenomena which I have to describe are so simple that it is possible to put them before you without the help of any of those pictures or diagrams which are needed when matters are more complicated, and which, if I had to refer to them here, would involve the necessity of my turning away from you now and then, and thereby increasing very largely my difficulty (already sufficiently great) in making myself heard. And thirdly, I have chosen this subject because I know of no familiar subsiance forming part of our every-day knowledge and experience, the examination of which, with a little care, tends to open up such very considerable issues as does this substance-yeast.

In the first place, I should like to call your attention to a fact with which the whole of you are, to begin with, perfectly acquainted, I mean the fact that any liquid containing sugar, any liquid which is formed by pressing out the succulent parts of the fruits of plants, or a mixture of honey and water, if left to itself for a short time, begins to undergo a peculiar change. No matter how clear it might be at starting, yet after a few hours, or at most a few days, if the temperature is high, this liquid begins to be turbid. and by-and-by bubbles make their appearance in it, and a sort of dirty-looking yellowish foam or scum collects at the surface; while at the same time, by degrees, a similar kind of matter, which we call the "lees," sinks to the bottom.

The quantity of this dirty-looking stuff, that we call the scum and the lees, goes on increasing until it reaches a certain amount, and then it stops ; and by the time it stops, you find the liquid in which this matter has been formed has become altered in its quality. To begin with it was a mere sweetish substance, having the flavour of whatever might 
be the plant from which it was expressed, or having merely the taste and the absence of smell of a solution of sugar; but by the time that this change that I have been briefly describing to you is accomplished the liquid has become completely altered, it has acquired a peculiar smell, and, what is still more remarkable, it has gained the property of intoxicating the person who drinks it. Nothing can be more innocent than a solution of sugar; nothing can be less innocent, if taken in excess, as you all know, than those fermented matters which are produced from sugar. Well, again, if you notice that bubbling, or, as it were, seething of the liquid, which has accompanied the whole of this process, you will find that it is produced by the evolution of little bubbles of air-like substance out of the liquid; and I dare say you all know this air-like substance is not like common air ; it is not a substance which a man can breathe with impunity. You often hear of accidents which take place in brewers' vats when men go in carelessly, and get suffocated there without knowing that there was anything evil awaiting them. And if you tried the experiment with this liquid I am telling of while it was fermenting, you would find that any small animal let down into the vessel would be similarly stifled; and you would discover that a light lowered down into it would go out. Well, then, lastly, if after this liquid has been thus altered you expose it to that process which is called distillation; that is to say, if you put it into a still, and collect the matters which are sent over, you obtain, when you first heat it, a clear transparent liquid, which, however, is something totally different from water; it is much lighter; it has a strong smell, and it has an acrid taste; and it possesses the same intoxicating power as the original liquid, but in a much more intense degree. If you put a light to it, it burns with a bright flame, and it is that substance which we know as spirits of wine.

Now these facts which I have just put before you-all but the last-have been known from extremely remote antiquity. It is, I hope, one of the best evidences of the antiquity of the human race, that among the earliest records of all kinds of men, you find a time recorded when they got drunk. We may hope that that must have been a very late period in their history. Not only have we the record of what happened to Noah, but if we turn to the traditions of a different people, those forefathers of ours who 
lived in the high lands of Northern India, we find that they were not less addicted to intoxicating liquids; and I have no doubt that the knowledge of this process extends far beyond the limits of historically recorded time. And it is a very curious thing to observe that all the names we have of this process, and all that belongs to it, are names that have their roots not in our present language, but in those older languages which go back to the times at which this country was peopled. That word "fermentation" for example, which is the title we apply to the whole process, is a Latin term; and a term which is evidently based upon the fact of the effervescence of the liquid. Then the French, who are very fond of calling themselves a Latin race, have a particular word for ferment, which is levâre. And, in the same way, we have the word "leaven," those two words having reference to the heaving up, or to the raising of the substance which is fermented. Now those are words which we get from what I may call the Latin side of our parentage; but if we turn to the Saxon side, there are a number of names connected with this process of fermentation. For example, the Germans call fermentation-and the old Germans did so- " gähren;" and they call anything which is used as a ferment by such names, such as "gheist" and "geest," and finally in low German, "yest ;" and that word you know is the word our Saxon forefathers used, and is almost the same as the word which is commonly employed in this country to denote the common ferment of which I have been speaking. So they have another name, the word " hefe," which is derived from their verb " heben," which signifies to raise up ; and they have yet a third name, which is also one common in this country (I do not know whether it is common in Lancashire, but it is certainly very common in the Midland counties), the word " barm," which is derived from a root which signifies to raise or to bear up. Barm is a something borne up ; and thus there is much more real relation than is commonly supposed by those who make puns, between the beer which a man takes down his throat and the bier upon which that process, if carried to excess, generally lands him, for they are both derived from the root signifying bearing up; the one thing is borne upon men's shoulders, and the other is the fermented liquid which was borne up by the fermentation taking place in itself.

Again, I spoke of the produce of fermentation as " spirit $66-\mathrm{N}$ 
of wine." Now what a very curious phrase that is, If you come to think of it. The old alchemists talked of the finest essence of anything as if it had the same sort of relation to the thing itself as a man's spirit is supposed to have to his body ; and so they spoke of this fine essence of the fermented liquid as being the spirit of the liquid. Thus came about that extraordinary ambiguity of language, in virtue of which you apply precisely the same substantive name to the soul of man and to a glass of gin ! And then there is still yet one other most curious piece of nomenclature connected with this matter, and that is the word " alcohol" itself, which is now so familiar to everybody. Alcohol originally meant a very fine powder. The women of the Arabs and other Eastern people are in the habit of tinging their eyclashes with a very fine black powder which is made of antimony, and they call that "kohol ;" and the "al" is simply the article put in front of it, so as to say " the kohol." And up to the 17 th century in this country the word alcohol was employed to signify any very fine powder; you find in Robert Boyle's works that he uses " alcohol " for a very fine subtle powder. But then this name of anything very fine and very subtle came to be specially connected with the fine and subtle spirit obtained from the fermentation of sugar ; and I believe that the first person who fairly fixed it as the proper name of what we now conmonly call spirits of wine, was the great French chemist Lavoisier, so comparatively recent is the use of the word alcohol in this specialised sense.

So much by way of general introduction to the subject on which I have to speak to-night. What I have hitherto stated is simply what we may call common knowledge, which everybody may acquaint himself with. And you know that what we call scientific knowledge is not any kind of conjuration, as people sometimes suppose, but it is simply the application of the same principles of common sense that we apply to common knowledge, carried out, if I may so speak, to knowledge which is uncommon. And all that we know now of this substance, yeast, and all the very strange issues to which that knowledge has led us, have simply come out of the inveterate habit, and a very fortunate habit for the human race it is, which scientific men have of not being content until they have routed out all the different chains and connections of apparently simple phenomena, until they have taken them to pieces and understood the condi- 
tions upon which they depend. I will try to point out to you now what has happened in consequence of endeavouring to apply this process of " analysis," as we call it, this teazing out of an apparently simple fact into all the little facts of which it is made up, to the ascertained facts relating to the barm or the yeast; secondly, what has come of the attempt to ascertain distinctly what is the nature of the products which are produced by fermentation; then what has come of the attempt to understand the relation between the yeast and the products ; and lastly, what very curious side issues if I may so call them-have branched out in the course of this inquiry, which has now occupied somewhere about two centuries.

The first thing was to make out precisely and clearly what was the nature of this substance, this apparently mere scum and mud that we call yeast. And that was first commenced seriously by a wonderful old Dutchman of the name of Leeuwenhoek, who lived some two hundred years ago, and who was the first person to invent thoroughly trustworthy microscopes of high powers. Now, Leeuwenhoek went to work upon this yeast mud, and by applying to it high powers of the microscope, he discovered that it was no mere mud such as you might at first suppose, but that it was a substance made up of an enormous multitude of minute grains, each of which had just as definite a form as if it were a grain of corn, although it was vastly smaller, the largest of these not being more than the two-thousandth of an inch in diameter ; while, as you know, a grain of corn is a large thing, and the very smallest of these particles were not more than the seven-thousandth of an inch in diameter. Leeuwenhoek saw that this muddy stuff was in reality a liquid, in which there were floating this immense number of definitely shaped particles, all aggregated in heaps and lumps and some of them separate. That discovery remained, so to speak, dormant for fully a century, and then the question was taken up by a French discoverer, who, paying great attention and having the advantage of better instruments than Leeuwenhoek had, watched these things and made the astounding discovery that they were bodies which were constantly being reproduced and growing; that when one of these rounded bodies was once formed and had grown to its full size, it immediately began to give off a little bud from one side, and then that bud grew out until it had attained the full size of the first, and that, in this way, the ycast particle was 
undergoing a process of multiplication by budding, just as effectual and just as complete as the process of multiplication of a plant by budding; and thus this Frenchman, Cagniard de la Tour, arrived at the conclusion-very creditable to his sagacity, and which has been confirmed by every observation and reasoning since-that this apparently muddy refuse was neither more nor less than a mass of plants, of minute living plants, growing and multiplying in the sugary fluid in which the yeast is formed. And from that time forth we have known this substance which forms the scum and the lees as the yeast plant; and it has received a scientific namewhich I may use without thinking of it, and which I will therefore give you-namely, "Torula." Well, this was a capital discovery. The next thing to do was to make out how this torula was related to other plants. I won't weary you with the whole course of investigation, but I may sum up its results, and they are these - that the torula is a particular kind of a fungus, a particular state rather, of a fungus or mould. There are many moulds which under certain conditions give rise to this torula condition, to a substance which is not distinguishable from yeast, and which has the same properties as yeast-that is to say, which is able to decompose sugar in the curious way that we shall consider by-and-by. So that the yeast plant is a plant belonging to a group of the Fungi, multiplying and growing and living in this very remarkable manner in the sugary fluid which is, so to speak, the nidus or home of the yeast.

That, in a few words, is, as far as investigation-by the help of one's eye and by the help of the microscope-has taken us. But now there is an observer whose methods of observation are more refined than those of men who use their eye, even though it be aided by the microscope; a man who sees indirectly further than we can see directlythat is, the chemist ; and the chemist took up this question, and his discovery was not less remarkable than that of the microscopist. The chemist discovered that the yeast plant being composed of a sort of bag, like a bladder, inside which is a peculiar soft, semifluid material-the chemist found that this outer bladder has the same composition as the substance of wood, that material which is called "cellulose," and which consists of the elements carbon and hydrogen and oxygen, without any nitrogen. But then he also found (the first person to discover it was an Italian chemist, named 
Fabroni, in the end of the last century) that this inner matter which was contained in the bag, which constitutes the yeast plant, was a substance containing the elements carbon and hydrogen and oxygen and nitrogen; that it was what Fabroni called a vegeto-animal substance, and that it had the peculiarities of what are commonly called "animal products."

This again was an exceedingly remarkable discovery. It lay neglected for a time, until it was subsequently taken up by the great chemists of modern times, and they, with their delicate methods of analysis, have finally decided that, in all essential respects, the substance which forms the chief part of the contents of the yeast plant is identical with the material which forms the chief part of our own muscles, which forms the chief part of our own blood, which forms the chief part of the white of the egg; that, in fact, although this little organism is a plant, and nothing but a plant, yet that its active living contents contain a substance which is called "protein," which is of the same nature as the subtance which forms the foundation of every animal organism whatever.

Now we come next to the question of the analysis of the products, of that which is produced during the process of fermentation. So far back as the beginning of the 16th century, in the times of transition between the old alchemy and the modern chemistry, there was a remarkable man, Von Helmont, a Dutchman, who saw the difference between the air which comes out of a vat where something is fermenting and common air. He was the man who invented the term "gas," and he called this kind of gas "gas silvestre"-so to speak gas that is wild, and lives in out of the way placeshaving in his mind the identity of this particular kind of air with that which is found in some caves and cellars. Then, the gradual process of investigation going on, it was discovered that this substance, then called "fixed air," was a poisonous gas, and it was finally identified with that kind of gas which is obtained by burning charcoal in the air, which is called " carbonic acid." Then the substance alcohol was subjected to examination, and it was found to be a combination of carbon, and hydrogen, and oxygen. Then the sugar which was contained in the fermenting liquid was examined and that was found to contain the three elements carbon, hydrogen, and oxygen. So that it was clear there were in sugar the fundamental elements which are contained in the 
carbonic acid, and in the alcoliol. And then came that great chemist Lavoisier, and he examined into the subject carefully, and possessed with that brilliant thought of his which happens to be propounded exactly apropos to this matter of fermentation-that no matter is ever lost, but that matter only changes its form and clianges its combinations-he endeavoured to make out what became of the sugar which was subjected to fermentation. He thought he discovered that the whole weight of the sugar was represented by the weight of the alcohol produced, added to the weight of the carbonic acid produced ; that in other words, supposing this tumbler to represent the sugar, that the action of fermentation was as it were the splitting of it, the one half going away in the shape of carbonic acid, and the other half going away in the shape of alcohol. Subsequent inquiry, careful research with the refinements of modern cliemistry, have been applied to this problem, and they liave shown that Lavoisier was not quite correct; that what he says is quite true for about 95 per cent. of the sugar, but that the other 5 per cent., or nearly so, is converted into two other things ; one of them, matter which is called succinic acid, and the other matter which is called glycerine, which you all know now as one of the commonest of household matters. It may be that we have not got to the end of this refined analysis yet, but at any rate, I suppose I may say-and I speak with some little hesitation for fear my friend Professor Roscoe here may pick me up for trespassing upon his province-but I believe I may say that now we can acount for 99 per cent. at least of the sugar, and that that 99 per cent. is split up into these four things, carbonic acid, alcohol, succinic acid, and glycerine. So that it may be that none of the sugar whatever disappears, and that only its parts, so to speak, are re-arranged, and if any of it disappears, certainly it is a very small portion.

Now these are the facts of the case. There is the fact of the growth of the yeast plant; and there is the fact of the splitting up of the sugar. What relation have these two facts to one another?

For a very long time that was a great matter of dispute. The early French observers, to do'them justice, discerned the real state of the case, namely, that there was a very close connection between the actual life of the yeast plant and this operation of the splitting up of the sugar; and that one was in some way or other connected with the other. All 
Investigation subsequently has confirmed this original idea. It has been shown that if you take any measures by which other plants of like kind to the torula would be killed, and by which the yeast plant is killed, then the yeast loses its efficiency. But a capital experiment upon this subject was made by a very distinguished man, Helmholz, who performed an experiment of this kind. He had two vessels-one of them we will suppose full of yeast, but over the bottom of it, as this might be, was tied a thin film of bladder ; consequently, through that thin film of bladder all the liquid parts of the yeast would go, but the solid parts would be stopped behind; the torula would be stopped, the liquid parts of the yeast would go. And then he took another vessel containing a fermentable solution of sugar, and he put one inside the other ; and in this way you see the fluid parts of the yeast were able to pass through with the utmost ease into the sugar, but the solid parts could not get through at all. And he judged thus: if the fluid parts are those which excite fermentation, then, inasmuch as these are stopped, the sugar will not ferment; and the sugar did not ferment, showing quite clearly, that an immediate contact with the solid, living torula was absolutely necessary to excite this process of splitting up of the sugar. This experiment was quite conclusive as to this particular point, and has had very great fruits in other directions.

Well, then, the yeast plant being essential to the production of fermentation, where does the yeast plant come from ? Here, again, was another great problem opened up, for, as I said at starting, you have, under ordinary circumstances in warm weather, merely to expose some fluid containing a solution of sugar, or any form of syrup or vegetable juice to the air, in order, after a comparatively short time, to see all these phenomena of fermentation. Of course the first obvious suggestion is, that the torula has been generated within the fluid. In fact, it seems at first quite absurd to entertain any other conviction; but that belief would most assuredly be an erroneous one.

Towards the beginning of this century, in the vigorous times of the old French wars, there was a Monsieur Appert, who had his attention directed to the preservation of things that ordinarily perish, such as meats and vegetables, and in fact he laid the foundation of our modern method of preserving meats ; and he found that if he boiled any of these substances and then tied them so as to exclude the air, that 
they would be preserved for any time. He tried these experiments, particularly with the must of wine and with the wort of beer; and he found that if the wort of beer had been carefully boiled and was stopped in such a way that the air could not get at it, it would never ferment. What was the reason of this ? That, again, became the subject of a long string of experiments, with this ultimate result, that if you take precautions to prevent any solid matters from getting into the must of wine or the wort of beer, under these circumstances-that is to say, if the fluid has been boiled and placed in a bottle, and if you stuff the neck of the bottle full of cotton wool, which allows the air to go through, and stops anything of a solid character however fine, then you may let it be for ten years and it will not ferment. But if you take that plug out and give the air free access, then, sooner or later fermentation will set up. And there is no doubt whatever that fermentation is excited only by the presence of some torula or other, and that that torula proceeds in our present experience, from pre-existing torulæ. These little bodies are excessively light. You can easily imagine what must be the weight of little particles, but slightly heavier than water, and not more than the twothousandth or perhaps seven-thousandth of an inch in diameter. They are capable of floating about and dancing like motes in the sunbeam; they are carried about by all sorts of currents of air ; the great majority of them perish ; but one or two, which may chance to enter into a sugary solution, immediately enter into active life, fond there the conditions of their nourishment, increase and multiply, and may give rise to any quantity whatever of this substance yeast. And, whatever may be true or not be true about this "spontaneous generation," as it is called, in regard to all other kinds of living things, it is perfectly certain, as regards yeast, that it always owes its origin to this process of transportation or inoculation, if you like so to call it, from some other living yeast organism; and so far as yeast is concerned, the doctrine of spontaneous generation is absolutely out of court. And not only so, but the yeast must be alive in order to exert these peculiar properties. If it be crushed, if it be heated so far that its life is destroyed, that peculiar power of fermentation is not excited. Thus we have come to this conclusion, as the result of our inquiry, that the fermentation of sugar, the splitting of the sugar into alcohol and carbonic acid, glycerine, and succinic acid, 
is the result of nothing but the vital activity of this little fungus, the torula.

And now comes the further exceedingly difficult inquiryhow is it that this plant, the torula, produces this singular operation of the splitting up of the sugar? Fabroni, to whom I referred some time ago, imagined that the effervescence of fermentation was produced in just the same way as the effervescence of a sedlitz powder, that the yeast was a kind of acid, and that the sugar was a combination of carbonic acid and some base to form the alcohol, and that the yeast combined with this substance, and set free the carbonic acid; just as when you add carbonate of soda to acid you turn out the carbonic acid. But of course the discovery of Lavoisier that the carbonic acid and the alcohol taken together are very nearly equal in weight to the sugar, completely upset this hypothesis. Another view was therefore taken by the French chemist, Thenard, and it is still held by a very eminent chemist, M. Pasteur, and their view is this, that the yeast, so to speak, eats a little of the sugar, turns a little of it to its own purposes, and by so doing gives such a shape to the sugar that the rest of it breaks up into carbonic acid and alcohol.

Well, then, there is a third hypothesis, which is maintained by another very distinguished chemist, Liebig, which denies either of the other two, and which declares that the particles of the sugar are, as it were, shaken asunder by the forces at work in the yeast plant. Now I am not going to take you into these refinements of chemical theory, I cannot for a moment pretend to do so, but I may put the case before you by an analogy. Suppose you compare the sugar to a card house, and suppose you compare the yeast to a child coming near the card house, then Fabroni's hypothesis was that the child took half the cards away; Thénard's and Pasteur's hypothesis is that the child pulls out the bottom card and thus makes it tumble to pieces; and Liebig's hypothesis is that the child comes by and shakes the table and tumbles the house down. I appeal to my friend here (Professor Roscoe) whether that is not a fair statement of the case.

Having thus, as far as I can, discussed the general state of the question, it remains only that I should speak of some of those collateral results which have come in a very remarkable way out of the investigation of yeast. I told you that it was very early observed that the yeast plant consisted of a bag made up of the same material as that which composes 
wood, and of an interior seminluid mass which contains a substance, identical in its composition, in a broad sense, with that which constitutes the flesh of animals. Subsequently, after the structure of the yeast plant had been carefully observed, it was discovered that all plants, high and low, are made up of separate bags or "cells," as they are called ; these bags or cells having the composition of the pure matter of wocd; liaving the same composition, broadly speaking, as the sac of the yeast plant, and having in their interior a more or less fluid substance containing a matter of the same nature as the protein substance of the yeast plant. And therefore this remarkable result came outthat however much a plant may differ from an animal, yet that the essential constituent of the contents of these various cells or sacs of which the plant is made up, the nitrogenous protein matter, is the same in the animal as in the plant. And not only was this gradually discovered, but it was found that these semifluid contents of the plant cell had, in many cases, a remarkable power of contractility quite like that of the substance of animals. And about 24 or 25 years ago, namely, about the year 1846, to the best of my recollection, a very eminent German botanist, Hugo Von Mohl, conferred upon this substance which is found in the interior of the plant cell, and which is identical with the matter found in tle inside of the yeast cell, and which again contains an animal substance similar to that of which we ourselves are made up-he conferred upon this that title of " protoplasm," which has brought other people a great deal of trouble since! I beg particularly to say that, because I find inany people suppose that I was the inventor of that term, whereas it has been in existence for at least twenty-five years. And then other observers, taking the question up, came to this astonishing conclusion (working from this basis of the yeast), that the differences between animals and plants are not so much in the fundamental substances which compose them, not in the protoplasm, but in the mamner in which the cells of which their bodies are built up have become modified. There is a sense in which it is true - and the analogy was pointed out very many years ago by some French botanists and chemists-there is a sense in which it is true that every plant is substantially an enormous aggregation of bodies similar to yeast cells, each having to a certain extent its own independent life. And there is a sense in which it is also perfectly true-although. 
It would be impossible for me to give the statement to you with proper qualifications and limitations on an occasion like this-but there is also a sense in which it is true that every animal body is made up of an aggregation of minute particles of protoplasm, comparable each of them to the individual separate yeast plant. And those who are acquainted with the history of the wonderful revolution which has been worked in our whole conception of these matters in the last thirty years, will bear me out in saying that the first germ of them, to a very great extent, was made to grow and fructify by the study of the yeast plant, which presents us with living matter in almost its simplest condition.

Then there is yet one last and most important bearing of this yeast question. There is one direction probably in which the effects of the careful study of the nature of fermentation will yield results more practically valuable to mankind than any other. Let me recall to your minds the fact which I stated at the beginning of this lecture. Suppose that I had here a solution of pure sugar with a little mineral matter in it ; and suppose it were possible for me to take upon the point of a needle one single, solitary yeast cell, measuring no more perhaps than the three-thousandth of an inch in diameter-not bigger than one of those little coloured specks of matter in my own blood at this moment, the weight of which it would be difficult to express in the fraction of a grain-and put it into this solution. From that single one, if the solution were kept at a fair temperature in a warm summer's day, there would be generated, in the course of a week, enough torulæ to form a scum at the top and to form lees at the bottom, and to change the perfectly tasteless and entirely harmless fluid, syrup, into a solution impregnated with the poisonous gas carbonic acid, impregmated with the poisonous substance alcohol; and that, in virtue of the changes worked upon the sugar by the vital activity of these infinitesimally small plants. Now you see that this is a case of infection. And from the time that the phenomenon of fermentation were first carefully studied, it has constantly been suggested to the minds of thoughtful physicians that there was a something astoundingly similar between this phenomena of the propagation of fermentation by infection and contagion, and the phenomena of the propagation of diseases by infection and contagion. Out of this suggestion has grown that remark- 
able theory of many diseases which has been called the " germ theory of disease," the idea, in fact, that we owe a great many diseases to particles having a certain life of their own, and which are capable of being transmitted from one living being to another, exactly as the yeast plant is capable of being transmitted from one tumbler of saccharine substance to another. And that is a perfectly tenable hypothesis, one which in the present state of medicine ought to be absolutely exhausted and shown not to be true, until we take to others which have less analogy in their favour. And there are some diseases most assuredly in which it turns out to be perfectly correct. There are some forms of what are called malignant carbuncle which have been shown to be actually effected by a sort of fermentation, if I may use the phrase, by a sort of disturbance and destruction of the fluids of the animal body, set up by minute organisms which are the cause of this destruction and of this disturbance; and only recently the study of the phenomena which accompany vaccination has thrown an immense light in this direction, tending to show by experiments of the same general character as that to which I referred as performed by Helmholz, that there is a most astonishing analogy between the contagion of that healing disease and the contagion of destructive diseases. For it has been made out quite clearly, by investigations carried on in France and in this country, that the only part of the vaccine matter which is contagious, which is capable of carrying on its influence in the organism of the child who is vaccinated, is the solid particles and not the fluid. By experiments of the most ingenious kind, the solid parts have been separated from the fluid parts, and it lias then been discovered that you may vaccinate a child as much as you like with the fluid parts, but no effect takes place, though an excessively small portion of the solid particles, the most minute that can be separated, is amply sufficient to give rise to all the phenomena of the cow pock, by a process which we can compare to nothing but the transmission of fermentation from one vessel into another, by the transport to the one of the torula particles which exist in the other. And it has been shown to be true of some of the most destructive diseases which infect animals, such diseases as the sheep pox, such diseases as that most terrible and destructive disorder of horses, glanders, that in these, also, the active power is the living solid particle, and that 
the inert part is the fluid. However, do not suppose that I am pushing the analogy too far. I do not mean to say that the active, solid parts in these diseased matters are of the same nature as living yeast plants; but, so far as it goes, there is a most surprising analogy between the two; and the value of the analogy is this, that by following it out we may some time or other come to understand how these diseases are propagated, just as we understand, now, about fermentation; and that, in this way, some of the greatest scourges which afflict the human race may be, if not prevented, at least largely alleviated.

This is the conclusion of the statements which I wished to put before you. You see we have not been able to have any accessories. If you will come in such numbers to hear a lecture of this kind, all I can say is, that diagrams cannot be made big enough for you, and that it is not possible to show any experiments illustrative of a lecture on such a subject as I have to deal with. Of course my friends the chemists and physicists are very much better off, because they can not only show you experiments, but you can smell them and hear them! But in my case such aids are not attainable, and therefore I have taken a simple subject and have dealt with it in such a way that I hope you all understand it, at least so far as I have been able to put it before you in words; and having once apprehended such of the ideas and simple facts of the case as it was possible to put before you, you can see for yourselves the great and wonderful issues of such an apparently homely subject. 
1

8-

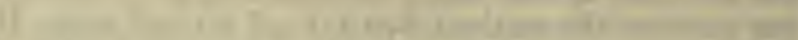

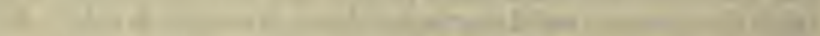

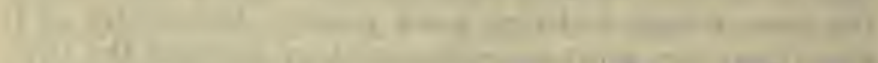

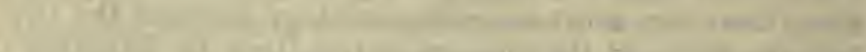
1. 1.1 1

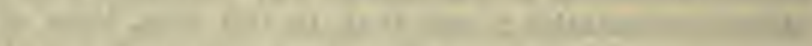

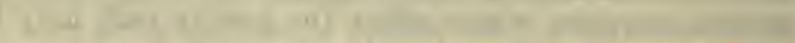

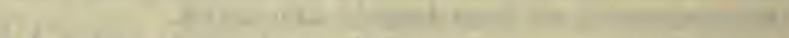

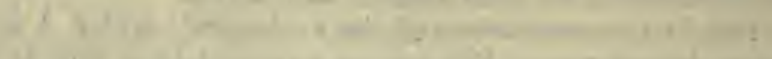

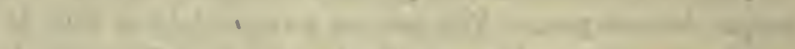

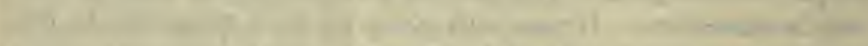
-

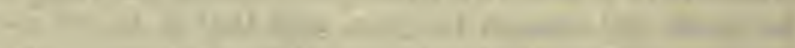
10.

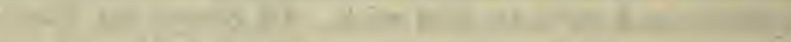

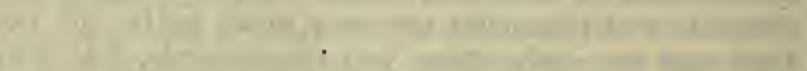
.

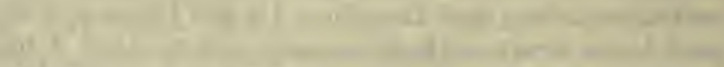

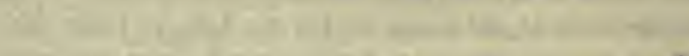
1

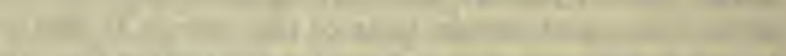

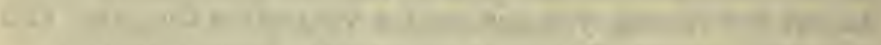

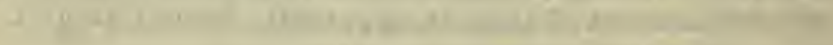




\section{WILLIAM HARVEY}

AND THE

\section{DISCOVERY OF THE CIRCULATION OF THE BLOOD}




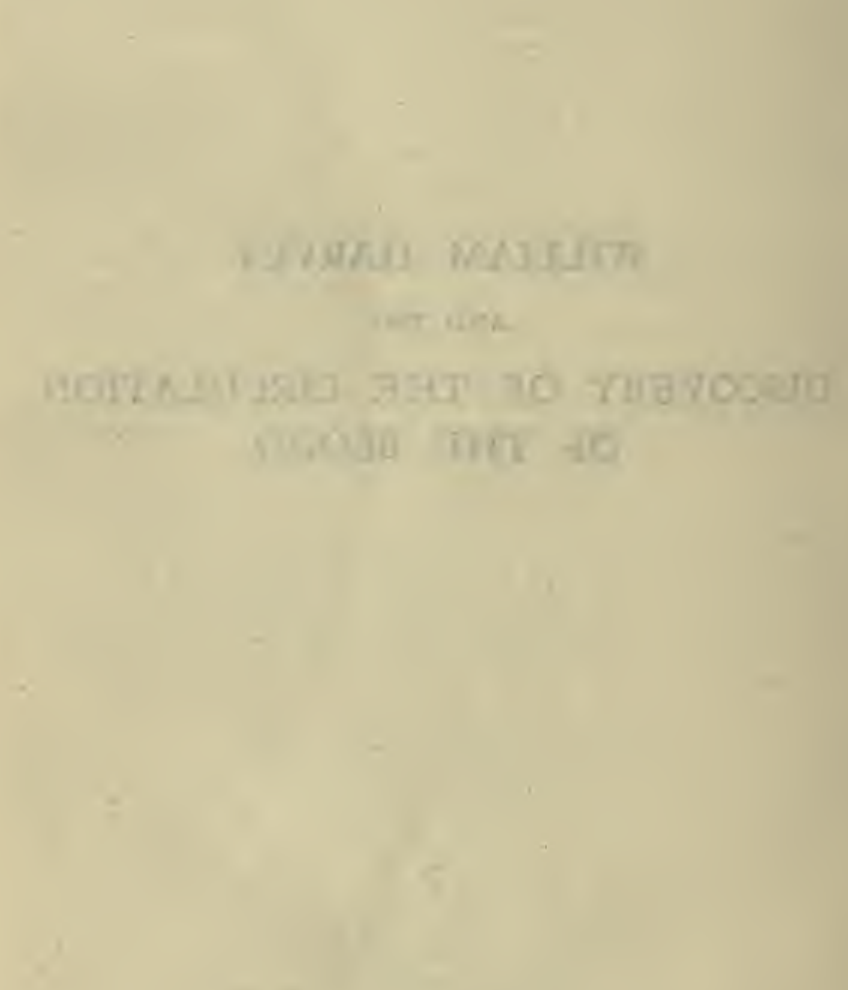




\section{THE CIRCULATION OF THE BLOOD *}

I DESIRE this evening to give you some account of the life and the labours of a very noble Englishman-William Harvey.

William Harvey was born in the year 1578, and, as he lived until the year 1657, he very nearly attained the age of 80. He was the son of a small landowner in Kent, who was sufficiently wealthy to send this, his eldest son, to the University of Cambridge; while he embarked the others in mercantile pursuits, in which they all, as time passed on, attained riches.

William Harvey, after pursuing his education at Cambridge, and taking his degree there, thought it was advisable -and justly thought so, in the then state of University education-to proceed to Italy, which at that time was one of the great centres of intellectual activity in Europe, as all friends of freedom hope it will become again, sooner or later. In those days the University of Padua had a great renown; and Harvey went there and studied under a man who was then very famous-Fabricius of Aquapendente. On his return to England, Harvey became a member of the College of Physicians in London, and entered into practice; and, I suppose, as an indispensable step thereto, proceeded to marry. He very soon became one of the most eminent members of the profession in London; and, about the year 1616, he was elected by the College of Physicians their Professor of Anatomy. It was while Harvey held this office that he made public that great discovery of the circulation of the blood and the movements of the heart, the nature of which I shall endeavour by-andby to explain to you at length. Shortly afterwards, Charles the First having succeeded to the throne in 1625, Harvey became one of the king's physicians; and it is much to the credit of the unfortunate monarch-who, whatever his 
faults may have been, was one of the few English monarchs who have shown a taste for art and science-that Harvey became his attached and devoted friend as well as servant; and that the king, on the other hand, did all he could to advance Harvey's investigations. But, as you know, evil times came on ; and Harvey, after the fortunes of his royal master were broken, being then a man of somewhat advanced years-over 60 years of age, in fact-retired to the society of his brothers in and near London, and among them pursued his studies until the day of lis deatl. Harvey's career is a life which offers no salient points of interest to the biographer. It was a life devoted to study and investigation; and it was a life the devotion of which was amply rewarcied, as I shall have occasion to point out to you, by its results.

Harvey, by the diversity, the variety, and the thoroughness of his investigations, was enabled to give an entirely new direction to at least two branches-and two of the most important branches-of what now-a-days we call Biological Science. On the one hand, he founded all our modern physiology by the discovery of the exact nature of the motions of the heart, and of the course in which the blood is propelled through the body; and, on the other, he laid the foundation of that study of development which has been so much advanced of late years, and which constitutes one of the great pillars of the doctrine of evolution. This doctrine, I need hardly tell you, is now tending to revolutionise our conceptions of the origin of living things, exactly in the same way as Harvey's discovery of the circulation in the seventeetl century revolutionised the conceptions which men had previously entertained with regard to physiological processes.

It would, I regret, be quite impossible for me to attenipt, in the course of the time I can presume to lold you here, to unfold the history of more than one of these great investigations of Harvey. I call them "great investigations," as distinguished from "large publications." I have in my hand a little book, which those of you who are at a great distance may have some difficulty in seeing, and which I value very much. It is, I am afraid, sadly thumbed and scratched with annotations by a very lumble successor and follower of Harvey. This little book is the edition of 1651 of the Exercitationes de Generatione; and if you were to add another little book, printed in the same small 
type, and about one-seventh of the thickness, you would have the sum total of the printed matter which Harvey contributed to our literature. And yet in that sum total was contained, I may say, the materials of two revolutions in as many of the main branches of biological science. If Harvey's published labours can be condensed into so small a compass, you must recollect that it is not because he did not do a great deal more. We know very well that he did accumulate a very considerable number of observations on the most varied topics of medicine, surgery, and natural history. But, as I mentioned to you just now, Harvey, for a time, took the royal side in the domestic quarrel of the Great Rebellion, as it is called; and the Parliament, not unnaturally resenting that action of his, sent soldiers to seize his papers. And while I imagine they found nothing treasonable among those papers, yet, in the process of rummaging through them, they destroyed all the materials which Harvey had spent a laborious life in accumulating; and hence it is that the man's work and labours are represented by so little in apparent bulk.

What I chiefly propose to do to-night is to lay before you an account of the nature of the discovery which Harvey made, and which is termed the Discovery of the Circulation of the Blood. And I desire also, with some particularity, to draw your attention to the methods by which that discovery was achieved; for, in both these respects, I think, there will be much matter for profitable reflection.

Let me point out to you, in the first place, with respect to this important matter of the movements of the heart and the course of the blood in the body, that there is a certain amount of knowledge which must have been obtained without men taking the trouble to seek it-knowledge which must have been taken in, in the course of time, by everybody who followed the trade of a butcher, and still more so by those people who, in ancient times, professed to divine the course of future events from the entrails of animals. It is quite obvious to all, from ordinary accidents, that the bodies of all the higher animals contain a hot red fluidthe blood. Everybody can see upon the surface of some part of the skin, underneath that skin, pulsating tubes, which we know as the arteries. Everybody can see under the surface of the skin more delicate and softer looking tubes, which do not pulsate, which are of a bluish colour, and are termed the veins. And every person who 
has seen a recently killed animal opened knows that these two kinds of tubes to which I have just referred, are connected with an apparatus which is placed in the chest, which apparatus, in recently killed animals, is still pulsating. And you know that in yourselves you can feel the pulsation of this organ, the heart, between the fifth and sixth ribs. I take it that this much of anatomy and physiology has been known from the oldest times, not only as a matter of curiosity, but because one of the great objects of men, from their earliest recorded existence, has been to kill one another, and it was a matter of considerable importance to know which was the best place for hitting an enemy. I can refer you to very ancient records for most precise and clear information that one of the best places is to smite him between the fifth and sixth ribs. Now that is a very good piece of regional anatomy, for that is the place where the heart strikes in its pulsations, and the use of smiting there is that you go straight to the heart. Well, all that must have been known from time immemorial-at least for 4,000 or 5,000 years before the commencement of our era -because we know that for as great a period as that the Egyptians, at any rate, whatever may have been the case with other people, were in the enjoyment of a highly developed civilisation. But of what knowledge they may have possessed beyond this we know nothing; and in tracing back the springs of the origin of everything that we call "modern science" (which is not merely knowing, but knowing systematically, and with the intention and endeavour to find out the causal connection of things) - I say that when we trace back the different lines of all the modern sciences we come at length to one epoch and to one country - the epoch being about the fourth and fifth centuries before Christ, and the country being ancient Greece. It is there that we find the commencement and the root of every branch of physical science and of scientific method. If we go back to that time we have in the works attributed to Aristotle, who flourished between 300 and 400 years before Christ, a sort of encyclopædia of the scientific knowledge of that day-and a very marvellous collection of, in many respects, accurate and precise knowledge it is. But, so far as regards this particular topic, Aristotle, it must be confessed, has not got very far beyond common knowledge. He knows a little about the structure of the heart. I do not think that his knowledge is so inaccurate as many 
people fancy, but it does not amount to much. A very few years after his time, however, there was a Greek philosopher, Erasistratus, who lived about three hundred

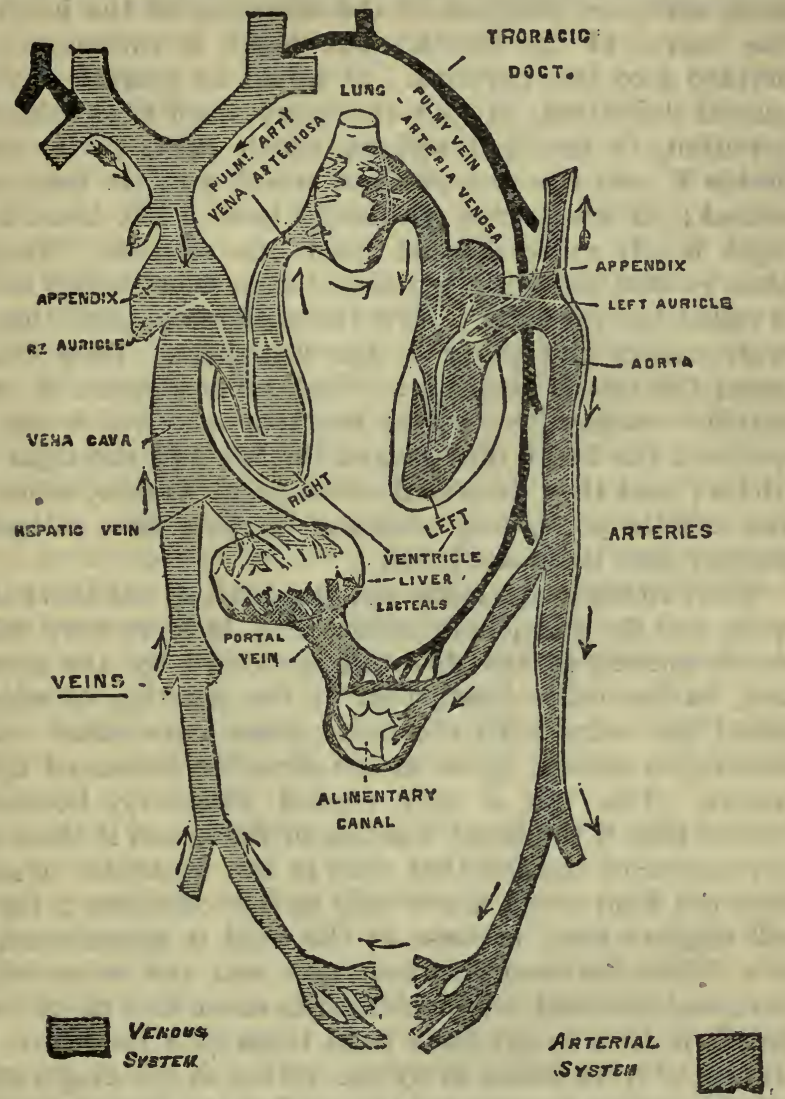

Fra. 1. - The apparatus of the circulation, as at present known. The capillary vessels, which connect the arteries and veins, are omitted, on account of their small size. The shading of the "venous system" is given to all the vessels which contain venous blood; that of the " arterial system to all the vessels which conțain arțerial blood.

years before Christ, and who must have pursued anatomy with much care, for he made the important discovery that there are membranous flaps, which are now called "valves," at the origins of the great vessels; and that 
there are certain other valves in the interior of the heart itself.

I have here (Fig. 1) a purposely rough, but, so far as it goes, accurate, diagram of the structure of the heart and the course of the blood. The heart is supposed to be divided into two portions. It would be possible, by very careful dissection, to split the heart down the middle of a partition, or so-called septum, which exists in it, and to divide it into the two portions which you see here represented; in which case we should have a left heart and a right heart, quite distinct from one another. You will observe that there is a portion of each heart which is what is called the ventricle. Now the ancients applied the term heart simply and solely to the ventricles. They did not count the rest of the heart-what we now speak of as the auricles-as any part of the heart at all; but when they spoke of the heart they meant the left and the right ventricles; and they described those great vessels, which we now call the pulmonary veins and the vena cava, as opening directly into the hcart itself.

What Erasistratus made out was that, at the roots of the aorta and the pulmonary artery (Fig. 1) there were valves, which opened in the direction indicated by the arrows; and, on the other hand, that at the junction of what he called the veins with the heart there were other valves, which also opened again in the direction indicated by the arrows. This was a very capital discovery, because it proved that if the heart was full of fluid, and if there were any means of causing that fluid in the ventricles to move, then the fluid could move only in one direction; for you will observe that, as soon as the fluid is compressed, the two valves between the ventricles and the veins will be shut, and the fluid will be obliged to move into the arteries; and, if it tries to get back from them into the heart, it is prevented from doing so by the valves at the origin of the arteries, which we now call the semilunar valves (half-moon shaped valves); so that it is impossible, if the fluid move at all, that it should move in any other way than from the great veins into the arteries. Now that was a very reinarkable and striking discovery.

But it is not given to any man to be altogether right (that is a reflection which it is very desirable for every man who has had the good luck to be nearly right once, always to bear in mind) ; and Erasistratus, while he made this capital and 
important discovery, made a very capital and-important error in another direction, although it was a very natural error. If, in any animal which is recently killed, you open one of those pulsating trunks which I referred to a short time ago, you will find, as a general rule, that it either contains no blood at all or next to none; but that, on the contrary, it is full of air. Very naturally, therefore, Erasistratus came to the conclusion that this was the normal and natural state of the arteries, and that they contained air. We are apt to think this a very gross blunder; but, to anybody who is acquainted with the facts of the case, it is, at first sight, an exceedingly natural conclusion. Not only so, but Erasistratus might have very justly imagined that he had seen his way to the meaning of the connection of the left side of the heart with the lungs; for we find that what we now call the puimonary vein is connected with the lungs, and branches out in them (Fig. 1). Finding that the greater part of this system of vessels was filled with air after death, this ancient thinker very shrewdly concluded that its real business was to receive air from the lungs, and to distribute that air all through the body, so as to get rid of the grosser humours and purify the blood. That was a very natural and a very obvious suggestion, and a highly ingenious one, though it happened to be a great error. You will observe that the only way of correcting it was to experiment upon living animals, for there is no other way in which this point could be settled.

And hence we are indebted, for the correction of the error of Erasistratus, to one of the greatest experimenters of ancient or modern times, Claudius Galenus, who lived in the second century after Christ. I say it was to this man more than any one else, because he knew that the only way of solving physiological problems was to examine into the facts in the living animal. And because Galen was a skilful anatomist, and a skilful experimenter, he was able to show in what particulars Erasistratus had erred, and to build up a system of thought upon this subject which was not improved upon for fully 1,300 years. I have endeavoured, in Fig. 2, to make clear to you exactly what it was he tried to establish. You will observe that this diagram is practically the same as that given in Fig. 1, only simplified. The same facts may be looked upon by different people from different points of view. Galen looked upon these facts from a very different point of view from that which we ourselves occupy ; 
but, so far as the facts are concerned, they were the same for him as for us. Well then, the first thing that Galen did was to make out experimentally that, during life, the arteries are not full of air, but that they are full of blood. And he describes a great variety of experiments which he made upon living animals with the view of proving this point, which he did prove effectually and for all time ; and that you will observe was the only way of settling the matter. Furtlermore, he demonstrated that the cavities of the left side of the heart-what we now call the left auricle and the left ventricle-are, like the arteries, full of blood during life, and that that blood was of the scarlet kind-arterialised, or as he called it " pneumatised," blood. It was known before, that the pulmonary artery, the right ventricle, and the veins, contain the darker kind of blood, which was thence called venous. Having proved that the whole of the left side of the heart, during life, is full of scarlet arterial blood, Galen's next point was to inquire into the mode of communication between the arteries and veins. It was known before his time that both arteries and veins branched out. Galen maintained, though he could not prove the fact, that the ultimate branches of the arteries and veins communicated together somehow or other, by what he called anastomoses, and that these anastomoses existed not only in the body in general but also in the lungs. In the next place, Galen maintained that all the veins of the body arise from the liver; that they draw the blood thence and distribute it over the body. Pcople laugh at that notion now-a-days; but if anybody will look at the facts he will see that it is a very probable supposition. There is a great vein (hepatic vein-Fig. 1) which rises out of the liver, and that vein goes straight into the vena cava (Fig. 1) which passes to the heart, being there joined by the other veins of the body. The liver itself is fed by a very large vein (portal vein-Fig. 1), which comes from the alimentary canal. The way the ancients looked at this matter was, that the food, after being received into the alimentary canal, was then taken up by the branches of this great vein, which are called the vena portæ, just as the roots of a plant suck up nourishment from the soil in which it lives; that then it was carried to the liver, there to be what was called " concocted," which was their phrase for its conversion into substances more fitted for nutrition than previously existed in it. They then supposed that the next thing to be done was to distribute this fluid through the 
body ; and Galen, like his predecessors, imagined that the " concocted" blood, having entered the great vena cava, was distributed by its ramifications all over the body. So that, in his view (Fig. 2), the course of the blood was from the intestine to the liver, and from the liver into the great vena cava, including what we now call the right auricle of the heart, whence it was distributed by the branches of the veins. But the whole of the blood was not thus disposed of. Part of the blood, it was supposed, went through what we now call the pulmonary arteries (Fig. 1), and, branching out there, gave exit to certain " fuliginous " products, and at the same time took in from the air a something which Galen calls the pneuma. He does not know anything about what we call oxygen; but it is astonishing how very easy it would be to turn his language into the equivalent of modern chemical

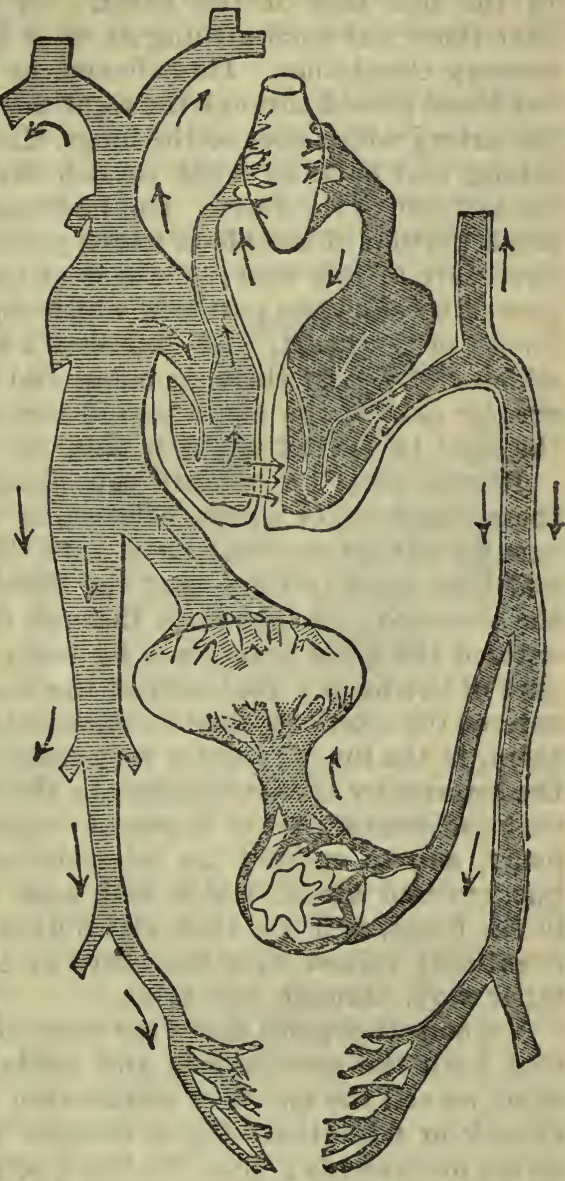

Frg. 2.-The Course of the Blood according to Galen (A.D. 170). theory. The old philosopher had so just a suspicion of the real state of affairs that you could make use of his language in many cases, if you substituted the word "oxygen," which 
we now-a-days use, for the word pneuma. Then he imagined that the blood, further concocted or altered by contact with the pneuma, passed to a certain extent to the left side of the heart. So that Galen believed that there was such a thing as what is now called the pulmonary circulation. He believed, as much as we do, that the blood passed through the right side of the heart, through the artery which goes to the lungs, through the lungs themselves, and back by what we call the pulmonary veins to the left side of the heart. But he thought it was only a very small portion of the blood which passes to the right side of the heart in this way; the rest of the blood, he thought, passed through the partition which separates the two ventricles of the heart. He describes a number of small pits, which really exist there, as holes, and he supposed that the greater part of the blood passed through these holes from the right to the left ventricle (Fig. 2).

It is of great importance you should clearly understand these teachings of Galen, because, as I said just now, they sum up all that anybody knew until the revival of learning ; and they come to this-that the blood having passed from the stomach and intestines through the liver, and having cntered the great veins, was by them distributed to every part of the body; that part of the blood, thus distributed, entered the arterial system by the anastomoses, as Galen called them, in the lungs; that a very small portion of it entered the arteries by the anastomoses in the body generally; but that the greater part of it passed through the septum of the heart, and so entered the left side and mingled with the pneumatised blood, which had been subjected to the air in the lungs, and was then distributed by the arteries, and eventually mixed with the currents of blood, coming the other way, through the veins.

Yet one other point about the views of Galen. He thought that both the contractions and dilatations of the heartwhat we call the syslole or contraction of the heart, and the diastole or dilatation-Galen thought that these were both active movements; that the heart actively dilated, so that it had a sort of sucking power upon the fluids which had access to it. And again, with respect to the movements of the pulse, which anybody can feel at the wrist and elsewhere, Galen was of opinion that the walls of the arteries partook of that which he supposed to be the nature of the walls of the heart, and that they had the power of alternately actively 


\section{THE CIRCULATION OF THE BLOOD}

contracting and actively dilating. So that he is careful to say that the nature of the pulse is comparable, not to the movement of a bag, which we fill by blowing into it, and which we empty by drawing the air out of it, but to the action of a bellows, which is actively dilated and actively compressed.

After Galen's time came the collapse of the Roman Empire, the extinction of physical knowledge, and the repression of every kind of scientific inquiry, by its powerful and consistent enemy, the Church; and that state of things lasted until the latter part of the Middle Ages saw the revival of learning. That revival of learning, so far as anatomy and physiology are concerned, is due to the renewed influence of the philosophers of ancient Greece, and, indeed, of Galen. Arabic commentators had translated Galen, and portions of his works had got into the language of the learned in the Middle Ages, in that way; but, by the study of the classical languages, the original text became accessible to the men who were then endeavouring to

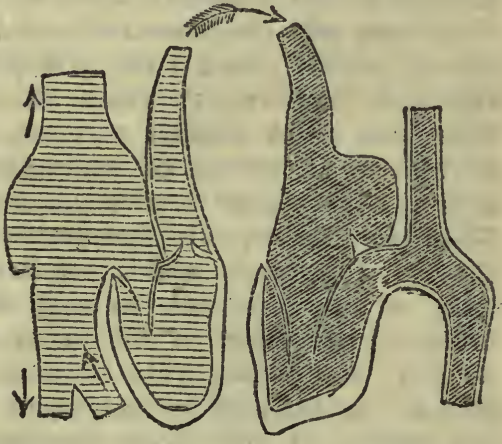

Fra. 3.-The course of the blood from the right to the left side of the heart (Realdus Columbus, 1559).

learn for themselves something about the facts of nature. It was a century or more before these men, finding themselves in the presence of a master-finding that all their lives were occupied in attempting to ascertain for themselves that which was familiar to him -I say it took the best part of a hundred years before they could fairly see that their business was not to follow him, but to follow his example-namely, to look into the facts of nature for themselves, and to carry on, in his spirit, the work he had begun. That was first done by Vesalius, one of the greatest anatomists who ever lived; but his work does not specially bear upon the question we are now concerned with. So far as regards the motions of the heart and the course of the blood, the first man in the Middle Ages, and indeed the only man who did anything which was of 
real importance, was one Realdus Columbus, who was professor at Padua in the year 1559, and published a great anatomical treatise. What Realdus Columbus did was this ; once more resorting to the method of Galen, turning to the living animal, experimenting, he came upon new facts, and one of these new facts was that there was not merely a subordinate communication between the blood of the right side of the heart and that of the left side of the heart, through the lungs, but that there was a constant steady current of blood, setting through the pulmonary artery on the right side, through the lungs, and back by the pulmonary veins to the left side of the heart (Fig. 3). Such was the capital discovery and demonstration of Realdus Columbus. He is the man who discovered what is loosely called the pulmonary circulation; and it really is quite absurd, in the face of the fact, that twenty years afterwards we find Ambrose Paré, the great French surgeon, ascribing this discovery to him as a matter of common notoriety, to find that attempts are made to give the credit of it to other people. So far as I know, this discovery of the course of the blood through the lungs, which is called the pulmonary circulation, is the one step in real advance that was made between the time of Galen and the time of Harvey. And I would beg you to note that the word "circulation" is improperly employed when it is applied to the course of the blood through the lungs. The blood from the right side of the heart, in getting to the left side of the heart, only performs a half-circle-it does not perform a whole circle-it does not return to the place from whence it started; and hence the discovery of the so-called "pulmonary circulation" has nothing whatever to do with that greater discovery which I shall point out to you by-and-by was made by Harvey, and which is alone really entitled to the name of the circulation of the blood.

If anybody wants to understand what Harvey's great desert really was, I would suggest to him that he devote himself to a course of reading, which I cannot promise shall be very entertaining, but which, in this respect at any rate, will be highly instructive-namely, the works of the anatomists of the latter part of the 16th century and the beginning of the 17 th century. If anybody will take the trouble to do that which I have thought it my business to do, he will find that the doctrines respecting the action of the heart and the 
motion of the blood which were taught in every university in Europe, whether in Padua or in Paris, were essentially those put forward by Galen, plus the discovery of the pulmonary course of the blood which had been made by Realdus Columbus. In every chair of anatomy and physiology (which studies were not then separated) in Europe, it was taught that the blood brought to the liver by the portal vein, and carried out of the liver to the vena cava by the hepatic vein, is distributed from the right side of the heart, through the other veins, to all parts of the body ; that the blood of the arteries takes a like course from the heart towards the periphery; and that it is there, by means of the anastomoses, more or less mixed up with the verous blood. It so happens, by a curious chance, that up to the year 1625 there was at Padua, which was Harvey's own university, a very distinguished professor, Spigelius, whose work is extant, and who teaches exactly what I am now telling you. It is perfectly true that, some time before, Harvey's master, Fabricius, had not only re-discovered, but had drawn much attention to certain pouch-like structures, which are called the valves of the veins, found in the muscular parts of the body, all of which are directed towards the heart, and consequently impede the flow of the blood in the opposite direction. And you will find it stated by people who have not thought much about the matter, that it was this discovery of the valves of the veins which led Harvey to imagine the course of the circulation of the blood. Now it did not lead Harvey to imagine anything of the kind. He had heard all about it from his master, Fabricius, who made a great point of these valves in the veins, and he had heard the theories which Fabricius entertained upon the subject, whose impression as to the use of the valves was simply this-that they tended to take off any excess of pressure of the blood in passing from the heart to the extremities ; for Fabricius believed, with the rest of the world, that the blood in the veins flowed from the heart towards the extremities. This, under the circumstances, was as good a theory as any other, because the action of valves depends altogether upon the form and nature of the walls of the structures in which they are attached; and, without accurate experiment, it was impossible to say whether the theory of Fabricius was right or wrong. But we not only have the evidence of the facts themselves that these could tell Harvey nothing about the circulation, but we have 


\section{THE CIRCULATION OF THE BLOOD}

his own distinct declaration as to the considerations which led him to the true theory of the circulation of the blood, and amongst these the valves of the veins are not mentioned.

Now then we may come to Harvey himself. When you read Harvey's treatise, which is one of the most remarkable scientific monographs with which I am acquainted-it occupies between 50 and 60 pages of a small quarto in Latin, and is as terse and concise as it possibly can be-when you come to look at Harvey's work, you will find that he had long struggled with the difficulties of the accepted doctrine of the circulation. He had received from Fabricius, and from all the great authorities of the day, the current view of the circulation of the blood. But he was a man with that rarest of all qualities-intellectual honesty; and by dint of cultivating that great faculty, which is more moral than Intellectual, it had become impossible for him to say he believed anything which he did not clearly believe. This is a most uncomfortable peculiarity-for it gets you into all sorts of difficulties with all sorts of people-but, for scientific purposes, it is absolutely invaluable. Harvey possessed this peculiarity in the highest degree, and so it was impossible for him to accept what all the authorities told him, and he looked into the matter for himself. But he was not hasty. He worked at his new views, and he lectured about them at the College of Physicians for nine years; he did not print them until he was a man of fifty years of age; and when he did print them he accompanied them with a demonstration which has never been shaken, and which will stand till the end of time. What Harvey proved, in short, was this (see Fig. 4) - that everybody had made a mistake, for want of sufficiently accurate experimentation as to the actual existence of the fact which everybody assumed. To anybody who looks at the blood-vessels with an unprejudiced eye it seems so natural that the blood should all come out of the liver, and be distributed by the veins to the different parts of the body, that nothing can seem simpler or more plain; and consequently no one could make up his mind to dispute this apparently obvious assumption. But Harvey did dispute it; and when he came to investigate the matter he discovered that it was a profound mistake, and that, all this time, the blood had been moving in just the opposite direction, namely, from the small ramifications of the veins towards the right side of the heart. Harvey 
further found that, in the arteries, the blood, as had previously been known, was travelling from the greater trunks towards the ramifications. Moreover, referring to the ideas of Columbus and of Galen (for he was a great student of literature, and did justice to all his predecessors), Harvey accepts and strengthens their view of the course of the blood through the lungs, and he shows how it fitted into his general scheme. If you will follow the course of the arrows in Fig. 4 you will see at once that-in accordance with the views of Columbus - the blood passes from the right side of the heart, through the lungs, to the left side. Then, adds Harvey, with abundant proof, it passes through the arteries to all parts of the body; and then, at the extremities of their branches in the different parts of the body, it passes (in what way he could not tell, for his. means of investiga-

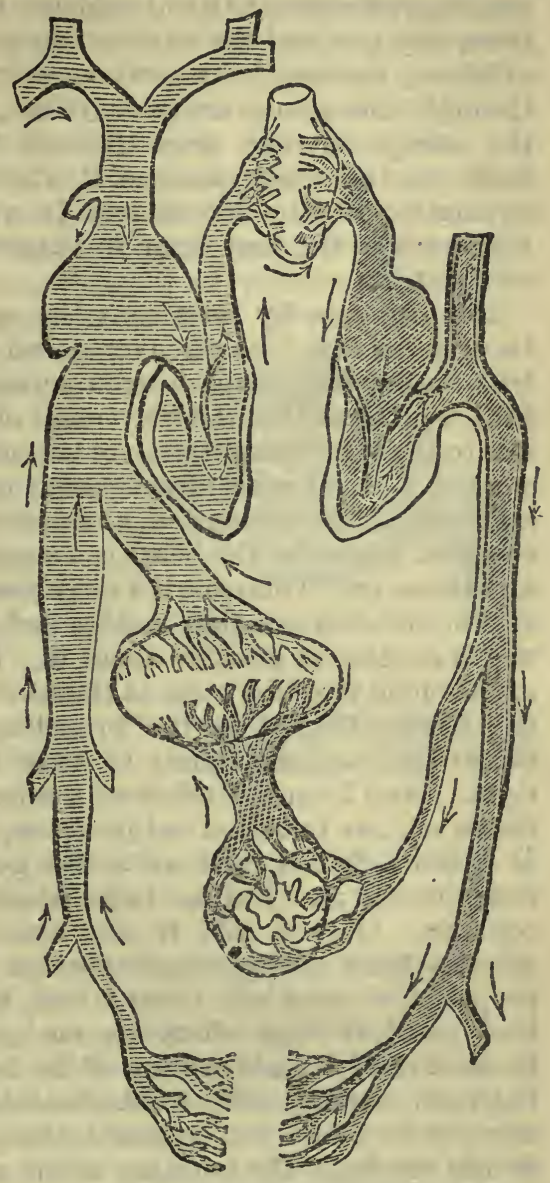
tion did not allow him to say) into the roots of the veins-then from the roots of the veins it goes into the trunk veins-then to the right side of the heart-and then to the lungs, and so on. 
That, you will observe, makes a complete circuit; and it was precisely here that the originality of Harvey lay. There never yet has been produced, and I do not believe there can be produced, a tittle of evidence to show that, before his time, any one had the slightest suspicion that a single drop of blood, starting in the left ventricle of the heart, passes through the whole arterial system, comes back through the venous system, goes through the lungs, and comes back to the place whence it started. But that is the circulation of the blood, and it was exactly this which Harvey was the first man to suspect, to discover, and to demonstrate.

But this was by no means the only thing Harvey did. He was the first who discovered and who demonstrated the true mechanism of the heart's action. No one, before his time, conceived that the movement of the blood was entirely due to the mechanical action of the heart as a pump. There were all sorts of speculations about the matter, but nobody had formed this conception, and nobody understood that the so-called systole of the heart is a state of active contraction, and the so-called diastole is a mere passive dilatation. Even within our own age that matter had been discussed. Harvey is as clear as possible about it. He says the movement of the blood is entirely due to the contractions of the walls of the heart-that it is the propelling apparatus-and all recent investigation tends to show that he was perfectly right. And from this followed the true theory of the pulse. Galen said, as I pointed out just now, that the arteries dilate as bellows, which have an active power of dilatation and contraction, and not as bags which are blown out and collapse. Harvey said it was exactly the contrary-the arteries dilate as bags simply because the stroke of the heart propels the blood into them; and, when they relax again, they relax as bags which are no longer stretched, simply because the force of the blow of the heart is spent. Harvey has been demonstrated to be absolutely right in this statement of his ; and yet, so slow is the progress of truth, that, within my time, the question of the active dilatation of the arteries has been discussed.

Thus Harvey's contributions to physiology may be summed up as follows: In the first place, he was the first person who ever imagined, and still more who demonstrated, the true course of the circulation of the blood in the body; in the second place, he was the first person who ever under- 
stood the mechanism of the heart, and comprehended that its contraction was the cause of the motion of the blood; and thirdly, he was the first person who took a just view of the nature of the pulse. These are the three great contributions which he made to the science of physiology; and $J$ shall not err in saying-I speak in the presence of distinguished physiologists, but I am perfectly certain that they will endorse what I say-that upon that foundation the whole of our knowledge of the human body, with the exception of the motor apparatus and the sense organs, has been gradually built up, and that upon that foundation the whole rests. And not only does scientific physiology rest upon it, but everything like scientific medicine also rests upon it. As you know-I hope it is now a matter of popular knowledge-it is the foundation of all rational speculation about morbid processes; it is the only key to the rational interpretation of that commonest of all indications of disease, the state of the pulse; so that, both theoretically and practically, this discovery, this demonstration of Harvey's, has had an effect which is absolutely incalculable, and

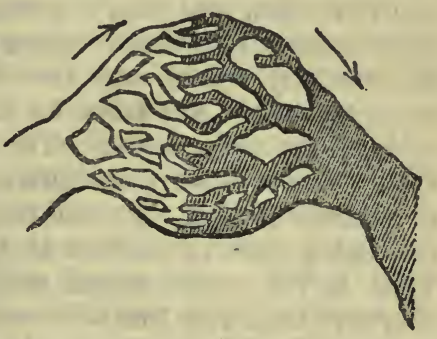

FIG. 5.-The junction of the arteries and veins by capillary tubes, discovered by Malpighi (A.D. 1664). the consequences of which will accumulate from age to age until they result in a complete body of physiological science.

I regret that I am unable to pursue this subject much further; but there is one point I should mention. In Harvey's time, the microscope was hardly invented. It is quite true that in some of his embryological researches he speaks of having made use of a hand glass; but that was the most that he seems to have known anything about, or that was accessible to him at that day. And so it came about, that, although he examined the course of the blood in many of the lower animals - watched the pulsation of the heart in shrimps, and animals of that kind-he never could put the final coping-stone on his edifice. He did not know to the day of his death, although quite clear about the fact that the arteries and the veins do communicate, how it is that they 
communicate-how it was that the blood of the arteries passed into the veins. One is grieved to think that the grand old man should have gone down to his tomb without the vast satisfaction it would have given to him to see what the Italian naturalist Malpighi showed only seven years later, in 1664, when he demonstrated, in a living frog, the actual passage of the blood from the ultimate ramifications of the arteries into the veins. But that absolute ocular demonstration of the truth of the views he had maintained throughout his life it was not granted to Harvey to see. What he did experience was this: that on the publication of his doctrines, they were met with the greatest possible opposition; and I have no doubt savage things were uttered in those old controversies, and that a great many people said that these new-fangled doctrines, reducing living processes to mere meclıanism, would sap the foundations of religion and morality. I do not know for certain that they did, but they said things very like it. The first point was to show that Harvey's views were absolutely untrue ; and not being able to succeed in that, opponents said they were not new ; and not being able to succeed in that, that they didn't matter. That is the usual course with all new discoveries. But Harvey troubled himself very little about these things. He remained perfectly quiet; for although reputed a lottempered man, he never would have anything to do with controversy if he could help it; and he only replied to one of his antagonists after twenty years' interval, and then in the most charming spirit of candour and moderation. But he had the great satisfaction of living to see his doctrine accepted upon all sides. At the time of his death, there was not an anatomical school in Europe in which the doctrine of the circulation of the blood was not taught in the way in which Harvey had laid it down. In that respect he had a happiness which is granted to very few men.

I have said that the other great investigation of Harvey is not one which can be dealt with to a general audience. It is very complex, and therefore I must ask you to take my word for it that, although not so fortunate an investigation, not so entirely accordant with later results as the doctrine of the circulation; yet that still, this little treatise of Harvey's has in many directions exerted an influence hardly less remarkable than that exerted by the Essay upon the Circulation of the Blood. 


\section{THE CIRCULATION OF THE BLOOD 451}

And now let me ask your attention to two or three closing remarks.

If you look back upon that period of about 100 years which commences with Harvey's birth-I mean from the year 1578 to 1680 or thereabouts-I think you will agree with me, that it constitutes one of the most remarkable epochs in the whole of that thousand years which we may roughly reckon as constituting the history of Britain. In the commencement of that period, we may see, if not the setting, at any rate the declension of that system of personal rule which had existed under previous sovereigns, and which, after a brief and spasmodic revival in the time of George the Third, has now sunk, let us hope, into the limbo of forgotten things. The latter part of that 100 years saw the dawn of that system of free government which has grown and flourished, and which, if the men of the present day be the worthy descendants of Eliott and Pym, and Hampden and Milton, will go on growing as long as this realm lasts. Within that time, one of the strangest phenomena which I think I may say any nation has ever manifested arose to its height and fell-I mean that strange and altogether marvellous phenomenon, English Puritanism. Within that time, England had to show statesmen like Burleigh, Strafford, and Cromwell-I mean men who were real statesmen, and not intriguers, seeking to make a reputation at the expense of the nation. In the course of that time, the nation had begun to throw off those swarms of hardy colonists which, to the benefit of the world-and as I fancy, in the long run, to the benefit of England herself-have now become the United States of America; and, during the same epoch, the first foundations were laid of that Indian Empire which, it may be, future generations will not look upon as so happy a product of English enterprise and ingenuity. In that time we had poets such as Spenser, Shakspere, and Milton; we had a great philosopher, in Hobbes ; and we had a clever talker about philosophy, in Bacon. In the beginning of the period, Harvey revolutionized the biological sciences, and at the end of it, Newton was preparing the revolution of the physical sciences. I know not any period of our historyI doubt if there be any period of the history of any nationwhich has precisely such a record as this to show for a hundred years. But I do not recall these facts to your recollection for a mere vainglorious purpose. I myself am of opinion that the memory of the great men of a nation is 
one of its most precious possessions-not because we have any right to plume ourselves upon their having existed as a matter of national vanity, but because we have a just and rational ground of expectation that the race which has brought forth such products as these may, in good time and under fortunate circumstances, produce the like again. I am one of those people who do not believe in the natural decay of nations. I believe, to speak frankly, though perhaps not quite so politely as I could wish-but I am getting near the end of my lecture - that the whole theory is a speculation invented by cowards to excuse knaves. My belief is, that so far as this old English stock is concerned it has in it as much sap and vitality and power as it had two centuries ago; and that, with due pruning of rotten branches, and due hoeing up of weeds, which will grow about the roots, the like products will be yielded again. The "weeds" to which I refer are mainly three : the first of them is dishonesty, the second is sentimentality, and the third is luxury. If William Harvey had been a dishonest man-I mean in the high sense of the word-a man who failed in the ideal of honesty-he would have believed what it was easiest to believe-that which he received on the authority of his predecessors. He would not have felt that his highest duty was to know of his own knowledge that that which he said he believed was true, and we should never have had those investigations, pursued through good report and evil report, which ended in discoveries so fraught with magnificent results for science and for man. If Harvey had been a sentimentalist-by which I mean a person of false pity, a person who has not imagination enough to see that great, distant evils may be much worse than those which we can picture to ourselves, because they happen to be immediate and near (for that, I take it, is the essence of sentimentalism)-if Harvey had been a person of that kind, he, being one of the kindest men living, would never have pursued those researches which, as he tells us over and over again, he was obliged to pursue in order to the ascertainment of those facts which have turned out to be of such inestimable value to the human race ; and I say, if on such grounds he had failed to do so, he would have failed in his duty to the human race. The third point is that Harvey was devoid of care either for wealth, or for riches, or for ambition. The man found a higher ideal than any of these things in the pursuit of truth and the benefit of his fellow-men. If we all go and do likewise, I think there is no 
fear for the decadence of England. I think that our children and our successors will find themselves in a commonwealth, different it may be from that for which Eliott, and Pym, and Hampden struggled, but one which will be identical in the substance of its aims-great, worthy, and well to live in. 
Printed BY

Cassell \& Company, limited, La Belle Sauvage, LONDON, E.C. 


\title{
THE PEOPLE'S LIBRARY
}

\section{THE \\ FIRST HUNDRED \\ VOLUMES}

\author{
1 to 35 , Now Ready
}

36 to 50, March 13th, 1908

51 to 60 . April 10th, 1908

61 to 70 . May 15th, 1908

71 to 100 , Later

A LIST FOR REFERENCE 
3. Treasure Island and Kidnapped

8. Adam Bede

8. East Lynne

4. The Essays of Elt

5: A Tale of Two Cities

6. Iranhoo

7. Poems, 1830-1865 TENNYSON

8. Westward Ho! KINGSLEY

9. Sesamo and Lilles, Unto This Iast, \& The Polltical Economy of Art

RUSKIN

10. The scarlet Lettor HAWTHORNE

11. Cloister and the Hearth

12. The Christmas Books

RBADB DICKENS

13. Tom Brown's Schooldays HUUGHES

14. King Solomon's Mines

15. Pooms, 1833-1865

HAGGARD

16. John Halffax, Contloman BROWNING

CRATK

17. Essays and other Writings

BACON

18. The Milu on the Floss BIIOT

19. The Autocrat of the Breal:fast Table

20. Kenllworth

21. Jane Eyre

23. Robinson Crusoo

23. Waverley BOTMES SCOTT

BRONTE DEFOE SCOTT

26 old Curtosity shop DICKENS

25. Essays and other Writings

26. Cranford

27. 8llas Marner

28. Poetlcal Work:

QASERLL

EIIOT

89. Last Days of Pompoil

LONGFEILOW

80. Fimond

IYTTON

81. Pride and Prejudice

82. Tower of London

AUSTEN

39. Bible in Spain

84. Iast of the Moblcans

ATNSWORTH BORROW

COOPER

85. The Oplum Eater and other Writings DEQUINCEY 86-39. Complete Works

SEAKESPEARE

40. Barnaby Rudgo DICKENS

11. Last of the Barons IYTTON

12. Palry Talos ANDERSEN

43. Vicar of Wakefleld and Poems GOLDSMITH

44. The Deerslayer COOPER

45. Senge and Sensibiltty

AUSTEN

46. Poems and Songs BURNs

42. The Three Mus reteers

48. The Channings
49. The Ingoldsby Logends

0. 0iver Twist BARHAM

DICKFNS

51. Tho ritie Minister BARKIF

52. Fairy Tales

53. Meditations

GRIMM

MARCUS AURELIUS

54. Uncle Tom's Cabin STOWE

55. History of Selborne WHITE

56. The Two Paths and other Essays RUSKIN

57. The Pathfinder COOPER

58. Tales from Shakespeare

IAMB

59. Woman in White coLIINS

60. Bartor Resartus and Essays on Burns and scott

CARLYLE

61. It Is Nover Too Late to Mond

READE

62. Pilgrim's Progress BUNYAN

68. Shirley

BRONTE

64. Tales, Pooms, and sketches

65. Hypatia

66. Essays

BRET HARTE

67 Handy Andy LOVER

68. Voyages of biscovery COOK

69. Mr. Midshipman Easy MARRYA Essays on Goethe

71. Masterman Ready

CARLYLE

72. Our Viuage MARRYAT

73. Origin of \&pecles DARWIN 74. The Three Midshipren

75. Qulliver's Travels BWIFT

76. The Tallsman

77. Harold

78. Plays

SCOTI

IXYTON

SAERIDA

80. Vanity Fair THACKERAY

81. Peter the Whaler KINGSTON

82. Wonder Book \& Tanglewood Tales

HAWTHORNB

83. Charles O'Malley

LEVER

84. Historical Essays and Lays of Ancient Rome MACAULAY

85. Wathering Heights BRONTB

86. Guy Mannering

87. Hard Cash

SCOTT

88. Whitefriars

READE

89. Poems

90. Lesends

ROBINSON

PROCTER

91. Two Years Ago KINGSIEY

92. Heart of Midlothlan SCOTT

93. Barchester Towers

94. Peter simple MARRYAT

95. Life of Nelson SOUTHEY

06. Tales of Mystery \& Imagina. tion

97. Ifife of Christ

POE

98. Paust

PARRAR

99. S wiss Family Robinson

100. Compleat Angler WALTON 



$$
207 \geq 3
$$


3

1

$-$ 




\section{EINDING SECT. JAN 281974.}

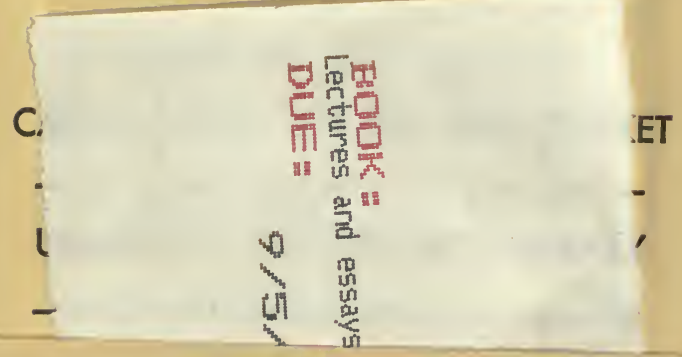

$$
\text { Lintica? }
$$




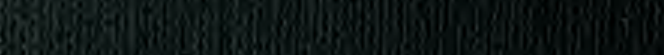

tom

avo

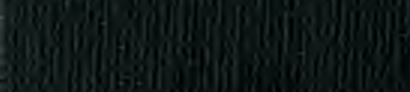

6.

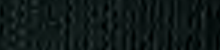

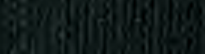

8.

(a) 39.8

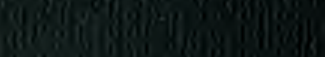

(6)

(6)

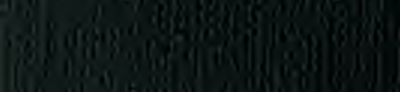

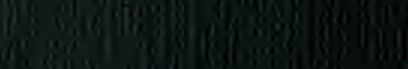

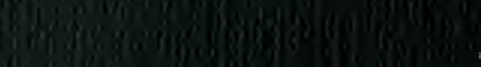

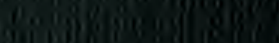

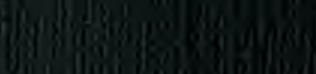

Pigsid

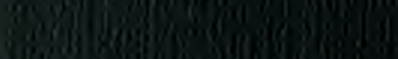

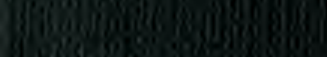

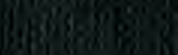

(3)

sindi?

(1)

vong

d

(1)

s)

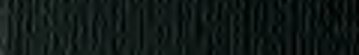

693

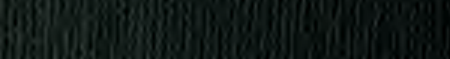

II

tions

dies

(1)

ing

is 